Contracts for field projects and supporting research on ...

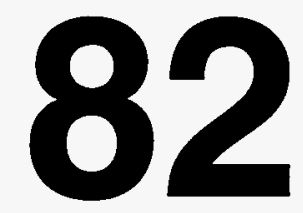

Enhanced Oil Recovery

Reporting Period January-March 1995

DOE/BC-95/2

(DE96001209)

PROGRESS REVIEW

Quarter Ending March 31, 1995

PECEIVED

JUL 231996

OSTI

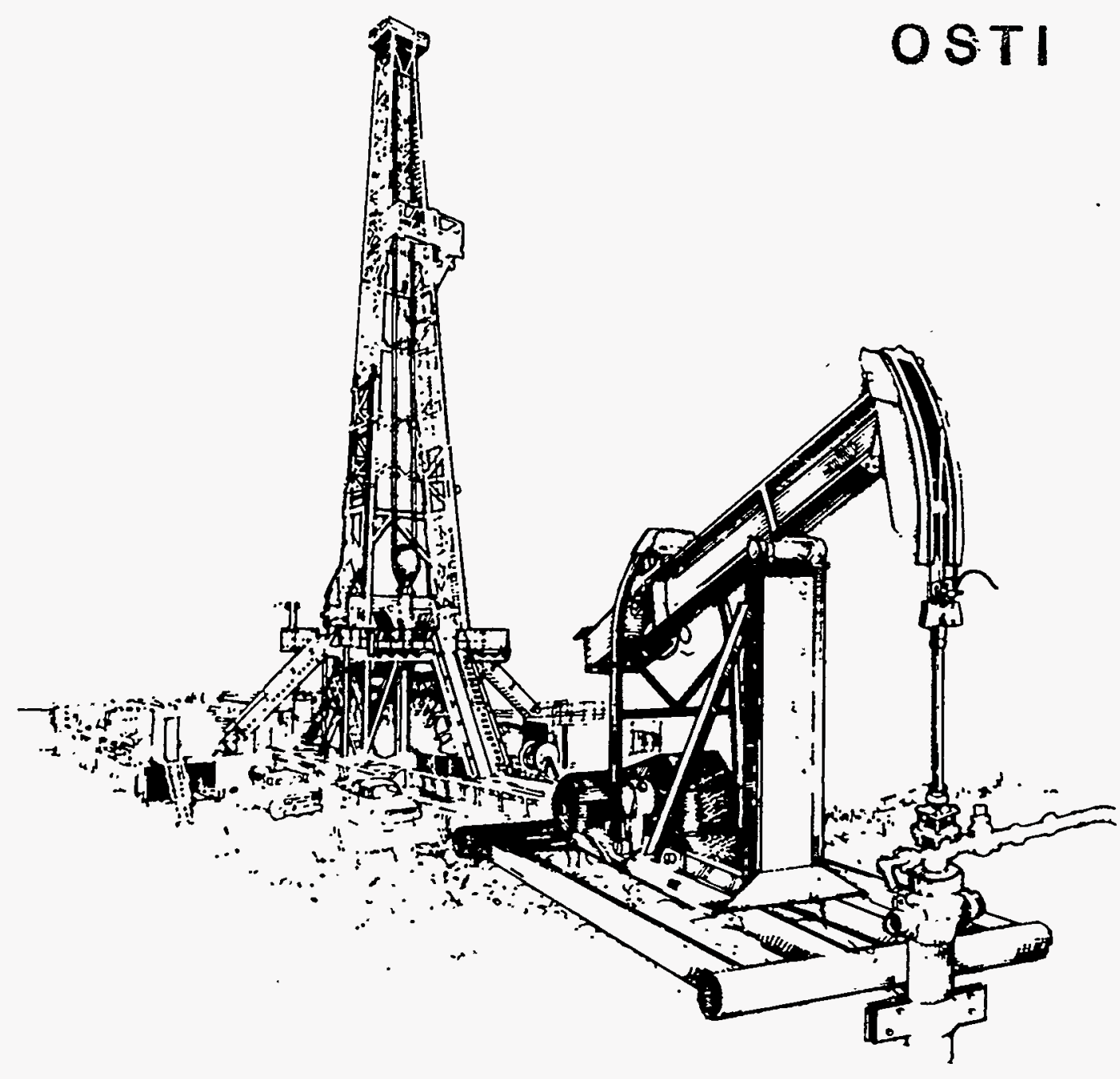

MASTER

United States Department of Energy and Bartlesville Project Office 


\title{
DISCLAIMER
}

\begin{abstract}
This report was prepared as an account of work sponsored by an agency of the United States Government. Neither the United States Government nor any agency thereof, nor any of their employees, makes any warranty, express or implied, or assumes any legal liability or responsibility for the accuracy, completeness, or usefulness of any information, apparatus, product, or process disclosed, or represents that its use would notinfringe privately owned rights. Reference herein to any specific commercial product, process, or service by trade name, trademark, manufacturer, or otherwise does not necessarily constitute or imply its endorsement, recommendation, or favoring by the United States Government or any agency thereof. The views and opinions of authors expressed herein do not necessarily state or reflect those of the United States Government or any agency thereof.
\end{abstract}

Available to DOE and DOE contractors from the Office of Scientific and Technical Information, P.O. Box 62, Oak Ridge, Tennessee 37831; prices available from (423) $576-8401$.

Available to the public from the U.S. Department of Commerce, Technology Administration, National Technical Information Service, Springfield, Virginia 22161; prices available from (703) 487-4650. 
U.S. Department of Energy

Washington, D.C. 20545

PATRICIA GODLEY

Assistant Secretary for Fossil Energy

Room 4G-084 Forrestal Building

Telephone Number 202-586-4695

REGINAL SPILLER

Deputy Assistant Secretary for Gas and Petroleum Technologies

SANDRA WAISLEY

Director for Oil and Gas Exploration and Production

Bartlesville Project Office P.O. Box 1398

Bartlesville, Oklahoma 74005

Telephone No. 918-337-4401

THOMAS C. WESSON

Director

R. M. RAY

Deputy Director

BETTY J. FELBER

Program Coordinator, Enhanced Oil Recovery

HERBERT A. TIEDEMANN

Project Manager for

Technology Transfer
DOE/BC--95/2

(DE96001209)

Distribution Category UC-122

\section{CONTRACTS FOR FIELD PROJECTS AND SUPPORTING RESEARCH ON ENHANCED OIL RECOVERY}

Date Published - June 1996 


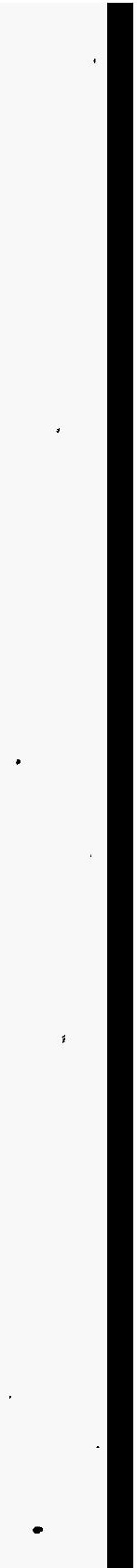




\section{DISCLAIMER}

Portions of this document may be illegible in electronic image products. Images are produced from the best available original document. 
. 


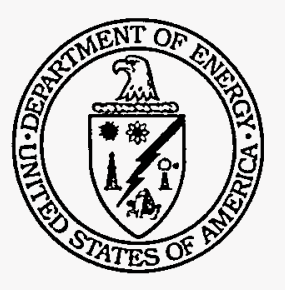

PUBLICATIONS LIST

Bartlesville Project Office

Thomas C. Wesson, Director

\section{AVATLABILTTY OF PUBLICATIONS}

The Department of Energy makes the results of all DOE-funded research and development efforts available to DOE and DOE contractors from the $O$ fflce of Scientific and Technical Information, P.O. Box 62, Oak Ridge, TN 37831; prices available from (615) 576-8401.

Available to the public from the National Technical Information Service, U.S. Department of Commerce, 5285 Port Royal Road, Springfield, VA 22161; prices avallable from (703) 487-4650.

Give the full title of the report and the report number.

Sometimes there are slight delays between the time reports are shipped to NTIS and the time it takes for NTIS to process the reports and make them available. Accordingly, we will provide one copy of any individual report as long as our limited supply lasts. Please help us in our effort to eliminate wasteful spending on government publications by requesting only those publications needed. Order the report number listed at the beginning of each citation and enclose $a$ self-addressed mailing label. Available from DOE Bartlesville Project OEfice, ATTN: Herbert A. Tiedemann, P.O. Box 1398, Bartlesville, OK 74005; (918) 337-4293.

\section{Quarterly Reports}

DOE/BC-94/3

Contracts for Field Projects and Supporting Research on Enhanced Oll Recovery. Progress Review No. 79. Quarter ending June 30, 1994. August 1995. 117 pp. Order No. DE94000200. Status reports are given for various enhanced oil recovery and gas recovery projects sponsored by the Department of Energy. The field tests and supporting research on enhanced ofl recovery include chemical flooding, gas displacement, thermal/heavy oil, resource assessment, geoscience technology, microbial technology, field demonstrations in high-priority reservoir classes, novel technology, and environmental technology.

\section{DOE/BC-94/4}

Contracts for Field Projects and Supporting Research on Enhanced Oll Recovery. Progress Review No. 80. Quarter Ending September 30, 1994. November 1995. 156 pp. Order No. DE96001206. Status reports are given for various enhanced oil recovery and gas recovery projects sponsored by the Department of Energy. The field tests and supporting research on enhanced oil recovery include chemical flooding, gas displacement, thermal/heavy oil, resource assessment, geoscience technology, microbial technology, field demonstrations in high-priority reservoir classes, novel technology, and environmental technology.

\section{Chemical Flooding}

\section{DOE/BC/14881-12}

Improving Reservoir Conformance Using Gelled Polymer Systems. Annual Report forSeptember 25, 1993 to September 24, 1994. The University of Kunsas. July 1995. 96 pp. Order No. DE95000158. The objectives of the research program are to identify and develop polymer systems which have potential to improve reservoir conformance of fluid displacement processes; to determine the performance of these systems in bulk and in porous media; and to develop methods to predict their performance in field applications. The research focuses on three types of aqueous gel systems - a polysaccharide (KUSP1) that gels as a function of $\mathrm{pH}$, a polyacrylamide-chromium(III) system and a polyacrylamide-aluminum citrate system. This report describes work conducted during the second year of a three-year program. Progress was made in the utilization of KUSP1 as a gelling agent. It was shown that gels can be formed in situ in porous media using $\mathrm{CO}_{2}$ or ester hydrolysis to lower $\mathrm{pH}$. An ester was identified that could be used in field-scale operations. It was determined that KUSP1 will form strong gels when ortho boric acid is added to the system. It was also determined, in cooperation with Abbott Laboratories, that KUSP1 can be produced on a commercial scale. Rheological studies showed that shear rate significantly affects gelation time and gel strength. The effect of rock-fluid interactions at alkaline conditions was examined experimentally and through mathematical modeling.

\section{DOE/BC/14884-12}

Surfactant Loss Control in Chemical Flooding Spectroscopic and Calorimetric Study of Adsorption and Precipitation on Reservoir Minerals. Annual Report for September 30, 1993 to September 30, 1994. Columbla University. June 1995. $60 \mathrm{pp}$. Order No. DE95000157. The aim of this project is to elucidate the mechanisms underlying adsorption and surface precipitation of flooding surfactants on reservoir minerals. Effect of surfactant structure, surfactant combinations, other inorganic and polymeric species is being studied. A multi-pronged approach consisting of micro and nano spectroscopy, microcalorimetry, electrokinetics, surface tension and wettability is used to achieve the goals. The results of this study should help in controlling surfactant loss in chemical flooding and also in developing optimum structures and conditions for efficient chemical flooding processes.

\section{DOE/BC/14885-10 Development of Cost-Effective} Surfactant Flooding Technology. Annual Report for September 30, 1993 to September 29, 1994. University of Texas. August 1995. 104 pp. Order No. DE95000180. This research consists of the parallel development of a new chemical flooding simulator and the application of our existing UTCHEM simulation code to model surfactant flooding. The new code is based upon a completely new numerical method that combines for the first time higher-order finite-difference methods, flux limiters, and implicit algorithms. Results indicate that this approach has significant advantages in some problems and will likely enable us to simulate much larger and more realistic chemical floods once it is fully developed. Additional improvements have also been made to the UTCHEM code, and it has been applied to the study of stochastic reservoirs with and without horizontal wells to evaluate methods to reduce the cost and risk of surfactant flooding. During the second year of this contract, significant progress has already been made on both of these tasks. 


\section{DOE/BC/14886-14}

Investigation of Oll, Recovery Improvement by Coupling an Interfacial Tension Agent and a Mobility Control Agent in Light Oil Reservolrs. Final Report. Surtek, Inc. December 1995. 72 pp. Order No. DE96001204. This report studied the oil recovery potential of flooding light oil reservoirs by combining interfacial tension reducing agent(s) with a mobility control agent. The first objective was to define the mechanisms and limitations of co-injecting interfacial tension reduction agent(s) and a mobility control agent to recover incremental oil. Specifically, the study focused on the fluid-fluid and fluid-rock interactions. The fluid-fluid evaluations defined how the various alkalis and surfactants interact to develop low interfacial tension values and how physical parameters affect these interactions. The fluid-rock studies evaluated the effect of rock type on the oil recovery efficiency. The second objective was to evaluate the economics of the combination technology and investigate methods to make the process more profitable. Specific areas of study were to evaluate different chemical concentration tapers and the volume of chemical injection required to give optimal oil recovery.

\section{NIPER/BDM-0074 Chemical Systems for Improved OIl \\ Recovery: Phase Behavior, Oil}

Recovery, and Mobility Control Studies. Topical Report. BDM-Oklahoma, Inc. September 1995. 76 pp. Order No. DE95000183. Selected surfactant systems containing a series of ethoxylated nonionic surfactants in combination with an anionic surfactant system have been studied to evaluate phase behavior as well as oil recovery potential. These experiments were conducted to evaluate possible improved phase behavior and overall oil recovery potential of mixed surfactant systems over a broad range of conditions. The importance of maximizing the production of oil initially mobilized by surfactant chemical systems resulted in an evaluation of mobility control polymers for selected experimental conditions. Both polyacrylamide polymers and Xanthan biopolymers were evaluated. In addition, studies were initiated to use a chemical flooding simulation program, UTCHEM, to simulate oil recovery for laboratory and field applications and evaluate its use to simulate oil saturation distributions obtained in CT-monitoring of oil recovery experiments.

\section{Thermal Recovery}

\section{CONF-9502114}

Fueling for a Clean and Safe Environment. Volume 1. Proceedings for the 6th UNITAR International Conference on Heavy Crude and Tar Sands on February 12-17, 1995. 811 pp. Order No. DE95000188. The theme for the conference was "Fueling for a Clean and Safe Environment." The program included 167 technical papers and poster presentations by authors representing 20 countries. Sessions subjects included Production, Field Projects, Processing and Refining, Environment, laboratory Studies, Upgrading, Numerical Simulation, Equipment, Reservoir Characterization, Handling and Transportation, Analytical Properties, Resource Development, and other Worldwide Activities.

\section{CONF-9502114}

Fueling for a Clean and Safe Environment. Volume 2. Proceedings for the 6th UNITAR International Conference on Heavy Crude and Tar Sands on February 12-17, 1995.733 pp. Order No. DE95000189. The theme for the conference was "Fueling for a Clean and Safe Environment:" The program included 167 technical papers and poster presentations by authors representing 20 countries. Sessions suibjects included Production, Field Projects, Processing and Refining, Environment, laboratory Studies, Upgrading, Numerical Simulation, Equipment, Reservoir Characterization, Handling and Transportation, Analytical Properties, Resource Development, and other Worldwide Activities.

\section{DOE/BC/14864-14}

Study of Hydrocarbon Misclble Solvent Slug Injection Process for Improved Recovery of Heavy Oll from Schrader Bluff Pool, Mllne Point Unit, Alaskr. Annual Report for January 1, 1994 to December 31, 1994. University of Alaska Aairtanks. July 1995, 120 pp. Order No. DE95000162. The oil production in Alaska has started to decline in the early 1990's which is attributed to decline in the production from supergiant Prodhoe Bay field. In the 1990's, the National Energy Strategy Plan developed by U.S. Department of Energy called for 900,000 barrels/day production of heavy oll in the mid 1990's to meet the national demand. To meet this goal, it is imperative that Alaskan heavy oil fields be brought into production. Schrader Bluff reservoir, located in the Milne Point Unit, which is part of the heavy oil field known as West Sak, is estimated to contain 1.5 billion barrels of (14 to 21 degree API) oil-in-place. The field is currently under production by primary depletion. However, the primary recovery was expected to be much less than expected value of $12 \%$ because of complex reservoir structure. Hence, waterflood has been implemented earlier than anticipated. The eventual implementation of enhanced oil recovery (EOR) techniques will be vital for the recovery of additional oil from this reservoir.

\section{DOE/BC/14899-24}

Flow and Displacement of Bingham Plastico in Porous Media. Topical Report. University of Southem Califomia. July 1995. 32 pp. Order No. DE95000165. Bingham plastics, which exhibit a finite yteld stress at zero shear rate, have been used to model the flow behavlor of certain heavy oils at reservoir conditions (Barenblatt et al., 1990). In such fluids, the onset of flow and displacement occurs only after the applied pressure gradient exceeds a minimum value. Understanding the flow behavior of such fluids has been limited to phenomenological approaches (Barenblatt et al., 1990, Wu et al. 1992). Numerical simulations and experimental visualization of flow and immiscible displacement of Bingham plastics in porous media using micromodels are presented. First, a novel pore network simulation approach to determine the onset of flow is described. The dependence of the critical yield stress on the pore-size distribution is discussed. Visualization experiments of the constant-rate immiscible displacement of Bingham plastics in glass micromodels and Hele-Shaw cells are next presented. The process is subsequently simulated in a pore network. Experiments are successfully simulated with the pore network model. The effect of the yield stress and injection rate on the displacement patterns is discussed. A classification of the displacement patterns, similar to that for Newtonian displacement is proposed (Lenormand, 1989).

\section{DOE/BC/14899-25}

Visualization and Simulation of Immiscible Displacement in Fractured Systems Using Micromodels: Steam Injection. University' of Southem Califomla. July 1995. 36 pp. Order No. DE95000150. A study of steam and hot water injection processes in micromodel geometries that mimic a matrix-fracture system was undertaken. The following was observed: light components existing in the crude oil generated a very high efficient gas-drive at elevated temperatures. This gas generation in conjunction with natural surfactant existing in the crude oil lead to the formation of a foam in the fracture and to improved displacement in the matrix. It was observed that the steam enters the fracture and the matrix depending on whether the steam rate exceeds or not the critical values. The resulting condensed water also moves preferentially into the matrix or the fracture depending on the corresponding capillary number. Since steam is a non-uretting phase as a vapor, but becomes a wetting phase when condensed in a water-wet system, steam injection involves both drainage and imbibition. It was found that all of the oil trapped by the condensed water can be mobilized and recovered when in contact with steam. 


\section{DOE/BC/14899-26}

Visuallzation and Simulation of Immiscible Displacement in Fractured Systems Using Micromodels: Imbibition. University of Southem Callfomia. July 1995, 52 pp. Order No. DE95000149. A study of imbibition processes in micromodel geometries that mimic a matrixfracture system was undertaken. Experiments in glass micromodels and pore network simulation were conducted. It was observed that, at low capillary number values the wetting fluid preferentially invaded the matrix. Two critical capillary numbers were identified, one for the start of penetration in the fracture when the viscosity ratio was much less than one, and another for which the rate of propagation of the front in the fracture is the same with that in the matrix, when the viscosity ratio was greater than one. These critical capillary numbers were well matched with the results of a pore network simulation. A simplified theory for both critical numbers was developed. Free imbibition in fractured system was investigated and compared favorably with pore network simulation. This process first involves the rapid invasion of the matrix, followed by the subsequent penetration of the fracture.

\section{DOE/BC/14899-27}

Scaling of Bubble Growth in a Porous Medium. Toplcal Report. University of Southem Callfornia. July 1995. $16 \mathrm{pp}$. Order No. DE95000166. Processes involving liquid-to-gas phase change in porous medis are routinely encountered, for example in the recovery of oil, geothermal processes, nuclear waste disposal or enhanced heat transfer. They involve diffusion (and convection) in the pore space, driven by an Imposed supersaturation in pressure or temperature. Phase change proceeds by nucleation and phase growth. Depending on pore surface roughness, number of nucleation centers exist, thus phase growth occurs from a multitude of clusters. Contrary to growth in the bulk or in a Hele-Shaw cell, however, growth patterns in porous media are disordered and not compact. As in immiscible displacements, they reflect the underlying pore microstructure. The competition between multiple clusters is also different from the bulk. For example, cluster growth may be controlled by a combination of diffusion with percolation. Novel growth patterns are expected from this competition.

\section{DOE/BC/14899-28}

SUPRI Heavy Oil Research Program. Annual Report for February 8, 1994 to February 7, 1995. Stanford University. July 1995. 184 pp. Order No. DE95000167. The goals of this project are to 1) assess the influence of different reservoir conditions (temperature and pressure) on the absolute and relative permeability to oil and water and on capillary pressure; 2) evaluate the effect of different reservoir parameters on the in-situ combustion process. This project includes the study of the kinetics of the reactions; 3) develop and understand the mechanisms of the process using commercially available surfactants for reduction of gravity override and channeling of steam; 4) develop and improve techniques of formation evaluation such as tracer tests and pressure transient tests; and 5) provide technical support for design and monitoring of DOE-sponsored or industry-initiated fleld projects.

\section{DOE/BC/95000151}

Multifrequency Crosshole EM Imaging for Reservoir Characterization. FY 1994 Annual Report. Lawrence Berkeley Laboratory. June 1995. 12 pp. Order No. DE95000151. Electrical conductivity of sedimentary rock is controlled by the porosity, hydraulic permeability, temperature, saturation, and the pore fluid conductivity. These rock parameters play important roles in the development and production of hydrocarbon (petroleum and natural gas) resources. For these reasons, resisttvity well logs have long been used by geologists and reservoir engineers in petroleum Industrles to map variations in pore fluid, to distinguish between rock types, and to determine completion intervals in wells. It is therefore a natural extension to use the electrical conductivity structure to provide additional information about the reservoir. Reser- voir simulation and process monitoring rely heavily on the physical characteristics of the reservoir model. At present, numerical codes use point measurements of porosity, permeability, and fluid saturation and extrapolate these data throughout a three-dimensional (3-D) grid. The knowledge of a high-resolution geophysical parameter such as electrical conductivity would aid this extrapolation and improve the reservoir simulation effort. In addition, since conductivity is sensitive to changes in the composition and state of fluids in pores and fractures it becomes an ideal method for monitoring a reservoir process.

\section{DOE/BC/95000152}

Electrical and Electromagnetic Methods for Reservoir Description and Process Monitoring. Annual Report for October 1, 1992 to September 30, 1993. Lawrence Berkeley Laboratory. July 1995. 20 pp. Order No. DE95000152. At the beginning of FY 91 a coordinated electri$\mathrm{cal}$ and electromagnetic (EM) geophysical research program for petroleum reservoir characterization and process monitoring was initiated. The overall objectives of the program were to: integrate research funded by DOE for hydrocarbon recovery into a focused effort to demonstrate the technology in the shortest time with the least cost; assure industry. acceptance of the technology developed by having industry involvement in the planning, implementation, and funding of the research; and focus the research on real world problems that have the potential for solution in the near term with significant energy payoff. Specific research activities conducted through this integrated effort have been in the following five general areas: EM modeling development, data interpretation methods development, hardware and instrumentation development, EOR and reservoir characterization, and controlled field experiments.

\section{DOE/BC/95000153}

Electrical and Electromagnetic Methods for Reservoir Description and Process Monitoring. Annual Report for October 1, 1991 to September 30, 1992. Lawrence Berkeley Laboratory. July 1995. 28 pp. Order No. DE95000153. One of the important geophysical parameters that can be used to help monitor and characterize a petroleum reservoir is the electrical conductivity. The electrical conductivity of rock is dominantly a function of fluid type, its saturation, the porosity, and hydraulic permeability of the rock. For these reasons, resistivity well logs have long been used by geologists and reservoir engineers in petroleum industries to map variations in pore fluid, to distinguish between rock types, and to determine completion intervals in wells. It is therefore a natural extension to use the electrical conductivity structure to provide additional information about the reservoir. Reservoir simulation and process monitoring rely heavily on the physical characteristics of the reservoir model. At present, numerical codes use point measurements of porosity, permeability, and fluid saturation and extrapolate these data throughout a three-dimensional (3-D) grid. The knowledge of a highresolution geophysical parameter such as electrical conductivity would aid this extrapolation and improve the reservoir simulation effort. In addition, since conductivity is sensitive to changes in the composition and state of fluids in pores and fractures it becomes an ideal method for monitoring a reservoir process.

\section{DOE/BC/95000168}

Foam Flow Through a Transparent Rough-Walled Rock Fracture. Lawrence Berkeley Laboratory. July 1995. 36. pp. Order No. DE95000168. This paper presents an experimental study of nitrogen, water, and aqueous foam flow through a transparent replica of a natural rough-walled rock fracture with a hydraulic aperture of roughly $30 \mu \mathrm{m}$. It is established that single-phase flow of both nitrogen and water is well described by analogy to flow between parallel plates. Inertial effects caused by fracture roughness become important in single-phase flow as the Reynolds number approaches 1 . Foam exhibits effective control of gas mobility. Foam flow resistances are approximately 10 to 20 times 
greater than those of nitrogen over foam qualities spanning from 0.60 to 0.99 , indicating effective gas-mobillty control. Because previous studies of foam flow have focused mainly upon unfractured porous media, little information is available about foam flow mechanisms in fractured media. The transparency of the fracture allowed tlow visualization and demonstrated that foam theology in fractured media depends upon bubble shape and size. Changes in flow behavior are directly tied to transitions in bubble morphology.

\section{DOE/BC/95000169}

Population Balance Model for Transient and Steady-State Foam Flow in Boise Sandstone. Lawrence Berkeley Laboratory. July 1995. 60 pp. Order No. DE95000169. An experimental and mechanistic-modeling study is reported for the transient flow of aqueous foam through

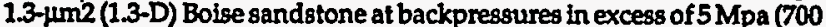
psi) over a quality range from 0.80 to 0.99 . Total superficial velocities range from as little as 0.42 to $2.20 \mathrm{~m} /$ day $(1.4 \mathrm{ft} /$ day to $7 \mathrm{ft} /$ day). Sequential pressure taps and gamma-ray densitometry measure flow resistance and in-situ liquid saturations, respectively. Experimental pressure and saturation profiles in both the transient and steady states are gamered. Adoption of a mean-size foam-bubble conservation equation along with the traditional reservoir simulation equations allows mechanistic foam simulation.

\section{Geoscience}

\section{DOE/BC/14477-18}

An Experimental and Theoretical Study to Relate Uncommon RockJ Fluld Properties to Oil Recovery. Final Report. Pennsylvania State University. July $1995.340 \mathrm{pp}$. Order No.DE95000164. The most commonly used secondary oil recovery technique is waterflooding. Macroscopic (or common) rock-pore characterlstics such as porosity, permeability, and irreducible water saturation and fluid properties such as viscosity have been shown by previous investigators to influence the results of waterflooding and consequently ultimate oil recovery. The objectives of this study are to consider the influence of microscopic (or uncommon) rock-pore characteristics such as wettability, tortuosity, mercury intrusion volume, pore surface area, specific surface area, average pore diameter, median pore-throat diameter, pore length, apparent (skeletal) density and mercury recovery efficiency on residual oil saturation and oil recovery realized in linear-core waterfloods. The results were statistically analyzed to determine the quantitative relations between the various properties, and empirical equations were developed for predicting waterflood performance. The characteristics were analyzed and modeled at both breakthrough and floodout.

\section{Resource Assessment Technology}

\section{DOE/BC14831-14}

Oil from Reservoin in the Guif of Medco. Annual Report for February 18, 1994 to February 18, 1995. Louidiana State University. September 1995. 2A4 pp. Order No. DE95000185. During the past year, a report on the simulation work performed on the U-8 reservoir was completed. Also, modifications to handle steeply dipping reservoirs have been successfully implemented in the MASTER simulator and critical process parameter laboratory experiments and computer simulations of the experiments have been completed. In addition, development of predictive models for undeveloped oil and immisctble/miscible processes began. The methodology for determination of undeveloped potential has been completed. The design of the miscible and updip displacement models as well as the design of the economic and timing models is under way. The coding and calibration of the models began. Data validation, map measurements, model development and supporting cost data collection was in progress.

\section{Gas Displacement}

\section{DOE/BC/14862-10}

Productivity and Injectivity of Horizontal Wells. Annull Report for March 10, 1994 to March 9, 1995. Stanford Univerity. July 1995. 172 pp. Orcler No. DE95000163. This project has elght principal goals to be studied and developed over a five-year period. These goals are as follows: Task 1 is to develop special gridding techniques and nssociated averaging algorithms for accurate simulation of HW-performance. Task 2 is to study impacts of various types of heterogeneity and develop methods for incorporating their effects in both fine-grid and coarse-grid models. Task 3 is to plan, execute, and interpret two-phase flow experiments at an oil company research facility, and use results to analyze/validate a new two-phase model. Task 4 is to define improved methods for computing two-phase pseudo-functions for effective relative permeabilitles for coarse grid blocks near an HW - determine sensitivitles to heterogeneities, flow conditions, skin factors, etc. Task 5 is to develop numerical techniques and software in a parallel computing architecture capable of interactively coupling multiple detailed HW - models to a large scale reservoir simulator. Task 6 is to work with affiltate's member companies to establish HW-modeling capabilities from field measurements, particularly for pathological problem cases. Task 7 is to provide and implement practical HW aspects into modeling of EOR processes miscible gas, steam displacement, in-situ combustion. Task 8 is to seek field opportunities for HW's and study their best implementation in vartous reservolr scenarios eg., multiple laterals, hydraullc fracture varlants, etc.

\section{DOE/BC114977-6 Improved Effielency of Misclble} $\mathrm{CO}_{2}$ Floods and Enhanced Prospects for $\mathrm{CO}_{2}$ Flooding Heterogeneous Reservolrs. Annual Report for April 14, 1994 to April 13, 1995. New Mexico Inatitute of Mining and Technology. September 1995. 80 pp. Order No. DE95000187. The overall goal of this project is to improve the efficiency of misclble $\mathrm{CO}_{2}$ floods and enhance the prospects for flooding heterogeneous reservolrs. This objective is being accomplished by extending experimental research in three task areas: 1) foams for selective mobility control in heterogeneous reservoirs, 2) reduction of the amount of $\mathrm{CO}_{2}$ required in $\mathrm{CO}_{2}$ floods, and 3) miscible $\mathrm{CO}_{2}$ flooding in fractured reservoirs. In the first task, a desirable characteristic of $\mathrm{CO}_{2}$-foam called Selective Mobility Reduction (SMR) that promises an improvement in displacement efficiency by reducing the effects of reservoir heterogeneity is investigated. In the second task, preliminary results on the phase behavior tests of a West Texas crude with $\mathrm{CO}_{2}$ are reported. In the third task, the resuits of prediction of multicomponent, reservoir condition interfacial tension (IFT) àre reported.

\section{Reserooir Characterization}

DOE/BC/14894-5

Application of Artificial Intelligence to Reservoir Characterization. Annual Report for October 1993 to October 1994. The Univerdity of Tulsa. July 1995. 72 pp. Order No. DE95000145. The basis of this research is to apply novel techniques from Artificial Intelligence and Expert Systems in capturing, integrating and articulating key knowledge from geology, geostatistics, and petroleum engineering to develop accurate descriptions of petroleum reservoirs. The ultimate goal is to design and implement a single powerful expert system for use by small producers and independents to efficiently exploit reservoirs.

\section{DOE/BC114896-6 Geological and Petrophyalcal}

Characterlzation of the Ferron Sand-

stone for 3-D Simulation of a Fluvial-Deltalc Reservoix. Annual Report for September 29, 1993 to September 29, 1994. Utah Geological 
Survey. July 1995. $52 \mathrm{pp}$. Order No. DE95000172. The objective of the Ferron Sandstone project is to develop a comprehensive, interdisciplinary, quantitative characterization of a fluvial-deltaic reservoir to allow realistic inter-well and reservoir-scale models to be developed for improved oll-field development in similar reservoirs worldwide. Quantitative geological and petrophysical information on the Cretaceous Ferron Sandstone in east-central Utah will be collected. Both new and existing data will be integrated into a three-dimensional model of spatial variations in porosity, storativity, and tensorial rock permeability at a scale appropriate for inter-well to regional-scale reservoir simulation. Simulation results could improve reservoir management through proper infill and extension drilling strategies, reduction of economic risks, increased recovery from existing oil fields, and more reliable reserve calculations. Transfer of the project results to the petroleum industry is an integral component of the project. This report covers research activities for fiscal year 1993-94, the first year of the project. Most work consisted of developing feld methods and collecting large quantities of existing and new data.

\section{DOE/BC/14897-6}

Anisotropy and Spatial Variation of Relative Permeabillty and Lithologic Character of Tensleep Sandstone Reservoirs in the Bighom and Wind River Basins, Wyoming. Annual Report for September 15, 1993 to September 30, 1994. Unlversity of Wyoming. July $1995.80 \mathrm{pp}$. Order No. DE95000156. This research will associate spatial distributions and anisotropy of relative permeability with the depositional subfacies and zones of diagenettc alteration found within the Tensleep Sandstone. The associations between depositional lithofacies diagenetic alteration, and pore geometry will link relative permeability with the distinct and measurable dimensions of lithofacies, and authigenic mineral facles. Effects of the depositional processes and burial diagenesis will be investigated. The primary goal of this task is to establish the regional trends and variations in lithologic character of the eolian and marine subfacies of the upper Tensleep Sandstone in the Bighom and Wind River basins.

\section{Field Demonstrations}

DOE/BC/14953-10

Increased Oll Production and Reserves from Improved Complethon Techniques in the Bluebell Fleld, Uinta Basin, Utah Annual Report for September 30, 1993 to September 30, 1994. Utah Geological Survey. July 1995. 132 pp. Order No. DE95000171. The Bluebell field produces from the Tertiary lower Green River and Wasatch Formations of the Uinta Basin, Utah. The productive interval consists of thousands of feet of interbedded fractured clastic and carbonate beds deposited in a fluvial-dominated deltaic lacustrine environment. Although some wells have produced over 1 million barrels $(159,000 \mathrm{~m} 3)$ of oil, many have produced only 100,000 to 250,000 barrels $(15,000-31,000 \mathrm{~m} 3)$, or less, of oil. The lower portion of the productive interval is overpressured, requiring that approximately 10,000 feet $(3,050 \mathrm{~m})$ of intermediate casing be set. The final 2,000 to 4,000 feet $(610-1,220 \mathrm{~m})$ of drilling is slow and difficult requiring weighted mud. Wells are typically completed by perforating 40 or more beds over 1,000 to 3,000 vertical feet ( $305-915 \mathrm{~m}$ ), then applying an acid-frac treatment to the entire interval. This completion technique is belleved to leave many potentially productive beds damaged and/or untreated, while opening up some water and thief zones.

\section{DOE/BC/14954-5}

Advanced Secondary Recovery Demonstration for the Sooner Unit. Annual Report for October 1992 to May 1993. Diversified Operating Corporation. July 1995. $160 \mathrm{pp}$. Order No. DE95000170. The objective of this project is to demonstrate the effectiveness of a multi-disciplinary approach to targeted infill drilling and improved reservoir manage- ment. The first phase of the project involves geophysical, geological and engineering data acquisition and analysis to identify optimum well sites and to develop a reservoir operations plan, maximizing secondary recovery using water injection and gas recycling. The second phase will involve drilling of up to three geologically targeted infill wells and establishing production/injection schedules. Reservoir simulation, transient well tests and careful production monitoring will be used to evaluate the results. The third phase will involve technology transfer through a series of technical papers and presentations of a short course. Emphasis will be on the economics of the project and the implemented technologies. This report summarizes the activities, results and conclusions from Phase 1 activities of the Sooner Unit Project. The Sooner Unit is located in Weld County, Colorado and produces from the " $\mathrm{d}$ " sandstone member of the Upper Cretaceous Graneros formation at a depth of about $6,300 \mathrm{ft}$. DOE/BC14955-8 $\quad \begin{aligned} & \text { Applications of Advanced } \\ & \text { Petroleum Production Technology }\end{aligned}$ and Water Alternating Gas Injection for Enhanced Oil Recovery - Mattoon Oil Fleld, Illinois. Final Report. American Oll Recovery, Inc. September 1995. 80 pp. Order No. DE95000184. Phase I results of a $\mathrm{CO}_{2}$-assisted oil recovery demonstration project in selected Cypress Sandstone reservoirs at Mattoon Field, Ilinois; are reported. The design and scope of this project included $\mathrm{CO}_{2}$ injectivity testing in the Pinnell and Sawyer units, well stimulation treatments with $\mathrm{CO}_{2}$ in the Strong unit, and infill well drilling, completion and oil production. The field activities were supported by extensive $\mathrm{CO}_{2}$-oil-water coreflood experiments, $\mathrm{CO}_{2}$-oil phase interaction experiments, and integrated geologic modeling and reservoir simulations. Five Cypress Sandstone layers ("A", "B", "C", "D", "E") were identified within the study area in Mattoon Field. Three-dimensional geologic models, created from well data, were used to interpret the location, size and continuity of the productive intervals. The $\mathrm{CO}_{2}$ injectivity tests were performed in the " $\mathrm{A}$ " interval in the Pinnell unit, " $E$ " interval in the Sawyer unit and " $D$ " interval in the Strong unit.

\section{DOE/BC/14957-7}

Improved Oil Recovery in Fluvial Dominated Deltaic Reservoirs of Kansas - Near-Term. Annual Report for June 18, 1993 to June 18, 1994. The University of Kansas. October 1995. 204 pp. Order No. DE95000161. Common oil field problems exist in fluvial dominated deltaic reservoirs in Kansas. The problems are poor waterflood sweep and lack of reservoir management. The poor waterflood sweep efficiency is the result of 1) reservoir heterogeneity, 2) channeling of injected water through high permeability zones or fractures, and 3) clogging of water injection wells with solids as a result of poor water quality. In many instances the lack of reservoir management results from failure to 1) collect and organize data, 2) integrate analyses of existing data by geological and engineering personnel, and 3) identify optimum recovery techniques.

DOE/BC/14958-11 Green River Formation Water Flood Demonstration Project. Annual

Report for April 1, 1994 to March 31, 1995. Lomax Exploration Company. September 1995. 72 Pp. Order No. DE95000182. The successful water flood of the Green River Formation in the Monument Butte unit was analyzed in detail in the last yearly report. It was shown that primary recovery and the water flood in the unit were typical of oil production from an undersaturated oil reservoir close to its bubble point. The reservoir performance of the smaller Travis unit was also analyzed. The Monument Butte unit is currently producing at around 300 barrels per day of oil. Two of the new wells drilled in the unit had zones pressurized by the water flood. The third well produced from pressurized as well as from zones which were unaffected by the water flood. The water flood response of the Travis unit is slow, possibly because of problems 
with reservoir continuity. Water injection continues in the unit and the reservoir pressure is increasing steadily. The new well that was drilled in Travis did not intersect the Lower Douglas Creek Sand into which most of the water has been injected. Plans for water flooding the Boundary unit were drawn.

\section{DOE/BC/14959-13}

Revitalizing a Mature Oll Play: Strategies for Finding and Produc ing Unrecovered Oil in Frio Fluvial-Deltaic Sandstone Reservoirs of South Texas. Annual Report for October 1993 to October 1994. The University of Texas at Austin. July 1995. 168 pp. Order No. DE98000160. The objectives of this project are to develop interwell-scale geological facies models of Frio fluvial-deltaic reservoirs from selected fields in South Texas and combine them with engineering assessments to characterize reservoir architecture and flow-unit boundaries and to try to determine the controls that these characteristics exert on the location and volume of unrecovered mobile ànd residual oil. Results of these studies should lead directly to the identification of specific nearterm opportunities to exploit these heterogeneous reservoirs for incremental recovery by recompletion and strategic infill drilling.

\section{DOE/BC/14959-15}

Strategies for Reservoir Characterization and Identification of Incremental Recovery Opportunities in Mature Reservoirs in Frio Fluvial-Deltaic Sandstones, South Texas: An Example from Rincon Field, Starr County. Topical Report. The University of Texas at Austin. November 1995. 120 pp. Order No. DE95000190. Fluviai-deltaic sandstone reservoirs in the United States are being abandoned at high rates, yet they still contain more than 34 billion barrels of unrecovered oll. The mature Oligocene-age fluvial-deltaic reservoirs of the Frio Formation along the Vicksburg Fault Zone in South Texas are typical of this class in that, after more than three decades of production, they still contain 61 percent of the original mobile oil in place, or 1.6 billion barrels. This resource represents a tremendous target for advanced reservoir characterization studies that integrate geological and engineering analysis to locate untapped and incompletely drained reservoir compartments isolated by stratigraphic heterogeneities.

\section{DOE/BCH4960-8}

Post Waterflood $\mathrm{CO}_{2}$ Misclble Flood in Light Oil, Fluvial-Dominated Deltaic Reservolr. Annual Report for October 1, 1993 to September 30, 1994. Texaco Exploration and Production. July 1995. 52 pp. Order No. DE95000173. Texaco Exploration and Production Inc. (TEPI) and the U.S. Department of Energy (DOE) entered into a cost sharing cooperative agreement to conduct an Enhanced Oil Recovery demonstration project at Port Neches. The field is located in Orange County near Beaumont, Texas. The project will demonstrate the effectiveness of the $\mathrm{CO}_{2}$ miscible process in Fluvial Dominated Deltaic reservoirs. It will also evaluate the use of horizontal $\mathrm{CO}_{2}$ injection wells to improve the overall sweep effliency. A database of FDD reservoirs for the gulf coast region will be developed by Louisiana State University, using a screening model developed by Texaco Research Center in Houston. Finally, the results and the information gained from this project will be disseminated throughout the oil industry via a series of Society of Petroleum Engineers papers and industry open forums.

\section{DOE/BC/14962-7}

The Utilization of the Microflosa Indigenous to and Present in OilBearing Formations to Selectively Plug the More Porous Zones Thereby Increasing Oll Recovery During Waterflooding. Annual Report for January 1, 1994 to December 31, 1994. Hughes Eastern Cor poration. August 1995. 60 pp. Order No. DE95000177. This project is a fleld demonstration of the ability of in-situ indigenous microorganisms in the North Blowhom Creek Oil Field to reduce the flow of injec- tion water in the more permeable zones thereby diverting flow to other areas of the reservoir and thus increasing the efficiency of the waterflooding operation. This effect is to be accomplished by adding inorganic nutrients in the form of potassium nitrate and orthophosphate to the injection water. Work on the project is divided into three phases, Planning and Analysis (9 months), Implementation (45 months), and Technology Transfer (12 months).

\section{DOE/BC/14983-5}

Recovery of Bypassed Oil in the Dundee Formation Using Horizontal Drains. Annual Report for April 1994 to June 1995. Michigan Technological Univerity. August 1995. 260 pp. Order No. DE95000181. Devonian rocks have been the most prolific hydrocarbon producers in the Michigan Basin. The Traverse, Dundee, and Lucas Formations have produced more than half of Michigan's oil since the late 1920's. The Dundee Formation is Michigan's all-time leader with 352 million barrels of oil and 42 billion cubic feet of gas. About $30 \%$ of the original oll in place and $80 \%$ of the original gas in place is usually recovered from hydrocarbon reservoirs during the initial production phase. This project will demonstrate through a field trial that horizontal wells can substantially increase oil production in older reservoirs that are at or near their economic limit. To maximize the potential of the horizontal well and to ensure that a comprehensive evaluation can be made, extensive reservoir characterization will be performed. In addition to the proposed fleld trial at Crystal Field, 29 additional Dundee fields in a seven-county area have been selected for study in the reservoir characterization portion of this project.

\section{DOE/BC/14984-5}

Improved Recovery Demonstration for Williston Basin Carbonates. Annual Report for June 10, 1994 to June 9, 1995. Luff Exploration Company. September 1995. 88 pp. Onder No. DE95000186. The purpose of this project is to demonstrate targeted infill and extension drilling opporturities, better determinations of oil-in-place, methods for improved completion efficiency and the suitability of waterflooding in Red River and Ratcliffe shallow-shelf carbonate reservoirs in the Willigton Basin, Montana, North Dakota and South Dakota. Improved reservoir characterization utilizing three-dimensional and multi-component seismic are being investigated for identification of structural and stratigraphic reservoir compartments. These seismic characterization tools are integrated with geological and engineèring studies. Improved completion efficiency is being tested with extended-reach jetting lance and other ultra-short-radius lateral technologies. Improved completion efficiency, additional wells at closer spacing and better estimates of oil in place will result in additional oil recovery by primary and enhanced recovery processes.

\section{Environmental}

\section{DOE/MT/92006-9}

The Cost of Wetland Creation and Restoration. Final Report. University of Maryland. August 1995. 120 pp. Order No. DE95000174. This report examines the economics of wetland creation, restoration, and enhancement projects, especially as they are used within the context of mitigation for unavoidable wetland losses. Complete engineering-costaccounting profiles of over 90 wetland projects were developed in collaboration with leading wetland restoration and creation practitioners around the country to develop a primary source database. Data on the costs of over 1,000 wetland projects were gathered from published sources and other available databases to develop a secondary source database. Cases in both databases were carefully analyzed and a set of baseline cost per acre estimates were developed for wetland creation, restoration, and enhancement. 


\section{DOE/MT/92007-9}

Characterization of Oil and Gas Waste Disposal Practices and Assescment of Treatment Costs. Final Report. Rice University. August 1995, 220 pp. Order No. DE95000175. This study examines wastes assoclated with the onshore exploration and production of crude oil and natural gas in the United States. The objective of this study was to update and enhance the current state of knowledge with regard to oll and gas waste quantities, the potential environmental impact of these wastes, potential methods of treatment, and the costs associated with meetting various degrees of treatment. To meet this objective, the study consisted of three tasks: 1) the development of a Production Environmental Database (PED) for the purpose of assessing current oll and gas waste volumes by state and for investigating the potential environmental impacts associated with current waste disposal practices on a local scale; 2) the evaluation of available and developing technologies for treating produced water waste streams and the identification of unit process configurations; and 3) the evaluation of the costs associated with yarious degrees of treatment achievable by different treatment configurations.

\section{DOE/MTT/92008-10}

Oil Production Enhancement Through a Standardized Brine Treatment. Final Report. Pennuylvania State University. August 1995. 272 pp. Order No. DE95000179. The Pennsylvania Oil and Gas Association (POGA) approached the Pennsylvania State University to develop a program designed to demonstrate that a treatment process to meet acceptable discharge conditions and effluent limitations can be standandlzed for all potentlal stripper well brine discharge. This profect has been under way since 1987. A bench-scale prototype model was developed for conducting experiments in laboratory conditlons. The experiments in the laboratory conditions were focused on the removal of ferrous tron from synthetically made brine. The results of a number of experiments in the lab were indicative of the capability of the proposed brine treatment process in the removal of iron. In the second phase of this project, a field-based prototype was developed to evaluate and demonstrate the treatment process effectiveness. These experiments were conducted under various conditions and included the testing on five brines from different locations with dissolved constituents.

\section{DOE/MT/92010-10}

Wetland Treatment of Oil and Gas Well Wate Waters. Final Report.

Undvenity of Michigan. August 1995. 64 pp. Order No. DE95000176. Constructed wetlands are small, on-site systems that possess three of the most desirable components of an industrial waste water treatenent scheme: low cost, low maintenance and upset resistance. The main objectives of the present study is to extend the knowiedge base of wetland treatment bystems to include processes and substances of particular importance to smail, on-site systems recelving oll and gas well wastewaters. Alist of the most relevant and comprehensive publications on the design of wetlands for water quality improvement was compiled and critically reviewed. Based on our literature search and conversations with researchers in the private sector, toxicorganics such as phenolics and b-naphthoic acid, (NA), and metals such as $\mathrm{Cu}$ (II) and $\mathrm{Cr}$ (VI) were selected as target adsorbates. A total of 90 lysimeteres equivalent to a laboratory-scale wetland were designed and built to monitor the uptake and transformation of toxic organics and the immobilization of metal ions.

DOE/MT/92011-12 Geologic, Geochemical, and Geographic Controls on NORM in Produced Water from Texas OUl, Gas, and Geothermal Reservolrs. Final Report. The University of Texas at Austin. August 1995. 76 pp. Onder No. DE95000178. Water from Texas oil, gas, and geothermal wells contains natural radioactivity that ranges from several hundred to several thousand picocuries per liter ( $\mathrm{pC} / \mathrm{L}$ ). This natural radioactivity in produced fluids and the scale that forms in producing and processing equipment can lead to increased concerns for worker safety and additional costs for handling and disposing of water and scale. Naturally occurring radioactive materials (NORM) in oil and gas operations are mainly caused by concentrations of radium-226 and radium-228, daughter products of uranium-238 and thorium-232, respectively, in barite scale. The following areas are examined (1) the geographic distribution of high NORM levels in oil-producing and gas-processing equipment, (2) geologic controls on uranium, thorium, and radium in sedimentary basins and reservoirs, (3) mineralogy of NORM scale, (4) chemical variability and potential to form barite scale in Texas formation - waters, (5) radium activity in Texas formation waters, and (6) geochemical controls on radium isotopes in formation water and barite scale to explore natural controls on radioactivity. The approach combined extensive compilations of published data, collection and analyses of new water samples and scale material, and geochemical modeling of scale precipitation and radium incorporation in barite.

\section{Microbial Technology}

\section{BNL 60119}

Effects of Selected Thermophilic Microorganisms on Crude Olls at

Elevated Temperatures and Pressures. Final Report. Brookhaven National Laboratory. July 1995. 184 Pp. Order No. DE95000159. During the past several years, a considerable amount of work has been carried out showing that microbially enhanced oll recovery (MEOR) is promising and the resulting biotechnology may be deliverable. At the Brookhaven National Laboratory (BNL), systematic studies have been conducted which dealt with the effects of thermophilic and thermoadapted bacteria on the chemical and physical properties of selected types of crude oils at elevated temperatures and pressures. Current studies indicate that during the biotreatment several chemical and physical properties of crude oils are affected. 

Page

Colorado School of Mines

Interdisciplinary Study of Reservoir Compartments

Columbia University

Dynamic Enhanced Recovery Technologies

Surfactant Loss Control in Chemical Flooding: Spectroscopic and Calorimetric Study of Adsorption and Precipitation on Reservoir Minerals

Diversified Operating Corporation Advanced Secondary Recovery Demonstration for the Sooner Unit

Hughes Eastern Corporation

The Use of Indigenous Microbes To Selectively Plug the More Porous Zones To Increase Oil Recovery During Waterflooding

Fina Oil and Chemical Company

Application of Integrated Reservoir Management and Reservoir Characterization To Optimize Infill Drilling

Laguna Petroleum Corporation An Integrated Study of the Grayburg/San Andres Reservoir, Foster and South Cowden Fields, Ector County, Texas

Lawrence Livermore National Laboratory

Oil Field Characterization and Process Monitoring Using Electromagnetic Methods

Lomax Exploration Company

Green River Formation Waterflood Demonstration Project, Uinta Basin, Utah

Louisiana State University

Assist in the Recovery of Bypassed Oil from Reservoirs in the Gulf of Mexico

Improved Recovery from Gulf of Mexico Reservoirs

\section{Luff Exploration Company}

Improved Recovery Demonstration for Williston Basin Carbonates

Michigan Technological University

Recovery of Bypassed Oil in the Dundee Formation Using Horizontal Drilling

Visual Display of Reservoir Parameters Affecting Enhanced Oil Recovery
New Mexico Institute of Mining and Technology Improved Efficiency of Miscible $\mathrm{CO}_{2}$ Floods and Enhanced Prospects for $\mathrm{CO}_{2}$ Flooding Heterogeneous Reservoirs Improved Techniques for Fluid Diversion in Oil Recovery

Page

Integration of Advanced Geoscience and Engineering Techniques To Quantify Interwell Heterogeneity

\section{Oklahoma Geological Survey}

Continued Support of the Natural Resources Information System for the State of Oklahoma: Inclusion of a Native American Focused Effort

Identification and Evaluation of Fluvial-Dominated Deltaic (Class I Oil) Reservoirs in Oklahoma

Oxy USA, Inc.

Application of Reservoir Characterization and Advanced Technology To Improve Recovery and Economics in a Lower Quality Shallow Shelf Carbonate Reservoir

ParaMagnetic Logging, Inc.

Fabrication and Downhole Testing of Moving Through Casing Resistivity Apparatus

Reservoir Engineering Research Institute Research Program on Fractured Petroleum Reservoirs

Stanford University

Productivity and Injectivity of Horizontal Wells

Scaleup of Miscible Flood Processes

Research on Oil Recovery Mechanisms in Heavy Oil Reservoirs

Surtek, Inc. Investigation of Oil Recovery Improvement by Coupling an Interfacial Tension Agent and a Mobility Control Agent in Light Oil Reservoirs

Texaco Exploration and Production, Inc. $\mathrm{CO}_{2}$ Huff ' $n$ ' Puff Process in a Light Oil Shallow Shelf Carbonate Reservoir

Post Waterflood $\mathrm{CO}_{2}$ Miscible Flood in Light Oil Fluvial-Dominated Deltaic Reservoirs

University of Alaska

Study of Hydrocarbon Miscible Solvent Slug Injection Process for Improved Recovery of Heavy Oil from Schrader Bluff Pool, Milne Point Unit, Alaska 
University of Kansas

Improved Oil Recovery in Fluvial-Dominated Deltaic Reservoirs of Kansas-Near Term Improved Oil Recovery in Mississippian Carbonate Reservoirs of Kansas-Near Term-Class II

Improving Reservoir Conformance Using Gelled Polymer Systems

\section{University of Oklahoma}

Gypsy Field Project in Reservoir Characterization

\section{University of Southern California}

Modification of Reservoir Chemical and Physical Factors in Steamfloods To Increase Heavy Oil Recovery

\section{University of Southern Mississippi}

Responsive Copolymers for Enhanced Petroleum Recovery

\section{University of Texas}

Development of Cost-Effective Surfactant Flooding Technology

Geoscience/Engineering Characterization of the Interwell Environment in Carbonate Reservoirs Based on Outcrop Analogs, Permian Basin, West Texas and New Mexico

Revitalizing a Mature Oil Play: Strategies for Finding and Producing Unrecovered Oil in Frio Fluvial-Deltaic Reservoirs of South Texas

$$
\begin{aligned}
& \text { University of Tulsa } \\
& \text { Integrated Approach Toward the Application } \\
& \text { of Horizontal Wells To Improve Waterflooding } \\
& \text { Performance }
\end{aligned}
$$

University of Wyoming

Anisotropy and Spatial Variation of Relative Permeability and Lithologic Characterization of Tensleep Sandstone Reservoirs in the Bighorn and Wind River Basins, Wyoming

Utah Geological Survey

Geological and Petrophysical Characterization of the Ferron Sandstone for Three-Dimensional Simulation of a Fluvial-Deltaic Reservoir

Increased Oil Production and Reserves from Improved Completion Techniques in the Bluebell Field, Uinta Basin, Utah

Increased Oil Production and Reserves Utilizing Secondary/Tertiary Recovery Techniques on Small Reservoirs in the Paradox Basin, Utah

\section{CONTENTS BY EOR PROCESS}

Chemical Flooding-Supporting Research

Gas Displacement-Supporting Research

Thermal Recovery-Supporting Research

Geoscience Technology

Resource Assessment Technology

79 
DOE Technical Project Officers for

Enhanced Oil Recovery

DIRECTORY

\begin{tabular}{cc}
\hline Name & Nhone number \\
U. S. Department of Energy \\
Gas and Petroleum Technology \\
Oil and Gas Exploration and Production \\
3E-028/FORS Washington, D.C. 20585.
\end{tabular}

Bartlesville Project Office

P. O. Box 1398

Bartlesville, Oklahoma 74005

\begin{tabular}{|c|c|c|}
\hline Edith Allison & $918-337-4390$ & $\begin{array}{l}\text { Columbia University } \\
\text { Diversified Operating Corporation } \\
\text { Lomax Exploration Company } \\
\text { University of Texas } \\
\text { Utah Geological Survey }\end{array}$ \\
\hline Jerry Casteel & $918-337-4412$ & $\begin{array}{l}\text { Columbia University } \\
\text { New Mexico Institute of Mining and Technology } \\
\text { Stanford University } \\
\text { Surtek, Inc. } \\
\text { Texaco Exploration and Production, Inc. } \\
\text { University of Kansas } \\
\text { University of Southern Mississippi } \\
\text { University of Texas }\end{array}$ \\
\hline Robert Lemmon & $918-337-4405$ & $\begin{array}{l}\text { Colorado School of Mines } \\
\text { Michigan Technological University } \\
\text { New Mexico Institute of Mining and Technology } \\
\text { ParaMagnetic Logging, Inc. } \\
\text { Reservoir Engineering Research Institute } \\
\text { University of Oklahoma } \\
\text { University of Texas } \\
\text { University of Wyoming } \\
\text { Utah Geological Survey }\end{array}$ \\
\hline Rhonda Lindsey & $918-337-4407$ & $\begin{array}{l}\text { Fina Oil and Chemical Company } \\
\text { Hughes Eastern Corporation } \\
\text { Oklahoma Geological Survey } \\
\text { University of Kansas } \\
\text { University of Tulsa } \\
\text { Utah Geological Survey }\end{array}$ \\
\hline Chandra Nautiyal & $918-337-4409$ & $\begin{array}{l}\text { Laguna Petroleum Corporation } \\
\text { Luff Exploration Company } \\
\text { Michigan Technological University } \\
\text { Oxy USA, Inc. } \\
\text { Texaco Exploration and Production, Inc. } \\
\text { University of Kansas }\end{array}$ \\
\hline R. Michael Ray & $918-337-4403$ & Oklahoma Geological Survey \\
\hline Thomas Reid & $918-337-4233$ & $\begin{array}{l}\text { Lawrence Livermore National Laboratory } \\
\text { Stanford University } \\
\text { University of Alaska } \\
\text { University of Southern Califomia }\end{array}$ \\
\hline
\end{tabular}

\begin{tabular}{lcc}
\hline & $\begin{array}{c}\text { Metairie Site Office } \\
900 \text { Commerce Road, East } \\
\text { New Orleans, Louisiana 70123 }\end{array}$ \\
\hline Gene Pauling & $504-734-4131$ & Louisiana State University \\
\hline
\end{tabular}




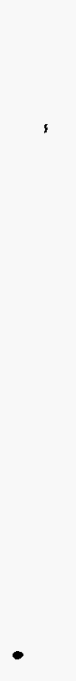




\section{CHEMICAL FLOODING- SUPPORTING RESEARCH}

\section{IMPROVED TECHNIQUES FOR FLUID DIVERSION IN OIL RECOVERY}

\author{
Contract No. DE-AC22-92BC14880
}

\section{New Mexico Institute of Mining and Technology Petroleum Recovery Research Center Socorro, N. Mex.}

Contract Date: Sept. 17, 1992

Anticipated Completion: Sept. 30, 1995

Government Award: \$200,054

\section{Principal Investigators:}

Randall S. Seright

F. David Martin

Project Manager: Jerry Casteel

Bartlesville Project Office

Reporting Period: Jan. 1-Mar. 31, 1995

\section{Objectives}

This project has two general objectives. The first objective is to compare the effectiveness of gels in fluid diversion with those of other types of processes. Several different types of fluid-diversion processes are being compared, including those using gels, foams, emulsions, and particulates. The ultimate goals of these comparisons are to (1) establish which of these processes is most effective in a given application and (2) determine whether aspects of one process can be combined with those of other processes to improve performance. Analyses are being performed to assess where the various diverting agents will be most effective (e.g., in fractured vs. unfractured wells, in deep vs. near-wellbore applications, in reservoirs with vs. without crossflow, or in injection wells vs. production wells). Experiments are being performed to verify which materials are the most effective in entering and blocking high-permeability zones. Another objective of the project is to identify the mechanisms by which materials (particularly gels) selectively reduce permeability to water more than to oil. In addition to establishing why this occurs, this research attempts to identify materials and conditions that maximize this disproportionate permeability reduction.

\section{Summary of Technical Progress}

\section{Correlation of Fracture Width and Permeability}

.While examining gel properties in fractured cores, conductivity has been routinely used to characterize fractures. Fracture conductivity $\left(\mathrm{k}_{\mathrm{f}} \mathrm{w}_{\mathrm{f}}\right)$ is the product of fracture permeability $\left(k_{f}\right)$ and fracture width $\left(w_{f}\right)$. Fracture conductivities are 
reported because they can be determined conveniently and accurately from pressure drops, flow rates, and the Darcy equation. ${ }^{1}$ For the experiments to date, fracture conductivities have ranged from 23 to $57,000 \mathrm{D}-\mathrm{cm}$.

Perhaps the flow properties of fractures would be understood more readily if a given $\mathrm{k}_{\mathrm{f}} \mathrm{w}_{\mathrm{f}}$ could be separated into its components of permeability and width. For this separation, one of the components must be measured by an independent method. In concept, $w_{f}$ could be measured directly if the fracture faces were smooth and parallel; they usually are neither.

Results from tracer studies have been used for an independent estimate of the average width of the fractures in core experiments. The cores were initially saturated with brine with no tracer. Brine with a potassium iodide tracer was then injected, and the tracer concentration in the effluent was measured spectrophotometrically. Because the flow capacities of the fractures were at least 12 times as great as the flow capacities of the adjacent rock, ${ }^{2}$ the first tracer detected in the core effluent gives a good estimate of the fracture volume $\left(V_{f}\right)$. Because the lengths $\left(L_{f}\right)$ and heights $\left(h_{f}\right)$ of the fractures are known accurately, average fracture widths can be calculated with the use of Eq. 1.

$$
w_{f}=\frac{V_{f}}{L_{f} h_{f}}
$$

By dividing $k_{f} w_{f}$ by $w_{f}, k_{f}$ can be estimated. These calculations were used to generate Fig. 1, which plots fracture width vs. fracture permeability for several of the fractured cores. Fracture widths ranged from 0.02 to $0.16 \mathrm{~cm}$, and the estimated fracture permeabilities ranged from 1,650 to $360,000 \mathrm{D}$.

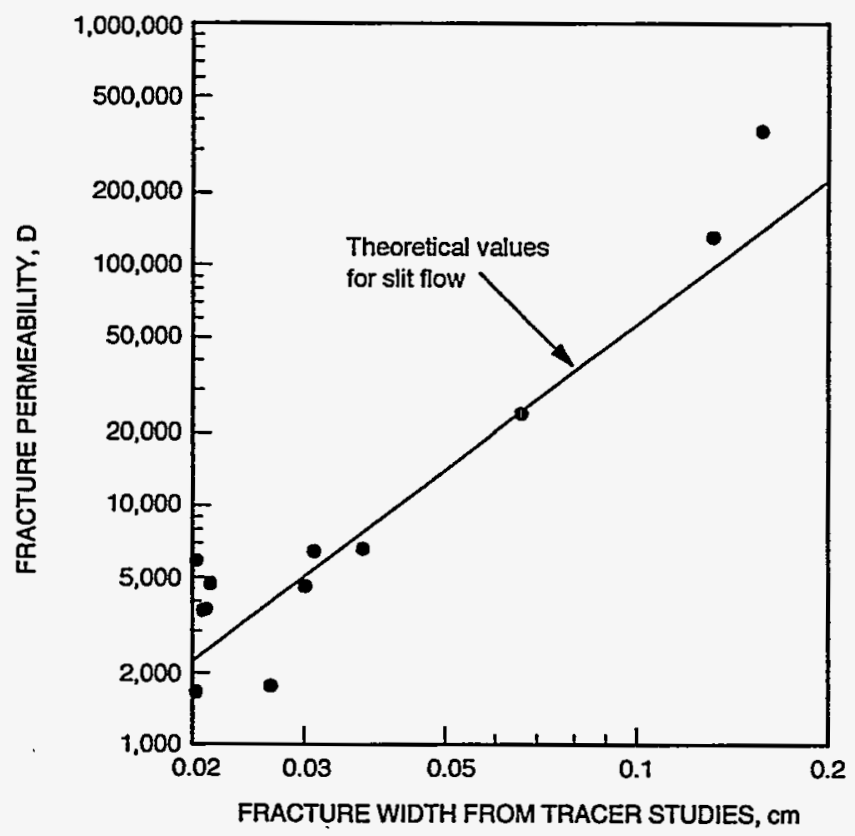

Fig. 1 Correlation of fracture width with fracture permeability.
The solid line in Fig. 1 shows the relation predicted between fracture width and fracture permeability for laminar flow through a slit (parallel plates). ${ }^{3}$ The theoretical relation is given by Eq. 2 , where $\mathrm{w}_{\mathrm{f}}$ is in centimeters and $\mathrm{k}_{\mathrm{f}}$ is in darcys. The predictions match the data reasonably well.

$$
k_{f}=\frac{w_{f}^{2}}{12} \times 1.013 \times 10^{8}
$$

\section{Propagation of Gels Through Fractures}

Gels can be dehydrated as they extrude through fractures. This dehydration can substantially retard the rate of gel propagation through a fracture. Additional experiments were performed to investigate this behavior. In these experiments, fractured Berea sandstone cores that were $115 \mathrm{~cm}$ in length and $14.5 \mathrm{~cm}^{2}$ in cross section (square) were used. Four internal pressure taps were equally spaced along the length of the fracture. The conductivities of these fractures ranged from 138 to $56,600 \mathrm{D}-\mathrm{cm}$, estimated fracture widths ranged from 0.029 to $0.16 \mathrm{~cm}$, and estimated fracture permeabilities ranged from 4,760 to $360,000 \mathrm{D}$.

Preformed Cr(II)-acetate-HPAM gels containing 0.5\% HPAM (Allied Colloids Alcoflood $935^{\circledR}$, molecular weight $\approx 5 \times 10^{6}$ daltons, degree of hydrolysis; 5 to $10 \%$ ), $0.0417 \%$ $\mathrm{Cr}(\mathrm{III})$-acetate, and $1 \%$ sodium chloride $(\mathrm{NaCl})(\mathrm{pH}=6)$ were forced through these fractures. The gelation time for this composition was roughly $5 \mathrm{~h}$ at $41^{\circ} \mathrm{C}$. The gels were aged at $41^{\circ} \mathrm{C}$ for either 10 or $24 \mathrm{~h}$ before injection. Through observation of the effluent from a given core and the pressures along the core, the gel front could be monitored in the fracture during gel injection. Figure 2 shows the results for experiments in three fractured cores. The position of the gel front was plotted vs. the fracture volumes of gel injected. Fracture volumes ranging from $12.6 \mathrm{~mL}$ for the least conductive fracture to $73.1 \mathrm{~mL}$ for the most conductive fracture were determined from tracer studies.

The solid curve (without data points) in Fig. 2 shows the ideal case expected if gel propagation was not retarded by gel dehydration or other factors (i.e., the fracture would be completely filled with gel after injecting one fracture volume of gel). For the three corefloods performed, gel transport was retarded to varying degrees, depending on the fracture conductivity and the age of the gel. The greatest retardation occurred for the 24-h-old gel in the least conductive fracture $\left(\mathrm{k}_{\mathrm{f}} \mathrm{w}_{\mathrm{f}}=138 \mathrm{D}-\mathrm{cm}\right)$. In that case, 35 fracture volumes were required for the gel to reach the end of the core (open circles in Fig. 2). An average pressure gradient of $65.4 \mathrm{psi} / \mathrm{ft}$ was required to extrude the gel through this fracture. For comparison, a 24-h-old gel in a fracture with $\mathrm{k}_{\mathrm{f}} \mathrm{w}_{\mathrm{f}}=17,300 \mathrm{D}-\mathrm{cm}$ reached the end of the fracture after injection of 7.7 fracture volumes of gel (solid circles in Fig. 2). In this case the average pressure gradient was $10.8 \mathrm{psi} / \mathrm{ft}$ during gel injection. For the third coreflood (solid diamonds in Fig. 2), a 10-h-old gel was 


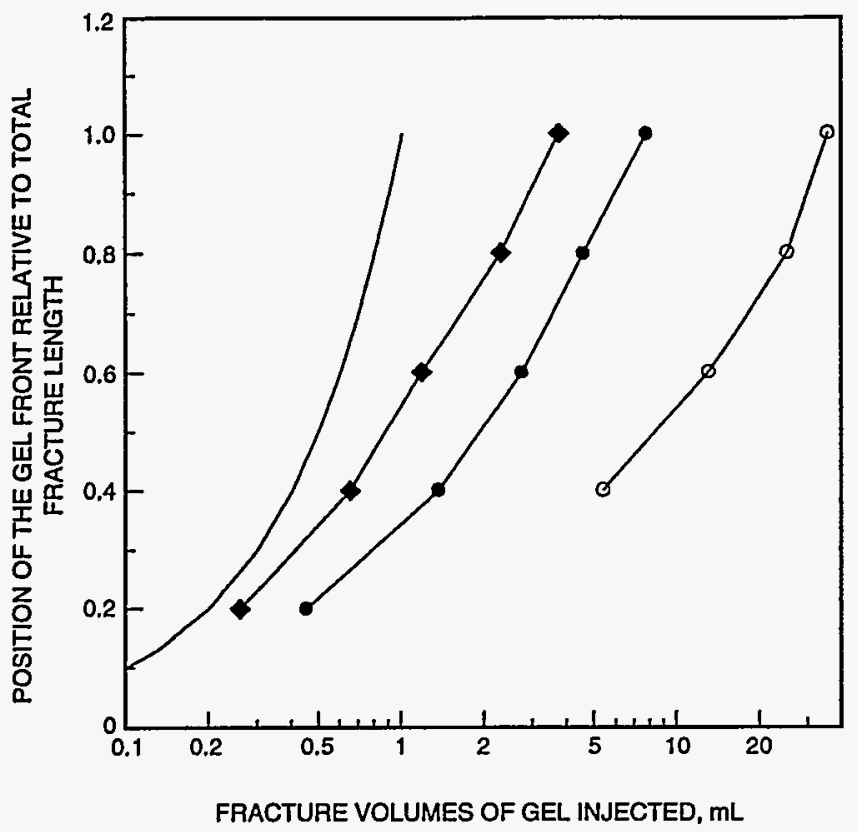

Fig. 2 Propagation of $\mathrm{Cr}(\mathrm{III})$-acetate-HPAM gels through 115-cmlong fractured cores. -, ideal case. $\downarrow$, gel age, $10 \mathrm{~h} ; \mathrm{w}_{\mathrm{f}}, 0.16 \mathrm{~cm} ; \mathrm{k}_{\mathrm{f}} \mathrm{w}_{\mathrm{f}}$, $56,600 \mathrm{D}-\mathrm{cm}$. $\bullet$, gel age, $24 \mathrm{~h} ; w_{\mathrm{f}}, 0.13 \mathrm{~cm} ; k_{\mathrm{f}} w_{\mathrm{f}}, 17,300 \mathrm{D}-\mathrm{cm} . \circ$, gel age, $24 \mathrm{~h} ; \mathrm{w}_{\mathrm{f}}, 0.029 \mathrm{~cm} ; \mathrm{k}_{\mathrm{f}} \mathrm{w}_{\mathrm{f}}, 138 \mathrm{D}-\mathrm{cm}$.

extruded through a fracture with $\mathrm{k}_{\mathrm{f}} \mathrm{w}_{\mathrm{f}}=56,600 \mathrm{D}-\mathrm{cm}$. In this experiment the gel reached the core outlet after injection of 3.7 fracture volumes of gel, and the average pressure gradient was $9.9 \mathrm{psi} / \mathrm{ft}$. For consistency with earlier results, ${ }^{4}$ a minimum pressure gradient was required to extrude a given gel through a given fracture. In other words, the pressure gradient was fairly insensitive to injection rate during extrusion of a given gel through a fracture.

The results in Fig. 2 indicate that the rate of gel propagation decreases and the degree of gel dehydration increases as $\mathrm{k}_{\mathrm{f}} \mathrm{w}_{\mathrm{f}}$ decreases. Of course, for a given injection rate, the pressure gradient increases with decreasing $\mathrm{k}_{\mathrm{f}} \mathrm{w}_{\mathrm{f}}$. It seems likely that the level of gel dehydration is closely tied to the pressure gradient experienced by the gel.

\section{Microorganisms as Blocking Agents}

An extensive literature survey was conducted to determine if microorganisms can be superior to gels as blocking agents. Details of the survey and its analysis can be found in Ref. 5 . The literature survey indicated that selective plugging could be achieved if the nutrients or the microorganisms could be placed selectively into high-permeability thief zones. Because the flow properties of the nutrients are no different from those of gelants, their placement characteristics are similar to those of gelants. Specifically, for a given distance of penetration into a high-permeability zone, the distance of penetration into a less-permeable zone will be no less for the nutrient than for a gelant with a water-like mobility. If a viscous nutrient is used (e.g., molasses or corn syrup), nutrient penetration into less-permeable zones increases.

From one perspective, microorganisms could be viewed as particulates. Because of their narrow size distribution, certain microorganisms could, in concept, provide the advantageous placement characteristics associated with monodisperse particulates. A suspension of microorganisms could penetrate readily into a high-permeability zone, whereas size restrictions prevent them from entering less-permeable zones. Most microorganisms, however, are rod-shaped. The rod-shaped microorganisms act as particulates with a size distribution. Theoretical analyses were performed on the basis of Darcy's law and basic formation damage concepts to examine how particle shape affects the apparent size distribution. ${ }^{5}$ These analyses revealed that, for a given permeability contrast, there is a maximum aspect ratio (length/diameter) that should not be exceeded for rod-shaped microorganisms to be more selective than a waterlike gelant during placement. The maximum allowable aspect ratio for the rod-shaped microorganisms increases with increasing permeability contrast between high- and low-permeability zones. Maximum selectivity is achieved when the aspect ratio approaches one (i.e., near spherical). When it is near spherical, the placement characteristics of the uniformly sized microorganisms approach those of monodisperse particulates.

\section{References}

1. R. S. Seright, Improved Techniques for Fluid Diversion in Oil Recovery Processing, Annual Report, DOE Contract No. DE-AC22-92BC14880, p. 118, December 1993.

2. R. S. Seright, Improved Techniques for Fluid Diversion in Oil Recovery Processes, Annual Report, DOE Contract No. DE-AC22-92BC14880, pp. 65-113, March 1995.

3. R. B. Bird, W. E. Stewart, and E. N. Lightfoot, Transport Phenomena, John Wiley \& Sons, New York, N.Y., 1960.

4. R. S. Seright, Gel Placement in Fractured Systems, paper SPE 27740 presented at the Ninth Society of Petroleum Engineers/U.S. Department of Energy Symposium on Improved Oil Recovery, Tulsa, Okla., April 17-20, 1994.

5. J. Liang and R. S. Seright, Use of Microorganisms as Blocking Agents, Report PRRC 95-2, New Mexico Petroleum Recovery Research Center, January 1995. 


\section{INVESTIGATION OF OIL RECOVERY \\ IMPROVEMENT BY COUPLING AN \\ INTERFACIAL TENSION AGENT AND \\ A MOBILITY CONTROL AGENT \\ IN LIGHT OIL RESERVOIRS}

Contract No. DE-AC22-92BC14886

Surtek, Inc.

Golden, Colo.

Contract Date: Sept. 28, 1992

Anticipated Completion: Sept. 30, 1995

Government Award: \$219,925

(Current year)

Principal Investigator:

Malcolm J. Pitts

Project Manager:

Jerry Casteel

Bartlesville Project Office

Reporting Period: Jan. 1-Mar. 31, 1995

\section{Objectives}

The objęctives of this study are to investigate two major areas concerning coinjecting an interfacial tension reduction agent(s) and a mobility control agent into petroleum reservoirs. The first objective will consist of defining the mechanisms of interaction of an alkaline agent, a surfactant, and a polymer on a fluid-fluid and a fluid-rock basis. The second is the improvement of the economics of the combined technology. This report examines the alteration of the concentration of alkali and polymer on the oil recovery economics of alkaline-surfactant-polymer (ASP) solution.

\section{Summary of Technical Progress}

For coreflooding and chemical makeup, $1000 \mathrm{mg} / \mathrm{L}$ of $\mathrm{NaCl}$ solution was used. Crude oil was from the Adena field, Morgan County, Colorado, a fluvial-deltaic reservoir. Crude oil has an API gravity of $42^{\circ}$. The crude is a dead oil with a viscosity of $3.8 \mathrm{cP}$ at $72^{\circ} \mathrm{F}$ and $1.3 \mathrm{cP}$ at the $180^{\circ} \mathrm{F}$ reservoir temperature. All studies performed for this report were performed at $150^{\circ} \mathrm{F}$. Dead crude oil viscosity was $1.4 \mathrm{cP}$ at $150^{\circ} \mathrm{F}$.

A previous series of corefloods indicated that the addition of polymer to the alkaline-surfactant solution prevented mobility ratio increases and improved oil recovery. ${ }^{1}$ As the result of the injection of $\mathrm{Na}_{2} \mathrm{CO}_{3}$-surfactant-polymer, up to $30 \%$ of the waterflood residual oil was recovered. The lithology of the rock matrix significantly affects oil recovery by ASP solutions. ${ }^{2}$
The ASP flood economics can be improved either by decreasing chemical use or by increasing oil recovery efficiency. Table 1 lists the cost of the ASP injectants used in this portion of the study.

\section{TABLE 1}

Cost of Injected Alkaline-Surfactant-Polymer Solution

\begin{tabular}{lccc}
\hline \multicolumn{1}{c}{ Chemical } & $\begin{array}{c}\text { Cost per } \\
\text { injected barrel, } \\
\$ / \mathbf{b b l}\end{array}$ & $\begin{array}{c}\text { Pore volume } \\
\text { injected }\end{array}$ & $\begin{array}{c}\text { Cost, } \\
\$ / \mathrm{bbl} \mathrm{PV}\end{array}$ \\
\hline $1.0 \mathrm{wt} \% \mathrm{Na}_{2} \mathrm{CO}_{3}$ & 0.228 & 0.30 & 0.068 \\
$0.2 \mathrm{wt} \%$ Petrostep B-100 & 0.665 & 0.30 & 0.200 \\
$500 \mathrm{mg} / \mathrm{L}$ Flopaam 3330S & 0.262 & 0.60 & 0.157 \\
\hline
\end{tabular}

Polymer and surfactant are the most costly injectants and therefore are the key components to affect economics. Either decreasing surfactant concentration in the ASP injected slug or decreasing the volume of ASP solution injected resulted in a decline in oil production. ${ }^{2}$

Two series of corefloods were performed to improve ASP oil recovery economics. In these series of corefloods, the objective was to increase oil recovery by changing the chemical injection sequence. An alkaline gradient was evaluated in the first series of corefloods. Radial corefloods with the use of Berea core were performed in which a pre-flush of alkaline-polymer solution was injected before the ASP solution. An injection of $30 \%$ pore volume (PV) of $1.0 \mathrm{wt} \%$ sodium carbonate $\left(\mathrm{Na}_{2} \mathrm{CO}_{3}\right)+0.2$ wt \% Petrostep B-100+ $500 \mathrm{mg} / \mathrm{L}$ Flopaam $3330 \mathrm{~S}$ was followed by $30 \% \mathrm{PV}$ of $500 \mathrm{mg} / \mathrm{L}$ Flopaam $3330 \mathrm{~S}$. A $5 \%$ PV of $2.0 \mathrm{wt} \% \mathrm{Na}_{2} \mathrm{CO}_{3}+$ $500 \mathrm{mg} / \mathrm{L}$ Flopaam $3330 \mathrm{~S}$ followed by $5 \%$ PV of $1.5 \mathrm{wt} \%$ $\mathrm{Na}_{2} \mathrm{CO}_{3}+500 \mathrm{mg} / \mathrm{L}$ Flopaam $3330 \mathrm{~S}$ was injected before the ASP solution in the coreflood with an alkaline-polymer pre-flush. A water flush of 1.5 to $2 \mathrm{PV}$ followed chemical injection. The pre-flush objective was to inject sufficient alkali to satiate consumption and to force the surfactant to go through optimum IFT and phase behavior states. Figure 1 compares radial coreflood cumulative oil recovery and oil cut of a coreflood with a graded alkaline-polymer pre-flush with a coreflood without an alkaline gradient. Incremental oil recovery increased $24 \%$ from $0.106 \mathrm{PV}$ (30.3\% waterflood residual oil) to 0.131 PV (38.6\% waterflood residual oil) when an alkaline-gradient pre-flush was injected.

The effect on the oil recovery economics of an alkalinepolymer pre-flush is shown in Table 2 . Oil recovery as well as the mass of alkali and polymer injected increased; thus the cost per incremental barrel of oil was unchanged.

The cost of an alkaline-polymer pre-flush is based on additional time as well as chemicals. Therefore the second series of corefloods investigated placed the alkaline gradient within the ASP slug. In this case, $5 \% \mathrm{PV}$ of $2.0 \mathrm{wt} \% \mathrm{Na}_{2} \mathrm{CO}_{3}$ $+0.2 \mathrm{wt} \%$ Petrostep B-100+500 $\mathrm{mg} / \mathrm{L}$ Flopaam $3330 \mathrm{~S}$ was 


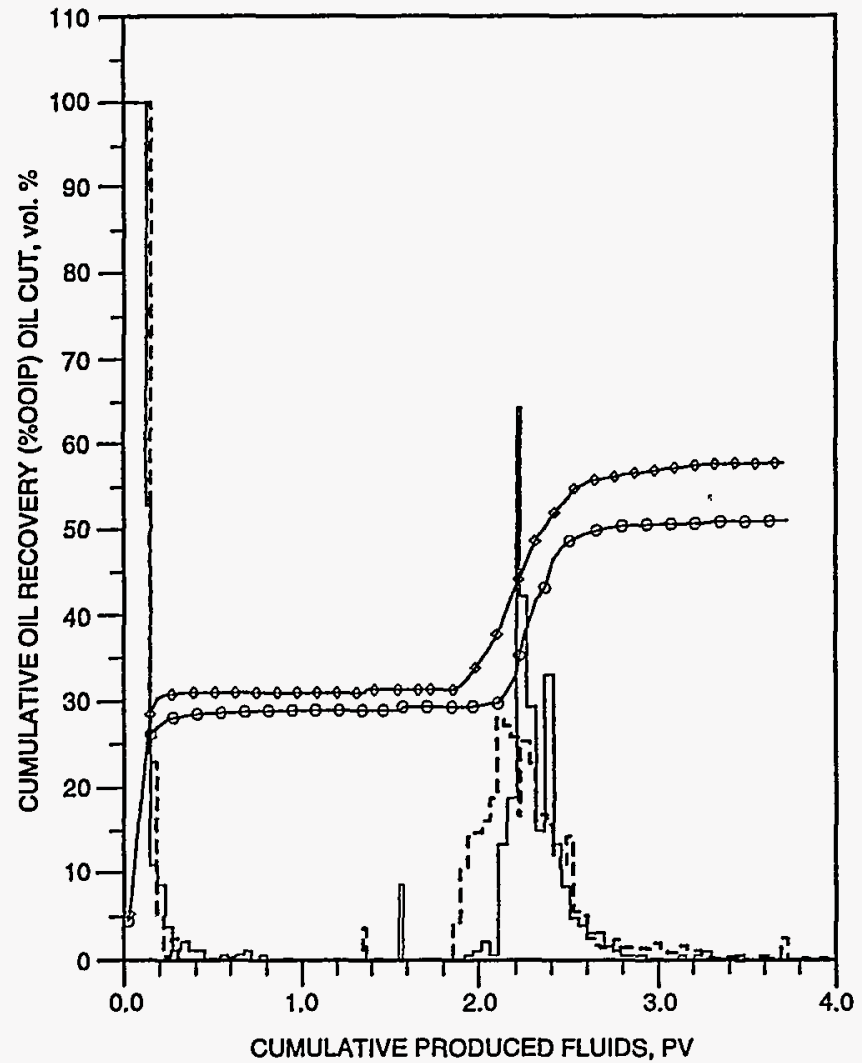

Fig. 1 Alkali gradient effect on alkaline-surfactant-polymer solution oil recovery $\left(0.3 \mathrm{PV}\right.$ of $\mathrm{Na}_{2} \mathrm{CO}_{3}+0.2 \mathrm{wt} \%$ Petrostep B-100 $+500 \mathrm{mg} / \mathrm{L}$ Flopaam 3330S). - - -, oil cut , 2.0 to $1.5 \mathrm{wt} \% \mathrm{Na}_{2} \mathrm{CO}_{3}+500 \mathrm{mg} / \mathrm{L}$ Flopaam $3330 S$ prior to ASP slug. $-\diamond-$, cumulative oil recovery, 2.0 to $1.5 \mathrm{wt} \% \mathrm{Na}_{2} \mathrm{CO}_{3}+500 \mathrm{mg} / \mathrm{L}$ Flopaam $3330 \mathrm{~S}$ prior to ASP slug. - oil cut, 1.0 wt $\% \mathrm{Na}_{2} \mathrm{CO}_{3}$, no gradient. -- , cumulative oil recovery, 1.0 wt \% $\mathrm{Na}_{2} \mathrm{CO}_{3}$, no gradient.

TABLE 2

\section{Cost per Incremental Barrel of Oil}

\begin{tabular}{lccc}
\hline $\begin{array}{c}\text { ASP injection } \\
\text { sequence }\end{array}$ & $\begin{array}{c}\text { Injectant } \\
\text { cost, } \\
\mathbf{\$} \mathbf{b b l ~ P V}\end{array}$ & $\begin{array}{c}\text { Incremental } \\
\text { oil recovery, } \\
\mathbf{P V}\end{array}$ & $\begin{array}{c}\text { Cost per } \\
\text { incremental bbl, } \\
\mathbf{\$} / \mathbf{b b l}\end{array}$ \\
\hline No gradient & 0.425 & 0.106 & 4.01 \\
Alkali gradient as pre-flush & 0.532 & 0.131 & 4.06 \\
Alkali gradient in ASP slug & 0.451 & 0.122 & 3.69 \\
\hline
\end{tabular}

injected followed by $5 \% \mathrm{PV}$ of $1.5 \mathrm{wt} \% \mathrm{Na}_{2} \mathrm{CO}_{3}+0.2 \mathrm{wt} \%$ Petrostep B-100 $+500 \mathrm{mg} / \mathrm{L}$ Flopaam $3330 \mathrm{~S}, 20 \%$ PV of 1.0 wt $\% \mathrm{Na}_{2} \mathrm{CO}_{3}+0.2$ wt \% Petrostep B-100 + $500 \mathrm{mg} / \mathrm{L}$ Flopaam $3330 \mathrm{~S}$, and ultimately by $30 \%$ PV of $500 \mathrm{mg} / \mathrm{L}$ Flopaam 3330S. A water flush of 1.5 to 2 PV followed chemical injection. Figure 2 shows the comparison of the corefloods. Placing the alkaline gradient within the ASP slug has little effect on oil recovery, but the cost per incremental barrel decreased, as shown in Table 2.

Figure 3 depicts the incremental increase as the result of an alkaline gradient within the ASP slug for a $\mathrm{Na}_{2} \mathrm{CO}_{3}-\mathrm{LXS}$

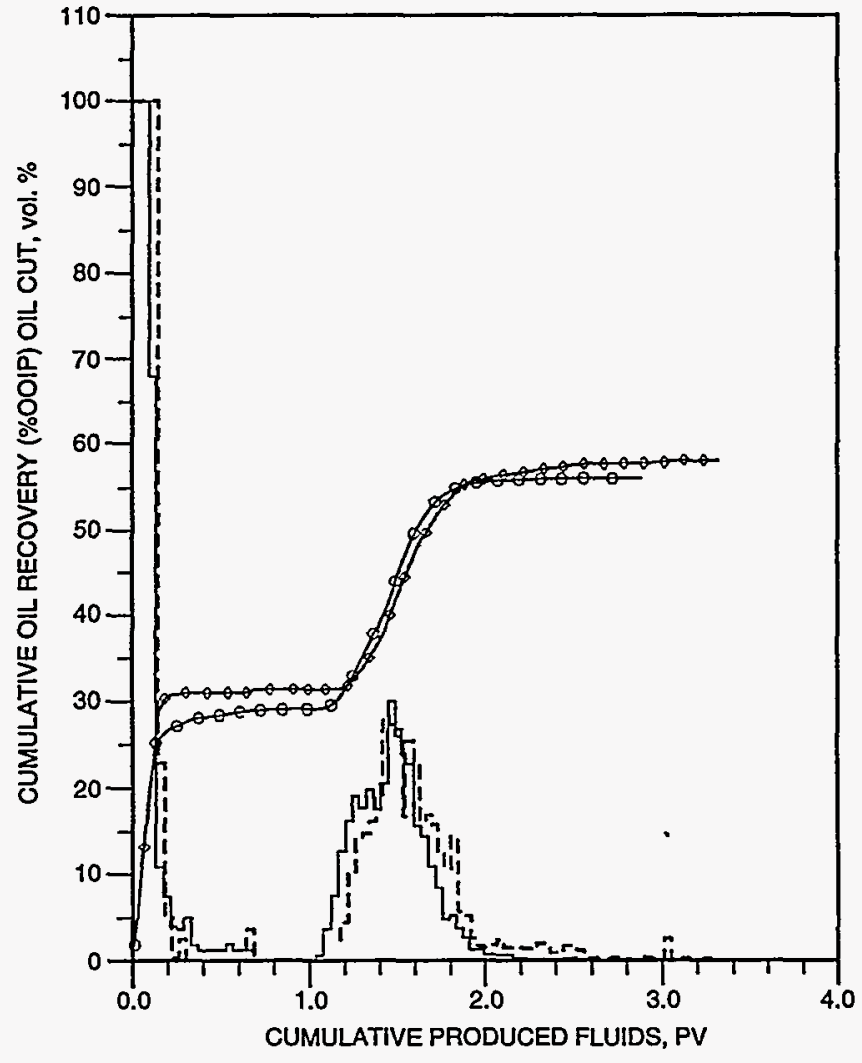

Fig. 2 Alkali gradient placement effect on alkaline-surfactantpolymer solution oil recovery $\left(0.3 \mathrm{PV}\right.$ of $\mathrm{Na}_{2} \mathrm{CO}_{3}+0.2 \mathrm{wt} \%$ Petrostep B-100 + $500 \mathrm{mg} / \mathrm{L}$ Flopaam 3330S). - - - , oil cut, 2.0 to $1.5 \mathrm{wt} \% \mathrm{Na}_{2} \mathrm{CO}_{3}$ $+500 \mathrm{mg} / \mathrm{L}$ Flopaam $3330 \mathrm{~S}$ prior to ASP slug. $-\diamond-$, cumulative oil recovery, 2.0 to 1.5 wt $\% \mathrm{Na}_{2} \mathrm{CO}_{3}+500 \mathrm{mg} / \mathrm{L}$ Flopaam $3330 \mathrm{~S}$ prior to ASP slug. - oil cut, 2.0 to 1.0 wt $\% \mathrm{Na}_{2} \mathrm{CO}_{3}$ gradient in ASP slug. $-\infty$, cumulative oil recovery, 2.0 to $1.0 \mathrm{wt} \% \mathrm{Na}_{2} \mathrm{CO}_{3}$ gradient in ASP slug.

420-Flopaam 3330S chemical combination. In this case, incremental oil recovery as the result of the ASP solution increased by $116 \%$ [from 0.065 PV $(19.4 \%$ waterflood residual oil) to $0.141 \mathrm{PV}$ (43.6\% waterflood residual oil)] when an alkaline gradient was included in the ASP slug. Cost per incremental barrel of oil decreased from $\$ 6.37$ to $\$ 2.89$.

The second series of corefloods was performed to determine if incremental oil recovery can be increased either by extending the polymer drive volume with a concentration taper or by increasing the polymer concentration initially in ASP solution with a polymer concentration taper through the polymer drive. In both cases the mass of polymer injected was identical to the previous evaluations. Figure 4 compares an alkaline gradient ASP followed with a block polymer drive coreflood with a coreflood having an extended polymer drive with a polymer concentration taper in addition to the alkaline gradient. The extended polymer drive followed by a polymer taper injection sequence was $5 \% \mathrm{PV}$ of 2.0 wt $\% \mathrm{Na}_{2} \mathrm{CO}_{3}+0.2 \mathrm{wt} \%$ Petrostep B-100 $+500 \mathrm{mg} / \mathrm{L}$ Flopaam $3330 \mathrm{~S}$ followed by $5 \% \mathrm{PV}$ of $1.5 \mathrm{wt} \% \mathrm{Na}_{2} \mathrm{CO}_{3}+$ 0.2 wt \% Petrostep B-100 $+500 \mathrm{mg} / \mathrm{L}$ Flopaam 3330S, $20 \%$ PV of $1.0 \mathrm{wt} \% \mathrm{Na}_{2} \mathrm{CO}_{3}+0.2 \mathrm{wt} \%$ Petrostep B-100+ 


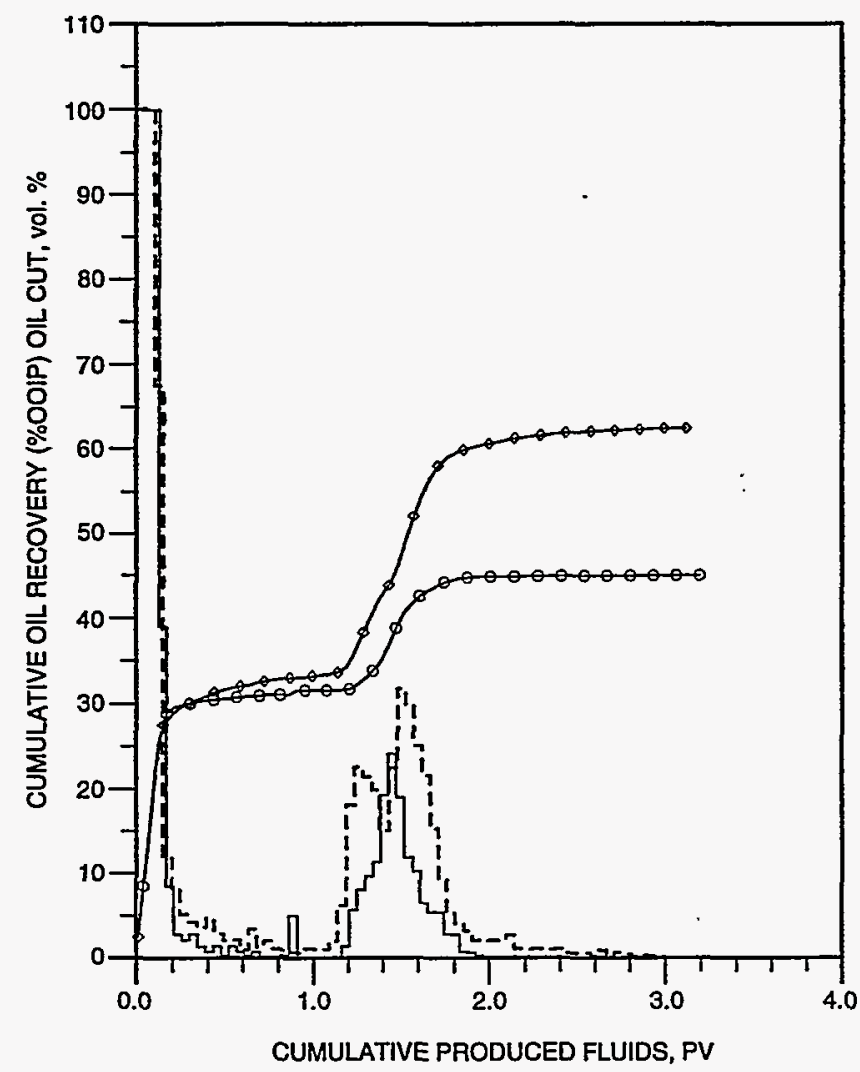

Fig. 3 Alkali gradient effect on alkaline-surfactant-polymer solution oil recovery $\left(0.3 \mathrm{PV}\right.$ of $\mathrm{Na}_{2} \mathrm{CO}_{3}+0.1 \mathrm{wt} \% \mathrm{LXS} 420+500 \mathrm{mg} / \mathrm{L}$ Flopaam $3330 \mathrm{~S}$ ). - - - , oil cut, 1.5 to $1.0 \mathrm{wt} \% \mathrm{Na}_{2} \mathrm{CO}_{3}+500 \mathrm{mg} / \mathrm{L}$ Flopaam $3330 \mathrm{~S}$ prior to ASP slug. - - - cumulative oil recovery, 1.5 to $1.0 \mathrm{wt} \%$ $\mathrm{Na}_{2} \mathrm{CO}_{3}+500 \mathrm{mg} / \mathrm{L}$ Flopaam $3330 \mathrm{~S}$ prior to ASP slug. —, oil cut, 0.5 wt \% $\mathrm{Na}_{2} \mathrm{CO}_{3}$, no gradient. $\longrightarrow$, cumulative oil recovery, 0.5 wt $\% \mathrm{Na}_{2} \mathrm{CO}_{3}$, no gradient.

$500 \mathrm{mg} / \mathrm{L}$ Flopaam $3330 \mathrm{~S}$, and ultimately by a polymer drive consisting of $15 \% \mathrm{PV}$ of $500 \mathrm{mg} / \mathrm{L}$ Flopaam $3330 \mathrm{~S}$ followed by $15 \%$ PV of $330 \mathrm{mg} / \mathrm{L}$ Flopaam $3330 \mathrm{~S}$ followed by $15 \%$ PV of $160 \mathrm{mg} / \mathrm{L}$ Flopaam $3330 \mathrm{~S}$. A water flush of 1.5 to $2 \mathrm{PV}$ followed chemical injection. No difference in oil recovery was observed.

Figure 5 compares an alkaline gradient ASP flood followed by ablock concentration polymer drive with a coreflood having a higher initial polymer concentration and a polymer concentration taper beginning in the alkaline gradientsurfactant-polymer slug, which continued through the polymer drive. The higher initial polymer concentration, polymer taper beginning in the alkaline gradient-surfactantpolymer slug injection sequence was $5 \% \mathrm{PV}$ of $2.0 \mathrm{wt} \%$ $\mathrm{Na}_{2} \mathrm{CO}_{3}+0.2$ wt \% Petrostep B-100 $+985 \mathrm{mg} / \mathrm{L}$ Flopaam

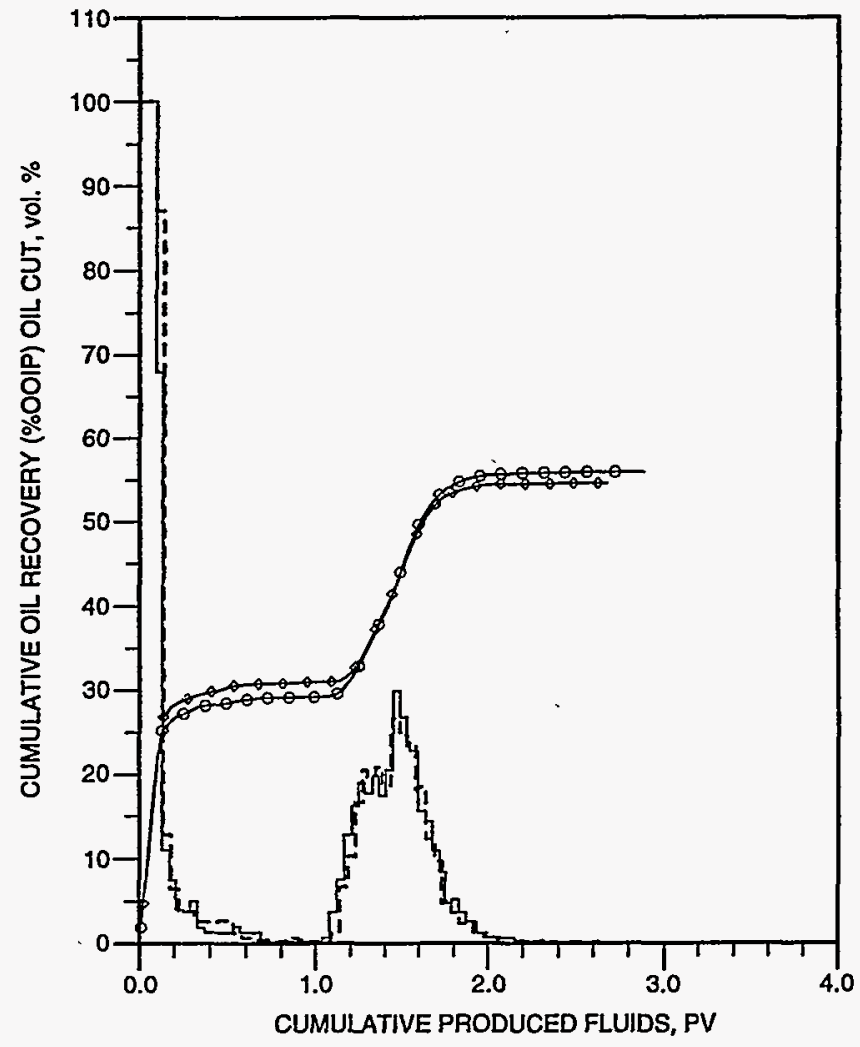

Fig. 4 Polymer drive solution concentration taper effect on alkalinesurfactant-polymer solution oil recovery $(0.3 \mathrm{PV}$ of 2.0 to $1.0 \mathrm{wt} \%$ $\mathrm{Na}_{2} \mathrm{CO}_{3}+0.2 \mathrm{wt} \%$ Petrostep B-100 + Flopaam 3330S). --- , oil cut, 500 to $160 \mathrm{mg} / \mathrm{L}$ Flopaam 3330S. $-\diamond-$, cumulative oil recovery, 500 to $160 \mathrm{mg} / \mathrm{L}$ Flopaam $3330 \mathrm{~S}$.— , oil cut, $500 \mathrm{mg} / \mathrm{L}$ Flopaam $3330 \mathrm{~S}$, no polymer taper. $-\infty-$, cumulative oil recovery, $500 \mathrm{mg} / \mathrm{L}$ Flopaam 3330S, no polymer taper.

$3330 \mathrm{~S}$ followed by $5 \% \mathrm{PV}$ of $1.5 \mathrm{wt} \% \mathrm{Na}_{2} \mathrm{CO}_{3}+0.2 \mathrm{wt} \%$ Petrostep B-100 + $980 \mathrm{mg} / \mathrm{L}$ Flopaam $3330 \mathrm{~S}, 10 \% \mathrm{PV}$ of 1.0 wt $\% \mathrm{Na}_{2} \mathrm{CO}_{3}+0.2$ wt \% Petrostep B-100 $+725 \mathrm{mg} / \mathrm{L}$ Flopaam $3330 \mathrm{~S}, 10 \% \mathrm{PV}$ of $1.0 \mathrm{wt} \% \mathrm{Na}_{2} \mathrm{CO}_{3}+0.2 \mathrm{wt} \%$ Petrostep B-100 $+500 \mathrm{mg} / \mathrm{L}$ Flopaam 3330S, and ultimately by a polymer drive consisting of $10 \% \mathrm{PV}$ of $500 \mathrm{mg} / \mathrm{L}$ Flopaam $3330 \mathrm{~S}$ followed by $10 \% \mathrm{PV}$ of $300 \mathrm{mg} / \mathrm{L}$ Flopaam $3330 \mathrm{~S}$ followed by $10 \% \mathrm{PV}$ of $160 \mathrm{mg} / \mathrm{L}$ Flopaam 3330S. A water flush of 1.5 to 2 PV followed chemical injection. In agreement with previous investigations, ${ }^{1}$ no additional oil recovery was observed when the concentration of polymer in the ASP slug was increased.

The study of methods to improve ASP economics will continue. The alteration of polymer concentration in the polymer drive will be studied in more detail. 


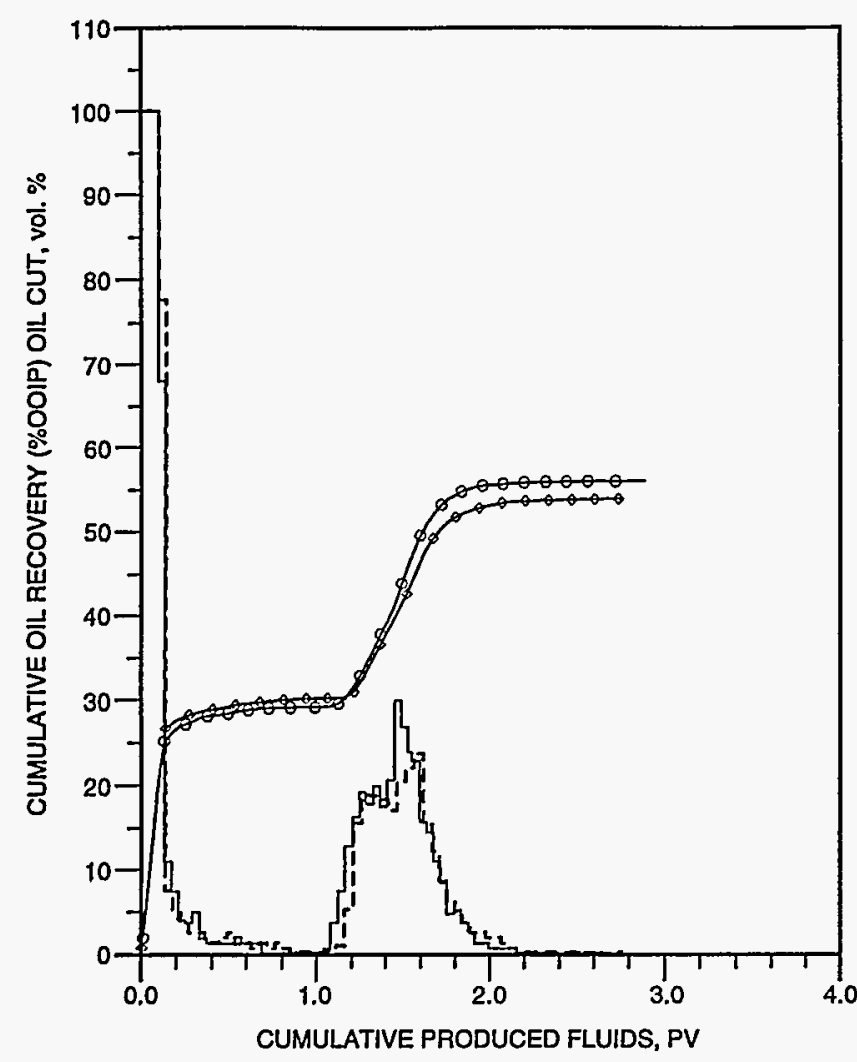

Fig. 5 Effect of higher initial polymer concentration with polymer taper beginning in the alkaline-surfactant-polymer solution on oil recovery (0.3 PV of 2.0 to $1.0 \mathrm{wt} \% \mathrm{Na}_{2} \mathrm{CO}_{3}+0.2 \mathrm{wt} \%$ Petrostep B-100 + Flopaam $3330 \mathrm{~S}$ ). - - - , oil cut , 985 to $160 \mathrm{mg} / \mathrm{L}$ Flopaam $3330 \mathrm{~S}$. - $\diamond-$, cumulative oil recovery, 985 to $160 \mathrm{mg} / \mathrm{L}$ Flopaam 3330S. _- oil cut, $500 \mathrm{mg} / \mathrm{L}$ Flopaam 3330S, no polymer taper. $-\infty$, cumulative oil recovery, $500 \mathrm{mg} / \mathrm{L}$ Flopaam 3330S, no polymer taper.

\section{References}

1. M. J. Pitts, Investigation of Oil Recovery Improvement by Coupling an Interfacial Tension Agent and a Mobility Control Agent in Light Oil Reservoirs, Annual Report, September 1994.

2. M. J. Pitts, Investigation of Oil Recovery Improvement by Coupling an Interfacial Tension Agent and a Mobility Control Agent in Light Oil Reservoirs, Quarterly Report, April 1-June 30, 1994.

\section{IMPROVING RESERVOIR CONFORMANCE USING GELLED POLYMER SYSTEMS}

Contract No. DE-AC22-92BC14881

\author{
University of Kansas \\ Center for Research \\ Lawrence, Kans.
}

Contract Date: Sept. 25, 1992

Anticipated Completion: Sept. 24, 1995

Government Award: \$707,123

\author{
Principal Investigators: \\ Don W. Green \\ G. Paul Willhite \\ Project Manager: \\ Jerry Casteel \\ Bartlesville Project Office
}

Reporting Period: Jan. 1-Mar. 31, 1995

\section{Objectives}

The general objectives of this project are to (l) identify and develop gelled polymer systems that have potential to improve reservoir conformance of fluid displacement processes, (2) determine the performance of these systems in bulk and in porous media, and (3) develop methods to predict the capability of these systems to recover oil from petroleum reservoirs.

This work focuses on three types of gel systems-an aqueous polysaccharide (KUSP1) system that gels as a function of $\mathrm{pH}$, the chromium(III)-polyacrylamide system, and the aluminum citrate-polyacrylamide system. Laboratory research is directed at the fundamental understanding of the physics and chemistry of the gelation process in bulk form and in porous media. This knowledge will be used to develop conceptual and mathematical models of the gelation process. Mathematical models will then be extended to predict the performance of gelled polymer treatments in oil reservoirs.

\section{Summary of Technical Progress}

\section{Physical and Chemical Characterization of Gel Systems}

Work has continued on a procedure to determine the size of polymer-gel aggregates that form during the gelation of the polyacrylamide-aluminum citrate system. The principal step in this procedure is the separation of the aggregates by size with the use of membrane dialysis. A material-balance check of the polymer charged and removed from the dialysis cells indicated a problem. Experiments are under way to determine why the material balance did not close. 


\section{Mechanisms of In Situ Gelation}

Flow experiments were conducted to determine the effect of residual oil on permeability reduction treatments with the use of the KUSP1-ester gel system. The KUSP1 biopolymer gels when the $\mathrm{pH}$ is reduced below a value of approximately 10.8. The $\mathrm{pH}$ is reduced by a reaction between the ester and water.

A 1-ft-long Berea core and a 2-in.-long carbonate field plug were flooded to residual oil saturation (ROS). Several pore volumes (PVs) of the KUSP1-ester gel system were injected through the cores. Posttreatment permeabilities were determined after the cores were shut in for a period of time to allow for gelation. Permeabilities of the cores are given in Table 1.

The treatments reduced the permeability of the Berea core by a factor of 84 and the permeability of the carbonate field plug by a factor of 350 in the presence of ROS. The long-term stabilities of the treatments are being assessed.

Flow experiments are in progress to study the permeability reduction by the polyacrylamide-aluminum citrate system in sandpacks. A displacement experiment in which a polymer solution without aluminum citrate was used was conducted to provide a basis for assessing the permeability reduction produced by the gel system. Ten $\mathrm{PV}$ of a $300-\mathrm{ppm}$, $\mathrm{HiVis} 350$ polymer solution were injected through a 4-ftlong sandpack over a period of $20 \mathrm{~d}$. No excessive flow resistance was observed. Brine was then injected to displace the polymer solution and to measure permeability. The polymer flood reduced the initial brine permeability of $3450 \mathrm{mD}$ by factors between 2.5 and 3.0, depending on flow rate.

A second flow experiment was conducted to assess permeability reduction produced by a gel solution containing $300 \mathrm{ppm}$ HiVis polyacrylamide and $15 \mathrm{ppm}$ aluminum. Solutions of polyacrylamide and aluminum citrate were mixed in line before injection into a 40-in.-long sandpack having an initial permeability of $3900 \mathrm{mD}$. A gel solution volume of 3.3 PV was injected over a period of $85 \mathrm{~h}$. No excessive flow resistance was observed along the sandpack length. The sandpack was shut in for $5 \mathrm{~d}$, and then several PV of brine were injected to displace the gel solution. The posttreatment permeability was then determined. The permeability was reduced by a factor ranging from 1.7 to 2.7 , depending on flow rate. The permeability reduction was

\section{TABLE 1}

Brine Permeabilities

\begin{tabular}{lccc}
\hline & \multicolumn{3}{c}{ Brine permeability, mD } \\
\cline { 2 - 4 } & $\begin{array}{c}\text { At } \mathbf{1 0 0 \%} \text { brine } \\
\text { saturation }\end{array}$ & $\begin{array}{c}\text { At residual oil } \\
\text { saturation }\end{array}$ & $\begin{array}{c}\text { After gel } \\
\text { treatment }\end{array}$ \\
\hline Berea core & 640 & 46 & 0.55 \\
Carbonate field plug & 39 & 14 & 0.04 \\
\hline
\end{tabular}

comparable to the polymer flood in which the injected solution contained no aluminum. Additional flow experiments are planned to determine if the polyacrylamidealuminum citrate system will significantly reduce permeability at other experimental conditions.

\section{Mathematical Modeling of Gel Systems}

A numerical model for in situ gelation of cross-linking polymer solutions is being developed. Preliminary simulations were performed to study viscous crossflow in a twolayered radial system. Initially, the assumption was made that the well had attained steady-state behavior after an extended period of waterflooding and that pressure was equalized across the height of the reservoir. At time $t=0$, a viscous solution was injected at a constant bottomhole pressure. Table 2 summarizes the values of the parameters used in the simulation.

Figure 1 describes the transport of the injected solution in the two layers as a function of time. The dark region denotes the initial solution, whereas the white region denotes the injected solution. The injected solution propagates at a faster rate in the top layer (higher permeability) than in the bottom layer (lower permeability), as expected. Consequently, the separation of the fronts of the injected solution in the two layers increases with time.

Some degree of viscous crossflow exists at the interface of the two layers. This crossflow is directed from the top layer toward the bottom layer in the region between the fronts of the injected solution in the two layers. Within a period of $24 \mathrm{~h}$, the injected solution from the top layer penetrates a distance of $50 \mathrm{~cm}$ into the bottom layer in the region between the two concentration fronts. This penetration is mainly the result of convective forces arising from viscous crossflow and not physical dispersion.

TABLE 2

\begin{tabular}{ll}
\hline Simulation Parameters for Radial \\
Flow in a Two-Layered Reservoir \\
\hline Bottomhole pressure, psi & 1000 \\
Wellbore radius, cm & 20 \\
External radius, cm & $1.54 \times 10^{4}$ \\
Compressibility, psi & $5.0 \times 10^{-5}$ \\
Initial viscosity, cP & 1 \\
Injected viscosity, cP & 10 \\
Top layer & \\
Height, cm & 0 to 500 \\
Radial permeability, mD & 100 \\
Vertical permeability, $\mathrm{mD}$ & 100 \\
Porosity & 0.20 \\
Bottom layer & \\
Height, cm & 500 to 1000 \\
Radial permeability, $\mathrm{mD}$ & 10 \\
Vertical permeability, mD & 10 \\
Porosity & 0.20 \\
\hline
\end{tabular}




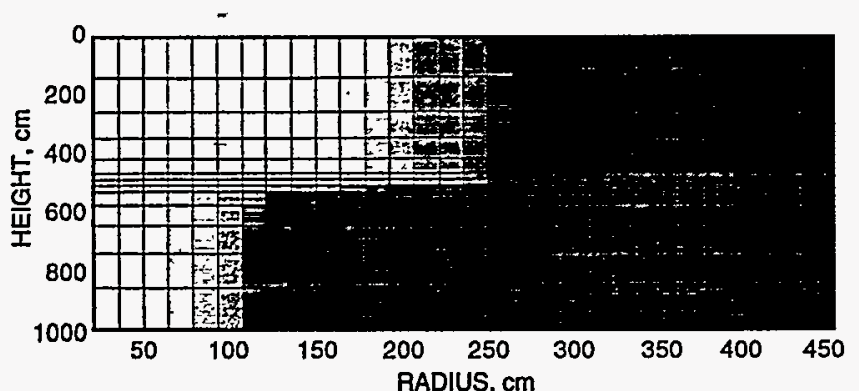

(a)

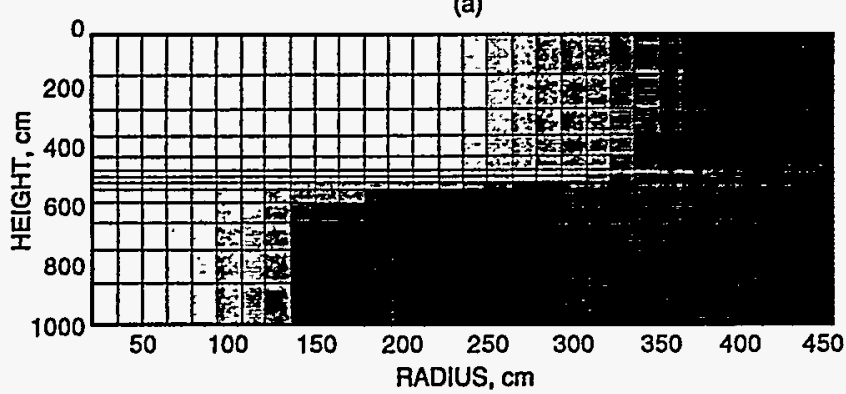

(b)

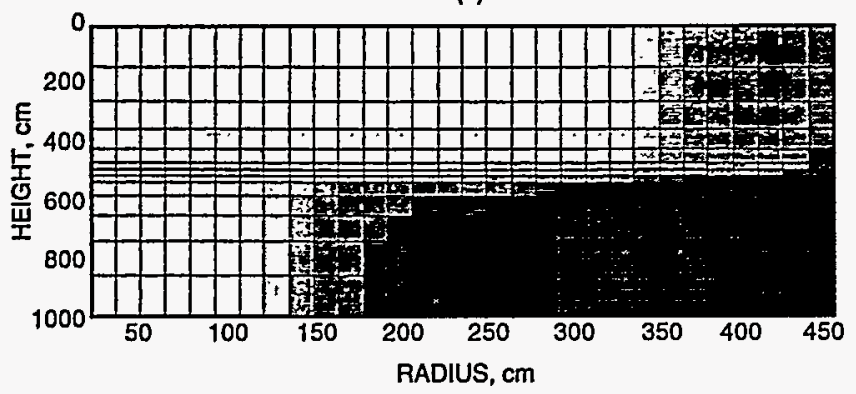

(c)

Fig. 1 Concentration profiles in a two-layered radial system with viscous crossflow. (a) Injected solution after $6 \mathrm{~h}$. (b) Injected solution after $12 \mathrm{~h}$. (c) Injected solution after $24 \mathrm{~h}$.

\section{SURFACTANT LOSS CONTROL \\ IN CHEMICAL FLOODING: \\ SPECTROSCOPIC AND CALORIMETRIC \\ STUDY OF ADSORPTION AND \\ PRECIPITATION ON RESERVOIR \\ MINERALS}

Contract No. DE-AC22-92BC14884

Columbia University
New York, N.Y.

Contract Date: Sept. 30, 1992

Anticipated Completion: Sept. 29, 1995

Government Award: \$200,535

(Current year)

Principal Investigator:

P. Somasundaran

Project Manager:

Jerry Casteel

Bartlesville Project Office

Reporting Period: Jan. 1-Mar. 31, 1995

\section{Objective}

The objective of this research is to elucidate the mechanisms of adsorption and surface precipitation of flooding surfactants on reservoir minerals. The effect of surfactant structure, surfactant combinations, and other inorganic and polymeric species will also be determined. Solids of relevant mineralogy and a multipronged approach consisting of microspectroscopy and nanospectroscopy, microcalorimetry, electrokinetics, surface tension, and wettability will be used to achieve the goals. The results of this study should help in controlling surfactant loss in chemical flooding and also in developing optimum structures and conditions for efficient chemical flooding processes.

\section{Summary of Technical Progress}

Earlier reported results on the absorption-desorption behaviors of single surfactant as well as mixtures of surfactant of tetradecyl trimethyl ammonium chloride (TTAC) and pentadecyl ethoxylated nonyl phenol (NP-15) indicated that the phenomena in mixed surfactant systems are more complex than those in single surfactant systems. So that the mechanisms involved in adsorption and desorption processes of a mixed surfactant system can be betterunderstood, changes in the ratios of TTAC:NP-15 mixtures after adsorption both at the alumina-water interface and in the bulk are discussed. The initial mixing ratios of TTAC:NP-15 changed significantly after adsorption over the concentration ranges studied. The 
adsorption behavior is directly related to these changes of mixing ratios. The possible structure of the adsorbed layer is also discussed for different mixing ratios. In the low concentration range, electrostatic attraction between the cationic surfactant (TTAC) and the negatively charged alumina surface is dominant, and the adsorption of TTAC is higher than that of NP-15. With an increase in total surfactant concentration, pre-adsorbed TTAC molecules function as anchors and induce the adsorption of NP-15. Strong synergism between the two surfactants is observed over this concentration range. Adsorbed NP-15 provides a steric barrier to further adsorption of TTAC, and the adsorption of TTAC is suppressed. For the development of a model that can predict adsorption of both components as a function of their activity in the mixed surfactant system, the monomer concentrations of TTAC and NP-15 in mixtures of different ratios were measured with ultrafiltration. Interestingly, the monomer concentrations measured by the ultrafiltration method were different from the predictions of the regular solution theory. This result exposes the limitations of the regular solution theory for the current mixed surfactant system; a more suitable model needs to be developed.

\section{Changes in Surfactant Ratios of TTAC to NP-15 After Adsorption}

Changes in surfactant ratio for an initial TTAC to NP-15 mixture of 4:1 are plotted in Fig. 1. The ratios of TTAC: NP- 15 both at the alumina-water interface and in the supernatant after adsorption are constantly changing over the concentration range studied.

The TTAC adsorbs first on alumina through electrostatic interaction. As a result of this preferential adsorption, the ratio of TTAC to NP-15 is lower than 4.0 in the initial stages. Once sufficient TTACadsorbs at the interface, NP-15 is co-adsorbed through interactions between the hydrocarbon chains. Preadsorbed TTAC will function as anchors and induce the adsorption of NP-15, which leads to formation of mixed surfactant aggregates at the interface. The activity of the NP-15 is higher than that of the TTAC, which results in excess TTAC in the supernatant and thus leads to a high ratio of TTAC to NP-15 in the supernatant. This is also seen as a decrease of the surfactant ratio at the interface. The NP-15 molecule is larger than the TTAC molecule, and hence the steric hindrance to the further adsorption of TTAC leads to depression of TTAC adsorption. Once adsorption of NP-15 is complete, TTAC adsorption continues, and eventually equilibrium is attained. At high concentrations of surfactant, the initial mixing ratio is reflected both at the interface and in bulk solution after adsorption. Thus partitioning of surfactant to the interface does not depend on the initial mixing ratio, particularly at low concentrations. A combination of electrostatic and hydrophobic interactions is responsible for the observed phenomena.

Similar changes for a 1:1TTAC:NP-15 mixture are shown in Fig. 2. The adsorption behavior in this system is similar to

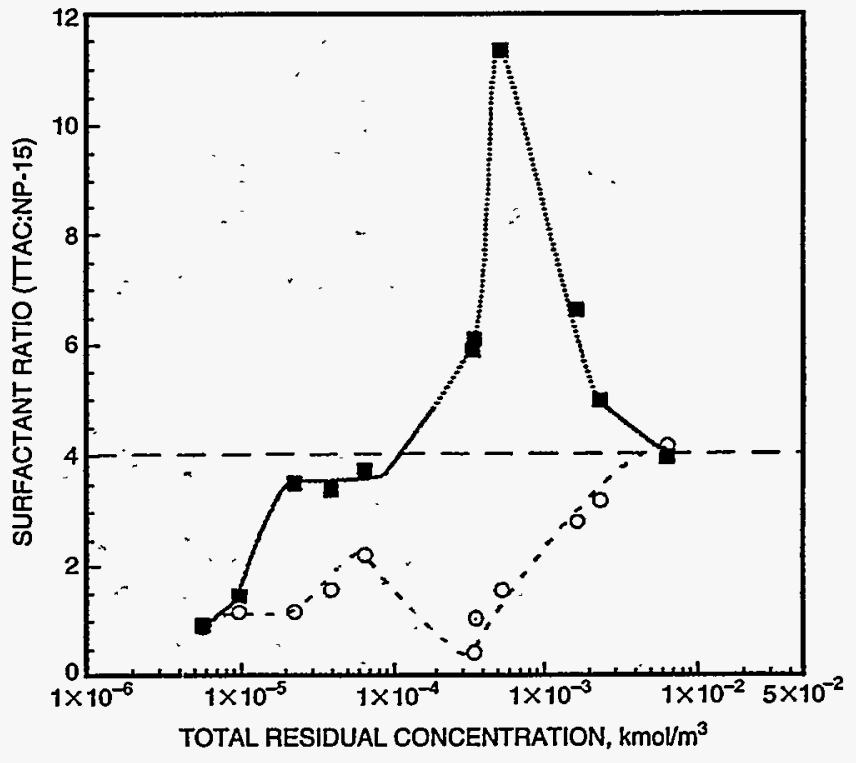

Fig. 1 Changes in surfactant ratios (TTAC to NP-15) after adsorption for an initial 4:1 mixing ratio. $n$, supernatant. $O$, interface.

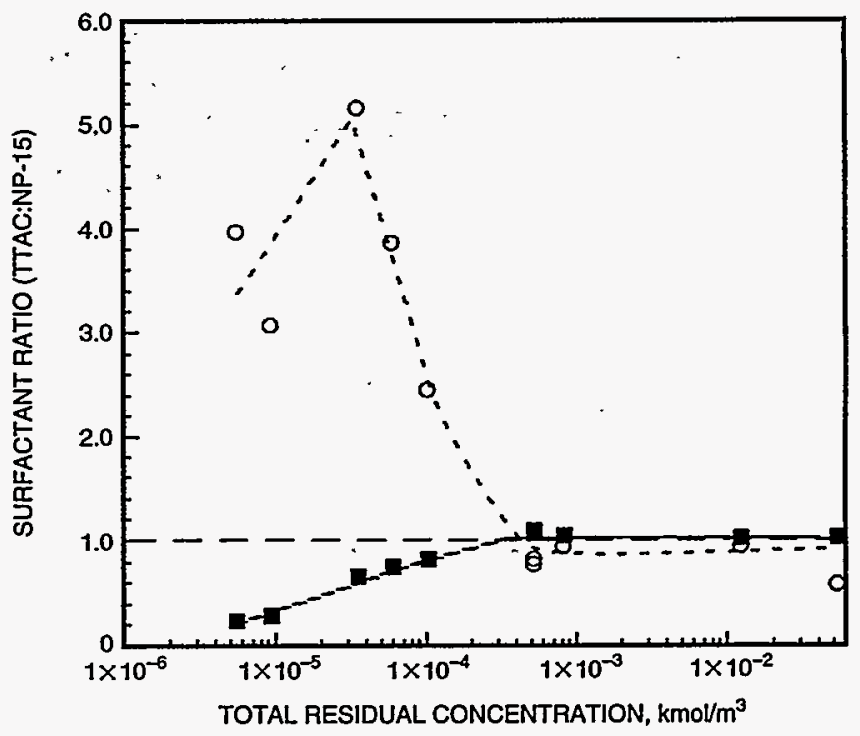

Fig. 2 Changes in surfactant ratios (TTAC to NP-15) after adsorption at the alumina-water interface for an initial mixing ratio of 1:1. $O$, interface. $m$, supernatant.

that in the 4:1 TTAC:NP-15 mixture system. At low concentrations, more TTAC molecules will be adsorbed at the alumina-water interface by electrostatic attraction and the mixing ratio in supernatant is lower than 1.0 , but the ratio at the interface is far greater than 1.0. The maximum surfactant ratio at the interface is higher than that in the 4:1 TTAC: NP-15 system (Fig. 1). This indicates that the synergism between these two surfactants is stronger in the 1:1 TTAC: NP-15 system than in the 4:1 TTAC:NP-15 system. The behavior in the supernatant is, however, not very complicated, and at high concentrations the initial mixing ratio is reflected both in the bulk and at the interface. 
For a 1:4 TTAC:NP-15 mixture, the changes in mixing ratio indicate similar interactions, particularly at low concentrations (Fig. 3).

Because the TTAC content is very low, adsorption of TTAC also will be low and thus lead to lower NP-15 adsorption as well. There was no maximum or minimum observed for the ratios either in the supernatant or at the interface. The concentration of pre-adsorbed TTAC molecules is not enough to induce significant co-adsorption of NP-15.

A comparison of the changes in mixing ratios after adsorption for the different mixtures shows that the adsorption behavior in this system depends on both the relative mixing ratio and the absolute concentration ranges. If the synergism and steric hindrance in these systems are considered, it can be concluded that adsorption of TTAC will be decided by the relative and absolute quantity of NP-15 in the mixture. If the relative and absolute quantity of NP-15 is low, synergism between these two surfactants can be seen. At high concentrations, the absolute quantity of NP-15 is significant and steric hindrances will be dominant; thus the adsorption of TTAC will be suppressed. Conversely, adsorption of NP-15 will simply depend on the mixing ratio of TTAC:NP-15 in the mixtures. With the increase of TTAC ratio, the adsorption of NP-15 will be enhanced.

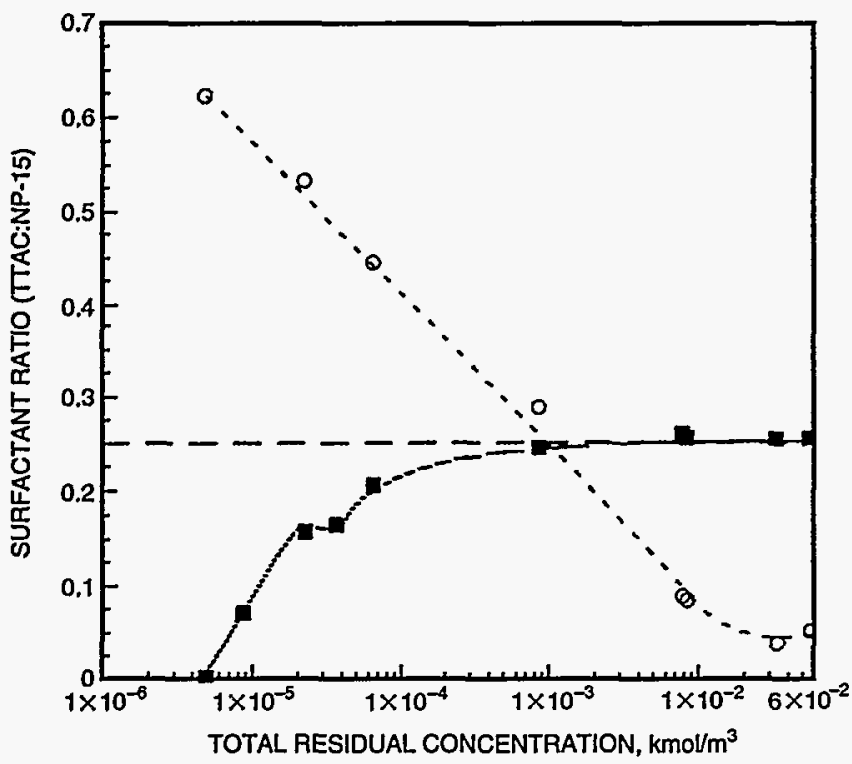

Fig. 3 Changes in surfactant ratios (TTAC to NP-15) after adsorption at the alumina-water interface for an initial mixing ratio of 1:4. $\circ$, interface. $\square$, supernatant.

\section{Monomer Concentrations of TTAC and NP-15 in Their Mixed Solutions}

The monomer concentrations of both TTAC and NP-15 in their mixtures were measured with ultrafiltration. A YM-3 membrane from Amicon Company, with a molecular-weight cutoff of 3000 , was used for ultrafiltration. All experiments were performed at an ionic strength of $0.2 \mathrm{M}$ sodium chloride.
The monomer concentrations of TTAC in its mixtures with NP-15 are shown in Fig. 4.

The TTAC monomer concentrations are lower in mixtures with NP-15 than in TTAC alone. With an increase of NP-15 content in the mixtures, the monomer concentrations of TTAC are further decreased. Monomer concentrations of TTAC in the mixtures keep increasing even above the critical micelle concentration (CMC) of the mixtures. This is in contrast to the single surfactant system, where the monomer concentration is relatively constant above the CMC. The TTAC monomer concentrations were also calculated with the use of the regular solution theory. A comparison of the two shows that the TTAC monomer concentrations in this mixed surfactant system measured by ultrafiltration and calculated with the use of regular solution theory are similar. This is not the case for NP-15 because the monomer concentrations measured by ultrafiltration are different from those calculated with the use of regular solution theory (see Fig. 5). The ultrafiltration results show the monomer concentrations to be constant over the concentrations immediately above the mixed CMC

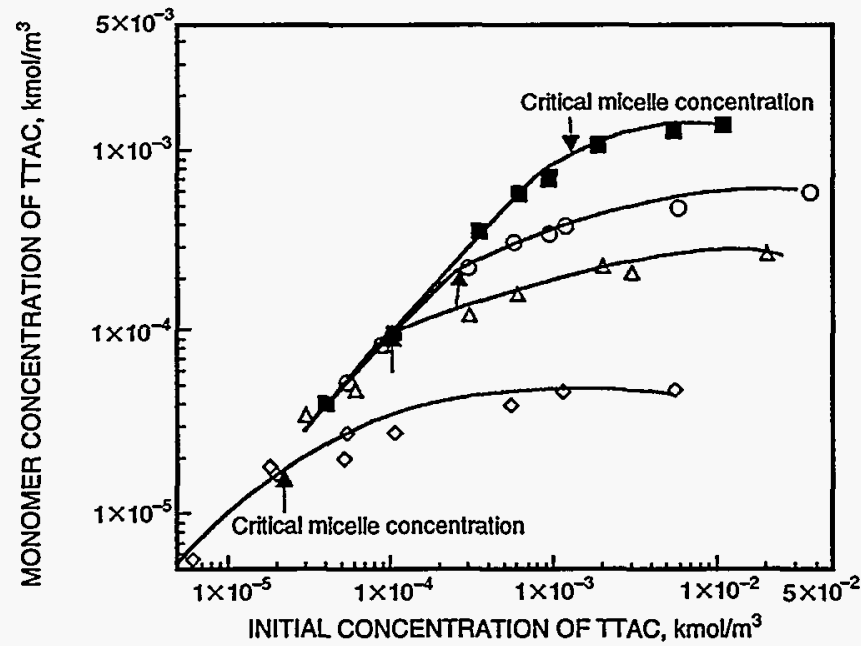

(a)

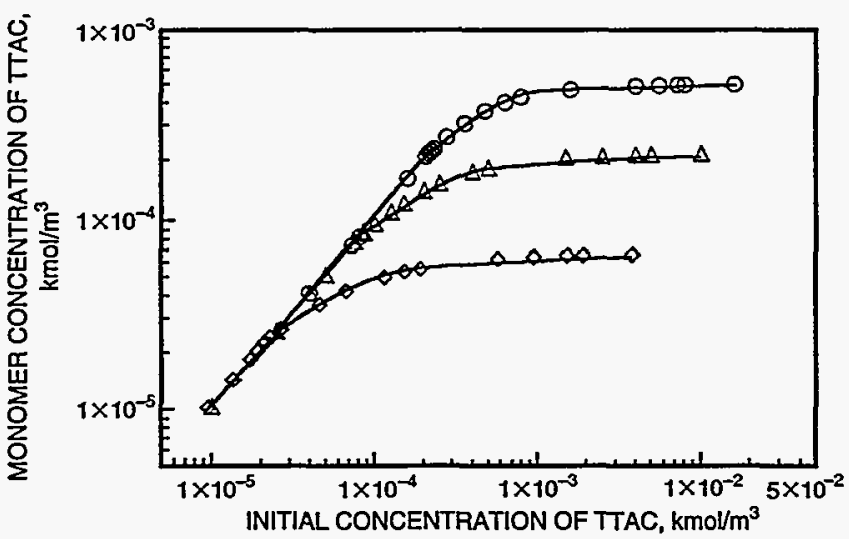

(b)

Fig. 4 Monomer concentrations of TTAC in mixtures with NP-15 as measured by ultrafiltration (a) and also calculated with regular solution theory (b). $₫, 0 \%$ NP-15. $0,20 \%$ NP-15. $\Delta, 50 \%$ NP-15. $\diamond, 80 \%$ NP-15. 


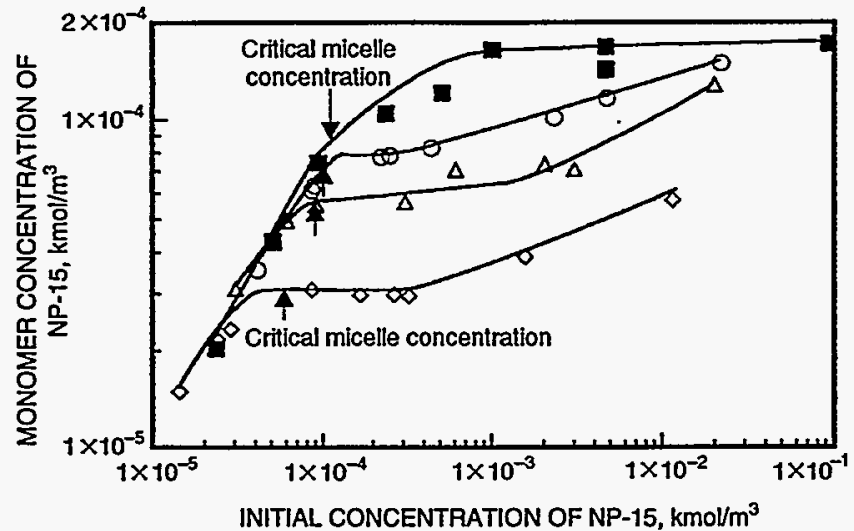

(a)

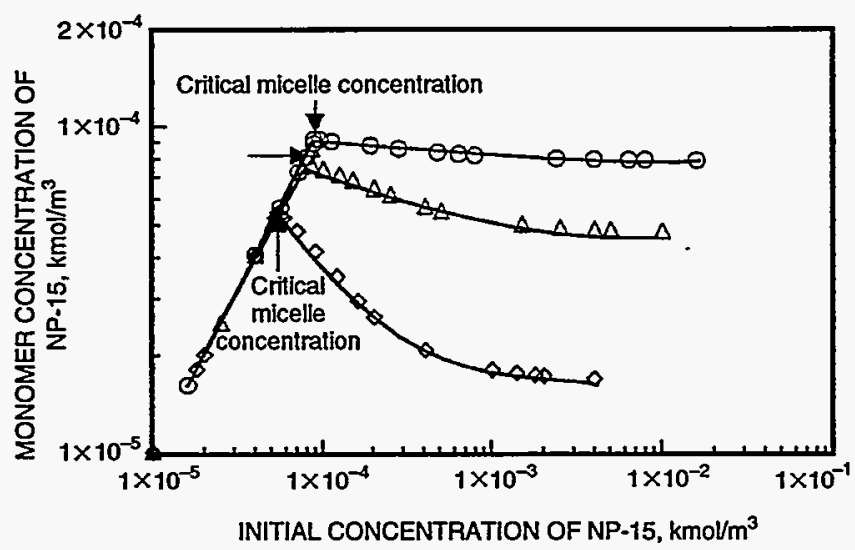

(b)

Fig. 5 Monomer concentrations of NP-15 as measured by ultrafiltration (a) compared with those calculated using regular solution theory (b), $₫, 0 \%$ TTAC. $\circ, 20 \%$ TTAC. $\triangle, 50 \%$ TTAC. $\diamond, 80 \%$ TTAC.

(depending on mixed ratio) and then to increase af higher concentrations. Regular solution theory, however, predicts a decrease in monomer concentration above the mixed CMC. These results clearly suggest that regular solution theory is not suitable for the TTAC and NP-15 mixture system. In subsequent work, monomer concentration in the mixtures will be measured after adsorption in order to correlate these monomer concentrations to the adsorption mechanisms and to enable the development of a more-suitable model to describe interactions among surfactant mixtures.

\section{RESPONSIVE COPOLYMERS FOR ENHANCED PETROLEUM RECOVERY}

Contract No. DE-AC22-92BC14882

University of Southern Mississippi

Hattiesburg, Miss.

Contract Date: Sept. 22, 1992

Anticipated Completion: Sept. 21, 1995

Government Award: \$273,400

(Current year)

\section{Principal Investigators: \\ Charles McCormick \\ Roger Hester}

Project Manager:

Jerry Casteel

Bartlesville Project Office

Reporting Period: Jan. 1-Mar. 31, 1995

\section{Objective}

The overall objective of this research is the development of advanced water-soluble copolymers for use in enhanced oil recovery (EOR) that rely on reversible microheterogeneous associations for mobility control and reservoir conformance.

\section{Summary of Technical Progress}

\section{Hydrophobically Modified Acrylamide/Acrylic Acid Copolymer Synthesis}

This study reports the synthesis and solution properties of terpolymers of acrylamide (Am), acrylic acid (AA), and $\mathrm{N}$-[(4-decyl)-phenyl]acrylamide (DPAm) polymerized in the presence of specified concentrations of sodium dodecyl sulfate (SDS). The structures of these monomers are shown in Fig. 1. This work complements the studies using fluorescently labeled hydrophobic monomers in which the surfactant-to-hydrophobe molar ratio was originally identified as the defining parameter for the control microstructural architecture of hydrophobically modified water-soluble copolymers and terpolymers. ${ }^{1}$ The purpose of this study is twofold: (1) to extend the concepts of the micellar polymerization to more complex systems, including those which use ionizable monomers; and (2) to explore the electrolyteresponsive nature of these hydrophobically modified polyelectrolytes by tailoring of the microstructure through manipulation of the surfactant/hydrophobic monomer molar ratio (SMR) during polymerization. This study shows further evidence that the initial polymerization conditions 


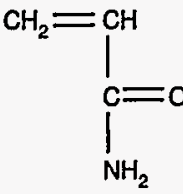

1

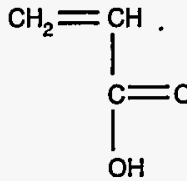

2

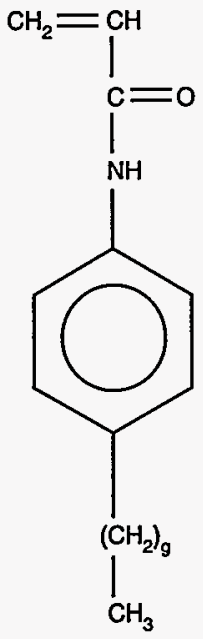

3
Fig. 1 Monomers for micellar polymerizations: 1, acrylamide (Am); 2, acrylic acid (AA); and 3, N-[(4-decyl)phenyl]acrylamide (DPAm).

dictated by the SMR have profound effects on the associative behavior of the resulting microblocky terpolymers.

\section{Materials}

All materials were purchased from Aldrich. Am (electrophoresis grade), 4-decylaniline (DA), triethylamine (TEA), succinic anhydride (SA), and SDS were used as received; $A A$ and acryloyl chloride $(A C)$ were distilled under vacuum before use; potassium persulfate $\left(\mathrm{K}_{2} \mathrm{~S}_{2} \mathrm{O}_{8}\right)$ was recrystallized from water; and pyrene was recrystallized three times from ethanol. High-pressure liquid chromatography indicated a purity of $>99.9 \%$.

\section{Monomer and Polymer Synthesis}

The synthesis ofDPAm was accomplished by a procedure adapted from previous methods. 2,3

The micellar polymerization method of Turner et al. ${ }^{4}$ was used to determine polymer synthesis. Total monomer concentration was $0.44 M$ with the following feed ratios: Am, 0.695 ; AA, 0.30; and DPAm, 0.005. SDS was used as the surfactant to solubilize the hydrophobic comonomer, and $\mathrm{K}_{2} \mathrm{~S}_{2} \mathrm{O}_{8}$ was used as a free radical initiator. The SMR was varied from 40 to 100 , and $\left.\left[\mathrm{K}_{2} \mathrm{~S}_{2} \mathrm{O}_{8}\right)\right] /[$ monomer] was kept constant at $1 / 3000$. The method of McCormick et al..$^{2,5}$ was followed except as noted. The AA monomer was reacted in its acidic form and neutralized after polymerization. Polymerization was conducted at $\mathrm{pH} 4$ to 5 for 3 to $3.5 \mathrm{~h}$ at $50^{\circ} \mathrm{C}$. Polymers were isolated by precipitation into acetone followed by drying and redissolution into water. After 1 week of dissolution, the $\mathrm{pH}$ was adjusted to 7 to 8 and the polymers were dialyzed against deionized water in SpectraPor ${ }^{\circledR}$ No. 4 dialysis tubing (molecular-weight cutoff, 10 to $14 \times 10^{3} \mathrm{~g} / \mathrm{mol}$ ) for at least 1 week. The samples were then lyophilized to a constant weight.

\section{Characterization of Molecular Structure and Solution Behavior}

\section{Sample Preparation}

Samples for viscosity measurements were made by preparing stock solutions of $0.20 \mathrm{~g} / \mathrm{dL}$ of polymer in deionized water $\left(\mathrm{H}_{2} \mathrm{O}\right)$ and adjusting the $\mathrm{pH}$ to approximately 7.5 to 7.7 with the use of microliter amounts of sodium hydroxide $(\mathrm{NaOH})$ and hydrochloric acid $(\mathrm{HCl})$ solutions. The solutions were shaken on an orbital shaker for at least 1 week before dilutions were made. For samples containing added salt, the dry sodium chloride $(\mathrm{NaCl})$ was added to the polymer solutions. Samples were equilibrated a minimum of $24 \mathrm{~h}$.

Samples for pyrene probe experiments were prepared by adding microliter amounts (typically 1 to $2 \mu \mathrm{L}$ ) of a stock solution (pyrene in methanol), which was necessary to give a final pyrene concentration of $10^{-6} \mathrm{M}$, to polymer solutions of the desired concentration and ionic strength. These solutions were allowed to equilibrate for a minimum of $24 \mathrm{~h}$.

Samples for $\mathrm{dn} / \mathrm{dc}$ and light-scattering measurements were prepared by dissolving the appropriate amount of polymer in the desired solvent. After a minimum of 1 week, the $\mathrm{pH}$ of the solution was adjusted to between 7.1 and 7.5 with microliter amounts of $\mathrm{NaOH}$ and $\mathrm{HCl}$ solutions. Solutions were filtered through 0.2 - or $0.45-\mu \mathrm{m}$ Millipore filters.

The amphiphilic polyelectrolytes of this study were prepared from 1, Am; 2, AA; and 3, DPAm (Fig. 1). The Am monomer has a high $\mathrm{k}_{\mathrm{p}}^{2} / \mathrm{k}_{\mathrm{t}}$ and is the hydrophilic component along with the $\mathrm{pH}$ and electrolyte-responsive AA units. DPAm was synthesized by the procedure similar to that reported previously for $\mathrm{N}$-[(4-butyl)phenyl]acrylamide. ${ }^{2}$ This monomer has both the hydrophobic character and chromophore desired. The DPAm model compound $\mathrm{N}$-[(4-decyl)phenylamido]propionic acid (DPAPA, not depicted) was synthesized by a procedure similar to that previously reported for $\mathrm{N}$-[(4-butyl)phenylamido]propionic acid. ${ }^{2}$ The molar absorptivity $(\varepsilon)$ of this model compound in water was determined to be $10,700 \mathrm{M}^{-1} \mathrm{~cm}^{-1}$ at $250 \mathrm{~nm}$. Polymerization was carried out under micellar reaction conditions in $\mathrm{SDS} / \mathrm{H}_{2} \mathrm{O}$ with the use of $\mathrm{K}_{2} \mathrm{~S}_{2} \mathrm{O}_{8}$ as the initiator. A control copolymer of Am/AA (4) was synthesized in the presence of surfactant. The feed compositions are shown in Table 1. Identical feed ratios were used for the terpolymers (5 to 8), and the terpolymer microstructure was varied by changing the surfactant concentration as discussed in the following text. In this study, compositions of the terpolymers (5 to 8) and copolymer (4) (Table 1) were determined by a combination of elemental analysis and ultraviolet spectroscopy by the previously published methods. ${ }^{2}$ The amount of AA in the polymers is slightly greater than the feed composition, which is consistent with reactivity ratio predictions. ${ }^{6}$ Polymerization at low $\mathrm{pH}$ eliminates ionic interferences between the charges on the growing polymer radical and the negatively charged SDS micelles. In the case of the terpolymers, percent conversions were approximately the same (52 to $57 \%$ ). 
TABLE 1

Compositional Data for the Am/AA Copolymer 4 and Am/AA/DPAm Terpolymers 5 to 8

\begin{tabular}{ccccccc}
\hline Sample & SMR* & $\begin{array}{c}\text { Am:AA } \\
\text { feed } \\
\text { ratio }\end{array}$ & $\begin{array}{c}\text { Am, } \\
\text { mol \% }\end{array}$ & $\begin{array}{r}\text { AA, } \\
\text { mol \% }\end{array}$ & $\begin{array}{c}\text { DPAm, } \\
\text { mol \% }\end{array}$ & $\begin{array}{c}\text { Conversion, } \\
\text { \% }\end{array}$ \\
\hline $\mathbf{4}$ & Unmodified & $70: 30$ & 60.4 & 39.6 & 0 & 25 \\
$\mathbf{5}$ & 40 & $69.5: 30$ & 62.2 & 37.4 & 0.4 & 53 \\
$\mathbf{6}$ & 60 & $69.5: 30$ & 63.6 & 35.9 & 0.5 & 53 \\
$\mathbf{7}$ & 80 & $69.5: 30$ & 64.9 & 34.7 & 0.4 & 57 \\
$\mathbf{8}$ & 100 & $69.5: 30$ & 64.8 & 35.9 & 0.5 & 52 \\
\hline
\end{tabular}

* Surfactant/hydrophobic monomer (DPAm) ratio.

The addition of $\mathrm{NaCl}$ to hydrophobically modified polyelectrolytes would be expected to result in the loss of hydrodynamic volume of the individual polymer coils by the shielding of intra-coil ionic repulsions and the enhancement of hydrophobic associations. Figure 2 shows plots of apparent viscosity vs. polymer concentration in $0.5 \mathrm{M} \mathrm{NaCl}$. At low polymer concentration, all the polymers exhibit very low viscosities and thus hydrodynamic volumes, which are indicative of collapse of the individual polymer coils. Under these conditions the behavior of the terpolymers is identical to that of the unmodified polymer at low concentration. At sufficient polymer concentration, three of the four terpolymers exhibit sharp increases in apparent viscosity as the result of hydrophobic associations of individual polymer coils. At this ionic strength, a correlation between SMR of the polymerization and the associative properties of the resulting

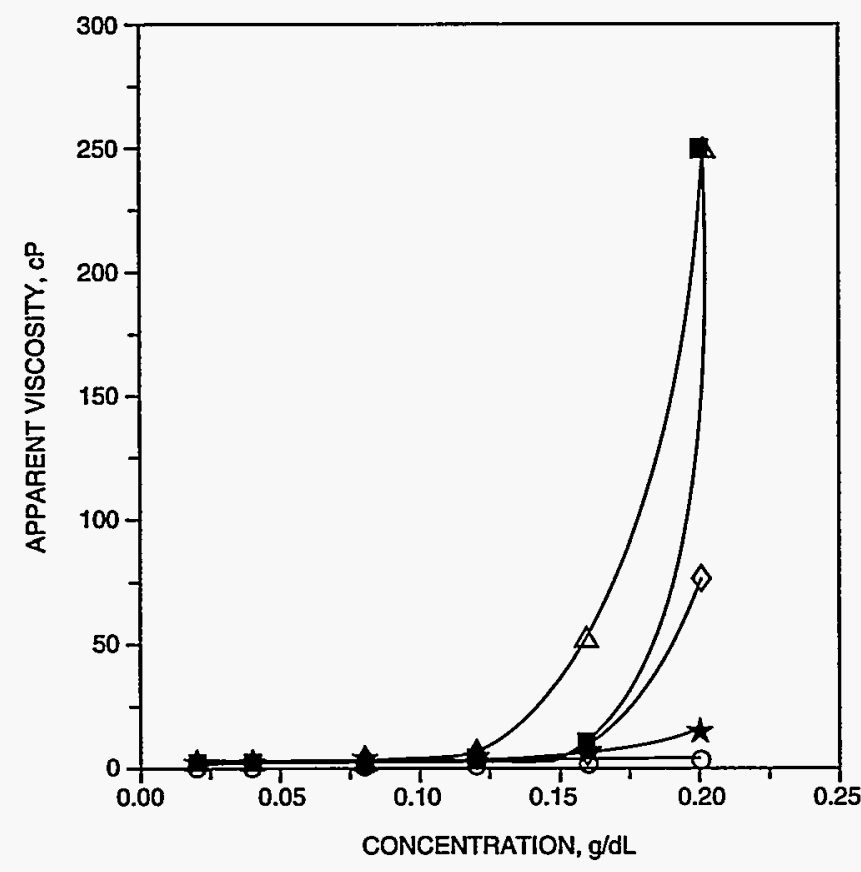

Fig. 2 Apparent viscosities as a function of polymer concentration in $0.5 \mathrm{M} \mathrm{NaCl}$ at $25^{\circ} \mathrm{C}$ and a shear rate of $6 \mathrm{~s}^{-1}$. 0 , unmodified.., SMR 40 . $\triangle$, SMR 60. $\diamond$, SMR 80. $\star$, SMR 100 . terpolymers is noted. Terpolymers 5 and 6 with SMR values of 40 and 60 appear to be the most strongly aggregated, with the latter having the lowest $\mathrm{C}^{*}$ (about $0.13 \mathrm{~g} / \mathrm{dL}$ ). Terpolymers 5 and 7 (SMR 80) appear to have approximately the same C* (about $0.16 \mathrm{~g} / \mathrm{dL}$ ), but 5 appears to be more strongly aggregated. Terpolymers 5 and 6 have higher viscosities than 7 above $C^{*}$, even though the latter has the highest hydrodynamic volume in water below $C^{*}$. Terpolymer 8 (SMR 100) exhibits the lowest viscosity; rheological properties are similar to that of the unmodified copolymer 4.

The different viscometric responses of the terpolymers result from differences in apparent microstructures formed during polymerization. ${ }^{1,7,8}$ Decreasing SMR results in an initially larger number of DPAm molecules per micelle. This should theoretically increase the length of the runs of hydrophobic mers in the resulting polymers. In this system, where the number of hydrophobes per micelle initially present is approximately 2 or less, some hydrophobe migration or aggregate coalescence process would be necessary to obtain blocks of a sufficient length. Large differences in association are exhibited by the terpolymers in this series, which indicates that hydrophobe migration might occur to build blocks of larger size than predicted. Also, the differences in associative properties, and thus hydrophobe migration, appear to be augmented at lower SMR. These observations are in agreement with other studies which indicate that polymer heterogeneity is greatest at higher numbers of hydrophobes/micelle. ${ }^{9}$

\section{Acrylamide/Acrylic Acid/Sulfobetaine Terpolymer Synthesis}

The goals of this research are to synthesize polymers that will display either polyampholytic or polyelectrolytic behavior, depending on the $\mathrm{pH}$ of the environment. Special attention has been focused on monomers that contain the carboxylate group. Thus the synthesis and solution behavior of terpolymers of $\mathrm{AA}, \mathrm{Am}$, and a sulfobetaine monomer will be discussed.

\section{Experimental Materials}

AM from Aldrich was recrystallized twice from acetone and vacuum dried at room temperature. AA from Aldrich 
was distilled before use. 3-(2-Acrylamido-2-methylpropanedimethylammonio)-1-propanesulfonate(AMPDAPS) was synthesized by the ring opening reaction of 1,3-cyclopropanesultone with 2-acrylamido-2-methylpropanedimethylamine as previously reported. ${ }^{10} \mathrm{~K}_{2} \mathrm{~S}_{2} \mathrm{O}_{8}$ from J. T. Baker was recrystallized twice from deionized water. All other materials were used as received.

\section{Synthesis of Terpolymers of}

3-(2-acrylamido-2-methylpropane

dimethylammonio)-1-propanesulfonate, Acrylamide, and Acrylic Acid

The terpolymers of AMPDAPS, AM, and AA (the AADAPS series) were synthesized by free radical polymerization in a $0.5 \mathrm{M} \mathrm{NaCl}$ aqueous solution under nitrogen at $30^{\circ} \mathrm{C}$ with the use of $0.1 \mathrm{~mol} \% \mathrm{~K}_{2} \mathrm{~S}_{2} \mathrm{O}_{8}$ as the initiator at a $\mathrm{pH}$ of 8 . The feed ratio of AMPDAPS:AA:AM was varied from 5:5:90 to 40:40:20 mol \% with the total monomer concentration held constant at $0.45 \mathrm{M}$.

In a typical synthesis, specified quantities of each monomer were dissolved in small volumes of $0.5 \mathrm{M} \mathrm{NaCl}$ solution. The separate solutions were then combined and diluted to a $0.45 \mathrm{M}$ monomer concentration with $0.5 \mathrm{M} \mathrm{NaCl}$ solution. One equivalent of sodium hydroxide $(\mathrm{NaOH})$ per equivalent of AA was then added and the $\mathrm{pH}$ adjusted to 8 . The reaction mixture was sparged with nitrogen and then initiated with $0.1 \mathrm{~mol} \% \mathrm{~K}_{2} \mathrm{~S}_{2} \mathrm{O}_{8}$. The reaction was usually terminated at $<55 \%$ conversion because of the high viscosity of the reaction medium and as a precaution against copolymer drift. The polymers were precipitated in acetone, redissolved in deionized water, and then dialyzed with Spectra/Por ${ }^{\circledR} 4$ dialysis bags with molecular-weight cutoffs of 12,000 to 14,000 $\mathrm{g} / \mathrm{mol}$. Half of the samples were dialyzed against deionized water adjusted to $\mathrm{pH} 4$, whereas the other half were dialyzed against deionized water adjusted to $\mathrm{pH} 8$. Polymers containing $25 \mathrm{~mol} \%$ or more of AMPDAPS and AA in the feed (AADAPS-25 and AADAPS-40) precipitated during dialysis against deionized water adjusted to $\mathrm{pH} 4$. After dialyzing for 2 weeks, the polymers were isolated by lyophilization. Conversions were determined gravimetrically.I.R.: AADAPS40 copolymer isolated at $\mathrm{pH} 4(\mathrm{KBr}$ pellet): $\mathrm{O}-\mathrm{H} 3600-$ $2600 \mathrm{~cm}^{-1}$ (bd); N-H $3280 \mathrm{~cm}^{-1}$ (s); C-H $3050 \mathrm{~cm}^{-1}$ (m) and $2980 \mathrm{~cm}^{-1}(\mathrm{~m}) ; \mathrm{C}=\mathrm{O} 1700,1655,1637 \mathrm{~cm}^{-1} ; \mathrm{N}-\mathrm{H}$ $1560 \mathrm{~cm}^{-1}(\mathrm{~m})$; C-O-H $1460 \mathrm{~cm}^{-1}(\mathrm{~m})$; C-O $1208 \mathrm{~cm}^{-1}$ (s); S-O $1189,1042 \mathrm{~cm}^{-1}(\mathrm{~s})$.

\section{Synthesis of Copolymers of 3-(2-acrylamido-2-methylpropane dimethylammonio)-1-propanesulfonate with Acrylamide and Acrylic Acid with Acrylamide}

The polymerization procedures for copolymers of AMPDAPS with AM were previously reported by Salazar and McCormick. ${ }^{10}$ Copolymers of AM and AA were prepared with the use of similar techniques for the terpolymer synthesis.

\section{Characterization of Molecular Structure and Solution Behavior Copolymer Characterization}

Carbon-13 nuclear magnetic resonance spectra of the polymers were obtained at $50.3 \mathrm{MHz}$ on a Bruker AC 200 spectrometer with the use of 10 to $15 \mathrm{wt} \%$ aqueous $\left(D_{2} \mathrm{O}\right)$ polymer solutions with DSS as a reference. A recycle delay of $6 \mathrm{~s}, 90^{\circ}$ pulse length, and gated decoupling to remove all nuclear Overhauser effects was used for quantitative spectral analysis. Fourier transform infrared spectra were obtained with a Mattson Galaxy 2020 series spectrometer. Molecular-weight studies were performed on a Chromatix KMX-6 low-angle laser light-scattering instrument. Refractive index increments were obtained with a Chromatix KMX-16 laser differential refractometer. For quasi-elastic light scattering, a Langley-Ford Model LF1-64 channel digital correlator was used in conjunction with the KMX-6. All measurements were conducted at $25^{\circ} \mathrm{C}$ in $1 M \mathrm{NaCl}$ at a $\mathrm{pH}$ of 8.

\section{Viscosity Measurements}

Stock solutions of $\mathrm{NaCl}$ were prepared by dissolving the appropriate amount of salt in deionized water adjusted to either $\mathrm{pH} 4$ or 8 in volumetric flasks. Polymer stock solutions were made by dissolving designated amounts of polymer in the salt solutions. The solutions were then diluted to appropriate concentrations and allowed to age for 7 to $10 \mathrm{~d}$ before being analyzed with a Contraves LS- 30 rheometer. The Huggins equation was used to evaluate the intrinsic viscosities.

\section{Compositional Analysis}

The terpolymers of AMPDAPS, AM, and AA (the AADAPS series) were synthesized by varying the feed ratios of AMPDAPS:AA:AM from 5:5:90 to $40: 40: 20 \mathrm{~mol} \%$. Copolymers of AM and AA (the AAAM series) were synthesized by varying the feed ratio of AA:AM from 10:90 to 25:75 mol \%. Copolymers of AMPDAPS and AM (the DAPSAM series) were synthesized previously. ${ }^{10}$ All polymers reported are shown in Fig. 3. The polymer compositions were determined by the integration of the carbonyl resonances and agree favorably with past results. The incorporation of AMPDAPS and AM in both the AADAPS and DAPSAM series approximated the feed composition, which indicated little preference for the addition of either monomer. The incorporation of AA in both the AADAPS and AAAM series was approximately half the feed composition, which denoted a partiality toward the addition of the acrylamido-type monomers.

Figure 4 examines the effect of increasing $\mathrm{NaCl}$ concentration on the intrinsic viscosities of the AADAPS, AAAM, and DAPSAM terpolymer polymer series. In Fig. 4, a structural comparison between AADAPS-25 and DAPSAM-25 may tentatively be drawn because molecular weights and the degree of polymerization are similar. At low ionic strengths, 
<smiles>CC(C)(C)CC(=O)C(C)(C)C(=O)O[Na]</smiles>

AAAM series

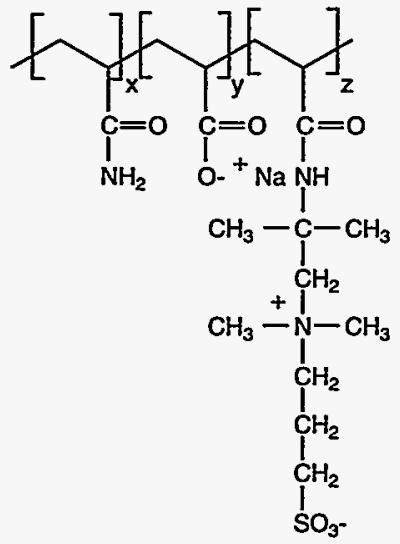

AADAPS series

Fig. 3 Acrylamide copolymer and terpolymer structures.

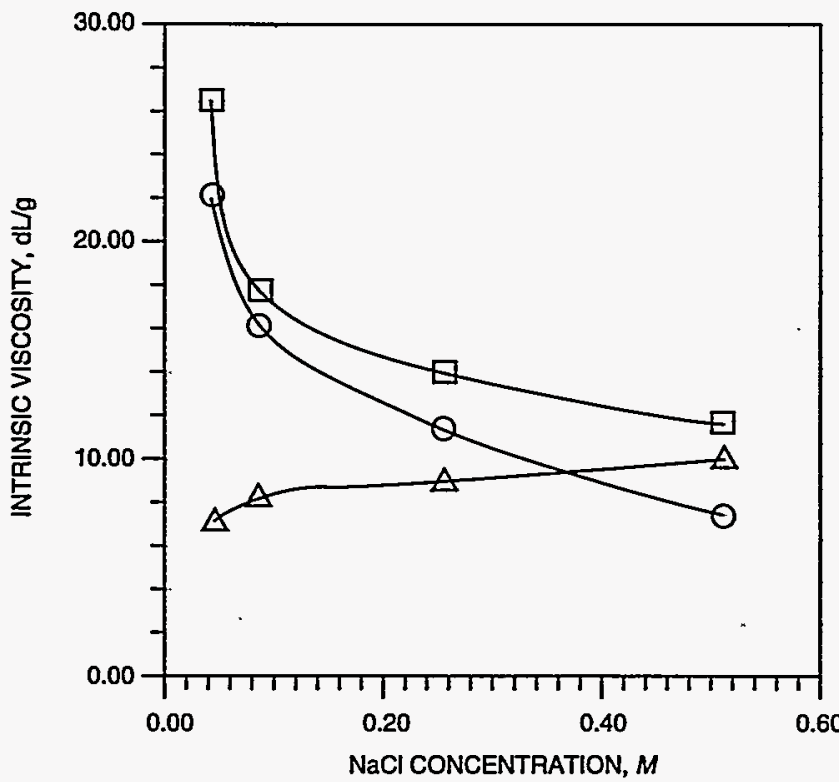

Fig. 4 Dependence of intrinsic viscosity as a function of $\mathrm{NaCl}$ concentration (determined at a shear rate of $6 \mathrm{~s}^{-1}$ and $\mathrm{pH}$ 8). $\square$, AADAPS-25. o, AAAM-25. $\triangle$, DAPSAM-25.

AADAPS-25 has a higher intrinsic viscosity because of the charge imbalance of the polymer chain. At higher ionic strengths, AADAPS-25 still maintains a higher intrinsic viscosity than DAPSAM- 25 because of the presence of the carboxylate functionalities, which enhance the solvation of the polymer chain. This is in accord with previously discussed $\mathrm{A}_{2}$ values. ${ }^{11}$

\section{Solution Flow Characterization in Porous Media}

The flow resistance of dilute polymer aqueous solutions through beds of uniform size spheres can be used to characterize the extensional viscosity of the solutions. As shown by Durst, ${ }^{12}$ the solution flow resistance or pressure drop across a bed of uniform solid spheres was strongly dependent upon flow rate, polymer molecular weight, number of macromolecules per unit volume of fluid, and the size of the individual polymer coils. The theoretical explanations on polymer coil extension in packed beds given by Durst, however, were not compatible with all the solution properties he observed. In particular, the Durst explanation does not address the reduction he observed in normalized solution flow resistance (NSFR) at higher fluid flow rates through the bed.

In this laboratory, solution flow through packed bed experiments was carried out at conditions similar to those in the experiments performed by Durst. The dilute solution flow properties of several high-molecular-weight Am-based copolymers ${ }^{13}$ were also found to have a maximum and then a reduction in NSFR at higher flow rates through the bed. An example of this behavior is shown in Fig. 5 .

In an effort to explain the preceding maximum in NSFR, a model of polymer coil response in a fluid extensional flow field has been proposed. Two major assumptions are used to develop this model. The first major assumption concerns the mechanical definition of a polymer coil in solution. The second assumption deals with the description of the packed bed extensional fluid flow field.

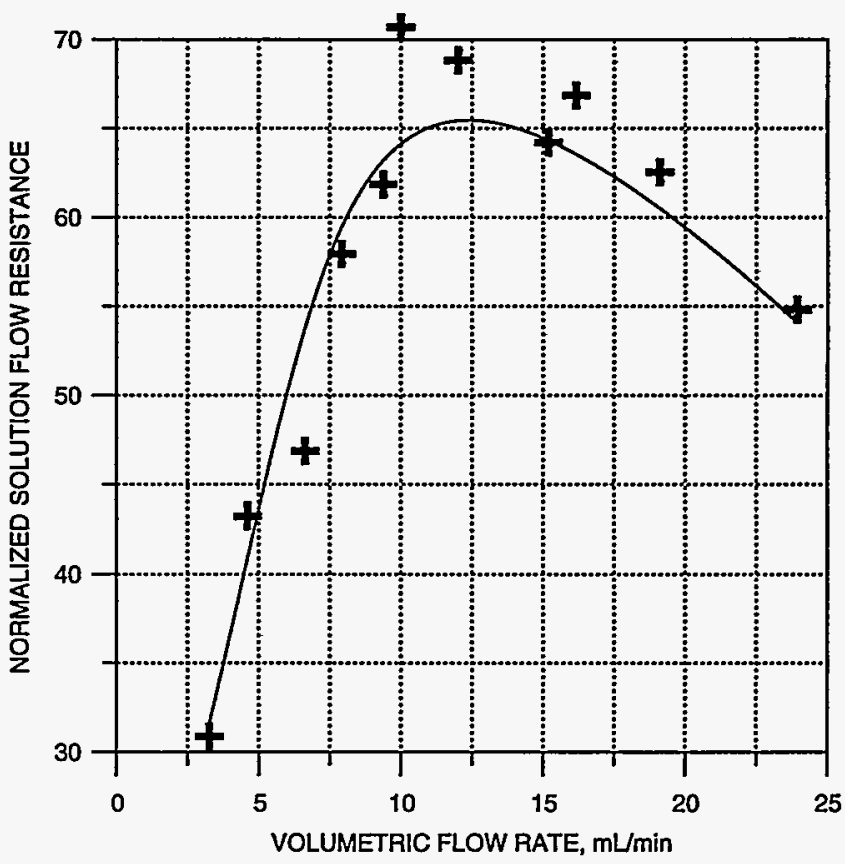

Fig. 5 Normalized solution flow resistance vs. volumetric flow rate through a bed packed with uniform size solid spheres. Data shown as + and model fit to the data shown as a solid line. See Table 1. 
The fit of the model to experimental data with the use of the NSFR vs. Deborah number plotting technique of Durst is shown in Fig. 5. The model is consistent with the data and provides a maximum for the NSFR. Coil strain depends on the Deborah number and ranges from 10 at low Deborah numbers to a maximum of 43 at a Deborah number of 0.15 . These strain values are much less than that for a fully extended macromolecule but are larger than expected. Future work will center on understanding the physical meaning of the coil viscosity and modulus and their relationship to macromolecular and solvent properties.

\section{References}

I. K. D. Branham, J. C. Middleton, and C. L. McCormick, Polym. Prepr., Am. Chem. Soc. Div. Polym. Chem., 32: 106 (1991).

2. C. L. McCormick, J.C. Middleton, and C. E. Grady, Polymer, 33:4184 (1992).
3. K. D. Branham, D. L. Davis, J. C. Middleton, and C. L. McCormick, Polymer, 35: 4429 (1994).

4. S. R. Turner, D. B. Siano, and J. Bock, U.S. Patent 4520182.

5. C. L. McCormick, J. C. Middleton, and D. F. Cummins, Macromolecules, 25: 1201 (1992).

6. D. A. Mortimer, Polym. Int., 25: 29 (1991).

7. S. A. Ezzell and C. L. McCormick, Macromolecules, 25: 1881 (1992).

8. S. A. Ezzell, C. E. Hoyle, D. Creed, and C. L. McCormick, Macromolecules, 25: 1887 (1992).

9. S. Biggs, A. Hill, J. Selb, and F. Candau, J. Phys. Chem., 96: 1505 (1992).

10. C. L. McCormick and L. C. Salazar, Polymer, 33: 4617 (1992).

11. E. E. L. Kathmann, D. L. Davis, and C. L. McCormick, Macromolecules, 27: 89 (1994).

12. F. Durst and R. Hass, Rheol. Acta, 20: 179 (1981).

13. R. D. Hester and C. L. McCormick, paper SPE/DOE 27823 presented at the 9th Symposium on Improved Oil Recovery, Tulsa, Okla., April 17-20, 1994.

\section{DEVELOPMENT OF COST-EFFECTIVE SURFACTANT FLOODING TECHNOLOGY}

\author{
Contract No. DE-AC22-92BC14885
}

\author{
University of Texas \\ Austin, Tex. \\ Contract Date: Sept. 30, 1992 \\ Anticipated Completion: Sept. 29, 1995 \\ Government Award: \$765,557 \\ Principal Investigators: \\ Gary A. Pope \\ Kamy Sepehrnoori \\ Project Manager: \\ Jerry Casteel \\ Bartlesville Project Office
}

Reporting Period: Jan. 1-Mar. 31, 1995

\section{Objective}

The objective of this research is to develop cost-effective surfactant flooding technology by using surfactant simulation studies to evaluate and optimize alternative design strategies taking into account reservoir characteristics, process chemistry, and process design options such as horizontal wells. Task 1 is the development of an improved numerical method for the simulator so that a wider class of these difficult simulation problems can be solved accurately and affordably. Task 2 is the application of this simulator to the optimization of surfactant flooding to reduce its risk and cost.

\section{Summary of Technical Progress}

The goal of Task $l$ is to obtain accurate numerical solutions for multidimensional, multicomponent, multiphase chemical flow problems that are the specific focus of this project. The numerical method used in the simulation studies is a true vertical depth (TVD) flux-limited high-order finite-difference scheme with a fully implicit formulation. On the basis of this method, a fully implicit, high-resolution compositional chemical flooding simulator is under development. The basic structure, flow equations, and transport property modeling in this simulator have been reported previously, ${ }^{1}$ and the results of simple problems in one, two, and three dimensions (1-D, 2-D, and 3-D) demonstrate that the simulator gives more accurate solutions with the use of the high-resolution method than with the use of the conventional numerical methods and is more computationally efficient than IMPES simulators that require very small time-step sizes for certain problems. The increase in accuracy through the use of this new algorithm makes it possible to reduce the overall computational cost by taking larger time-step sizes and fewer nonlinear iterations without sacrificing accuracy or stability compared with the use of conventional methods.

Recent work has focused on code optimization with moreefficient solvers to improve the computational efficiency. As an example, results of using both a direct solver (band-LU decomposition) and an iterative solver (ORTHOMIN with Jacobi preconditioner) ${ }^{2}$ for a 3-D tracer flood problem are given. The results were also compared with those obtained with the use of the IMPES simulator (UTCHEM). The comparison demonstrates that the implicit simulator has superior numerical stability and is more computationally efficient than the IMPES simulator when the iterative solver is used.

The reservoir simulation domain is rectangular with a size of $1000 \mathrm{ft}$ by $1000 \mathrm{ft}$ by $100 \mathrm{ft}$ in $\mathrm{x}, \mathrm{y}$, and $\mathrm{z}$ directions, 
respectively, and a porosity of 0.2 . The permeabilities in each direction are $200 \mathrm{mD}$. The injected fluid with tracer has propertiesidentical to those of the resident fluid. A $10 \times 10 \times 10$ uniform grid was used with an injector at $(1,1,1)$ and a producer at $(10,10,10)$. The injection rate was $1781 \mathrm{bbl} / \mathrm{d}$, and the total injection time was $6000 \mathrm{~d}$ [three pore volumes]. So that the validity of the iterative solver used could be established, tracer production histories obtained with the use of the iterative solver were compared with those with the usse of the direct solver and identical results were achieved. The central processing unit (CPU) time ratio of using the direct solver to that of using the iterative solver is about 124 on a DEC- $\alpha$ workstation. The results and CPU time of the implicit simulator were compared with those of the UTCHEM simulator. Good agreement was achieved when a small time-step size was used, $0.16 \mathrm{~d}$ for the UTCHEM simulator and $2 \mathrm{~d}$ for the implicit simulator, which correspond to Courant numbers (dimensionless time-step sizes) of 0.08 and 1.0 (Fig. 1). The IMPES simulator, however, failed

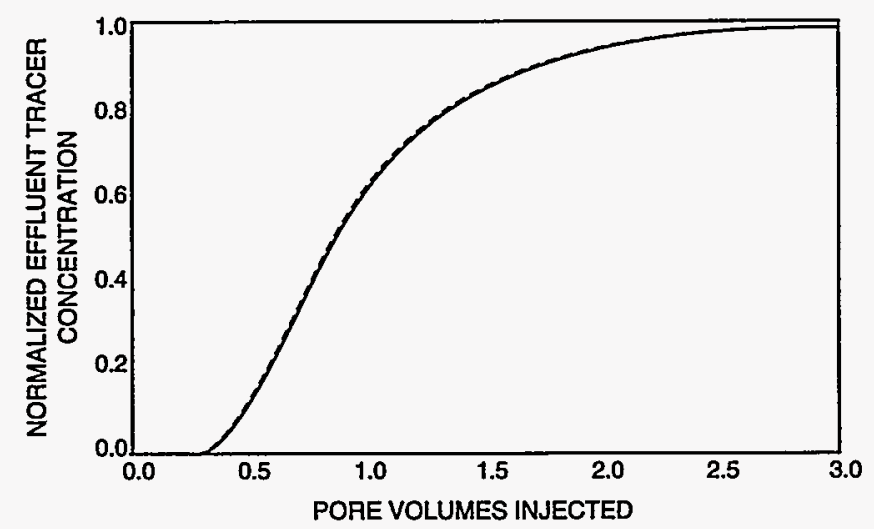

Fig. 1 Simulation of a three-dimensional tracer flood using the fully implicit simulator $(-, \Delta t=2 \mathrm{~d}, \lambda=1)$ and the IMPES simulator $(-\cdots-, \Delta \tau=0.16 \mathrm{~d}, \lambda=0.08)$. Number of gridblocks, $10 \times 10 \times 10$. Peclet number, 10.

\section{References}

1. G. A. Pope and K. Sepehmoori, Development of Cost-Effective Surfactant Flooding Technology, Annual Report, DOEContractNo. DE-AC2292BC14885, March 1994. at a time-step size of $0.17 \mathrm{~d}$, which corresponds to a Courant number of 0.085 , whereas the implicit simulator, because of its stability and the high-order time accuracy, gives good results even when using a time-step size of $200 \mathrm{~d}$, which corresponds to a Courant number of 100 . There are no significant differences in the results with the use of the time-step sizes of 2, 20, and $200 \mathrm{~d}$, which correspond to Courant numbers of 1,10 , and 100 (Fig. 2). The CPU time for the implicit simulator with the use of the iterative solver with a time-step size of $200 \mathrm{~d}$ is $614 \mathrm{~s}$ compared with $9127 \mathrm{~s}$ for the IMPES simulator with a time-step size of $0.16 \mathrm{~d}$, a speedup of 14.8 .

Testing the implicit simulator on problems involving more interactions caused by the combinations of various physicalchemical properties is continuing. The code is being optimized to improve the computational efficiency and to make it more user friendly.

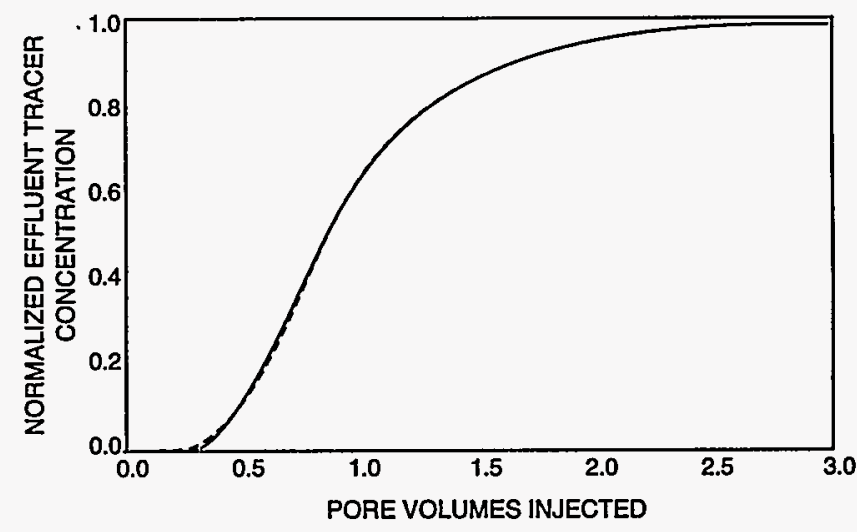

Fig. 2 Simulation of a three-dimensional tracer flood with the use of the fully implicit simulator. Number of gridblocks, $10 \times 10 \times 10$. Peclet number, 10. - $-\Delta \mathrm{t}=2 \mathrm{~d}, \lambda=1 .--, \Delta \mathrm{t}=20 \mathrm{~d}, \lambda=10 . \cdots \cdots$, $\Delta \mathrm{t}=200 \mathrm{~d}, \lambda=100$.

2. T. C. Oppe, W. D. Joubert, and D. R. Kincaid, NSPCG User's Guide Version 1.0, A Package for Solving Large Sparse Linear Systems by Various Iterative Methods, Center for Numerical Analysis, University of Texas, Austin, Tex., April 1988. 


\section{GAS DISPLACEMENT- SUPPORTING RESEARCH}

\section{IMPROVED EFFICIENCY OF MISCIBLE $\mathrm{CO}_{2}$ FLOODS AND ENHANCED PROSPECTS FOR $\mathrm{CO}_{2}$ FLOODING HETEROGENEOUS RESERVOIRS}

Contract No. DE-FG22-94BC14977

New Mexico Institute of Mining and Technology Petroleum Recovery Research Center Socorro, N. Mex.

Contract Date: Apr. 14, 1994

Anticipated Completion: Apr. 13, 1997

Government Award: $\$ 320,000$

Principal Investigators:

Reid B. Grigg

John P. Heller

David S. Schechter

Project Manager: Jerry Casteel

Bartlesville Project Office

Reporting Period: Jan. 1-Mar. 31, 1995

\section{Objective}

The objective of this experimental research is to improve the effectiveness of carbon dioxide $\left(\mathrm{CO}_{2}\right)$ flooding in heterogeneous reservoirs. Activities are being conducted in three closely related areas: (1) further exploration of the applicability of selective mobility reduction (SMR) in the use of foam flooding, (2) possible higher economic viability of floods at slightly reduced $\mathrm{CO}_{2}$ injection pressures, and (3) taking advantage of gravitational forces during low interfacial tension (IFT) $\mathrm{CO}_{2}$ flooding in tight, vertically fractured reservoirs.

\section{Summary of Technical Progress}

\section{$\mathrm{CO}_{2}$ Foams for Selective Mobility Reduction}

Progress was made this quarter on several different experiments, all aimed at obtaining information about the use of SMR in field applications of $\mathrm{CO}_{2}$ foam. This work has included mobility measurements of single cores, of two cores (of different permeabilities) in separate coreholders in series arrangement, and of a composite core in which flow is through two different permeability regions in parallel. These experiments were performed at high pressure. In addition, plans are 
under way for the next tests to be made in quest of further information on the use of SMR.

Laboratory tests on single cores and on series arrangements were conducted with two surfactants, Chaser CD1045 and $C D 1050$, on a few reservoir core samples from a dolomitic carbonate field. These measurements of the mobility of $\mathrm{CO}_{2}$ foam were continuations of those on quarried rock samples. The reservoir rock was supplied by the Phillips Petroleum Co. as a portion of slabbed core that was retrieved from an observation well located at the East Vacuum Grayburg/San Andres Unit field.

With the use of the Petroleum Recovery Research Center scanning minipermeameter, 286 permeabilities were measured on the flat surface of this core slab with a 0.05 -in.-square grid. The permeabilities varied from 0.1 to $900 \mathrm{mD}$ on a small surface (15-in. square). From the permeability map made from these data, it was clear that the permeabilities are not uniformly distributed and are mostly below $70 \mathrm{mD}$. Nevertheless, by carefully locating the high- and low-permeability region on this core slab, several core plugs for the SMR tests were cut.

Two tests were also completed with the use of the current experimental setup, in which the fluids flow through two cores in series. In each test the permeability ratio of two core samples in the system is approximately two to one. The permeabilities of the higher permeability composite core range from 200 to $500 \mathrm{mD}$, whereas those of the lower permeability core range from 50 to $200 \mathrm{mD}$.

The total mobility of $\mathrm{CO}_{2}$ and surfactant-free brine, as measured from this experiment, is lower in the preserved reservoir rock than in a quarried rock (oil-free Berea sandstone or Baker dolomite), presumably because of the remaining oil saturation in the core. This finding is in accord with earlier results reported in the single-core standard mobility measurement. Conversely, less SMR was found-mobility reduction caused by $\mathrm{CO}_{2}$ foam in these tests is less dependent on the original core permeabilities. That result is not in agreement with earlier observations in the single-core experimental system, where CD1050 yielded a favorable SMR in the reservoir rock samples. The tests will be repeated as necessary to resolve the conflict.

A somewhat different type of series-flow experiment is under construction. This experiment involves a composite core with two different permeability sections arranged in series. In this new arrangement the two sections of core will be in the same coreholder-either being sections of the same rock or being separate cores-tightly butted together with a filter membrane to provide good capillary contact between them. As a first attempt to construct such a series-composite core, two fired Berea sandstone cores with air permeabilities of 100 and $500 \mathrm{mD}$, respectively, were used. A coreholder to contain such a core has also been fabricated. This coreholder is equipped with five pressure taps capable of measuring four pressure drops along the flow path. In this case two pressure drops across each section of the composite core can be measured at the same time. When a steady state is reached during the mobility measurement, the mobilities of fluid flowing through sections with different permeabilities, and in segments in each section, will be readily compared.

In a different set of laboratory experiments, with the goal of determining the effect of parallel flow, SMR has also been demonstrated in relatively homogeneous Berea cores of a larger size. This experiment was preliminary to the measurement of mobility in coaxial sections of the porous rock. First foam flow experiments have been completed with such a fabricated core sample. The core contains two parallel sections, of low and high permeability, which are in capillary contact. The outer section of this core assembly consists of a 3.7-cm-diameter by 7-cm-long fired Berea sandstone cylinder. It was first coated with thick epoxy and then cast into a stainless steel permanent sleeve with a thinner casting epoxy (to avoid trapping bubbles). A 1.6-cm hole was then drilled along the diameter of the core and filled with fine, unconsolidated, silica sand. Special end plates enable separate measurements of the flow through the two parallel sections of the core. The permeability ratio in this assembly was about 3.7 ; the higher permeability region was in the center of the core.

Several experiments were conducted with this core sample with the use of Chevron CD1045, CD1050, and Shell Enordet $\mathrm{X} 2001$ at 500- and 2500-ppm concentrations. Four different flow velocities were used, ranging from about 0.44 to $8.7 \mathrm{ft} / \mathrm{d}$ (darcy velocity). In the transient period preceding the attainment of steady state, these experiments, when compared with the experiments in which no surfactant was used, have indicated that foam (or the presence of surfactant) delays the $\mathrm{CO}_{2}$ breakthrough in the higher permeability section. In the steady-state tests that followed the transient period, when either CD1045 or Enordet X2001 was used at 500-ppm concentration, the fractional flow through the higher permeability zone was reduced significantly for lower flow rates. The steady state also was reached earlier when surfactant solution was present.

A second composite core was constructed in which the center hole is filled with finer unconsolidated sand such that the center zone has the lower permeability. A comparison of the preceding results with results from the second assembly will demonstrate any dependence on whether the higher permeability region is located in the center or the annulus.

Pressure-measurement facilities for this experiment will be facilitated by a gift. Recently, Amoco Production Co. donated several Honeywell transmitters to this project. These transmitters are being tested and assembled into the composite core, series experimental setup, where they will ease the experimental difficulties of making reliable but extended differential pressure measurements.

\section{Reduction of the Amount of $\mathrm{CO}_{2}$ Required in $\mathrm{CO}_{2}$ Flooding}

The objective of this task of the project is to demonstrate the feasibility of decreasing $\mathrm{CO}_{2}$ requirements for $\mathrm{CO}_{2}$ flooding. This objective can be achieved by using one or both of two 
approaches. First, at a constant temperature, the density of $\mathrm{CO}_{2}$ decreases with decreasing pressure, and thus reservoir fill volume can be achieved with less mass at a lower pressure. The density of $\mathrm{CO}_{2}$ is always less at the minimum miscibility pressure than at several hundred pounds pressure higher where most systems are being flooded with the density difference as much as $50 \%$. Thus advantage can perhaps be taken of this condition without significantly reducing sweep efficiency. Second, foaming agents can be used in conjunction with the injection scheme of water alternating with $\mathrm{CO}_{2}$ as a mobility control agent. The use of these two concepts together should provide a synergistic effect by greatly reducing $\mathrm{CO}_{2}$ requirements while maintaining or increasing the sweep efficiency of the process. This concept should be particularly applicable in the New Mexico-Texas region where many of the present and potential reservoirs for $\mathrm{CO}_{2}$ miscible flooding are located. The concept should also be applicable to any gas injection scheme. All the experimental tests and modeling work in this study are designed to increase understanding and to test concepts related to this process.

During this quarter, research has been focused on the development of a preprocessor program that can provide the parameters of the pseudocomponents as input to a compositional simulator such as UTCOMP. Currently, the preprocessor is set up to match the bubble-point pressure data by tuning the average molecular weight of $\mathrm{C}_{7+}$ fraction. After the matching of the bubble-point pressure, the generated parameters of the pseudocomponents can be used as input to a compositional simulator. The goal is to improve the preprocessor program by not only matching bubble-point pressure data but also matching other equilibrium data generated at static conditions.

In addition, the work on the implementation of a horizontal well model into MASTER continued. Major modifications that were made to MASTER include (1) allowing flexible well orientations (i.e., wells can be parallel to the $\mathrm{x}$-axis, $y$-axis, or z-axis) and (2) incorporating the well model by Babu et al. ${ }^{l}$ into the simulator. Coding of these modifications is complete. Validation of the horizontal well model will begin later.

\section{Low IFT Processes and Gas Injection in Fractured Reservoirs}

Research continues in two primary areas: (1) understanding the fundamentals of low IFT behavior via theory and experiment and the influence on multiphase flow behavior and (2) modeling low IFT gravity drainage for application of gas injection in fractured reservoirs. The subtleties of gas-oil IFT calculations have been accomplished via the parachor method, although the pendant-drop apparatus will be used to verify calculation methodology.

The calculation methodology developed is based on the parachor method. It has been established, by rigorous analysis of the physics and petroleum engineering literature, that neither the parachor nor the scaling exponent should be used as an adjustable parameter. On the basis of modern under- standing of critical phenomena, a simple procedure has been developed for the prediction of low IFTs for multicomponent reservoir fluid systems that adheres to current theoretical models of near-critical phase behavior. The procedure uses the Peng-Robinson equation of state to predict phase densities for application with the parachor method. Relatively accurate predictions of IFTs are possible for both gas condensate and $\mathrm{CO}_{2}$-crude oil systems. The parachors and parachor correlations for single oil components and $\mathrm{C}_{7+}$ fractions up to $\mathrm{C}_{45}$ have been recalculated on the basis of current interpretation of near-critical behavior.

From the limited multicomponent IFT data set in the literature, it is apparent that this method provides the most accurate predictions. A paper entitled "Parachors Based on Modern Physics and Their Application to Calculation of Multicomponent Reservoir Fluid Systems" will be presented at the 1995 SPE Annual Technical Conference.

For a demonstration of this methodology, the IFT was calculated as a function of pressure for $\mathrm{CO}_{2}-$ Spraberry crude oil system. The results are shown in Fig. 1. The minimum miscibility pressure of Spraberry stock tank oil with $\mathrm{CO}_{2}$ was measured in a slim tube. Results are shown in Fig. 2. These two figures indicate that maximum recovery in the slim tube is achieved at IFTs of around $1 \mathrm{mN} / \mathrm{m}$.

The construction of the pendant-drop apparatus is complete. It is now possible to circulate fluids and to form drops through a variety of needle bore sizes. The equilibrated phases are circulated through the densitometer. The densities of the

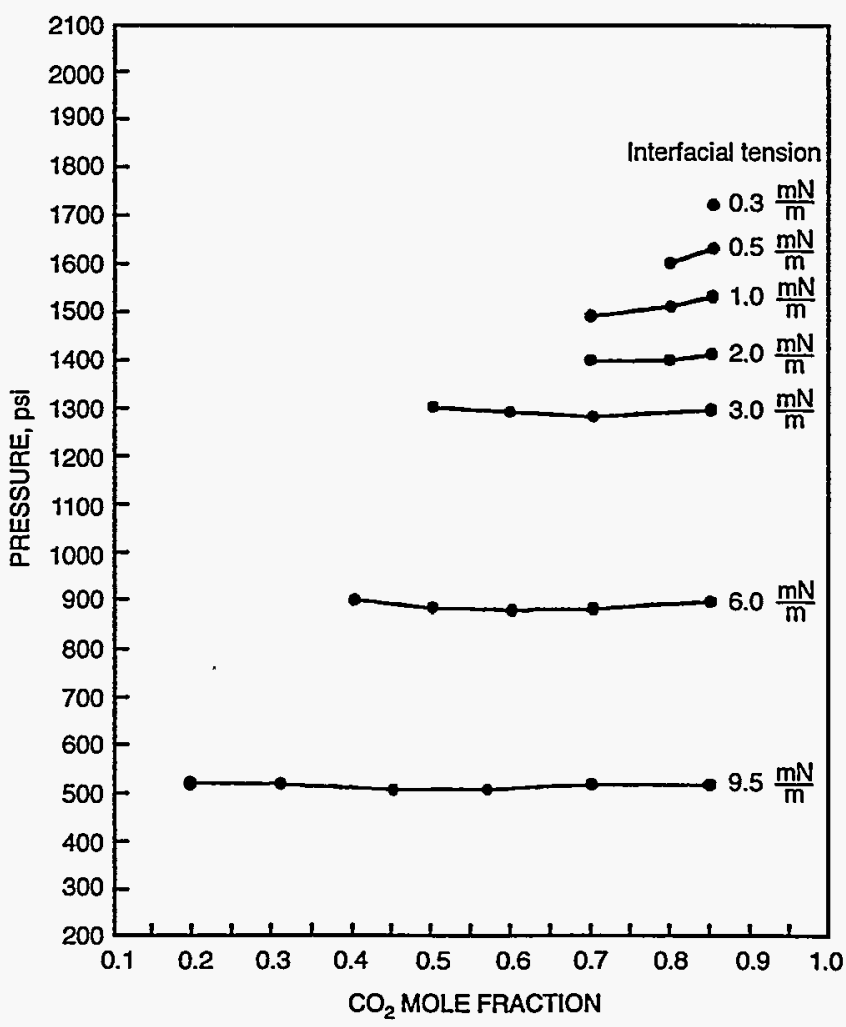

Fig. 1 Spraberry stock tank oil and $\mathrm{CO}_{2}$. 


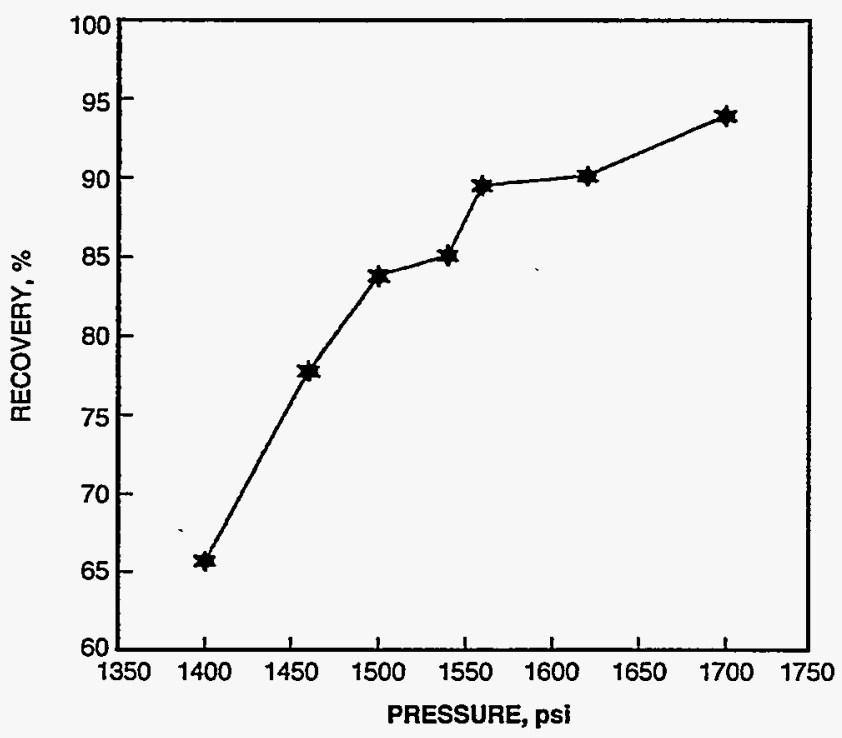

Fig. 2 Slim-tube results for Spraberry stock tank oil. Minimum miscibility pressure, -1500 psi.

coexisting phases are measured and a pendant drop is formed in one of the needles. Tests have been conducted with low-IFT alcohol-oil-water systems at low pressure and room temperature. Drops were formed at low IFT, although imaging problems were encountered The primary problem is the ability for the frame grabber and digitizer to image the entire drop. The contrast between the drop and background is obviously less pronounced at low IFT, so several different methods to improve the contrast are being tried.

Commercial code is being adapted to analyze the image to meet specific system requirements. The measurement cell is being pressure tested to delineate the upper limit of experimental measurements.

\section{Reference}

1. D. K. Babu, R.C.McCann, A.S. Odeh, and A.J.Al-Khalifa, The Relation Between Wellblock and Wellbore Pressures in Numerical Simulation of Horizontal Wells, SPE Reserv. Eng., 6(3): 324-328 (August 1991).

\section{PRODUCTIVITY AND INJECTIVITY OF HOFIZONTAL WELLS}

Contract No. DE-FG22-93BC14862

\author{
Stanford University \\ Stanford, Calif.
}

Contract Date: March 10, 1993

Anticipated Completion: March 10, 1998

Government Award: $\$ 359,000$

(Current year)

Principal Investigators:

F. John Fayers

Khalid Aziz

Thomas A. Hewett

\section{Project Manager: \\ Thomas Reid \\ Bartlesville Project Office}

Reporting Period: Jan. 1-Mar. 31, 1995

\section{Objectives}

The objectives of the project include (1) modeling horizontal wells to establish detailed three-dimensional (3-D) methods of calculation that will successfully predict horizontal well performance under a range of reservoir and flow conditions; (2) reservoir characterization studies to investigate reservoir heterogeneity descriptions of interest to applications of horizontal wells; (3) experimental planning and interpretation to critically review technical literature on twophase flow in pipes and the correlation of results in terms of relevance to horizontal wells; (4) defining methods for determining 3-D coarse grid approximations (e.g., pseudofunctions) for horizontal wells with calculations developed; (5) developing multi-well models interactively coupled to large-scale reservoir simulation; (6) test models with field examples; (7) enhanced oil recovery (EOR) extensions of models to handle compositional effects for miscible displacement, thermal effects for steam processes, and combination processes; and (8) application studies for horizontal wells.

\section{Summary of Technical Progress}

Two forms of special algebraic approximations to pressure and saturation equations have been developed for the generalized Voronoi gridding code. These have been coded in $\mathrm{C}++$ language and have been checked out in comparison with Eclipse simulator results for some simplified cases to check the validity of the two formulations and their coding implementation. Testing of the use of streamline methods to compute modified coarse-grid boundaries for very heterogeneous 
problems has continued. Very fast semianalytical, two-phase solutions along the streamlines have been successfully used to compute more-robust two-phase pseudos for the modified coarse-grid blocks. The predictions of the resulting breakthrough times and buildup of water/oil ratios are much better than those with conventional renormalization schemes. Studies on factors contributing to skin effects and the computation of the results of these studies are complete.

\section{Skin Factor Calculations for Vertical, Deviated, and Horizontal Wells}

Figure 1 shows a typical well completion and illustrates perforation geometry, the damaged zone caused by drilling fluids, the crushed zone surrounding the perforation tunnel, casing pipe, and the cement behind the pipe. The skin factor used, which is referred to as laminar skin, occurs because of near-wellbore damage to the formation or limited entry and is constant for all flow rates. It can be calculated as

$$
s=s_{p}+s_{d}+s_{c z}+s_{p p}+s_{\theta}
$$

with contributions from skins caused by perforations $\left(s_{p}\right)$, mud invasion $\left(\mathrm{s}_{\mathrm{d}}\right)$, crushed zone $\left(\mathrm{s}_{\mathrm{cz}}\right)$, partial penetration $\left(\mathrm{s}_{\mathrm{pp}}\right)$, and well deviation $\left(s_{\theta}\right)$.

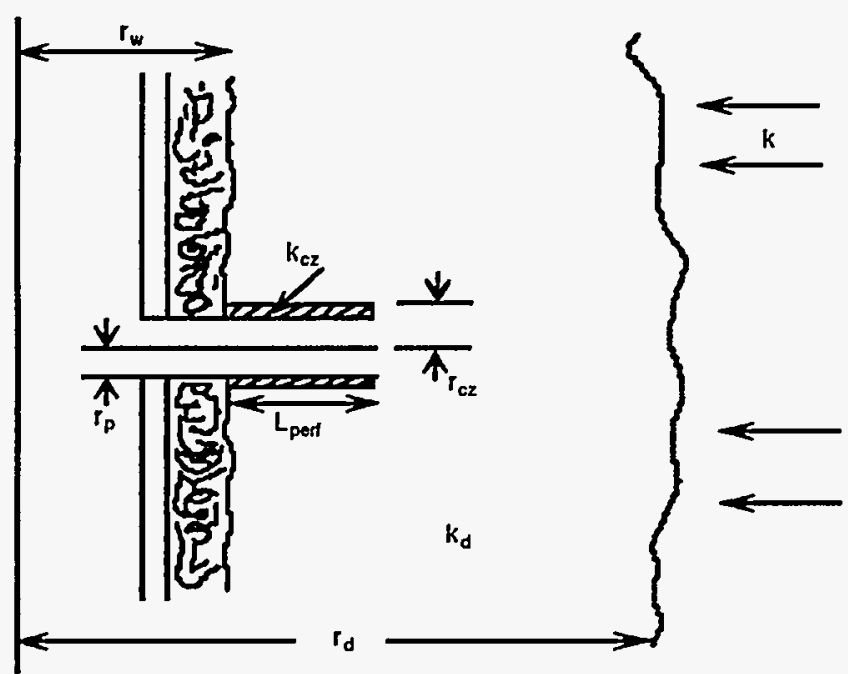

Fig. 1 Perforation geometry. $k$, permeability. $k_{d}$, permeability of damaged zone. $k_{c z}$, permeability of crushed zone. $L_{p e r f}$ perforation length. $r_{c z}$, radius of crushed zone. $r_{d}$, radius of damaged zone. $r_{p}$, radius of perforation. $r_{w}$, well radius.

\section{Calculation of Perforation Skin $\left(s_{p}\right)$}

The $s_{p}$ is the skin caused by the convergence of the flow lines into the perforations at the wellbore. Karakas and Tariq ${ }^{1}$ have presented a semianalytical expression for the calculation of the $s_{p}$ which they divide into components: the plane-flow $\operatorname{effect}\left(\mathrm{s}_{\mathrm{H}}\right)$, the vertical converging effect $\left(\mathrm{s}_{\mathrm{V}}\right)$, and the wellbore effect $\left(\mathrm{s}_{\mathrm{wb}}\right)$. Figure 2 illustrates some parameters in this model. With the use of a three-dimensional (3-D) finiteelement model, they formulated the dependency of $s_{p}$ on the angular perforation phasing $(\phi)$, the perforation length $\left(L_{\text {perf }}\right)$, and the well radius $\left(r_{w}\right)$.

The total $s_{\mathrm{p}}$ is given as ${ }^{2}$

where

$$
s_{p}=s_{H}+s_{v}+s_{w b}
$$

$$
s_{H}=\ln \frac{r_{w}}{r_{w a}(\phi)}
$$

$r_{w a}(\phi)$ is the effective wellbore radius and is a function of the phasing angle $(\phi)$. The skin as the result of the plane flow $\left(\mathrm{s}_{\mathrm{H}}\right)$ is obtained with the use of the effective well radius concept developed for vertical fractured wells by Prats. ${ }^{3}$

$$
r_{w a}(\phi)=\frac{L_{\text {perf }}}{4} \quad \text { for } \phi=0
$$

$$
r_{w a}(\phi)=a_{\phi}\left(r_{w}+L_{\text {perf }}\right) \quad \text { for } \phi \neq 0
$$

The constant $a_{\phi}$ depends on the perforation phasing and can be obtained from Table 1 . The numerical values for $a_{\phi}$ were obtained with finite-element simulations. ${ }^{1}$ This skin effect $\left(s_{H}\right)$ is negative (except for $\phi=0$ ), but its total contribution is usually small, ${ }^{2}$ and

$$
s_{V}=10^{a} h_{D}^{b-1} r_{D}^{b}
$$

where

$$
\begin{gathered}
h_{D}=\frac{h_{\text {perf }}}{L_{\text {perf }}}\left(\frac{k_{H}}{k_{V}}\right)^{1 / 2} \\
r_{D}=\frac{r_{\text {perf }}}{2 h_{\text {perf }}}\left[1+\left(\frac{k_{V}}{k_{H}}\right)^{1 / 2}\right] \\
a=a_{1} \log r_{D}+a_{2} \\
b=b_{1} r_{D}+b_{2}
\end{gathered}
$$

$a_{1}, a_{2}, b_{1}$, and $b_{2}$ are all functions of the perforation phasing and are given in Table 1. For large values of $h_{\text {perf }}$ (less number of shots per foot), $s_{\mathrm{V}}$ can be large. $s_{\mathrm{V}}$ values can be minimized with deep penetrating perforators and/or high shot density perforating guns. ${ }^{2}$ 


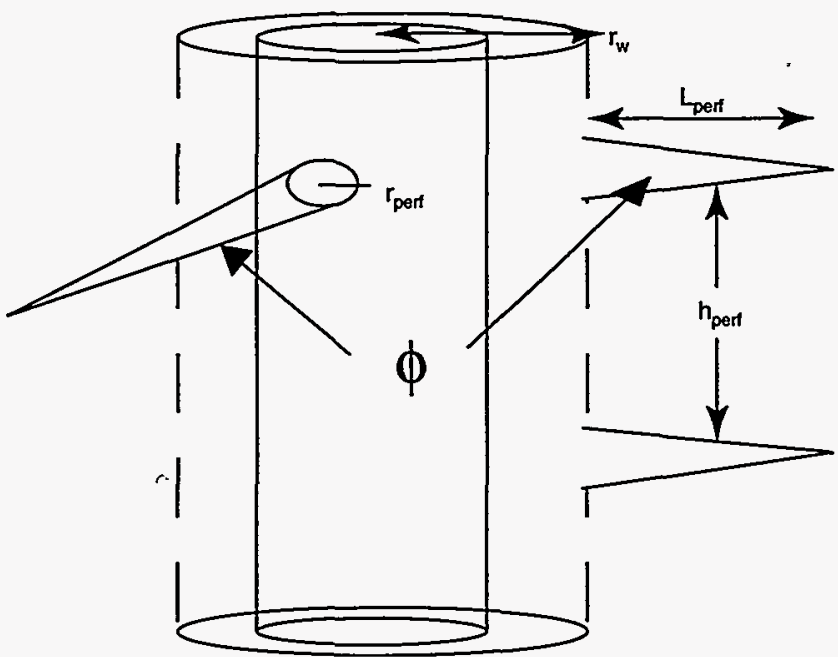

Fig. 2 Perforation skin calculation. $h_{\text {perf }}$ perforation height. $L_{\text {perf }}$ perforation length. $r_{\text {perf }}$ radius of the perforation. $r_{w}$, well radius. $\phi$, phasing angle.

\section{TABLE 1}

\section{Constants for Perforation Skin Effect Calculation}

\begin{tabular}{lccccccc}
\hline $\begin{array}{c}\text { Perforation- } \\
\text { phasing } \\
\text { angle }\end{array}$ & $\mathbf{a}_{\mathbf{6}}$ & $\mathbf{a}_{\mathbf{1}}$ & $\mathbf{a}_{\mathbf{2}}$ & $\mathbf{b}_{\mathbf{1}}$ & $\mathbf{b}_{\mathbf{2}}$ & $\mathbf{c}_{\mathbf{1}}$ & $\mathbf{c}_{\mathbf{2}}$ \\
\hline $0(360)$ & -0.250 & -2.091 & 0.0453 & 5.1313 & 1.8672 & $1.6 \times 10^{-1}$ & 2.675 \\
180 & 0.500 & -2.025 & 0.0943 & 3.0373 & 1.8115 & $2.6 \times 10^{-2}$ & 4.532 \\
120 & 0.648 & -2.018 & 0.0634 & 1.6136 & 1.7770 & $6.6 \times 10^{-3}$ & 5.320 \\
90 & 0.726 & -1.905 & 0.1038 & 1.5674 & 1.6935 & $1.9 \times 10^{-3}$ & 6.155 \\
60 & 0.813 & -1.898 & 0.1023 & 1.3654 & 1.6490 & $3.0 \times 10^{-4}$ & 7.509 \\
45 & 0.860 & -1.788 & 0.2398 & 1.1915 & 1.6392 & $4.6 \times 10^{-5}$ & 8.791 \\
\hline
\end{tabular}

The skin as the result of the wellbore effect is given as ${ }^{2}$

$$
s_{w b}=c_{1} \exp \left(c_{2} r_{w D}\right)
$$

where

$$
\mathrm{r}_{\mathrm{wD}}=\frac{\mathrm{r}_{\mathrm{w}}}{\mathrm{L}_{\text {perf }}+\mathrm{r}_{\mathrm{w}}}
$$

The constants $c_{1}$ and $c_{2}$ are also given in Table 1 . These constants are obtained from numerical simulations. This skin $\left(\mathrm{s}_{\mathrm{wb}}\right)$ was significantly larger for $0^{\circ}$ phasing than for the multidirectional phasings.

\section{Calculation of Damaged Zone Skin $\left(s_{\boldsymbol{d}}\right)$}

Because of the flow of drilling mud into the formation, the permeability around the wellbore is reduced. Let $k_{d}$ be the permeability and $r_{d}$ the radius of this damaged zone. If the well is completed along the entire length of the formation, then the Hawkin's formula ${ }^{4}$ can be used to calculate the resulting skin.

$$
s_{d}=\left(\frac{k}{k_{d}}-1\right) \ln \frac{r_{d}}{r_{w}}
$$

Now, if the well is only partially completed (as shown in Fig. 3), then Jones et al..$^{5}$ suggest that Hawkin's formula can no longer be used because the flow into the well is no longer radial. On the basis of the results from their numerical model, they presented an adaptation of Hawkin's formula that can be used when the well is partially completed.

$$
\mathrm{s}_{\mathrm{d}}=\frac{\mathrm{h}}{\mathrm{h}_{\mathrm{p}}}\left(\overline{1}-0.2 \frac{\mathrm{r}_{\mathrm{d}}-\mathrm{r}_{\mathrm{w}}}{\mathrm{h}_{\mathrm{p}}}\right)\left(\frac{\mathrm{k}}{\mathrm{k}_{\mathrm{d}}}-1\right) \ln \frac{\mathrm{r}_{\mathrm{d}}}{\mathrm{r}_{\mathrm{w}}}
$$

where $h_{p}$ is the height of the perforated interval. This result theoretically applies only when $h_{p}$ is small compared with $\mathrm{h}$ (total bed thickness) and when the perforated interval is in the center of the productive zone. For most cases of practical interest, however, these restrictions can be ignored.

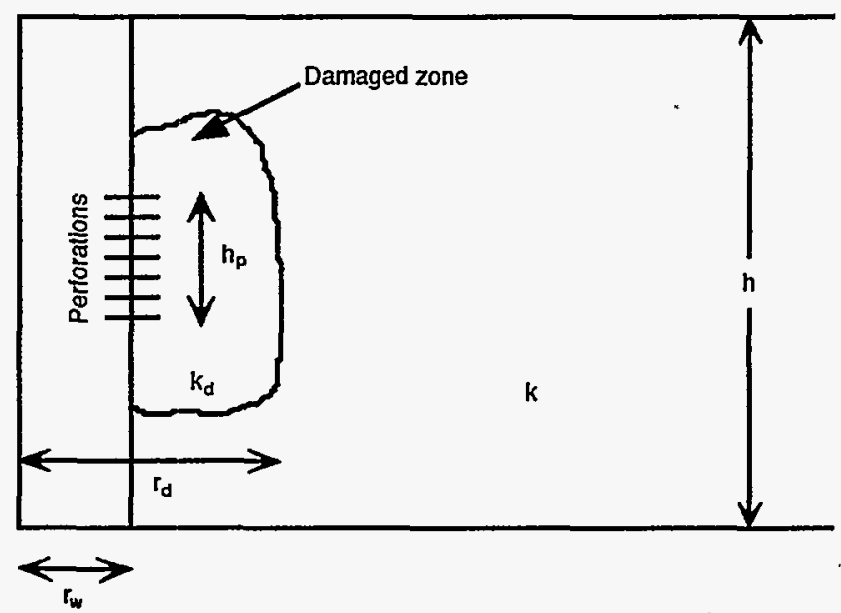

Fig. 3 Partial completion of a well. $h$, total bed thickness. $h_{p}$, height of perforated interval. $k$, permeability. $k_{d}$, permeability of damaged zone. $r_{d}$, radius of damaged zone. $r_{w}$, well radius.

\section{Calculation of Crushed Zone Skin $\left(\mathrm{s}_{\mathrm{cz}}\right)$}

The crushed zone around each perforation is about $0.5 \mathrm{in}$. thick. ${ }^{6-8}$ The permeability of this zone can be smaller or larger than the near-wellbore permeability, depending on whether compaction or collapse occurs. The equation for laminar skin through the crushed zone can be derived from radial flow equations ${ }^{6}$ and is given as

$$
s_{c z}=\frac{h}{L_{\text {perf }} n_{p}}\left(\ln \frac{r_{c z}}{r_{p}}\right)\left(\frac{k}{k_{c z}}-\frac{k}{k_{d}}\right)
$$

where $r_{p}$ is the radius of the perforation and $r_{c z}$ and $k_{c z}$ are the radius and permeability of the crushed zone, respectively. When $k_{c z}=k_{d}$, then no additional damage was done as the result of the crushed particles, and hence $s_{\mathrm{cz}}$ becomes zero. 


\section{Calculation of Partial Penetration Skin $\left(\mathrm{s}_{\mathrm{pp}}\right)$}

A positive skin results from a partially penetrating well. The necessary theoretical development is presented by Nisle $^{9}$ and by Brons et al. ${ }^{10}$ This skin is calculated from

$$
s_{p p}=\frac{(1-b)}{b}\left[\ln \left(\frac{h\left(k_{H} / k_{V}\right)^{1 / 2}}{r_{w}}\right)-G(b)\right]
$$

where

$$
G(b)=2.948-7.363 b+11.45 b^{2}-4.675 b^{3}
$$

and $b$ is the fractional penetration of the well. Equation 16 was determined numerically. ${ }^{\text {II }}$

\section{Calculation of Well Deviation Skin $\left(s_{\theta}\right)$}

A deviated well gives negative skin because of the increase in the producing interval area exposed to flow. Cinco et al. ${ }^{4}$ developed a pseudo-skin factor that gives the difference between the dimensionless pressure created by a slanted well and that created by a vertical well. They suggested that standard well-test analysis methods are valid to analyze transient pressure data of a slanted well during the pseudo-radial flow period because the pressure-time relationship for this case is similar to that for a vertical well. The calculation of skin factor, however, must be modified because of the difference between the pressure of a slanted well and that of a vertical well. For slant angles from 0 to $75^{\circ}$ and $\left(h / r_{w}\right)>40$, the skin for a deviated well was evaluated as

$$
s_{\theta}=-\left(\frac{\theta^{\prime}}{41}\right)^{2.06}-\left(\frac{\theta^{\prime}}{56}\right)^{1.865} \log _{10}\left(\frac{h_{w d}}{100}\right)
$$

where

$$
\theta^{\prime}=\tan ^{-1}\left[\left(k_{\mathrm{V}} / \mathrm{k}_{\mathrm{H}}\right)^{1 / 2} \tan \theta\right]
$$

and

$$
h_{w d}=\frac{h}{r_{w}}\left(k_{H} / k_{V}\right)^{1 / 2}
$$

\section{Non-Darcy Flow}

Non-Darcy flow occurs primarily in the near-wellbore region where fluid velocities are high. Whereas this effect is usually negligible for single-phase oil flow, it becomes important for gas flow at the wellbore. The equation for calculating the non-Darcy flow coefficient for gas flow comprises three components: crushed zone, damaged zone, and near-wellbore reservoir rock. ${ }^{12}(\beta$ is the turbulence factor).

$$
\begin{aligned}
\mathrm{D}=2.22 \times 10^{-15} \frac{\mathrm{kh} \gamma_{\mathrm{g}}}{\mu_{\mathrm{g}}} & {\left[\frac{\beta_{\mathrm{cz}}}{\mathrm{n}_{\mathrm{p}}^{2} \mathrm{~L}_{\text {perf }}^{2}}\left(\frac{1}{\mathrm{r}_{\mathrm{p}}}-\frac{1}{\mathrm{r}_{\mathrm{cz}}}\right)\right.} \\
+ & \left.\frac{\beta_{\mathrm{d}}}{\mathrm{h}_{\mathrm{p}}^{2}}\left(\frac{1}{\mathrm{r}_{\mathrm{w}}}-\frac{1}{\mathrm{r}_{\mathrm{d}}}\right)+\frac{\beta}{\mathrm{h}^{2}}\left(\frac{1}{\mathrm{r}_{\mathrm{d}}}-\frac{1}{\mathrm{r}_{\mathrm{e}}}\right)\right]
\end{aligned}
$$

where

$$
\begin{aligned}
& \beta=\frac{2.6 \times 10^{10}}{\mathrm{k}^{1.2}} \\
& \beta_{\mathrm{d}}=\frac{2.6 \times 10^{10}}{\mathrm{k}_{\mathrm{d}}^{1.2}} \\
& \beta_{\mathrm{cz}}=\frac{2.6 \times 10^{10}}{\mathrm{k}_{\varsigma 2}^{1.2}}
\end{aligned}
$$

\section{Pressure Drop Caused by the Gravel Pack}

Wells are usually completed with gravel pack to prevent formation loss at the wellbore. This causes additional pressure drop to the flow of formation fluids. This pressure drop is a result of two components: gravel in the perforation tunnel and gravel between the liner and the casing. For a gas well, the pressure loss through the gravel pack can be calculated ${ }^{13-14}$ by

$$
\begin{aligned}
p_{w f}^{2}-p_{w p e r f}^{2}= & \frac{8.93 z T \mu_{g} q_{g} L_{\text {perf }}}{k_{g r} A_{p}} \\
& +\frac{1.247 * 10^{-16} \beta_{g} z T \gamma_{g} L_{\text {perf }} q_{g}^{2}}{A_{p}^{2}}
\end{aligned}
$$

where $\mathrm{k}_{\mathrm{gr}}$ is the gravel permeability in millidarcys, $A_{p}=$ $\mathrm{n}_{\mathrm{p}} \pi \mathrm{r}_{\mathrm{p}}^{2}$, and

$$
p_{\text {wperf }}^{2}-p_{\text {wliner }}^{2}=\frac{1424 \mu_{\mathrm{g}} \mathrm{zTq} \mathrm{g}_{\mathrm{g}}}{\mathrm{k}_{\mathrm{gr}} \mathrm{h}}\left(\ln \frac{\mathrm{r}_{\mathrm{c}}}{\mathrm{r}_{\mathrm{L}}}-0.5+\mathrm{Dq}_{\mathrm{g}}\right)
$$

where

$$
\mathrm{D}=\frac{2.22 * 10^{-15} \beta \gamma_{\mathrm{g}} \mathrm{k}_{\mathrm{g}}}{\mathrm{h}_{\mathrm{p}} \mu_{\mathrm{g}}}\left(\frac{1}{\mathrm{r}_{\mathrm{L}}}-\frac{1}{\mathrm{r}_{\mathrm{c}}}\right)
$$

\section{References}

1. M. Karakas and S. Tariq, Semi-Analytical Productivity Models for Perforated Completions, paper SPE 18247 presented at the 63rd Annual Society of Petroleum Engineers Technical Conference, Houston, Tex., October 2-5, 1988.

2. M. J. Economides, A. D. Hill, and C. Ehlig-Economides, Petroleum Production Systems, pp. 83-117, Prentice Hall, Englewood Cliffs, N.J., 1993.

3. M. Prats, The Effect of Vertical Fractures on Reservoir BehaviorIncompressible Fluid Case, Soc. Pet. Eng. J., 1(4): 105-117 (June 1961).

4. H. Cinco-L.,F.G.Miller, and H.J.Ramey,Jr., Unsteady-State Pressure Distribution Crested by a Directionally Drilled Well, J. Pet. Technol., 27(11): 1392-1400 (November 1975). 
5. L. G. Jones and J. W. Watts, Estimating Skin Effects in a Partially Completed Damaged Well, J. Pet. Technol., 23(2): 249-252 (February 1971).

6. H. O. McLeod, Jr., The Effect of Perforating Conditions on Well Performance, J. Pet. Technol., 35(1): 31-39 (January 1983).

7. J.A. Klotz, R. F. Krueger, and D. S. Pye, Effect of Perforation Damage on Well Productivity, J. Pet. Technol., 26(11): 1303-1314 (November 1974).

8. R. J. Saucier and J. F. Lands, Jr., A Laboratory Study of Perforations in Stressed Formation Rocks, J. Pet. Technol., 30(9): 1347-1353 (September 1978).

9. R. G. Nisle, The Effect of Partial Penetration on Pressure Build-Up in Oil Wells, Trans. Am. Inst. Min. Eng., 213: 85 (1958).

10. F. Brons and V. E. Marting, The Effect of Restricted Fluid Entry on Well Productivity, paper SPE 1322-G presented at the 34th Annual Society of Petroleum Engineers Fall Meeting, Dallas, Tex., October 4-7, 1959.

11. F.Brons and V.E.Marting, The Effect of Restricted Fluid Entry on Well Productivity, J. Pet. Technol., 13(2): 172-174 (February 1961).

12. A. Firoozabadi and D. L. Katz, Analysis of High-Velocity Gas Flow Through Porous Media, J. Pet. Technol., 31(2): 211-216 (February 1979).

13. L. G. Jones and E. M. Blount, Use of Short-Term Multiple Rate Flow Tests to Predict Performance of Wells Having Turbulence, paper SPE 6133 presented at the 51st Society of Petroleum Engineers Annual Technical Conference, New Orleans, La., October 3-6, 1976.

14. R. J. Saucier, Considerations in Gravel Pack Design, J. Pet. Technol., 26(2): 205-212 (February 1974).

15. L. K. Thomas, C. E. Evans, R. G. Plerson, and S. L. Scott, Well Performance Model, J. Pet. Technol., 44(2): 220-229 (February 1992).

\section{SCALEUP OF MISCIBLE FLOOD PROCESSES}

\section{Contract No. DE-FG22-92BC14852}

\section{Stanford University \\ Stanford, Calif.}

Contract Date: Sept. 30, 1992

Anticipated Completion: Sept. 30, 1995

Government Award: $\$ 349,985$

\author{
Principal Investigator: \\ Franklin M. Orr, Jr. \\ Project Manager: \\ Jerry Casteel \\ Bartlesville Project Office
}

Reporting Period: Jan. 1-Mar. 31, 1995

\section{Objective}

The objective of this project is to quantify through a systematic research effort the relationships between process mechanisms that can lead to improved oil recovery from gas injection processes performed in heterogeneous Class 1 (fluvial-deltaic) and Class 2 (carbonate) reservoirs. Results of the study will provide a rational basis for the design of displacement processes that take advantage of crossflow attributed to capillary, gravity, and viscous forces to partially offset the adverse effects of heterogeneity. In effect, the highpermeability zones are used to deliver fluid by crossflow to zones that would otherwise be flooded only very slowly. The research effort is divided into five areas:

1. Development of miscibility in multicomponent systems.

2. Design estimates for nearly miscible displacements.

3. Design of miscible floods for fractured reservoirs.

4. Compositional flow-visualization experiments.

5. Simulation of near-miscible flow in heterogeneous reservoirs.

\section{Summary of Technical Progress}

Work continued in the following areas:

1. Development of Miscibility in Multicomponent Systems. Progress continues on the creation of a systematic theory of miscibility development in multicomponent systems. The mathematical theory developed at Stanford University has been extended to study the effects of initial concentration of methane $\left(\mathrm{CH}_{4}\right)$ in nitrogen $\left(\mathrm{N}_{2}\right)$ floods. 'The sensitivity of the performance of high-pressure displacements by $\mathrm{N}_{2}$ or $\mathrm{N}_{2}$ mixtures to changes in the composition of oil or the injected gas has been demonstrated, and the development of miscibility in such systems has been examined. The analysis of fourcomponent systems explains why the literature contains contradicting reports about the dependence of minimum miscibility pressure (MMP) on the amount of $\mathrm{CH}_{4}$ present in the oil displaced or the injection gas. Some systems show only weak dependence on the amount of $\mathrm{CH}_{4}$ present, whereas others are quite sensitive. That behavior is explained by the positions of the tie lines that extend through the initial and injection compositions relative to the position of the crossover tie line. As the MMP is approached, one of those three tie lines becomes a critical tie line. Consider, for example, displacement of a $\mathrm{CH}_{4}$-butane-decane $\left(\mathrm{C}_{10}\right)$ mixture by a $\mathrm{CH}_{4}-\mathrm{N}_{2}$ mixture. Whether a displacement performance is sensitive to the initial $\mathrm{CH}_{4}$ concentration depends on which tie line controls development of miscibility. If the initial tie line, which depends quite strongly on $\mathrm{CH}_{4}$ concentration, becomes critical as the MMP is approached, then the MMP is sensitive to initial $\mathrm{CH}_{4}$ concentration. Conversely, if the crossover tie line controls miscibility, then the MMP is sensitive to the initial $\mathrm{CH}_{4}$ concentration only if the crossover tie line changes as the initial $\mathrm{CH}_{4}$ concentration is changed. For systems with relatively low initial $\mathrm{CH}_{4}$ concentration, the crossover tie line changes as the initial $\mathrm{CH}_{4}$ concentration is changed. For a system with a relatively low initial $\mathrm{CH}_{4}$ concentration, the 
crossover tie line hardly changes, so such systems would be insensitive to the $\mathrm{CH}_{4}$ concentration. In systems with more $\mathrm{CH}_{4}$ present initially, however, the crossover tie line no longer controls miscibility. Instead, the initial tie line does so, and displacement performance is again sensitive to initial $\mathrm{CH}_{4}$ concentration. Thus sensitivity observed for low $\mathrm{CH}_{4}$ concentration is very different from that observed for high $\mathrm{CH}_{4}$ concentration. The analytical theory explains clearly why such behavior occurs.

A comprehensive analysis of the mass transfer involved in rising bubble experiments for determination of MMP or minimum miscibility enrichment (MME) has been carried out. ${ }^{2}$ Numerical simulations of composition exchanges at the bubble interface of a three-component system show that the direction that the intermediate component moves is very important for observations of the development of miscibility. When the intermediate component transfers from the liquid phase into the bubble, the composition path leads to low interfacial tension (IFT) such as those which occur in vaporizing gas drives, whereas in condensing gas drives the intermediate component moves from the bubble into the surrounding liquid phase. As a result, bubble compositions near the surface move away from critical point, and the IFT increases. Thus a single rising bubble experiment would not be able to determine MMP or MME for condensing gas drives; however, a falling drop experiment would be an alternative way to determine MME for condensing gas drives. In this version, an oil drop would descend through the gas phase, and the resulting composition changes would drive the composition path close to the critical point and produce low IFT at the MME. Thus either process mechanism could be identified by comparing rising bubble and falling drop measurements for the same compositions. Questions remain, however, concerning how to interpret bubble observations for condensing/vaporizing $(\mathrm{C} / \mathrm{V})$ displacements. These experiments and theory indicate that it may be difficult or impossible to determine MMP or $\mathrm{MME}$ by the rising bubble or falling drop methods for $\mathrm{C} / \mathrm{V}$ displacements.

2. Design Estimates for Nearly Miscible Displacements. Network simulations of gas injection processes with three-phase flows are being conducted to study the effects of IFT changes on final oil recoveries. Recent experimental and theoretical results suggest that the stability of an oil layer is crucial for the determination of the final oil recovery of a gas injection process when all three phases move. ${ }^{3}$ The conditions for the stability of an oil layer have been derived by examining the configurations of three phases in a single pore. The ratios of the oil-water and gas-oil IFTs and capillary pressures control the stability of the oil layer. The final oil recovery is a strong function of the displacement history.

3. Design of Miscible Floods for Fractured Reservoirs. Experiments conducted to quantify the threephase gravity drainage theory developed from a vertical equilibrium analysis are continuing. ${ }^{4}$ The theory suggests that a near-zero residual oil saturation (ROS) can be obtained in the upper part of a reservoir if the reservoir is water-wet and if the system has a positive initial spreading coefficient. Systems of water, hydrocarbons, and air were used to carry out experiments on water-wet sand columns. Hexane $\left(\mathrm{C}_{6}\right)$, isooctane $\left(\mathrm{iC}_{8}\right)$, and $\mathrm{C}_{10}$ have been used to vary the oil-phase properties. Measurements for $\mathrm{C}_{6}$ systems show that the ROSs in the upper part of the column can be as low as $0.1 \%$ of the pore volume (PV). For $\mathrm{C}_{10}$ systems that have a negative initial spreading coefficient, however, the ROSs in the upper part are about $2.0 \%$ of PV. Investigations on the effects of wettability on ROSs are also in progress.

The high-pressure drainage experiment continues to produce new data from drainages of Means crude in the presence of carbon dioxide $\left(\mathrm{CO}_{2}\right)$. Results have been obtained from drainage of Means at pressures of 900,1500 , and 1700 psia on two sandstone cores of 100 and $500 \mathrm{mD}$. The data show that increases in pressure (for the same temperature) result in increases in oil recovery, probably as a result of the reduction in IFT between gas and oil phases.

4. Flow Visualization Experiments. The effort on conducting visualization experiments has been extended. Twophase displacements of matched viscosity but different densities have been performed to investigate gravity effects without the influence of stabilizing or unstabilizing created by viscous forces. The observations from those experiments will be reproduced by the particle-tracking simulator. Experiments to investigate the scaling parameters for gravity and viscous forces in layered systems are also being conducted by comparing the fluid distributions on two models of same heights but different lengths.

5. Simulation of Near-Miscible Flow in Heterogeneous Reservoirs. The investigation of the streamline approach as a numerical alternative to conventional finite-difference simulators to be used in predicting near-miscible gas injection in heterogeneous reservoirs is continuing. The streamline method has been generalized to include gravity, compositional effects, and dispersion in three dimensions. ${ }^{5}$ In cases where the principal flow directions are governed by the pattern of permeability, comparisons of results from high-resolution simulation and streamline techniques show that streamline techniques can predict flow patterns accurately and are free from numerical dispersion in two to four orders of magnitude less computer time.

Substantial progress has been made on a new effort in this area. A three-dimensional (3-D) network model for threephase flows is being built. This network model is aimed to generate three-phase relative permeabilities by taking into account detailed mechanisms of three-phase flow in the pore levels. This model will also be capable of evaluating the relative contributions of various flow mechanisms to macroscopic flow behaviors in different systems.

\section{Pore-Level Modeling of Three-Phase Flow in Porous Media}

Three-phase flow is an important process in enhanced oil recovery (EOR), gravity drainage, solution gas drives, and 
pollutant transport and cleanup. Multiphase flow in porous media is characterized by capillary pressure and relative permeability functions. For three-phase flow, these functions are extremely difficult to determine for the full range of saturation values. ${ }^{6}$ In simulation studies, empirical correlations are necessary to compute relative permeability. These correlations are either fits to the experimental data or correlations that extrapolate the two-phase (gas-water, oil-water, and gas-oil) functions into the three-phase region. ${ }^{7-9}$ These functions cannot properly represent the intricacies of the flow phenomena. For the understanding of three-phase flow in porous media, the physics must be studied at the pore level. When three phases are in contact with each other, their behavior is partly determined by the spreading coefficient $C_{s}$, which is defined as

$$
C_{s}=\gamma_{g w}-\left(\gamma_{o w}+\gamma_{g o}\right)
$$

where initially $\gamma_{g w}, \gamma_{g w}$, and $\gamma_{g o}$ are the gas-water, oil-water, and gas-oil IFTs, respectively, measured on pure fluids before they are brought into contact with each other. Three different situations can arise: ${ }^{10}(1)$ If $\mathrm{C}_{s}<0$, the three-phase contact line shown in Fig. 1 is stable. Examples include medium- and long-chain alkanes, such as dodecane in contact with air and water. (2) If $\mathrm{C}_{\mathrm{s}}>0$, the contact line between the three phases is unstable and the oil spreads. Many solvents, hydrocarbons, and crude oils have a positive spreading coefficient. ${ }^{11} \mathrm{An}$ equilibrium spreading coefficient $\left(\mathrm{C}_{\mathrm{s}}^{\mathrm{c}}\right)$ can be defined from Eq. 1, where the IFTs are measured in thermodynamic equilibrium. If $\mathrm{C}_{\mathrm{s}}>0$, the water surface is coated by a thin oil film, which lowers the effective gas-water IFT and $\mathrm{C}_{s}<0$. Excess oil remains in a droplet in equilibrium with the film. Many hydrocarbons, such as benzene, and solvents, such as carbon tetrachloride, have a positive initial spreading coefficient but a negative equilibrium spreading coefficient. The film generally is approximately of molecular thickness, between 0.5 and $5 \mathrm{~nm}$ across. (3) The third possibility is that the oil film can swell without limit. Once the oil film is thicker than the range of intermolecular forces, $C_{s}^{e}=0 . .^{12-14}$ An example of this behavior is Soltrol 170, a commercial mixture of hydrocarbons. ${ }^{15,16} \mathrm{It}$ is assumed that the system has reached thermodynamic equilibrium, and hence the distribution of fluid is controlled by the equilibrium spreading coefficient, which is either zero or negative.
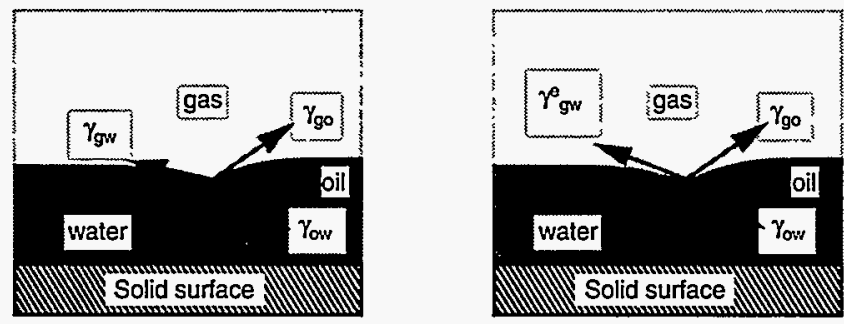

Fig. 1 Three fluids in contact near a solid surface.
If gas is introduced into a system containing water and residual oil, spreading allows the oil to form a continuous layer between gas and water and thus enables the oil to flow. This phenomenon has been suspected as an important mechanism for oil recovery by inert gas injection since the work of Dumore and Schols ${ }^{17}$ and was confirmed by careful experimental measurements on sandstone cores and unconsolidated media. ${ }^{16,18-20}$ Two-dimensional (2-D) etched-glass micromodels by Kantzas et al., ${ }^{21}$ Oren etal., ${ }^{15}$ and Kalaydjian ${ }^{22}$ were used to directly observe the drainage of oil layers. Kalaydjian ${ }^{22}$ and Oren et al. ${ }^{15,23}$ demonstrated that a system with a positive value of $C_{s}$ gives better oil recovery than one in which $C_{s}<0$. Recently, three-phase gravity drainage was studied theoretically and experimentally. Flow in stable oil layers in crevices of the pore space enable the achievement of very low ROSs. ${ }^{4}$

Three-phase flow allows a series of double displacement mechanisms in which one fluid displaces another that displaces the third. This was observed and described by Oren et al. ${ }^{15}$ with reference to double drainage, where gas displaces oil that displaces water. Here a three-phase porelevel numerical model is described that incorporates the effects of oil layers and double displacement mechanisms. A percolation network model of three-phase flow was first proposed by Heiba et al., ${ }^{24}$ and more-sophisticated models, including the effects of flow in oil films ${ }^{25}$ and both oil films and double drainage, ${ }^{23}$ have been shown to reproduce the results of 2-D micromodel experiments. This model will extend the previous work to three dimensions and to include the full range of possible drainage and imbibition mechanisms. This description of the pore-level physics inevitably leads to a macroscopic description of three-phase flow that is very different from the conventional Darcy law formulation.

\section{A Pore Level Network Model}

The pore space is represented as a cubic array of wide pores connected together by narrower throats. Arbitrary distributions of pore and throat radii may be specified except that a pore is always larger than any of the six throats connected to it. In this model, both the pores and throats have a square cross section, although this restriction can be changed easily. The flow of three phases is simulated by allowing a sequence of individual pore events. ${ }^{3}$ Oil flow through a stable oil layer has been found to be one of the controlling mechanisms when determining final oil saturation. ${ }^{3}$ The stability analysis of an oil layer in the pore space is discussed in the following text.

\section{An Oil Layer in the Pore Space}

Figure 2 shows three phases in a wedge. It is assumed that the water is wetting and that the oil-water contact angle is smaller than the gas-oil contact angle. This arrangement may be stable even if the spreading coefficient is negative. The oil layer here will be on the order of a few microns thick-much thicker than the nanometer-size molecular oil films on flat surfaces. The radius of curvature of the gas-oil interface is $r_{g o}$, 


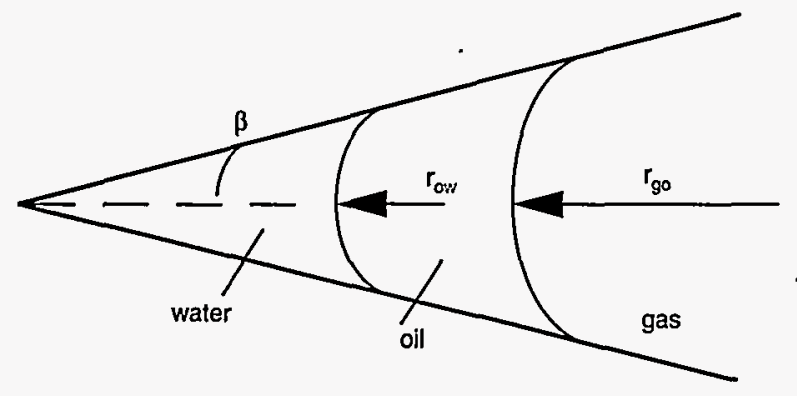

(a)

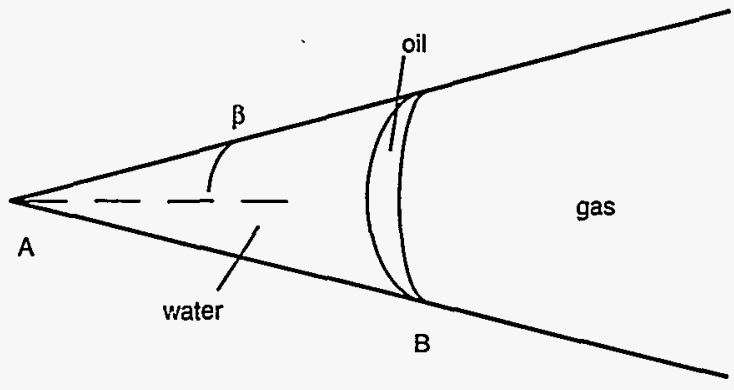

(b)

Fig. 2 (a) Three phases in a wedge of half angle $\beta$. (b) At this point, the oil layer first becomes unstable.

and the curvature of the oil-water interface is $r_{\text {ow. }}$. It is assumed that there is no curvature in the direction perpendicular to the plane of part a of Fig. 2. Then from the Young-Laplace equation, $P_{c_{g o}}=\gamma_{g o} / r_{g o}$, where $P_{c_{g o}}$ is the local gas-oil capillary pressure, and with a similar expression for $P_{c_{\text {ow }}}$, the oil-water capillary pressure,

$$
\mathrm{R}=\frac{\mathrm{r}_{\mathrm{go}}}{\mathrm{r}_{\mathrm{ow}}}=\frac{\gamma_{\mathrm{go}} \mathrm{P}_{\mathrm{c}_{\mathrm{ow}}}}{\gamma_{\mathrm{ow}} \mathrm{P}_{\mathrm{c}_{\mathrm{go}}}}
$$

For large values of $R$, the oil layer is thick. At a critical value $\left(R_{c}\right)$, the arrangement of fluid shown in part a of Fig. 2 is no longer possible, and it is unlikely that the oil layer will remain stable. This happens when the point of contact of the oil-water interface with the surface and the gas-oil contact coincide, as shown in part b of Fig. 2. The distance $A B$ marked in part $b$ of Fig. 2 is

$$
\mathrm{AB}=\mathrm{r} \frac{\cos (\theta+\beta)}{\cos \beta}
$$

for an interface of radius $r$, contact angle $\theta$, and wedge of half angle $\beta$. Hence the critical ratio $\left(R_{c}\right)$ is

$$
R_{c}=\frac{\cos \left(\theta_{o w}+\beta\right)}{\cos \left(\theta_{g o}+\beta\right)}
$$

If the case where the water is completely wetting and covers the solid surface with a thin film of molecular thickness is considered, then the microscopic arrangement of water, gas, and oil at the solid surface is similar to that illustrated in Fig. 1 except that the water surface is flat. The vertical force balance is maintained by intermolecular forces in the water film, but the horizontal balance of forces implies that

$$
\gamma_{\mathrm{gw}}=\gamma_{\mathrm{go}} \cos \theta_{\mathrm{go}}+\gamma_{\mathrm{ow}}
$$

or

$$
\cos \theta_{\mathrm{go}}=1+\frac{\mathrm{C}_{\mathrm{s}}^{\mathrm{e}}}{\gamma_{\mathrm{go}}}
$$

as derived by Kalaydjian et al. ${ }^{6}$ and Kalaydjian. ${ }^{22}$ Notice that the equilibrium value of the spreading coefficient is used here because the water film may itself be coated by a thin film of oil.

If Eq. 6 is used for the gas-oil contact angle, and if it is assumed that $\theta_{\text {ow }}=0$, then, after some algebra, Eq. 4 becomes

$$
\frac{1}{R_{c}}=1+\frac{C_{s}^{e}}{\gamma_{g o}}-\left(-\frac{C_{s}^{c}}{\gamma_{g o}}\right)^{1 / 2}\left(2+\frac{C_{s}^{e}}{\gamma_{g o}}\right)^{1 / 2} \tan \beta
$$

As an example, consider benzene in contact with water and air, for which $\mathrm{C}_{\mathrm{s}}^{\mathrm{e}}=-1.6 \mathrm{mN} \mathrm{m}^{-1}$ and $\gamma_{\mathrm{go}}=28.8 \mathrm{mN} \mathrm{m}^{-1}$. Then, for a square wedge with $\beta=\pi / 4, R_{c}=1.6$. An oil layer is stable for larger values of $R$ and is unstable for $R$ below this critical value. If the equilibrium spreading coefficient is zero, $\mathrm{R}_{\mathrm{c}}=1$.

This is a very simple geometric argument for the stability of an oil layer in a wedge that ignores the complex geometry of a real pore space. However, the analysis does give an indication of the expected behavior: oil layers are stable even for negative spreading coefficient, but the range of capillary pressures over which a layer is stable decreases with decreasing spreading coefficient.

When oil layers are stable, the oil is connected and cannot be trapped in the presence of gas. This allows very low oil saturations to be achieved during gas injection. For $R<R_{c}$, there are no oil layers, and oil can be trapped by both gas and water. If the initial spreading coefficient is positive, the water will still be coated by an oil film of molecular thickness, but this film is far too thin to allow any significant oil flow. The flow of oil through molecular films will be ignored in the calculations that follow. 
How the Network Model Simulates

Fluid Invasion

Displacement proceeds by one pore or throat filling at a time. The capillary pressures for all the possible displacement processes mentioned in the previous section are stored in a sorted list. At the beginning, the model is completely saturated with water. Fluid is injected through one face of the model and produced through the opposite face. Periodic boundary conditions are in the other two directions. Oil is injected into the network. Subsequently water, gas, or oil, or all three, may be injected and displaced in any order. When all three phases are present in the model, two capillary pressures must be specified. If $\mathrm{P}_{\mathrm{c}_{\mathrm{go}}}$ and $\mathrm{P}_{\mathrm{c}_{\mathrm{ow}}}$ are specified, the gas-water capillary pressure is defined as $\mathrm{P}_{\mathrm{c}_{\mathrm{gw}}}=\mathrm{P}_{\mathrm{c}_{\mathrm{go}}}+\mathrm{P}_{\mathrm{c}_{\text {ow }}}$. One of the capillary pressures is held constant (for example, the gas-oil pressure). Then a small change in the oil-water capillary pressure is made. If the assumption is made that drainage is being considered, which means that the oil-water capillary pressure is increasing, then, ofall possible two-phase and three-phase displacements, the one that has the lowest oil-water capillary pressure (if $P_{c_{g o}}$ ) is some known, fixed value. This could be an event where oil displaces water, oil displaces gas, or gas displaces water, or one of the double-displacement mechanisms. For imbibition, the event with the highest oil-water capillary pressure is found. In the next step, either keep $P_{c_{g 0}}$ constant and proceed as before or hold $P_{c_{\text {ow }}}$ fixed at its previous value. In the latter case, the displacement is performed with the lowest value of $P_{c_{g 0}}$ (for $a$ drainage step) or the highest value (for imbibition).

If a phase (for instance, oil) does not span the network, local oil-water and gas-oil capillary pressures, which are found from the radii of curvature of the last pore or throat that oil either invaded or was displaced from, can still be defined. The network model simulates any sequence of three-phase flow by incremental changes in capillary pressure. The saturations of each phase

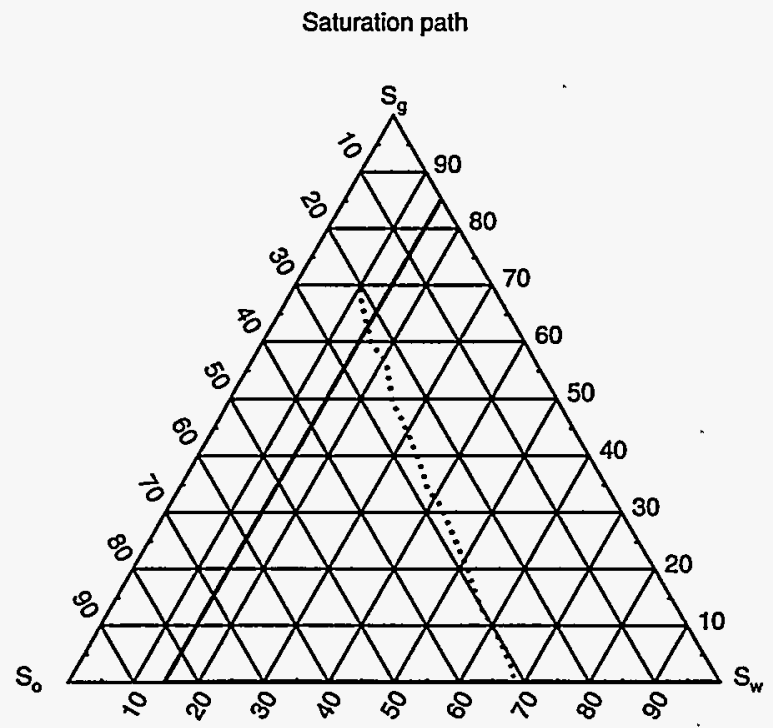

at each step are recorded. As an example, Fig. 3 is a picture of a 2-D three-phase simulation on an 80 by 80 network. The picture shows gas breakthrough during gas injection into water and oil.

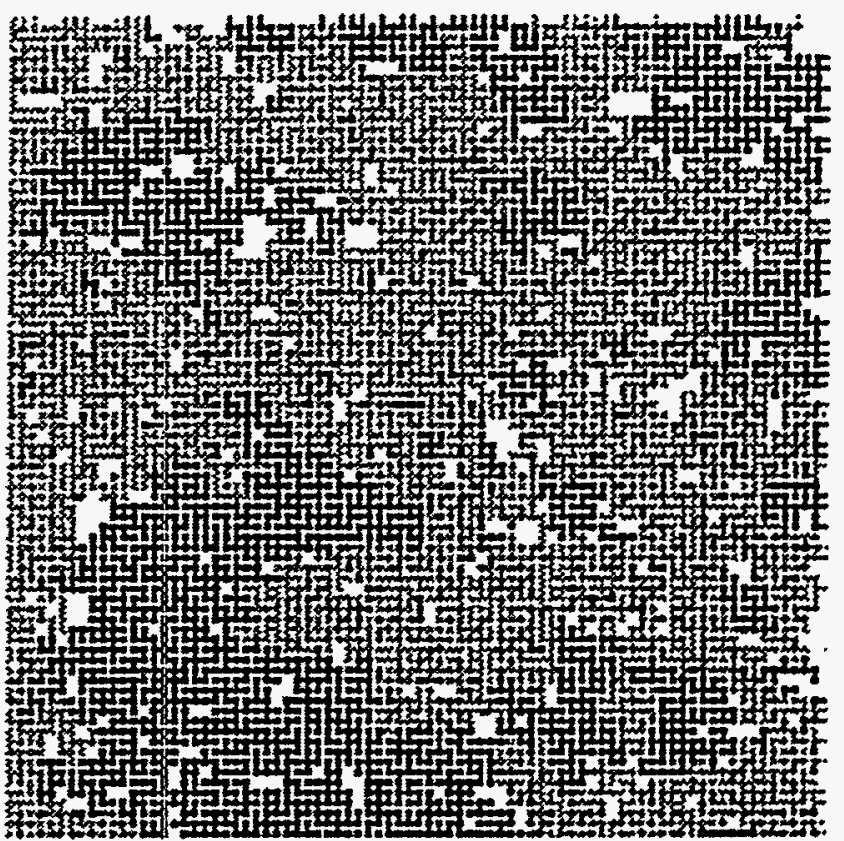

Fig. 3 Gas injection into oil and water atgas breakthrough simulated on an 80 by 80 square network. The fluids have a spreading coefficient of zero. Gas is gray, oil is black, and water is white. Both the water and oil phases are connected through layers in the corners of the pore spaces.

\section{Why a Conventional Darcy Law \\ Description Cannot Be Valid}

Figure 4 shows the saturation path and corresponding capillary pressures for three-phase displacements with a zero

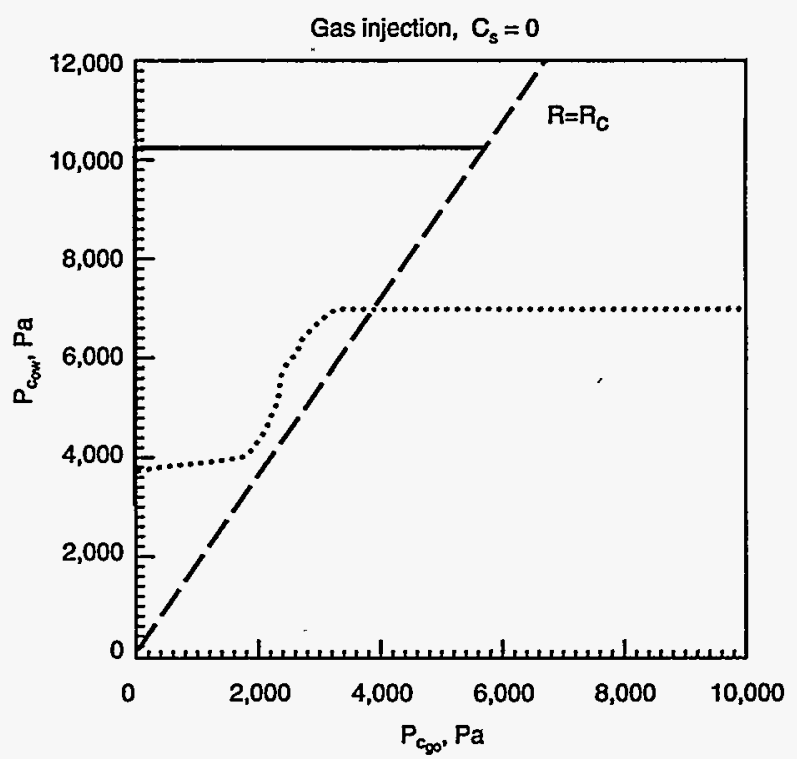

Fig. 4 Different pathways in capillary pressure and saturation space representing gas injection into waterflood residual oil for fluids with a spreading coefficient of zero. 
spreading coefficient simulated on a 20 by 15 by 15 network. Initially the network model is completely saturated with water. The oil-water capillary pressure is then increased to $11,000 \mathrm{~Pa}$, where the water saturation is $15 \%$. Waterflooding was then simulated, and the resulting ROS in water was just over $30 \%$. The injection of gas was modeled for two cases. The first, indicated by the solid line, is when the oil-water capillary pressure is increased to and then maintained at $11,000 \mathrm{~Pa}$. This represents the injection of gas into connate water and oil. All the oil is recovered. Before the gas is injected, all the oil is connected. The oil-water capillary pressure is determined by the smallest throat that the oil has entered. When the gas is first injected, oil layers are stable, so the oil remains connected. For zero spreading coefficient, the point at which oil layers disappear (when $R=R_{c}=1$ in Fig. 4) also corresponds exactly to the gas-oil capillary pressure necessary for gas to enter the smallest oil-filled throat. Thus the gas is able to displace all the oil while oil layers are present, which results in $100 \%$ recovery. This is the ideal case.

The dotted line in Fig. 4 indicates gas injection into waterflood residual oil and water. In this simulation the oil phase never spans the network. Oil layers are no longer stable at a lower value of $P_{c_{80}}$ than in the first example. Not all the oil has been contacted by gas when the layers disappear. The remaining oil recovery for $R<R_{c}$ is the result of double drainage alone. The final oil saturation, when $P_{c_{g o}}=42,000$ $\mathrm{Pa}$ (off the scale in Fig. 4), is $20 \%$, approximately $10 \%$ lower than the waterflood residual.

Figure 5 illustrates the same two displacements for fluids with an equilibrium spreading coefficient of $-4 \mathrm{~m} \mathrm{Nm}^{-1}$, which is similar to a decane-water-air system. ${ }^{10}$ In this example, oil layers are stable for a more-restricted range of capillary pressure, as indicated in Fig. 5. For both cases, drainage through stable oil layers makes very little contribution to recovery, and displacement of oil is predominantly by double drainage. For gas injection into waterflood residual oil, the final oil saturation is virtually the same as that for the zero spreading coefficient case. In contrast, much less oil is recovered when gas is injected into a higher oil saturation, and the remaining oil saturation $(40 \%)$ is higher than the waterflood residual (35\%).

The conventional multiphase Darcy law relates the oil flow to a pressure gradient in the oil phase. If the oil is not connected, but there is recovery by double drainage, the oil flow has no macroscopic pressure gradient in the oil. This process can only be modeled by cross terms, where the flow of oil is related to pressure gradients in the continuous gas and water phases. This demonstrates one inadequacy of conventional three-phase relative-permeability models.

Hysteresis, in which different final oil saturations after gas injection, depending on the saturation (or capillary pressure) history, are obtained, is present in two-phase flow, but in three-phase flow, particularly at low oil saturation, it is very significant.

How can the network model be used to predict the oil recovery from gas injection? It has been demonstrated that the ROS is sensitive to capillary pressure history, but there is no way of knowing a priori what route in capillary pressure space a given displacement would take. Imagine attempting to predict a one-dimensional (1-D) displacement where gas is injected into waterflood residual oil. Conventionally, predetermined relative-permeability and capillary pressure functions would be used in the conservation equations for the fluid phases. The equations could be solved and the route in capillary pressure space that the displacement takes at some fixed spatial location could be found. It has been shown,
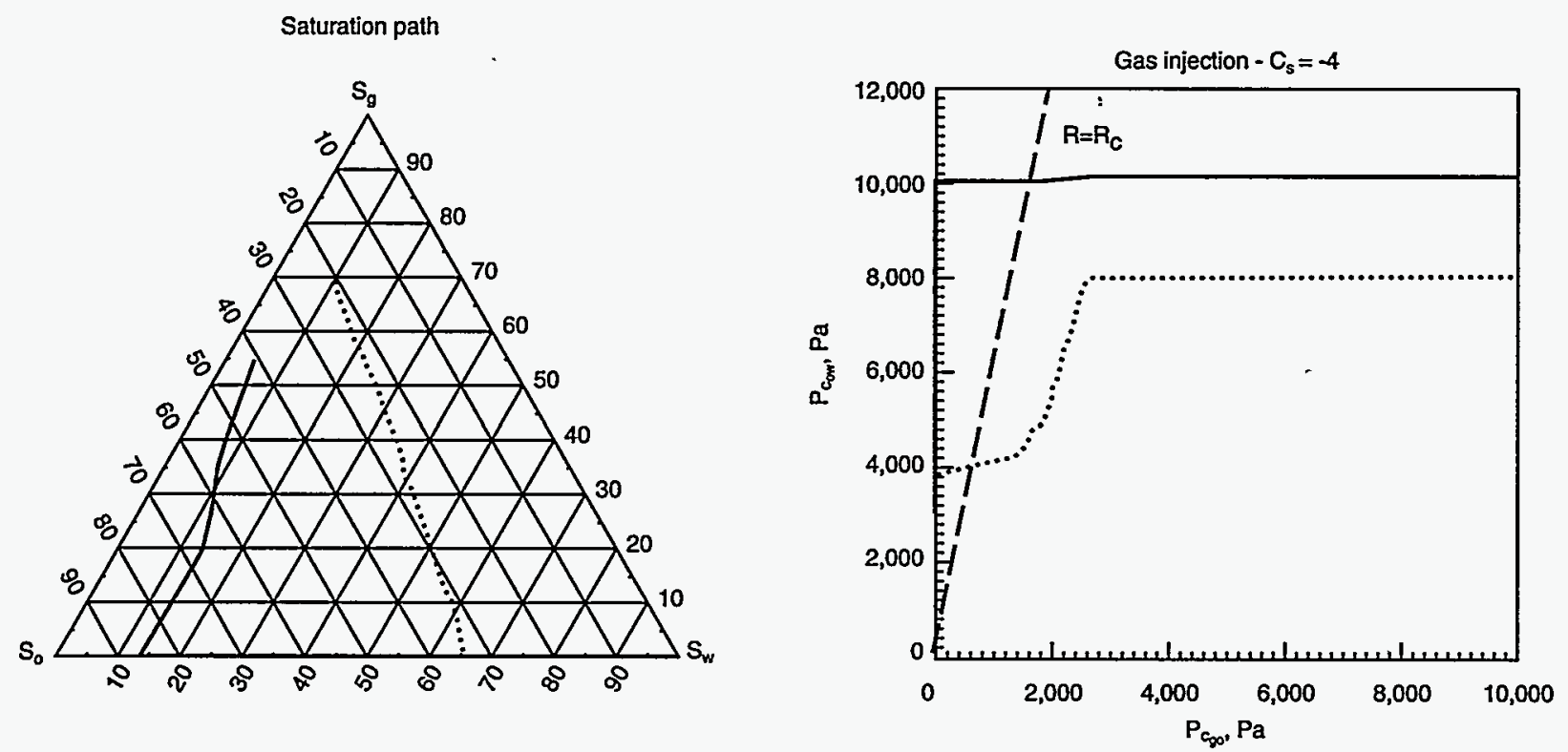

Fig. 5 Different pathways in capillary pressure and saturation space representing gas injection into waterflood residual oil for fluids with a spreading coefricient of $-4 \mathrm{~m} \mathrm{Nm}^{-1}$. 
however, that the final oil saturation (and consequently the relative permeability and capillary pressure) is a strong function of this path (for instance, if an oil bank of large oil saturation develops, very good recovery for zero spreading coefficient would be predicted, whereas if no oil bank is formed, this corresponds to gas injection with a low value of $\mathrm{P}_{\mathrm{c}_{\text {ow }}}$ and the recovery is much poorer). With the use of a network model, capillary pressure and relative permeabilities for a given pathway in capillary pressure space can be computed. It is necessary to find relative permeabilities and capillary pressures that, when placed in a conservation equation, give the same sequence of saturation changes that were used to compute them in the first place. This self-consistency requirement is particularly important for a correct understanding of the mobilization of residual oil by gas and water. This can be achieved with network modeling but clearly cannot be incorporated in conventional numerical models or readily measured experimentally for the full range of possible types of displacement.

\section{Conclusions}

In thermodynamic equilibrium, the spreading coefficient of oil between water and gas is either zero or negative; however, it is still possible for three bulk phases to coexist in a pore throat, and the conditions in which an oil layer would be stable in a wedge have been found. A 3-D, three-phase network model has been described that incorporates threephase drainage and imbibition displacement mechanisms. Conventional models of capillary pressure and relative permeability are likely to give an inadequate representation of oil flow at low saturation because of the significant and subtle effects of hysteresis. This was shown by considering different possible sequences of saturation changes during gas flooding. Further work on a description of three-phase flow in a variety of different circumstances is planned.

\section{References}

1. B. Dindoruk, F. M. Orr, Jr., and R. Johns, Analytical Theory of Multicontact Miscible Displacement with Nitrogen, paper SPE 30771 to be presented at the Annual SPE Technical Conference and Exhibition, Dallas, Tex., October 22-25, 1995.

2. D. Zhou and F. M. Orr, Jr., An Analysis of Rising Bubble Experiments for Determination of Minimum Miscibility Pressure (MMP), paper SPE 30786 to be presented at the 70th Annual SPE Technical Conference and Exhibition, Dallas, Tex., October 22-25, 1995.

3. D. H. Fenwick and M. J. Blunt, Pore Level Modelling of Three-Phase Flow in Porous Media, paperpresented at the 8th European Symposium on Improved Oil Recovery, Vienna, Austria, May 15-17, 1995.

4. M.J.Blunt,D.Zhou, andD. H. Fenwick, Three PhaseFlow and Gravity Drainage in Porous Media, in Transport in Porous Media, Vol. 20, pp. 77-103, 1995.

5. M.J. Blunt, K.Liu, and M. R. Thiele,A Generalized Streamline Method to Predict Reservoir Flow, paper presented at the 8th European Symposium on Improved Oil Recovery, Vienna, Austria, May 15-17, 1995.
6. F. J.-M. Kalaydjian, J.-C. Moulu, O. Vizika, and P. K. Munkerud, Three-Phase Flow in Water-Wet Porous Media: Determination of Gas/ Oil Relative Permeabilities Under Various Spreading Conditions, paper SPE 26671 presented at the 68th Annual SPE Technical Conference and Exhibition, Houston, Tex., October 3-6, 1993.

7. L. E. Baker, Three-Phase Relative Permeability Correlations, paper SPE 17369 presented at the Sixth SPE/DOE Symposium on Enhanced Oil Recovery, Tulsa, Okla., April 17-20, 1988.

8. F. J. Fayers, Extension of Stone's Method 1 and Conditions for Real Characteristics in Three-Phase Flow, SPE Reserv. Eng., 4: 437-445 (1989).

9. H. L. Stone, Estimation of Three-Phase Relative Permeability and Residual Data, J. Can. Pet. Technol., 12: 53-61 (1973).

10. G. J. Hirasaki, Structural Interactions in the Wetting and Spreading of van der Waals Fluids, J. Adhes., 7(3): 285-322 (1993).

11. M. Muskat, Principles of Oil Production, McGraw Hill, Boston, Mass., 1949.

12. A. A. Adamson, Physical Chemistry of Surfaces, John Wiley \& Sons, Inc., New York, N.Y., 1990.

13. J. W. Gibbs, The Collected Works of J. Willard Gibbs, Longmans, Green, New York, N.Y., 1928.

14. J. S. Rowlinson, Molecular Theory of Capillarity, Clarendon Press, Oxford, England, 1989.

15. P. E. Oren, J. Billiotte, and W. V. Pinczewski, Mobilization of Waterflood Residual Oil by Gas Injection for Water-Wet Conditions, SPE Formation Evaluation, 7(1): 70-78 (March 1992).

16. O. Vizika, Effect of the Spreading Coefficient on the Efficiency of Oil Recovery with Gravity Drainage, paper presented at the Symposium on Enhanced Oil Recovery before the Division of Petroleum Chemistry, Inc., Denver, Colo., March 28-April 2, 1993.

17. J.M. Dumoré and R. S. Schols, Drainage Capillary Pressure Functions and the Influence of Connate Water, Soc. Pet. Eng. J., 14: 437-444 (1974).

18. M. J. Blunt, D. Fenwick, and D. Zhou, What Determines Residual Oil Saturation in Three Phase Flow?, paper SPE 27816 presented at the Ninth SPE/DOE Symposium on Improved Oil Recovery, Tulsa, Okla., April 17-20, 1994.

19. I. Chatzis, A. Kantzas, and F. A. L. Dullien, On the Investigation of Gravity-Assisted Inert Gas Injection Using Micromodels, Long Berea Sandstone Cores, and Computer-Assisted Tomography, paper SPE 18284 presented at the 63rd Annual SPE Technical Conference and Exhibition, Houston, Tex., October 2-5, 1988.

20. A. Kantzas, I. Chatzis, and F. A. L. Dullien, Enhanced Oil Recovery by Inert Gas Injection, paper SPE 17379 presented at the Sixth SPE/DOE Symposium on Enhanced Oil Recovery, Tulsa, Okla., April 17-20, 1988.

21. A. Kantzas, I. Chatzis, and F. A. L. Dullien, Mechanisms of Capillary Displacement of Residual Oil by Gravity-Assisted Inert Gas Injection, paper SPE 17506 presented at the SPE Rocky Mountain Regional Meeting, Casper, Wyo., May 11-13, 1988.

22. F. J.-M. Kalaydjian, Performance and Analysis of Three-Phase Capillary Pressure Curves for Drainage and Imbibition in Porous Media, paper SPE 24878 presented at the 67th Annual SPE Technical Conference and Exhibition, Washington, D.C., October 4-7, 1992.

23. P-E. Oren, J. Billiote, and W. V. Pinczewski, Pore-Scale Network Modelling of Waterflood Residual Oil Recovery by Immiscible Gas Flooding, paper SPE 27814 presented at the Ninth SPE/DOE Symposium on Improved Oil Recovery, Tulsa, Okla., April 17-20, 1994.

24. A.A.Heiba,H.T.Davies, andL.E.Scriven, Statistical Network Theory of Three-Phase Relative Permeability, paper SPE 12690 presented at the Fourth Symposium on Enhanced Oil Recovery, Tulsa, Okla., April 16-18, 1984.

25. W. E. Soll, and M. A. Celia, A Modified Percolation Approach to Simulating Three-Fluid Capillary Pressure-Saturation Relationships, Adv. Water Resour., 16: 107-126 (1993). 


\section{THERMAL RECOVERY- SUPPORTING RESEARCH}

\section{RESEARCH ON OIL RECOVERY MECHANISMS IN HEAVY OIL RESERVOIRS}

Contract No. DE-FG22-93BC14899

\author{
Stanford University \\ Petroleum Research Institute \\ Stanford, Calif.
}

Contract Date: Feb. 8, 1993

Anticipated Completion: Feb. 7, 1997

Government Award: $\$ 800,000$

(Current year)

Principal Investigators:

William E. Brigham

Henry J. Ramey, Jr.

Project Manager:

Thomas Reid

Bartlesville Project Office

Reporting Period: Jan. 1-Mar. 31, 1995

\section{Objectives}

The goal of the Stanford University Petroleum Research Institute (SUPRI) is to conduct research directed toward increasing the recovery of heavy oils. SUPRI is working in five main directions:

1. Flow properties studies-to assess the influence of different reservoir conditions (temperature and pressure) on the absolute and relative permeability to oil and water and on capillary pressure.

2. In situ combustion - to evaluate the effects of different reservoir parameters on the in situ combustion process; this project includes the study of the kinetics of the reactions.

3. Steam injection with additives-to develop and understand the mechanisms of the process using commercially available surfactants for reduction of gravity override and channeling of steam.

4. Formation evaluation-to develop and improve techniques of formation evaluation, such as tracer tests and pressure transient tests.

5. Field support services-to provide technical support for design and monitoring of U.S. Department of Energy (DOE)-sponsored or industry-initiated field projects. 


\section{Summary of Technical Progress}

\section{Flow Properties Studies}

The report on end effects and errors in measuring relative permeability is in the draft stage, and completion is expected by June 1995.

Two-phase saturation mapping with the computerized tomography (CT) scanner is now possible and has been verified to be accurate on various phantoms. Work on threephase saturation measurements is still in progress. Existing interpretation software is being adapted to the new scanner data. Image processing software from the National Institutes of Health is being tested for different cores and fluids. Sandstone phantoms will be used to verify the results of porosity, density, and saturation calculations on known samples. Display and printing of the results are working satisfactorily. The next calibration step will involve a comparison of the $C T$ results with material balance calculations during displacement experiments.

The core holder for the steam-water relative-permeability experiments was built. Acculam G7 plastic was chosen because of its low thermal conductivity, temperature resistance up to $450^{\circ} \mathrm{F}$, and low X-ray adsorption coefficient. A 2-in.diameter by 8 -in.-long sandstone core will be used first. As a first step, water will be displaced by nitrogen to avoid heattransfer problems and to ensure accurate saturation measurements. Steam displacing water and steady-state steam-water flows will follow.

A new project aimed at quantification of gravity drainage began. This work will involve measurements of three-phase saturations in a vertical core. Design of the experiment and preliminary numerical simulations are in progress. This project would be impossible without the vertical positioning capability of the new scanner.

The flow system for isothermal studies of flow through fractured media is being built. Once the plumbing is complete, experiments will start. This study aims at understanding matrix-fracture transfers in oil-water systems. The first set of experiments will deal with water imbibition in a matrix block initially saturated with oil. Pressures and saturation distributions will be monitored during the experiments.

\section{In Situ Combustion}

The report describing and analyzing the effect of iron nitrate used as a metallic additive during the combustion of Saudi tar is in preparation. Two new combustion tube runs are planned to investigate the effect of tin used as an additive in combustion. Detailed analyses of the original crude and the crude produced by combustion are planned, with emphasis on quantification of upgrading and sulfur removal by combustion.

\section{Steam Injection with Additives}

Work continued on the fractured model. History matching of the experiments and modeling of the heat losses were emphasized this quarter. Different analytical heat-transfer models were used to model the experiments. A heat-transfer model with a convective outer boundary and a time-dependent temperature inner boundary gave the best match. Preliminary results from the numerical simulations show that heat conduction is the main mechanism for heating the matrix.

The three-dimensional (3-D) steam injection model was repacked with coarse sand (28-35 mesh) to reduce the settling problems previously experienced with a fine-mesh sand. The model was scanned while fully saturated and was then vacuumed and scanned dry. Dual energy baseline scans were obtained for both. Oil was then flooded through the system to residual water saturation, and dual energy scans were made. Steamfloods and waterfloods are now being made.

The literature review of foam flow through micromodels was presented during the Industry Advisory Committee meeting (SUPRI, March 16-17, 1995). Discussion of the proposed research yielded the following ideas:

- The models are adequate for studies of multiphase flow in porous media, including foam flow.

- The mechanisms of foam-oil interaction still need to be identified.

- The models should also be used for basic three-phase relative-permeability studies and could be used for bubblepoint determination and critical gas saturation studies.

- Higher permeability models would facilitate the experiments. This could be achieved by deeper etching of the new batch of micromodels.

New micromodel work includes saturation of the model with water, displacement by a single component oil (decane, for example), waterflood to residual oil saturation, air injection, and observation of three-phase interaction. In parallel, studies of oil-foam interaction will continue with the same fluids, and an oil-sensitive and an oil-insensitive surfactant in the aqueous phase will be compared.

\section{Formation Evaluation}

No work was performed during this reporting period.

\section{Field Support Services}

A paper summarizing field experience of use of foam in gas injection has been accepted for presentation at the 8th European Improved Oil Recovery Symposium to be held in Vienna, Austria, May 15-17, 1995.

\section{Technology Transfer}

Two papers were presented at the 6th UNITAR International Conference on Heavy Crude and Tar Sands, Houston, Tex., February 12-17, 1995.,2

\section{References}

1. D. Mamora and W. E. Brigham, Implications of Low-Temperature Oxidation in Kinetic and Combustion Tube Experiments, paper presented at the 6th UNITAR International Conference on Heavy Crude and Tar Sands, Houston, Tex., February 12-17, 1995. 
2. S. Joshi, L. M. Castanier, W. E. Brigham, and M. C. Wood, Steam Flooding a Water Flooded Reservoir-Performance Evaluation and
Prediction, paper presented at the 6th UNITAR International Conference on Heavy Crude and Tar Sands, Houston, Tex., February 12-17, 1995.

\section{STUDY OF HYDROCARBON MISCIBLE SOLVENT SLUG INJECTION PROCESS FOR IMPROVED RECOVERY OF HEAVY OIL FROM SCHRADER BLUFF POOL, MILNE POINT UNIT, ALASKA}

Contract No. DE-FG22-93BC14864

\author{
University of Alaska \\ Fairbanks, Alaska
}

Contract Date: Dec. 1, 1992

Anticipated Completion: June 30, 1996

Total Project Cost: DOE Funding for FY95 $\$ 200,000$ Contractor

Total 129,726 $\$ 329,726$

Principal Investigator:

G. D. Sharma

Project Manager:

Thomas Reid

Bartlesville Project Office

Reporting Period: Jan. 1-Mar. 31, 1995

\section{Objectives}

The ultimate objective of this 3-yr research project is to evaluate the performance of the hydrocarbon miscible solvent slug process and to assess the feasibility of this process for improving recovery of heavy oil from Schrader Bluff reservoir. This will be accomplished through measurement of pressure-volume-temperature (PVT) and fluid properties of Schrader Bluff oil, determination of phase behavior of Schrader Bluff oil-solvent mixtures, asphaltene precipitation tests, slim-tube displacement tests, coreflood experiments, and reservoir simulation studies. The expected results from this project include determination of optimum hydrocarbon solvent composition suitable for hydrocarbon miscible solvent slug displacement process, optimum slug sizes of solvent needed, solvent recovery factor, solvent requirements, extent and timing of solvent recycle, displacement and sweep efficiency to be achieved, and oil recovery.

\section{Summary of Technical Progress}

The performance of first-contact miscible displacements and the effect of slug size were studied by conducting three displacement experiments with varying slug sizes of 0.05 , 0.10 , and 0.20 pore volume (PV). Propane was used as the first-contact miscible solvent to displace live Schrader Bluff oil from the 4-ft-long sandpack. These three runs were conducted in a gravity-stabilized mode by arranging the sandpack in a vertical configuration and injecting the solvent slug from the top. The solvent slugs were followed by water.

\section{Run 1 (0.05-PV Slug)}

The oil recovery as a function of PV injection for this run is shown in Fig. 1. At 1.2-PV injection, oil recovery was $70 \%$. This recovery is less than that obtained from a multicontact miscible slug process with the use of a solvent mixture of $50 \%$ Prudhoe Bay gas (PBG) and 50\% natural gas liquids (NGL). The water breakthrough also occurred earlier than in the multicontact miscible run. The poor performance of the firstcontact miscible displacement can be attributed to viscous fingering and/or channeling of the injected propane slug along the walls of the coreholder. The fingering or channeling of the injected slug is indicated by the plot of gas/oil ratio (GOR) (Fig. 2) as a function of PV injection. The solvent slug breaks through at about 0.2-PV injection, and most of the solvent is quickly produced, as indicated by the sharp peak in the GOR (Fig. 2). This very early breakthrough and rapid production of the solvent suggests the likelihood of the solvent channeling along the walls of the coreholder.

\section{Run 2 (0.10-PV Slug)}

In this run an oil recovery of $75.5 \%$ at $1.2-\mathrm{PV}$ injection was observed (Fig. 3). Water breakthrough occurred at $0.45-\mathrm{PV}$ injection, and the water/oil ratio (WOR) increased sharply thereafter. In this case also the solvent breakthrough occurred at about 0.2-PV injection, and most of the solvent was then produced quickly. The plot of pressure drop vs. PV injection in Fig. 4 clearly shows the effect of channeling or viscous fingering of the solvent occurring in the sandpack during the displacement. The solvent seems to channel through the entire length of the sandpack at 0.2-PV injection, as indicated by a pressure drop of only $1.65 \mathrm{psi}$ against the oil-phase pressure drop of about $12.5 \mathrm{psi}$ in the 3 - to 4 -ft section of the sandpack. 


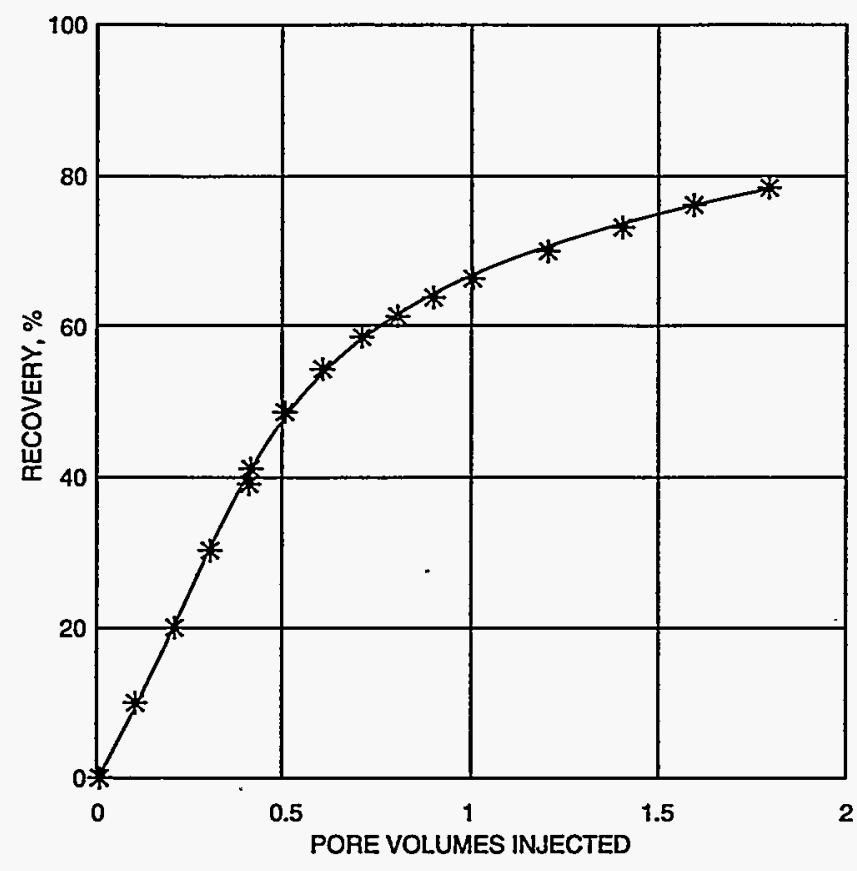

Fig. 1 Oil recovery vs. pore volume injection for run 1.

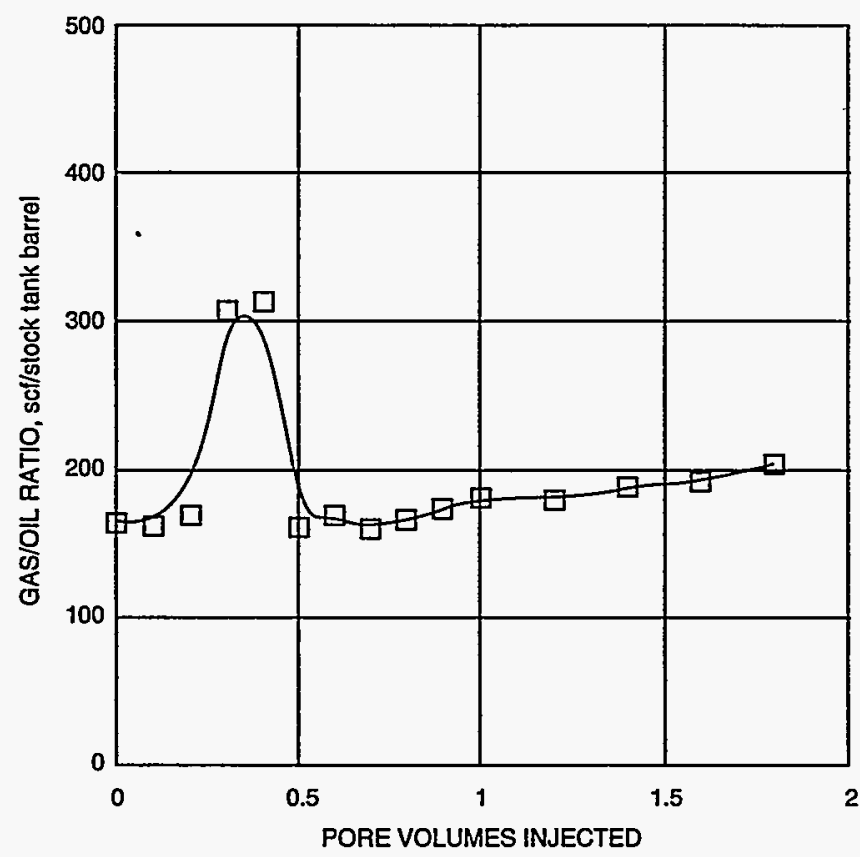

Fig. 2 Gas/oil ratio vs. pore volume injection for run 1.

The pressure drops increase after 0.3-PV injection because of the better mobility control provided by the water front behind the propane slug.

\section{Run 3 (0.20-PV Slug)}

The injection of a $0.20-\mathrm{PV}$ propane slug increased the oil recovery to $78.5 \%$ at $1.2-\mathrm{PV}$ injection (Fig. 5). This recovery is slightly higher than that obtained from a similar multicontact

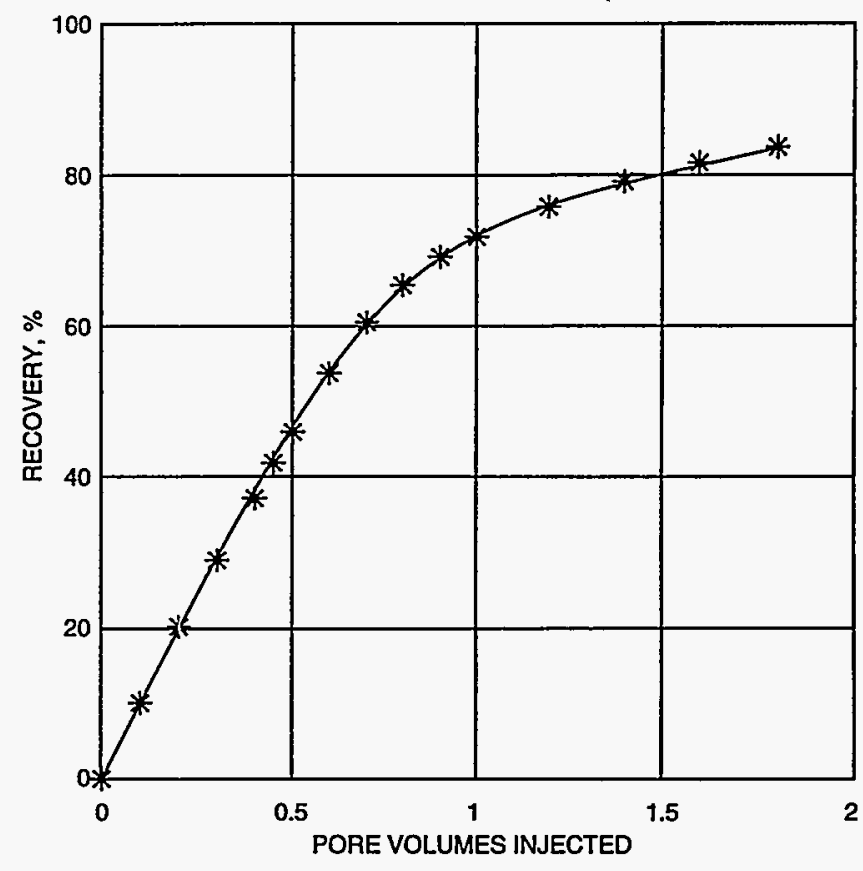

Fig. 3 Oil recovery vs. pore volume injection for run 2.

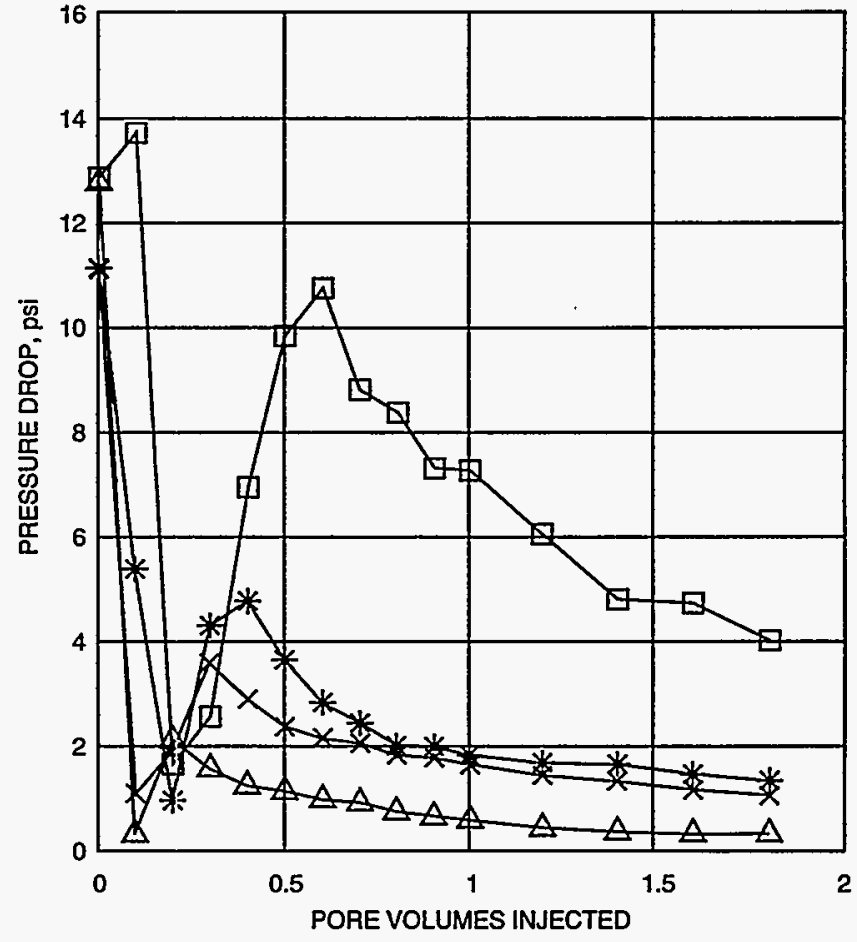

Fig. 4 Pressure drop vs. pore volume injection for run $2 . \Delta, 1 \mathrm{ft}$. $-\times-, 2 \mathrm{ft} . \mathrm{F}^{*}, 3 \mathrm{ft} . \longrightarrow \square, 4 \mathrm{ft}$.

miscible displacement. The water breakthrough occurred at $0.5-P V$ injection. The behavior of GOR and pressure drops was similar to that observed in runs 1 and 2 , once again indicating the occurrence of channeling and/or viscous fingering during the displacement process. 


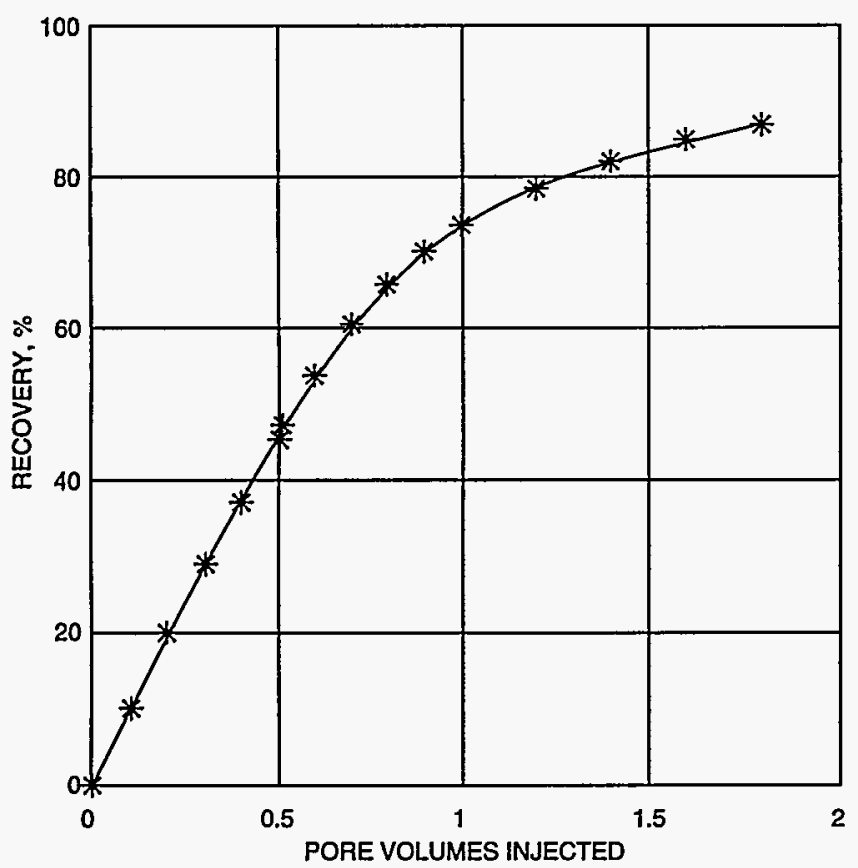

Fig. 5 Oil recovery vs. pore volume injection for run 3.

\section{MODIFICATION OF RESERVOIR CHEMICAL AND PHYSICAL FACTORS IN STEAMFLOODS TO INCREASE HEAVY OIL RECOVERY}

\section{Contract No. DE-FG22-93BC14899}

\author{
University of Southern California \\ Los Angeles, Calif.
}

Contract Date: Feb. 22, 1993

Anticipated Completion: Feb. 21, 1996

Government Award: $\$ 150,000$

(Current year)

Principal Investigator:

Yanis C. Yortsos

Project Manager:

Thomas Reid

Bartlesville Project Office

Reporting Period: Jan. 1-Mar. 31, 1995

\section{Objective}

The objectives of this research are to continue previous work and to carry out new fundamental studies in the following areas of interest to thermal recovery: displacement and flow properties of fluids involving phase change (condensation-evaporation) in porous media; flow properties of mobility control fluids (such as foam); and the effect of reservoir heterogeneity on thermal recovery. The specific projects are motivated by and address the need to improve heavy oil recovery from typical reservoirs as well as from less conventional fractured reservoirs producing from vertical or horizontal wells.

Thermal methods, and particularly steam injection, are currently recognized as the most promising for the efficient recovery of heavy oil. Despite significant progress, however, important technical issues remain open. Specifically, knowledge of the complex interaction between porous media and the various fluids of thermal recovery (steam, water, heavy oil, gases, and chemicals) is still inadequate, and the interplay of heat transfer and fluid flow with pore- and macro-scale heterogeneity is largely unexplored.

\section{Summary of Technical Progress}

\section{Vapor-Liquid Flow}

During this quarter work focused on conducting sensitivity studies with the use of the steam displacement pore network simulator. Effects of injection rate, vapor density, latent heat, and thermal conductivity on the displacement patterns are being investigated. The results of this work will be used to model relative permeabilities and capillary characteristics of steam-water systems. ${ }^{1}$ Work also continues on the extension to a three-phase system involving oil, water vapor, and water liquid under conditions that simulate steam displacement of oil. Work continues in the analysis of the stability of phasechange fronts in porous media with the use of a macroscopic approach.

\section{Heterogeneity}

Work has continued on the optimization of recovery processes in heterogeneous reservoirs with the use of optimal control methods. A general theory has been developed for the injection strategy that maximizes the recovery efficiency at breakthrough for general systems, which involves multiple injectors and one producer, where capillary or gravity effects are negligible. The efficiency is maximized by an on-off injection schedule. Current work consists of identifying the switch time in terms of the well spacing and other geometrical parameters. Experiments with the use of simple geometries are also under way.

Study has continued on the dynamics of invasion fronts in heterogeneous porous media of large aspect ratio at low rates. In parallel, a study on the effects of long-range correlations (for example, with the use of fractional Brownian motion statistics) on invasion percolation has been completed. The results show that the invasion features (for example, the capillary pressure curve) are not deterministic but stochastic. Information on the average behavior and the standard deviation was also obtained. ${ }^{2}$ 
Work has also continued on the development of rigorous viscous fingering models based on the concept of transverse flow equilibrium (TFE). Emphasis in the past quarter was on the use of the theory of small fluctuations to obtain viscous fingering models. A system has been developed consisting of three equations in terms of three unknowns (namely, the finger width, the finger concentration, and the variance of the concentration fluctuations inside the finger). The properties of this system are under study.

\section{Chemical Additives}

Work continued on the behavior of non-Newtonian fluid flow and on foam displacements in porous media. The invasion process recently identified for the onset of mobilization of foams and of Bingham plastics ${ }^{3}$ is being used to study the displacement of foams. During this quarter a technical paper was presented on the displacement at low rates of Bingham plastics, the application being on heavy oil recovery as well as on sand production (wormholes). ${ }^{4}$

\section{References}

1. C. Du, C. Satik, and Y. C. Yortsos, Invasion Percolation in fBm Lattices, submitted for publication, 1995.

2. C. Satik and Y. C. Yortsos, Pore Network Studies of Steam Injection in Porous Media, paper SPE 30751 to be presented at the 70th Annual Society of Petroleum Engineers Technical Conference, Dallas, Tex. October 22-25, 1995.

3. H. Kharabaf and Y. C. Yortsos, Invasion Percolation with Memory, submitted for publication, 1995.

4. C. B. Shah, H. Kharabaf, and Y. C. Yortsos, Flow and Displacement of Bingham Plastics in Porous Media, paper presented at the 6th UNITAR International Conference on Heavy Crudes and TarSands, Houston, Tex., February 12-16, 1995.

\section{OIL FIELD CHARACTERIZATION AND PROCESS MONITORING USING ELECTROMAGNETIC METHODS}

\author{
Lawrence Livermore National Laboratory \\ Livermore, Calif.
}

Contract Date: Oct. 1, 1984

Anticipated Completion: Oct. 1, 1995

Government Award: $\$ 350,000$

Principal Investigator:
Mike Wilt

Project Manager:

Thomas Reid

Bartlesville Project Office

Reporting Period: Jan. 1-Mar. 31, 1995

\section{Objectives}

The objectives of this project are to apply surface and borehole electromagnetic (EM) methods for oil field characterization and monitoring of in situ changes in the electrical conductivity during enhanced oil recovery (EOR) operations and to develop practical tools for geophysical characterization of oil strata and monitoring of EOR processes in a developed field. Crosshole and borehole-to-surface (BTS) EM methods are being applied to map oil field structure and to provide images of subsurface electrical conductivity changes associated with EOR operations.

\section{Summary of Technical Progress}

Partly as a result of the recent Lawrence Livermore National Laboratory (LLNL) crosshole electromagnetic surveys at the Lost Hills No. 3 field, Mobil Development and Producing U.S. has run a series of borehole temperature and induction logs in observation well No. $35 \mathrm{~W}$. The logs, which were made to measure downhole conditions in steamflooded oil sands, confirmed that the steam is present only in the basal two of the three oil sands. The logs also show that in the lower sands the steam has traveled from injector 5035 to beyond well No. $35 \mathrm{~W}$, as predicted by the earlier EM results.

Progress is being made on the development of an inversion code for interpretation of surface-to-borehole EM data. The code, which uses a similar scheme to the presently used crosshole inversion, is under development by a University of California, Berkeley, graduate student. In contrast to the crosshole code, it is a three-dimensional (3-D) interpretation scheme, which is more appropriate with surface-to-borehole data. The code will initially be used to invert field data collected this past year at the University of California Richmond field station.

\section{Lost Hills Logging Results}

Several sets of crosshole EM data collected at Lost Hills No. 3 have yielded time-lapse images of the development of an underground steam chest. As shown in an earlier progress report, ${ }^{1}$ the steam was largely confined to the basal two of the three Tulare oil sands undergoing steam injection and that the steam plume was moving more quickly westward than eastward. 
In February 1995, Mobil contracted for a repeat induction resistivity $\log$ in observation borehole No. $35 \mathrm{~W}$ to go with the periodic temperature logs made in the same well. The observation well is located $25 \mathrm{~m}$ westward from steam injection well No. 5035 in the updip direction. Both sets of logs are shown in Fig. 1.

The borehole logs in well No. $35 \mathrm{~W}$ show significant increases in downhole temperature at depths below $80 \mathrm{~m}$ and a corresponding reduction in resistivity associated with the high-temperature zones. The peak of the high-temperature zone corresponds to the depth of the middle Tulare sand, which indicates that in this layer the injected steam had reached beyond well No. $35 \mathrm{~W}$. There are no indications of high-temperature zones as yet from steam flow into the upper or lower Tulare sands.

The induction logs show that the resistivity has decreased by 40 to $60 \%$ within the steamed interval, which is in close agreement with changes reported by the crosshole EM

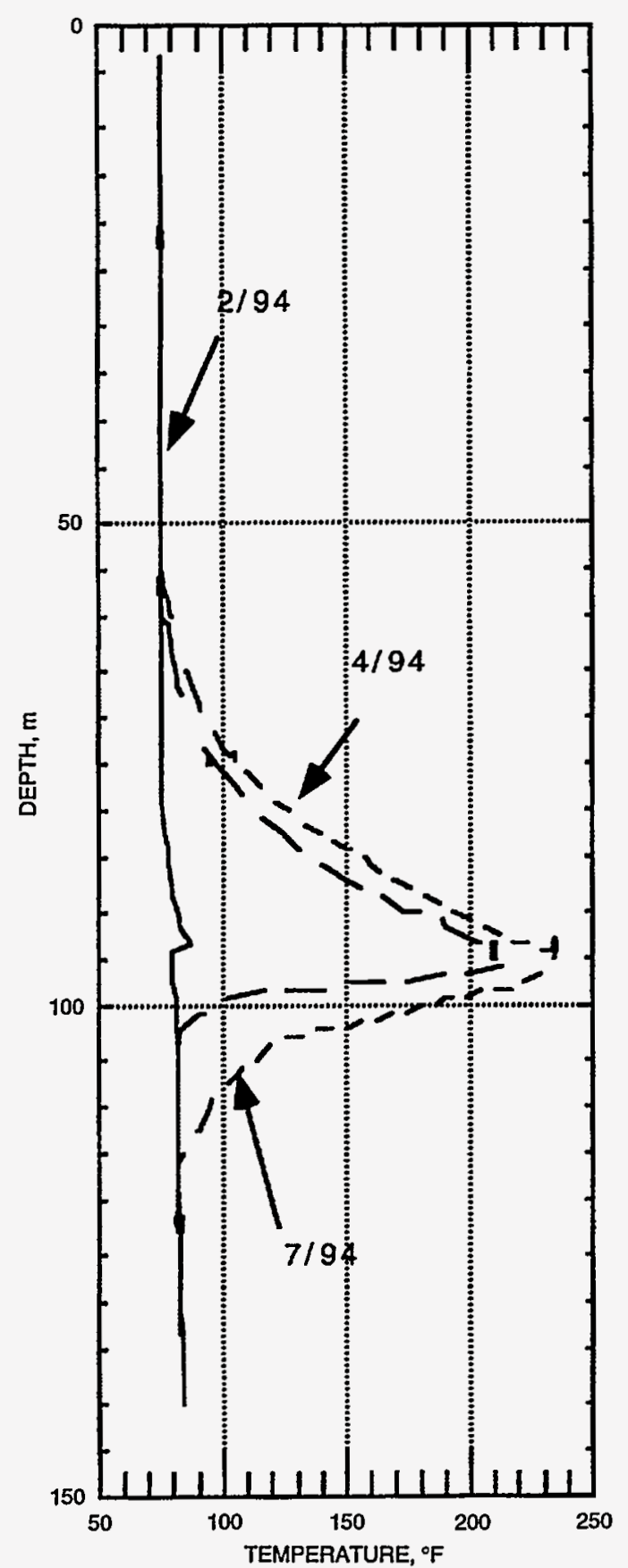

(a)

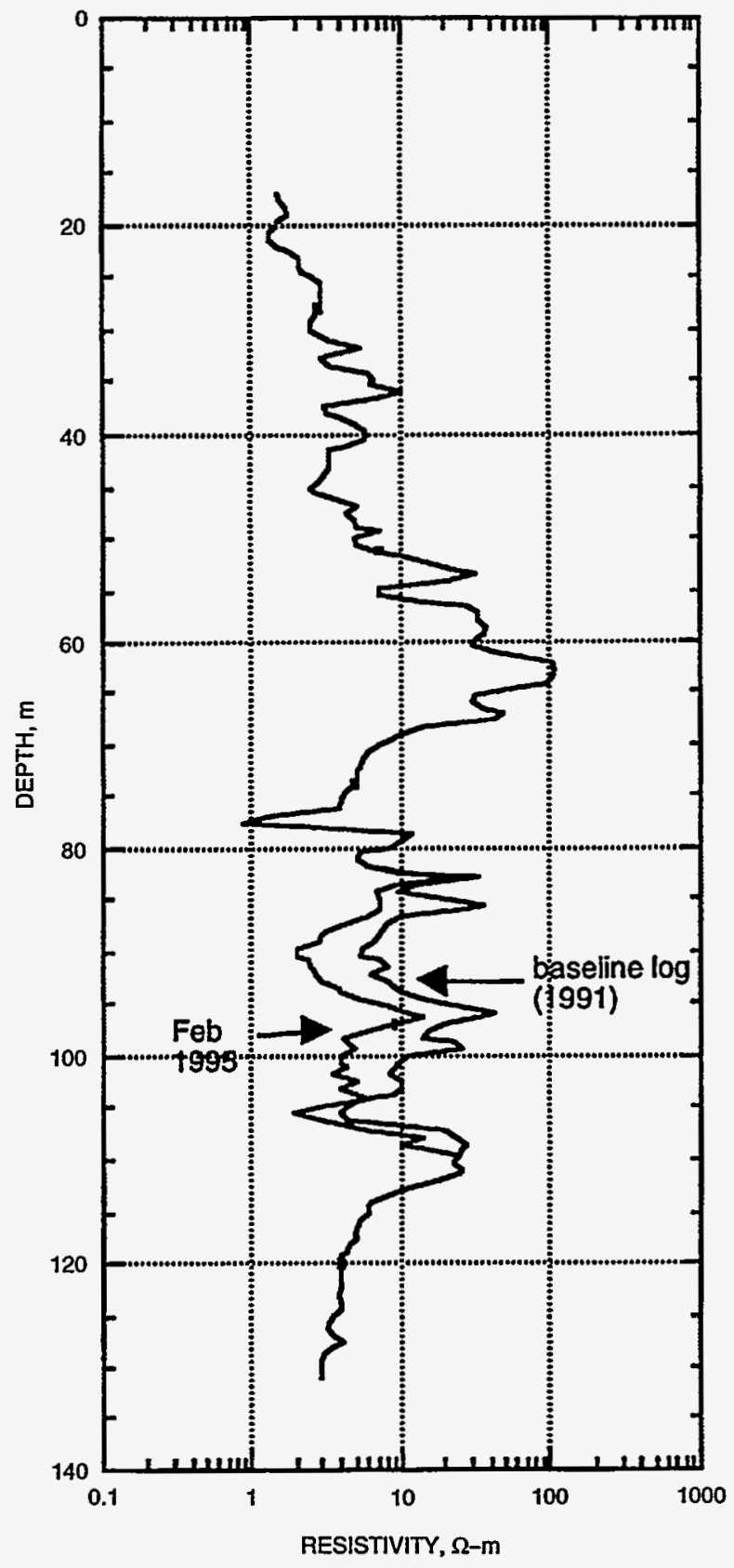

(b)

Fig. 1 Temperature (a) and induction resistivity (b) logs before and after steaming at Lost Hills No. 3. Data were collected in observation well No. 35W, which is located $25 \mathrm{~m}$ west of the steam injector. 
surveys. ${ }^{2}$ Although other factors, such as saturation and fluid salinity, also affect resistivity, the reduction in resistivity in a commercial steamflood is mainly caused by the temperature increase $^{3}$ (for example, if it is assumed that the resistivity change was due to temperature alone, known relations between temperature and resistivity can be used to predict the temperature increase from the resistivity to within a few degrees of the observed value).

An area of concern for Mobil engineers is that the primary target, the upper Tulare sand, does not seem to be responding to steam injection. The borehole logs in well No. 35W show no change in these sands, and crosshole EM data suggest only the beginning of steam plume development. It is likely that the steam chest is developing much more slowly in the upper Tulare because of its greater porosity, thickness, and higher oil viscosity. In this case, the effects may not be observed for 6 months to a year. A less attractive alternative, however, is that the steam intended for the upper Tulare may be shunted upward into an air-filled sand or downward into the existing steam plume in the middle and lower Tulare.

The knowledge of steam plume location in such a shallow steamflood can have significant impact on field development decisions at Lost Hills No. 3. If the plume is simply slower in developing, then its impact on production will be felt at a later time, but if it is filling a shallow air sand, for example, then a future blowout is possible. The possibility of obtaining this information is what makes the EM monitoring experiment interesting to the field engineers.

Plans are to re-deploy the field system to Lost Hills No. 3 in the summer and fall of 1995 in an effort to track the steam chest. Both the crosshole and surface-to-borehole configurations will be used.

\section{Surface-to-Borehole Inversion Code Development}

Surface-to-borehole EM data sets involve the deployment of instruments (either sources or receivers) in one borehole and on the surface to image the resistivity distribution at depth well away from the borehole. This configuration has considerable logistical advantages over the crosshole configuration and improved sensitivity over surface deployments. An obvious problem with interpretation of these data is that the near-surface geology strongly affects the measurements, but it is not the target of the imaging. A related problem is that a much larger volume of earth must be discretized in order to interpret the results, and 3-D interpretation schemes must be considered. This results in much larger numerical meshes and slower and more cumbersome software.

Some success has been seen in the development of a 3-D surface-to-borehole inversion code based on the "extended" Born approximation. ${ }^{4}$ Initial trials with the code show it to be more than five times as fast as traditional 3-D algorithms, but, because of the extensive meshes required and the need to consider the surface layer, even this may be inadequate (for example, even with the faster forward code, it is estimated that a "typical" 3-D inversion would require several days on a fast computer workstation).

Several other schemes to speed up the data interpretation are being considered, and a usable code is expected in time to interpret some of the new surface-to borehole data at the Lost Hills No. 3 oil field this fall or winter.

\section{References}

1. M. Wilt, Oil Field Characterization and Process Monitoring Using Electromagnetic Methods, EOR Thermal Processes Quarterly Progress Report, Report DOE/BC 94/4, 1994.

2. M.Wilt, K. Lee, D. Alumbaugh, H.F.Morrison, A. Becker,H. W.Tseng, and C. Torres-Verdin, Crosshole Electromagnetic Tomography-ANew Technology for Oil Field Characterization, The Leading Edge of Exploration, pp. 173-177, Society of Exploration Geophysicists, 1995.

3 A. J. Mansure, R. F. Meldua, and H. V. Weyland, Field Examples of Electrical Resistivity Changes During Steamflooding, paper SPE 20539, Society of Petroleum Engineers, 1990.

4. T. Habashy, R. Groom, and B. Spies, Beyond the Born and Rytor Approximations: A Nonlinear Approach to Electromagnetic Scattering, J. Geophys. Res., 98-B2: 1759-1775 (1993). 


\section{GEOSCIENCE TECHNOLOGY}

\section{ASSIST IN THE RECOVERY OF BYPASSED OIL FROM RESERVOIRS IN THE GULF OF MEXICO}

Contract No. DE-AC22-92BC14831

\section{Louisiana State University}

Baton Rouge, La.

Contract Date: Feb. 18, 1992

Anticipated Completion: June 30, 1995

Government Award: \$2,025,755

Principal Investigator:

Philip A. Schenewerk

Project Manager:

Gene Pauling

Metairie Site Office

Reporting Period: Jan. 1-Mar. 31, 1995

\section{Objective}

The objective of this research is to assist the recovery of noncontacted oil from known reservoirs on the Outer Continental Shelf (OCS) in the Gulf of Mexico. Mature offshore reservoirs, declining oil reserves, declining production, and other natural forces are accelerating the abandonment of offshore oil resources and production platforms. As these offshore wells are plugged and the platforms are abandoned, an enormous volume of remaining oil will be permanently abandoned. Project research will proceed under three broad phases: data analysis, supporting research, and technology transfer.

Data Analysis. The Tertiary Oil Recovery Information System (TORIS)-level data will be collected on the major fields located in the piercement salt dome province of the Gulf of Mexico OCS. Representative reservoirs will be studied in detail to evaluate undeveloped and attic oil reserve potential. These detailed investigations will be used to calibrate the TORIS-level predictive models and to assess the recovery potential of advanced secondary and enhanced oil recovery (EOR) processes and the exploitation of undeveloped and attic oil zones for salt dome reservoirs in the Gulf of Mexico.

Supporting Research. Supporting research will focus on the modification of public-domain reservoir simulation models to simulate accurately the conditions encountered in the piercement salt dome province of the Gulf of Mexico. Laboratory research will focus on the development of fluid relationships to be used in the simulation of miscible and immiscible processes in the project area.

Technology Transfer. A significant effort is planned to transfer the results of this project to potential users of the technology. 


\section{Summary of Technical Progress}

\section{TORIS Predictive Modeling}

Progress continues in reducing the TORIS data to fit a simplified model and redescribing the resource to accommodate known production behavior and certain geologic assumptions. In addition, final reports are being prepared.

\author{
INTERDISCIPLINARY STUDY OF \\ RESERVOIR COMPARTMENTS \\ Contract No. DE-AC22-93BC14891 \\ Colorado School of Mines \\ Golden, Colo. \\ Contract Date: Sept. 29, 1993 \\ Anticipated Completion: Sept. 30, 1996 \\ Government Award: \$753,266 \\ Principal Investigator: \\ Craig W. Van Kirk \\ Project Manager: \\ Robert Lemmon \\ Bartlesville Project Office
}

Reporting Period: Jan. 1-Mar. 31, 1995

\section{Objective}

The objective of this research project is to document the integrated team approach for solving reservoir engineering problems. A field study integrating the disciplines of geology, geophysics, and petroleum engineering will be the mechanism for documenting the integrated approach. The goal is to provide tools and approaches that can be used to detect reservoir compartments, reach a better reserve estimate, and improve profits early in the life of a field.

\section{Summary of Technical Progress}

\section{Project Integration}

Figures 1 to 3 show the project integration during the quarter. Figure 1 is a horizontal permeability (kh) map over the area covered by the three-dimensional (3-D) seismic survey. The permeability for the kh map was based on a relationship between mini-permeameter measurements for permeability, log-derived parameters, and internal architec-

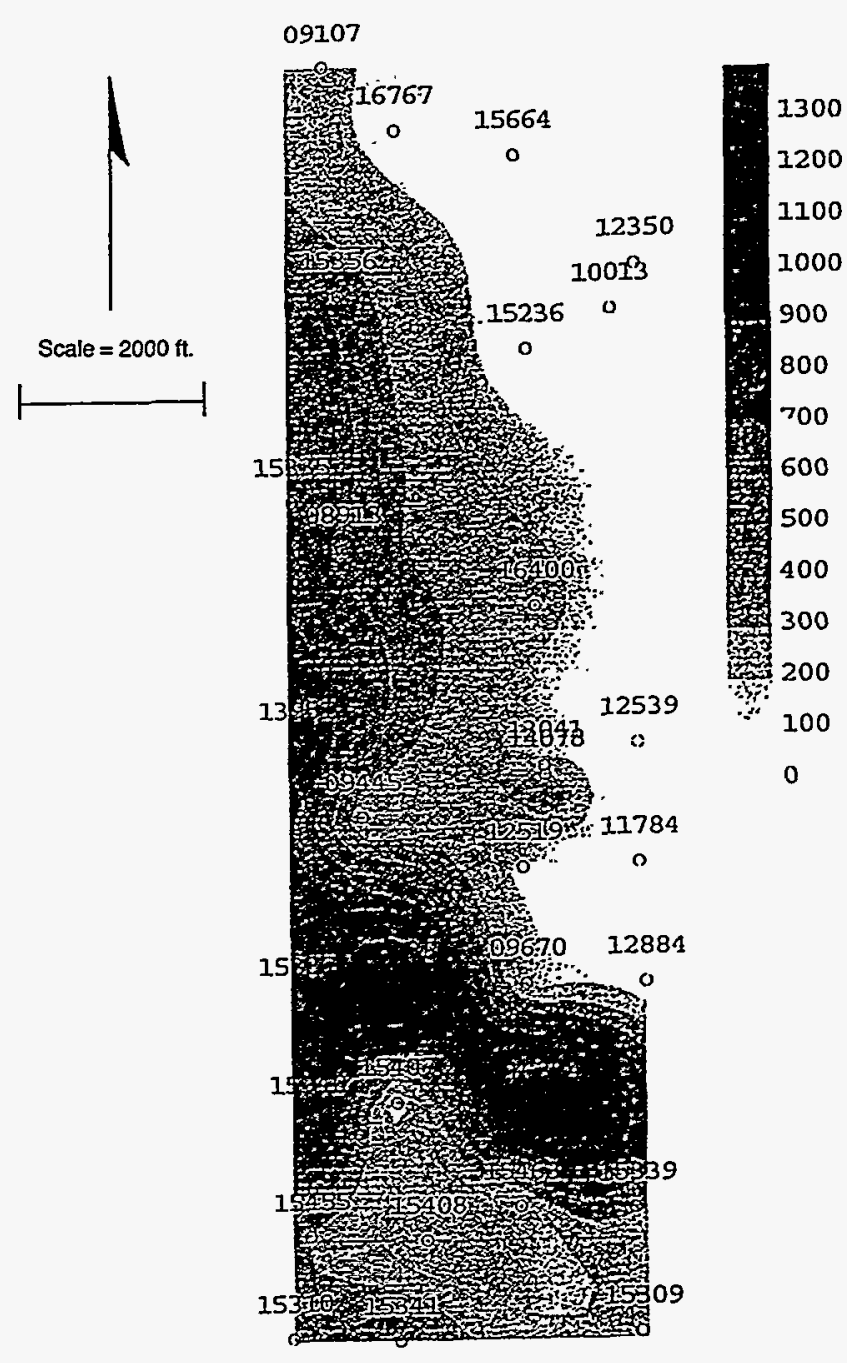

Fig. 1 Horizontal permeability map of area covered by 3-D seismic survey Petrophysical inferences of permeability thickness: secs. 17, 20, and 29, 4 N., 65 W., Weld County, Colo. (Art reproduced from best available copy.)

ture descriptions. The correlation was then applied to the wells in the 3-D seismic area to develop the kh map with the facies identified in the internal architecture description.

Figure 2 is the geological structure map derived from wellbore data. The fault mapping from well log correlations compares favorably with fault mapping based on 3-D horizon slice mapping. Smaller faults appear to be more readily mappable from log correlations, coupled with well data, than from seismic data, however.

Figure 3 is the geophysical map from the 3-D seismic survey. A comparison of the three figures supports the preliminary structural and stratigraphic interpretations. The kh map agrees with the geologic and geophysical interpretations, which indicate a gradual decreasing reservoir quality to the northeast.

The petrophysical parameters coupled with the geologic and geophysical fault interpretations and production data 


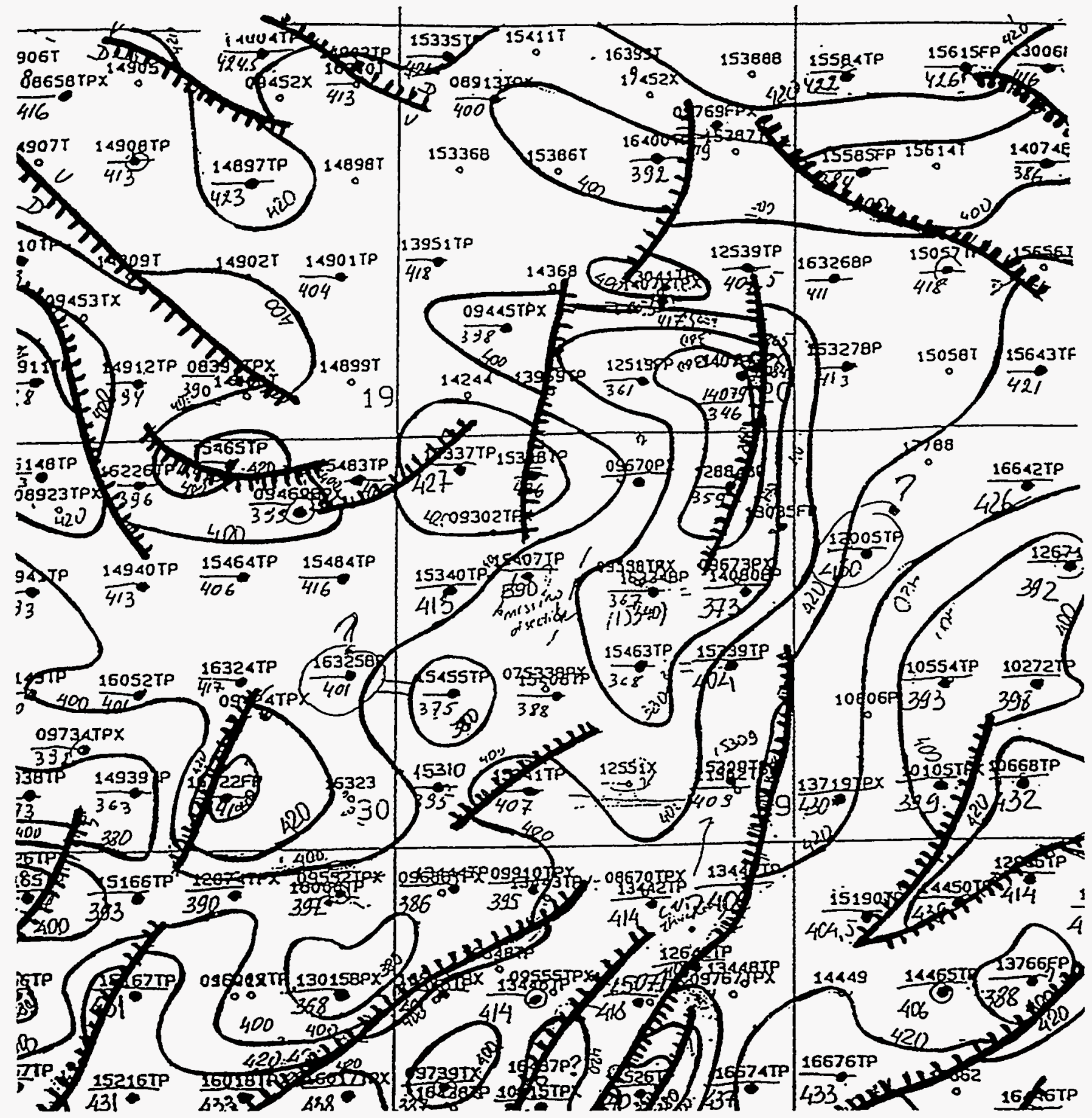

Fig. 2 Geological structure map derived from Wellbore data, secs. 19-21 and 28-33, 4 N., 65 W., Weld County, Colo. (Reproduced from the best available copy.)

support the interpretation of sealing faults. The faulting is postulated to be associated with diagenetic events that damage the reservoir quality of the rocks. The petrophysical data from the HSR Salisbury well No. 6-29 (very low porosity) support this theory. This well appears to be in a down-dropped fault block. It is postulated that this block has experienced diage- netic cementing, which has almost completely diminished the primary porosity. Producing gas/oil ratios (GORs) also confirm the compartmentalized nature of the reservoir with faults being a major factor to the compartmentalization.

Well test analysis of two wells emphasizes the difficulty in obtaining good well tests in this type of reservoir. Multirate 


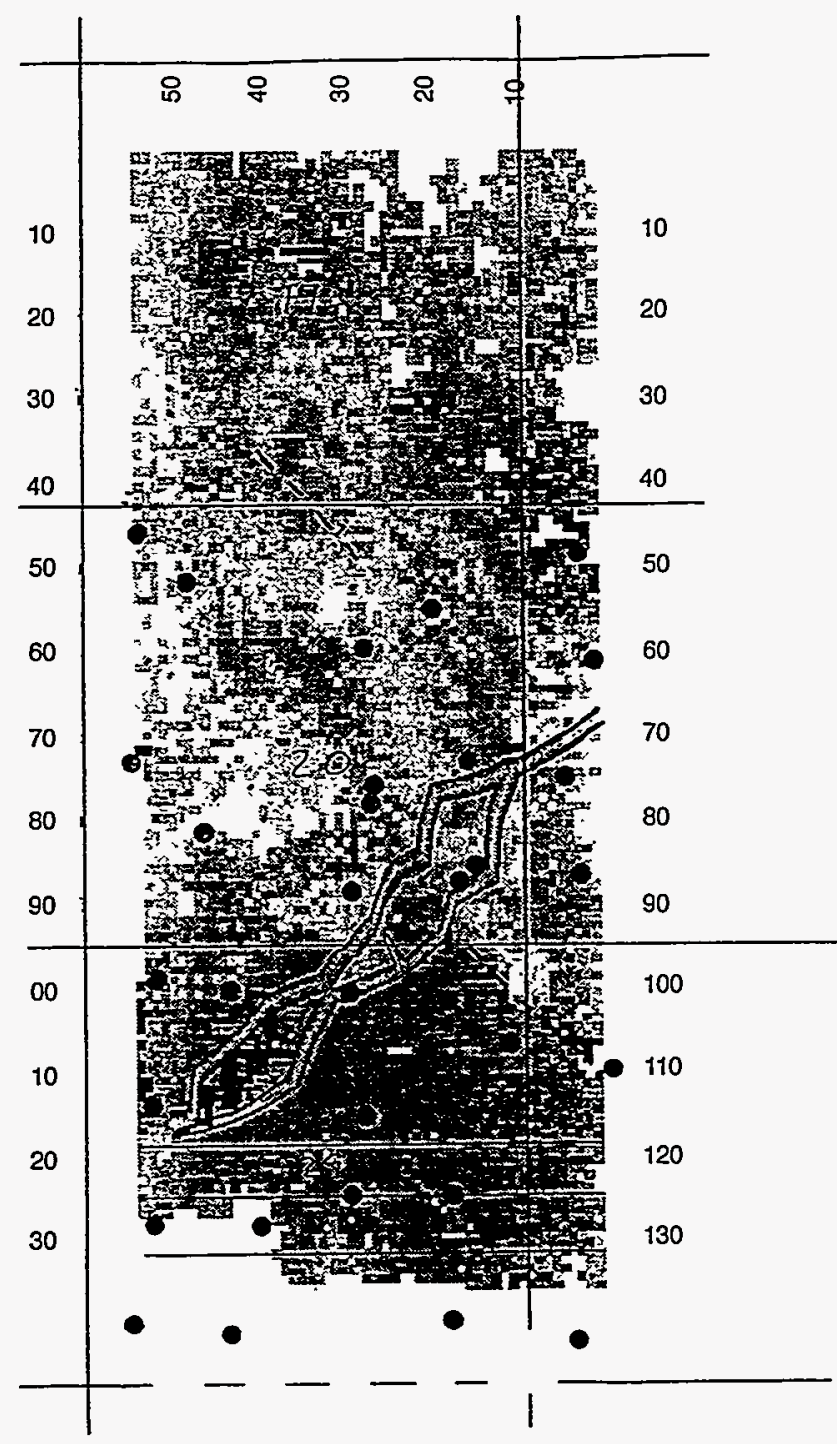

Fig. 3 Geophysical map from 3-D seismic survey, secs. 17, 20, and 29, 4 N., 65 W., Weld County, Colo.

testing methods are important and will be investigated further in a study of well test methods.

\section{Log Analysis and Correlations}

Thirty-one wells have been digitized and analyzed for their petrophysical information. Apparently there are several anomalous wells. HSR Salisbury well No. 6-29 (15407) has a very low porosity, and when compared with the 3-D seismic and the geological interpretation, this well appears to be in a down-dropped fault block. It is postulated that this block has experienced diagenetic cementing, which has almost completely diminished primary porosity. This indicates that these faults are sealing and compartmentalizing the reservoir.

Bohlender well No. 29-13 (16334) has anomalously high invasion, but this may be attributed to the quality of the original hard copy of the log. This well seems to have two zones of high resistivity, the typical basal sand and one above.

Shable well No. 17-10G was added near the compilation of this report and may change after the data quality is checked.

Geological and geophysical information for sections 17 and 20 agree with the kh map in terms of the gradually decreasing reservoir quality to the northeast.

Mapping petrophysical parameters has helped with the interpretation of sealing faults and has a positive comparison to the sparse production information.

Logs are being digitized in secs. 31,32 , and 33 of $4 \mathrm{~N}$. $65 \mathrm{~W}$. to allow the comparison of the oil and gas portions of the reservoir. Comparison of petrophysical data vs. cumulative production and GORs may give some insight into what tool best indicates the contrast between gas and oil.

\section{Internal Architecture}

Work has continued on refining a structural map that adequately represents the complex structural pattern at Hambert-Aristocrat. The principle fault trend is SW-NE, with numerous small-throw normal faults, probably also with some strike-slip component. A secondary fault system trends SE-NW. On the basis of GOR and initial production (IP) data discussed in previous quarterly reports, the SW-NE system is sealing to the migration of hydrocarbons, at least in terms of field-development time (as opposed to geologic time). Individual fault blocks may represent isolated reservoirs, not in mutual communication. The fault map has been finalized and checked with the 3-D seismic data that cover part of the area. Fault mapping from well log correlations compares favorably with fault mapping based on 3-D horizon slice mapping, though smaller faults appear to be more readily mappable from $\log$ correlations coupled with well data than from seismic data. Geologic and geophysical maps are being combined into a final fault map that can be input into the reservoir simulator.

Stratigraphic characterization has been refined to an additional level of complexity than previously reported because it is this level of complexity that will affect reservoir fluid flow and well performance. The Terry sandstone has been subdivided into a series of shoreface sandstone parasequences. Each parasequence is capped by a transgressive shale and grades eastward (paleo-seaward) from foreshore-upper shoreface (blocky log pattern) to lower shoreface-shelf (cleaning-upward log pattern). Transgressive shales are laterally continuous; thus they have the potential to be significant vertical barriers to fluid flow. The permeability structure probably varies laterally and vertically within a parasequence; lower shoreface sequences probably have the best permeability at their top, whereas foreshore-upper shoreface sequences probably have the best permeability at their base.

Reconnaissance work has begun on selecting a suitable outcrop analog for Hambert-Aristocrat.

Two presentations related to the project were made at the 1995 Annual AAPG Convention. ${ }^{1-2}$ 


\section{Detailed Seismic Analysis}

Fault mapping from the 3-D seismic data is complete and integrated with geological and engineering data. A dominant northeast-trending fault zone occurs in the southern portion of the 3-D seismic area at the Terry sandstone interval. This fault is part of a fault zone that exhibits a negative flower structure associated with strike-slip faulting in the Denver Basin. The 3-D seismic fault portrays that the fault is part of a fault system that branches upward as a flower structure. Another branch to this system occurs just south of the 3-D grid and is portrayed on geological maps.

This fault style is a new fault style for the Denver Basin and was first interpreted from two-dimensional (2-D) seismic data from Hambert field by Davis. ${ }^{3}$ The importance of this fault style is reservoir compartmentalization by fault offset and by diagenetic events associated with these faults. Primary porosity and permeability are now occluded along these faults by diagenetic overprints related to calcite and silica cementation. Clays also can be a factor in causing sealing conditions associated with these fault systems.

Recognition of faults and sealing conditions associated with these faults is of primary significance as to the role of geophysics in this integrated project. Considerable acreage has been written off in the Denver Basin because of the perception that diagenesis is pervasive in parts of the deep basin. The awareness of fault control of the diagenesis can lead to new exploration and development in the Basin and elsewhere in similar settings throughout the world.

Although the structural interpretation of the 3-D seismic data is complete, additional work involving the extent of diagenetic influence on reservoir mapping still needs to be done. Integrated analysis of both the compressional and shear wave volumes combined with geological and engineering data and analysis may enable more accurate mapping of reservoir parameters, porosity, permeability, and fracture density. The degree to which the 3-D seismic data will contribute to this determination is uncertain at this time until seismic attributes are extracted from the data volumes and correlated with reservoir parameters.

\section{Investigation of Well Testing Methods (Hambert Field)}

The Jack C. Noel No. 1 and Warren McMillen No. 1 wells produce a wet gas from the Sussex sandstone member of the Hygiene group in the DJ Basin. Completed in the 1970s, the wells were perforated and hydraulically fractured to produce from the low-permeability sand. The wells were not tested before the fracture treatments, so well test analysis goals include determining effective reservoir permeability along with estimating fracture half-length. The analysis results indicate that permeability is $0.02 \mathrm{mD}$ and the fracture half-length is approximately $700 \mathrm{ft}$ on the Jack C. Noel. The permeability and half-length were used along with a set of production rate type curves for infinite conductivity vertical fractures to estimate the drained reservoir volume. The short duration of the Warren McMillen test makes the interpretation much more subjective. A high-permeability streak $(0.6 \mathrm{mD})$ appears to dominate the test. The interpretation results are

Jack C. Noel Warren McMillen No. 1 No. 1

\begin{tabular}{lrr}
\hline Permeability, mD & 0.016 & $<0.6$ \\
Fracture, half-length, ft & 730 & $\approx 700$ \\
\hline
\end{tabular}

The reservoir parameters used in the interpretation are

Noel No. 1 McMillen No. 1

\begin{tabular}{lrr}
\hline Porosity, fraction & 0.1 & 0.12 \\
Net pay, ft & 34 & 54 \\
Water saturation, fraction & 0.5 & 0.5 \\
Conductivity, $\left(\times 10^{6}\right) \mathrm{psi}^{-1}$ & 450 & 450 \\
Temperature, $^{\circ} \mathrm{F}$ & 170 & 170 \\
\hline
\end{tabular}

\section{Permeability Experiment}

The rock properties and flow characteristics have been measured for the Sussex formation in the Hambert area. The measured rock properties were coupled with descriptive interpretations of core sections and subsequently linked with logderived values to develop a correlation for permeability estimates. This integration of data permits estimates of permeability on a field-wide basis. Relative permeability, compressibility, shear and compressional velocities, Poisson's ratio, and Young's modulus were also measured.

Reservoir core samples of the Machi Ross No. 1 (sec. 4, 32 N. 65 W.), Vern Marshall No. 1 (NW SW 32, 4 N. 65 W.), and Eckhardt No. 1 (sec. 15, 4 N. 66 W.) wells were available and are located in a south-east to north-west trend in the Hambert field in the Denver Basin of Colorado. The wells in the Hambert field produce oil and gas from the Cretaceous Terry sandstone (also referred as Sussex sandstone). This sandstone is thought to have been deposited as sands reworked into offshore ridge complexes during marine transgression. Six facies of different characteristics were identified and classified.

A permeability-depth profile for each core was obtained with the pressure decay profile permeameter ${ }^{\circledR}$. Results from the three cores showed a low-permeability formation, in the range of 0.015 to $9 \mathrm{mD}$, with variations of permeability related to the facies control. Permeability-depth profile measurements of the whole cores showed a good correlation to the facies distribution and to the log-calculated values. Production comes from four facies. The Vern Marshall No. 1 well produces gas from facies 1 and 2 and oil from facies 3 and 4 . 
Core plugs were taken from the Vern Marshall No. 1 well for further analysis. A multidisciplinary team of geologists, petroleum engineers, and geophysicists selected 17 horizontal and 4 vertical core plugs to constitute a representative set for the well. The core plugs ( 1 in. in diameter and 3 in. in length) from three productive facies were cut on the basis of the permeability profile results and variations in the depositional sequences.

Porosity and permeability as a function of the net confining stress were determined from the vertical and horizontal core plugs. Permeability and porosity measurements were performed with the use of the CMS-300 equipment under confining stress conditions of $500,1000,2000,3000,4000$, and $4500 \mathrm{psig}$. The porosity was found to be in the range of 12 to $16 \%$ under ambient conditions, and under the maximum applied confining stress of $4500 \mathrm{psig}$, the porosity was reduced on the order of $1 \%$ porosity unit. The horizontal permeability was found to be in the order of $0.05 \mathrm{mD}$ to 1.8 under ambient conditions, and under the maximum applied confining stress of $4500 \mathrm{psig}$, these values were reduced by $40 \%$. The vertical permeability measured in four core plugs showed values in the range of 0.01 to $0.2 \mathrm{mD}$. Under the maximum confining stress applied of $4500 \mathrm{psig}$, these values were reduced 75 to $95 \%$. The vertical-to-horizontal permeability ratios under ambient conditions varied from 0.11 to 0.15 . The vertical-to-horizontal permeability ratios under the maximum confining stress conditions of $4500 \mathrm{psig}$ resulted in lower values, ranging from 0.017 to 0.063 .

Compressional (P) and shear (S) wave-propagation velocities $\left(V_{p} / V_{s}\right)$ were measured in the horizontal and vertical core plugs under effective stresses of $500,1000,2000,3000,4000$, and 4500 psig. These measurements were made under gas(dry) and liquid-saturated conditions. For the dry samples, no correlation between the seismic velocities and lithology was found. For the saturated measurements, $a V_{p} / V_{s}$ ratio of approximately 1.7 indicates a cleaner sandstone (higher reservoir quality), and a ratio of 1.8 indicates a shalier sandstone (lower reservoir quality). Samples were grouped as good (samples 5, 6, 14, and 17) and poor (samples 16, 19, and 20) reservoir quality rocks. When saturated, the good reservoir quality rocks (high porosity and permeability values) have a higher $V_{s}$ and a lower $V_{p} / V_{s}$ ratio than the poorer reservoir quality rocks. The elastic rock properties (shear modulus, Young's modulus, bulk compressibility, and Poisson's ratio) were determined for the selected core plugs.

A description of the whole core and clay content determinations were complemented with petrographic (epoxyimpregnation thin-section analysis) and scanning electron microscope (SEM) analysis on the Vern Marshall No. 1 (NW SW 32, 4 N. 65 W.), Moser No. 1 (SE NW 34, 4 N. 65 W.), Kinsman No. 1 (SE SW 18, 4 N. 65 W.), Moser No. 1 (SE NW 34, 4 N. 65 W.) and the Prima Oil Burke 24-3S (SE SE $24,4 \mathrm{~N}$. $65 \mathrm{~W}$.) wells. The sandstones examined from all four wells are generally fine-grained, predominantly feldspathic, with variable amounts of carbonate cement, mainly calcite. Laminae with almost no carbonate or clay often exhibit extensive quartz cementation. Stylolites are common in the Terry sandstone in the study area. Clay laminae exhibit incipient stylolites that can inhibit vertical movement of reservoir fluids. The stylolites, however, are typically discontinuous over long lateral distances. Diagenetic evidence suggests an offshore origin for the sandstones. Petrographic analysis suggests the presence of microporosity. Equivalent pore entry radius calculated from mercury-air capillary pressure experiment indicates an abundance of less than $2 \mu \mathrm{m}$ equivalent pore entry radius. Analysis of the SEM indicates that most pores in the sandstones are on the order of a few microns in diameter (microporosity) and that there are few large $(>0.01-\mathrm{mm})$ pores.

Water-oil displacements were used to determine relative permeabilities and capillary pressures. An experimental apparatus capable of working under lab and confining stress conditions of up to $5000 \mathrm{psig}$ and at a reservoir temperature of $140^{\circ} \mathrm{F}$ was fabricated. Experiments were performed with $50,000 \mathrm{ppm}$ sodium chloride $(\mathrm{NaCl})$ and potassium chloride $(\mathrm{KCl})$ brine and kerosene. Berea core plugs were used for preliminary work to test the apparatus and establish a standard reference. For relative permeability experiments, the core plug number 4 from the Vern Marshall well No. 1 was selected on the basis of its homogeneity and relatively high permeability. Measurements were taken on core samples under lab conditions and under in situ conditions. Under the maximum net applied confining stress of 3500 psig and a reservoir temperature of $140^{\circ} \mathrm{F}$, the relative permeability curves were found to shift slightly to the right while maintaining their characteristic shape. The end points exhibited a minor or no shift. Mercury-air capillary pressures were determined, and the transformation to water-oil capillary pressure was found to be in excellent agreement with the experimental water-oil displacement. A numerical simulation of the experimental water-oil displacement experiments was also performed.

The experimental results have been integrated with the other tasks. Experimental porosity and permeability estimates were compared with log-derived estimates. A relationship between log-derived values and permeability values permits estimates of the permeability in other wells that have logs but no core samples. Also, these properties are related to the $V_{s}$ and the $V_{s} / V_{p}$ ratio. The results of the analysis of $V_{p}$ and $V_{s}$ wave-propagation velocities from core-plug samples are used to calibrate the tools used in the geophysical 3-D seismic interpretation. The petrographic analysis suggests carbonaterich and carbonate-poor (silica) cement and supports the offshore origin for these sandstones. The rock compressibility, capillary pressures, and relative permeabilities will be used as a starting point for the numerical simulation study.

\section{Reservoir Simulator}

A one-cell material balance tank model was run to develop a general overview of the field behavior. This model was run in addition to the material balance presented before and takes into account the mobility of fluids as a function of the relative permeability of the phases present in the reservoir. This produces gross estimates of the remaining oil at the abandonment pressure $\left(\mathrm{P}_{a b} 300\right.$ psia) and an indication of the relative 
permeabilities based on actual production and material balance calculations.

The Petroleum Workbench, an integrated software package developed by Scientific Software Intercomp, which includes production decline analysis, well test analysis, reservoirdescription, and reservoir simulation modules, has been installed. The Simbest II reservoir simulator module of the Workbench is a 3-D, three-phase, single- and dual-porosity, fully implicit reservoir simulator that is being used for the reservoirsimulation task.

Preliminary tests were performed by setting up the simulator as a simple tank model to compare with the earlier tank model. The basic model was set up and successfully run. Refinement of input data to fit the earlier model is in progress.

A one-well radial model simulator without a hydraulic fracture has been set up and is in progress. Also, this model will illustrate the limitations of the reservoir under nostimulation treatment. This model will be run for a dualporosity reservoir without stimulation treatment.

Other models to be set up and run before the final full-field model are (1) a one-well model with hydraulic fracture in a single- and dual-porosity system, (2) one-well multilayer options of the preceding models, and (3) a cross-section multilayer model with a single and dual porosity. These models will be built for the oil well case (Vern Marshall No. 1 well) and for the gas well case (Jack Noel No. 1 well).

The one-well with hydraulic fracture model in a singleand dual-porosity system will be evaluated against production history data and also against the well test performed for the JackNoel No. 1 well. The cross-section multilayer model with single and dual porosity will evaluate the behavior of the wells under a minimum configuration of the gross layers defined by the geology study and under a more-refined model with additional sublayers. The investigation of these models should lead to a better understanding of the behavior of the wells and to a better model selection in terms of the need for single- or dual-porosity capability and the appropriate number of layers for the full-field simulation.

\section{References}

1. R. M. Slatt, M. H. Al-Raisi, and M. K. Decker, Structural and Stratigraphic Compartmentalization of the Terry Sandstone, and Effects on Reservoir Fluid Distributions, Latham Bar Trend, Denver Basin Trend, Denver Basin, Colorado, paper presented at the 1995 Annual American Association of Petroleum Geologists, Houston, Tex., March 5-8, 1995.

2. D. E. Edington, R. M. Slatt, and H. Araujo, Structural and Stratigraphic Compartmentalization of the Terry Sandstone, and Effects on Reservoir Fluid Distributions in Hambert-Aristocrat Fields, Denver Basin, Colorado, paper presented at the 1995 Annual American Association of Petroleum Geologists, Houston, Tex., March 5-8, 1995.

3. T. L. Davis, Seismic Evidence of Tectonic Influence on Development of Cretaceous Listric Normal Faults, Boulder-Wattenburg-Greeley Area, Denver Basin, Colorado, The Mountain Geologist, 22(2): 47-54 (1985).

\section{INTEGRATION OF ADVANCED GEOSCIENCE AND ENGINEERING TECHNIQUES TO QUANTIFY INTERWELL HETEROGENEITY}

\section{Contract No. DE-AC22-93BC14893}

\author{
New Mexico Institute of Mining and Technology \\ Socorro, N. Mex. \\ Contract Date: Sept. 29, 1993 \\ Anticipated Completion: Sept. 30, 1996 \\ Government Award: \$250,896 \\ Principal Investigators: \\ Jill Buckley \\ William Weiss \\ Ahmed Ouenes \\ Project Manager: \\ Robert Lemmon \\ Bartlesville Project Office
}

Reporting Period: Jan. 1-Mar. 31, 1995

\section{Objective}

The objective of this project is to integrate advanced geoscience and reservoir engineering concepts with the goal of quantifying the dynamics of fluid-rock and fluid-fluid interactions as they relate to reservoir architecture and lithologic characterization. This interdisciplinary effort will integrate geological and geophysical data with engineering and petrophysical results through reservoir simulation. Subcontractors from Stanford University (SU) and the University of Texas at Austin (UT) are collaborating on the project: SU is supervising the geophysical research and UT is supervising the hydrologic and tracer research. Several members of the Petroleum Recovery Research Center (PRRC) staff are developing an improved reservoir description by integrating the field and laboratory data as well as developing quantitative reservoir models to aid performance predictions.

\section{Summary of Technical Progress}

\section{Geological Studies}

\section{Field Work}

Field work in the Carlsbad area is continuing. Fifty more permeability samples have been collected in the Rocky Arroyo area (Fig. 1). Samples were collected on a more regular grid pattern than had previously been used, so data will be more useful for geostatistical modeling. Because of the many difficulties encountered when using the field minipermeameter, the samples were collected and returned to the lab for permeability and porosity measurements. 


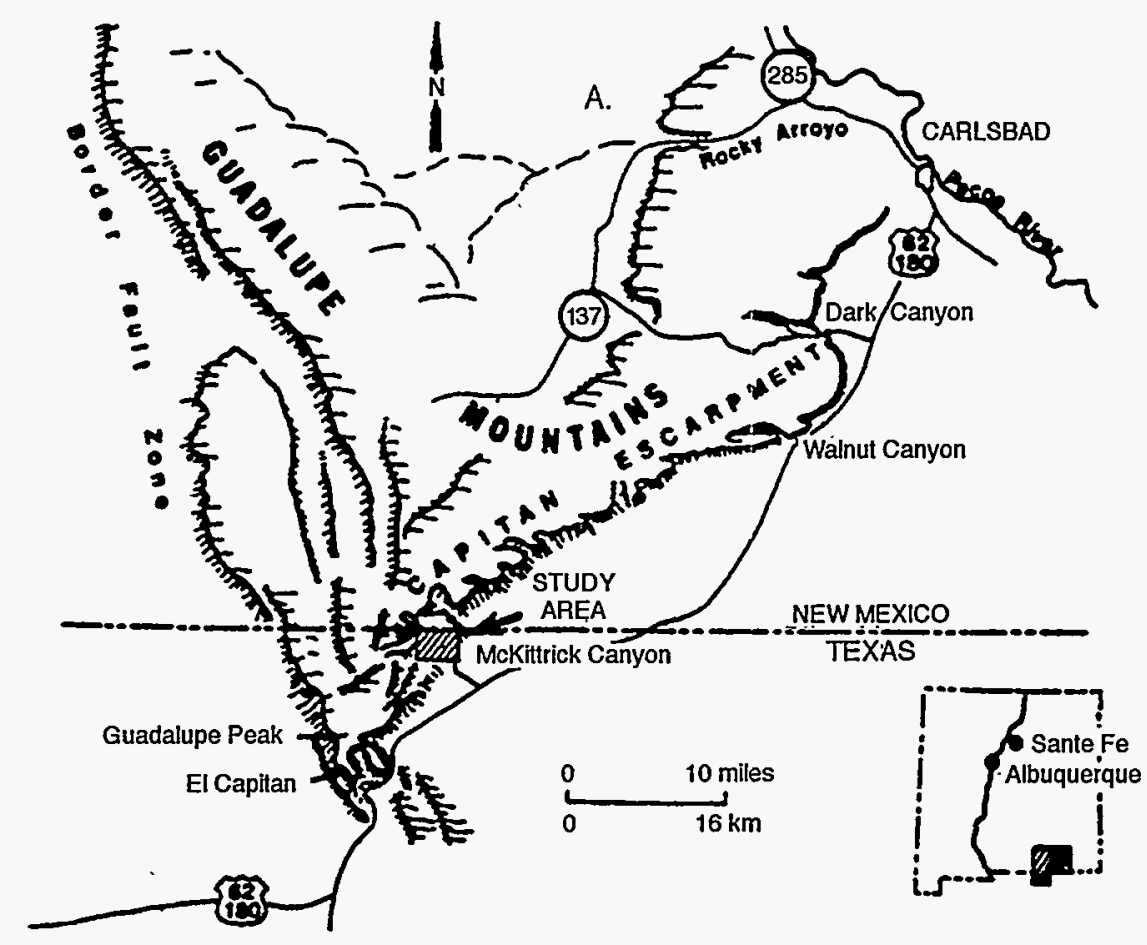

Fig. 1 Generalized map of area for future field study. Letter A marks area north of Rocky Arroyo where future efforts will be concentrated.

Data measurement is under way. Most samples were collected with the use of a portable rock drill provided by New Mexico Bureau of Mines and Mineral Resources. With the use of this drill, samples were obtained that are free of surficial weathering effects and samples were taken in places where rocks were too indurated to break off large pieces for transport back to the lab.

Another outcrop of Queen sandstone was located north of the Rocky Arroyo area (Fig. 1). This area contains rocks that are farther up into the evaporitic section of the Queen and are therefore more analogous to those in the Sulimar field than in any other area examined to date.

\section{Subsurface Mapping}

All well data have been entered into the Landmark Graphics database, and the data are being interpreted. Figure 2 shows a base map of the Sulimar Queen field with sections lines, the unit boundaries, and well spots indicated. Figure 3 is a structural contour map made on the top of the Shattuck sand or upper pay zone of the Queen. This top was picked at a flexion point on the gamma-ray log where there is a strong deflection to the right (increasing API count). Structure shows a general dip from the northwest to the southeast part of the field with a few local highs and lows. Structure maps on top of the overlying Seven Rivers and Yates formations are similar, which indicates that current structural trends are probably post-Permian in nature.
Figure 4 shows a gross sand thickness map for the upper Queen pay zone. Sand thickness for this map was either picked from logs or from previously published data where logs were not available. A bottom pick for the sand was difficult because some of the gamma-ray logs did not actually extend to the bottom of the hole; in these cases the pick was made from the neutron log. Preliminary results on using a neural network to estimate porosity from the old neutron logs are encouraging. Logging tool resolution is not sufficient to distinguish small interbedded siltstones and shales within the coarser sand body, so no net pay sand map was generated. These maps differ somewhat from previously published maps, ${ }^{1}$ particularly the sand thickness map (Fig.2). This may be because the thicknesses shown on this map are derived primarily from $\log$ data, whereas those in the preliminary study are from scout reports, logs, and cuttings. None of these methods can provide truly accurate thickness measurements, particularly on such thin units as the Shattuck sandstone. Also, log picks may depend on whether one uses a flexion point or a cutoff value as the pick point.

\section{Geophysical Data}

The two-dimensional (2-D) seismic lines and the preliminary cross-well tomography data have been entered into Landmark SeisWorks, a geophysical interpretation software package. Time-depth conversions are needed before interpretation of this data can commence. 


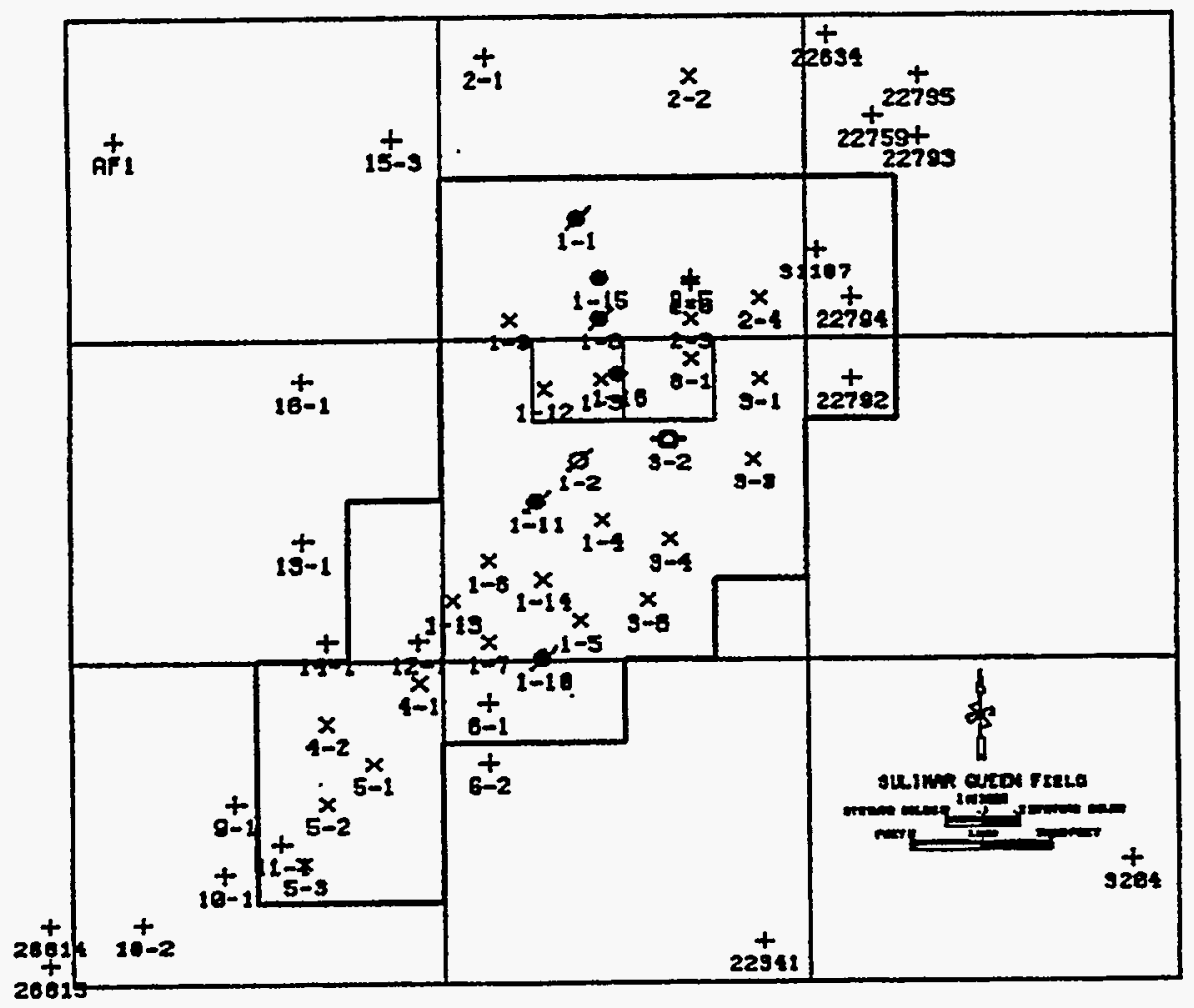

Fig. 2 Base map of Sulimar Queen field.

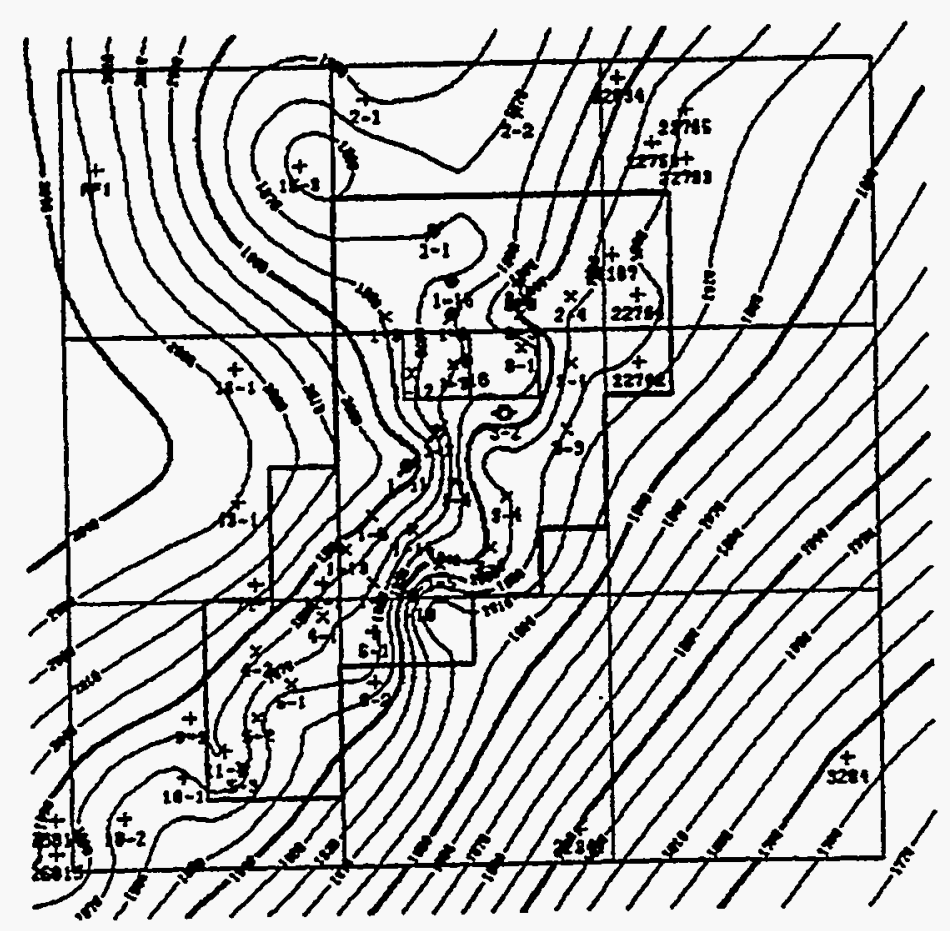

Fig. 3 Structural contour map of top of Queen sand. 


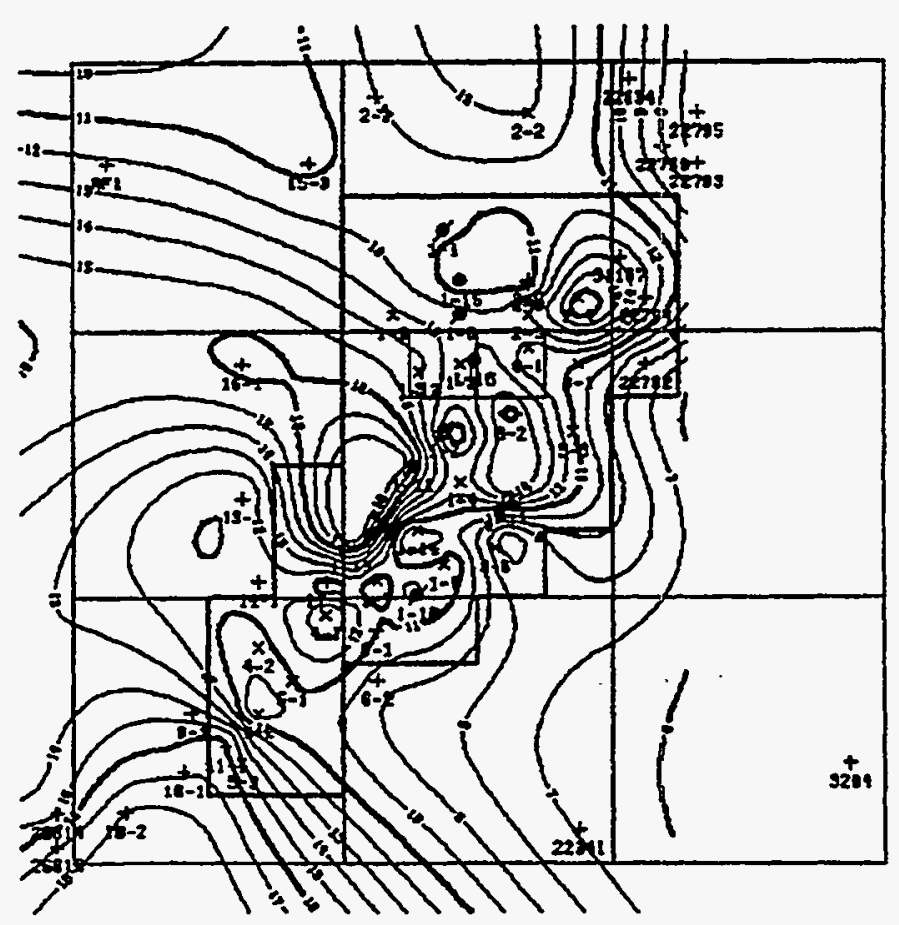

Fig. 4 Gross thickness contour map of Queen sand.

\section{Hydrologic and Tracer Research}

This report describes the preliminary simulation design study of the single-well wettability tracer test (SWWTT) that is planned for the Sulimar Queen reservoir. The design may change when more information is obtained about the reservoir. The design is based on a single-layered radial model. Three cases of wetting conditions were used in the design: moderately water-wet (MWW), weakly water-wet (WWW), and weakly oil-wet (WOW).

The design shown in this report is called the base case, which is the current best estimate of the unknown parameters for the reservoir and the tracers. The sensitivity studies are done by using this base case and changing one parameter at a time. The base case will be described here.

The injection is in two parts, water slug and oil slug. The water slug is injected with the water material-balance tracer, methanol $(\mathrm{MeOH})$, and the reactant tracer, ethyl formate $(\mathrm{EtFr})$. The injected tracer concentration is $0.5 \mathrm{vol} \%(5,000 \mathrm{ppm})$ for the $\mathrm{MeOH}$ and 1 vol \% $(10,000 \mathrm{ppm})$ for the EtFr. After the injection of the water slug with the tracers, a water buffer is used to push the tracers farther away from the well. The buffer also contains the material-balance tracer $(\mathrm{MeOH})$ at the same concentration. The oil slug is injected with the oil material-balance tracer, octanol $(\mathrm{OcOH})$, and the reactant tracer, propyl formate $(\mathrm{PrFr})$. The injected tracer concentration is $0.5 \mathrm{vol} \%$ $(5,000 \mathrm{ppm})$ for the $\mathrm{OcOH}$ and 1.5 vol $\%(15,000 \mathrm{ppm})$ for the PrFr. After the injection of the oil slug with the tracers, the oil buffer is used to push the tracers farther away from the well; the buffer also contains the material-balance tracer $(\mathrm{OcOH})$ at the same concentration. The injection time and tracers slug sizes for the base case are shown in Table 1.

After injection of the tracers and buffer fluid, the well is shut in for $1 \mathrm{~d}$ to allow the tracers in the oil slug additional reaction time. The well is finally produced for $15.48 \mathrm{~d}$ (twice the injection duration) at a rate of 46.5 stock tank barrels (STB)/d.

The reactant tracers are shown in Table 2 along with their partition coefficient ( $\mathrm{K}$-value) and hydrolysis constant ( $k$-value). The partition coefficients were measured at UT. A series of standards of known concentration were prepared with the use of the field brine for calibration of the gas chromatograph. A $5.0-\mathrm{cm}^{3}$ aliquot of the highest standard concentration $(1000 \mathrm{ppm})$ was placed in a vial with an equal volume of the crude oil sent from the site. Duplicate samples were prepared and shaken for $5 \mathrm{~min}$. The samples were

\section{TABLE 1}

Injection Time and Tracer Slug Size for Base Case

\begin{tabular}{|c|c|c|c|c|}
\hline Injection & $\begin{array}{c}\text { Volume, } \\
\text { bbl }\end{array}$ & $\begin{array}{l}\text { Rate, } \\
\text { bbl/d }\end{array}$ & $\begin{array}{c}\text { Time, } \\
\text { d }\end{array}$ & Tracers \\
\hline Water slug with tracers & 15 & 15.5 & 0.97 & $\mathrm{MeOH}$ and $\mathrm{EtFr}$ \\
\hline Water buffer & 40 & 15.5 & 2.58 & $\mathrm{MeOH}$ \\
\hline Oil slug with tracers & 15 & 15.5 & 0.97 & $\mathrm{OcOH}$ and $\mathrm{PrFr}$ \\
\hline Oil buffer & 50 & 15.5 & 3.23 & $\mathrm{OcOH}$ \\
\hline Total & 120 & 15.5 & $\overline{7.74}$ & \\
\hline
\end{tabular}


TABLE 2

The Reactant Tracers*

\begin{tabular}{lcl}
\hline Tracer & K-value, $\mathbf{m L} / \mathbf{L}$ & k-value, $\mathrm{d}^{-\mathbf{1}}$ \\
\hline Ethyl formate & 4.03 & 0.1351 \\
Propyl formate & 10.25 & 0.12 \\
\hline
\end{tabular}

*Sulimar Queen Reservoir: Temperature $30^{\circ} \mathrm{C}$, which equals $86^{\circ} \mathrm{F}$, and salinity is $300,000 \mathrm{ppm}$ TDS.

centrifuged at approximately $1000 \mathrm{~g}$ for $45 \mathrm{~min}$. Two aliquots of the brine were removed from each sample and analyzed with gas chromatography. Concentrations were calculated from the calibration curve, and the K-value was calculated. Measurements were made at ambient temperature. The hydrolysis rate constant for the PrFr was obtained from Ref. 2 . The product tracers are ethanol (EtOH) and normal propyl alcohol (NPA).

The relative permeability curves and the capillary pressure curves for the three wetting conditions are shown in Figs. 5 and 6 , respectively. The parameters used with the wetting conditions are shown in Table 3. Other important design parameters are shown in Table 4.

The water cut for the three wetting conditions is shown in Fig. 7. As shown in this figure, the water cut responds faster as the wetting conditions shift toward more oil-wet. The total tracer concentration for the water slug tracers is shown in Fig. 8. The distance between the peaks of the reactant and the product tracer is the measure of wettability. As shown in this figure, the distance increases when the wetting conditions shift to more oil-wet. The total tracer concentration for the oil slug tracers is shown in Fig. 9. As shown in this figure, the distance between the peaks of PrFr and the NPA increases

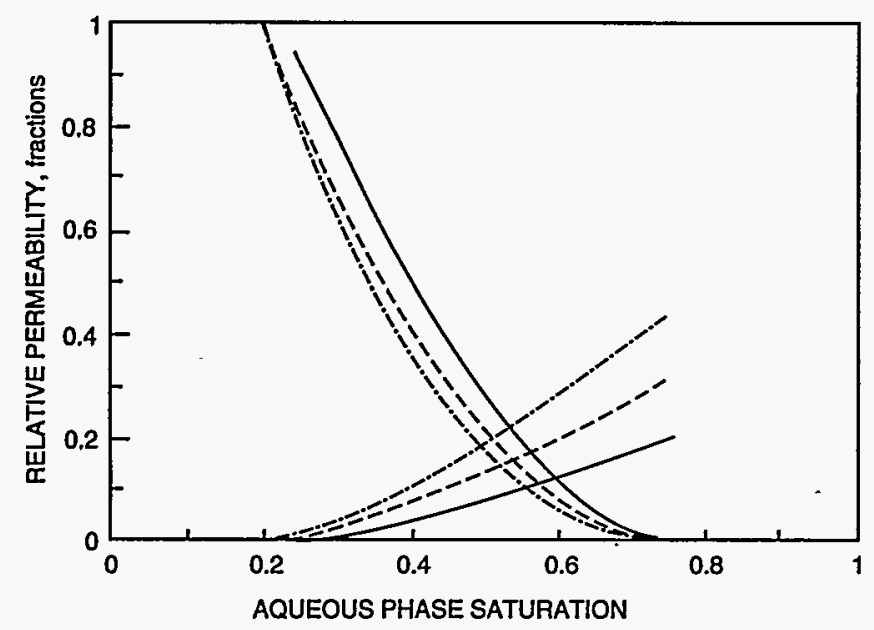

Fig. 5 Relative permeability curves of different wetting systems. $\longrightarrow$, moderately water-wet. --- , weakly water-wet. $-\cdot-$, weakly oil-wet. when the wetting conditions shift to more oil-wet. The shifts for these tracers is greater than that for the $\mathrm{EtOH}$ and $\mathrm{EtFr}$ tracers.

Parameters under investigation are kinetics (reaction rate of the tracers), heterogeneity, dispersion, and relative permeability (end points and residual saturations). When the singlewell, pump-in, pump-out sodium thiocyanate $(\mathrm{NaSCN})$ test is

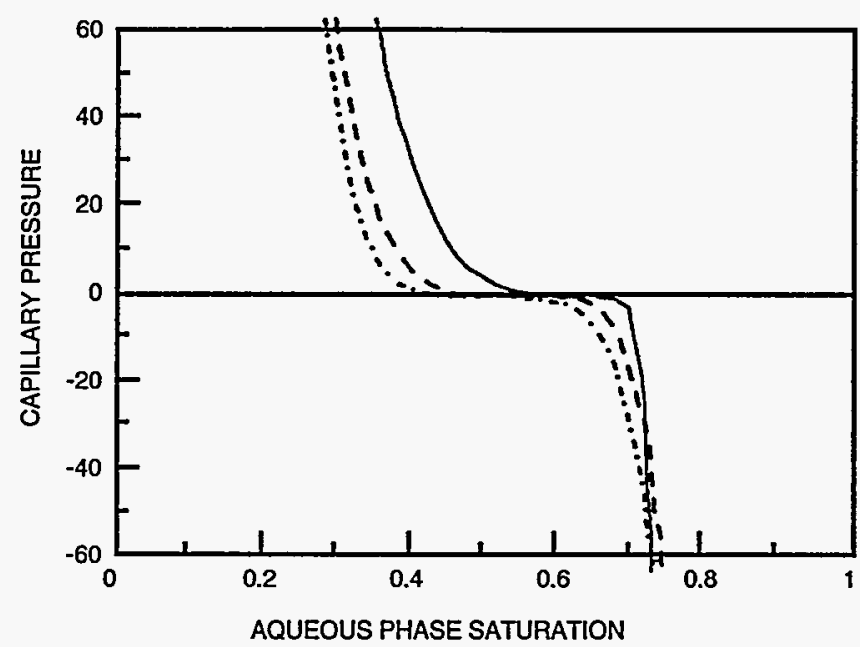

Fig. 6 Capillary pressure curves of different wetting systems. moderately water-wet. $-\ldots-$, weakly water-wet, $-\cdot-$, weakly oil-wet.

TABLE 3

Wetting Conditions

\begin{tabular}{lccccccccccc}
\hline Name & $\mathbf{S}_{\mathrm{wr}}$ & $\mathbf{S}_{\mathrm{or}}$ & $\mathbf{k}_{\mathrm{rw}}^{\circ}$ & $\mathbf{k}_{\mathrm{ro}}^{0}$ & $\mathbf{e}_{\mathrm{w}}$ & $\mathbf{e}_{\mathbf{0}}$ & $\mathbf{C}_{\mathrm{pcw}}$ & $\mathbf{C}_{\mathrm{pco}}$ & $\mathbf{n}_{\mathrm{pcw}}$ & $\mathbf{n}_{\mathrm{pco}}$ & $\mathbf{S}^{*}$ \\
\hline MWW & 0.23 & 0.25 & 0.20 & 1.0 & 1.4 & 1.7 & 15 & -10 & 4 & 6 & 0.65 \\
WWW & 0.20 & 0.20 & 0.35 & 1.0 & 1.4 & 2.2 & 15 & -15 & 4 & 6 & 0.53 \\
WOW & 0.20 & 0.20 & 0.50 & 1.0 & 1.4 & 2.5 & 15 & -15 & 4 & 6 & 0.47 \\
\hline
\end{tabular}

Note: MWW, moderately water-wet; WWW, weakly water-wet; and wow, weakly oil-wet.

\section{TABLE 4}

Reservoir Conditions

\begin{tabular}{|c|c|c|c|}
\hline Reservoir temperature, ${ }^{\circ} \mathrm{F}$ & 86 & $\begin{array}{c}\text { Aqueous longitudinal } \\
\text { dispersivity, } \mathrm{ft}\end{array}$ & 0.1 \\
\hline Porosity, \% & 17.9 & $\begin{array}{c}\text { Aqueous transverse } \\
\text { dispersivity, } \mathrm{ft}\end{array}$ & 0.003 \\
\hline Permeability, $\mathrm{mD}$ & 45 & $\begin{array}{r}\text { Oleic longitudinal } \\
\text { dispersivity, } \mathrm{ft}\end{array}$ & 0.1 \\
\hline Depth, $f t$ & 2000 & $\begin{array}{c}\text { Oleic transverse } \\
\text { dispersivity, } \mathrm{ft}\end{array}$ & 0.003 \\
\hline Thickness of reservoir, $\mathrm{ft}$ & 11 & $\begin{array}{l}\text { Water viscosity @res. } \\
\text { temp., cP }\end{array}$ & 1.20 \\
\hline Reservoir pressure, psia & 711 & $\begin{array}{l}\text { Oil viscosity @res. temp., } \\
\mathbf{c P}\end{array}$ & 4.0 \\
\hline Initial water cut & 0.94 & Skin factor & 2.6 \\
\hline
\end{tabular}




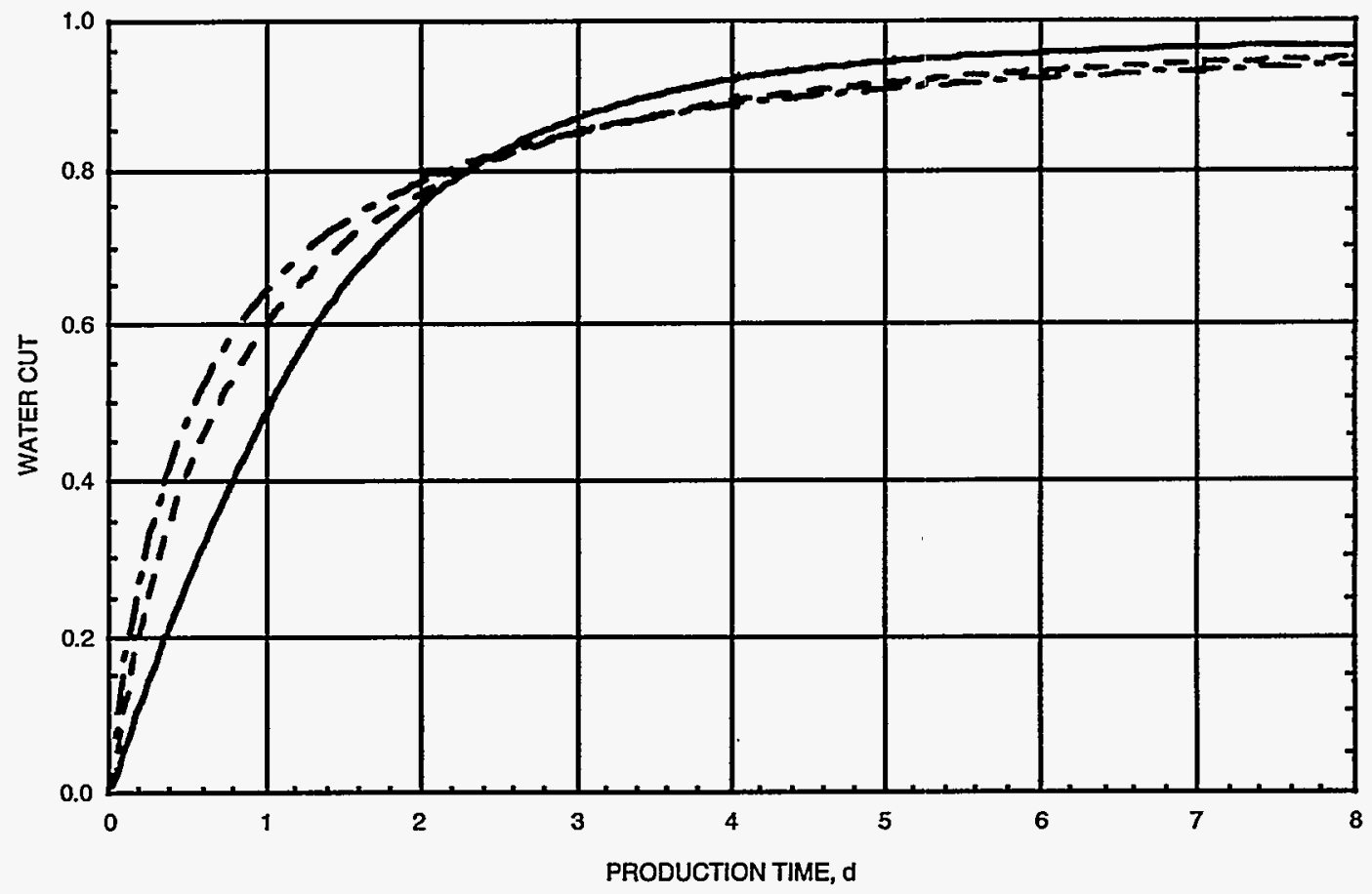

Fig. 7 Water-cut histories for three wetting conditions._-, moderately water-wet. - - -, weakly water-wet. -..-, weakly oil-wet.

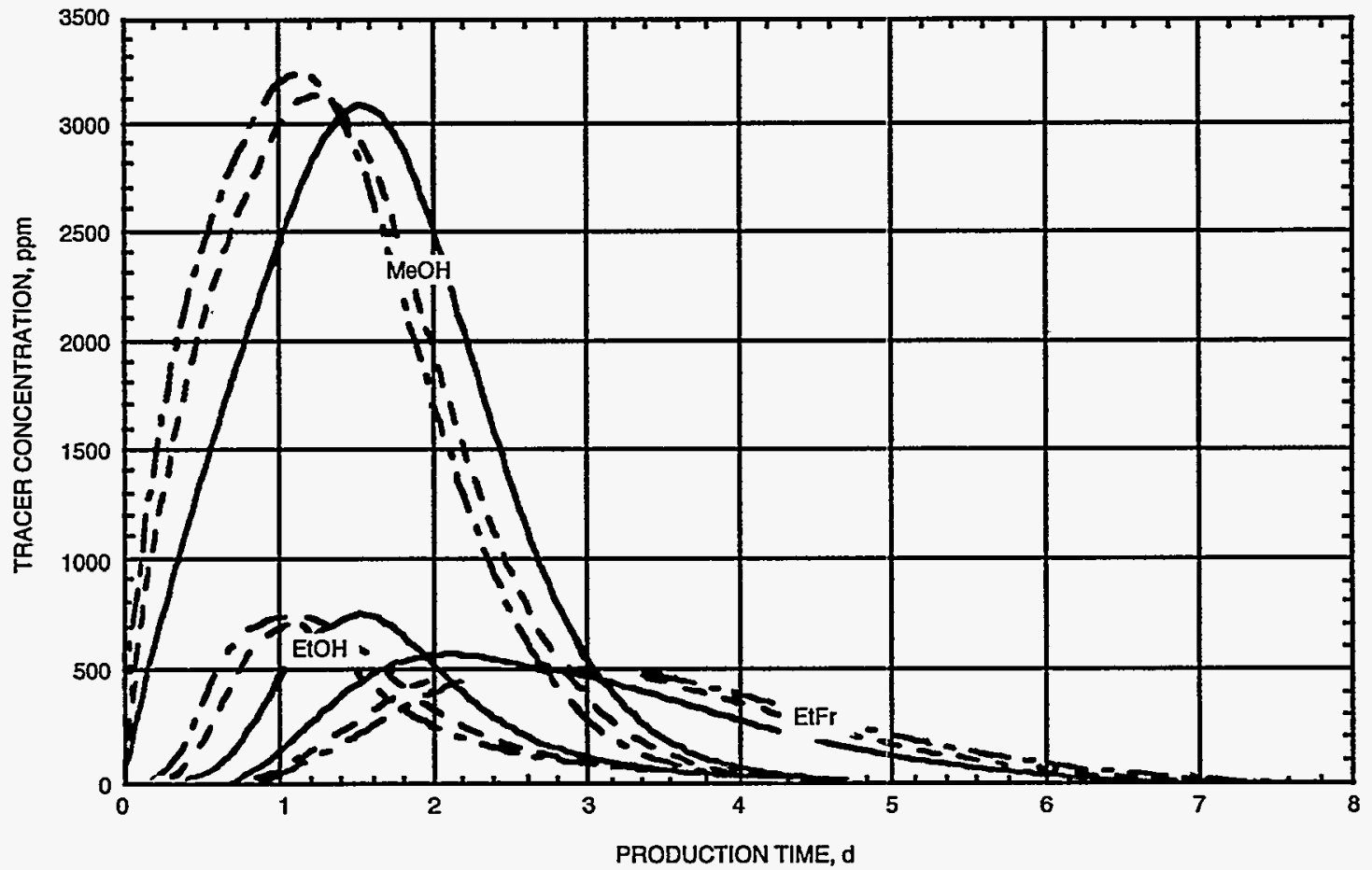

Fig. 8 Total tracer concentration (vol.) histories for the water slug tracer.—, imoderately water-wet. - - -, weakly waterwet. -.-, weakly oil-wet. 


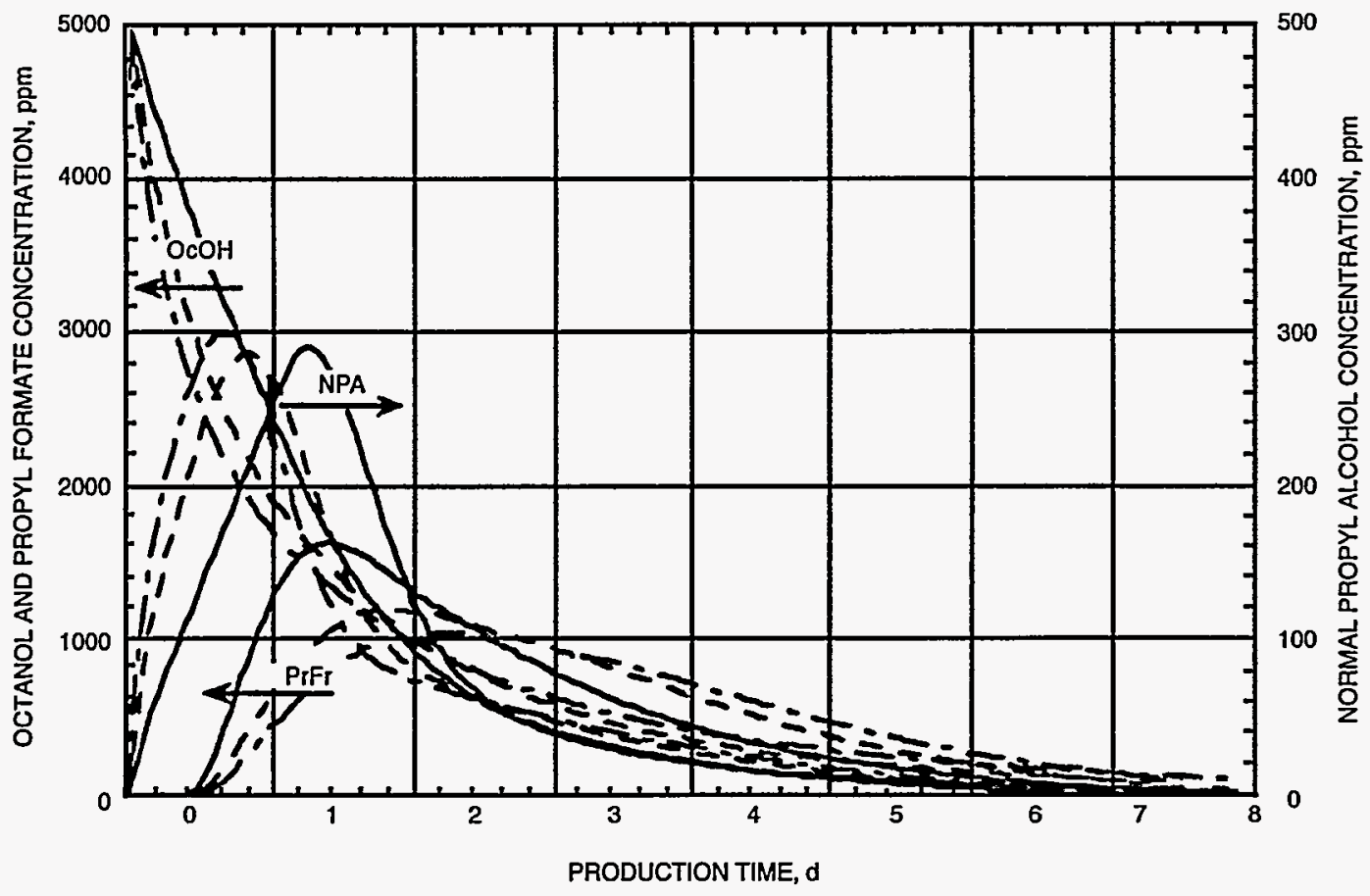

Fig. 9 Total tracer concentration (vol.) histories for the oil slug tracer._-, moderately water-wet.---, weakly waterwet. -.-, weakly oil-wet.

complete, more-accurate values of some of the parameters that are most sensitive to the SWWTT design should be available. The base case will also be run with a three-layered radial reservoir and other alternative reservoir descriptions.

\section{Geophysical Research}

In cross-well seismic imaging, the objective is to use the sound signal emanated from a source well and recorded within a receiver well to interpret the medium between the two wells. The primary objective with the Sulimar Queen cross-well survey data set is to obtain two types of images or sets of information as a function of position within the medium, which are velocity tomogram and reflection image.

A velocity tomogram yields localized information on the velocity at which sound propagates through the medium. Different types of rocks allow sound waves to propagate through them at different speeds. Therefore a velocity tomogram can be an indicator of variations of rock type and possible porosity and permeability. A reflection image yields localized information on the impedance contrasts within the medium. Therefore a reflection image can indicate where the geological structure of the medium is changing. Tomography uses the travel time of the direct arrival, and reflection mapping uses the full wave form of the reflection arrivals. Tomography is the low wave-number resolution of the medium, and reflection imaging is a higher wave number resolution of the medium.

\section{Preliminary Processing}

Field data contain many different wave modes, and full wave-form cross-well data are very complicated. A series of processes are required to obtain useful information from the data. The process is started by correlating the data with the source sweep and tube wave attenuation.

\section{Field Data}

The data recorded in the field test at the Sulimar site were generated by a linear source sweep from 350 to $2000 \mathrm{~Hz}$. Before the data are analyzed, they must be correlated with the source sweep by cross-correlation of all the traces with the linear source sweep from 350 to $2000 \mathrm{~Hz}$.

\section{Tube-Wave Attenuation}

The data contain strong tube-wave noise. The tube wave is the wave train that propagates within the borehole and then hits a perforation at the top or bottom of the well casing and propagates toward the receiver well. Tube waves are one of the main sources of noise within a cross-well survey. Before any processing for tomography or reflection imaging can be done, as much of the tube-wave noise as possible needs to be removed. Moveout in source and receiver gathers of the tube waves is close to linear, and the waveform and frequency content of the tube waves is nearly constant. Within source and receiver gathers, a trace mix subtraction operation along the moveout of the tube wave has been performed. This is a 
convolutional operator in space over a moving window of traces. The size of trace-mix window is the size of the convolutional operator, which makes a large difference on the effect of the data. After several different window sizes were tried, the optimal window size was chosen. After this tracemix procedure, the tube-wave noise was reduced, which makes additional processing easier.

\section{Tomography}

The preliminary picks on this gather indicate some reasonable velocities and an indication of variation in the velocity; however, a more well-defined first arrival or another piece of information is needed to calibrate the first arrival picks. Such procedures as Hilbert transforming of the data to obtain some instantaneous phase and frequency information and modeling where the first arrival is expected to be by using sonic logs to do some synthetic modeling of the expected wavefield are being tried to enhance the direct arrival and to make accurate travel time picks.

If, with the use of the Hilbert transform, which is a relative of the Fourier transform that searches for the amplitude envelope of the data, the envelope of the first arrival can be found, then the envelope can be picked for tomography. Additionally, a synthetic wavefield is being created by forward modeling with the use of the sonic logs to create a onedimensional velocity model of the medium doing this, evidence of where the first arrival is expected can be found and some of the apparent changes in velocity in the data can be verified.

\section{Reflection Imaging}

Reflection imaging is based on being able to separate the desired reflection energy from the rest of the complex crosswell wavefield. The difficulty of this depends on the signal-tonoise ratio of the data. This is a function of well spacing, source strength, bandwidth, reservoir pressure, and p- and $\mathrm{s}$-wave velocities. Some wavefield processing (cross correlation and tube-wave attenuation) has been done. For reflection imaging, additional wavefield processing will be necessary. Each individual data set has its own unique wavefield separation problems.

One p-wave reflection arrival coming from just below the survey has been noted. By some new developments in crosswell reflection imaging, this event is estimated to be at about $1980 \mathrm{ft}$, which makes it possible that it marks the top of the Queen boundary. This event can be seen in the common offset domain and through a range of filters, which indicates that it is a reflection event.

\section{References}

1. T. Cowen, F. Beck, and J. MacMillan, Preliminary Reservoir Study Sulimar Queen Field, Chaves County, New Mexico, New Mexico Petroleum Recovery Research Center, New Mexico Institute of Mining and Technology, Socorro, New Mex., unpublished, 1989.

2. S. Majoros and H. A. Deans, Single-Well Chemical Tracer Tests Since 1968, U.S. Department of Energy, Washington, D.C., 1980.

\section{FABRICATION AND DOWNHOLE TESTING OF MOVING THROUGH CASING RESISTIVITY APPARATUS}

Contract No. DE-FG22-93BC14966

ParaMagnetic Logging, Inc. Woodinville, Wash.

Contract Date: Mar. 23, 1993

Anticipated Completion: June 30, 1995

Government Award: \$109,000

Principal Investigator:

W. Banning Vail

Project Manager:

Robert Lemmon

Bartlesville Project Office

Reporting Period: Jan. 1-Mar. 31, 1995

\section{Objective}

The objective of this project is to validate recently discovered technology dealing with oil well measurement instrumentation that will allow the industry to find missed oil and bypassed gas. This breakthrough technology, already endorsed in principle by the oil and gas industries, will allow identification of missed oil and bypassed gas locations in abandoned fields as well as in existing offshore wells and will also allow increased productivity from low-production wells. There is no other proven technology that can detect such oil behind steel casing, lower the discovery risk, and improve the success rate of recovery of otherwise accessible but undetected oil and gas reserves.

\section{Summary of Technical Progress}

The analysis has begun on the completely successful test results obtained at the MWX-2 well (blind test of the technology). More than 100 figures have been completed to provide a complete record of the data for future theoretical analysis.

A parallel analysis of the theory has been undertaken that shows that ParaMagnetic Logging, Inc.'s calibration constant $\mathrm{K}$ can be calculated from first principles. Such first principles calculation gives adequate agreement with the empirically determined calibration constant $\mathrm{K}$ used at the MWX-2 well and at prior wells. 


\section{GYPSY FIELD PROJECT IN \\ RESERVOIR CHARACTERIZATION}

Contract No. DE-FG22-94BC14970

\author{
University of Oklahoma \\ Norman, Okla.
}

Contract Date: May 19, 1994

Anticipated Completion: May 18, 1995

Government Award: $\$ 348,000$

(Current year)

\section{Principal Investigator: \\ Daniel J. O'Meara, Jr.}

Project Manager:

Robert E. Lemmon

Bartlesville Project Office

Reporting Period: Jan. I-Mar. 31, 1995

\section{Objective}

The overall objective of this project is to use the extensive Gypsy field laboratory and data set as a focus for developing and testing reservoir characterization methods that are targeted at improved recovery of conventional oil. The Gypsy field laboratory' consists of coupled outcrop and surface sites that have been characterized to a degree of detail not possible in a production operation. Data from these sites entail geological descriptions, core measurements, well logs, vertical seismic surveys, a three-dimensional (3-D) seismic survey, cross-well seismic surveys, and pressure-transient well tests.

The project consists of four interdisciplinary sub-projects: (1) modeling depositional environments, (2) integrated 3-D seismic interpretation, (3) sweep efficiency, and (4) tracer testing.

The first of these aims at improving the ability to model complex depositional environments that trap movable oil. The second is a development geophysics project that proposes to improve the quality of reservoir geological models through better use of 3-D seismic data. The third investigates the usefulness of a new numerical technique for identifying unswept oil through rapid calculation of sweep efficiency in large reservoir models. The fourth explores what can be learned from tracer tests in complex depositional environments, particularly those which are fluvial dominated.

\section{Summary of Technical Progress}

During this quarter, the main activities involved the tracer testing and sweep efficiency projects. The tracer and pressure cases for the 18 block homogeneous cases suggest that well-to-well tracer and well-to-well pressure responses can possess enough information to identify the presence of heterogeneities except for the symmetric cases. In equal storage capacity layered systems, tracer breakout timing, particularly long retention periods, can help identify the existence of the layers.

Both tracer and pressure tests can help identify and quantify the existence and orientation of a high-permeability channel for the diagonal and channel cases. For two-layer, block homogeneous systems with thin high-permeability layers, tracer data can clearly identify the existence of two layers for all cases by the doublepeak responses. The existence and orientation of a high-permeability channel for the diagonal and channel reservoirs can be identified from tracer and pressure data.

The main contribution of the sweep efficiency project entails setting up a way to calibrate results obtained with the use of the cubature method. The approach has been to construct simple models that will be evaluated against standard second- and fourth-order finite difference schemes. During this quarter, the 3-D model was formulated and is being programmed. The second- and fourth-order finite-difference schemes were applied for comparison of the accuracy of calculations.

\section{Tracer Testing}

For the study of the inter-channel scale observability of tracer tests in a heterogeneous porous medium, 18 case studies were run with the use of the tracer option in Intera Petroleum Services' ECLIPSE simulator. The case studies used a five-spot pattern similar to that of the Gypsy subsurface site. Three different model reservoirs were simulated to represent different conceptual heterogeneous reservoirs. The studies were forblock homogeneous models, a simplified form of heterogeneous porous medium. A block homogeneous reservoir is a reservoir composed of two or more regions. Within individual regions, porosity and permeability are constant; however, properties in different regions are not equal, and the reservoir is heterogeneous. The concept of block homogeneity is that the individual regions result from a single depositional event and represent channels adjacent to each other. Flow between adjacent units was allowed because it appeared that this would be the more difficult problem.

The geometry and properties of the simulation system were chosen to approximate those measured for the Gypsy subsurface site. ${ }^{1}$ The geometry of interest was a closed five spot. The $26,900-\mathrm{m}^{2}(5.75$-acre) area, $164 \mathrm{~m}$ by $164 \mathrm{~m}(500 \mathrm{ft}$ by $500 \mathrm{ft})$, was divided into 25 blocks in each horizontal direction. This resulted in $6.6 \mathrm{~m}$ by $6.6 \mathrm{~m}(20 \mathrm{ft}$ by $20 \mathrm{ft}$ ) equal-sized blocks. The net thickness used was $16.4 \mathrm{~m}(50 \mathrm{ft})$, a uniform porosity equal to the average $19 \%$ was chosen, and the permeabilities were chosen to result in a reservoir average of $520 \mathrm{mD}$ The center injection well operated at an injection rate of $159 \mathrm{cubic} \mathrm{m}^{3} / \mathrm{d}$ (1000 bbl/d), and production wells at each corner of the reservoir each produced $39.7 \mathrm{~m}^{3} / \mathrm{d}(250 \mathrm{bbl} / \mathrm{d})$. In all cases, a 0.1 pore volume (PV) slug of unit (1.00) concentration tracer was injected; this took $42 \mathrm{~d}$. Tracer responses at the four producing wells were monitored to investigate behavior in the corresponding quarter of the five-spot. A total of $3 \mathrm{PV}$ of fluids was injected and produced during the 1250-d simulation period. 


\section{Simulation Results}

For comparison, a homogeneous base case was run. Tracer material reached the production wells at $0.25 \mathrm{PV}$ injected, $147 \mathrm{~d}$, and reached a peak concentration of 0.15 at $0.85 \mathrm{PV}$ injected, $336 \mathrm{~d}$. After the peak the tracer concentration decreased and reached its minimum measurable value after $2.8 \mathrm{PV}$ injected, $1,150 \mathrm{~d}$. A 0.57 -psi steady-state pressure difference between the injection well and the producers resulted from the uniform $520-\mathrm{mD}$ permeability. For comparison, all the block homogeneous cases were designed to maintain this $520-\mathrm{mD}$ average permeability.

\section{Single-Layer Cases of Block Homogeneous Fields}

The first block homogeneous case had a $940-\mathrm{mD}$ highpermeability zone (channel) that bisected the reservoir on the diagonal. This zone contained the injection well and two producers at the diagonal corners. The other two production wells were located in two $100-\mathrm{mD}$ low-permeability zones that incorporate the cross-diagonal corners. The two low-permeability zones represented half the PV, and the high permeability zone made up the other half of the reservoir. As expected, the two diagonal wells had earlier breakthroughs $(0.20 \mathrm{PV})$, higher peak concentrations $(0.18)$, and a shorter retention time (2.2PV) than the homogeneous base case. The cross-diagonal wells producing from the low-permeability zones have later breakthroughs ( $0.30 \mathrm{PV})$, lower peak concentrations ( 0.12$)$, and longer retention periods ( $>3 \mathrm{PV}$ ) than the base case. Tracer responses in diagonal and cross wells indicate the presence of a highpermeability channel and its orientation as a result of symmetry of response. This is further confirmed by pressure differences of $32 \mathrm{psi}$ between diagonal wells and the injector $(926 \mathrm{mD})$ and 117 psibetween cross-diagonal wells and the injector $(253 \mathrm{mD})$. The harmonic average permeability of $535 \mathrm{mD}$ is close to the $520 \mathrm{mD}$ of the base case.

The second block homogeneous case was a case in which the 940-mD high-permeability zone (channel) contained the injection well; however, the high-permeability zone ran parallel to two rows of production wells located in two $100-\mathrm{mD}$ lowpermeability zones. The volumes of the high- and lowpermeability zones were again equal. This case was completely symmetric because the channel equally divided the reservoir and was located mid way between the two rows of producers. Although the system was heterogeneous, tracer responses and bottomhole pressures for all four production wells were identical because of symmetry. The tracer responses were almost identical to the base homogeneous case: breakthrough at $0.25 \mathrm{PV}$, peak value of 0.15 , time to peak of $0.82 \mathrm{PV}$, and retention time of $3.0 \mathrm{PV}$. Although the pressure differences at wells were twice the base case (109) psi, they still implied homogeneity of permeability at $270 \mathrm{mD}$.

The third block homogeneous case had the $940-\mathrm{mD}$ highpermeability channel located to one side of the reservoir. Two producers were located in it, and two producers were located in the $100-\mathrm{mD}$ low-permeability zone. The injector was located at the boundary between the two zones. At the wells located in the high-permeability zone, tracer first arrived at $0.22 \mathrm{PV}$ and reached a peak concentration of 0.23 at $0.78 \mathrm{PV}$ with a retention time slightly less than that of the base-case wells. For the wells producing from the low-permeability zone, tracer was first produced at $0.28 \mathrm{PV}$ and reached a peak concentration of 0.12 at $1.00 \mathrm{PV}$ with a retention time greater than the $3.0 \mathrm{PV}$ of the simulation period. The steady-state pressure differences between the injection well and the producers ( $34 \mathrm{psi}$ for the highpermeability zone and $126 \mathrm{psi}$ ) gave steady-state permeability estimates of $871 \mathrm{mD}$ and $235 \mathrm{mD}$ respectively.

From the four single-layer simulation runs, the following observations can be made. Tracer concentration data can identify the presence of block permeability heterogeneity if the wells are favorably located. The tracer data do not contain sufficient unique information to allow extraction of permeability values. If pressure data are also available, the data can confirm the existence of the heterogeneities, and estimates of between well permeabilities can be made. A heterogeneous reservoircan yield data that imply homogeneous properties if symmetry is maintained by the well field. Apparently, tracer tests may be useful to confirm a particular reservoir model but are not likely to contain a rich enough source of data to develop a unique reservoir model.

\section{Two-Layer Cases with Equal Storage Capacity}

Nine two-layer block homogeneous cases with equal storage capacity layers were run to represent connected systems of multiple-channel sand bodies. The orientations of the channels were modeled after those of the single-layer cases. In all cases the volume-averaged permeability was $520 \mathrm{mD}$. The purpose of these cases was to examine the observability of tracer and pressure responses in layered systems where the layers and channels had different permeability contrasts.

Three two-layer diagonal systems were studied. Permeability contrasts between the high- and low-permeability zones of the system were $9.4,4.2$, and 2.5 . The tracer responses at the wells located in the high-permeability diagonal channels had early breakthroughs with high peak values compared with the off-diagonal wells located in the low-permeability zones. In general, all wells had long retention periods compared with tracer responses for single-layer diagonal cases. The long retention period results from crossflow between the layers as the result of permeability differences. The long tracer retention can be used to identify the presence of crossflow and permeability contrasts. Unfortunately, the steady-state bottomhole pressures for all three systems were identical, and which implies that little information about layered permeability contrasts can be gleaned from pressure data.

Three two-layer symmetric systems with three different permeability contrasts werestudied. The steadystate bottomhole pressures and tracer responses at all four producers were identical for the three cases because of the symmetry of the systems. There were minor differences in values of the injection and production well pressures because of the more complex heterogeneities; however the permeability contrast between layers 
could not be identified. Although the tracer responses were identical for all cases, the early breakthrough times, times to peak tracer concentrations, and long retention times compared with the homogeneous case identify the presence of the layered heterogeneities of the symmetric systems.

Three two-layer channel systems with different permeability contrasts were studied. Just as in the single-layer case, it was easy to distinguish the channel heterogeneity from a homogenous field from steady-state bottomhole pressures and tracer responses at wells. The tracer responses at the production wells located in the high-permeability channels had early breakthroughs, high peak concentrations, short times to peak values, and short retention periods, whereas the production wells located in the low-permeability zones are later, lower, and longer compared with the homogeneous case. The steady-state bottomhole pressure differences between the injection and production wells also reflect this block permeability pattern.

The nine two-layer cases of block homogeneous fields with equal storage capacities in each layer suggest that tracer responses can identify the presence of layered heterogeneity in terms of high peak values and/or timing of breakthrough and retention periods compared with homogeneous systems. This is probably because the fraction of tracer injected into each layer is proportional to the permeability of that layer at the injection well. As a result, the bulk of the tracer is rapidly transported through the high-permeability layers with transport through the low-permeability zones causing the long retention periods in the effluent curves.

\section{Two-Layer Cases with Equal Permeability-Thickness Products}

Six cases of two-layer, block homogeneous fields with equal permeability thickness products (conductivities) for each layer were studied. These cases were designed to represent formations where a thin high-permeability channel is located within a relatively thicker and lower permeability background deposit. In the six cases, each layer had different values of permeability and thickness, but each layer had the same product of 13,000 (mD-ft). This results in equal amounts of tracer entering each layer at the injection well. The primary purpose of these six cases was to investigate the effects of storage capacity on tracer responses and to examine the observability of tracer and pressure responses.

One diagonal heterogeneous case was run with the permeabilities of the 3.28-m (10-ft) lower layer four times as large as those of the 13.1-m (40-ft) upper layer. Interestingly, the tracer responses at all four wells clearly had two peaks. The first peak with a short breakthrough time corresponded to tracer transport through the high-permeability thin lower layer, and the second relatively low peak resulted from transport through the thicker lower permeability layer. The existence of multiple peaks helps identify the existence of multiple flow channels. The tracer responses at the wells located in the channel had earlier breakthroughs, higher peak concentrations, and shorter retention periods than the tracer responses at the wells located outside the channel and indicated the existence and orientation of the high-permeability channel. This was confirmed by the steady-state bottomhole pressure differences between the injection and production wells.

Two symmetric cases were run with permeability contrasts of four and three between the thin high lower permeability layer and the thicker low-permeability upper layer. The tracer responses and steady-state pressure drops were identical at all wells for each case because of symmetry. They were slightly different from case to case. Just as with earlier symmetric cases, pressure differences could not identify the permeability contrast between layers, and tracer responses could not be used to identify the existence of the high-permeability channel. The tracer responses did have second peaks, however, and did identify the existence of two distinct layers. Timing of the peaks depended on the permeability contrast between layers.

Three channel cases were run with permeability contrasts between layers and between the two zones in the same layer. The tracer production curves for all wells clearly had two concentration peaks reflecting transport through the two different permeability layers. The tracer concentration curves and bottomhole pressures at production wells located in the channel zones compared with those from the production wells located outside the channel identified the existence and orientation of the highpermeability channel zones.

\section{Sweep Efficiency}

The primary purpose of this study is to develop an efficient numerical simulator with the use of the cubature method and to compare results from it with the finite-difference method for calculation of sweep efficiency in large, heterogeneous, and anisotropic reservoirs. Simple cases and a finite-difference method of the second and fourth orders were used as a starting point. This provides base cases for calibrating the application of the cubature method. During this quarter the 3-D model was formulated and programming began. This programming effort will carry into the next quarter. In this quarter, the second- and fourth-order finite-difference schemes were applied for comparison of the accuracy of calculations. A sixth-order finitedifference solution is being conducted. Following this work, the cubature scheme will be programmed and compared with the second, fourth, and sixth finite-difference solutions.

In modeling equations, the following assumptions were made: zero capillary pressure, zero density differences between phases, and anisotropic and homogeneous permeability. The rock matrix and fluids are compressible. These assumptions were made to reduce the complexity of the model for comparative studies.

A quarter of a five-spot pattern was taken as the base to calculate pressure and water saturation distribution and hence the sweep efficiency with an implicit pressure, explicit saturation method. The bottomhole pressures of the injection and production wells were fixed at prescribed values.

Numerical solution of the pressure equation is accomplished by the Gauss-Seidel iteration method, whereas the saturations are calculated explicitly. This scheme will be particularly 
advantageous when the simplifying assumptions are removed for more general applications. The second-order space formulation leads to the usual five-point scheme and uses a first-order time discretization. A fourth-order space formulation was programmed according to Liu, Liu, and McCormick ${ }^{2}$ which uses a second-order time discretization.

The programming of the sixth-orderfinite-difference scheme is continuing. This scheme is somewhat comparable with the cubature scheme. Therefore it is a necessary step for comparison of the finite-difference and cubature methods on the same basis as the grid system. Following this work the cubature scheme will be formulated and the comparative work will be conducted.

Because both the finite-difference and cubature methods are numerical schemes, their accuracy can be best evaluated by comparison with an analytical solution of a model problem; however, analytical solutions for two-phase flow problems only exist for simplified cases of linear flow. These solutions can be applied for radial and spherical coordinates upon transformation. Work is under way to generate the analytical test solutions for radial and spherical coordinates. For test problems, a square domain of the radial immiscible displacement problem and a cubical domain of the spherical immiscible displacement problem with boundary conditions prescribed according to the analytical solutions will be considered.

\section{References}

1. J. D. Doyle, D. J. O'Meara, Jr., and E. J. Witterholt, The Gypsy Field Research Program in Integrated Reservoir Characterization, paper SPE 24710 presented at the 67 th Annual Meeting of the Society of Petroleum Engineers Technical Conference, Washington, D.C., October, 4-7, 1992.

2. C.Liu and Z. Liu, High Order Finite Difference and Multigrid Method for Spatially Evolving Instability in a Planar Channel, J. Comput. Phys., 106: 92 (1993).
RESEARCH PROGRAM ON FRACTURED

PETROLEUM RESERVOIRS

\section{Contract No. DE-FG22-93BC14875}

\author{
Reservoir Engineering Research Institute \\ Palo Alto, Calif.
}

Contract Date: Sept. 30, 1993

Anticipated Completion: Sept. 29, 1996

Government Award: $\$ 447,000$

Principal Investigator:

Abbas Firoozabadi

Project Manager:
Robert Lemmon
Bartlesville Project Office

Reporting Period: Jan. 1-Mar. 31, 1995

\section{Objective}

The main objective of this project is to develop a full understanding of the role of diffusive, capillary, gravity, and viscous forces in the flow of fluids in fractured porous media. The plan is to conduct a comprehensive experimental and theoretical research program to better understand the basic mechanisms of oil recovery and recovery enhancement of fractured petroleum reservoirs.

\section{Summary of Technical Progress}

Work this quarter was focused on two projects, solution-gas drive in light and heavy oil reserves and water injection in fractured/layered porous media.

\section{Solution-Gas Drive in Light and Heavy Oils}

So that the efficiency of solution-gas drive for both heavy and light oils could be determined, three sets of tests (two tests for model light oil, two for heavy oil, and two for light oil) were conducted. For these tests, a special visual coreholder was designed to visually observe the appearance and growth of gas bubbles and gas flow.

A schematic of the experimental apparatus is shown in Fig. 1. The setup, with slight differences, was used for the three sets of tests. The main components of the apparatus include the visual coreholder, a high-pressure chromatography pump, pressure transducers, a system for providing a constant temperature of $77^{\circ} \mathrm{F}\left( \pm 0.3^{\circ} \mathrm{F}\right)$, and a video recording system.

The experiments consisted of starting with the core system saturated with the test fluid at a pressure above the bubble-point pressure, usually in the neighborhood of $650 \mathrm{psia}$. The pump was 


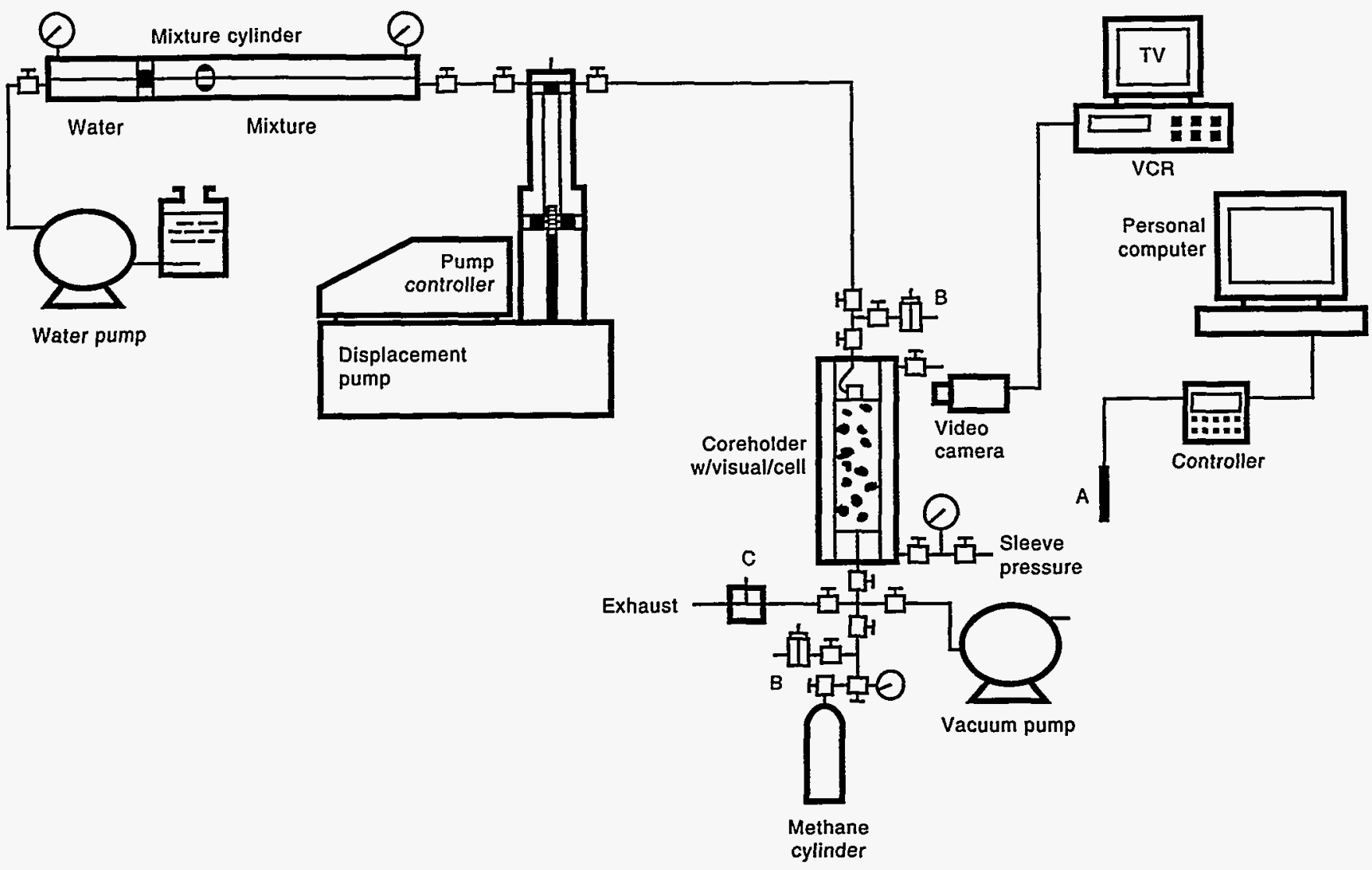

Fig. 1 Apparatus diagram for critical gas experiments. A, temperature sensor. B, pressure transducer. C, back-pressure regulator. Note: Coreholder is located in insulated box.

then placed in the constant-volume expansion mode. A computer interface system was used to $\log$ the pressure measured at either end of the core with transducers.

\section{Model Light Oil}

A mixture of $C_{l} / C_{3}-15.125 \mathrm{~mol} \% C_{1}$ and $84.875 \mathrm{~mol} \%$ $\mathrm{C}_{3}$-was used in the following tests. The calculated bubblepoint pressure of the mixture at $77^{\circ} \mathrm{F}$ was 478 psia (with the Peng-Robinson equation of state). ${ }^{1}$ The surface tension and the viscosity at the bubble point were 4.5 dyne/cm (Ref. 2), and $0.08 \mathrm{cP}$ (Ref. 3), respectively.

In test 1 the $C_{1} / C_{3}$ mixture at an initial pressure of 650 psia was expanded at a rate of $0.3 \mathrm{~cm}^{3} / \mathrm{h}$. The expansion was carried out by fluid extraction from the bottom. At the top of the core, an open space of $10 \mathrm{~cm}^{3}$ was provided to be filled by the gas from the core. About $4 \mathrm{~cm}^{3}$ of this space (the cap) could be viewed.

Figure 2 shows pressure-volume expansion data for this test. As shown in the figure in the single-phase liquid state the pressure declines rapidly to an expanded volume of $1.25 \mathrm{~cm}^{3}$ (to $472 \mathrm{psia}$ ). Then the pressure rises slowly, which indicates the evolution of the gas phase. After the volume has expanded to $2.8 \mathrm{~cm}^{3}$, the pressure decreases with a slope of about $-1.6 \mathrm{psi} / \mathrm{cm}^{3}$
For this test, on the basis of the observation of the first continuous gas flow from the top face of the core (at volume expansion of $2.59 \mathrm{~cm}^{3}$ ), the critical gas saturation was estimated to be around $1 \%$ of PV. The displacement efficiency at the end of the test at $14 \mathrm{~cm}^{3}$ expansion was, however, around $2 \%$. A pressure increase of 2.5 psia was measured at the termination of the test, which indicates a supersaturation of $2.5 \mathrm{psia}$. The pressure increase occurred in a period of $5 \mathrm{~h}$.

The expansion rate $\left(0.06 \mathrm{~cm}^{3} / \mathrm{h}\right)$ was five times less than in the first test. But similar to test 1 , the withdrawal was from the bottom face of the core. The fluid mixture in the core was initially at $650 \mathrm{psia}$, and expansion into the pump started from this pressure. Figure 2 shows the pressure vs. volume expansion from a pressure of around $595 \mathrm{psia}$. The same figure also shows the pressure-expansion data of test 1 . Before gas evolution the expansion behavior for these tests was nearly identical. Around an expansion volume of $1.2 \mathrm{~cm}^{3}$, the slope of the pressure-expansion volume plot changes. The pressure has a slight increasing trend from an expansion of 1.2 to $2.8 \mathrm{~cm}^{3}$. Thereafter it reduces linearly with a slope of about $-1.1 \mathrm{psi} / \mathrm{cm}^{3}$. The critical supersaturation pressure (the pressure at which gas evolves from the supersaturated liquid) is around $475 \mathrm{psia}$, which is slightly higher than the critical supersaturation pressure for test 1 . The maximum superstation for this test is therefore around 3 psi. 


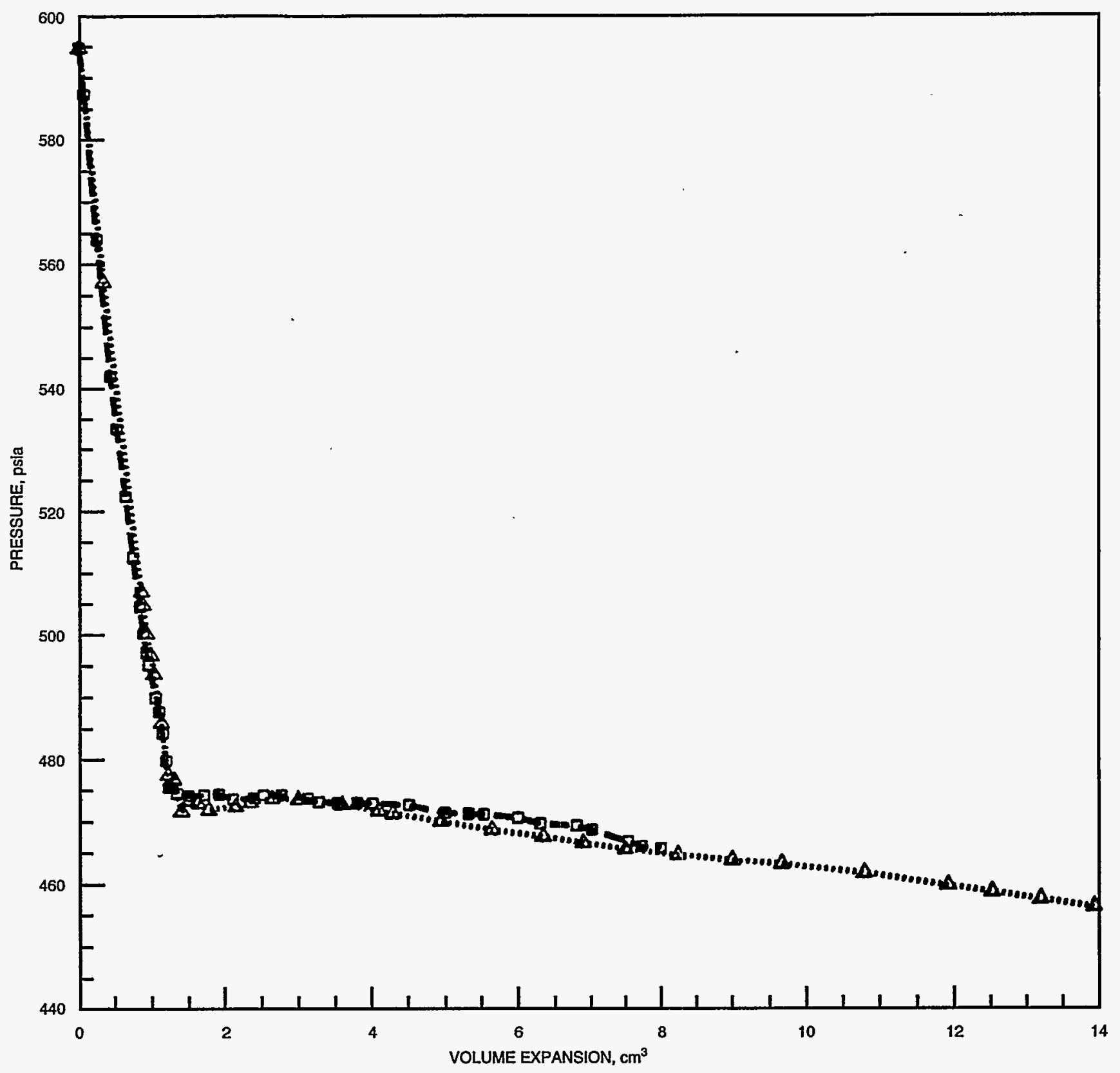

Fig. 2 Pressure-volume expansion data for tests 1 and $2 . \cdots \cdots \Delta \cdots \cdots$, test $1 .--\square--$, test 2.

Based on the basis of the observation of the first flow of gas, the critical gas saturation for test 2 is estimated to be around $0.5 \%$. The displacementefficiency of solution-gas drives seems to be very low for this test-around $1 \%$ of PV at the end. A very high gas mobility precludes high recovery efficiency.

\section{Heavy Oil}

A heavy oil with a bubble-point pressure of 445 psia at a temperature of $76^{\circ} \mathrm{F}$ was used for the following tests. The oil was prepared by mixing a stock tank oil (STO) of $11^{\circ} \mathrm{API}$ gravity and methane with a ratio of $10 \mathrm{~cm}^{3}$ of methane to $1 \mathrm{~cm}^{3}$ of STO at standard conditions of 14.69 pressure and $60^{\circ} \mathrm{F}$. The viscosity of the saturated oil at $57^{\circ} \mathrm{F}$ was $17,000 \mathrm{cP}$. The compressibility of the live oil above the bubble-point pressure was $1.8 \times 10^{-5} \mathrm{psia}^{-1}$. The compressibility of the total rock fluid system in the single-phase state at $76^{\circ} \mathrm{F}$ was $2.5 \times 10^{-5} \mathrm{psia}^{-1}$. The saturation of the core with the heavy oil was a challenge. It took more than 2 months to saturate the core.

In the first test on heavy oil (test 3$)$, the expansion $\left(0.06 \mathrm{~cm}^{3} / \mathrm{h}\right.$ expansion rate) was carried out from an initial pressure of $645 \mathrm{psia}$. The production was from the bottom end of the core. On the top the volume of the cap (open space) was about $4 \mathrm{~cm}^{3}$. This whole volume could be viewed.

Figure 3 shows the measured pressure-volume expansion data. The two data sets correspond to the output of the two pressure transducers. Both upper and lower pressures continued 


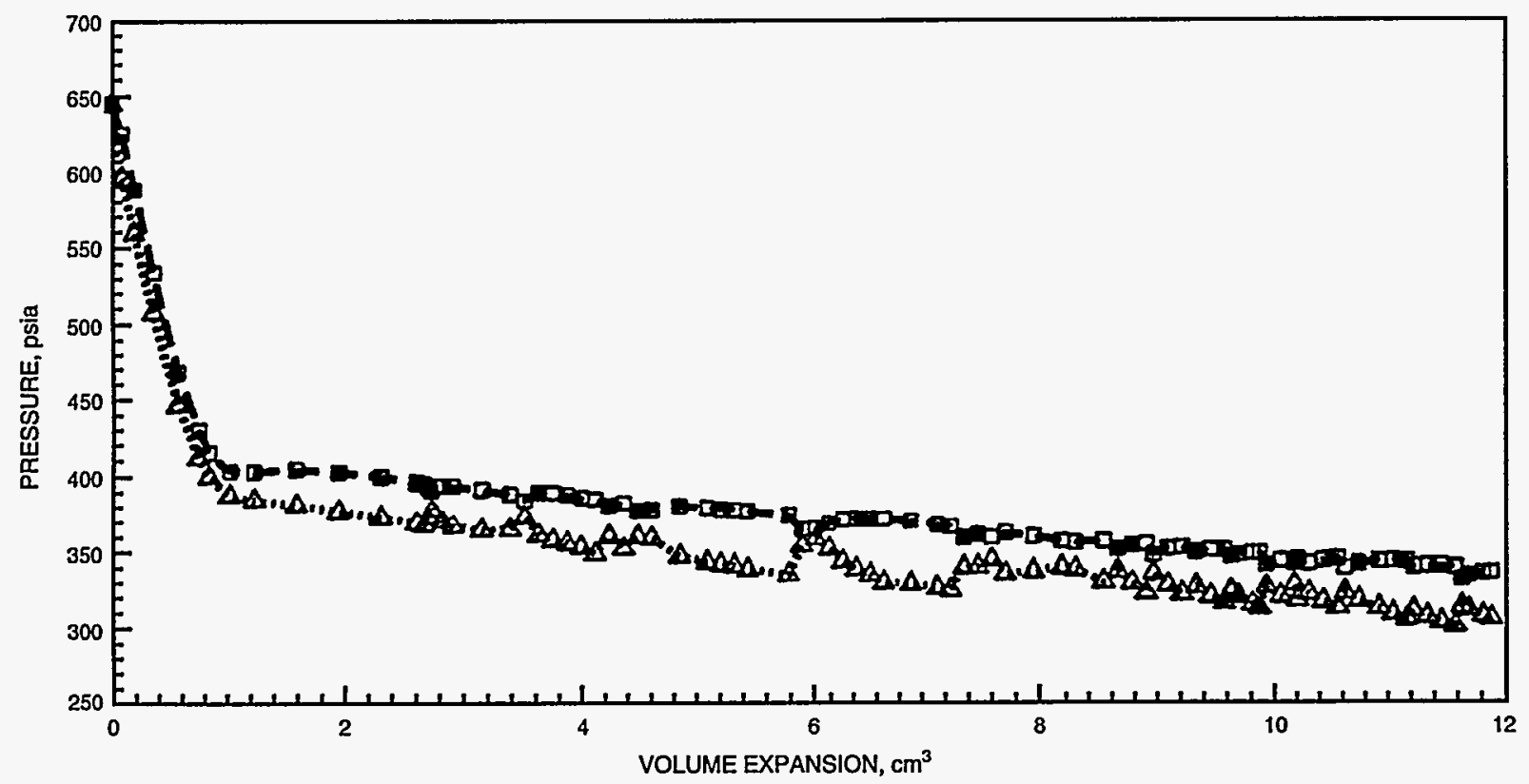

Fig. 3 Pressure-volume expansion data for test $3, \cdots \cdots \Delta \cdots$, , expansion side (bottom). $--\square--$, closed side (top)

to decrease to pressures of 405 and 385 psia at a volume expansion of $1 \mathrm{~cm}^{3}$. At this point, both curves flatten out, which indicates the evolution of the gas phase. The supersaturations at an expansion of $1 \mathrm{~cm}^{3}$ are 40 and $60 \mathrm{psi}$ for the top and bottom sides. Note that there is a substantial difference between the upper and lower pressures. The high pressure drop could be partly attributed to a narrow outlet at the bottom face of the core (diameter, $3 \mathrm{~mm}$ ).

The main finding from this test is the very high recovery of about $10 \%$ heavy oil from the solution-gas drive processes to a pressure of some $320 \mathrm{psia}$. This finding confirms that solutiongas drive can be an important recovery process for some heavy oil reservoirs.

In test $4\left(0.06-\mathrm{cm}^{3} / \mathrm{h}\right.$ expansion rate) the direction of flow was reversed; the expansion pump was connected to the top of the coreholder, rather than to the bottom, to measure the flow of the gas from the core in the cap at the top. Figure 4 shows the measured pressure-volume expansion data. During the initial stage of expansion in the single-phase liquid state, the pressures on both sides of the core were a few psi different. Both pressures

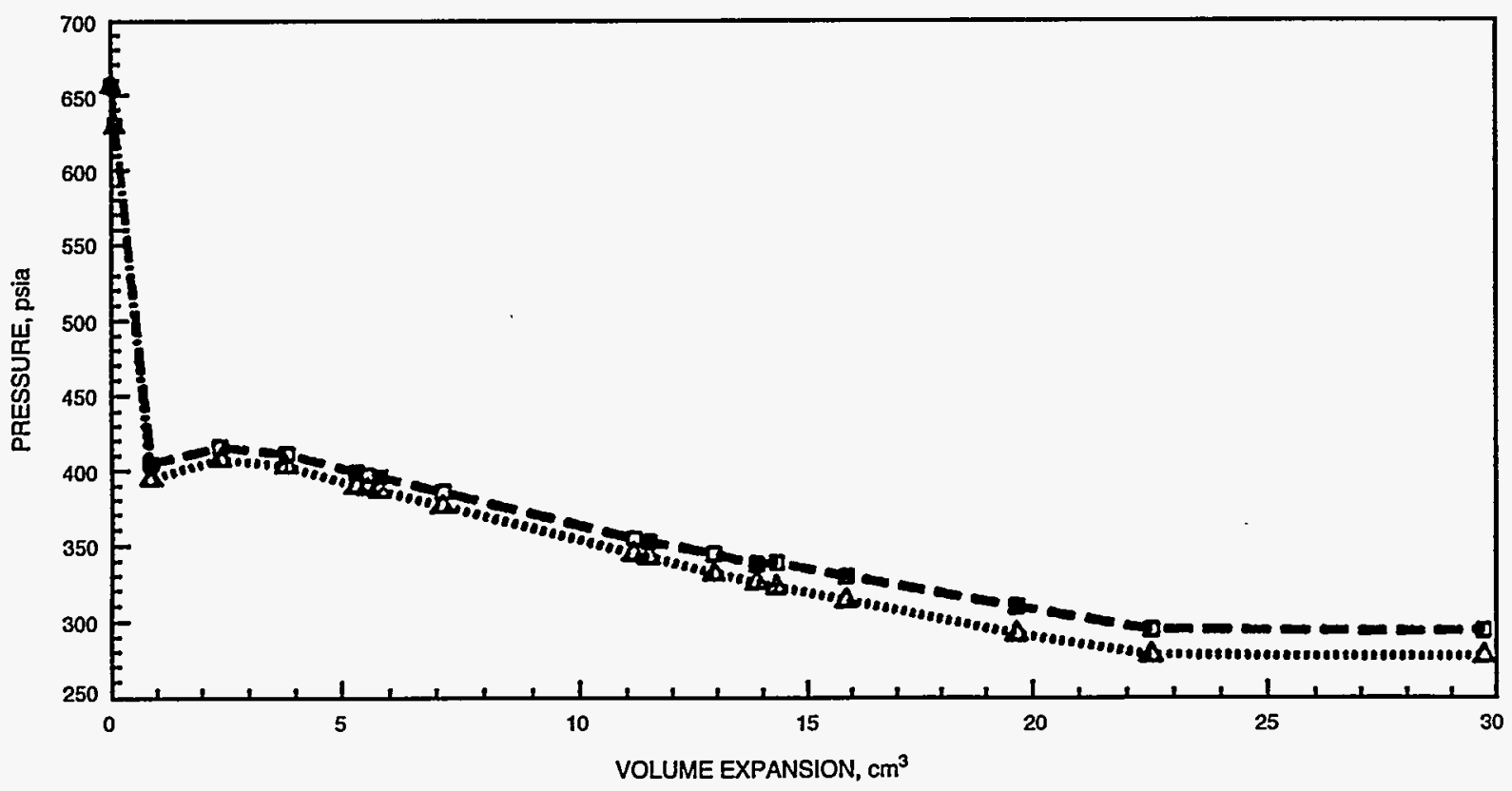

Fig. 4 Pressure-volume expansion data for test $4 . \cdots, \Delta \cdots$, , expansion side (top). $--\square--$, closed side (bottom). 
continued to decrease to 404 and 395 psia at an expansion of $0.86 \mathrm{~cm}^{3}$. This point corresponds to a local minimum for both pressures, which indicates evolution of the gas phase. The critical supersaturation is therefore 40 to $50 \mathrm{psi}$. The data plotted in Fig. 4 are from manual readings and do not include data points where pressure fluctuations similar to those in Fig. 3 are observed. But, as Fig. 4 shows, the difference between the two pressures increases with volume expansion. The gas and oil production for this test is shown in Table 1 .

The critical gas saturation for this test is estimated to be around 2.5\% (see Fig. 5), but oil mobility seems to be significant even after gas flow. A comparison of tests 3 and 4 reveals much higher recovery from solution-gas drive when flow occurs from the bottom. But, even for test 4 , where the production was from the top, about $6.5 \%$ heavy oil recovery was achieved by the end of the test.

\section{Light Oil}

For the following tests, a $35^{\circ} \mathrm{API}$ gravity oil from the North Sea was mixed with pure methane; $16.2 \mathrm{~cm}^{3}$ of methane was mixed with $1 \mathrm{~cm}^{3}$ of STO at standard conditions of $14.69 \mathrm{psia}$ and $60^{\circ} \mathrm{F}$. The bubble-point pressure of the mixture at $77^{\circ} \mathrm{F}$ is around $585 \mathrm{psia}$. The surface tension at the bubble point was estimated to be around 15 dyne/cm (Ref. 4). Viscosity at $77^{\circ} \mathrm{F}$ was not available, but the viscosity of the saturated oil at 585 psiaand $187^{\circ} \mathrm{F}$ was around $1 \mathrm{cP}$. The measured compressibility of the light oil used in the following tests was $10^{-5} \mathrm{psia}^{-1}$ (at $77^{\circ} \mathrm{F}$ in the pressure interval of 625 to $700 \mathrm{psia}$ ). The measured compressibility of the total coreholder system with single-phase oil was around $2.5 \times 10-5 \mathrm{psia}^{-1}$.

In test $5\left(0.3-\mathrm{cm}^{3} / \mathrm{h}\right.$ expansion rate) as well as test 6 , the system pressure was initially $690 \mathrm{psia}$, and the expansion from

TABLE 1

Gas and Oil Production Data for Test 4

\begin{tabular}{ccccccc}
\hline $\begin{array}{c}\text { Time } \\
\text { h }\end{array}$ & $\begin{array}{c}\text { Expansion, } \\
\text { cm }^{3}\end{array}$ & $\begin{array}{c}\text { Oil in } \\
\text { pump, } \\
\mathbf{c m}^{\mathbf{3}}\end{array}$ & $\begin{array}{c}\text { Gas in } \\
\text { pump, } \\
\mathbf{c m}^{\mathbf{3}}\end{array}$ & $\begin{array}{c}\text { Oil from } \\
\text { core, } \\
\mathbf{c m}^{3}\end{array}$ & $\begin{array}{c}\text { Closed side } \\
\text { pressure, } \\
\text { psia }\end{array}$ & $\begin{array}{c}\text { Expansion side } \\
\text { pressure, } \\
\text { psia }\end{array}$ \\
\hline 187.7 & 11.26 & 8.35 & 2.91 & 4.95 & 356 & 346 \\
238.3 & 14.30 & 8.77 & 5.53 & 5.37 & 340 & 324 \\
327.8 & 19.67 & 9.43 & 10.24 & 6.03 & 311 & 293 \\
375.5 & 22.53 & 9.50 & 13.03 & 6.10 & 296 & 269 \\
495.3 & 29.72 & 10.05 & 19.67 & 6.65 & 269 & 248 \\
\hline
\end{tabular}

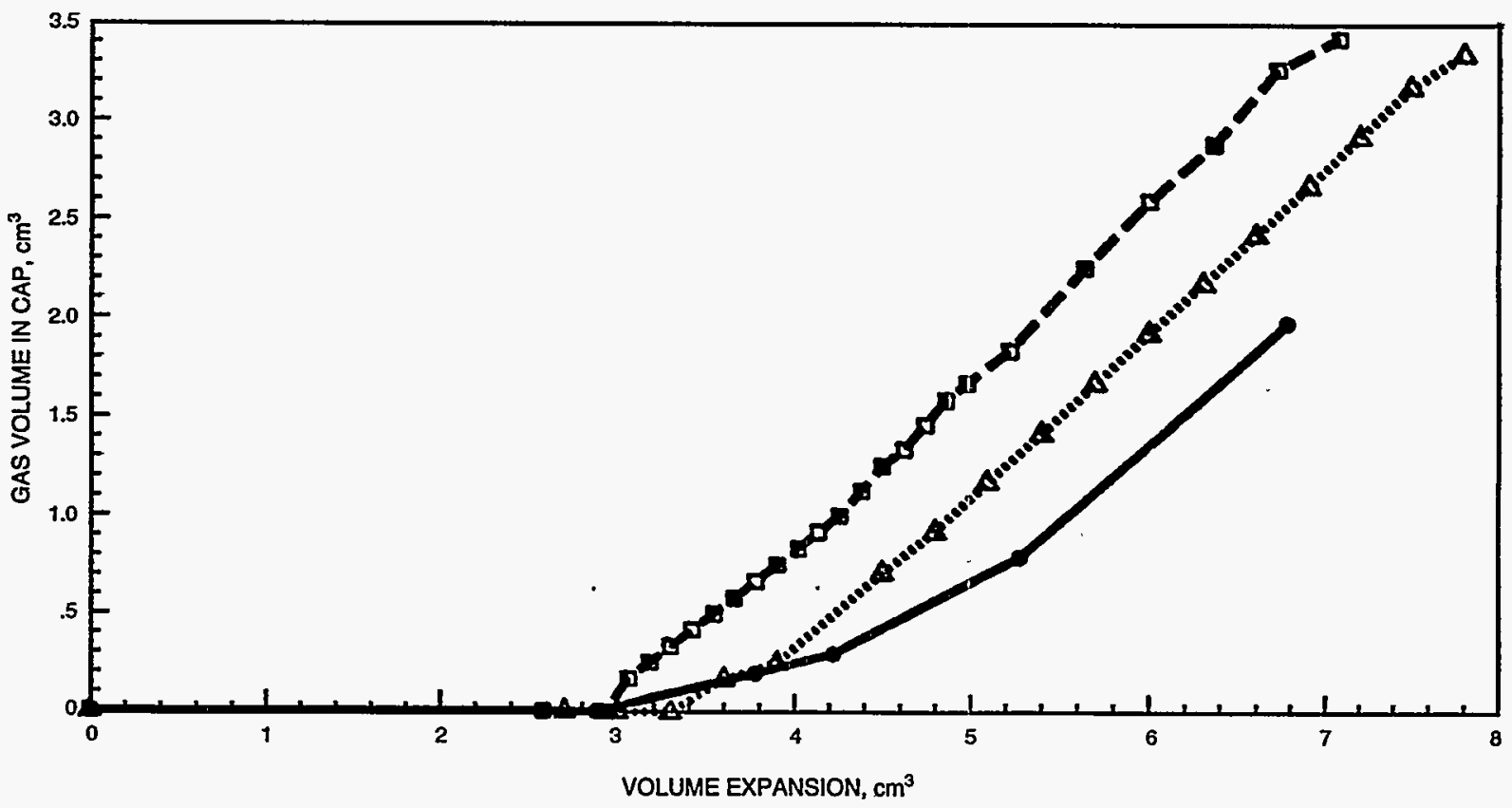

Fig. 5 Gas production from the core into the top cap. - - , test $4 . \cdots \cdots \Delta \cdots \cdots$, test $5 .--\square--$, test 6. 
the top started from this pressure. Figure 6 shows the pressure-volume expansion data. The same figure also shows the data from the expansion of $120 \mathrm{~cm}^{3}$ of oil in the pump isolated from the core system. Because of compressibilities, test 5 and pump results in the single liquid phase state (from 690 to about 500 psia expansion) differ by a small volume. The critical supersaturation pressure for the oil in the pump (i.e, open space) was slightly less than the corresponding value of test 5 . The growth of gas phase was, however, faster in the pump; after gas evolution, supersaturation decreased very fast in the pump.

The supersaturation test 5 and the pump test was measured at the end. For the pump, the pressure increased about $6 \mathrm{psi}$ after halting expansion. For test 5 , the supersaturation was $8 \mathrm{psi}$. There was practically no increase in pressure after $1 \mathrm{~d}$.

Figure 7 shows the pressure-volume expansion $\left(0.6-\mathrm{cm}^{3} / \mathrm{h}\right.$ expansion rate) for test 6 as well as that for test 5 . At about

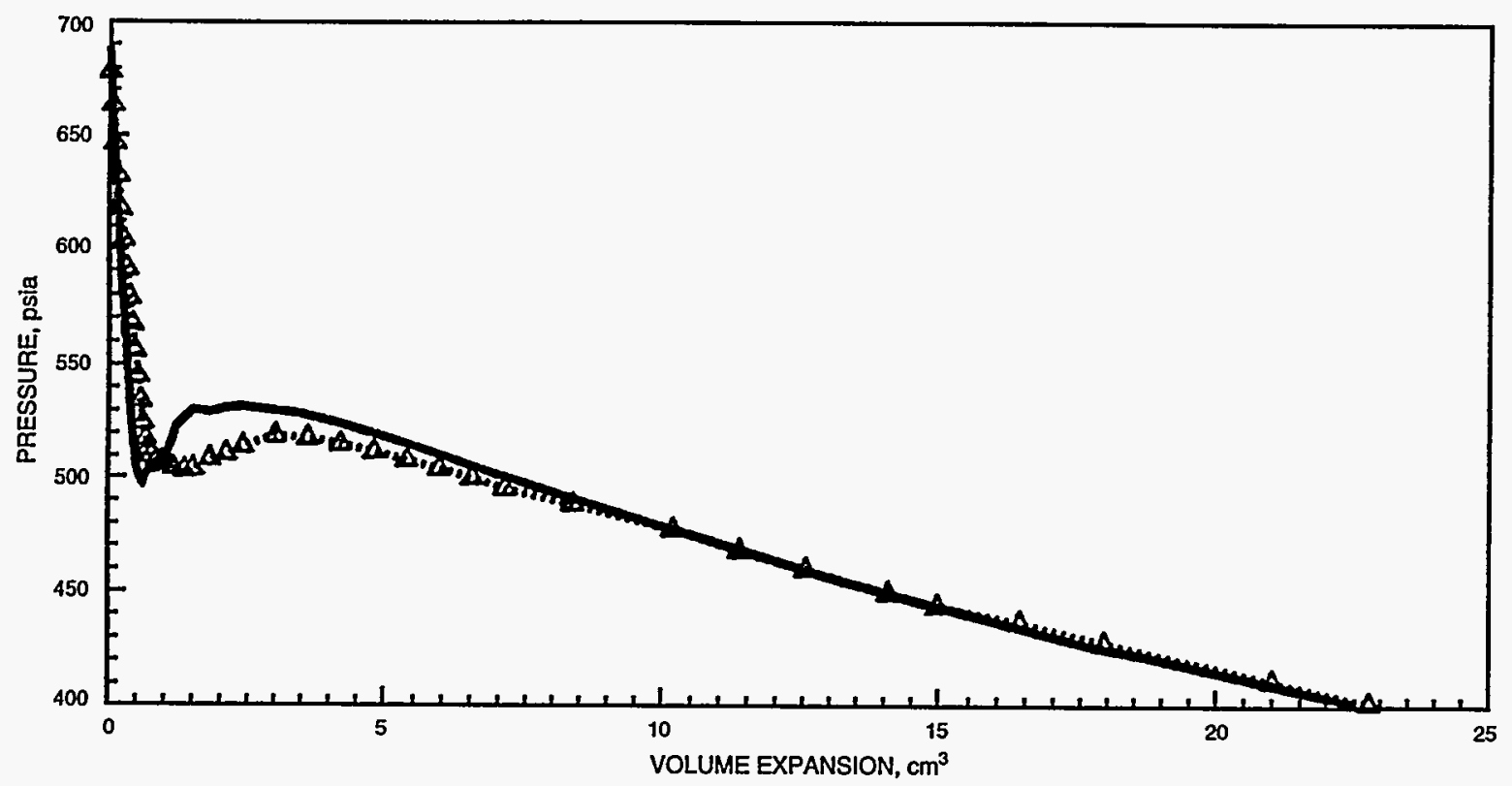

Fig. 6 Pressure-volume expansion for test 5 and the isolated pump. $\cdots \cdots \Delta \cdots \cdots$, test $5 . \longrightarrow$, pump.

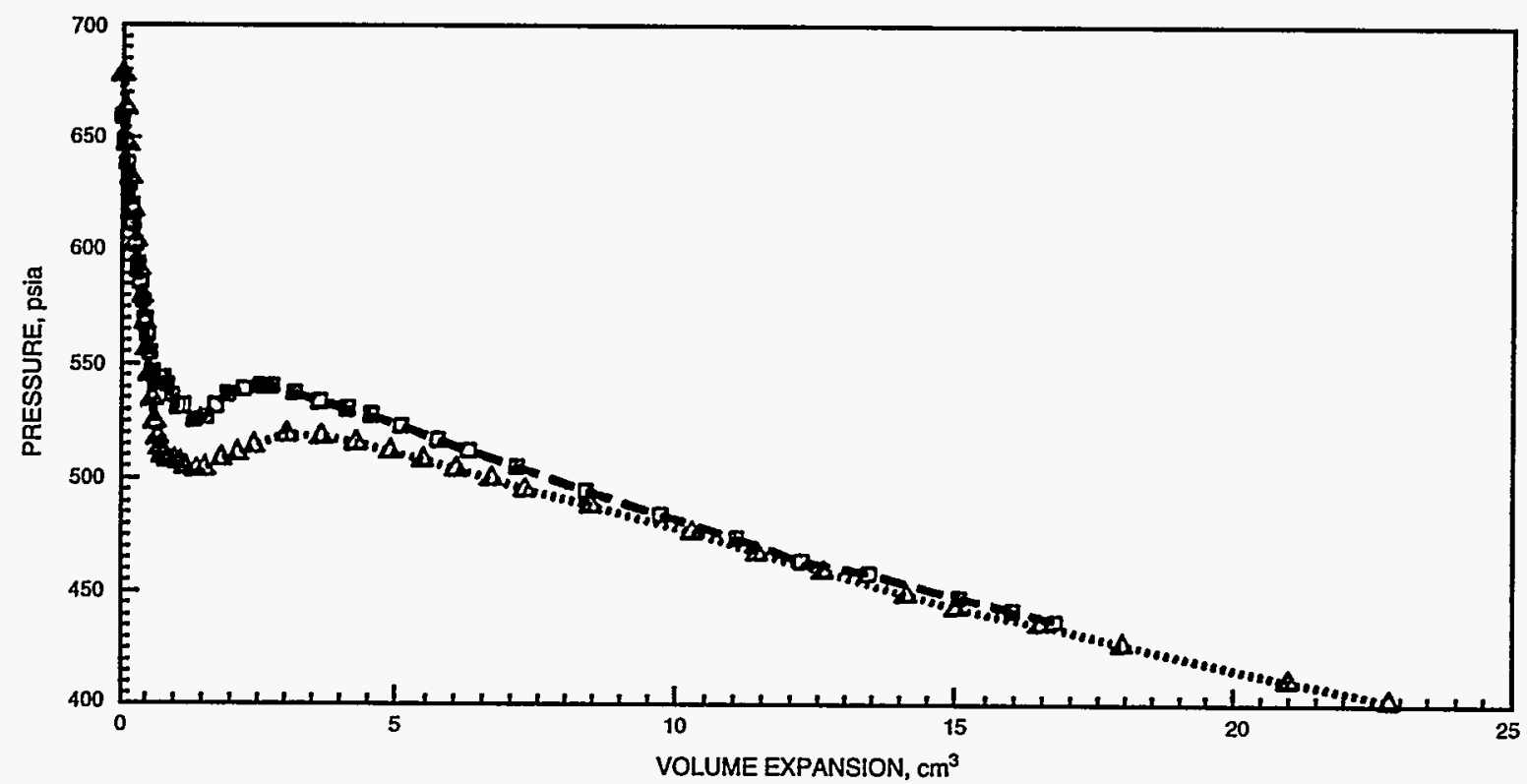

Fig. 7 Pressure-volume expansion for tests 5 and $6, \cdots \cdots \Delta \cdots \cdots$, test $5 .--\square--$, test 6. 
$0.5-\mathrm{cm}^{3}$ expansion, the pressure decline rate decreased considerably, but no gas bubbles were visible on the outer surface of the core to a volume expansion of about $0.9 \mathrm{~cm}^{3}$. At this expansion some 7 to 10 gas bubbles were visible on the core outer surface. From then on these bubbles grew. The growth of gas bubbles was similar to test 5 . The only difference is that the number of bubbles in test 6 is less than that in test 5 . As Fig. 7 reveals, a major difference between test 5 and 6 is the high supersaturation of the latter test at the early stages of gas bubble growth.

At the end of the test, the supersaturation was measured. Over a period of $1 \mathrm{~d}$, the pressure increased from 438 to 442 psia, which gives a supersaturation of about 4 psi for the end of expansion.

\section{Conclusions}

An important issue in the interpretation of the experiments is whether the number of bubbles visible on the surface of the core represents the bubble density within the core. On the basis of the following reasoning, the number of bubbles on the core surface and within the core are believed to be related. In the design of the coreholder, the core was tightly sealed with a heat-shrunken Teflon sleeve, and the overburden pressure was kept at a pressure of at least 200 psi higher than the pressure inside the core. The permeability of the core within the setup and outside was the same. In addition, the Teflon does not wet the liquid, and nucleation-active sites are not believed to be initiated from the Teflon surface.

The most important conclusion of the work is that solutiongas drive for a heavy oil in porous media can be a very efficient process. The bubble density (number of bubbles per unit area or volume) is very high. Because of high oil viscosity, the pattern of bubble growth may be such that gas mobility is low; consequently oil mobility may be appreciable. Recovery of $10 \%$ of heavy oil with a bubble-point pressure of 445 psia to a pressure of about 320 psia from solution-gas drive is an indication of high recovery efficiency. From visual observations, all that was observed was high bubble density and a pattern of gas bubble growth, which were different for a light oil.

Other major conclusions drawn from this work are:

- Critical gas saturation is a measurable quantity.

- The number of nucleated bubbles is a function of the rate of pressure decline; the higher the rate of pressure decline, the higher the number of bubbles.

- The measured critical saturation for the fluids and rock of this work is in the range of 0.5 to $3 \%$.

- The nucleation in porous media is an instantaneous nucleation process.

\section{Water Injection in Fractured/ Layered Porous Media}

This report provides an account of the first effort toward the understanding of water injection in fractured and layered reservoirs. Two tests were performed. The fractured porous media used for the experimental investigation consisted of a stack of
12 Berea slabs, three layers of four blocks each. Figure 8 shows the matrix slabs and the configuration of the fractured porous media. A diagram of the apparatus is shown in Fig. 9.

The core system was evacuated at approximately $100 \mathrm{mTorr}$ for $1 \mathrm{wk}$ before it was saturated with normal decane $\left(\mathrm{nC}_{10}\right)$. The pore volume of the system measured via volume of $\mathrm{nC}_{10}$ used for saturation is estimated to be $8800 \mathrm{~cm}^{3}$. The brine used for displacement consisted of $1 \mathrm{wt} \%$ sodium chloride $(\mathrm{NaCl})$ and distilled water.

\section{Results and Observations}

The only difference between the two tests was the injection rate.

In the first test the injection rate was approximately $10 \mathrm{~cm}^{3} / \mathrm{h}$. - A plot of the volume of $\mathrm{nC}_{10}$ produced vs. the volume of brine injected is shown in Fig. 10. As shown in the plot, the production

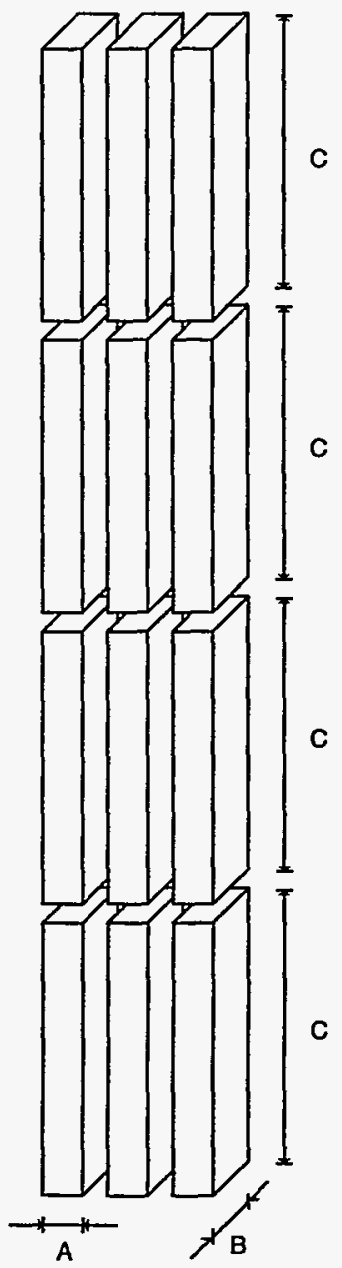

Fig. 8 Matrix slab arrangement used for water injection. A, $4.89 \mathrm{~cm}$;

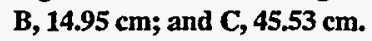




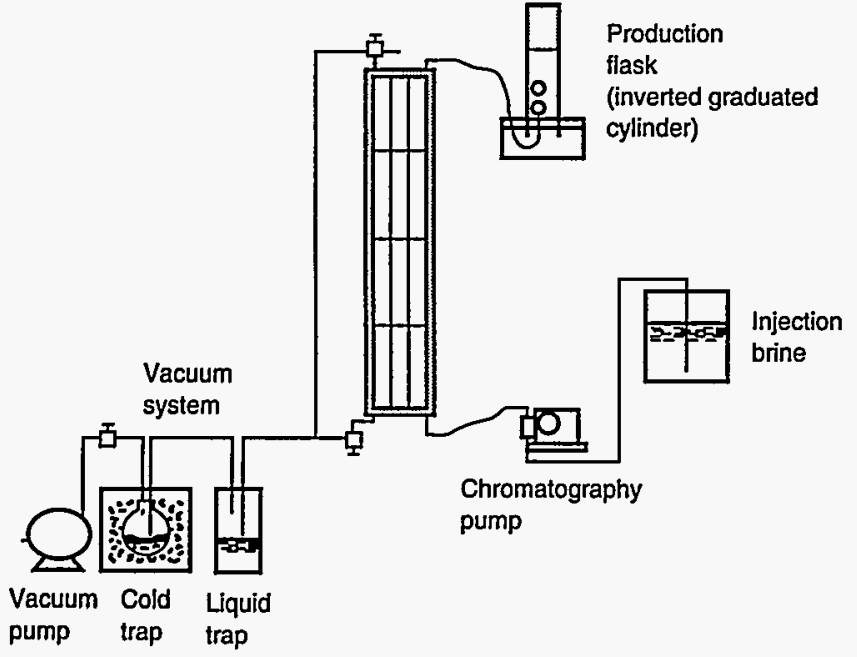

Fig. 9 Schematic of apparatus.

of oil follows the injection rate up to a volume of about $4200 \mathrm{~cm}^{3}$ (about $28 \mathrm{~h}$ ), where water and oil are seen in the production line. This is when water breakthrough occurs. Therefore the recovery at breakthrough is around $48 \%$. A transition period occurs for the next $20 \mathrm{~h}$, when the oil production rate continues to decrease to a steady-state rate of $6 \mathrm{~cm}^{3} / \mathrm{h}$. The cumulative oil production at this time is about $5,000 \mathrm{~cm}^{3}$ (or $57 \% \mathrm{PV}$ ). At an injection of $15,000 \mathrm{~cm}^{3}$ (about 1.7PV) water, the injection was curtailed and imbibition was allowed to proceed for about $3 \mathrm{~d}$. The water injection was then resumed. A brief period of pure $\mathrm{nC}_{10}$ produc- tion (about $30 \mathrm{~cm}^{3}$ ) was observed, after which the system returned to a very slow production rate.

In the second test the injection rate was about $198 \mathrm{~cm}^{3} / \mathrm{h}$. The volume of $\mathrm{nC}_{10}$ produced vs. the volume of brine injected is also shown in Fig. 10. As indicated in the figure, the results from the two tests are similar. In the second test the production of oil follows the injection rate up to a volume of about $4200 \mathrm{~cm}^{3}$ (about $21 \mathrm{~h}$ ), where water breakthrough occurs. In the two-phase production period of the next $15 \mathrm{~h}$, the oil production rate continued to decrease to a steady-state rate of about $6 \mathrm{~cm}^{3} / \mathrm{h}$. The cumulative production at this time was about $5000 \mathrm{~cm}^{3}$ (about $57 \% \mathrm{PV}$ ), which is the same as the first test. At an injection of $18,200 \mathrm{~cm}^{3}$ (about $2 \mathrm{PV}$ ) water, the injection was curtailed and imbibition was allowed to proceed for about $4 \mathrm{~d}$. The water injection was then resumed. A brief period of pure $\mathrm{nC}_{10}$ production (about $28 \mathrm{~cm}^{3}$ ) was observed, after which the system returned to a negligible production rate.

Figure 11 shows the gravity drainage performance of the same system where air replaces the drained $\mathrm{nC}_{10}$. The results show that, after a brief period of about $3 \mathrm{~h}$, the rate of drainage decreases to less than $100 \mathrm{~cm}^{3} / \mathrm{h}$. The cumulative production after $14 \mathrm{~d}$ is close to $3800 \mathrm{~cm}^{3}$ (about $0.43 \mathrm{PV}$ ), which is substantially less than the results from water injection at breakthrough.

Water injection in the fractured configuration of Fig. 8 seems to be effective in oil production; however, in order to understand the process, the results should be interpreted by a theoretical model or a numerical simulation.

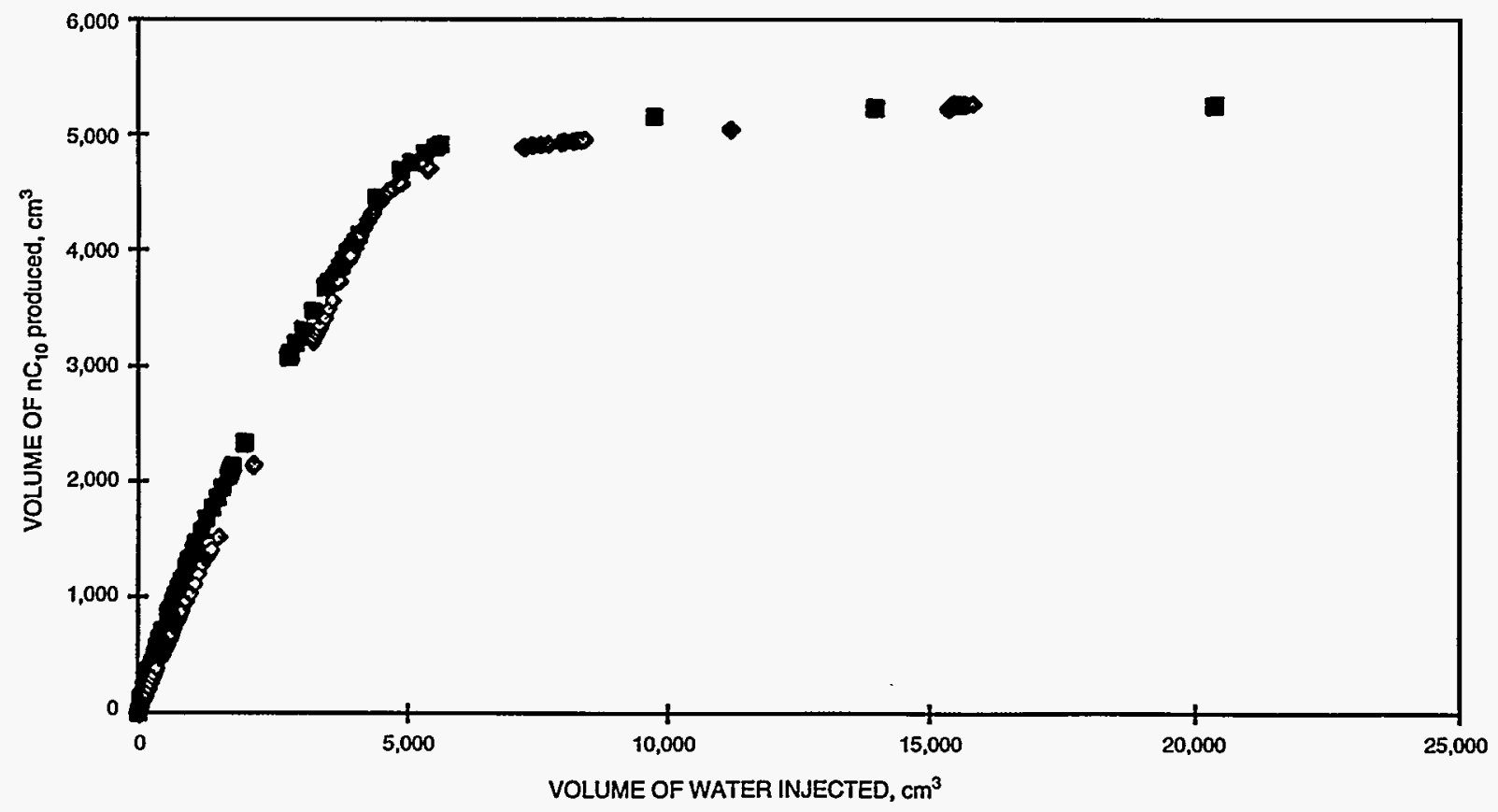

Fig. 10 Volume of water injected vs. volume of $\mathrm{nC}_{10}$ produced for tests 1 and 2 . $\downarrow$, test $1 . n$, test 2. 


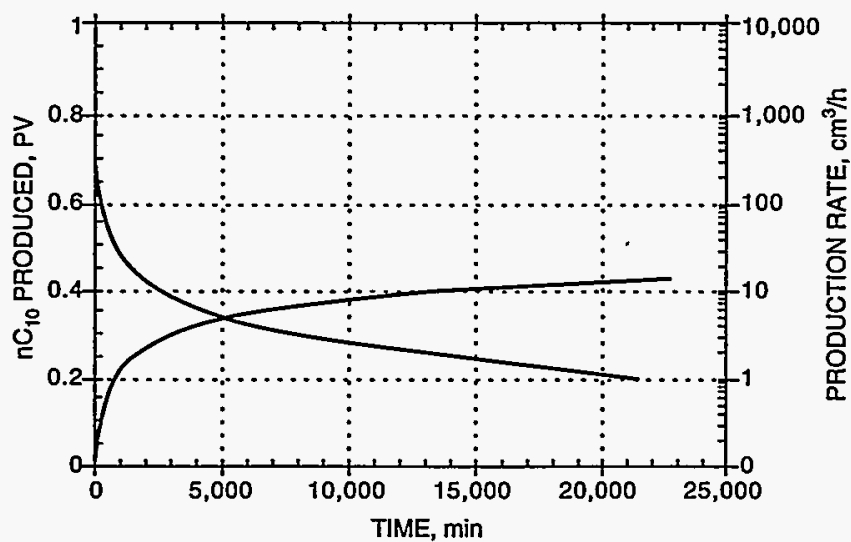

Fig. 11 Normal decane $\left(\mathrm{nC}_{10}\right)$ produced vs. time for gravity drainage.

\section{References}

1. D. Y. Peng ànd D. B. Robinson, A New Two-Constant Equation of State, Ind. Eng. Chem. Fund., 15(1): 59-64 (1976).

2. C. F. Weinaug and D. L. Katz, Surface Tensions of Methane-Propane Mixtures, Ind. Eng. Chem., 35: 239-246 (1943).

3. L. B. Bicherand D. L. Katz, Viscosity of the Methane-Propane Mixtures, Ind. Eng. Chem., 35: 754 (1943).

4. A. Firoozabadi, D. L. Katz, H. Soroosh, and V. A. Sajjadian, Surface Tension of Reservoir Crude-Oil/Gas Systems Recognizing the Asphalt in the Heavy Fraction, SPE Reser. J., (2): 265-272 (February 1988).
GEOLOGICAL AND PETROPHYSICAL CHARACTERIZATION OF THE FERRON SANDSTONE FOR THREE-DIMENSIONAL SIMULATION OF A FLUVIAL-DELTAIC RESERVOIR

Contract No. DE-AC22-93BC14896

Utah Geological Survey

Salt Lake City, Utah

Contract Date: Sept. 29, 1993

Anticipated Completion: Sept. 29, 1996

Government Award: \$1,225,482

Principal Investigator:

M. Lee Allison

Project Manager:

Robert Lemmon

Bartlesville Project Office

Reporting Period: Jan. 1-Mar. 31, 1995

\section{Objective}

The objective of this project is to develop a comprehensive, interdisciplinary, and quantitative characterization of a fluvialdeltaic reservoir that will allow realistic interwell and reservoirscale modeling to be used for improved oil field development in similar reservoirs worldwide. The geological and petrophysical properties of the Cretaceous Ferron sandstone in east-central Utah (Fig. 1) will be quantitatively determined. Both new and

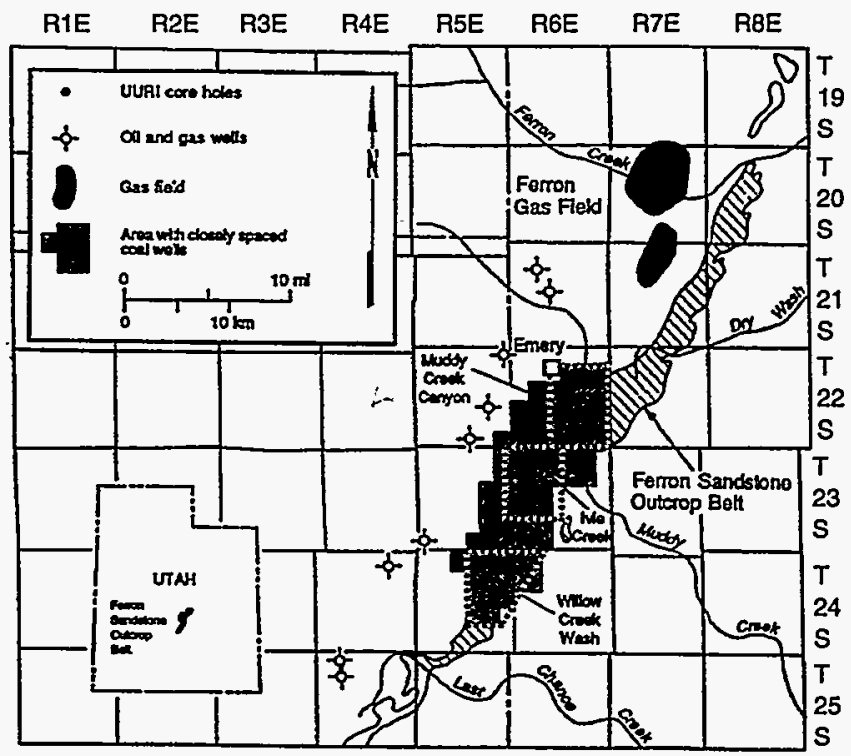

Fig. 1 Location map of the FerronSandstonestudy area (cross-hatched) showing detailed case-study sites (outlined by heavy dashed lines). UURI, University of Utah Research Institute. 
existing data will be integrated into a three-dimensional (3-D) representation of spatial variations in porosity, storativity, and tensorial rock permeability at a scale appropriate for interwell to regional-scale reservoirs simulation. Results could improve reservoir management through proper infill and extension drilling strategies, reduce economic risks, increase recovery from existing oil fields, and provide more-reliable reserve calculations. Transfer of the project results to the petroleum industry is an integral component of the project.

\section{Summary of Technical Progress}

The technical progress for this quarter is divided into sections for the Regional Stratigraphy and Case Studies tasks of the project.

\section{Regional Stratigraphy}

\section{Surface Mapping/Interpretation of the Outcrop Belt}

The Utah Geological Survey (UGS) continues to combine digitized land-based and aerial photographs of the Ferron sandstone outcrop belt into reproducible photomosaics with the use of image-editing software. A total of 1823 photos depict 80 miles $(130 \mathrm{~km})$ of Ferron sandstone outcrop. Interpretation of parasequence boundaries, lithofacies, and various field data (such as measured section and gamma-ray transect locations) are being plotted on the photomosaics as part of both the regional and case-study analyses. These interpretations will be checked later in the field.

\section{Collection and Interpretation of Existing Surface and Subsurface Data}

The UGS has collected maps, measured sections, and compiled well logs, core descriptions, and other data that pertain to the study area. This information has been compiled into a project database. The drill-hole data contained in the database will allow others who are making detailed surface measurements of Ferron rock units in the area to correlate those surface rock units into the subsurface. In addition, the drill-hole data can be used by coal and petroleum companies evaluating the Emery coal field, an area of current coal-bed methane drilling activity. The UGS has released this information in both hard copy and a computer-readable format for the benefit of all interested parties.

Data were collected from wells that penetrate the Ferron sandstone in the area from Last Chance Creek in the south to Ferron Creek in the north (Fig. 1). Well data from coal-company exploration wells; oil, gas, and stratigraphic test wells; and government test wells were entered into the database (Table 1). First, a literature search was conducted and publicly available data were collected. Second, oil and gas geophysical well logs were copied from the UGS geophysical log library. Finally,

\section{TABLE 1}

Summary of Drill-Hole Data Entered Into the Ferron Sandstone Drill-Hole Database for the Ferron Sandstone Reservoir Characterization Study

\begin{tabular}{|c|c|c|}
\hline Data source & $\begin{array}{c}\text { Number of } \\
\text { wells with } \\
\text { lithologic logs }\end{array}$ & $\begin{array}{c}\text { Number of } \\
\text { wells with } \\
\text { geophysical } \\
\text { logs }\end{array}$ \\
\hline \multicolumn{3}{|l|}{ Coal Company } \\
\hline Consolidation Coal Co. & 348 & 62 \\
\hline Western States Minerals Corp. & 14 & 0 \\
\hline Hidden Valley Coal Company & 7 & 6 \\
\hline Rio Vista Oil Ltd. & 8 & 0 \\
\hline Marad Exploration & 19 & 0 \\
\hline \multicolumn{3}{|l|}{ Government Agency } \\
\hline Bureau of Land Management & 7 & 2 \\
\hline University of Utah Research Institute & 2 & 2 \\
\hline U.S. Geological Survey & 35 & 15 \\
\hline \multicolumn{3}{|l|}{ Petroleum Company } \\
\hline ARCO Exploration Company & 7 & 7 \\
\hline Other & 42 & 42 \\
\hline Total & 489 & 136 \\
\hline
\end{tabular}

unpublished data were requested from companies known to have drilled in the area. Lithologic data were transcribed from published or company core and cutting descriptions onto standard data entry forms before entry into the database. When available, geophysical well logs were interpreted, and the lithologies were transcribed onto the data entry forms.

The Ferron sandstone drill-hole data were extracted from the larger, integrated UGS geoinformation digital database application developed under the working name of INTEGRAL*gim. INTEGRAL*gim was created at the UGS with the use of a commercially available database manager. The database contains drill-hole data sorted by township, range, and section. It consists of header or well-location information and lithologic descriptions for each well. The header information includes county name, operator name, well name and number, API number, field or area name, cadastral location, meridian, surface elevation, and total depth or length of information recorded. Each record also includes latitude and longitude location (in decimal degrees) and quadrangle mapnames. The lithology data include the depth below surface at which the top of each rockunit was penetrated by drilling, the unit name, and the unit description. Table 1 provides a list of the data sources and the number of data records from each information source in the database.

\section{Case Studies}

\section{Reservoir Architecture}

Parasequence designations in the stratigraphic section have been standardized by combining facies descriptions and photomosaic interpretations. In Ferron deltaic deposits, parasequences may be considered as primary resevoir building blocks because marine and/or delta-plain shales act as laterally 
extensive permeability barriers and commonly separate parasequences. Fluid-flow communication may occur between parasequences where shales are absent by reason of erosion or nondeposition. Porosity and permeability values, dependent on lithofacies distribution, vary laterally and vertically within a parasequence. Mouth-bar and proximal-delta-front lithofacies are high-quality reservoirs; these lithofacies distributions are related to spatial arrangement of parasequences making up the reservoir. Therefore the initial stage in reservoir characterization must be an analysis of the architecture of parasequences and lithofacies within parasequences.

In the IvieCreekcase-study area(Fig. 1), three parasequences are present within the Ferron No. 1 sandstone parasequences set (Kf1). Delta-front sandstones of a modified Gilbert delta make up the sand-rich lithofacies of the basal parasequence, the Kfla. Clinoforms in the delta front dip 10 to $15^{\circ}$ and shale-out laterally within a mile $(1.6 \mathrm{~km})$ down depositional dip. This lateral change in composition occurs within the case-study area and will be incorporated into the reservoir modeling. The overlying sand-rich lithofacies of the Kflb and $\mathrm{Kflc}$ parasequences also vary in thickness within the case-study area. In contrast to the Kfla, delta-front clinoforms of these parasequences dip less than $5^{\circ}$. Thinning of sand-rich lithofacies occurs in both updepositional-dip and down-depositional-dip directions because of lateral lithofacies changes. Kflb may be completely absent in some locations as a result of erosion and/or nondeposition. Modeling of $\mathrm{Kfl}$ parasequences will aid understanding of reservoir production in fluvial-deltaic deposits that exhibit lateral changes over short distances.

The Ferron No. 2 sandstone parasequence set (Kf2) contains three parasequences, the Kf2a, Kf2b, and Kf2c. These parasequences show less lateral variation in lithofacies than the Kfl parasequences, possibly because of greatermodification by wave processes. Within the case-study area, there is little lateral variation in thickness of sand-rich lithofacies, even when lateral change occurs from one depositional subfacies to another. Modeling of $\mathrm{Kf} 2$ parasequences will improve understanding of reservoir production in fluvial-deltaic deposits that exhibit gradual lateral changes over great distances.

Data input and editing of 1994 field data (measured stratigraphic sections and paleocurrent measurements) into the UGS database began last quarter and ended this quarter. Stratigraphic data were transferred from the database to software that drafted stratigraphic sections and core descriptions. This software generated graphic logs of stratigraphic sections at scales of 1 in.: $2.5 \mathrm{ft}(2.5 \mathrm{~cm}: 0.8 \mathrm{~m})$ and 1 in.: $10 \mathrm{ft}(2.5 \mathrm{~cm}: 3 \mathrm{~m})$ (Fig. 2). Logs at both scales contain attributes, such as lithologies, sedimentary structures, and parasequence designations. General comments, grain sorting, grain roundness, and degree of consolidation were also noted on the 1 in.: $2.5 \mathrm{ft}$ ( $25 \mathrm{~cm}: 0.8$ ) logs. All attributes will be used to define reservoir components in the statistical and reservoir-modeling parts of the project.

Paleocurrent measurements, grouped by parasequence and by lithologic units composing parasequences, were plotted as rose diagrams (Fig. 2). Measurements plotted according to parasequence give an overall indication of the direction of parasequence progradation. Measurements plotted according to units within a parasequence give direction of sediment transport of components of the parasequence (for example, distributary channels, mouth bars, or parts of the delta front). In addition, paleocurrent measurements from wave ripples were plotted separately from measurements taken from unidirectional current ripples and cross beds (Fig. 2). Wave-ripple measurements provide information on direction of waves impinging on and modifying the delta front. Unidirectional measurements provide information on depositional processes that delivered sediments to the deltaic parasequence and can be used in modeling fluid flow in reservoirs.

Most field-interpreted photomosaics in the Ivie Creek casestudy area have been redrafted and acetate overlays added, which show the interpretation of parasequences and deltaic subfacies (Fig. 3). The photomosaics will be the base for construction of scaled cross sections. In return, the cross sections will form the base for construction of the 3-D model of the reservoir architecture.

\section{Preliminary Mini-Permeameter Results and Interpretations}

During this quarter the first phase of mini-permeability testing was completed, and test results were compiled and documented. A method for generating stochastic permeability fields and modeling subsurface fluid flow was also developed and tested. During this quarter the project team chose the part of the study area to be used for the reservoir simulation.

Approximately $110 \mathrm{ft}(34 \mathrm{~m})$ of slabbed core obtained from Ivie Creek Nos. 3, 5a, and 9a core holes (Fig. 4) were tested with an automated mini-permeameter provided by the Mobil Exploration and Production Technical Center. The distance between measurement points on the core ranged from 0.03 to $0.05 \mathrm{ft}(0.9$ to $1.5 \mathrm{~cm})$, yielding 1939 measurements. Core was selected for slabbing and testing after a series of reconnaissance mini-permeability tests were performed on segments of whole core. The reconnaissance results are shown with the corresponding gamma-ray profiles in Fig. 5. Each hole is approximately hung on the gamma-ray peak that represents the approximate interface between the Kf1 and $\mathrm{Kf} 2$ parasequences. The plots are arranged in a proximal-to-distal pattern when viewed from left to right (Fig. 5). Sections of core with higher reconnaissance permeability values were submitted for detailed testing because they provided a reasonable probability of obtaining a detailed sequence of permeability variation with values above the resolution of the instrument (above 1 to $2 \mathrm{mD}$ ).

Results of the detailed permeability testing and corresponding gamma-ray profiles are shown for Ivie Creek Nos. 9a, 5a, and 3 in Fig. 6). Visual inspection of the gamma-ray profiles indicates that they fail to capture variations that correspond to the detailed permeability variations. Additional work is required to exploremore fully relationships between the permeability and gamma-ray results. The detailed mini-permeameter measurements capture characteristic patterns of permeability associated with internal elements of the $\mathrm{Kf} 1$ and $\mathrm{Kf} 2$ parasequence sets. 


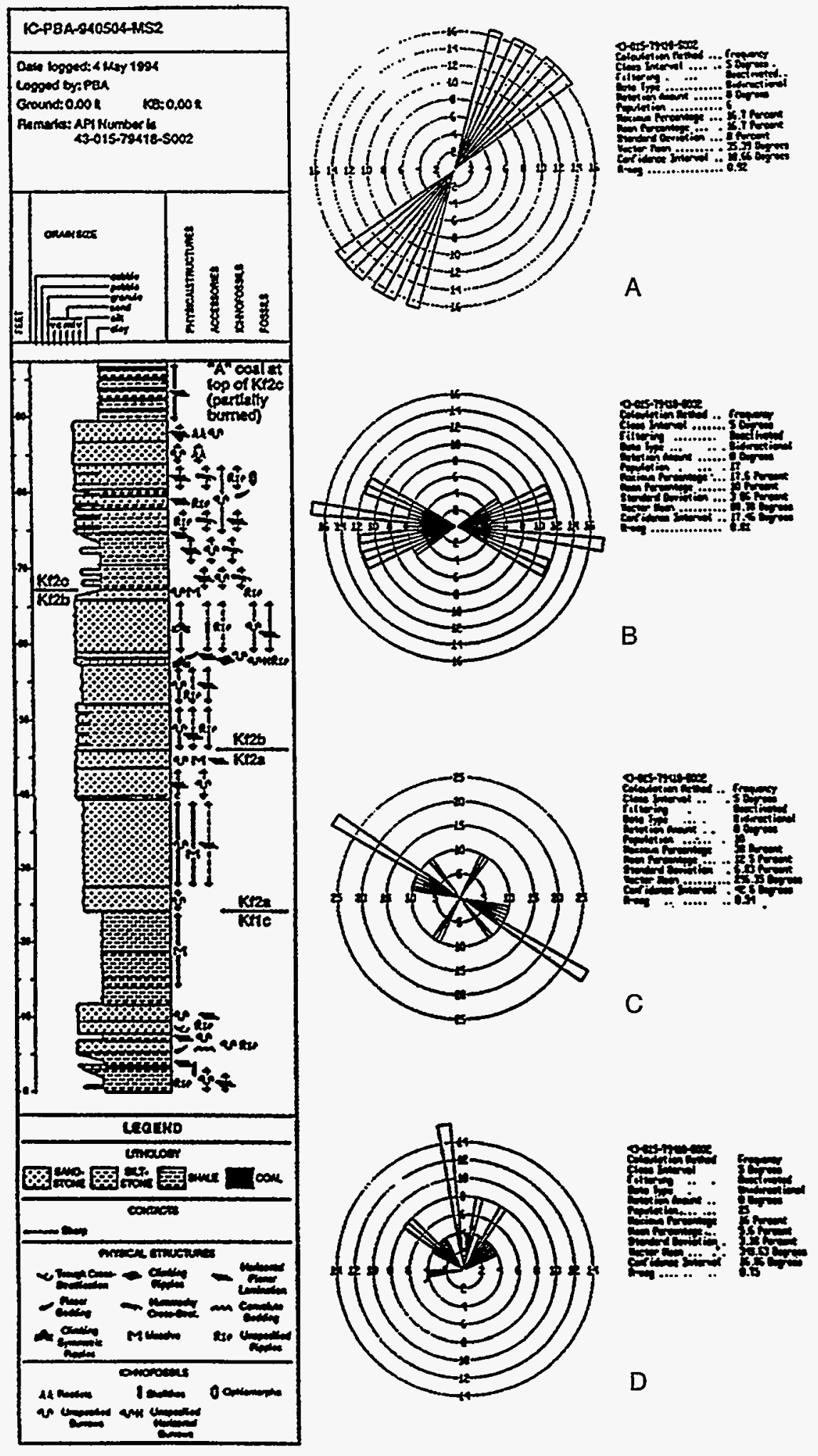

Fig. 2 On the left is a log of stratigraphic section IC-PBA-940504-MS2 from the Ivie Creek casestudy area (originally at a scale of 1 in.: $2.5 \mathrm{ft}$ ) showing lithologies, sedimentary structures, and parasequence designations. The outcrop and orientation of the transect where this section was measured are shown in Fig.3. On the right, paleocurrent rose diagrams for several parasequences are displayed: (A) shows bidirection data from $\mathrm{Kfzc}$, (B) shows bidirectional data from parasequence $\mathrm{Kf} \mathbf{b}$, (C) shows bidirectional data from parasequence Kflc, and (D) shows unidirectional data from parasequence Kflc. (Reproduced from the best available copy.) 


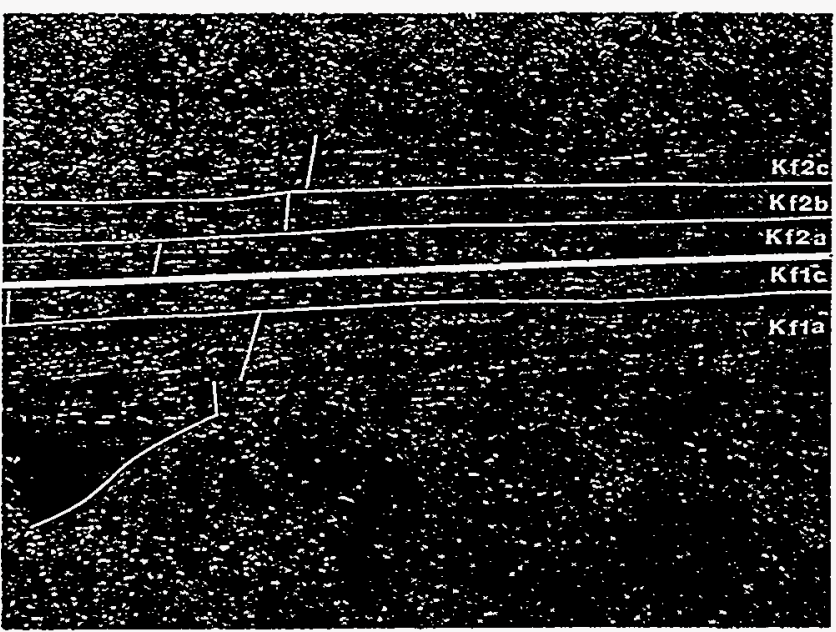

Fig. 3 Part of an east-west-oriented photomosaic from the Ivie Creek case-study area, north view, SW1/4 NE $1 / 4$ sec. 16, T. 23 S., R. 6. E. The heavy, white horizontal line is a parasequence set boundary and is underlain by parasequence set $\mathrm{Kfl}$ and overlain by parasequenceset $\mathrm{KR}$. The thin, white horizontal lines are parasequence boundaries. Parasequence Kflb, normally present between parasequences Kfla and $\mathrm{Kflc}$, is not present because of either post-directional erosion or nondeposition. The marine sandstone of $\mathrm{Kfz} \mathrm{c}$ is overlain by nonmarine sandstone and shale. The thin, white vertical and steeply inclined lines mark the location of two measured stratigraphic sections. Section IC-PBA-940504-MS1 describes Kfla, and section IC-PBA-940504-MS2 describes Kflc through Kf2c.
Core plugs (379plugs) collected during the 1994 field season were tested with the use of Mobil's portable mini-permeameter. A subset of these core plugs (220 plugs) was tested with the use of Mobil's Hassler cell equipment. All test results are compiled in a spreadsheet and plotted in graphical form.

Twenty core plugs were collected during the latter part of 1994 from blocks on talus slopes that appear to have fallen from the Kfla facies in the eastern part of the study area. Permeability measurements taken from these core plugs should aid understanding of permeability variations in what is inferred to be the most proximal exposure of the Kfla deltafront sandstones.

Mini-permeameter tests on the talus slope cores performed with Mobil's portable equipment yielded the results shown in Table 2. Samples were tested two ways. First, the samples were tested after only brushing off the drill cuttings (unprepared). Second, each sample was washed and then dried in an oven for $2 \mathrm{~d}$ in an effort to ensure that all moisture was removed from the samples before testing. Apparently, for the samples tested, sample preparation method has little impact on permeability test results.

Permeability (k) test results shown in Table 2 are consistent with results obtained for transects $\mathrm{T} 4$ and $\mathrm{T} 3$ located at progressively more distal positions in the Kfla lithofacies (see Fig. 7 for transect locations). Although the T3 and T4

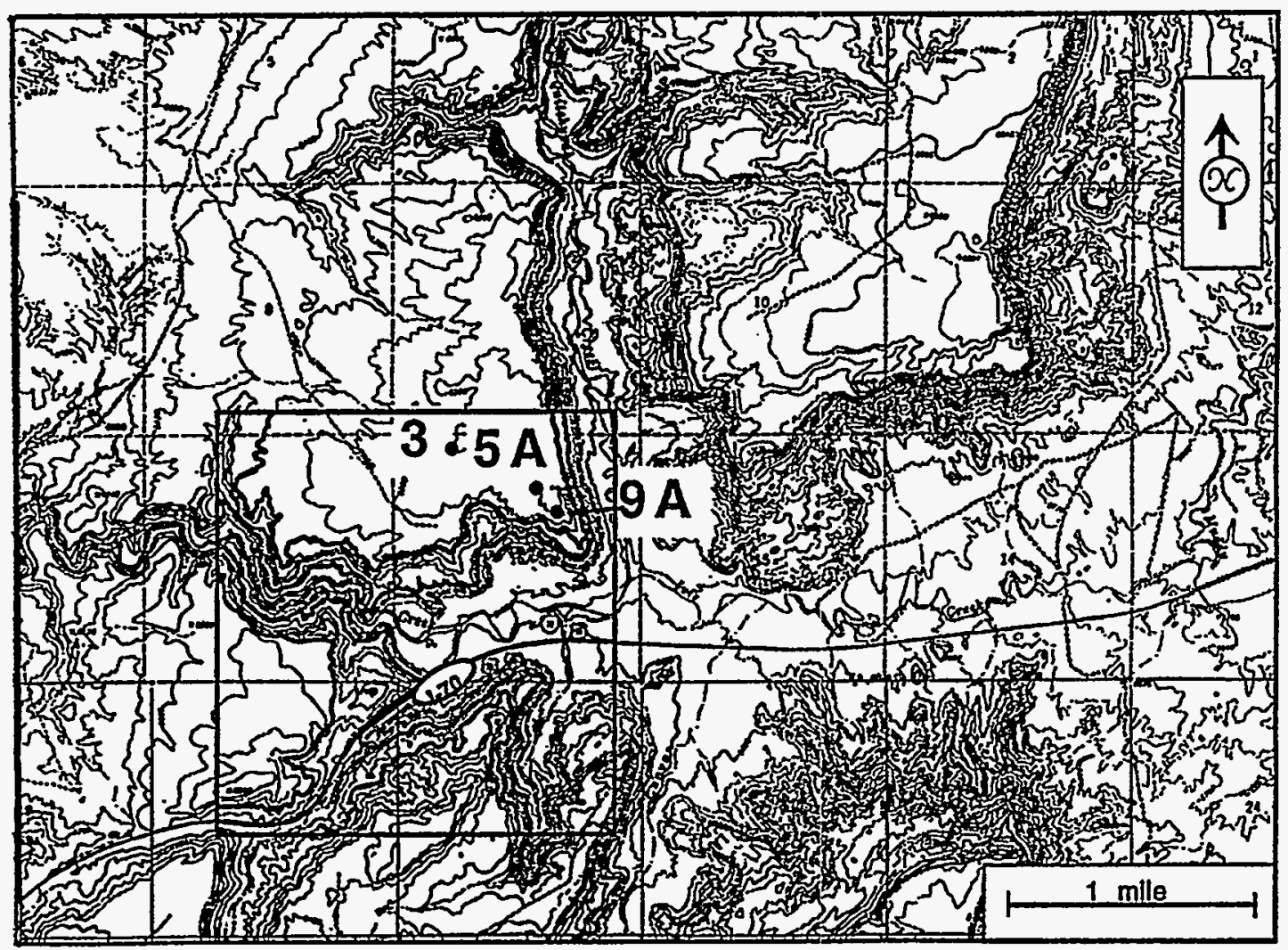

Fig. 4 Location map for the Ivie Creek Nos. 3, 5a, and 9a core holes. The 2-mile by 2-mile (3.2 km by $3.2 \mathrm{~km})$ detailed casestudy site at Ivie Creek is outlined by dark lines. 

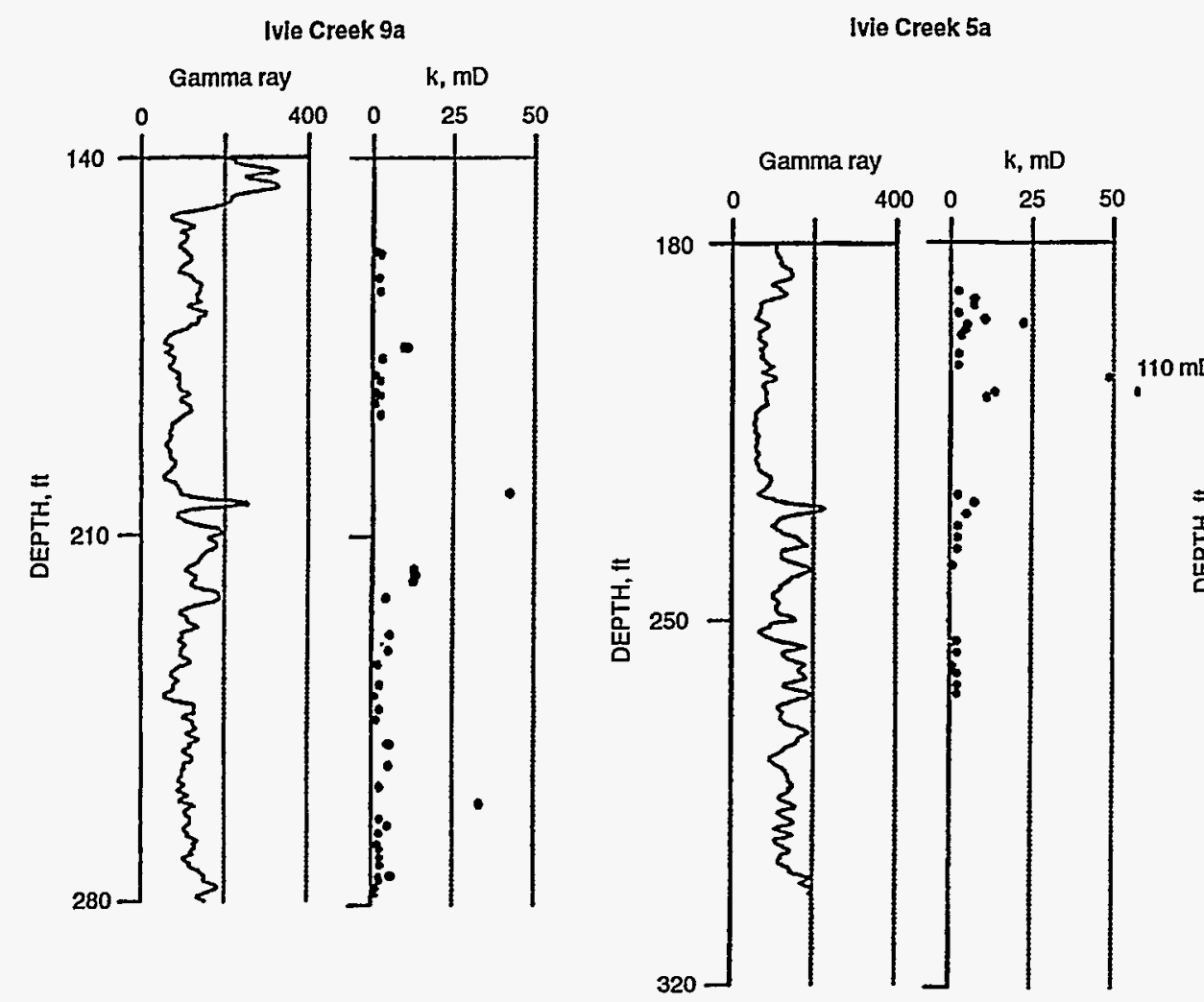

Ivie Creek 3

Proximal

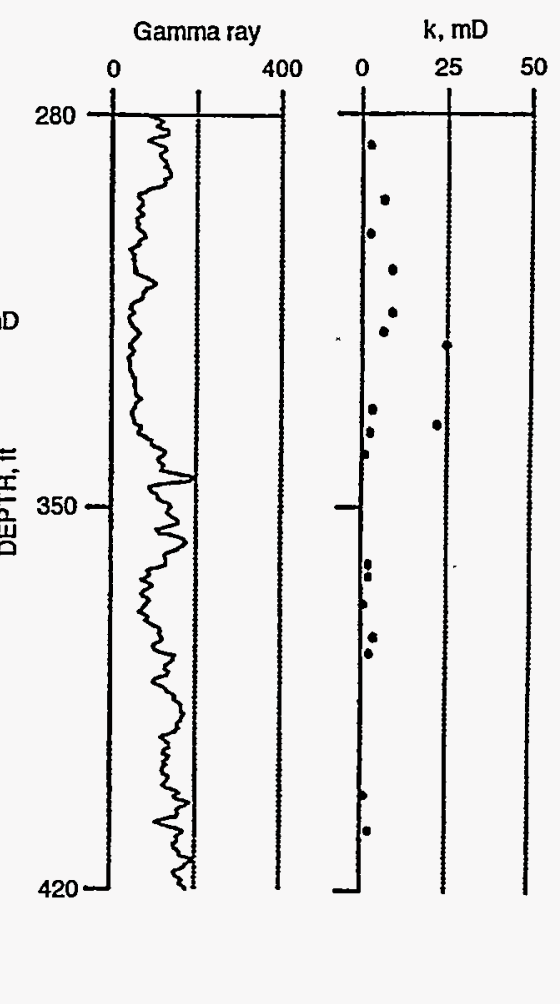

Fig. 5 Reconnaissance permeability (k) data and corresponding gamma-ray measurements (in API units) obtained for the Ivie Creek Nos. 9a, 5a, and 3 core holes. Plots are arranged to present changes in kand gamma-ray profiles that occur when moving from proximal to distal positions within the Kfla.
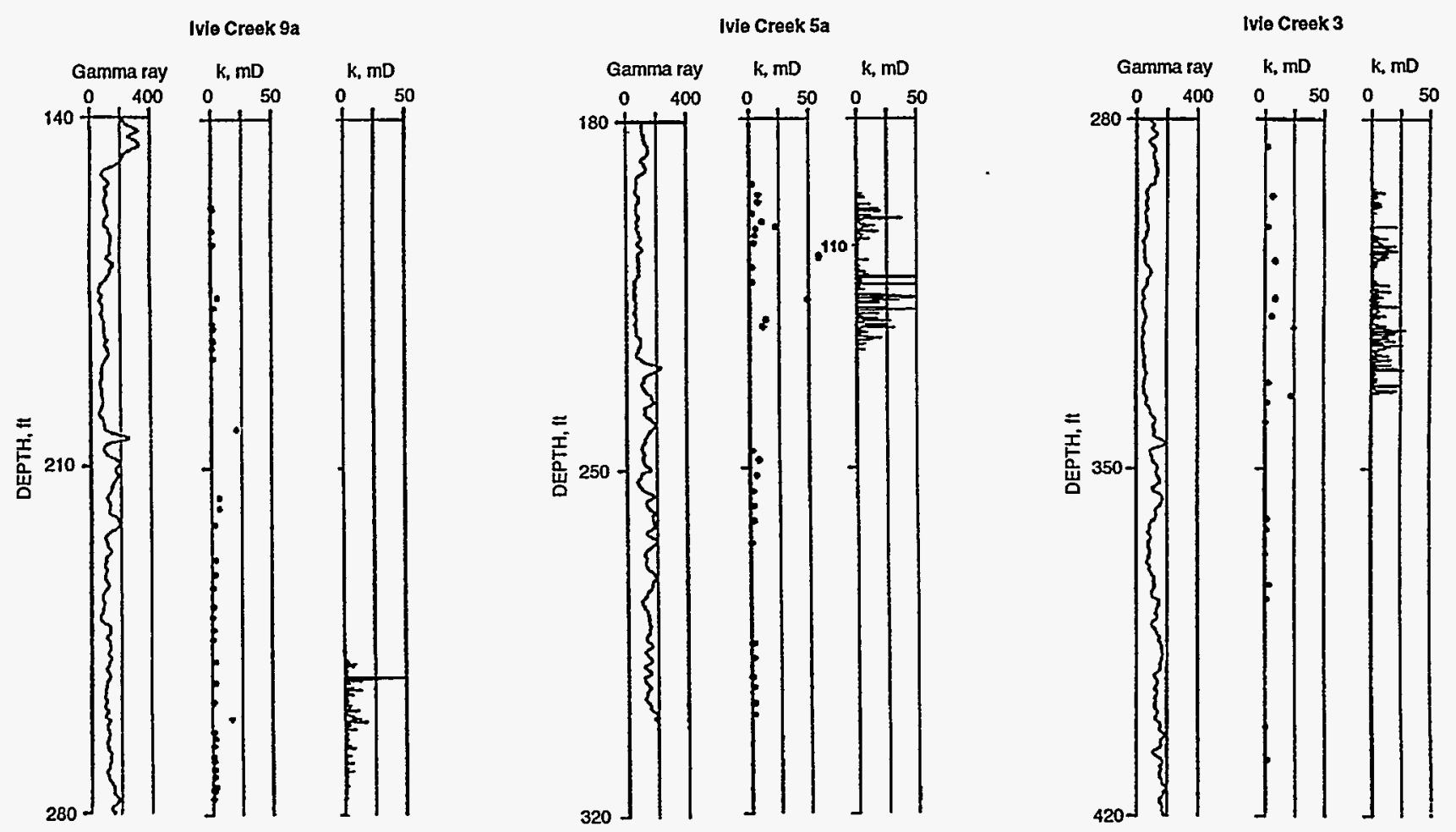

Fig. 6 Gamma-ray profile (in API units) and results of both reconnaissance permeability (k) tests on whole core (center graph) and automated $k$ tests (right graph) on slabbed core for $\mathrm{Kf1}$ and $\mathrm{Kf}$ for the Ivie Creek Nos. 9a, 5a, and 3 core holes. 
TABLE 2

Results of Permeability (k) Tests for Cores from Talus Slope Blocks of Kfla at Ivie Creek

\begin{tabular}{ccc}
\hline Core No. & $\begin{array}{c}\text { Unprepared } \\
\mathbf{k}, \mathbf{m D}\end{array}$ & $\begin{array}{c}\text { Rinsed and dried } \\
\mathbf{k}, \mathbf{m D}\end{array}$ \\
\hline 1 & 22.55 & 21.69 \\
2 & 13.41 & 10.16 \\
3 & 2.78 & 2.17 \\
4 & 22.85 & 23.77 \\
5 & 27.15 & 31.54 \\
6 & 6.12 & 4.93 \\
7 & 22.07 & 22.35 \\
8 & 6.35 & 5.11 \\
9 & 10.9 & 16.9 \\
10 & 19.62 & 18.47 \\
11 & 3.66 & 3.79 \\
12 & 0.82 & 0.8 \\
13 & 0.83 & 0.79 \\
14 & 6.47 & 11.78 \\
15 & 1.87 & 2.05 \\
16 & 14.42 & 13.23 \\
17 & 2.99 & 3.76 \\
18 & 2.21 & 2.26 \\
19 & 35.53 & 34.59 \\
20 & 2.93 & 2.26 \\
\hline
\end{tabular}

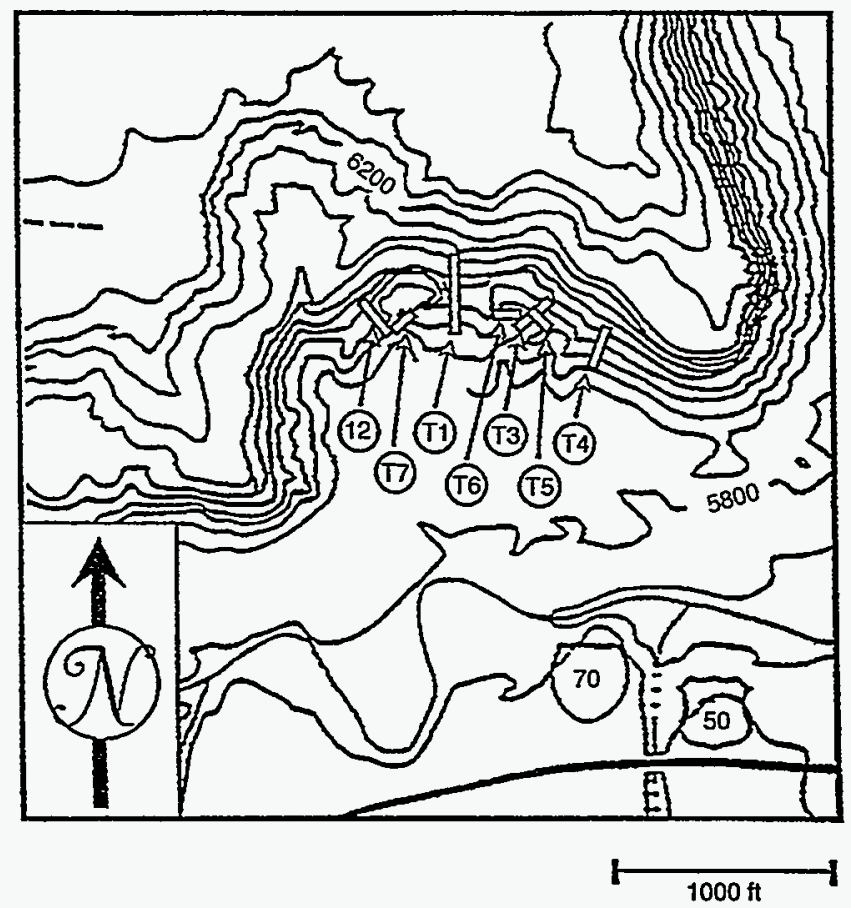

Fig. 7 Location of seven permeability transects (vertical and parallel to bedding) in the Ivie Creek case-study area, sec. 16, T. 23 S., R. 6 E., Emery County, Utah. (Base map modified from U.S. Geological Survey Mesa Butte and Walker Flat $71 / 2$ ft topographic maps; contour interval is $40 \mathrm{ft}$.) test results did yield $\mathrm{k}$ values in excess of $40 \mathrm{mD}$, the higher $\mathrm{k}$ values typically fall in the range of 10 to $20 \mathrm{mD}$

\section{Stochastic Modeling and Fluid-Flow Simulation}

A 2-mile by 2 mile (3.2-km by 3.2-km) region (Figs. 4 and 8) has been selected as the site where detailed, 3-D geological and petrophysical models will be developed as input to a series of reservoir simulations. Data needed for these model will be obtained by geological mapping, outcrop gamma-ray logging, petrophysical measurements on core plugs, and minipermeameter testing of slabbed core from the Ivie Creek Nos. $3 a, 5 a$, and 9a. The simulation study area encompasses both river-dominated and wave-modified sedimentary facies (Kf1 and $\mathrm{Kf} 2$ ) with thickness less than $200 \mathrm{ft}(61 \mathrm{~m})$. In addition, a well-defined distributary channel cuts through the upper $\mathrm{Kf} 2$ parasequence set.

\section{Technology Transfer}

Five technical presentations were made during the quarter as part of the Ferron sandstone project technology transfer activities. ${ }^{1-5}$ Project materials were displayed at the UGS booth during the 1995 annual AAPG convention, Houston, Tex., and during the 1995 regional convention of SPE, Denver, Colo.

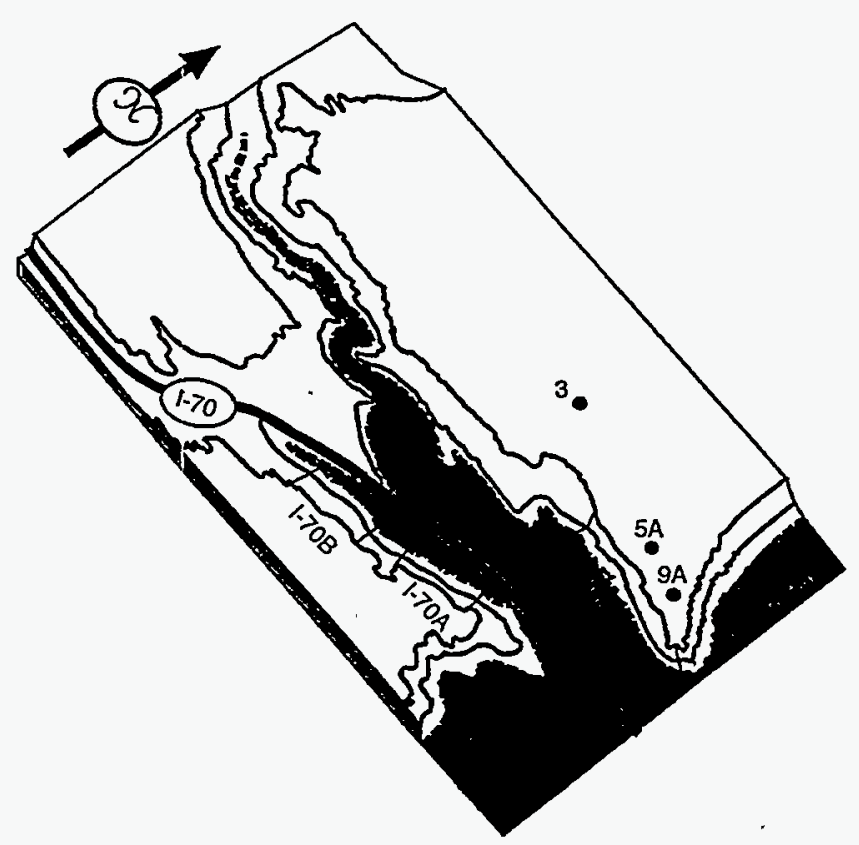

Fig. 8 Perspective view of the Ivie Creek detailed case-study site.

\section{References}

1. S. H. Snelgrove, The Ferron Reservoir Characterization Project: Using Outcrop Analogues to Characterize Fluvial-Deltaic Reservoirs at the Interwell Scale, Los Alamos National Laboratory, Los Alamos, New Mex., February 1995. 
2. M. L. Allison, Exciting New Oil and Gas Activities in Utah and Overview of Utah Geological Survey Reservoir Characterization Projects, Utah Association of Petroleum \& Mining Landmen, Salt Lake City, Utah, March 1995.

3. R. D. Adams, T. C. Chidsey, Jr., and M. D. Laine, Integrated Multidisciplinary Reservoir Characterization of a Deltaic System-1: Architecture and Lithofacies of the Cretaceous-Age Ferron Sandstone, East-Central Utah, paper presented at the American Association of Petroleum Geologists Annual Convention, Houston, Tex., March 5-8, 1995.

4. S. H. Snelgrove, C. B. Forster, and J. V. Koebbe, Integrated Multidisciplinary Reservoir Characterization of a Deltaic System-2:
Developing a Petrophysical Model for Reservoir Simulation Using Data from the Ferron Sandstone Utah, paper presented at the American Association of Petroleum Geologists Annual Convention, Houston, Tex., March 5-8, 1995.

5. J.A.Dewey,Jr., Depositional Environments, Sequence Stratigraphy, and Reservoir Quality of a Portion of the Ferron Sandstone, East-Central Utah, paper presented at the Spring Research Conference, College of Physical and Mathematical Sciences, Brigham Young University, and the American Chemical Society, Provo, Utah, March 1995.

\section{ANISOTROPY AND SPATIAL VARIATION \\ OF RELATIVE PERMEABILITY AND \\ LITHOLOGIC CHARACTERIZATION OF TENSLEEP SANDSTONE RESERVOIRS IN THE BIGHORN AND WIND RIVER BASINS, WYOMING}

\section{Contract No. DE-AC22-93BC14897}

\section{University of Wyoming \\ Laramie, Wyo.}

Contract Date: Sept. 15, 1993

Anticipated Completion: Sept. 14, 1996

Government Award: \$251,061

(Current year)

Principal Investigator:

Thomas L. Dunn

Project Manager:

Robert Lemmon

Bartlesville Project Office

Reporting Period: Jan. 1-Mar. 31, 1995

\section{Objectives}

The objectives of this multidisciplinary study are designed to provide improvements in advanced reservoir characterization techniques. These objectives are to be accomplished through (1) an examination of the spatial variation and anisotropy of relative permeability in the Tensleep sandstone reservoirs of Wyoming; (2) the placement of that variation and anisotropy into paleogeographic, depositional, and diagenetic frameworks; (3) the development of pore-system imagery techniques for the calculation of relative permeability; and (4) reservoir simulations testing the impact of relative-permeability anisotropy and spatial variation on Tensleep sandstone reservoir enhanced oil recovery (EOR).
Concurrent efforts are aimed at understanding the spatial and dynamic alterations in sandstone reservoirs that are caused by rock-fluid interaction during carbon dioxide $\left(\mathrm{CO}_{2}\right) \mathrm{EOR}$ processes. The work focuses on quantifying the interrelationship of fluid-rock interaction with lithologic characterization in terms of changes in relative permeability, wettability, and pore structure and with fluid characterization in terms of changes in chemical composition and fluid properties. This work will establish new criteria for the susceptibility of Tensleep sandstone reservoirs to formation alteration that results in change in relative permeability and in wellborescale damage. This task will be accomplished by flow experiments with the use of core material, examination of regional trends in water chemistry, examination of local water chemistry trends at field scale, and chemical modeling of both the reservoir and experimental systems to scale up the experiments to field scale.

\section{Summary of Technical Progress}

The compilation of $192,000 \mathrm{ft}$ of digitized porosity and gamma-ray well logs of the Tensleep formation is complete. This computer-based compilation covers the Bighorn and Wind River Basins and portions of the western Powder River Basin and northernmost Green River Basin. The correlation of internal stratification is under way.

The laboratory effort continues on schedule; the addition of a research scientist to the relative permeability measurement effort will allow these tasks to continue to improve productivity. The image analysis task is under way.

The water chemistry and scale formation task personnel performed another $\mathrm{CO}_{2}$ injection experiment at the Marathon Technology Center. Determinations of the important controls were made during this quarter.

\section{Regional Frameworks}

During this quarter, data acquisition and interpretation continued. As of March 31, 1995, 96 additional wells with 
digitized logs had been added to the Production Analyst ${ }^{\circledR}$ database for both the Bighorn and Wind River Basins. This brings the total to approximately $64,000 \mathrm{ft}$ each for gammaray, neutron, and density digitized well logs. Understanding of the well-log response of particular facies and bounding surfaces has been increased by describing Tensleep sandstone cores, which total approximately $2300 \mathrm{ft}$, and correlating them to the well-log response. These data have made it possible to expand the regional correlations of marine carbonate units across the Bighom Basin.

\section{Relative Permeability Measurements}

Relative-permeability measurements of Tensleep sandstone cores continue. Samples through letter I are complete for both vertical and horizontal measurements. At this point, results are being assembled through sample I, and an M.S. thesis is being compiled for submittal to the Department of Chemical and Petroleum Engineering. Conclusions follow:

- Dried air permeabilities are reasonably isotropic in these sands. A very slight deviation from equality of vertical and horizontal permeabilities exists, with the horizontal gas permeability being negligibly larger.

- When saturated with oil and then waterflooded, the residual oil saturation (ROS) and percent recovery of oil by waterflooding appear to be a random function. A wide range of ROSs exists with no preference toward vertical and horizontal.

- Relative-permeability ratios (water/oil) show a distinct trend in anisotropy. The horizontal relative-permeability ratio is regularly smaller (i.e., it has greater permeability for oil).

Reservoir simulation work has been initiated by considering the four computer programs already available at the University of Wyoming: Stiles, ${ }^{1}$ Dykstra-Parson, ${ }^{2}$ TETRAD (TM), and Buckley-Leverett. ${ }^{3}$ Each is operational on IBMcompatible personal computers (PC), and each has been considered for applicability to this relative-permeability anisotropy study. The Stiles program will not be used because it is predominantly designed to handle layers of differing absolute permeability with no account for relative-permeability equations. The Dykstra-Parsons program is a twodimensional (2-D) stream-tube model based on a simplified relative-permeability model. Although this appeared attractive at first, the existing program assumes equal relativepermeability parameters in all directions. Therefore DykstraParsons as it exists has no way to handle relative-permeability anisotropy accurately. The program also is limited to singlelayer modeling with no vertical cross flow between layers. TETRAD is used by the reservoir simulation class in petroleum engineering at the University of Wyoming. It is a general-purpose three-dimensional (3-D) black-oil simulator, streamlined to run on a 486 PC. Unfortunately, the streamlining process has limited the program to 200 finite-difference cells, which practically means that a user is limited to 2-D problems. Then the input and output of variables is complex, awkward, and slow. A single run of the program, from setup to compilation of results, can take many days. Finally, the license to the University is for classroom use only, so it would technically have to be upgraded for this project. A simpler, yet still theoretically sound approach is needed.

The Buckley-Leverett program is a simple onedimensional (1-D) program that follows accurately the complete relative-permeability behavior as predicted by the Buckley-Leverett theory. The major disadvantage of this program is the fact that it is 1-D. Its advantage is the adaptation to variable relative-permeability characteristics of oil/water systems. Each relative-permeability curve is input to the Buckley-Leverett program by characterizing the residual end-point saturations and then behavior between endpoints by a power-law relationship against dimensionless saturation. Because all results appear to follow power-law relationships quite well, the program seems well suited for this project. Sample runs have been completed, and only preliminary results are available. The 1-D limitations will be overcome by running the program once with horizontal permeability parameters. A comparison of the two separate runs will allow evaluation of approximate effects from anisotropy in oil and water production during waterflooding. These results can also be compared with previously published waterflooding simulation studies to assess the level of uncertainty imparted by accounting for relative-permeability anisotropy.

A slightly similar study was published by Kortekaas, ${ }^{4}$ in which reservoir simulation was performed with assumptions of varying water/oil displacement characteristics in cross-bedded reservoirs. In that work, however, the variations were assumed to be derived by scaling the reservoir at two sizes, once to account for the cross-bedding effects at a very fine scale'(small grids) and a second time to perform the actual reservoir simulation studies. No actual permeability measurements were included in that study. It was primarily a technique for handling small-scale (cross-bedding) variations with a large-scale (reservoir) simulation program. Many of the assumptions made in that work can be evaluated quantitatively with the laboratory data acquired.

\section{$\mathrm{CO}_{2}$ Flood-Formation Alteration and Wellbore Damage}

Studies show that Tensleep formation water chemistry can be classified into four groups, and the distribution of waters of each group in the Bighorn Basin is characteristic. These features reflect water-rock interaction between Tensleep sandstone minerals and post-Laramide meteoric water, depositional environments of the formation, and hydrogeology in the Bighorn Basin.

A computer simulation of carbonate scale formation in the Tensleep formation caused by $\mathrm{CO}_{2}$ flooding was carried out. Saturation index of aragonite, which is a common scale mineral caused by $\mathrm{CO}_{2}$ flooding, was calculated as a function of $\mathrm{P}_{\mathrm{CO}_{2}}$ caused by well-to-well $\mathrm{CO}_{2}$ flooding with the use of the SOLMINEQ.88 computer program. Through this 
simulation it was found that the dissolution rate of dolomite, which is a common cement mineral in the Tensleep, is the most important factor controlling scale formation of aragonite near production wells. More-detailed simulation is in progress.

The second run of the $\mathrm{CO}_{2}$ flooding experiment was carried out at the Petroleum Technology Center, Marathon Oil Co., Littleton, Colo., in January 1995. This run was a blank test to assess chemical, iron $(\mathrm{Fe})$ contamination from the apparatus and was run under the same conditions as those of the first run without cores $\left(80^{\circ} \mathrm{C}\right.$ and $\left.2400 \mathrm{psi}, \mathrm{P}_{\text {total }}=\mathrm{P}_{\mathrm{CO}_{2}}\right)$. It was observed that a fair amount of Fe (max., $515 \mathrm{ppm}$ ) came out of the apparatus. Results of the first run are being rechecked, taking into account $\mathrm{Fe}$ contamination measured in this run. From the results of these two runs, an attempt will be made to estimate the dissolution rate of dolomite under $\mathrm{CO}_{2}$ flooding conditions because it was found that this rate is an important factor controlling aragonite scale formation caused by $\mathrm{CO}_{2}$ treatments through the computer simulation. The third experiment will be run in the next quarter. The next experiment will run longer than the previous two and will focus, in particular, on the change of the degree of saturation of dolomite with time.

\section{Project Management and Technology Transfer}

Findings of the preceding tasks were presented in oral and poster sessions at the 1995 American Association of Petroleum
Geologists Annual Convention. ${ }^{1-2}$ The posterillustrated Tensleep depositional processes and the resultant effect on both large-and small-scale reservoir heterogeneity. Large photmosaics were used to illustrate the four basic reservoir fluid-flow units and their dimensions. The outcrop photos were integrated with subsurface cross sections to further illustrate the lateral geometries and dimensions of the eolian and marine facies.

The oral presentation on the water chemistry and $\mathrm{CO}_{2-}$ injection modeling presented evidence of the strong control of the dolomite dissolution rate on carbonate scale formation and hence on predictive modeling of scale formation.

A research scientist position was created to maintain the laboratory effort after the present research scientist graduates in the summer of 1995.

\section{References}

1. W. E. Stiles, Use of Permeability Distributions in Water-Flood Calculations, Trans. AIME 186: 9-13 (1949).

2. H. Dykstra and R. L. Parsons, The Prediction of Oil Recovery by Waterflood, Secondary Recovery of Oil in the United States, American Petroleum Institute, Dallas, Tex., 1950.

3. S. E. Buckley and M. C. Leverett, Mechanism of Fluid Displacement in Sands, Trans. AlME, 146: 107-116(1942).

4. T.F.M.Kortekaas, Water/OilDisplacementCharacteristics in Crossbedded ReservoirZones, SPEJ, Soc. Pet. Eng. J., 25: 917-926 (December 1985).
GEOSCIENCE/ENGINEERING

CHARACTERIZATION OF THE

INTERWELL ENVIRONMENT IN

CARBONATE RESERVOIRS BASED

ON OUTCROP ANALOGS, PERMIAN

BASIN, WEST TEXAS AND NEW MEXICO

Contract No. DE-AC22-93BC14895

\author{
University of Texas \\ Bureau of Economic Geology \\ Austin, Tex.
}

Contract Date: Sept. 29, 1993

Anticipated Completion: Sept. 28, 1996

Government Award: $\$ 354,400$

Principal Investigators:

F. J. Lucia

C. Kerans

Project Manager:

Robert Lemmon

Bartlesville Project Office

Reporting Period: Jan. 1-Mar. 31, 1995

\section{Objectives}

The primary objective of this project is to investigate styles of reservoir heterogeneity found in low-permeability, pelleted wackestone-packstone facies and mixed carbonate-clastic facies found in Permian Basin reservoirs by studying similar facies exposed in the Guadalupe Mountains. Specific objectives for the outcrop study include construction of a stratigraphic framework, petrophysical quantification of the framework, and testing the outcrop reservoir model for effects of reservoir heterogeneity on production performance. Specific objectives for the subsurface study parallel objectives for the outcrop study.

\section{Summary of Technical Progress}

\section{Outcrop Activities}

Two field trips in early 1995 were directed toward extending mapping of the three-dimensional (3-D) architecture of depositional sequences, high-frequency cycles, and component facies in Grayburg sequence 2. The initial 3-D analysis focused on five ooid grainstone-dominated cycles that accumulated during sea-level highstand. This work documents that the permeable grainstone bodies in these cycles are strikeelongate and exhibit good lateral continuity. Some of the 
grainstone units can be traced for $4000 \mathrm{ft}$ along dip and for at least $3000 \mathrm{ft}$ across strike. This good lateral continuity reflects reworking and amalgamation of ooid grainstone bodies in an accommodation-limited highstand setting.

Examination of ooid grainstone bodies in the Grayburg sequence 2 transgressive systems tract indicates that these permeable grainstones are less laterally continuous. ${ }^{\prime}$ The 3-D facies heterogeneity in these cycles is on being mapped on Plowman Ridge and in West Dog Canyon, $3000 \mathrm{ft}$ west of Plowman Ridge across depositional strike. This work is directed toward understanding the relationship between the geometry and lateral dimensions of grainstone bodies with their respective stratigraphic setting. This knowledge will improve the ability to predict the lateral extent of permeable grainstone units in subsurface reservoirs.

\section{Subsurface Activities}

Log-derived porosity, permeability values, and estimates of original water saturation derived from porosity-saturation relationships have been used to construct the initial reservoir model with the use of Stratamodel software. The model shows large heterogeneity in permeability distribution, which has resulted in recovery of only $20 \%$ of the original oil in place (OOIP) in the Moss Unit.
$\mathrm{X}$-ray-diffraction (XRD) analyses of 50 samples of the core from Emmons No. 210 showed only 3 samples that contained gypsum. These data are in agreement with thin-section analysis. ${ }^{2}$ Therefore the fact that in some wells the sonic porosity is over three porosity-units less than neutron-density porosity cannot be explained by the presence of bound water in gypsum. Also, there is not sufficient separate-vug porosity to account for the discrepancy. This discrepancy, however, appears to exist in wells in which the anhydrite is interpreted to have been dissolved, which created a patchy and microfractured pore geometry. It is hypothesized that the dissolution process increased porosity but did little to the rigidity of the rock; thus the neutron-density response was affected, but little affect was indicated on the acousting velocity.

\section{References}

1. R. J. Barnaby and W. B. Ward, Sequence Stratigraphic Framework, High-Frequency Cyclicity and Three-Dimensional Heterogeneity: Grayburg Formation, Brokeoff Mountains, New Mexico, in Carbonate Facies and Sequence Stratigraphy: Practical Applications of Carbonate Models, P. H. Pause and P. M. Candelaria (Eds.), Permian Basin Section of Society of Economic Paleontologists and Mineralogists (SEPM) Publication 95-36, pp. 37-50, 1995.

2. Roger Barnaby, oral presentation, Carbonate Facies and Sequence Stratigraphy: Practical Applications of Carbonate Models, Permian Basin Section of Society of Economic Paleontologists and Mineralogists (SEPM), Midland, Tex.

\section{VISUAL DISPLAY OF RESERVOIR PARAMETERS AFFECTING ENHANCED OIL RECOVERY}

\section{Contract No. DE-AC22-93BC14892}

\author{
Michigan Technological University \\ Houghton, Mich.
}

Contract Date: Sept. 29, 1993

Anticipated Completion: Sept. 30, 1996

Government Award: \$272,827

\section{Principal Investigator: James R. Wood \\ Project Manager: \\ Robert Lemmon \\ Bartlesville Project Office}

Reporting Period: Jan. 1-Mar. 31, 1995

\section{Objective}

The objective of this project is to provide the operators of small-to medium-size oil fields with the tools necessary for an enhanced oil recovery (EOR) evaluation of the same quality and sophistication that only large international oil companies have been able to afford to date.

\section{Summary of Technical Progress}

\section{Project Administration and Management}

\section{Spatial Database Manager}

Microsoft Visual Basic will be used to develop a spatial database manager (SDBM) shell/interface. This decision resulted from experiences in developing the multi-media program (MMP) shell for technology transfer. The evolution of both the MMP and the SDBM for technology transfer purposes has led to the use of Visual Basic as the programming tool of choice. As a result of development in the MMP, it has been determined that the MMP shell being developed can 
(with some planning and modification) provide an interface that can become an SDBM.

The SDBM will be a windows shell that provides access to an underlying database engine (Microsoft Access), a well log interpretation program (Crocker Petrolog), mapping and crosssection software [the GeoGraphix Exploration System (GES) Workbench], and a volume visualization application (yet to be determined). The SDBM will have the added benefit of online help and tutorial information.

\section{Database Management}

Data tables for geochemical and petrographic data, well logs, well header information, well production data, formation tops, and fault trace data are completed. Several additional tables will be developed to store information that is in image rather than in digital form, such as mud logs, drillers' logs, daily drill reports, and engineering reports. The decision was made to save digitized analog data [well logs, $\mathrm{X}$-ray and Fourier transform infrared (FTIR) spectral traces, etc.] in their native formats as individual files rather than reformatting them and transferring them to the Access database.

Cross-section and mapping software was evaluated. The GES Workbench was selected as the best system available because it is a seamless platform that provides the following capabilities: integrated database, digitization, land management, structural contouring, cross-section, deviated and horizontal well correction, reservoir evaluation, and economic estimation. It is fully integrated with the Windows environment and operates on a personal computer (PC).

\section{Data Collection}

Two cross sections through the study area are complete and three more are under construction with more to follow. The top of the Etchegoin formation and the top of the Miocene were correlated from the logs, and the top of the Miocene was mapped (Fig. 1). Digital Petrophysics Inc. (DPI) acquired county survey records that cover the project area and contain the State Plane coordinates for all surveyed section corners. DPI has also contacted a local surveyor to determine if other surveyed corners exist for the area.

\section{Data Collection, Analysis, and Measurement}

Contact was made with Chevron Petroleum Technology Co. for access to Chevron's technology in quantitative mineralogical characterization of reservoir rocks in exchange for collaborative involvement in the research effort. Several documents detailing Chevron's analytical procedures and quantitative data-reduction

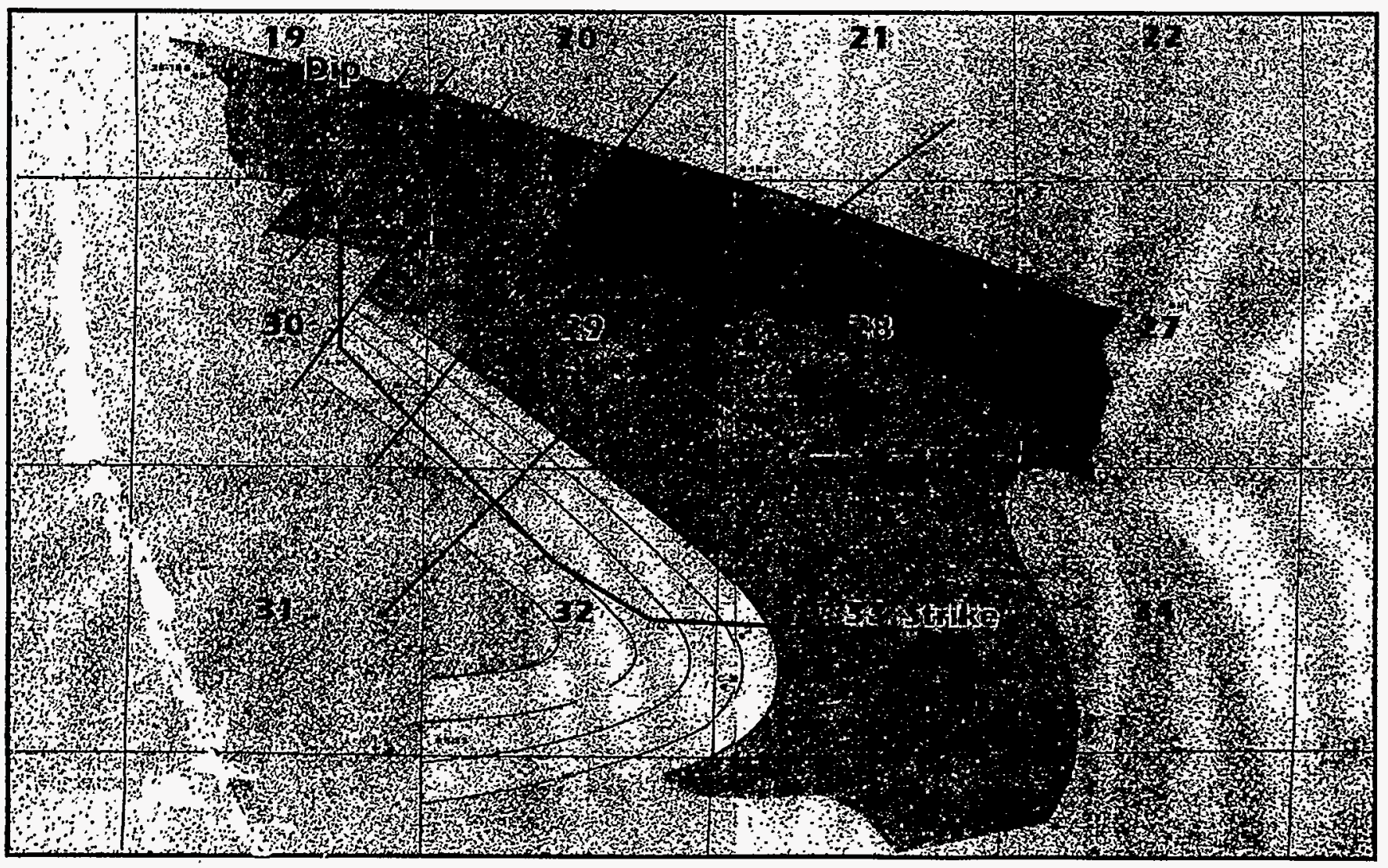

Fig. 1 Structure contour map on top of the Miocene. (Art reproduced from best available copy.) 
techniques were provided. Chevron has a proprietary code for computing the mineral percentages which they will use to run the calculations.

Spectral data on mineral standards are currently being collected for FTIR research at Michigan Technological University (MTU). Spectral data from standards will be input to a mathematical program that will generate non-negative leastsquares (NNLS) fits. The NNLS fits will be applied to FTIR spectral data gathered on core samples from the McKittrick Front wells and will be used for identification mineral assemblages.

The first set of specimens for scanning electron microscope (SEM) grain-mount examination and SEM/Energy Dispersive Spectroscopy (EDS) image analysis has been selected on the basis of optical petrographic analyses. Four grain mounts, one each from the Opal A, Opal A/Opal CT transitional, Opal CT, and chert diagenetic facies, will be examined for morphological character and phase changes. The grain-mount work will be done before image analysis because it will provide valuable information about spatial variations in microporosity and will therefore help guide the effort to understand and quantify porosity through image analysis. Optical petrographic analyses are complete for the 44 thin sections that have been prepared to date. Results include petrographic descriptions, $35 \mathrm{~mm}$ slides, and $35 \mathrm{~mm}$ prints of thin sections characteristic of each lithologic type.

Log normalization is complete, and parameter selection for the field study portion of the projecthas begun. A preliminary set of parameters was assembled last quarter from analysis of the cored wells. The parameter selection phase of the project will consist of extending these parameters to the rest of the project wells and ensuring that the analyses are valid and correct for all lithologies present.

\section{Modeling}

The geochemical modeling program CHILLER is being used to model fluid-rock interaction (Fig. 2). Investigation of the feasibility of porosity prediction with CHILLER is under way. Initial results show that identification and quantification of changes in porosity are possible. The geochemical mass transfer task was initiated this quarter.

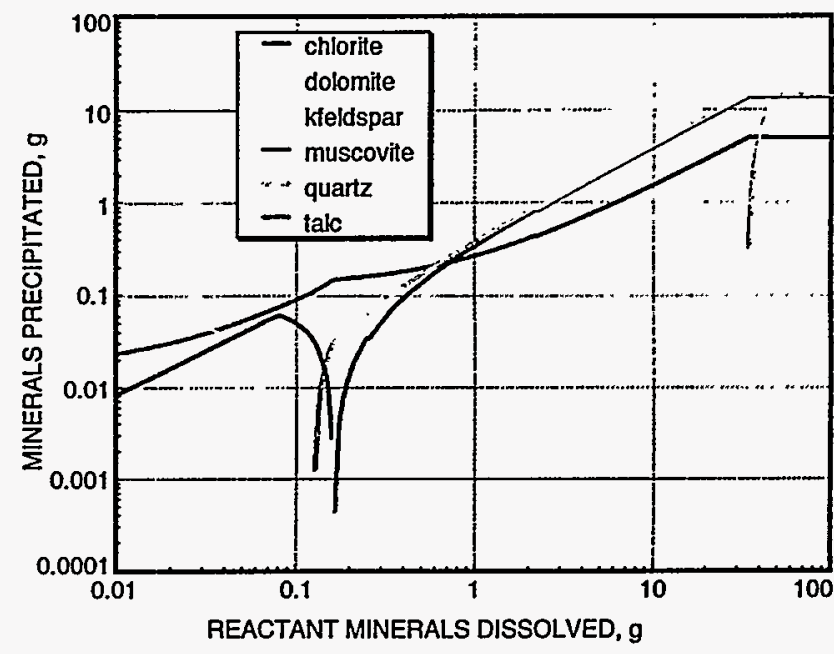

Fig. 2 Fluid-rock interaction.

\section{Technology Transfer}

Project members ran a booth in the Exhibits Hall at the American Association of Petroleum Geologists (AAPG) National Meeting in Houston, Tex., March 5-8, 1995. The booth included a poster display, which described project goals and progress to date, and a computer demonstration. Considerable interest was generated both in the project and in the multimedia program developed to achieve and display project results. Several independents and petroleum consultants were interested in the SDBM and MMP and asked to be kept abreast of project developments and to have quarterly reports mailed to them.

During this quarter decisions were made on graphics formats and on ways to keep interfaces consistent in the MMP. Scanned and digitized logs were added to the database, a compact disc containing all the MMP data and information was pressed, and the program was demonstrated at AAPG. Work is in progress to add hot links to the text, to find additional graphics formats that will work; and to further develop and refine the interface.

On January 19-20, 1995, a meeting was held at the University of South Florida to review both DOE projects. Each project member made a presentation. 


\section{RESOURCE ASSESSMENT TECHNOLOGY}

\section{CONTINUED SUPPORT OF THE NATURAL RESOURCES INFORMATION SYSTEM FOR THE STATE OF OKLAHOMA: INCLUSION OF A NATIVE AMERICAN FOCUSED EFFORT}

Contract No. DE-FG22-94BC14832

Oklahoma Geological Survey

University of Oklahoma

Norman, Okla.

Contract Date: Sept. 19, 1994

Anticipated Completion: Sept. 18, 1995

Government Award: $\$ 300,000$

Principal Investigators: Charles J. Mankin Mary Banken

Project Manager:

R. Michael Ray

Bartlesville Project Office

Reporting Period: Jan. 1-Mar. 31, 1995

\section{Objective}

The objective of this research program is to continue developing, editing, maintaining, using, and making publicly available the Oil and Gas Well History File portion of the Natural Resources Information System (NRIS) for the state of Oklahoma. This contract funds the ongoing development work as a continuation of earlier contract numbers DE-FG19-88BC14233,DE-FG22-89BC14483, andDE-FG2292BC14853. The Oklahoma Geological Survey (OGS), working with $\mathrm{Geo}$ Information Systems at the University of Oklahoma (OU) Sarkeys Energy Center, has undertaken the construction of this information system in response to the need for a computerized, centrally located library containing accurate, detailed information on the state's natural resources. Particular emphasis during this phase of NRIS well history development is being placed on oil and gas data for Osage County, which is under the authority of the Osage Tribal Council.

\section{Summary of Technical Progress}

The NRIS Well History File contains historical and recent completion records for oil and gas wells reported to the Oklahoma Corporation Commission (OCC) on Form 1002-A and reported to the Osage Tribal Council on the Osage County completion form. At the start of this quarter, the Well History File contained 382,807 records, providing geographical coverage for all of Oklahoma except the eastern portion of Osage County. Data elements on this file include American Petroleum Institute (API) well number, lease name and well number, location information, elevations, dates of significant activities for the well, and formation items (e.g., formation names, 
completion and test data, depths, and perforations). In addition to the standard Well History File process, special projects are undertaken to add supplemental data to the file from well logs, scout tickets, and core and sample documentation.

Processing of Oklahoma's oil and gas well completion reports (Form 1002-A and the Osage County form) is proceeding smoothly. Well records are being photocopied, prescanned, keyed, and edited for Osage County and for all new (or previously missing) records obtained from the OCC. Approximately 10,350 well records were keyed and added to the file this quarter. Thus, as of March 1995, there were 393,158 records on the database. The Well History File progress is shown by NRIS Regional Division in Table 1 . The current record counts by county are shown by Regional Division in Fig. 1 .

Both general and specialized edit procedures were continued on the well data. Search strategies are used to research well records with incorrect location data and well records that should be cross-referenced. Oklahoma Tax Commission (OTC) lease numbers are being assigned to well records through a combined machine and manual matching process between the lease and well files. Field names and codes are also added to well records on the basis of a matching process with field location data.

Although the geographical coverage for most of Oklahoma is considered complete, there are areas across the state in which

\section{TABLE 1}

Well History File Progress

\begin{tabular}{|c|c|c|c|c|}
\hline Area of coverage & $\begin{array}{l}\text { Start of } \\
\text { grant }\end{array}$ & $\begin{array}{l}\text { Start of } \\
\text { quarter }\end{array}$ & Current & $\begin{array}{l}\text { Quarter } \\
\text { increase }\end{array}$ \\
\hline Southeast region & 67,883 & 68,127 & 68,265 & 138 \\
\hline Southwest region & 72,955 & 73,284 & 73,517 & 233 \\
\hline Northeast region & 140,766 & 144,339 & 154,130 & 9791 \\
\hline Northwest region & 34,103 & 34,365 & 34,468 & 103 \\
\hline North-central region & 62,536 & 62,692 & 62,778 & 86 \\
\hline Total & 378,243 & 382,807 & 393,158 & 10,351 \\
\hline
\end{tabular}

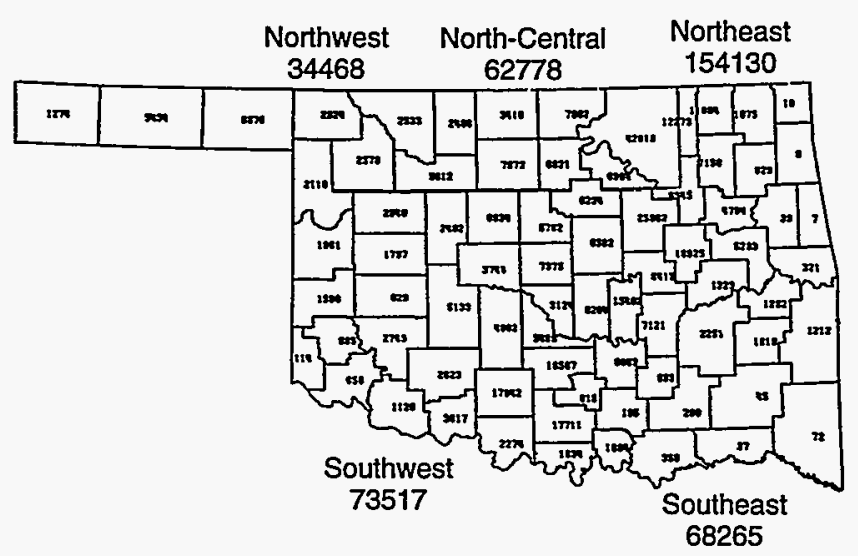

Fig. 1 Status of Well History database project as of Mar. 31, 1995. Total well records, 393,158. well completion reports are missing. Special efforts are being undertaken to identify these areas and obtain data on the missing wells (for example, the Lease File/Well File matching efforts described previously continue as a means of identifying areas with missing 1002-A forms). Identified wells that are not on the Well History File are sent to Sooner Well Log Service, and any missing 1002-A forms available through their collection are obtained and added to the file.

Efforts are ongoing to standardize the formation names on the Well History File. A personal computer(PC)-based program uses a conversion table to standardize spellings and allows the user to interactively build new entries for the conversion table as new spelling variations are encountered. Over $95 \%$ of the reported names in the state have been standardized through these efforts. This formations-editing process is further enhanced by the addition of a table to determine the standard Franklinized abbreviation for each reported name following the convention with which industry users are familiar.

One goal of the NRIS system involves efforts to assign leases and wells to fields on the basis of the official field outlines as designated by the Mid-Continent Oil and Gas Association's Oklahoma Nomenclature Committee (ONC). Some areas exist in which significant field extension drilling has taken place but the ONC has had insufficient resources to update the field boundaries accordingly. To assist the ONC in updating their field outlines, information packages are produced from the NRIS system for selected areas; these packages include well data listings and well spot maps. On the basis of this input, the ONC began by first updating several gas-field boundaries; emphasis has now shifted to oil-field boundaries as work proceeds on a separate U.S. Department of Energy (DOE) project involving the identification and evaluation of Oklahoma's fluvial-dominated deltaic reservoirs. Overall, unassigned gas production remains at $9 \%$ of the annual average production whereas $15 \%$ of the oil production is unassigned.

A data release was completed this quarter that included the first release of nearly 100 new data elements for the 1992 forms and the Osage County records. Documentation for those new data elements is under development.

\section{Public Data Release}

Since 1991 efforts have been made to disseminate NRIS information through meetings, workshops, OGS annual reports, and mass mailings to numerous individuals, companies, and organizations. As a result, a dramatic response to the release of NRIS data began during the summer of 1991 and has continued. Feedback from the public continues to reflect enthusiasm about this new resource for the oil and gas industry in Oklahoma. Data and analyses have been provided that would not have been feasible before construction of the NRIS system.

Two commercial firms subscribe to the Well History File, and several inquiries are received each quarter from small companies and independents who typically acquire NRIS subsets for particular project areas. NRIS well data are made available through the Oklahoma Geological Society Library 
with positive results. The high level of interest by library members has led to the acquisition of several thousand records by several members each quarter as well as constructive feedback on user-detected data anomalies. The Library is cataloging their extensive well-log collection and typing each log to the corresponding NRIS well record, which enhances efforts to locate missing well records.

The OGS is establishing a computing facility to promote user access to the NRIS data by Survey staff and by the public. This facility is scheduled to open to industry on June 1,1995 . Visual Basic user interfaces, along with a PC-level relational database management system (Oracle), are being developed to allow menu-driven retrieval systems customized to NRIS data. A new Novell network system has been installed to allow multiuser access to the databases. A large digitizer, large plotter, and desktop scanning equipment enhance the capabilities available through computer mapping software, such as ARC/INFO, a Geographical Information Systems spatial analysis tool. This quarter GeoGraphix Exploration Systems expanded its software donation to GeoInformation Systems and the OGS through their university program. Users in the computing facility can now benefit from multiuser access to contour mapping and production and log analyses programs that are widely used in industry. Additionally, Platte River Associates has donated their digital landgrid, which includes all the sections and townships for Oklahoma.

The NRIS data are a significant factor in several other in house projects. The lab described in the previous paragraph will become the central location for NRIS data access and distribution in the OGS's forthcoming role as Regional Lead Organization for the Southern Midcontinent under the Petroleum Technology Transfer Council program. Another project funded by DOE involves the study of Oklahoma's fluvial-dominated deltaic oil reservoirs and also includes technology transfer as an underlying goal.

\section{IMPROVED RECOVERY FROM GULF OF MEXICO RESERVOIRS}

\author{
Contract No. DE-FG22-95BC14802
}

\author{
Louisiana State University \\ Baton, Rouge, La.
}

Contract Date: Feb. 14, 1995

Anticipated Completion: Aug. 13, 1995

Government Award: \$1,266,667

\section{Principal Investigator: \\ P. Schenewerk}

\section{Project Manager: \\ Gene Pauling \\ Metairie Site Office}

Reporting Period: Jan. 1-Mar. 31, 1995

\section{Objectives}

This project is a 1-yr continuation of a research program to estimate the potential oil and gas reserve additions that could result from the application of advanced secondary and enhanced oil recovery technologies and the exploitation of undeveloped and attic oil zones in the Gulf of Mexico oil fields that are related to piercement salt domes. Work will continue in reservoir description, extraction processes, and technology transfer. Detailed data will be collected for two previously studied reservoirs: a South Marsh Island reservoir operated by
Taylor Energy and a South Pelto reservoir operated by Mobil. These data will include reprocessed two-dimensional (2-D) seismic data, newly acquired three-dimensional (3-D) data, fluid data, fluid samples, pressure data, well test data, well logs, and core data/samples. The new data will be used to refine reservoir and geologic characterization of these reservoirs. Further laboratory investigation will provide additional simulation input data in the form of pressure-volumetemperature (PVT) properties, relative permeabilities, capillary pressures, and water compatibility. Geological investigations will be conducted to refine the models of mud-rich submarine fan architectures used by seismic analysts and reservoir engineers. Research on advanced reservoir simulation will also be conducted. The research effort is being conducted in four major areas: (1) reservoir characterization, (2) simulation of extraction processes, (3) improved oil recovery, and (4) technology transfer.

\section{Summary of Technical Progress}

\section{Reservoir Characterization}

During this quarter work has concentrated on organizing, planning, and selecting the necessary data, software, and hardware.

\section{Simulation of Extraction Processes}

The modification of the BOAST simulator to incorporate adaptive, localized, grid-refinement capabilities with the use of finite methods continued. 



\section{RESERVOIR CLASS \\ FIELD DEMONSTRATIONS}

\section{APPLICATION OF INTEGRATED RESERVOIR MANAGEMENT AND RESERVOIR CHARACTERIZATION TO OPTIMIZE INFILL DRILLING}

Contract No. DE-FC22-94BC14989

Fina Oil and Chemical Company Midland, Tex.

Contract Date: June 13, 1994

Anticipated Completion: May 12, 1999

Government Award: \$1,174,264

Principal Investigator:

P. K. Pande

Project Manager:

Rhonda Lindsey

Bartlesville Project Office

Reporting Period: Jan. 1-Mar. 31, 1995

\section{Objective}

The objective of this project is to demonstrate the application of advanced secondary recovery technologies to remedy producibility problems in a typical shallow shelf carbonate reservoir of the Permian Basin, Texas. The technologies to be demonstrated are (1) development of an integrated reservoir description created with reservoir characterization and reservoir management activities and integration and modeling of the data from three-dimensional (3-D) simulation, (2) development of an integrated reservoir management plan through optimization of completion and stimulation practices and reservoir surveillance, and (3) field demonstration of the geologically targeted infill drilling and waterflood program.

\section{Summary of Technical Progress}

\section{Reservoir Characterization and Analysis}

\section{Geological Analysis}

The core-log rock typing algorithm is complete for all wells with the required modern well logs unit-wide. The algorithm is used to identify pay and nonpay rock types over the entire unit.

Correlative flow units (21 units) have been extended to include the Glorieta interval in all wells unit-wide. Structural and isopach maps for flow units and crossflow barriers were constructed to assist in the deterministic and geostatistical reservoir description. Predictive facies maps of primary pay, secondary pay, and nonpay rock types were constructed to show the distribution of rock types for each of the flow units.

The results of the geological analysis are being used as input parameters for the deterministic and geostatistical reservoir description and reservoir simulation studies. 


\section{Cross-Borehole Tomography}

Fina Oil and Chemical Co. has recommended to the U.S. Department of Energy (DOE) that no additional surveys be conducted. DOE approved this change in scope to the Statement of Work. The change was recommended because of operational difficulties and poor cost-benefit of the technology. In addition, theeffective application of this technology relies on the ability to obtain multiple surveys in a given area to provide a sufficient degree of confidence in the data. At present, it is economically and operationally difficult to support several surveys.

Data processing on the first cross-well survey on NRU 403 (source) and NRU 207 (receiver array) was completed by Reservoirs Imaging Inc. and Tomoseis. No results have been provided by Schlumberger.

The knowledge gained from the tomography will be passed on to industry through the project's technology transfer mechanisms.

\section{Fluid Properties Validation}

Fluid properties for the Upper and Lower Clearfork reservoir fluids were revised with pressure-volume-temperature (PVT)- $x$ for considering residual volume oil formation volume factor $\left(B_{0}\right)$ and solution gas-oil ratio $\left(R_{s}\right)$ in the differential liberation experiment. These properties have been provided to the University of Tulsa for the reservoir simulation initialization. No additional work in this area is planned.

\section{Reservoir Performance Analysis}

Production data for the North Robertson Unit (NRU) were analyzed with the use of material balance decline type-curve analysis. All primary (40-acre) and secondary (20-acre) producing wells were analyzed to determine total movable volumes and formation flow characteristics (permeability and skin factor) on the basis of individual well performance. Maps of original oil in place (OOIP), horizontal permeability (kh), and estimated ultimate recovery (EUR) with the use of primary production data and of kh and EUR with the use of secondary production data have been generated for comparison with the geological interpretation.

Decline type-curve and waterflood-performance analyses indicate that the NRU is not performing as well as expected under secondary recovery operations. This indicates the need for a complete review of the fluid flow behavior in the reservoir (required for reservoir simulation) and the completion/ stimulation procedures used in the past. This work is critical for the determination of the placement of the 10-acre-infill wells and for optimization of future completion and stimulation practices. In addition, a new waterflood performance type curve is being formulated to more accurately monitor the performance of individual wells and patterns.

Pressure-transient (buildup and falloff) data are being used to estimate reservoir pressure and formation flow characteristics. The estimated bottomhole pressures from buildup surveys conducted during 1987 to 1991 and the present pressure falloff tests were tabulated for use in the geostatistics and reservoir simulation. The analyses of the buildup tests indicate that the hydraulic fracture treatments were ineffective (short fracture half-lengths) in creating good pressure sinks at the wellbore because of the presence of large, discontinuous gross pay intervals containing many individual layers and possessing no effective barriers to vertical fracture propagation.

\section{Integrated Reservoir Description}

The stratigraphic and flow unit zonation of the Unit is complete and is being used for the deterministic and geostatistical reservoir description. A work meeting was held with the University of Tulsa in late February to ensure that all qualitative and quantitative aspects of the geological and engineering data are used for the reservoir description.

\section{Geostatistical Analysis}

A geostatistical reservoir description for the first modeling area is being generated by the University of Tulsa. A stepwise approach will be used to first complete spatial modeling of rock types by reservoir layer (variograms) and then to generate rocktype distributions. This is followed by the estimation of the petrophysical properties (porosity and permeability) consistent with the underlying rock type. The petrophysical parameters will be matched with the reservoir-scale well test data. A method of upscaling the foot-by-foot rock-type data to the grid block level will also be used.

\section{Reservoir Simulation}

The four areas for detailed reservoir simulation have been fine-tuned by considering reservoir performance attributes to define desirable features for infill drilling and poor candidate areas for infill drilling. Performance attributes of three of the four areas selected for detailed reservoir simulation indicated high productivity and poor connectivity.

The first simulation area is in sec. 329 and encompasses approximately 320 acres. Two PVT regions are being used, one for the Glorieta and Upper and Lower Clearfork and the second region for the Lower Clearfork. Available steadystate and unsteady-state relative permeability data are being used primarily to define displacement end points. Historical oil and water production data will also serve as relative permeability data for the history match. Initial water saturations will be obtained with well-log data from the 20-acre infill wells (which were drilled after unitization, 1987). Because these wells were drilled in virgin areas of the reservoir, they may be a reasonable reflection of initial water saturation. Calculations of water saturation on the original 40-acre producers would be difficult because of the lack of complete or accurate log suites for many wells drilled during the field's initial development. In addition, there are uncertainties as to the original water resistivity measurements.

Initially, a deterministic approach to reservoir description and history match will be used, and then a geostatistical reservoir description will be performed, from which the determination can be made if the geostatistical reservoir description provides a better history match. 
All the simulation areas have injectors as boundary wells, which is more practical for allocation. The assumption will be made that there is no flux across the modeling areas because they are located in multipatterned waterflood areas. From 18 to 32 wells are located in the modeling areas.

History match criteria have been developed and will primarily be production data because only limited reservoir pressure data are available.

\section{Integrated Reservoir Management}

Nine pressure falloff tests have been completed and one test in which surface pressure data acquisition is used is in progress. Initial results show that the current reservoir pressure in areas around the injection wells is between 3000 and 4000 psia. All the injection wells analyzed appear to be well stimulated; however, this is most likely the result of extensive fracture propagation caused by continuous injection at or near the fracture pressure of the formation. A few tests indicate that offset injection wells may be in contact with each other via hydraulic fractures.

Conformance control workovers will be considered to address this and other communication problems. These phenomena are typical waterfloods in low-permeability carbonate formations and result in early water breakthrough and poor sweep efficiency.

Falloff data acquisition will continue so that as much usable data as possible can be obtained for simulation history matching and subsequent infill drilling.

Additional bottomhole pressure buildup surveys are being recorded throughout the Unit to confirm the results of the pressure falloff program (in which surface pressure data acquisition is used) to provide further data for pressure matching during reservoir simulation and to locate areas of the reservoir (if any) that have not been effectively repressured. A new pressure data acquisition technique in which data are sent uphole real time with radio signals via the casing string will be used for several of the tests. The use of this emerging technology is believed to be in keeping with the goals of this project for the identification of such techniques. The cost of the survey is only slightly more than the usual pressure buildup test.

Available step-rate data were tabulated to determine the net increase in the required injection pressure rate over time and to help identify workover candidates. Additional tests cannot be accurately performed with surface (instead of bottomhole) gauges. Also, after the reservoir fill-up stage of the waterflood, the use of step-rate data to set individual well surface injection pressure limits should be discouraged because results no longer show the true fracture pressure of the reservoir because of pore pressure increases.
Thermal decay time (TDT) logs will be used to evaluate the current water saturation profile throughout the unit. The new data can be compared with original water saturation data for reservoir surveillance purposes and can be used as an additional history match parameter for reservoir simulation. Two surveys have been completed to date.

Additional analyses will be performed to identify the optimum completion and stimulation practices for the NRU wells. The results of the rock typing are being used to cross-check the existing completion intervals. A stimulation database will be set up to determine which stimulation methods, fluids, and volumes produce the best completions. Conformance workovers, used to ensure that the injected fluids (water) are being placed in the correct zones for optimum sweep efficiency, will also be studied and introduced.

\section{Technology Transfer}

Technology transfer activities this quarter included project personnel serving on conference programs and technical committees. One person is serving as Conference Co-Chairman and another is serving as Speaker Chairman for the 1996 Permian Basin Oil and Gas Recovery Conference. Others are serving on a joint Society of Petroleum Engineers (SPE)/ Society of Exploration Geophysicists (SEG) Forum Committee for the 1995-1996 SPE/SEG Forum on Application of Geophysics to Reservoir Development and Production.

Published papers and professional meeting presentations authored by project members include a paper presented at the 1995 American Association of Petroleum Geologists (AAPG) Annual Convention, ${ }^{1}$ a paper presented at the 1995 SPE Rocky Mountain Regional Meeting and Low Permeability Reservoirs Symposium, ${ }^{2}$ and a paper prepared for presentation at the 1995 Southwestern Petroleum Short Course. ${ }^{3}$

\section{References}

1. Flow Unit Modelling of a Heterogeneous Shallow Shelf Carbonate Reservoir (Clear Fork/Glorieta), North Robertson Unit, Gaines County, Texas, paper presented at the American Association of Petroleum Geologists Annual Convention, Houston, Tex., March 5-8, 1995.

2. An Integrated Geologic and Engineering Reservoir Characterization of the North Robertson (Clearfork Unit), Permian Basin, West TexasA Case Study, paper SPE 29594 presented at the SPE Rocky Mountain RegionalMeeting andLow Permeability Reservoirs Symposium, Denver, Colo., March 20-22, 1995.

3. An Integrated Geologic and Engineering Reservoir Characterization of the North Robertson (Clearfork Unit), Permian Basin, West TexasA Case Study, paper prepared for presentation at the Southwestern Petroleum Short Course, Lubbock, Tex., April 19-20, 1995. 


\section{THE USE OF INDIGENOUS MICROBES \\ TO SELECTIVELY PLUG THE MORE \\ POROUS ZONES TO INCREASE OIL \\ RECOVERY DURING WATERFLOODING}

\section{Contract No. DE-FC22-94BC14962}

\author{
Hughes Eastern Corporation \\ Jackson, Miss. \\ Contract Date: Jan. 1, 1994 \\ Government Award: \$524,983 \\ (Current year) \\ Principal Investigators: \\ Lewis R. Brown \\ Alex A. Vadie

\section{Project Manager: \\ Rhonda Lindsey \\ Bartlesville Project Office}

Anticipated Completion: June 30, 1999

Reporting Period: Jan. 1-Mar. 31, 1995

\section{Objective}

The objective of this work is to demonstrate the use of indigenous microbes as a method of profile control in waterfloods. It is expected that, as the microbial population is induced to increase, the expanded biomass will selectively block the more-permeable zones of the reservoir and thereby force injection water to flow through the less-permeable zones, which will result in improved sweep efficiency.

This increase in microbial population will be accomplished by the injection of a nutrient solution into four injectors. Four other injectors will act as control wells. During Phase I, two wells will be cored through the zone of interest. Special core analyses will be performed to arrive at the optimum nutrient formulation. During Phase II, nutrient injection will begin, the results will be monitored, and adjustments to the nutrient composition will be made, if necessary. This phase will also include the drilling of three wells for postmortem core analysis. Phase III will focus on technology transfer of the results. One outcome expected of this new technology is a prolongation of economical waterflooding operations (i.e., economical oil recovery should continue for much longer periods in the producing wells subjected to this selective plugging technique).

\section{Summary of Technical Progress}

\section{Phase I: Planning and Analysis}

Although the main purpose for drilling two wells was to obtain cores suitable for use in the laboratory work, a secondary purpose is to obtain production data that will indicate the sweep efficiency of the existing waterflood. At the conclusion of Phase I, a specific feeding regime will have been formulated for each of the injection wells. Because the injection wells all vary in terms of years of service, differences in channeling are anticipated, and a different feeding regime may be needed for each well. The work for Phase I of the project was divided into seven tasks. Five of these tasks, drilling of two new injection wells for the acquisition of core and other data, on-site handling of cores, core analysis to determine microbial enhanced oil recovery requirements, microbial analyses of cores, and laboratory waterflooding test of live cores, are complete. Work on the other two tasks, acquisition of baseline data and analysis of baseline data, is in progress.

\section{Acquisition of Baseline Data}

Chemical and microbiological analyses of injection water and production fluid are continuing and have been expanded to include all four patterns. Test patterns (control and test) involve 8 injectors and 28 producers. Routine tests are being conducted on the water to determine calcium carbonate, chloride, nitratenitrogen, phosphate, potassium, sulfate, sulfide, aerobic heterotrophs, anaerobic heterotrophs, aerobic oil-degrading bacteria, and anaerobic oil-degrading bacteria. Routine tests are being conducted on oil to determine aliphatic profile, gravity, viscosity, and surface and interfacial tension. Test data received from Hughes Eastern Corp. for wells located in all patterns (pilot and control) were entered into the database for the calculation of flow variation gas/oil ratio (GOR), and water/oil ratio (WOR).

\section{Analysis of Baseline Data}

The analysis of baseline data will begin when the data are collected.

\section{Phase II: Implementation}

This phase involves initiation of nutrient injection and the analysis of results.

\section{Task 2.1: Design of Field Demonstration}

Construction of the first nutrient injection skid was completed during the fourth quarter of 1994 . The skid was designed for mixing the dry nutrients into a solution made with field waterflood water and with the capability of pumping 100 to $300 \mathrm{gal}$ of solution per day at a pressure of $1300 \mathrm{psi}$.

Construction of three additional nutrient injection skids was completed in January 1995. The three skids were identical to the first one with the exception that the compressed air-powered injection pump was replaced with a more efficient direct-current (dc) electric-driven triplex pump.

The second injection pattern to receive nutrients was Test PatternNo.3; of which the North Blowhorn CreekUnit(NBCU) 11-5 No. 1 well is the injector. On Jan. 16, 1995, the same nutrient formulation as that used in Test Pattern No. 1 (NBCU 2-14 No. 1 well) was used to initiate nutrient injection into well 
NBCU 11-5 No. 1. Water injection into the well averaged $784 \mathrm{bbl} / \mathrm{d}$ at 1142 psi during February 1995.

The third and fourth injection pattems to receive nutrients were Test Pattern Nos. 2 and 4, of which the NBCU 34-9 No. 2 and 2-6 No. 1 wells, respectively, are the injectors. Nutrient injection into these two pattems began on February 27, 1995. The nutrient injection formula was modified from the previous two patterns to include inject of $0.1 \%$ molasses one day a week as a supplemental carbon source. During March 1995, the average water injection rate into NBCU $34-9$ No. 2 was $326 \mathrm{bbl} / \mathrm{d}$ at $1086 \mathrm{psi}$, and the average rate into NBCU 2-6 No. 1 was $425 \mathrm{bbl} / \mathrm{d}$ at $1188 \mathrm{psi}$.

To date, no injection problems have been experienced in any of the four wells receiving nutrients. Laboratory studies with cores are being run that parallel the nutrient injection in the field. If a problem were to arise from the use of molasses, the problem would be seen in the laboratory and could be corrected in the field before any harm is done. No problems have been experienced. No positive production response is expected in any of the producing wells until late 1995 at the earliest.

During the present quarter, analysis of produced water in Test Pattern No. 1 continued for the detection of tritium tracer, which was injected into NBCU 2-14 No. 1 on April 27, 1994. To date only one well, NBCU2-13 No. 1, has shown production of the tracer. Tracer production in that well peaked during January 1995. Through March 1995, it is estimated that the NBCU 2-13 No. 1 has produced about $30 \%$ of the total tracer injected.

\section{GREEN RIVER FORMATION WATERFLOOD DEMONSTRATION PROJECT, UINTA BASIN, UTAH}

Contract No. DE-FC22-93BC14985

\author{
Lomax Exploration Company \\ Salt Lake City, Utah \\ Contract Date: Oct. 21, 1992 \\ Anticipated Completion: Oct. 20, 1995 \\ Government Award: $\$ 1,304,000$ \\ Principal Investigators: \\ John D. Lomax \\ Dennis L. Nielson \\ Milind D. Deo \\ Project Manager: \\ Edith Allison \\ Bartlesville Project Office
}

Reporting Period: Jan. 1-Mar. 31, 1995

\section{Objective}

The project is designed to increase recoverable petroleum reserves in the United States. The Green River Formation in Utah's Uinta Basin contains abundant hydrocarbons that are hard to recover by primary means. The successful Lomax Monument Butte Unit waterflood will be evaluated under this contract, and, on the basis of this information, waterfloods will be initiated in nearby Travis and Boundary units. In 1987, Lomax Exploration Company started a waterflood in the Monument Butte Unit of a Douglas Creek member of the Green River Formation. This was a low-energy, geologically heterogeneous reservoir producing waxy crude oil. Primary production yielded about $5 \%$ of the original oil in place (OOIP). As a result of the waterflood project, total production will yield an estimated recovery of $20 \%$ OOIP.

\section{Summary of Technical Progress}

\section{Field Drilling and Production Results}

The Monument Butte Unit is being extended mainly on the west side and on the north side. Many of the new wells have only recently been completed. A new well No. 5-33 that was drilled and completed in the Travis Unit continues to produce oil and gas. Well No. 12-21 was drilled and completed in the Boundary Unit.

\section{Modeling the Boundary Unit}

A reservoirmodel for the Boundary Unit was produced. This was the most complicated reservoir model developed during the project. An effort was made to represent reservoir geology (porosity and thickness) at 2-ft resolution. Two types of reservoir models were developed: one without hydraulic fractures and one with hydraulic fractures. The simpler of the two models, without hydraulic fractures, is described in this report. This model had a total of 28 layers and about 6000 grid blocks.

\section{Reservoir Description}

Six wells in the Boundary Unit (Nos. 7-20, 9-20, 15-20, 5-21, 11-21, and 13-21) are complete in different regions. Out of these, well No. 5-21 has been shut down and has never been operational. The remaining five wells encompass different regions of essentially six types of sands [i.e., $D_{1}, D_{2}, C$, Castle Peak (CP), Lower Douglas Creek (LDC), and $\left.A_{3}\right]$. General descriptions of each of these sandstones follow.

$D_{1}$ sandstone. This is the uppermost sand layer and is present at an average depth of $5235 \mathrm{ft}$. $\mathrm{D}_{1}$ sandstone is located in well No. 13-21 only and has a gross thickness of $11 \mathrm{ft}$ and a net thickness of $6 \mathrm{ft}$. This sandstone is quite compact with an average porosity of $11.3 \%$. Because $D_{1}$ sandstone is located in well No. $13-21$ only, it is limited to a narrow region in the unit. 
$\mathbf{D}_{2}$ sandstone. The $\mathrm{D}_{2}$ sandstone is present in the maximum number of wells, covering four out of the five productive wells (i.e., Nos. 7-20, 9-20, 5-21, and 13-21). Log analyses have shown this sandstone to be divided into lobes; the lobes are separated layers of shale. Well No. 7-20 has $30 \mathrm{ft}$ of net $\mathrm{D}_{2}$ ( $36 \mathrm{ft}$ gross), which is divided into two lobes of 8 and $22 \mathrm{ft}$. The upper lobe of $8 \mathrm{ft}$ has an average porosity of $16.0 \%$, whereas the lower $22 \mathrm{ft}$ lobe has an average porosity of $16.2 \%$. The lower lobe of well No. 7-20 has a water-oil contact at a depth of about $10 \mathrm{ft}$ from the top. This complicates its modeling and representation in the simulator.

Well No. 9-20 has $11 \mathrm{ft}$ of net $D_{2}$ sandstone, which is also divided into two lobes of 6 and $5 \mathrm{ft}$ each. The log analysis shows the sand to be highly porous with an average porosity of $18.67 \%$ in the upper lobe and $18.0 \%$ in the bottom lobe.

Well No. $5-21$ has $13 \mathrm{ft}$ of net $\mathrm{D}_{2}$ (20 ft gross), which again is present in two lobes of 6 and $7 \mathrm{ft}$. The average porosities are $14.67 \%$ in the upper lobe and $13.71 \%$ in the lower lobe.

Well No. 13-21 also has $D_{2}$ in two lobes with net thicknesses of 4 and $12 \mathrm{ft}$ with average porosities of 15.0 and $17.0 \%$ for the upper and lower lobes, respectively.

A structural gradient also exists in the Boundary Unit. Well No. 7-20 is downdip of well No. 9-20, which is completed in zones structurally below well No. 13-21. The fact that oil-water contact was observed in well No. 7-20 is consistent with the reservoir structure.

C sandstone. $\mathrm{C}$ sandstone is present in two wells (i.e., Nos. 7-20 and 11-21). In well No. 7-20, there is net thickness of $7 \mathrm{ft}$ of $\mathrm{C}$ with an average porosity of $15.28 \%$. In well No. 11-21, $C$ sandstone is present in two lobes that are 9 and $6 \mathrm{ft}$ thick. The upper $9 \mathrm{ft}$ has an average porosity of $14.22 \%$, and the lower $6 \mathrm{ft}$ has an average porosity of $15.0 \%$. On the basis of the stratigraphic locations, the upper lobe of $\mathrm{C}$ sandstone in well No. 11-21 is represented to be communicating with the sand in well No.7-20, but the bottom lobe in well No. 11-21 is not in communication with any other well.

LDC sandstone. The LDC sandstone is present in well No. 15-20 only and has a net thickness of $41 \mathrm{ft}$ (54 ft gross). It is divided into three lobes. The upper lobe has a net thickness of $5 \mathrm{ft}$ and an average porosity of $12.6 \%$, the middle lobe has a net thickness of $13 \mathrm{ft}$ and an average porosity of $14.0 \%$, and the bottom lobe has a net thickness of $23 \mathrm{ft}$ and an average porosity of $13.6 \%$. Because LDC is present in well No. 15-20 only, this well does not communicate with any other well.

$\mathbf{A}_{3}$ sandstone. This sandstone is found in two wells (i.e., Nos. 7-20 and 9-20) only. The net $25 \mathrm{ft}$ of $A_{3}$ in well No. 7-20 is divided into three lobes with net thicknesses of $9 \mathrm{ft}, 6 \mathrm{ft}$, and $10 \mathrm{ft}$ and average porosities of $15.56,12.33$, and $14.6 \%$ in the upper, middle, and lower lobes, respectively. Well No. 9-20 has two lobes of $A_{3}$ sandstone. The upper lobe has a net thickness of $5 \mathrm{ft}$ and an average porosity of $13.2 \%$, whereas the lower lobe has a net thickness of $3 \mathrm{ft}$ and an average porosity of $11.67 \%$.

CP sandstone. The CP sandstone is present in well Nos. 9-20 and 5-21. This is the deepest sand in the reservoir. Well Nos. 13-21 and 11-21 were not drilled deep enough to verify the presence or absence of this sandstone in other areas of the reservoir. In well No. 5-21, CP sandstone is present as two beds with net thicknesses of sands of 2 and $8 \mathrm{ft}$ and average porosities of $11.0 \%$ each. In well No. 9-20, the sandstone has three components of 5,8 , and $6 \mathrm{ft}$ net and average porosities of $11.8,12.5$, and $13.67 \%$ in the upper, middle, and lower lobes, respectively. The beds are at the same stratigraphic horizons in both wells. The two lobes in well No. 5-21 are thus assumed to be communicating with the upper and the middle lobes in well No.9-20, whereas the bottom lobe in well No. 9-21 is independent.

\section{Simulation Analysis}

A 28-layer, $16 \times 13$ grid model was used to perform reservoir simulation of the Boundary Unit. The 28 layers consist of 14 oil-bearing sandstone layers, 1 aqueous layer, and the rest impermeable shale barriers separating the sandstones. Every attempt was made to incorporate the geologic information available as accurately as possible in the simulation data. A general description of the Boundary Unit is shown in Table 1. Computed average values of porosity were assigned to different layers, although the data were available at 2 - $\mathrm{ft}$ intervals because representing separate 2 - $\mathrm{ft}$ layers individually would have greatly increased the number of grid blocks and thus made a single simulator run impossible in a reasonable amount of computer processing unit (CPU) time, even on fast SPARC10 machines. In the order of increasing depths, the 14 oil-bearing layers were $D_{1}$ (1 layer), $D_{2}$ (2 layers), $C$ (2 layers), LDC (3 layers), $A_{3}$ (3 layers), and CP (3 layers). The parameters used in the simulation of the Boundary Unit are given in Table 2. The water-oil contact in well No. 7-20 was modeled as a separate aqueous layer directly beneath the lowest $D_{2}$ sandstone layer in well No.7-20. Assumptions were made as to the extent of the aquifer because enough data are not available to establish its extent. A comparison of the actual and simulated cumulative oil and cumulative gas produced in the Boundary Unit is shown in Figs. 1 and 2, respectively.

TABLE 1

\begin{tabular}{ll}
\hline Reservoir Description of the Boundary Unit \\
\hline Reservoir extent, $\mathrm{ft}$ & $7920 \times 6600$ \\
Grid & $16 \times 13 \times 28$ \\
Grid size (x and y), ft & Varying from 760 to 200 \\
Oil gravity, ${ }^{\circ} \mathrm{API}$ & 33 \\
Gas gravity & 0.77 \\
Initial oil saturation & 0.78 \\
Bottomhole pressure, psi & 1000 \\
\hline
\end{tabular}


TABLE 2

Reservoir Parameters Used in Simulation of Boundary Unit

\begin{tabular}{rrrrrr}
\hline $\begin{array}{c}\text { Layer No. in } \\
\text { the model }\end{array}$ & $\begin{array}{c}\text { Sand } \\
\text { identification }\end{array}$ & $\begin{array}{c}\text { Porosity, } \\
\%\end{array}$ & $\begin{array}{c}\text { Initrial reservoir } \\
\text { pressure, psi }\end{array}$ & $\begin{array}{c}\text { Bubble-point } \\
\text { pressure, psi }\end{array}$ & $\begin{array}{r}\text { Oil in } \\
\text { place, } \\
\text { MSTB }\end{array}$ \\
\hline 1 & D1 & 0.1133 & 2356 & 2300 & 253.6 \\
3 & D2 & 0.161 & 2388 & 2350 & 1370.0 \\
5 & D2 & 0.1623 & 2395 & 2360 & 1945.1 \\
8 & C & 0.15 & 2440 & 2400 & 679.2 \\
10 & C & 0.15 & 2444 & 2405 & 315.9 \\
12 & LDC & 0.126 & 2605 & 2550 & 50.3 \\
14 & LDC & 0.14 & 2614 & 2550 & 460.9 \\
16 & LDC & 0.136 & 2626 & 2550 & 739.5 \\
18 & A3 & 0.144 & 2609 & 2550 & 841.8 \\
20 & A3 & 0.12 & 2615 & 2575 & 376.1 \\
22 & A3 & 0.146 & 2636 & 2600 & 304.1 \\
24 & CP & 0.114 & 2760 & 2600 & 116.7 \\
26 & CP & 0.1175 & 2764 & 2650 & 340.4 \\
28 & CP & 0.1367 & 2768 & 2700 & 125.9 \\
\hline
\end{tabular}

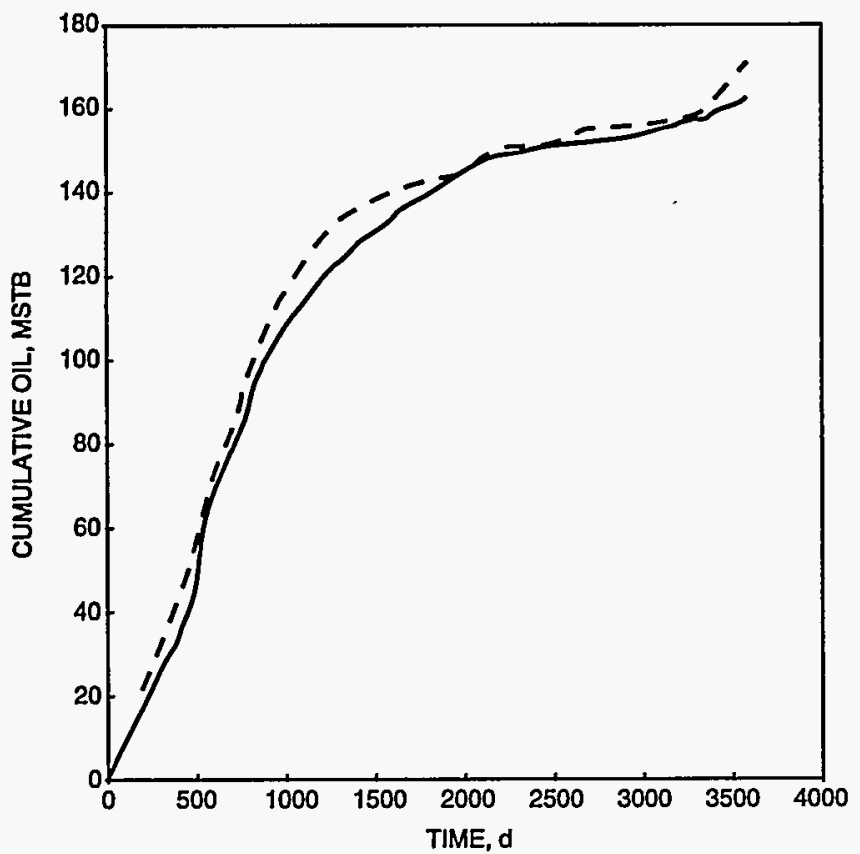

Fig. 1 Cumulative oil production from the Boundary Unit: comparison of actual (-) and simulated (- -) values. MSTB, thousand stock tank barrels.

\section{Technology Transfer}

A paper entitled "Solids Precipitation in Reservoirs Due to Nonisothermal Injections" was presented at the International Oil Field Chemistry Symposium in San Antonio, Tex., in February $1995 .{ }^{1}$

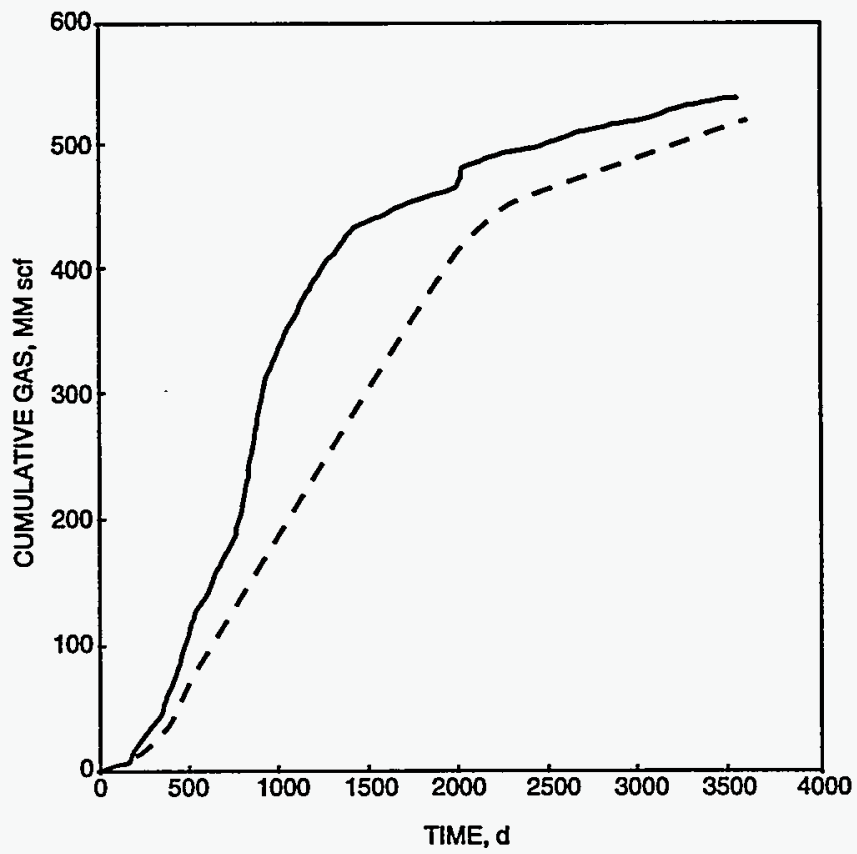

Fig. 2 Cumulativegasproduction from theBoundary Unit. Comparison of actual $(-)$ and simulated $(--)$ values. MM scf, million standard cubic feet.

\section{Reference}

1. M.D. Deo, A. Miharia, and R. Kumar, Solids Precipitation in Reservoirs Due To Nonisothermal Injection, paper SPE 28967 presented at the SPE International Symposium on Oil Field Chemistry, San Antonio, Tex. February 14-17, 1995. 


\section{IMPROVED RECOVERY DEMONSTRATION FOR WILLISTON BASIN CARBONATES}

\author{
Contract No. DE-FC22-94BC14984 \\ Luff Exploration Company \\ Denver, Colo. \\ Contract Date: June 10, 1994 \\ Anticipated Completion: June 9, 1997 \\ Government Award: $\$ 483,284$ \\ Principal Investigator: \\ Larry A. Carrell \\ Project Manager: \\ Chandra Nautiyal \\ Bartlesville Project Office
}

Reporting Period: Jan. 1-Mar. 31, 1995

\section{Objectives}

The objectives of this project are to demonstrate targeted infill and extension drilling opportunities, better determinations of oil in place, methods for improved completion efficiency, and the suitability of waterflooding in certain shallow-shelf carbonate reservoirs in the Williston Basin in Montana, North Dakota, and South Dakota.

\section{Summary of Technical Progress}

\section{Reservoir Characterization}

\section{Core Studies}

Five key Ordovician Red River formation slabbed cores from Bowman County, N. Dak., and Harding County, S. Dak., were examined and described in detail at the U.S. Geological Survey (USGS) Core Research Center, Lakewood, Colo. Documentation of all important rock facies, sedimentary structures, and diagenetic fabrics was completed via numerous closeup photos and 35-mm slides. The core work to date consists of approximately 380 linear feet $(116 \mathrm{~m})$ of slabs that provide excellent coverage of the lower porosity member of the Red River in the study area (see Table 1 and Fig. 1). A small amount of upper and middle Red River porosity member core was examined, but additional material currently at the North Dakota Geological Survey Core Depository (Grand Forks, N.Dak.) and the South Dakota Geological Survey (Vermillion, S. Dak.) is being identified for detailed study of the upper two Red River zones. Thirty-eight standard thin sections from four wells in the area were borrowed from the USGS for petrographic description under polarized and blue-light epi-fluorescence techniques as well as photo-documentation. A few additional thin sections may be prepared to microscopically examine key facies and diagenetic features in the cores studied to date. In addition, the USGS records were searched to obtain the results of previous core descriptions, core analysis, and other geological work for the Red River study area. Finally, published literature, previous core studies, and Luff Exploration Co. data on the Red River were reviewed so that earlier work could be integrated into the current Red River reservoir characterization.

A preliminary depositional and early diagenetic model was developed for the lower porosity member of the Red River formation (see Fig. 2) because it is the best represented within the core work to date. Many of the burrow-mottled rocks of the lower member are believed to be the result of storm-wave pumping on a storm-dominated shelf of shallow to moderate water depth. The modified tempestites that result in the best quality dolomite reservoirs were originally carbonate sands (grainstones and packstones) that were introduced into open burrow systems within shelf muds during major storm events. Dolomitization, differential compaction, and stylolite formation were largely controlled by the distribution of probable linear bands of tempestite burrow fills. Subsequent fracturing with solution enlargement developed orientations largely controlled by stylolite formation. This new integrated depositional and diagenetic model for the lower Red River zone for the project area should assist in determining the best reservoir development strategies.

Efforts have been made to locate cores for the Mississippian Ratcliffe member of the Charles formation in Richland County, Mont., and McKenzie County, N. Dak. Core material is very limited for the study area, but two or three key cores may be available within the collections of the North Dakota Geological Survey and the Montana Board of Oil and Gas (Billings, Mont.). These cores will be examined, described, and photodocumented. Appropriate samples will be selected for thinsection analysis. The limited number of pertinent cores may be supplemented with examinations of drill cuttings from key wells.

\section{TABLE 1}

\section{Red River Cores Processed}

Luff 1-6 Travers (SWSE sec. 6, T. 22 N., R. 5 E.)

API 40-063-20072

Red River lower member: 8957 to $9022 \mathrm{ft}$ (gross $65 \mathrm{ft}$ )

Depco 22-24 Travers (SENW sec. 24, T. 22 N., R. 4 E.)

API 40-063-20082

Red River lower member: 9070 to $9130 \mathrm{ft}$ (gross $50 \mathrm{ft}$ )

Depco 42-27 Federal (SENE sec. 27, T. 22 N., R. 5 E.)

API 40-063-20043

Red River lower member: 9019 to $9070 \mathrm{ft}$ (gross $51 \mathrm{ft}$ )

Tenneco 1-6 Schaaf (SESE sec. 6, T. 129 N., R. 103 W.)

API 33-011-00432

Red River upper member: 9275 to $9303 \mathrm{ft}$ (gross $28 \mathrm{ft}$ )

Amarillo 1-24 Ernest Fossum (NWNE sec. 24, T. 130 N., R. 104 W.)

API 33-011-00157

Red River upper member: 9419 to $9470 \mathrm{ft}$ (gross $51 \mathrm{ft}$ )

Red River middle member: 9504 to $9557 \mathrm{ft}$ (gross $53 \mathrm{ft}$ )

Red River lower member: 9583 to $9653 \mathrm{ft}$ (gross $70 \mathrm{ft}$ ) 


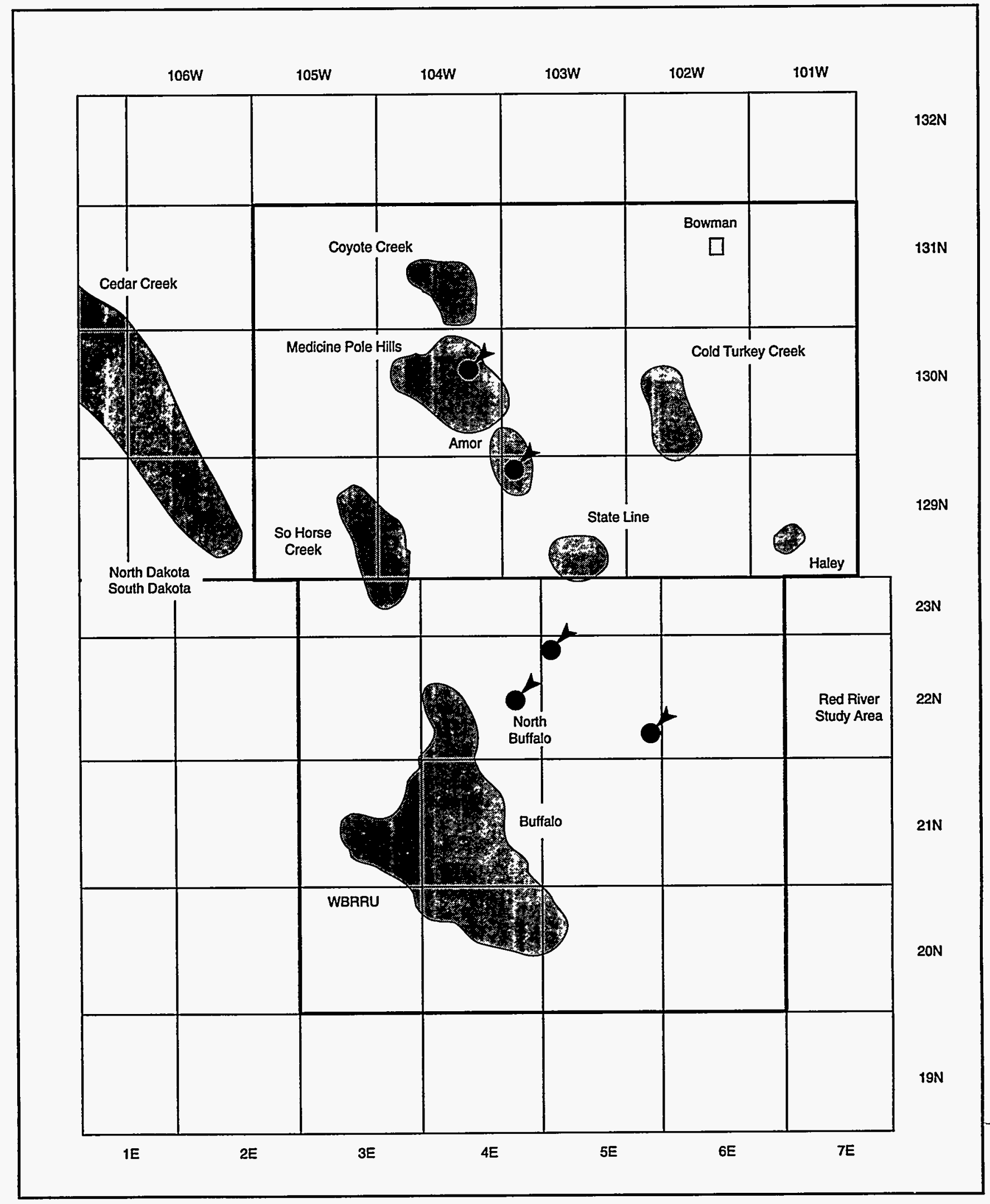

Fig. 1 Bowman-Harding Red River study area map showing locations of Red River cores that have been examined and described for the project. 


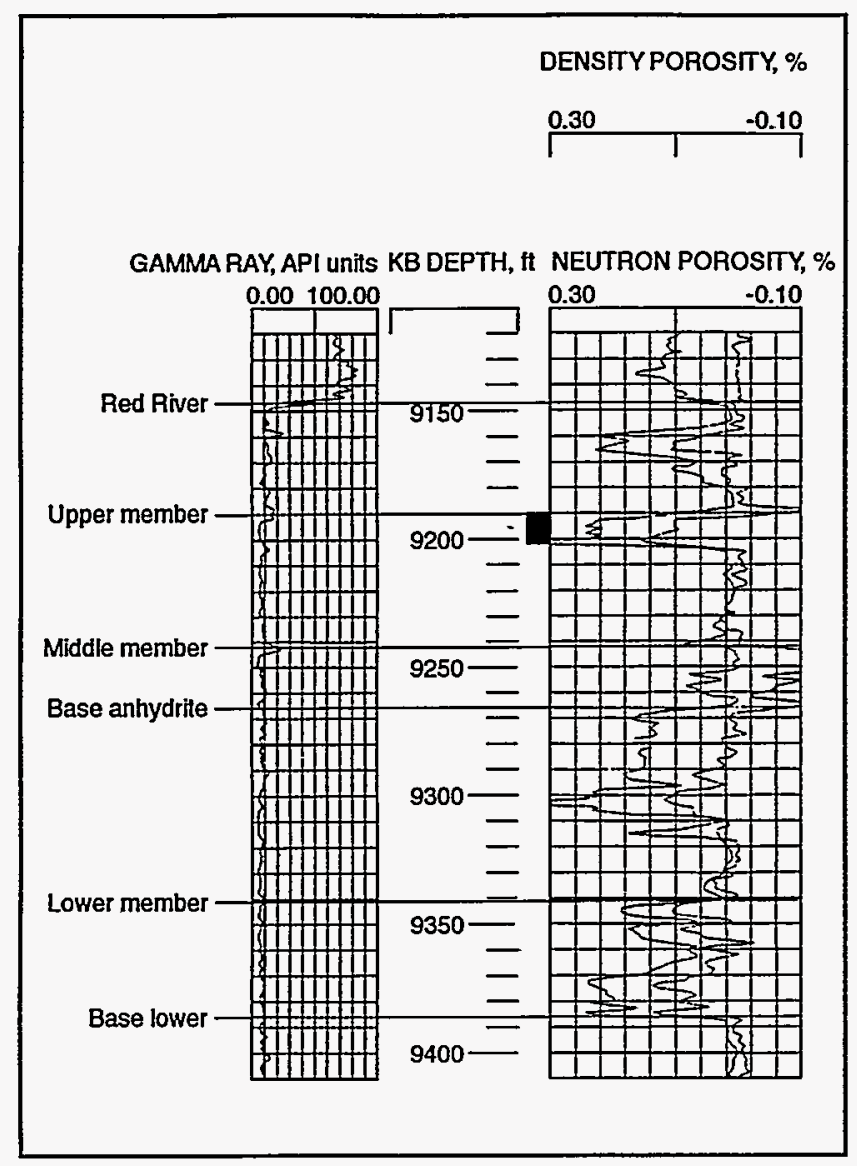

Fig. 2 Red River type-log showing development of the upper, middle, and lower porosity members. $\log$ is from the A-19 Stearns, North Buffalo field area (sec. 19, T. 22 N., R. 4 E., Harding County, S. Dak.).

\section{Three-Component Seismic Acquisition}

A contract was awarded to Reliable Exploration Inc. for acquisition of a 2.5 -mile, two-dimensional (2-D), threecomponent test line. This test is expected to aid in the determination of the application of shear waves for fracture detection in the North Sioux Pass (Ratcliffe), T. 26 N., R. 57-58 E., Richland County, Mont., study area (see Fig. 3). Permit and weather problems delayed acquisition. It became necessary to relocate the line to avoid skipped shots for water wells, and additional delays occurred. The line has been surveyed and should be drilled by late April or early May 1995 . The special three-component geophone strings were rented from the Colorado School of Mines and shipped to Billings, Mont., for testing in Reliable field office before being sent to Sidney for operations. The area is still experiencing some late spring snowfall, which might delay shot-hole drilling, but it is not expected to hamper recording once the source holes are drilled and loaded.

\section{Seismic Interpretation}

Three additional sets of 1970s vintage 2-D data were selected for reprocessing and interpretation. Two lines for a total of 7.0 miles in the Mrnak area (T.130N., R $102 \mathrm{~W}$.) and three lines (9.51 miles) in the Haley area in T. 129 N., R. 101 W. were

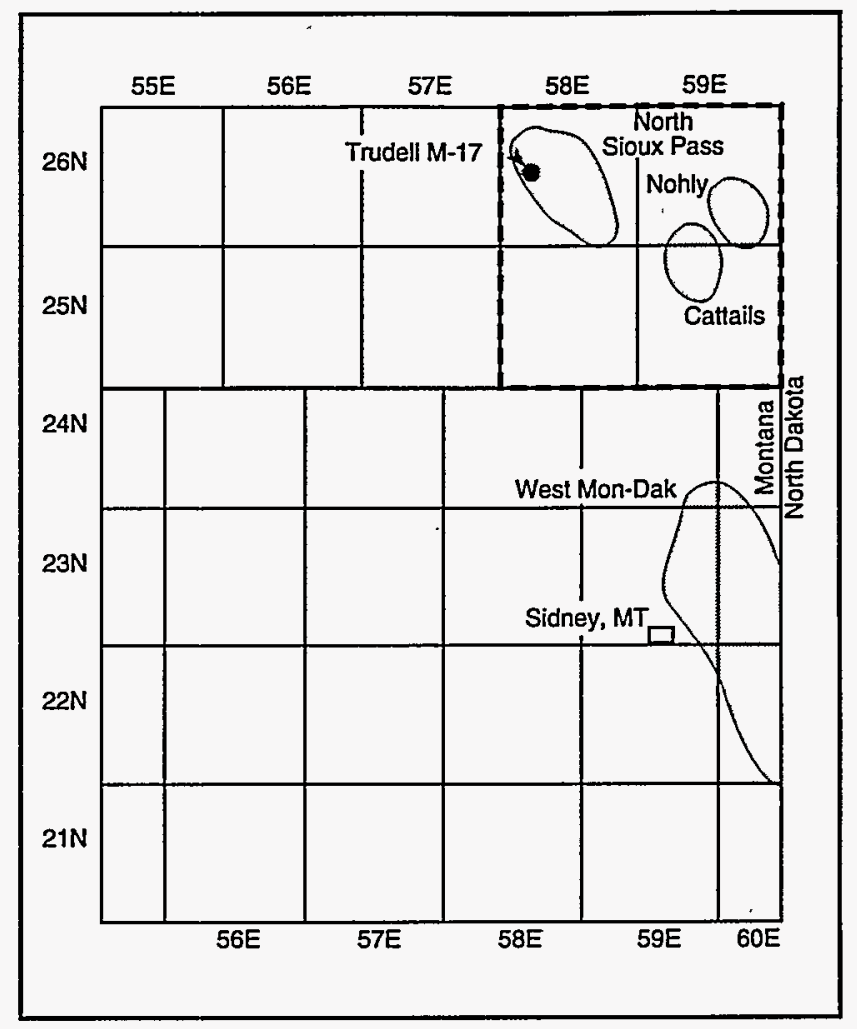

Fig. 3 Richland-Ratcliffe study area map showing location of Trudell M-17 well. This well had been used for pressure-transient testing before jetting-lance stimulation workovers.

reprocessed with radon stack and refraction statics. Two lines (8.33 miles) werealso added in the Stateline (T. 129N., R. 103 W.) area (see Fig. 4). These data have been interpreted and incorporated into a series of detailed study area seismic maps for Bowman County, N.Dak. The Haley area shows two large faults with some suggestion of lateral displacement along them. The Stateline area is complex and has a significant number of midsize faults. The Mrnak area is a northwest extension of the Cold Turkey Creek area and has a similar structural trend.

\section{3-D Seismic Acquisition}

Reliable Exploration Inc. has been contracted for the acquisition of a 4.35-square-mile three-dimensional (3-D) seismic survey in the Cold Turkey Creek (Red River) area (T. 130 N., R. 102 W., Bowman County, N. Dak.). The area was permitted and surveyed in anticipation of acquisition in March 1995. Approximately one-third of the 378 source holes were drilled and loaded with dynamite. The unusually warm winter has resulted in periodic snowfall followed by brief warm periods. Muddy conditions have prevented the use of heavy drilling equipment in the area, and therefore the remaining source holes have not been drilled. Where other crews have attempted operations in the northern part of the basin, environmental surface damage has been severe. Reliable Exploration Inc. has made progress on the project and expects to complete itrapidly when the area becomes dry. Acquisition may not commence before May 1, 1995. 


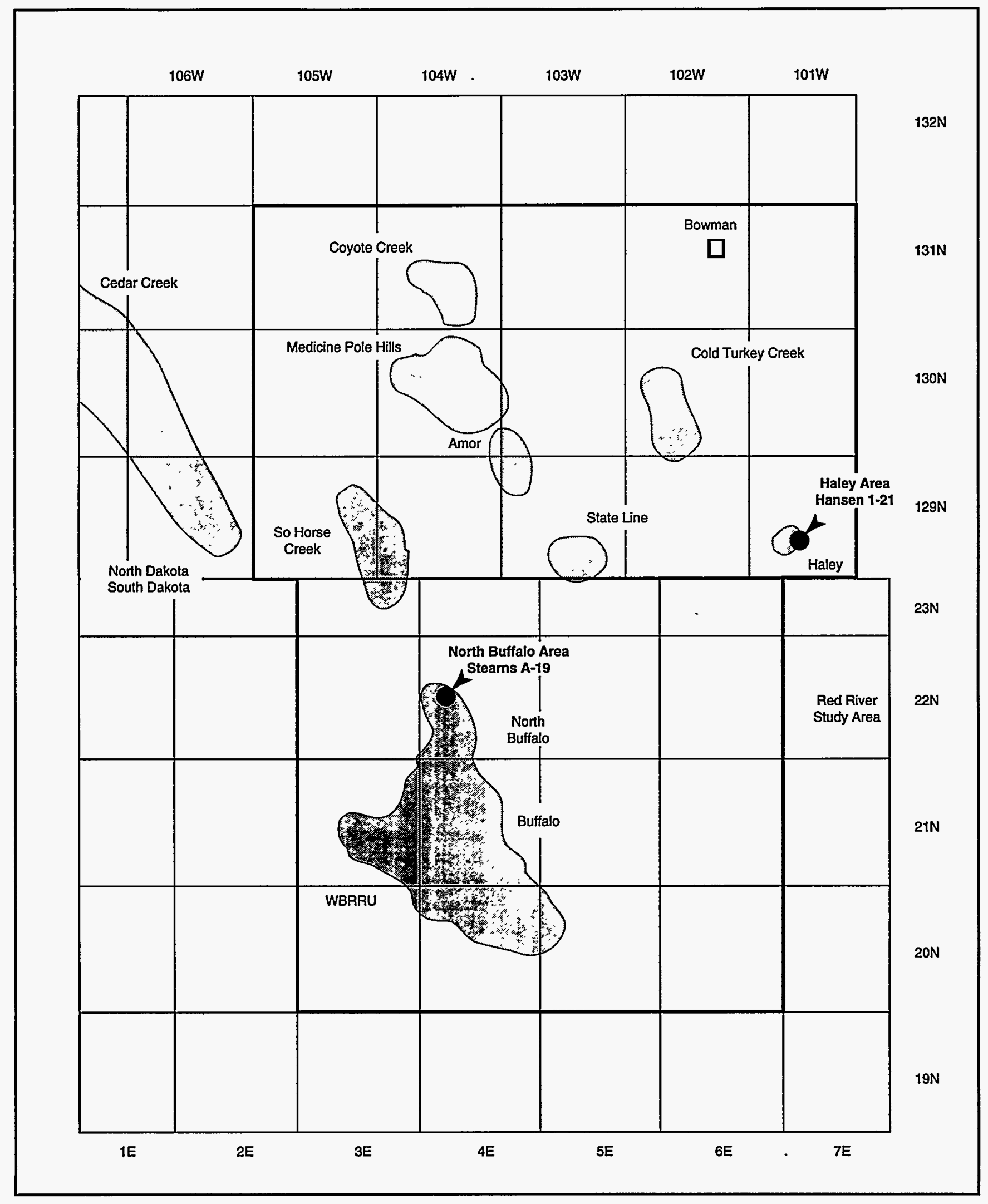

Fig. 4 Bowman-Harding Red River study area map showing locations of the Hansen 1-21 and Stearns A-19 wells. These wells had been used for pressure-transient testing before jetting-lance stimulation workovers. 


\section{Geological Evaluations}

Regional structure and isopach interpretations were completed in the four-township Richland-Ratcliffe study area. Well log data were used to complete depth structure of the Ratcliffe with isopachs of the Last Charles Salt, Ratcliffe, and MidaleBakken intervals.

Regional mapping of structure and isopachs is near completion in the Bowman-Harding Red River study area. Red River depth-structure is complete. Isopachs of the GreenhornMission Canyon, Mission Canyon-Interlake, Interlake-Red River, and Red River are near completion for the 40 -by 24 -mile regional study area.

\section{Project-Related Field Data for Selected Fields}

Preliminary engineering and geological descriptions of four of six key Red River fields in the Bowman-Harding area (Medicine Pole Hills, North Buffalo, West Buffalo Red River B Unit, and South West Amor) are complete. These Red River fields have been under or are candidates for secondary recovery. Data have been tabulated per guidelines from the U.S. Department of Energy (DOE) ProjectManager(Coop. Agreement Attach-ment C-6 through C-13) for inclusion in the Project Data Set.

\section{Producibility Problem Characterization}

Extended-time pressure buildup data were obtained from Trudell M-17 (Ratcliffe) and Hansen 1-21 (Red River) to provide baseline data for permeability thickness $(\mathrm{kh})$ and stimulation factor (S). These baseline data are part of the reservoir characterization attributes being collected for each reservoir study area and will also be used for comparison after jetting-lance stimulation work.

\section{Trudell M-17 (Ratcliffe) Pressure Buildup Evaluation}

The Trudell M-17 well (North Sioux Pass field area, API No. 25-083-200932, sec. 17, T. 26 N., R. 58 E., Richland County, Mont.) was completed in the Ratcliffe reservoir in March 1993 after an unsuccessful completion in the Red River. The well was perforated from 8701 to $8759 \mathrm{ft}$ and fracture stimulated with $105,000 \mathrm{gal}$ of gel-water and $204,000 \mathrm{lb}$ of sand. The neutron-density porosity log of the completion interval is shown in Fig. 5. Net productive thickness of the Ratcliffe member is indicated to be about $10 \mathrm{ft}$ with an average porosity of $10 \%$. Porosity development based on log data is better than average for the Ratcliffe member in the immediate area. The well had an initial rate of $77 \mathrm{bbl}$ of oil per day (BOPD) with 65 bbl of waterper day (BWPD) and a cumulative oil production of $15,430 \mathrm{bbl}$ as of Mar. 31, 1995. Production history is shown in Fig. 6.

The production rate vs. time and cumulative plots show a sharp initial decline and shallow decline rate after a period of 6 months. The water cut has been relatively constant at $55 \%$ of fluid production. Similarly, the gas/oil ratio is also constant from 500 to $700 \mathrm{scf} / \mathrm{bbl}$. Fetkovich production type-curve

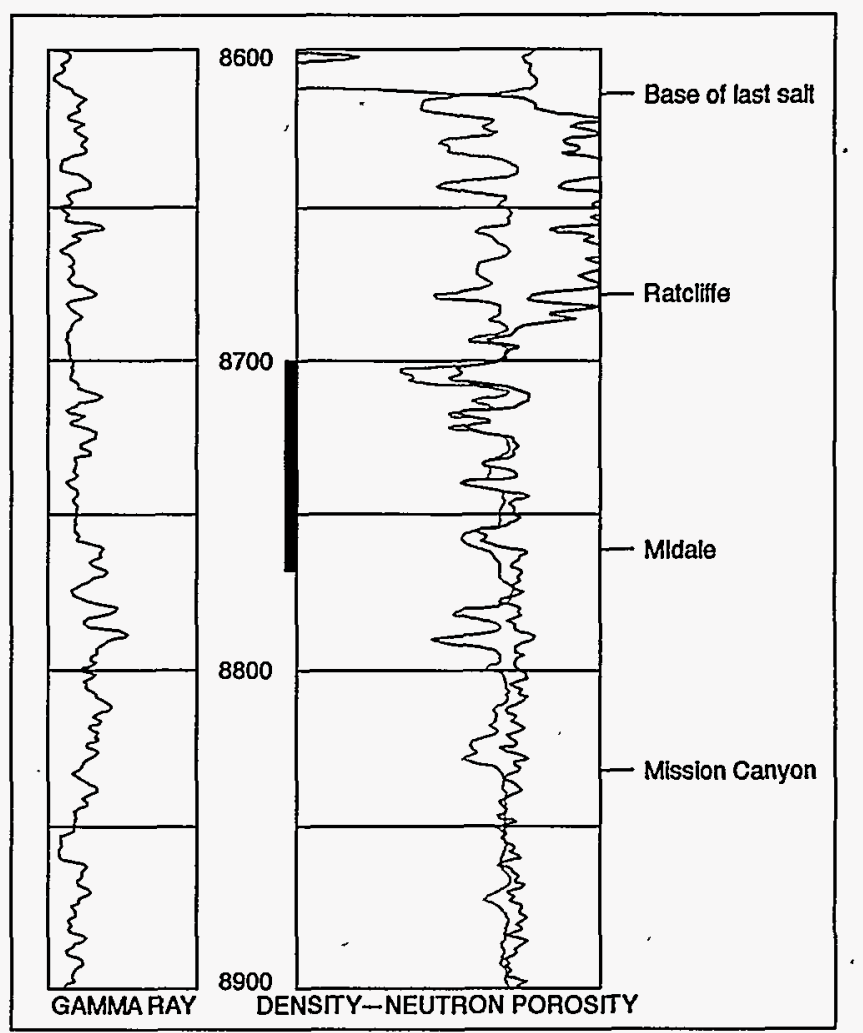

Fig. 5 Gamma-ray with density-neutron porosity $\log$ from the Trudell M-17 well (sec. 17, T. 26 N., R. 58 E., Richland County, Mont.) in the Ratcliffe reservoir.

analysis ${ }^{1-2}$ indicates a small radius/drainage (Rd) ratio of 10 , and that production is still in the transient-flow regime even after $2 \mathrm{yr}$ (see Fig. 7). The expected ultimate recovery from the type-curve analysis is 57,000 stock tank barrels (STB), or $12 \%$ of original oil in place (OOIP), in the 129-acre drainage area. The apparent drainage area of 129 acres is based on certain assumptions of fluid and reservoir properties. The primary properties affecting this calculation are system compressibility of $25 \times 10^{-6} \mathrm{vol} / \mathrm{vol} / \mathrm{psi}$ and $10 \mathrm{ft}$ of net pay with $12 \%$ porosity (see Fig. 7 for all parameters).

A pressure buildup test was performed in November and December 1994 with a total shut-in time of $332 \mathrm{~h}$. The producing rate at the time of the buildup test was 20 BOPD and 20 BWPD (pumping). An automated acoustic recorder with computer software was used to convert echo travel time and casing pressure to bottomhole pressure. A significant characteristic of the pressure datais exhibited by a semi-log Miller-DyesHutchison (MDH) plot in Fig. 8. The pressure trend with the logarithm of time is upwárdly curving throughout the test, which indicates a large negative skin in a low-permeability matrix. Indeed significant negative skin is expected from the largevolume fracture stimulation that was applied to the Ratcliffe.

The transmissibility $(\mathrm{kh} / \mu \mathrm{B})$ to oil is about $7 \mathrm{mD}-\mathrm{ft} / \mathrm{cP}$. The relative permeability to oil $\left(\mathrm{k}_{\mathrm{ro}}\right)$ is calculated to be $0.5 \mathrm{mD}$. At late time on the $\mathrm{MDH}$ plot, there is an upwardly break in slope. This suggests a linear boundary such as a fault. The distance to 


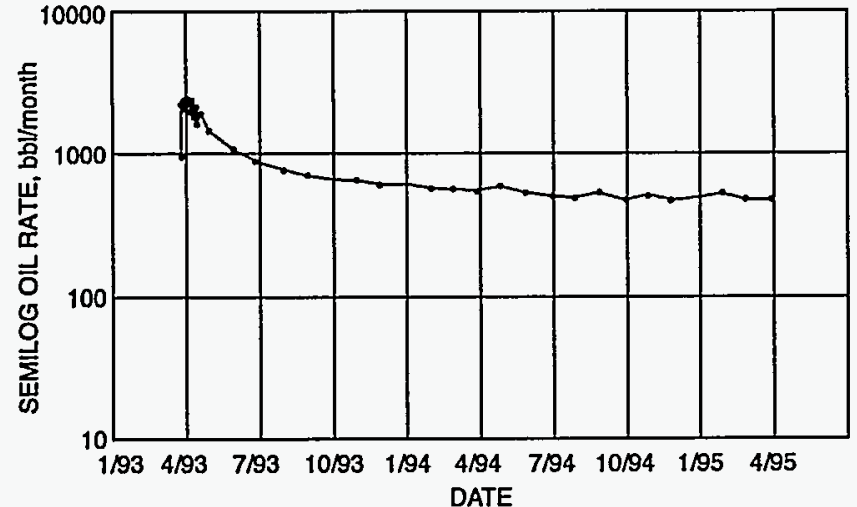

(a)

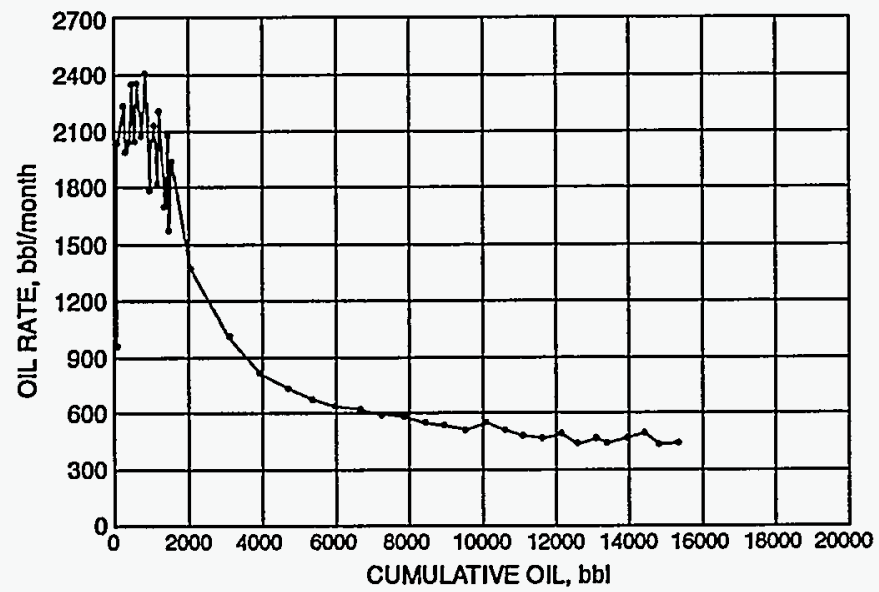

(b)

Fig. 6 Production signature plots [semilog oil rate vs. time (a) and oil rate vs. cumulative oil (b)] from the Trudell M-17 (Ratcliffe) (sec. 17, T. 26 N., R. 58 E., Richland County, Mont.).

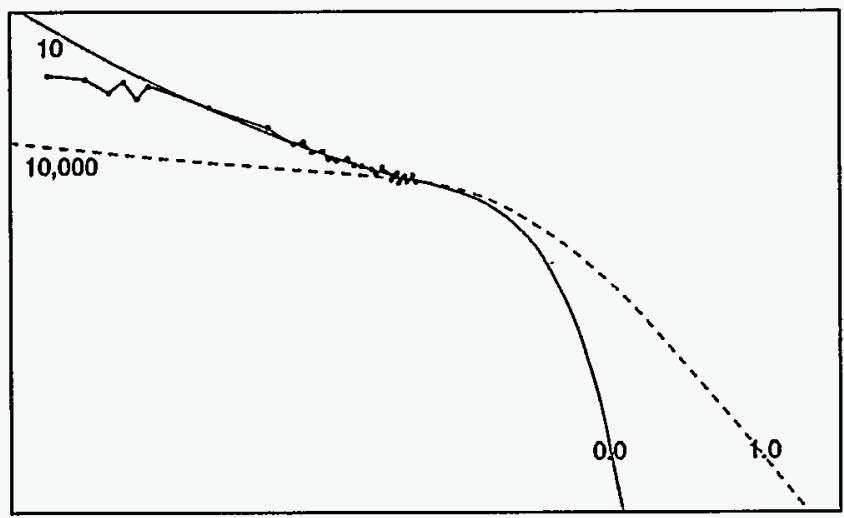

Rd: 10.000

Re: $1342.172 \mathrm{ft}$

Rw: $134.217 \mathrm{ft}$

S: -5.816

k: $0.095 \mathrm{mD}$

Cti: $25.000 \times 10^{-6}$

b: 0.000

Fig. 7 Fetkovich production type-curve match of data from the Trudell M-17 (Ratcliffe). A small radius/drainage (Rd) ratio of 10 indicates a large negative skin or a nonradial shape factor. The apparent drainage area is 129 acres.

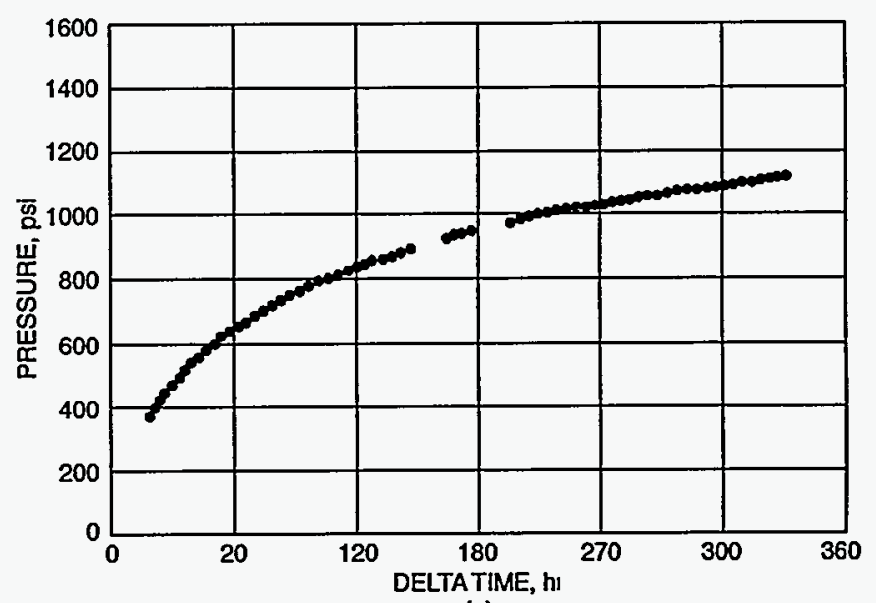

(a)

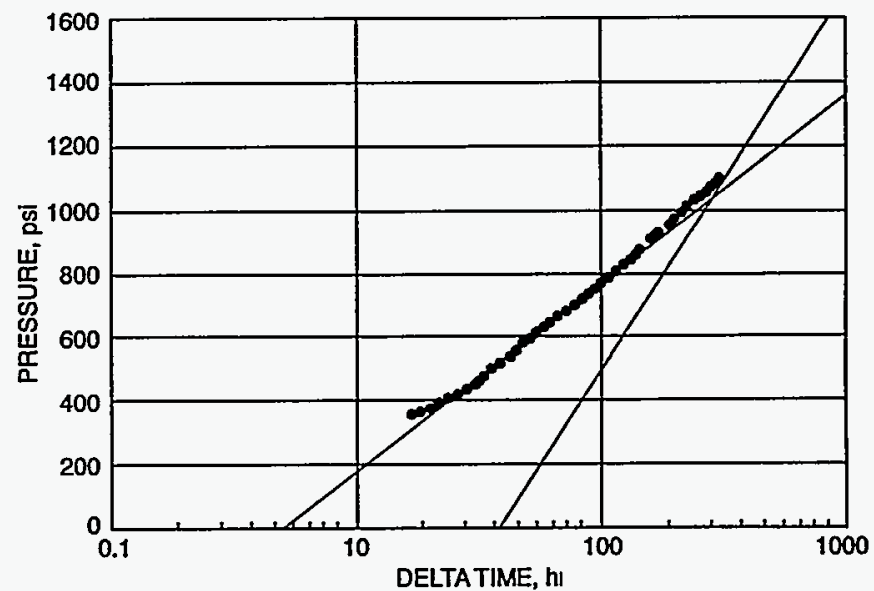

(b)

Fig. 8 Pressure buildup plots from the Trudell M-17 (Ratcliffe). A slope change during late time on the Miller-Dyes-Hutchinson (MDH) plot suggests a linear barrier. (a) Cartesian plot. (b) MDH analysis.

this possible linear boundary is $140 \mathrm{ft}$. The presence of a linear boundary and wellbore storage makes it difficult to confidently determine the skin factor (s) and effective fracture length. Semilog and radial type-curve analyses indicate an sof -4 to -5 . Analysis with the use of Greengarten infinite-conductivity fracture curves also indicates a $\mathrm{kh} / \mu \mathrm{B}$ to oil of $4 \mathrm{mD}-\mathrm{ft} / \mathrm{cP}$, $\mathrm{k}_{\mathrm{ro}}$ of $0.3 \mathrm{mD}$, and a fracture half-length of about $150 \mathrm{ft}$. The radius of investigation for the buildup test is from 290 to $370 \mathrm{ft}$ with $\mathrm{k}_{\mathrm{ro}}$ of $0.3 \mathrm{mD}$.

The Ratcliffe member was drill-stem tested when it was penetrated during drilling operations. The test recovery was only drilling mud at a calculated flow rate of $8 \mathrm{bbl} / \mathrm{d}$. Typecurve and semilog analyses of the drill-stem test (DST) data indicate a transmissibility $(\mathrm{kh} / \mu \mathrm{B})$ of 3 to $4 \mathrm{mD}-\mathrm{ft} / \mathrm{cP}$ and an initial reservoir pressure of about $3800 \mathrm{psi}$. The results from this DST are considered a poor show because most DSTs of the Ratcliffe yield some frothy oil with oil-cut mud.

Analysis of the production data with the use of the typecurve method of Fetkovich indicates a small Rd ratio of 10 , a $\mathrm{k}_{\mathrm{ro}}$ of about $0.1 \mathrm{mD}$, and an $\mathrm{s}$ of -5.8 (see Fig. 7). This method yields a $k_{\mathrm{ro}}$ that is about 20 to $33 \%$ of the values determined from pressure-transient analysis methods and greater negative 
skin. It is postulated that a reason for the indications of lesser permeability and greater negative skin factor is the presence of a linear boundary, which is suggested from the pressurebuildup analysis. The presence of a linear flow barrier (a possible fault) would change the drainage shape factor from radial and result in underestimation of permeability and overestimation of the stimulation effect. The presence of a flow barrier can explain why the well performance has been less than expected with the criteria of favorable porosity development based on log character.

The Trudell M-17 well is scheduled for workover with the use of jetting-lance technology. Following this work, the well will be produced for 4 to 6 weeks and shut in for a pressure buildup test.

\section{Hansen 1-21 (Red River) Pressure Buildup Evaluation}

The buildup test data for the Hansen 1-21 well (Haley field area, API No. 33-011-31900, sec. 21, T. 129 N., R. 101 W., Bowman County, N. Dak.) from Oct. 18 to Nov. 1, 1994, indicate nonradial drainage. The final bottomhole pressure was about $1550 \mathrm{psi}$ and still building after $329 \mathrm{~h}$ of shut-in time. A possible cause for the nonradial flow is a nearby fault or series of parallel faults.

The Hansen 1-21 well was drill-stem tested in the Red River upper member on Aug. 6, 1980. The test has a calculated flow rate of about $177 \mathrm{BOPD}$ with no water reported for the pipe or sample chamber recovery. The transmissibility $(\mathrm{kh} / \mu \mathrm{B})$ from the test data is calculated to be $38 \mathrm{mD}-\mathrm{ft} / \mathrm{cP}$ and is near the mean value from the many DST data of the Red River upper member in the Bowman-Harding area. In 1980, the initial extrapolated pressure was $3930 \mathrm{psi}$, which was slightly less than the original pressure of 4200 psi at the Jett 1-28 well (offset well located about 0.5 mile toward the southwest; see Fig. 4). The difference between the initial and final extrapolated pressures of the DST is $91 \mathrm{psi}$. This pressure drop may suggest a limited or bounded reservoir. At the time of completion of the Hansen 1-21 well, reasoning was that the reservoir surrounding the Hansen 1-21 should not be limited if the Hansen 1-21 DST indicated communication (drawdown) with the Jett 1-28 well. On the basis of the DST data, the conclusion is that the productivity or transmissibility of the upperRed River member in the Hansen 1-21 is about twice that of the Jett 1-28 well.

The Hansen well was perforated in the Red River upper member and stimulated with 2000 gal of $15 \%$ hydrochloric acid $(\mathrm{HCl})$. A copy of the porosity log from the Hansen well is shown in Fig. 9. The peak production rate was $80 \mathrm{BOPD}$ with 23 BWPD on the second day of production. Production quickly declined to 25 BOPD with 15 BWPD after 2 weeks. As of March 1995, cumulative production is 33,961 bbl of oil.

Production signature plots for the Hansen 1-21 well are shown in Figs. 10 and 11. Type-curve analysis of the production data indicates a low $\mathrm{k}_{\mathrm{ro}}$ of $0.06 \mathrm{mD}$ with an apparent large negative skin (s) of -5.6 . The ultimate recovery from the Red River upper member is projected to be $8.9 \%$ of the OOIP $(375,000 \mathrm{bbl})$, and the apparent drainage area is 85 acres. The

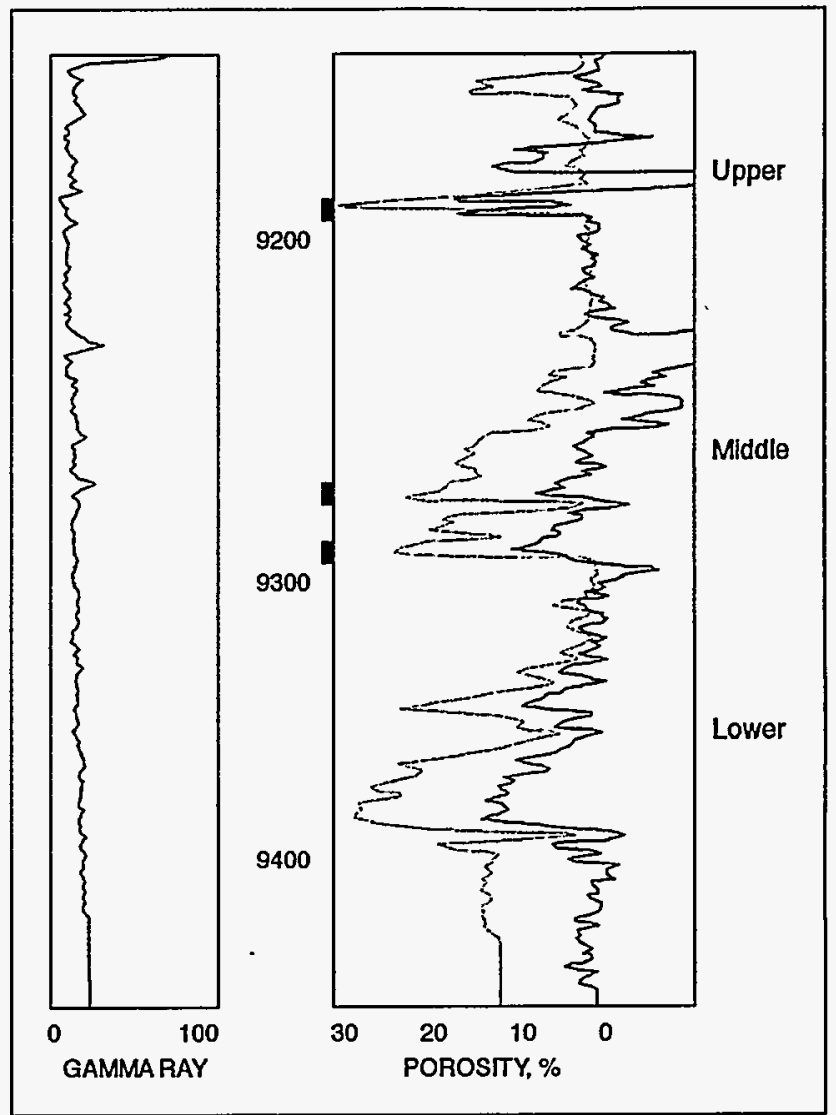

Fig. 9 Gamma-ray with density-neutron $\log$ from the Hansen 1-21 (Haley) well. Four holes were made in each of the upper and middle Red River porosity members with jetting-lance tools.

primary properties affecting this calculation are system compressibility of $25 \times 10^{-6} \mathrm{vol} / \mathrm{vol} / \mathrm{psi}$ and $6 \mathrm{ft}$ of net pay with $20 \%$ porosity (see Fig. 11 for all parameters).

The pressure data exhibit an upward-curving trend with the logarithm of time and do not bend over (see Fig. 12). Conventional MDH semilog analysis of the late-time trend indicates a transmissibility of $1.6 \mathrm{mD}-\mathrm{ft} / \mathrm{cP}$ and an $\mathrm{s}$ of -4.3 ; however, a better analysis is achieved by analytical simulation methods of the well between two parallel faults. A good history match of the pressure data can be achieved with this reservoir model and also with the transmissibility from the DST ( $36 \mathrm{mD}-\mathrm{ft} / \mathrm{cP}$ ). In simulation of the DST pressure data, a better history match is produced with the parallel-fault reservoir model than with a radial reservoir model. With the parallel-fault model, the initial pressure of the Red River upper member in the Hansen well is nearly $4200 \mathrm{psi}$ and closely matches the original pressure of the Jett 1-28 well in March 1974. Acceptance of this reservoir model leads to the conclusion that the two wells are not in good hydraulic communication.

Reinterpretation of 2-D seismic data in the Haley area indicates probable subtle faulting very near the Hansen 1-21 well. This fault trend runs northwest-southeast. The presence of a fault or series of parallel faults can explain the poor performance of the Hansen 1-21 well compared with the results from the DST. 


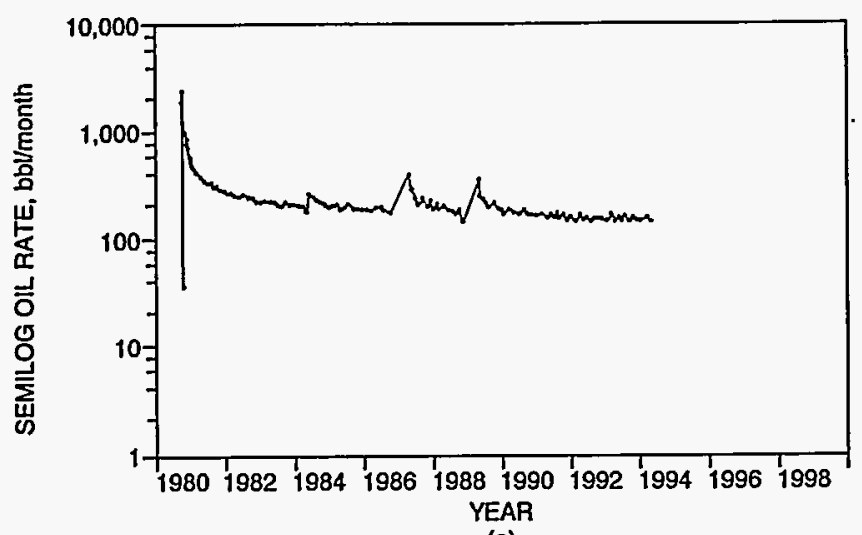

(a)

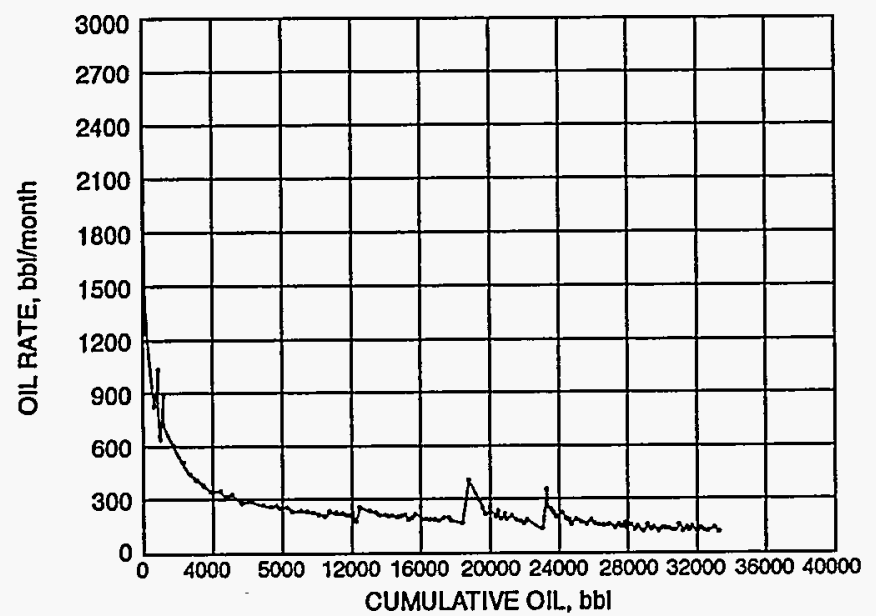

(b)

Fig. 10 Production signature plots [semilog oil rate vs. time (a) and oil rate vs. cumulative oil (b)] from the Hansen 1-21 (Red River) (sec. 21, T. 129 N., R. 101 W., Bowman County, N. Dak.).

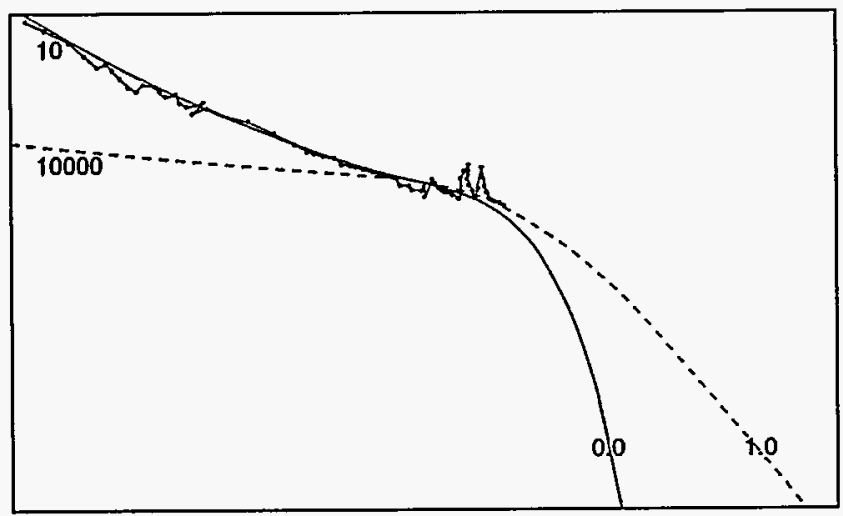

Rd: $10.000 \quad$ VP: $0.791 \mathrm{MMbbl}$

Re: $1085.645 \mathrm{ft} \quad$ Ad: 85.004 acres

Rw: $108.564 \mathrm{ft} \quad$ Phi $20.000 \%$

S: $-5.604 \quad$ h: $6.000 \mathrm{ft}$

k: $0.063 \mathrm{mD}$

Cti: $25.000 \times 10^{-6}$

b: 0.000 Abandon: $150 \mathrm{bbl} / \mathrm{month}$ Remaining: $0.000 \mathrm{MMbbl}$ OOIP: $0.375 \mathrm{MMbbl}$

Rec. Fact: $8.940 \%$

Qi: $263.194 \mathrm{bbl} / \mathrm{month} \quad$ Ultimate: $0.034 \mathrm{MMbbl}$
As of: $12 / 31 / 93$

Fig. 11 Fetkovich production type-curve match of datafrom the Hansen 1-21 well. A recovery factor of $8.9 \%$ is indicated from a drainage area of 85 acres.

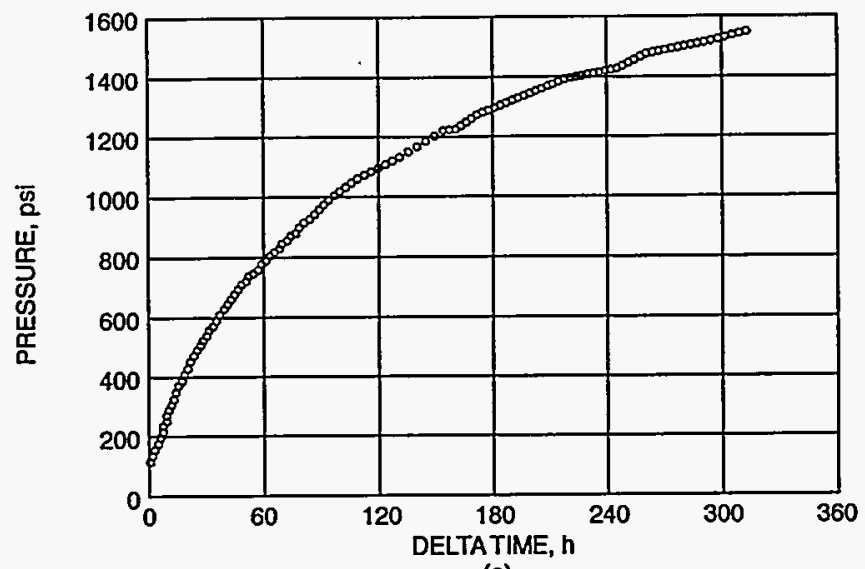

(a)

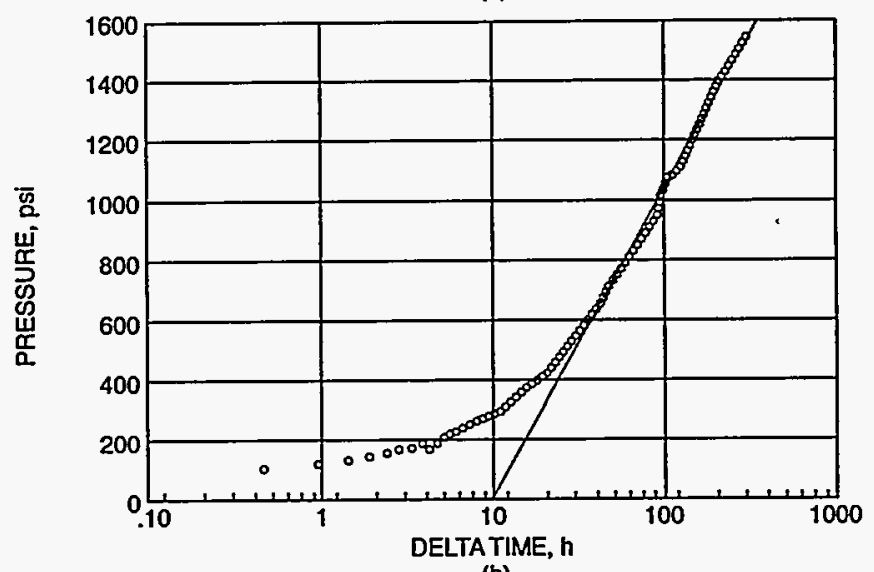

(b)

Fig. 12 Pressure buildup plots from the Hansen 1-21 well. Analytical simulation methods indicate a narrow drainage shape as a possible reservoir model for this well. (a) Cartesian plot. (b) Miller-DyesHutchinson analysis.

Jetting-lance technology will be used to restimulate the Hansen well. Following this work the well will be produced for 4 to 6 weeks and shut in for a pressure buildup test.

\section{Recovery Technology Evaluations}

\section{Stearns A-19 (Red River) Injectivity Test}

A 20-day water injection test commenced on Mar. 23, 1995, in the Stearns A-19 well (North Buffalofield area, APINo. 40-063-20368, sec. 19, T.22N., R.4E., Harding County, S.Dak.). Figure 2 shows Red River porosity development in the well, and Fig. 4 shows the well location in the study area. Water was injected at $100 \mathrm{bbl} / \mathrm{d}$ into the 15-ft Red River upper member at $8774 \mathrm{ft}$ with pressure gauges on the bottom for the duration of the test. The pressure data do not exhibit anomalies that would suggest nearby flow barriers or transmissibility changes (see Fig. 13). The reservoir characteristics from the pressure-transient analysis are:

Static reservoir pressure at start, psi 2273

Water transmissibility $(\mathrm{kh} / \mu \mathrm{B}), \mathrm{mD}-\mathrm{ft} / \mathrm{cP}$

Water permeability $\left(\mathrm{k}_{\mathrm{rw}}\right), \mathrm{mD}$

Skin factor (s)

Final injection pressure at end, psi 


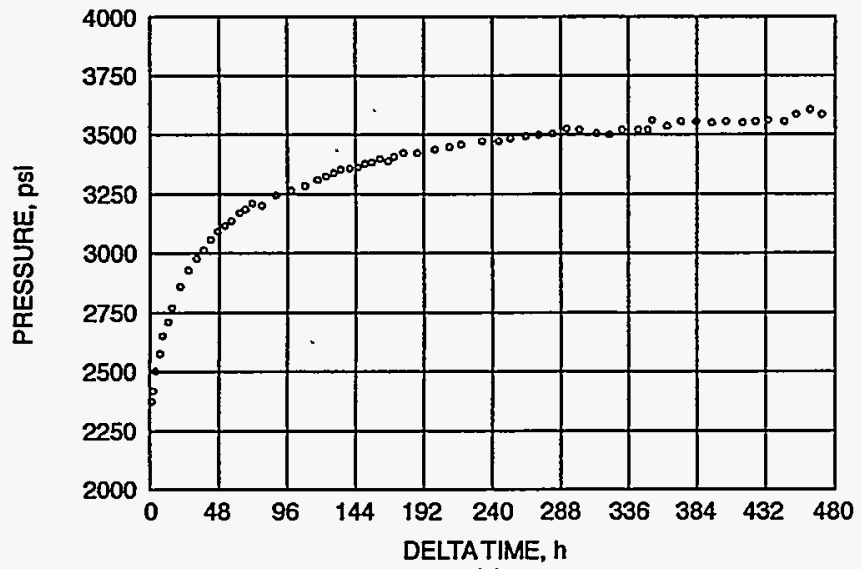

(a)

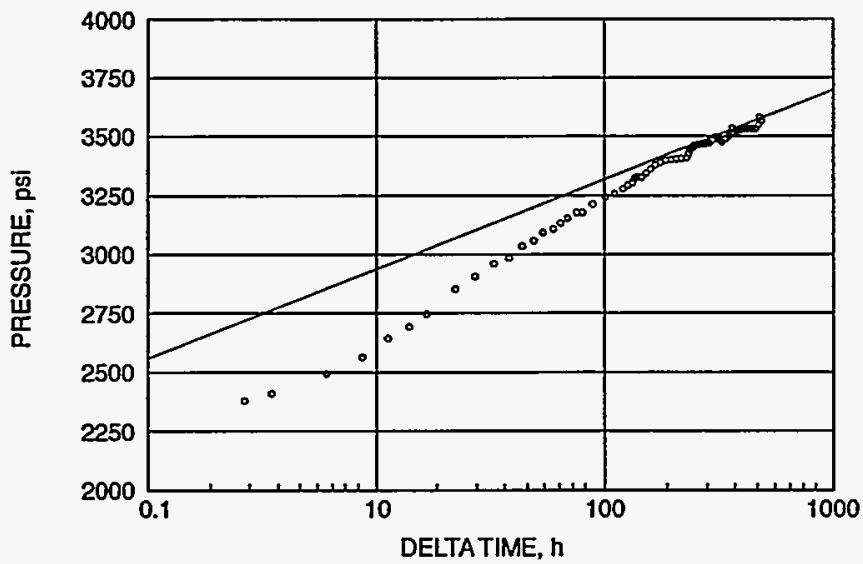

(b)

Fig. 13 Water injectivity and pressure buildup test results from the Red River upper member in the Stearns A-19 located in sec. 19, T. 22 N., R. 4 E., Harding County, S. Dak. The 20-d test indicates that the maximum stabilized injection rate would be $150 \mathrm{bbl}$ of water per day at fracture pressure. (a) Cartesian plot. (b) Miller-Dyes-Hutchinson analysis.

The results from this test indicate that the maximum stabilized injection rate would be about 150 BWPD at a parting pressure of $5500 \mathrm{psi}$. This injectivity can be equated to about 10 BWPD per foot of net pay.

A jetting-lance completion will be performed on the Red River upper member followed by a repeat of the injectivity test. Pressure-transient data from both tests will be compared to determine if the jetting-lance workover produces a change in apparent transmissibility $(\mathrm{kh} / \mu \mathrm{B})$ or $\mathrm{s}$.

\section{Hansen 1-21 (Red River) Jetting-Lance Stimulation}

A commercially available service (Penetrators, Inc.) was used to make jetting-lance perforations into the Red River upper and middle members (Haley field area, APINo. 33-011-31900, SWSEsec.21,T.129N.,R. 101 W., Bowman County, N.Dak.). Four holes weremade to a penetration depth of $10 \mathrm{ftin}$ each porosity member (see Fig. 9). The penetration of $10 \mathrm{ft}$ is the maximum capability from this tool design. If the oil rate increases, the zones will be isolated by a bridge plug to determine the production from each zone. The well was recently placed back on production, but there are no production figures to report at this time.

\section{Ratcliffe Hydraulic Fracture Stimulations}

Fracture stimulation type and volume were tabulated for $14 \mathrm{key}$ wells in the Richland-Ratcliffe study area. These unique wells had been initially completed with only an acid breakdown treatment and were produced for a short period of several months to a year before being hydraulically fractured. The production and decline characteristics of these wells provide an opportunity to quantify $\mathrm{kh}, \mathrm{s}$, and reserves before and after hydraulic fracture stimulation treatments. These data will be included in baseline data for comparison of jetting-lance completion efficiency and cost.

\section{References}

1. M. J. Fetkovich, Decline Curve Analysis Using Type-Curves, J. Pet. Technol., 32(6): 1065-1077 (June 1980).

2. M.J.Fetkovich andM.E. Vienot, Shape Factor, C, Expressed as Skin, Sca, J. Pet. Technol., 37(2): 321-322 (February 1985).

\section{RECOVERY OF BYPASSED OIL IN THE DUNDEE FORMATION USING HORIZONTAL DRILLING}

\section{Contract No. DE-FC22-94BC14983}

\section{Michigan Technological University}

Houghton, Mich.

Contract Date: Apr. 28, 1994

Anticipated Completion: Apr. 27, 1997

Government Award: \$295,000

(Current year)

Principal Investigator:

James R. Wood

Project Manager:

Chandra Nautiyal

Bartlesville Project Office

Reporting Period: Jan. 1-Mar. 31, 1995

\section{Objective}

The objective of this project is to demonstrate that oil production from fields in the Dundee Formation (Devonian) of Michigan can be substantially increased, perhaps restored to near-original production levels, with the use of horizontal drain wells. The approach combines proven, cost-effective horizontal drilling technology with modern reservoir characterization and management. In addition to field trial at Crystal Field, 30 Dundee fields will be characterized. Well logs, other well data, drilling, and production data and rock samples from the Dundee formation will be assembled and input into a 
commercial database manager specifically designed for gas and oil operations. Computer models describing the diagenetic, stratigraphic, and thermal evolution of the Michigan Basin will be developed and applied to the Crystal Field reservoir. A postmortem study is scheduled to monitor the effect of the horizontal well on Crystal Field production.

\section{Summary of Technical Progress}

\section{Project Management}

This task involves the management and administration of all Budget Period 1 activities. The cooperative agreement requirements are being performed in conjunction with the administrative functions necessary to coordinate with producing partners, vendors, subcontractors, consultants, and suppliers. A detailed Project Management Plan encompassing both Phases I and II, including cost, labor, and milestone plans, was prepared in accordance with the Reporting Requirements. All required reports are being prepared and submitted to the U.S. Department of Energy (DOE) in accordance with the Reporting Requirements.

Although project members are located at four sites (Tampa, Fla.; Houghton, Mich., Kalamazoo, Mich.; and Los Angeles, Calif.), project coordination has been successful. The computer network and server at Michigan Technological University (MTU) is a critical link in the communications network.

\section{Budget Management and Quarterly Reports}

The project budgets were reprogrammed, and a system was set up for logging, recording, and archiving all invoices related to this project. A convenient way to visualize the project budgets by monthly expenditures, cumulative expenditures, and projected expenditures with the use of Lotus graphics was developed.

\section{Reservoir Characterization}

Well and $\log$ data sets and production data sets for all 30 fields are complete. Tops have been picked on all formations in all wells. The well location and formation tops data sets are also complete.

\section{Well-Log Acquisition, Digitization, and Analysis}

The data-gathering phase of the well-log program is complete. Several hundred old spontaneous potential (SP)resistivity logs (mostly of the Dundee formation) from the mid-1940s and 1950s were also acquired. SP on these old logs is particularly good for calculating water resistivity $\left(R_{w}\right)$ values for formation waters.

A number of operations are being performed on selected wells to correct them. Among these operations are depthshifting, true vertical depth (TVD) and true stratigraphic thickness (TST) corrections, normalization, and environmental corrections.
Well $\log$ analysis with the use of TerraSciences Terra Station software began. Density-porosity and Pickett crossplots are being used for detailed analyses of wells with modern logs. Water saturations were calculated for several wells.

Regional studies. Production data were added to the wellfile database. The capability now exists for mapping production as well as geology. Well-location basemaps with permit numbers were constructed for all 30 fields. Contour maps were completed for all 30 fields, including maps on the top of the Dundee formation, the top of the Dundee porosity zone (which is well below the top of the Dundee and varies in stratigraphic position throughout most fields), Dundee to Traverse isopachs, and initial production values before and after well treatment. At least two simple computer-generated cross sections were constructed for each field. All these maps have been plotted on $81 / 2$ by 11 in. pages and have been compiled by field into single folio-sized poster sheets. More detailed cross sections are being constructed on field and regional scales.

Now that production data for all the fields are in the database, cumulative production maps can be constructed. Interval isopach maps of top Dundee to top Dundee porosity zone (which will map the number of feet that must be drilled beneath the top of the Dundee to hit pay) will also be constructed. Net-pay isopachs will be more difficult. Most wells are drilled to the top of the Dundee porosity and completed without ever crossing the oil-water contact. Therefore the positions of oil-water contacts can only be estimated from off-structure dry holes. Apparently the positions of oil-water contacts in about $25 \%$ of the fields can be reasonably estimated, which will allow construc-tion of volumetric maps for those fields. All these maps will be constructed after completion of the basic contour maps for each field.

Pressure data are also hard to obtain in many of these old fields. It is expected that the pressure decline curves can be produced for a few wells, though, and with the volumetric maps for most tightly constrained fields, recovery factors and other engineering parameters can be estimated in a few locations. These values can then be extrapolated to other fields with poor data.

Winterfield field. An M.S. thesis was completed on Winterfield field, which possesses more modern log data than most other Dundee fields. In Winterfield field, several wells penetrate the entire Dundee porosity zone, which allows a more thorough evaluation of the reservoir than could be done elsewhere. The purpose of the Winterfield study was to delineate possible economic zones of bypassed oil in the Dundee by characterizing the structural, stratigraphic, and lithological components of the Dundee with the use of well data (driller's logs and scout tickets), petrophysical log data, and production data.

The initial well data set used to create maps and plots was obtained from Petroleum Information Corp. Geophysical logs from Winterfield field were obtained in digital form from Maness Petroleum Co.; production data were obtained from the Michigan Department of Natural Resources, Geological Survey Division; and contour plots of formation tops and top porosity were constructed with CoPlot by CoHort Software. 
Porous dolomite above the oil-water contact, capped by either the Bell shale or tight Dundee limestone, is the producing lithology within the Dundee. The producing zones can be discriminated quite readily from a suite of geophysical logs containing gamma-ray, photoelectric function, and deeplaterolog logs. These logs can be further enhanced with the addition of the Compensated Neutron Log (CNL) and density logs to determine corrected porosity values in the producing interval. The KOBRA:XPLOT algorithm of TerraSciences' Terra Station software, which is based on Schlunberger cross plots, was used to calculate for all wells with available CNL and density well-log data. Water saturation $\left(S_{w}\right)$ values were calculated and averaged over the top $60 \mathrm{ft}$ of the reservoir. Water saturation values were subtracted from 1 to obtain the oil saturation. These values were plotted as contours.

Cross sections of Winterfield field illustrate the extreme variability in production that is so characteristic of these Dundee fields and show how the Dundee porosity zone varies in thickness across the field. The top of dolomite porosity drops below the oil-water contact in places, which leads to discontinuities in the reservoir that may result in bypassed oil. Thus understanding Dundee dolomitization is important to enhanced oil recovery operations.

Although the amount of bypassed oil in Winterfield field has not been accurately quantified, potential areas for further exploration can be delineated by looking for leases that appear to be underachievers relative to structural position, initial production tests, and relative production compared with surrounding areas that produce from similar lithologies. Dart Oil and Gas Co. drilled three wells in the mid 1980s with the Richfield formation as the target zone and inadvertently discovered oil in the Dundee in the western part of Winterfield field, where reservoir quality was previously thought too poor to produce. The discovery shows that pockets of economically producable oil still exist in this field and perhaps in many others.

\section{Core Acquisition and Analysis}

About 50 cores of the Dundee formation from throughout the state of Michigan have been identified and are available in publicrepositories [i.e., the WesternMichigan University (WMU) Core Research Lab., the University of Michigan Subsurface Lab., the Wayne State University core facility, the Central Michigan University core facility, and the Michigan Geological Survey core repository in Lansing]. Each of these cores will be described and samples will be taken for thin-section, X-raydiffraction (XRD), and scanning electron microscope (SEM) analyses to determine mineralogy and porosity characteristics. Cuttings samples from 60 to 100 Michigan wells are also available. Additional materials will be obtained from private sources. A database called.COREDAT, provided by Maness Petroleum Corp., is being used to search the drillers' reports and core analysis files for cores that were missed. Selected samples from WMU Core Research Lab. are being analyzed.

There are no cores in Crystal field, the site of the field trial in this study. The closest Dundee core is in an outpost well
8 to 10 miles away from Crystal field. Thus acquisition of a good vertical core through the Dundee in Crystal field is an essential element of the reservoir characterization study. Porosity (p), permeability (k), fluid saturation (s), and formation factor ( $f$ ) data are being gathered from core analysis reports and entered into the database. $P, k, s$, and $f$ analyses will be performed on the core from the well drilled at Crystal field. The porosity, permeability, and oil saturation data for all the Dundee cores from wells in a seven-county area surrounding Crystal field are available. This includes data from some cores that are no longer available to be sampled.

When all available core material has been identified, samples will be collected from each core. This phase of the project has just begun. Samples are being selected to provide good coverage of all the lithofacies and porosity types present in the Dundee formation. Samples from both producing and nonproducing intervals will be gathered, and an attempt will be made to link lithology to petrophysics so that different petrophysical facies can be identified. In areas where no cores are available, drill cuttings will be sampled. It would be ideal to map petrophysical facies because this approach leads to a better understanding of lithologic controls on variability in produc-tion rate, but sample coverage is sparse in these old fields, and this type of mapping may not be possible.

$\mathrm{X}$-ray-diffraction analyses of approximately 200 samples will be performed to determine the proportion of calcite, dolomite, and other major and accessory minerals. For the estimation of paleotemperatures and salinities and for the determination of the origin of the porosity-producing dolomitizing fluid, fluid-inclusion temperature and salinity measurements will be made on 40 to 60 samples. Paired oxygencarbon isotope measurements will be made on 100 to 200 samples.

Optical methods will be used to perform point counts for mineralogy and porosity on approximately 60 to 100 polished thin sections of core and cuttings samples. Identification and quantification of major mineral phases, clay mineral phases, pore space, and hydrocarbons will be determined where possible. Conventional SEM analyses will be performed on many of these same samples, and, if needed, SEM image analysis will be used to determine shape factor and rock texture and to supplement identification of phases.

Scanning electron microscope analyses of selected samples from the nearest cored well to Crystal field (Leonard Oil Co., Lee No. 1, Montcalm County, Mich.) are being performed at WMU to investigate microtextures in the Dundee reservoir, including intercrystalline porosity and fractures.

\section{Fourier Transform Infrared (FTIR) Spectroscopy}

Fourier transform infrared (FTIR) spectroscopy analyses have begun. At MTU, techniques are being developed for performing quantitative analyses of rock samples with the use of FTIR. Sample preparation, accumulation of a suite of mineral standards, and the development of reliable analytical techniques are critical to this endeavor. Spectral data were 
collected on mineral standards, which will be input into a mathematical program that will generate nonnegative leastsquares (NNLS) fits. The NNLS fits will be applied to FTIR spectral data gathered on core samples from Dundee wells and will be used for identification of mineral assemblages.

\section{Fluid Samples}

Hydrocarbon and produced-water samples from the Crystal field have yet to be collected and analyzed. If possible, arrangements will be made to sample fluids from other Dundee fields as well. Inorganic geochemical analyses of produced brines will be used in conjunction with isotope and fluidinclusion analyses of core and cuttings to determine the origin and history of the porosity-producing dolomitizing fluid.

Initial production (IP) maps show that a number of the Dundee fields have two markedly different producing regimes-a dolomite reservoir rock that comes on production at a few hundred barrels of oil per day (BOPD) and a vuggy dolomite reservoir rock that comes on production at 1000 to 2000 BOPD. Early wells in the fields, drilled in the 1930 s and 1940 s, were produced imprudently at very high flow rates, so they coned water and watered out in a matter of months. The best locations for spotting horizontal wells to recover bypassed oil may be in between wells that coned water in these high-IP areas.

The low-IP dolomites may have formed by a regional process, whereas the high-IP dolomites may represent zones of locally enhanced porosity where cross-formational fluid flow dolomitized fracture zones. If this is true, the two dolomitizing fluids could have very different chemistries, which may be reflected in the chemistry of present connate waters. Because fluid flow may provide the key to understanding the origin of high-production-rate areas, formation fluids from high- and low-IP dolomite areas will be sampled, and inorganic chemistry will be used to interpret dolomite origin.

\section{Database Management}

Project personnel at WMU are using TerraSciences' TerraStation software to analyze and archive project data. The MTU group is participating in another DOE project with the specific goal of developing and demonstrating an integrated system for database management and reservoir visualization. With the use of Microsoft Visual Basic 3.0, a spatial database manager (SDBM) shell-interface and a multimedia program (MMP) are being developed.

The SDBM is a Windows shell that provides access to an underlying database engine (Microsoft Access), a well-log interpretation program (Crocker Data Processing Petrolog), mapping and cross-section software (the GeoGraphix Exploration System Workbench), and a volume visualization application (yet to be determined). The SDBM will have the added benefit of online help and tutorial information. This system and all its components are available for use in the Dundee project.

Thirty Dundee fields are being studied in this project. Well-data (drillers' logs and scout tickets), log-data, and production-data sets for all 30 fields are complete. The data are stored in the TerraSciences' database at WMU. Digitized well logs from selected wells were read into the database during the last quarter. Specific intervals are being evaluated for $S_{w}$ and other calculated parameters.

\section{Drilling}

Drilling was delayed pending completion of an environmental site assessment. Terra Energy Corp. was reluctant to commence drilling before receiving a covenant from the Department of Natural Resources, state of Michigan, protecting them from lawsuits for preexisting environmental contamination. Terms of an agreement were recently agreed upon by Terra and the state of Michigan, and the covenant is awaiting signature in the Michigan State Attorney General's office. The document is expected to be signed soon, and drilling can commence in summer 1995. Cronus Development Corp., under contract to Terra Energy, will drill the well.

\section{Technology Transfer}

A newsletter announcing upcoming meetings of the Michigan Oilfield Research Consortium (MOFRC) will be mailed to independent oil producers and other interested parties. The initial mailing list of potential members of the MOFRC is complete.

\section{Multimedia Presentations on CD-ROM}

A multimedia program (MMP) shell-interface was designed and developed in Visual Basic 3.0 for this project and for another DOE project in which the MTU staff is participating. This shell is intended to be used as a technology transfer mechanism. All data and information associated with the project will be stored on hard disks and will be accessible via the MMP. At the end of the project, all data, graphics, tutorials, manuals, etc., will be stored on CD-ROM for distribution to DOE and to the target audience within the petroleum industry.

The MMP archives all project reports, tables, maps, photographs, animations, etc., either within the shell itself or as files opened from other applications that can be launched from the shell (e.g., Lotus 1-2-3 and Excel); provides tutorials and manuals to help less-knowledgeable users access and interpret each type of information; and provides user-defined pathways to, and sample data files for, some commonly used spreadsheet applications so that users can integrate their own data within the shell. Project information is available via pulldown menus in the archival mode. The MMP is operational.

\section{American Association of Petroleum Geologists (AAPG) National Meeting}

Project members ran a booth in the Exhibits Hall at the AAPG Annual Meeting in Houston, Tex., March 5-8, 1995. The booth included a poster display that described project goals and progress to date. Two adjacent booths, one for this 
project and one for the California DOE Advanced Process and Technology Program project, were operated. Several independent producers asked to be kept abreast of project developments and to have quarterly reports mailed to them. The impression is that if the horizontal well is commercially successful, there will be little trouble finding independents who are interested in drilling horizontal wells in areas that coned water and left behind bypassed oil in other Dundee fields.

\section{Tampa Workshop/Conference}

On January 19-20, 1995, a meeting was held at the University of South Florida in Tampa, Fla., to review both DOE projects. The Michigan project was discussed on January 19, and the California project was discussed on January 20. The meeting afforded project members an opportunity to learn what other operators were doing and to discuss project plans and accomplishments in an open forum.

\section{Basin Modeling}

Although the modeling task is not scheduled to begin until the second budget period, acquisition of software has begun. All the major hardware and software purchasing decisions have been made, and the purchases are in progress. Purchasing decisions were made with serious attention given to cost/benefit ratios. Because the target audience for technology transfer in this project consists mainly of small independent oil exploration and production companies, price and flexibility are critically important. During the last quarter, the following purchases were agreed upon:

\section{HP650C Color Plotter}

The HP650C color plotter is a versatile, wide-bed, continuous (roll) feed plotter than produces high-quality graphics output for display or analysis. This type of plotter is used by several small oil companies that were surveyed before making the purchase decision. It will be used to print postscript files, so an $\mathrm{HP}$ postscript card was also purchased. Software to make the printer compatible with many different types of graphics files is available. Such software was not purchased at this time because of the expense involved. The relatively inexpensive postscript card will be used throughout the project so that methods of output generation can be easily transferred to small operators.

\section{GeoGraphix Data Management and Visualization Software}

The GeoGraphix Exploration System is designed to facilitate data management and visualization. It uses the same type of geographic information system technology that is common in more-expensive types of software (e.g., ArcInfo and Intergraph) but is tailored to the needs of oil companies working with subsurface, rather than surface, data. It runs on personal computers (PC), which makes it attractive to smaller, independent oil companies.

\section{BasinMod One-Dimensional Basin Modeling Software}

The BasinMod system provides users with a relatively simple, user-friendly method for modeling the evolution of single wells. Multiple well histories can also be modeled to investigate variations in basin evolution that occur from one geographic locality to another. BasinMod allows modeling of burial histories, compaction, temperature histories, lithology, heat flow, hydrocarbon maturities, and pressures as well as multiwell mapping of variables. It is commonly used by both small and large oil companies. It will be used in conjunction with software that has been developed in-house.

\section{Akcess.basin Two-Dimensional, Three-Dimensional Basin Modeling Software}

This is an extremely powerful basin modeling system that is based on work performed as part of a DOE Class I project [Enhanced Akcess.Dynamic Recovery Technologies (field site located in the Eugene Island area of the Gulf of Mexico, offshore Louisiana)] that several MTU faculty members and graduate students participated in. The software uses a finiteelement formulation to examine the effects of thermal processes (conduction, convection, and advection), fluid-flow processes (compaction-driven, hydraulic-head driven), sealing mechanisms, and sedimentation-erosion during the development of a sedimentary basin. The program also predicts hydrocarbon generation (timing, location, and rate) and migration patterns. Although this software may be rather expensive for small operators, MTU acquired it as a result of the DOE Class I program. It will be used to perform regional modeling studies in the Michigan Basin. No other software offers the power and flexibility of Akcess.basin. Computational Mechanics Corp. installed the software at MTU.

\section{$\mathrm{CO}_{2}$ HUIFF 'N' PUFF PROCESS IN A LIGHT OIL SHALLOW SHELF CARBONATE RESERVOIR}

\section{Contract No. DE-FC22-94BC14986}

Texaco Exploration and Production, Inc. Midland, Tex.

Contract Date: Feb. 10, 1994

Anticipated Completion: Dec. 31, 1997

Government Award: $\$ 469,466$

(Current year)

\section{Principal Investigator: \\ Scott C. Wehner}

$$
\begin{aligned}
& \text { Project Manager: } \\
& \text { Jerry Casteel } \\
& \text { Bartlesville Project Office }
\end{aligned}
$$

Reporting Period: Jan. 1-Mar. 31, 1995 


\section{Objective}

The principal objective of the Central Vacuum Unit (CVU) carbon dioxide $\left(\mathrm{CO}_{2}\right)$ Huff ' $\mathrm{n}$ ' Puff $(\mathrm{HnP})$ project is to determine the feasibility and practicality of the technology in a waterflooded shallow shelf carbonate (SSC) environment. The results of parametric simulation of the $\mathrm{CO}_{2} \mathrm{HnP}$ process, coupled with the CVU reservoir characterization components, will determine whether this process is technically and economically feasible for field implementation. The technology transfer objective of the project is to disseminate, through an innovative plan, the knowledge gained in support of the U.S. Department of Energy's (DOE) objective of increasing domestic oil production and deferring the abandonment of SSC reservoirs.

Texaco Exploration and Production Inc.'s (TEPI) longterm plans are to implement a full-scale miscible $\mathrm{CO}_{2}$ project in the CVU. However, a common finding throughout the Permian Basin SSC reservoirs is that the current market precludes acceleration of such a capital-intensive project. The immiscible $\mathrm{CO}_{2} \mathrm{HnP}$ process might bridge this longer term miscible project with near-term results. A successful implementation would result in near-term production, or revenue, to help offset cash outlays. The DOE partnership provides some relief from the associated research and development risks, allowing TEPI to evaluate a proven Gulf Coast sandstone technology in a waterflooded carbonate environment. Numerous sites exist for widespread replication of this technology following a successful field demonstration.

\section{Summary of Technical Progress}

\section{Geostatistical Realizations}

Geostatistics is being used to distribute wellbore data to interwell locations (cells). A more realistic distribution of the data than the typical algorithm used in mapping software is expected as a result. Normalized porosity and permeability data from 455 wells in the project area were available for use. This figure has been reduced to 322 wells because of statistical variations being introduced by sonic logs, which do not account for secondary porosity. Markers within the pay were taken from the project database. Variograms suggest an easterly-westerly bias to the porosity distributions. Not surprisingly, this trend follows the strike of the Basin margin.

At 852,720 cells, the geostatistical exercises are handling a rather large volume of data for the study. The threedimensional (3-D) gridding consists of 170 layers within the Grayburg and San Andres formations with an aerial distribution of 76 rows by 66 columns. Three stratigraphic porosity grids were made for the study area-a 13-layer grid for the Grayburg dolomite, a 7-layer grid for the Grayburg sandstone, and a 150-layer grid for the combined Upper San Andres, Lovington sandstone, and Lower San Andres. Because no flow simulation is planned for this large study area, no conditional simulation was done-all grids were made with kriging. The layers are approximately $4 \mathrm{ft}$ thick. Each cell is $250 \mathrm{ft}$ by $250 \mathrm{ft}$ on a side. This work is being performed on a personal computer with a geostatistical software package developed by Texaco, called GRIDSTAT. The grid can be visually analyzed with Stratamodel.

Attention has focused on a smaller study area that encompasses the site-specific simulation area and impending initial field demonstration. The geostatistical exercise was repeated in this area for added modeling detail. For this smaller study area, 20 stratigraphic porosity grids were made. Five zones were created by kriging, and the same five zones were created by three successive conditional simulations. The five gridded zones are a 13-layer grid for the Grayburg dolomite, a 7-layer grid for the Grayburg sandstone, a 30-layer grid for the Upper San Andres, a 15-layer grid for the Lovington sandstone, and a 90-layer grid for the Lower San Andres. Each cell is $132 \mathrm{ft}$ by $132 \mathrm{ft}$ on a side. The layers are approximately $4 \mathrm{ft}$ thick. This model covers that same vertical component of gross pay as the larger study after excluding some nonpay footage from the bottom of the model. The site-specific model for compositional simulation will be extracted from this work.

It was originally anticipated that the variograms developed from the porosity data would be used to construct the perm-eability grids. This approach has been abandoned in favor of directly applying the neural network permeability relationships corresponding to the geostatistically distributed porosity. The original approach left concern regarding the redistribution of permeability data, which were partially defined on the basis of their 3-D spatial distribution in the reservoir.

\section{Parametric Simulation}

A parametric study of the $\mathrm{CO}_{2} \mathrm{HnP}$ technology was conducted with the use of the Western Atlas' VIP-COMP simulator. The equation of state developed previously was used. The basic objectives of the parametric study were to identify reservoir characteristics that might be favorable or unfavorable and to identify the best operational procedures. A radial model with 25 grid cells in the radial direction was used. A water injector was placed in the outside radial grid so that waterflooding could be simulated and pressure in the model could be maintained. Models with as little as 1 layer and as many as 14 layers were used. Results from different numbers of layers were qualitatively similar. Relative-permeability curves obtained from laboratory measurements were used. The porosity, permeability, and net pay were representative of the vicinity selected for the site-specific simulation study. The parameters studied included reservoir heterogeneity, the water/oil ratio (WOR) before the $\mathrm{HnP}$, and $\mathrm{HnP}$ operational procedures.

In addition to the parametric simulations, methods were identified that could be used during $\mathrm{HnP}$ history matching to compensate for the absence of flow mechanisms important for $\mathrm{HnP}$ processes. Commercial reservoir simulators such as the 
one that was used do not have a number of the mechanisms that have been identified or suggested as being present in $\mathrm{HnP}$ processes. The mechanisms that are absent include diffusion duringthe soak period and increased oil relative permeability (from relative-permeability curve hysteresis) during the production phase. These are important because diffusion permits $\mathrm{CO}_{2}$ to move away from the well and oil to move back toward the well during the soak and because increased oil relative permeability leads to a larger oil rate during the production phase. Methods were found to overcome these simulator limitations. Increasing the gas-oil capillary pressure to very large values was found to mimic diffusion, and a method was found to change the relative-permeability curves in midsimulation so that an increase in the oil relativepermeability curve during the production phase could be approximated. In addition, the VIP COMP simulator can include directional relative permeability so that a decrease in the gas relative permeability can be modeled. A decrease in the gas relative permeability is another mechanism claimed to occur in an HnP. Although these procedures to overcome simulator limitations were identified, they were not used during the parametric studies but were instead left to be used as needed for history matching. A moderately large gas-oil capillary pressure and trapped gas hysteresis were the only special relative-permeability features used in the parametric studies.

A typical result of an $\mathrm{HnP}$ is shown in Fig. $1 . \mathrm{ACO}_{2}$ volume

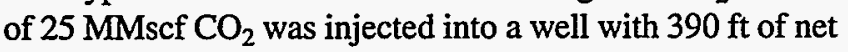
pay and an average porosity of about $9 \%$. The water cut was $85 \%$ before the HnP. The oil rates are shown for the puff and for a continued waterflood without an HnP. The peak oil rate for this case was doubled, being a typical result. The increased oil rate persisted for about as long as the $\mathrm{CO}_{2}$ was produced back. This period depends on the amount of $\mathrm{CO}_{2}$ injected. For 25-MMscf $\mathrm{CO}_{2}$ injected, incremental production typically lasted about 50 to $80 \mathrm{~d}$. The improved WOR also lasted this same amount of time (i.e., 50 to $80 \mathrm{~d}$ ). The initial period of production was one of essentially pure $\mathrm{CO}_{2}$, which lasted for about $10 \mathrm{~d}$. The length of this period could have been adjusted by changing the magnitude of the gas-oil capillary pressure and the gas relative permeability. The incremental oil attrib-

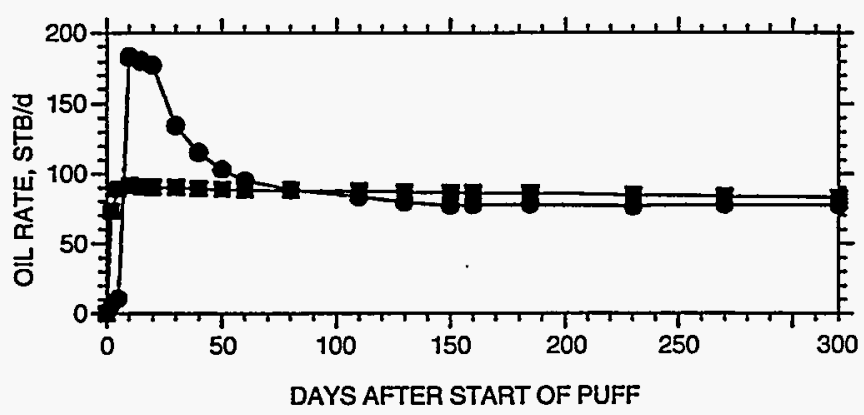

Fig. 1 Oil rate vs. days after start of production. - -, huff 'n' puff. $\rightarrow$-, waterflood. uted to the $\mathrm{CO}_{2}$ was calculated by determining the cumulative oil production during the demonstration until the oil rate crossed the rate for the extended waterflood (for this case, about $80 \mathrm{~d}$ ) and then subtracting the cumulative oil production for the extended waterflood at this point. The incremental oil for this particular example was 1400 stock tank barrels (STB). The incremental oil volumes typically ranged from about 500 to 2600 STBs with $25 \mathrm{MMscf}^{\mathrm{CO}} \mathrm{O}_{2}$ injected for the other cases studied. The apparent $\mathrm{CO}_{2}$ utilization factors were consequently about $10 \mathrm{Mscf} / \mathrm{STB}$ or greater. They were much greater than the factors of about $1 \mathrm{Mscf} / \mathrm{STB}$, which have previously been reported for HnP trials. The present utilization factors and the amount of incremental oil could have been increased somewhat by increasing the oil relative permeability during the injection phase. This was not done for most of the parametric cases because the objective was to compare the relative effects of selected parameters.

One effect of actual HnPs is to increase the total liquid production for an extended period of time. If this happens, the oil rate can increase for a substantial period of time without an improvement in the stabilized WOR. For the cases simulated here, this did not occur. The stabilized total liquid production rate and the WOR returned to pre-HnP levels.

One set of parameters that was investigated involved reservoir heterogeneity. The $\mathrm{HnP}$ process was not extremely sensitive to reservoir heterogeneity. Reservoir heterogeneity does not appear to degrade the HnP process substantially unless there are very high permeability zones without vertical permeability. The presence of vertical permeability largely prevents high-permeability streaks from degrading the process. A large amount of vertical permeability is not needed, and values as little as 0.1 to $0.2 \mathrm{mD}$ are effective. The vertical permeability makes a layered system with heterogeneity more effective than a completely homogeneous system. If vertical permeability is present, the $\mathrm{CO}_{2}$ enters the high-permeability streaks but can move vertically into other layers. If there is no vertical permeability, zones of very high permeability will degrade the process because the $\mathrm{CO}_{2}$ is confined primarily to the high-permeability layers. The only wells that should be excluded as candidates for HnP's are wells with very high permeability channels.

Another parameter that was investigated was the water cut before the HnP. The HnP process in an ongoing waterflood appears to work better for wells in which the water cut is high rather than very low. This would suggest doing the process for wells with a high water cut rather than recently drilled infill wells in which the oil rate is high and the WOR is still very small.

An important set of parameters focused in $\mathrm{HnP}$ operating conditions. The effect of reservoir pressure was examined, and the $\mathrm{HnP}$ was found to be more effective under immiscible rather than miscible conditions. The $\mathrm{CO}_{2}$ utilization factor was more advantageous for the immiscible case. In addition, another effective strategy was to inject the $\mathrm{CO}_{2}$ under immiscible conditions, let the pressure build during the soak, and then produce the well. However, it may not be possible to 
inject the $\mathrm{CO}_{2}$ under immiscible conditions in the field. The average reservoir pressure in the field is above the minimum miscibility pressure (MMP). The pressure changes in the near-well region were examined when the well was shut in. High-permeability layers reached the MMP after $1 \mathrm{~d}$. The low-permeability layers approached the MMP after about $3 \mathrm{~d}$. The original idea for operating the $\mathrm{HnP}$ was to inject the $\mathrm{CO}_{2}$ under immiscible conditions, let the pressure build, and put the well back on production. This may not be possible because simulation results suggest that the near-well region will reach the MMP after a few days even without the added pressure increase of the $\mathrm{CO}_{2}$ injection. The average pressure in the pattern (or model) could be decreased by stopping water injection; however, about $15 \mathrm{~d}$ without injection are required to reduce the average reservoir pressure by about $100 \mathrm{psi}$. A long period without injection would be required to reduce the average pressure below the MMP. A reservoir of different character than the one described may make this approach more advantageous. Because it appeared unlikely that the $\mathrm{HnP}$ could be operated below the MMP, a number of $\mathrm{CO}_{2}$ injection pressures above the MMP were examined. Surface injection pressures up to $2700 \mathrm{psi}$ did not reduce the effectiveness of the $\mathrm{HnP}$ if the injection pressure was already above the MMP.

The $\mathrm{CO}_{2}$ injected volume was another parameter that was investigated. Some additional investigation is needed, but apparently a volume of about $25 \mathrm{MMscfCO}_{2}$ is required for a well in which the net pay is almost $400 \mathrm{ft}$. This volume is much less than the $150+\mathrm{MMscf} \mathrm{CO}_{2}$ that would be required for the $\mathrm{CO}_{2}$ to penetrate to an idealized 100 - $\mathrm{ft}$ radius. A distance of $150 \mathrm{ft}$ for $\mathrm{CO}_{2}$ penetration has sometimes been proposed as a guideline for $\mathrm{HnP}$ operation in pressure-depleted reservoirs. Soak times of 5 to $30 \mathrm{~d}$ were examined. Similar to the results of other investigators, no essential differences were found with the simulator for different soak times.

\section{Waterflood Review}

A proper review of past operations is not complete without a proper relationship to the initial hydrocarbons in the formation. The procedures for calculating original oil-inplace (OOIP) within Stratamodel software have been developed and tested. The OOIP was calculated for each cell in the model. The calculation of OOIP in this manner requires porosity, permeability, and water saturation $\left(S_{w}\right)$ values for each cell in the model. Porosity is derived from the distribution of porosity data from each well location, permeability is determined for each cell using the neural network described previously, and initial $S_{\mathrm{w}}$ is calculated for each cell with the Leverett J function. Polygons for unit boundaries and waterflood patterns were added to the model. These polygons will allow summation of OOIP for specific areas and individual waterflood pattern review. Summation by stratigraphic sequence will also be possible, which will allow each of the five sequences to be summed individually. Many parameters, such as net pay and hydrocarbon pore volume, will now be mapped.
Preliminary OOIP volumes were calculated. Three separate reservoir models were generated with the use of deterministic, statistical, and geostatistical methods. The first two model descriptions were created with the use of algorithms within Stratamodel. The third is a separate topic discussed in this and previous reports. A comparison of the three models is under way. These values will be compared with historical estimates on the basis of more simplistic volumetric approaches and material balance.

A review of waterflood efficiencies is in progress. It is anticipated that this detailed review will allow proper selection of the eight sites for the field demonstration of the proposed technology. The results of the parametric simulation studies will be coupled with the waterflood review information. The intent is to be able to select a sufficient variation in reservoir conditions and character to support the parametric study findings with field demonstrations. Guidelines will ultimately be developed to assist operators in the selection of candidate sites on the basis of this information and actual field trials.

Initial findings suggest that the waterflood has performed very well. Recoveries are estimated to ultimately recover nearly $40 \%$ OOIP. Volumes and efficiencies fit with structural and geologic trends.

\section{Reservoir Characterization}

Final copies of the stratigraphic cross sections through all CVU and Vacuum Grayburg/San Andres Unit (VGSAU) wells are nearing completion with the use of Geographix solftware. A process was developed that converts perforation database information stored in an Excel spreadsheet format to a form usable by Geographix for display on the cross sections. This process involved a three-step procedure. First, an Access software module (Access Basic Program) was created to locate and check the existing log data against maximum perforation depth. In some cases, additional data points were added where log depth was less than perforation depth. Next, a module was created to read the spreadsheet data into the Access database for active perforations, squeezed perforations, plug-back depth, and casing shoe depth. Finally, an Access report was created to generate a logging ASCII standard (LAS) format log file for each well. In Geographix, the perforation information is treated as "other" log curve data being printed on the cross sections. In all, 25 north-south and 27 east-west cross sections are complete with perforation information. This information will be used to assist with interpretations of production abnormalities. This information is further needed for history matching and model setup for the site-specific simulation exercises.

\section{Technology Transfer}

The Petroleum Recovery Research Center continues to provide updates on the project in its quarterly newsletter. In addition, the newly formed Petroleum Technology Transfer Counsel, a joint venture between the Independent Producers 
Association of America and the U.S. Department of Energy, is providing complete quarterly and annual technical reports on an industry bulletin board called GO-TECH. This will allow a more timely dissemination of information to interested parties.

A consortium led by the Colorado School of Mines is considering the $\mathrm{CVU}$ as a site to conduct four-dimensional (4-D), three-(3-C) seismic studies. The project would attempt to monitor dynamic reservoir conditions associated with the introduction of $\mathrm{CO}_{2}$ into the reservoir along with stress field changes. The information gained through this proposed seismic demonstration would complement the subject project at no cost. The information may provide necessary data for refinements to the reservoir model (layering, flow capacity, fracture orientation, etc.) and fluid characterization (saturations, fluid flow, etc.). Their consideration of the CVU as a demonstration site is made possible by the fact that the accumulation of data from this $\mathrm{CO}_{2} \mathrm{HnP}$ project is available in the public domain.

\section{IMPROVED OIL RECOVERY IN MISSISSIPPIAN CARBONATE RESERVOIRS OF KANSAS- NEAR TERM-CLASS II}

\section{Contract No. DE-FC22-93BC14987}

\author{
University of Kansas \\ Lawrence, Kans.
}

Contract Date: Sept. 18, 1994

Anticipated Completion: Sept. 18, 1998

Government Award: \$3,169,252

\section{Principal Investigators: \\ Tim Carr}

Don W. Green

G. Paul Willhite

\section{Project Manager: \\ Chandra Nautiyal \\ Bartlesville Project Office}

Reporting Period: Jan. 1-Mar. 31, 1995

\section{Objective}

The objective of this project is to demonstrate incremental reserves from Osagian and Meramecian (Mississippian) dolomite reservoirs in western Kansas through application of reservoir characterization to identify areas of unrecovered mobile oil. The project addresses producibility problems in two fields: specific reservoirs target the Schaben field in Ness County, Kans., and the Bindley field in Hodgeman County, Kans. The producibility problems to be addressed include inadequate reservoir characterization, drilling and completion design problems, and nonoptimum recovery efficiency. The results of this project will be disseminated through various technology transfer activities.

\section{Summary of Technical Progress}

At the Schaben demonstration site, the Kansas team will conduct a field project to demonstrate better approaches to identify bypassed oil within and between reservoir units. The approach will include:

- Advanced integrated reservoir description and characterization, including integration of existing data and drilling, logging, coring, and testing three new wells through the reservoir intervals. Advanced reservoir techniques will include high-resolution core description, petrophysical analysis of pore system attributes, and geostatistical analysis and three-dimensional (3-D) visualization of interwell heterogeneity.

- Computer applications for managing, mapping, and describing the reservoir. Computer simulations will be used to design better recovery processes and to identify potential incremental reserves.

- Comparison of the reservoir geology and field performance of the Schaben field with that previously described for the slightly younger Bindley field in adjacent Hodgeman County.

- Drilling of new wells between older wells (infill drilling) to contact missed zones.

- Demonstration of improved reservoir management techniques and of incremental recovery through potential deepening and recompletion of existing wells and targeted infill drilling.

The project is an effort to make Kansas producers more aware of potentially useful technologies and to demonstrate in actual oil-field operations how to apply them. For many producers, especially independents, such information is important for continued production. A major emphasis of the Kansas project will be collaboration of University scientists and engineers with the independent producers and service companies operating in the state. An extensive technology transfer effort will be undertaken to inform other operators of the results of the project. In addition to traditional technology transfer methods (e.g., reports; trade, professional, and technical publications; workshops; and seminars), a publicdomain relational database and computerized display package will be made available through the Internet and other means of digital access. 


\section{Acquisition and Consolidation of Available Data}

Acquisition and consolidation of geologic and digital log data are complete, and all data have been loaded into a database management and analysis system. Work is not complete but is progressing on the addition of production data. Commercial oil sales data by lease are readily available for the field. Operators in the field have been contacted for moredetailed production data, and most operators have supplied production information for their wells. As the production data are assembled, additional sources will be investigated (e.g., Kansas Corporation Commission).

As a result of permitting and scheduling problems, the three new wells with modern log suites and core data were not drilled. Apparently these problems have been cleared up and the wells should be drilling soon. Discussion is under way on running, at a greatly reduced price, a magnetic resonance imaging (MRI) log in at least one of the three wells. The MRI device is not commonly run in Kansas and is still largely experimental in carbonate reservoirs. The MRI device is largely unknown to Kansas independents but has the potential to identify sections of the Schaben and other reservoirs that are prime candidates for additional oil recovery.

\section{Reservoir Characterization}

Petrophysical analysis is continuing; use is being made of newly developedanalysis package, PfEFFER(Petrofacies Evaluation of Formations for Engineering Reservoirs). The program is being developed at the Kansas Geological Survey, and the Schaben field data have provided a good test of the package. The program will be readily available to the small independent [i.e., personal computer(PC)-based] and requires only rudimentary computer expertise (use of EXCEL). Preliminary results indicate that the reservoir is highly vertically stratified, of variable lithology (limestone, dolomite, and chert), and has high bulk water volume (BWV). PfEFFER may provide a costeffective tool for identifying sections of the reservoir that are prime candidates for additional oil recovery and improved reservoir description. Several preliminary descriptive reservoir products are available (e.g., cross sections and structure maps).

\section{Technology Transfer}

The technology available to be transferred is limited; however, related work on the PfEFFER program has involved transfer of related technology to a dozen Kansas oil operators. Development of the online server continues, and information to be posted on the Internet is being supplied.

\section{REVITALIZING A MATURE OIL PLAY: STRATEGIES FOR FINDING AND PRODUCING UNRECOVERED OIL IN FRIO FLUVIAL-DELTAIC RESERVOIRS OF SOUTH TEXAS}

\section{Contract No. DE-FC22-93BC14959}

\section{University of Texas \\ Bureau of Economic Geology Austin, Tex.}

Contract Date: Oct. 21, 1992

Anticipated Completion: Aug. 31, 1996

Government Award: $\$ 817,911$

\section{Principal Investigators: \\ Noel Tyler \\ Raymond Levey}

\section{Project Manager:}

Edith Allison

Bartlesville Project Office

Reporting Period: Jan. 1-Mar. 31, 1995

\section{Objectives}

Project objectives are divided into three major phases. The first phase, reservoir selection and initial framework characterization, consisted of the initial tasks.of screening fields within the play to select representative reservoirs that have a large remaining oil resource and are in danger of premature abandonment and performing initial characterization studies on selected reservoirs to identify the potential in untapped, incompletely drained, and new pool reservoirs. The second phase will involve advanced characterization of selected reservoirs to delineate incremental resource opportunities. Subtasks include the volumetric assessments of untapped and incompletely drained oil and an analysis of specific targets for recompletion and strategic infill drilling. The third and final phase of the project will consist of a series of tasks associated with technology transfer and the extrapolation of specific results from reservoirs in this study to other heterogeneous fluvial-deltaic reservoirs within and beyond the Frio play in South Texas.

The goals of the industrial associates program that is the source of industry cofunding to this project are to develop an understanding of sandstone architecture and permeability structure in a spectrum of fluvial-deltaic reservoirs deposited in high- to low-accommodation settings and to translate this understanding into more-realistic, geologically constrained reservoir models. 


\section{Summary of Technical Progress}

Work during this quarter consisted of documentation of the second phase tasks associated with the delineation of incremental recovery opportunities in selected Frio fluvial-deltaic sandstone reservoirs in Rincon and Tijerina-Canales-Blucher (TCB) fields. So that full advantage could be taken of available data specific to each field and project objectives could be completed in the remaining available time, final objectives of reservoir delineation efforts were streamlined for each field area. Present efforts in Rincon field are focusing on the completion of petrophysical modeling and the subsequent apportioning of original oil in place (OOIP) and cumulative production within individual reservoir subunits to identify the locations and delineate the volumes of remaining mobile oil in a variety of untapped and/or incompletely drained compartments. Petrographic studies and special core analyses on Rincon cores are complete, and the results are being integrated to provide the basis for oil and water saturation estimates in selected reservoir subunits. More complete documentation and detailed quantification of reservoir attributes in selected Rincon reservoirs are being pursued because the complete data set that has been acquired for these reservoirs has wide applicability to many other reservoirs in South Texas within the Frio fluvial-deltaic sandstone play. The goal of streamlined TCB project studies is the specific recommendation of near-term infill and/or recompletion targets. For the completion of TCB reservoir delineation and documentation, the focus is on the identification and assessment of reserves residing in untapped reservoir compartments as defined primarily through stratigraphic analysis.

\section{Rincon Field Reservoir Studies}

\section{Delineation of Reservoir Architecture}

In Rincon field, stratigraphic heterogeneity and variability in reservoir quality exhibited within the Frio $D$ and $E$ reservoirs are directly responsible for the distribution of OOIP and have also been primary controls on present recovery efficiencies. Reservoir mapping and stratigraphic facies analysis have identified the distribution and geometry of eight separate flow units within the Frio D-E reservoir interval in Rincon field. Evaluation of net-sandstone-thickness patterns and facies distributions based on maps constructed over each reservoir flow unit indicates a systematic evolution of sediment transport style (Fig. 1). These are, in sequence: (1) aggradation in the lower-Frio E-4 and E-3 reservoir units, (2) retrogradation in the upper-Frio E-2 and E-1 units, (3) progradation in the lower-Frio D-6 and D-5 units, and (4) a return to aggradation in the upper-Frio D-4 and D-3 units. These different styles of deposition directly affect the reservoir geometry present within each sandstone unit. Aggradational and progradational channel sedimentation creates dip-oriented channel sandstones that may or may not be in communication with each other. Retrogradational units, in contrast, allow reworking of previously deposited sediment into long strike-oriented features that have potential for increased flow communication. Identification of flow barriers within and between individual Frio D reservoir units, which
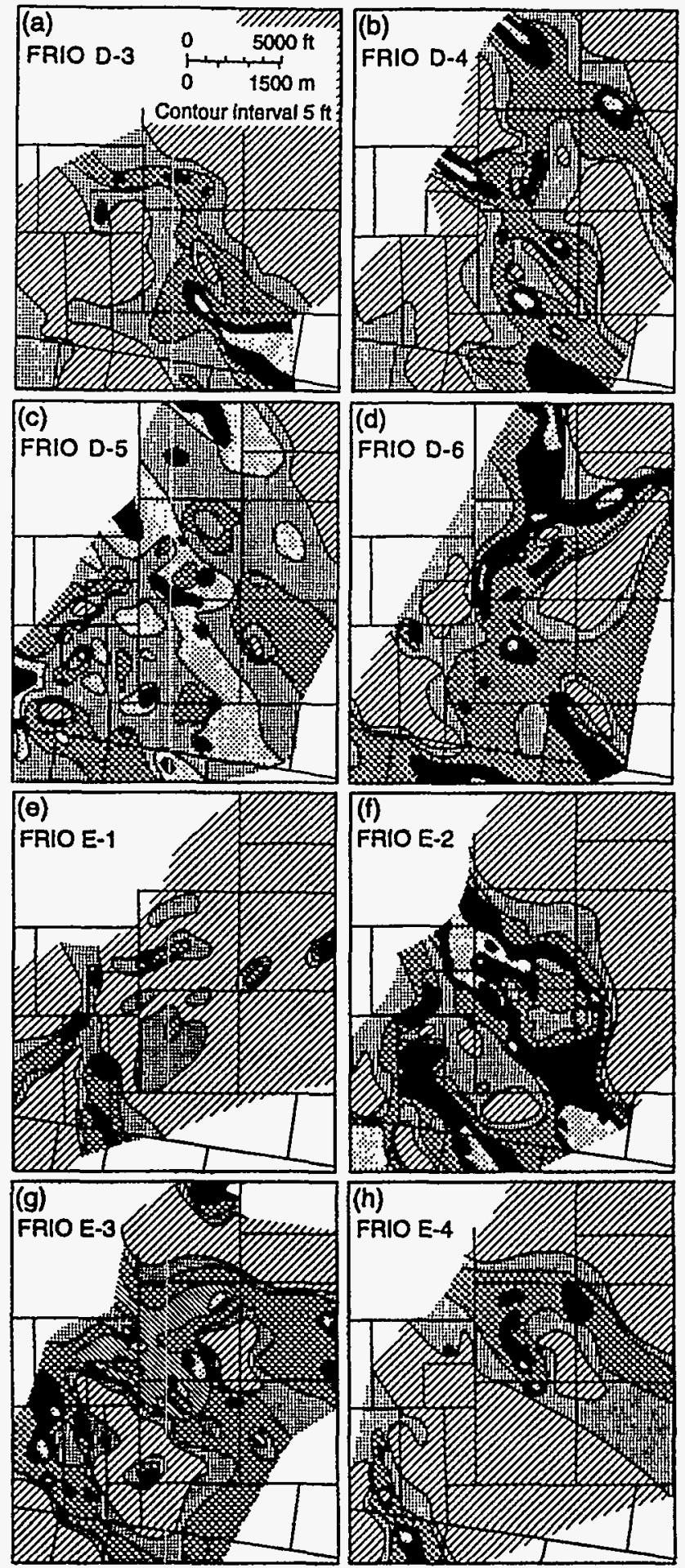

RESERVOIR AND NON-RESERVOIR FACIES (tt)

QUlA 0 (fioodpleininterdis-

O.5 (channelbar margin. or ovarbank facies)

5 - 10 (channel thalweg)

10 - 15 (channel thalweg) $15-20$ (primary channel axis and/or point bar) 20 - 25 (primary channel axis and/or point bar)

Fig. 1 Series of net-sandstone isopach and facies maps showing changes in the distribution of facies and sandstone facies geometry for the Frio $\mathrm{E}$ 4, E-3, E-2, and E-1 reservoir units and the D-6, D-5, D-4, and D-3 reservoir units. 
have an overall recovery efficiency of only $29 \%$, are the primary goals of studies in progress to understand styles of reservoir compartmentalization and to delineate the location of incompletely drained reservoir zones.

\section{Characterization of Petrophysical Reservoir Attributes}

The development of petrophysical models to calculate porosity, permeability, and water saturation in the Frio D and E reservoirs in Rincon field is based on thorough evaluation of wireline core analysis data and on results from petrographic studies and special core analyses. Core porosity and permeability data were integrated with reservoir mapping studies to characterize petrophysical reservoir attributes for various depositional facies and to identify differences between lithofacies types. A database was constructed that integrated measured porosity and permeability values for an associated sample depth with corresponding facies and subfacies types identified from map patterns and electric-log signatures, respectively. Core data were divided by reservoir subunit (i.e., D-3, D-4, D-5, and D-6) and by reservoir facies. Facies data were grouped according to channel and bar sandstone facies types as recognized on sandstone isopach maps, and channel facies were further subdivided into vertical subfacies identified from electric-log profiles. Basic descriptive statistics, including histograms and linear regressions of porosity vs. permeability, were calculated for each different subgroup of data.

In wells with sufficient core data, distinctly different values were usually recognized for the base, middle, and top portions of an individual channel sandstone unit. Porosity and permeability values exhibit a consistent vertical trend for channel facies with lowest values at channel bases [porosity mean, $16.9 \%$ (range, 6.9 to $27.3 \%$ ); mean permeability, $6 \mathrm{mD}$ (range, 0.1 to $157 \mathrm{mD}$ )] where development of a mud-chip lag is common. Permeability increases upward through midchannel [porosity mean, $21.2 \%$ (range: 8.2 to $30.7 \%$ ); permeability mean, $60 \mathrm{mD}$ (range, 0.1 to $1.530 \mathrm{mD}$ )] and then decreases at channel tops [porosity mean, $18.4 \%$ (range" 10.0 to $27.9 \%$ ); permeability mean, $14 \mathrm{mD}$ (range, 0.1 to $185 \mathrm{mD}$ )] where grain size decreases. This pattern is typical of fluvial channel deposits and reflects changes in grain size that normally occur through an upward-fining sequence. The decreased permeability at the bases of channel units is an important factor in determining the level of vertical communication between two channel units that are vertically stacked with no intervening mudstone. Significant porosity and permeability contrasts at the bases of channel deposits are attributed to the presence of clay clasts and other poorly sorted ductile fragments. If the concentrations of these components is high enough and if the components form laterally persistent beds, they may form partial or complete barriers to flow.

Evaluation of $\log$ facies and sandstone distribution for each of the reservoir subunits (Fig. 1) revealed three primary depositional facies types: (1) channel (dip-elongate) sandstone reservoir units, (2) bar (strike-oriented) sandstone reservoir units, and (3) overbank (levee and crevasse splay) units.
Channel units, on average, possess slightly higher values of porosity and permeability (20.5\% mean porosity, $60.8 \mathrm{mD}$ mean permeability) than the bar sandstone units $(18.5 \%$ mean porosity, $24.4 \mathrm{mD}$ mean permeability). Overbank facies have lower porosities (mean, 17.9\%) and substantially lower permeabilities (mean, $12.3 \mathrm{mD}$ ) than either channel or bar sandstones. Mean-permeability values, for thin, upwardcoarsening log patterns interpreted to be crevasse splays are $25 \mathrm{mD}$ (range, 0.3 to $199 \mathrm{mD}$ ) and are $5 \mathrm{mD}$ (range, 0.1 to $54 \mathrm{mD}$ ) in units with serrate log responses classified as levee facies. These poorer quality overbank facies generally are not significantreservoirs. Mean values of porosity and permeability for bar sandstone facies and for all channel facies were cross-plotted, and the resulting equations for the regression lines demonstrate the different porosity-permeability relationships between these reservoir types (Fig. 2). Similar

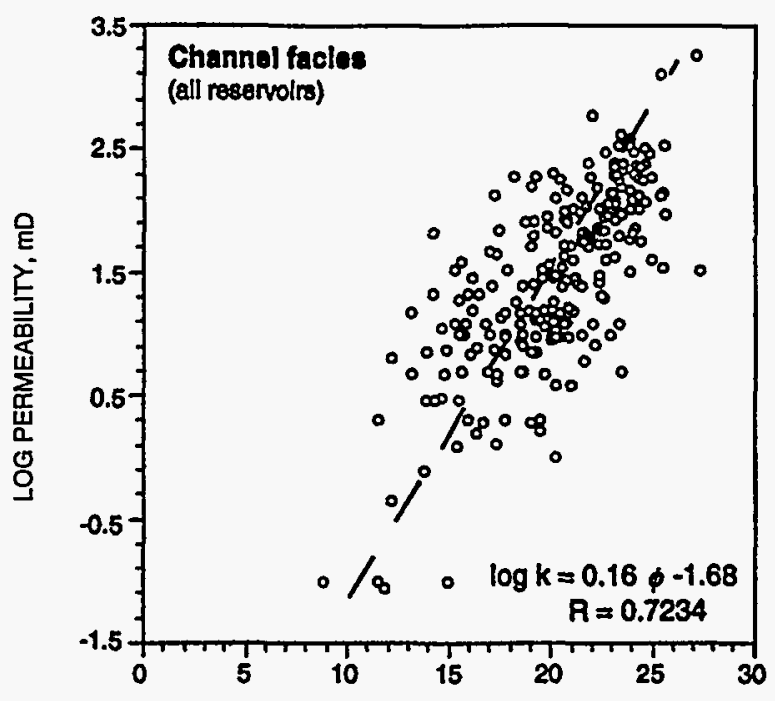

(a)

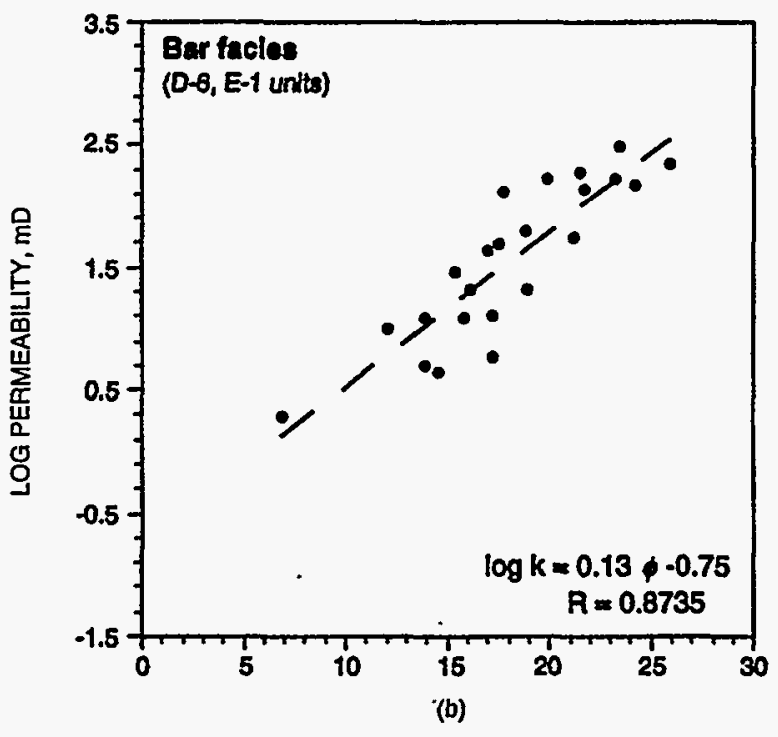

CORE POROSITY, \%

Fig. 2 Crossplots reveal different porosity-permeability relationships for two primary reservoir facies: (a) channel facies and (b) bar facies. 
porosity values have a lower corresponding permeability for channel sandstone facies than for bar sandstone facies. These two relationships will be incorporated into petrophysical porosity modeling.

\section{Petrographic and Special Core Analyses}

Petrographic studies were conducted on 22 samples selected from the Frio $D$ and $E$ reservoirs to identify framework compositions, textures, cement types, and distribution and to determine pore geometries within these sandstones. Samples selected are representative of each of the various reservoir facies and petrophysical rock types identified from core description and the statistical analysis of core data from throughout the study area. Sandstone grain sizes range from lower fine grained $(0.15 \mathrm{~mm})$ to pebbly lower medium grained $(0.3 \mathrm{~mm})$ with a mean grain size of $0.25 \mathrm{~mm}$. Most samples are poorly sorted, and sand grains are angular to subrounded. Rincon sandstones are classified as feldspathic litharenites with an average composition of $17 \%$ quartz, $33 \%$ feldspar, and $50 \%$ rock fragments $\left(\mathrm{Q}_{17} \mathrm{~F}_{33} \mathrm{R}_{50}\right)$. The majority of lithic fragments are volcanic rock fragments (VRF); on average, they compose $59 \%$ of all rock fragments and $18.7 \%$ of wholerock volume. Authigenic cements include minor grainrimming chlorite and kaolinite, but by far the most dominant cement is ferroan calcite (Table 1), which occurs as an intergranular cement with a sparry, nonpoikilotopic crystal habit. Most samples are only sparsely cemented and contain abundant, commonly oversized (as much as $0.45 \mathrm{~mm}$ in greatest dimension) pores. In heavily calcite-cemented samples (low porosity), cemented areas are commonly as much as two framework grain diameters wide and four grain diameters long.

Most of the visible thin-section porosity in these sandstones appears to be secondary and is developed as voids within partially dissolved framework grains (mainly feldspars and VRFs) and as oversized pores that once contained framework grains and/or calcite cement. Only minor primary porosity (average, $1.5 \%$ ), identified as small intergranular voids at least partially lined with chloride or calcite crystals growing into the voids within areas of closely spaced framework grains, was observed. These sandstones underwent at least two stages of dissolution, a leaching of framework constituents and subsequent dissolution of pore-filling calcite cement. Total visual porosity varies considerably from $2.5 \%$ of wholerock volume in heavily calcite-cemented samples to $28.0 \%$ in heavily leached samples (average, 15.7\%). The major diagenetic control on reservoir quality in these sandstones is the volume of calcite cement. Where calcite-cement volume is low because of dissolution and creation of porosity, sample porosity is higher. Calcite dissolution was a significant diagenetic stage that was magnified by the preceding and contemporaneous leaching of framework grains, particularly feldspars and VRFs. There is only minimal porosity-occluding

TABLE 1

Summary of Petrographic Data for Rincon Sandstones

\begin{tabular}{|c|c|c|c|c|c|c|c|c|c|c|c|c|c|c|c|}
\hline \multirow[b]{2}{*}{ Depth } & \multirow{2}{*}{$\begin{array}{l}\text { Reservoir } \\
\text { zone }\end{array}$} & \multirow{2}{*}{$\begin{array}{l}\text { Depositional } \\
\text { facies }\end{array}$} & \multicolumn{2}{|c|}{ Grain size- } & \multicolumn{3}{|c|}{$\begin{array}{l}\text { Framework } \\
\text { constituents }\end{array}$} & \multicolumn{3}{|c|}{$\begin{array}{l}\text { Lithic grain } \\
\text { compositions }\end{array}$} & \multirow{2}{*}{$\begin{array}{l}\mathrm{CaCO}_{3} \\
\text { cement }\end{array}$} & \multicolumn{3}{|c|}{$\begin{array}{l}\text { Visual porosity } \\
\text { estimates, \% }\end{array}$} & \multirow{2}{*}{$\begin{array}{c}\text { Percent } \\
\text { total } \\
2^{\circ} \varnothing\end{array}$} \\
\hline & & & $\mathbf{m m}$ & Phi & $\mathbf{Q}$ & $\mathbf{F}$ & $\mathbf{L}$ & Vrf & Srf & Crf & & $1^{\circ} \emptyset$ & $2^{\circ} \varnothing$ & Total $\varnothing$ & \\
\hline 3872.0 & D-5a & Channel-mid & 0.15 & 2.75 & 11 & 30 & 59 & 68 & 26 & 5 & 7.5 & 1.5 & 20.0 & 21.5 & 93 \\
\hline 3876.0 & D-5a & Channel-base & & & & & & & & & & & & & \\
\hline 3879.0 & D-5b & Channel-mid & 0.21 & 2.25 & 16 & 41 & 43 & 69 & 22 & 9 & 4.0 & 0 & 27.0 & 27.0 & 100 \\
\hline 3884.0 & D-5b & Channel-mid & 0.3 & 1.75 & 16 & 30 & 54 & 60 & 25 & 15 & 4.5 & 4.5 & 17.5 & 22.0 & 80 \\
\hline 3891.0 & D-5b & Channel-base & 0.3 & 1.75 & 25 & 27 & 48 & 59 & 27 & 13 & 14.0 & 0.5 & 16.5 & 17.0 & 97 \\
\hline 3895.0 & D-6 & Channel-mid & 0.30 & 1.75 & 11 & 35 & 54 & 47 & 42 & 11 & 15.0 & 2.0 & 14.0 & 16.0 & 88 \\
\hline 3900.0 & D.6 & Channel-base & 0.30 & 1.75 & 13 & 30 & 57 & 56 & 38 & 6 & 22.5 & 2.0 & 4.0 & 6.0 & 67 \\
\hline 3945.0 & E-1 & Channel-top & 0.15 & 2.75 & 7 & 45 & 48 & 73 & 22 & 4 & 7.5 & 1.0 & 14.5 & 15.5 & 94 \\
\hline 3950.0 & E-1 & Channel-mid & 0.30 & 1.75 & 12 & 36 & 52 & 63 & 29 & 8 & 4.5 & 3.5 & 15.0 & 18.5 & 81 \\
\hline 3954.0 & E-1 & Channel-mid (cc) & 0.30 & 1.75 & 14 & 37 & 49 & 66 & 28 & 5 & 32.5 & 0 & 1.5 & 1.5 & 100 \\
\hline 3959.0 & E-1 & Channel-base & 0.30 & 1.75 & 10 & 43 & 47 & 58 & 32 & 10 & 14.0 & 2.0 & 14.5 & 16.5 & 88 \\
\hline 3964.0 & $E-2$ & Splay & 0.21 & 2.25 & 21 & 46 & 33 & 94 & 0 & 6 & 0 & 0 & 2.5 & 2.5 & 100 \\
\hline 3967.3 & E-2 & Channel-top & 0.21 & 2.25 & 30 & 43 & 27 & 58 & 24 & 18 & 10.5 & 12.5 & 4.5 & 17.0 & 26 \\
\hline 3969.3 & E-2 & Channel-mid & 0.30 & 1.75 & 23 & 34 & 43 & 89 & 7 & 4 & 4.0 & 18.5 & 8.0 & 26.5 & 30 \\
\hline 3974.6 & $E-2$ & Splay & 0.21 & 2.25 & 15 & 27 & 58 & 64 & 29 & 7 & 24.5 & 5.0 & 7.0 & 12.0 & 58 \\
\hline 3987.0 & E-3 & Channel-top & 0.21 & 2.25 & 18 & 29 & 53 & 46 & 51 & 2 & 8.5 & 2.5 & 25.5 & 28.0 & 91 \\
\hline 3988.7 & $E-3$ & Channel-mid (cc) & 0.21 & 2.25 & 21 & 30 & 49 & 55 & 33 & 11 & 25.0 & 1.0 & 5.5 & 6.5 & 85 \\
\hline 3990.9 & E-3 & Channel-mid & 0.21 & 2.25 & 19 & 28 & 53 & 59 & 32 & 9 & 9.0 & 12.5 & 13.5 & 26.0 & 52 \\
\hline 3997.5 & E-3 & Channel-mid & 0.25 & 2.0 & 21 & 23 & 56 & 57 & 30 & 14 & 8.0 & 12.5 & 9.5 & 22.0 & 43 \\
\hline 3999.6 & E-3 & Channel-base & 0.25 & 2.0 & 16 & 34 & 50 & 47 & 44 & 9 & 5.5 & 3.5 & 18.0 & 21.5 & 84 \\
\hline 4008.3 & E-4 & Channel-mid & 0.30 & 1.75 & 23 & 25 & 52 & 41 & 46 & 13 & 9.0 & 11.5 & 18.0 & 29.5 & 61 \\
\hline
\end{tabular}

${ }^{*} \mathrm{Key}: \mathrm{Q}$, quartz; F, feldspar; L, lithics; Vrf, volcanic rock fragment; Srf, sedimentary rock fragment (clastic); Crf, carbonate rock fragment (intraformational); $1^{\circ} \emptyset$, primary porosity; $2^{\circ} \emptyset$, secondary porosity; Total $\emptyset$, total visual porosity $\left(1^{\circ}+2^{\circ}\right) ; 2^{\circ} \emptyset$, (\% total), percentage of total visual porosity that is secondary. 
ductile deformation of shaly rock fragments, which are consistently rare, and pressure solution at grain boundaries of carbonate lithic fragments.

Fifteen samples from the Frio $\mathrm{D}$ and $\mathrm{E}$ reservoir zones in two wells were selected for special core analyses. These samples represent the range of petrophysical rock types identified from core description and were chosen to demonstrate differences (if any) in measured petrophysical values (1) between the base and top of a single-story sandstone unit, (2) between the base and top of a multistoried/stacked channel unit, (3) in a thin crevasse splay sandstone, and (4) in carbonate-cemented and noncarbonate-cemented sandstones. Formation resistivity measurements were conducted to define the cementation exponent $m$, which is an important variable in the equation used to calculate formation water saturation $S_{w}$ (Table 2). Reported data on $m$ values from the Frio in South Texas are very limited, and the reported Frio values are all less than the value 2.0 , which is the standard default value generally used in the Archie equation for sandstones characterized by intergranular porosity. Higher values of $m$ result in higher calculated $S_{w}$ values, which will, in turn, result in lower estimates for oil in place (OIP). Accurate estimates of $S_{w}$ are critical to delineating reasonable volumes of OIP, and measurements of $m$ on these core samples will provide the best possible estimates of values and variations in $\mathrm{S}_{\mathrm{w}}$ in these Frio reservoir rock types.

Mercury-injection capillary pressure measurements were also performed on 15 samples to determine the distribution of pore-throat sizes and to estimate irreducible water saturation
$\left(\mathrm{S}_{\mathrm{wi}}\right)$. Results are shown in Table 3. These estimates of $\mathrm{S}_{\mathrm{wi}}$ will be used in subsequent resource calculations. Coreflood tests were also conducted to acquire data on residual oil saturation $\left(\mathrm{S}_{\mathrm{or}}\right)$ and end-point relative permeability. These results are being evaluated. There were no previous $S_{\text {or }}$ data for these reservoirs, and values for $S_{\text {or }}$ reported for reservoirs throughout the Frio play range widely from 10 to $38 \%$. $\mathrm{S}_{\mathrm{or}}$ data are obviously critical to obtaining reasonable estimates of remaining mobile oil. Petrographic data are being integrated with results from capillary pressure and formation resistivity tests to identify variations in pore geometry that may influence saturation and the possible controls on these variations. Detailed observations of pore geometry of selected samples with the use of scanning electron microscopy (SEM) are being made to supplement this work.

\section{T-C-B Field Reservoir}

Work in T-C-B field this quarter has focused on compartmentalization styles and infill opportunities in the Scott/ Whitehill reservoir interval of the middle Frio formation. This interval has been subdivided into four sections, the upper and lower Scott and the upper and lower Whitehill. Net sandstone maps have been prepared for these intervals, which range in gross interval thickness from 20 to $45 \mathrm{ft}$. Net sandstone maps show a series of dip-oriented sandstone thicks representing individual channel belts or areas of vertically overlapping channel belts. Upward-increasing sandstone content within the Scott/Whitehill interval, accompanied by changing

TABLE 2

Summary of Measured Petrophysical Values of Porosity, Permeability, Formation Resistivity, and Calculated Cementation Exponent for Rincon Field Reservoir Units*

\begin{tabular}{lccccccc}
\hline Unit & $\begin{array}{c}\text { Depth, } \\
\text { ft }\end{array}$ & $\begin{array}{c}\text { Visual } \\
\text { porosity, } \\
\text { \% }\end{array}$ & $\begin{array}{c}\text { Measured } \\
\text { porosity, } \\
\text { \% }\end{array}$ & $\begin{array}{c}\text { Measured } \\
\text { permeability, } \\
\text { mD }\end{array}$ & $\begin{array}{c}\text { Formation } \\
\text { resistivity } \\
\text { factor }\end{array}$ & $\begin{array}{c}\text { Cementation } \\
\text { exponent, } \\
\text { Archie m }\end{array}$ & $\begin{array}{r}\text { Calcite } \\
\text { cement, } \\
\text { \% volume }\end{array}$ \\
\hline D-5a & 3872 & 0.22 & 0.30 & 172.0 & 13.85 & 2.18 & 7.5 \\
D-5a & 3876 & & Disintigr. & - & - & - & - \\
D-5b & 3879 & 0.27 & 0.30 & 102.0 & 13.64 & 2.40 & 4.0 \\
D-5b & 3891 & 0.17 & 0.32 & 320.0 & 15.52 & 2.40 & 14.0 \\
D-6 & 3895 & 0.16 & 0.18 & 121.0 & 19.69 & 1.73 & 15.0 \\
E-1 & 3950 & 0.19 & 0.22 & 130.0 & 17.78 & 1.80 & 4.5 \\
E-1 & 3954 & 0.02 & 0.09 & 0.4 & 45.79 & 1.57 & 32.5 \\
E-1 & 3959 & 0.17 & 0.20 & 370.0 & 14.15 & 1.82 & 14.0 \\
E-2 & 3967.3 & 0.17 & 0.22 & 36.5 & 16.25 & 1.83 & 10.5 \\
E-2 & 3974.6 & 0.12 & 0.16 & 7.2 & 25.20 & 1.74 & 24.5 \\
E-3 & 3987.0 & 0.28 & 0.22 & 61.0 & 14.57 & 1.78 & 8.5 \\
E-3 & 3988.7 & 0.07 & 0.11 & 3.3 & 44.58 & 1.73 & 25.0 \\
E-3 & 3990.9 & 0.26 & 0.26 & 747.0 & 12.51 & 1.90 & 9.0 \\
E-3 & 3999.6 & 0.22 & 0.23 & 98.0 & 16.82 & 1.90 & 5.5 \\
E-4 & 4008.3 & & 0.18 & 27.5 & 20.47 & 1.74 & - \\
\hline
\end{tabular}

*Values for measured porosity and $\mathrm{m}$ for aggradational $\mathrm{D}$ sandstones are significantly higher than those measured from underlying $E$ reservoir units. High formation resistivity corresponds to low-porosity samples heavily cemented with calcite. 
TABLE 3

Comparison of Reservoir Units and Corresponding Depositional Facies Identified from Core Descriptions with Irreducible Water and Residual Oil Saturations Determined from Mercury-Injection Capillary Pressure Measurements and Coreflood Tests*

\begin{tabular}{llccccccc}
\hline Unit & $\begin{array}{c}\text { Depositional } \\
\text { facies }\end{array}$ & $\begin{array}{c}\text { Sample } \\
\text { depth, } \\
\mathbf{f t}\end{array}$ & $\begin{array}{c}\text { Residual } \\
\text { oil saturation } \\
\left(\mathbf{S}_{\mathbf{~} \mathrm{r}}\right), \boldsymbol{\%}\end{array}$ & $\begin{array}{c}\text { Irreducible } \\
\text { water saturation } \\
\left(\mathbf{S}_{\text {wi }}\right), \%\end{array}$ & $\begin{array}{c}\text { Medium pore- } \\
\text { throat } \\
\text { size, } \boldsymbol{\mu m}\end{array}$ & $\begin{array}{c}\text { Phi } \\
\text { size }\end{array}$ & $\begin{array}{c}\text { Permeability, } \\
\text { mD }\end{array}$ & $\begin{array}{c}\text { Cementation } \\
\text { exponent, } \\
\text { Archie m }\end{array}$ \\
\hline D-5a & Channel-mid & 3872.0 & 0.260 & 30.0 & 50 & 0.299 & 172.0 & 2.18 \\
D-5b & Channel-mid & 3879.0 & 0.393 & 30.0 & 15 & 0.297 & 102.0 & 2.40 \\
D-5b & Channel-base & 3891.0 & 0.154 & 36.0 & 21 & 0.319 & 320.0 & 2.40 \\
D-6 & Channel-mid & 3895.0 & - & 25.0 & 85 & 0.179 & 121.0 & 1.73 \\
E-1 & Channel-mid & 3950.0 & 0.453 & 20.0 & 80 & 0.224 & 130.0 & 1.80 \\
E-1 & Channel-mid (cc) & 3954.0 & 0.624 & 37.0 & 3 & 0.087 & 0.4 & 1.57 \\
E-1 & Channel-base & 3959.0 & 0.147 & 15.0 & 118 & 0.234 & 370.0 & 1.82 \\
E-2 & Channel-top & 3967.3 & 0.244 & 23.5 & 21 & 0.218 & 36.5 & 1.83 \\
E-2 & Splay & 3974.6 & 0.194 & 17.0 & 39 & 0.157 & 7.2 & 1.74 \\
E-3 & Channel-top & 3987.0 & 0.189 & 21.0 & 70 & 0.221 & 61.0 & 1.78 \\
E-3 & Channel-mid (cc) & 3988.7 & 0.286 & 36.0 & 10 & 0.111 & 3.3 & 1.73 \\
E-3 & Channel-mid & 3990.9 & 0.227 & 18.8 & 200 & 0.264 & 747.0 & 1.90 \\
E-3 & Channel-base & 3999.6 & 0.298 & 15.0 & 72 & 0.226 & 98.0 & 1.90 \\
E-4 & Channel-mid & 4008.3 & - & 27.0 & 40 & 0.176 & 27.5 & 1.74 \\
\hline
\end{tabular}

*Higher water saturations are present in the upper $E$ and Frio $D$ reservoir units as well as in calcite-cemented sandstones. Smaller pore-throat size distributions are characteristic of finer grained top-channel facies and samples with abundant carbonate cement.

compartmentalization style, may reflect changing accommodation and avulsion rates in the upper delta plain as a consequence of varying relative base level. A tentative model of fluvial response to base level has been developed and may be useful in allowing operators to predict the degree of compartmentalization in a reservoir on the basis of its position within a depositional cycle.

The operator has begun interpretation of a recently acquired three-dimensional (3-D) seismic data volume covering the bulk of the study area. These data indicate complex faulted patterns in the lower Frio section that are oriented differently from those interpreted with two-dimensional (2-D) seismic data. In addition, time structure-contour maps of markers in the middle Frio, near the Scott reservoir, yield more complete information on the subtle structural highs causing trapping at this level. Increases in precision over subsurface well control and 2-D seismic data will be crucial to explaining the distribution of trapped hydrocarbons in the Scott/Whitehill interval.

A preliminary assessment of the residency of remaining reserves in the Scott/Whitehill interval has been carried out by integrating the identified stratigraphic compartmentalization with new structural interpretations. Several infill and recompletion candidates in the upper Whitehill and upper Scott reservoirs have been tentatively defined.(Fig. 3). High water cuts in some completions in these reservoirs need to be explained before the operator acts upon these recommendations. Mechanical failure in these completions has been investigated and is unlikely. The answer may lie in the interaction of the low-relief structure with a strong water drive and complex reservoir compartmentalization.

\section{Characterization of Heterogeneity Style and Permeability Structure in a Sequence Stratigraphic Framework in Fluvial-Deltaic Reservoirs (Matching Funds Source)}

Because of the worldwide importance of resources in fluvial-deltaic reservoirs, a consortium of oil companies is funding research at the Bureau of Economic Geology aimed at reservoir characterization of fluvial-deltaic depositional systems. The goals of this program are to develop an understanding of sandstone architecture and permeability structure in a spectrum of fluvial-deltaic reservoirs and to translate this understanding into more realistic, geologically constrained reservoir models. The approach is to quantify the interrelationships between sequence stratigraphy, depositional architecture, diagenesis, and permeability structure through detailed outcrop characterization. This industrial associates program is the source of the 50\% cofunding for the Bureau's Class I Oil Project.

The project is currently focused on the Upper Cretaceous Ferron sandstone, a deltaic system deposited in a high-accommodation setting in Utah, and the Lower Cretaceous Fall River formation, a deltaic system deposited in a low-accommodation setting in South Dakota and Wyoming. The Ferron comprises seven short-term stratigraphic cycles arranged in a seaward-stepping, vertically stacked, and landward-stepping stacking pattern. Because major unconformities are absent and sediment preservation is high, depositional elements are the major control on fluid flow. Permeability structure, as determined from more than 10,000 minipermeameter data points, is strongly related to lithofacies distributions within depositional elements. 


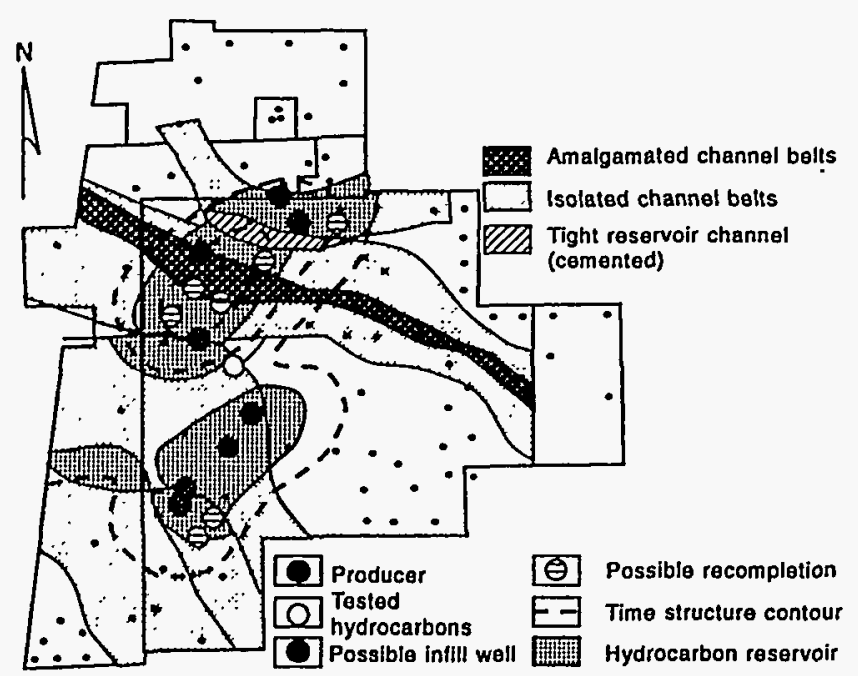

(a)

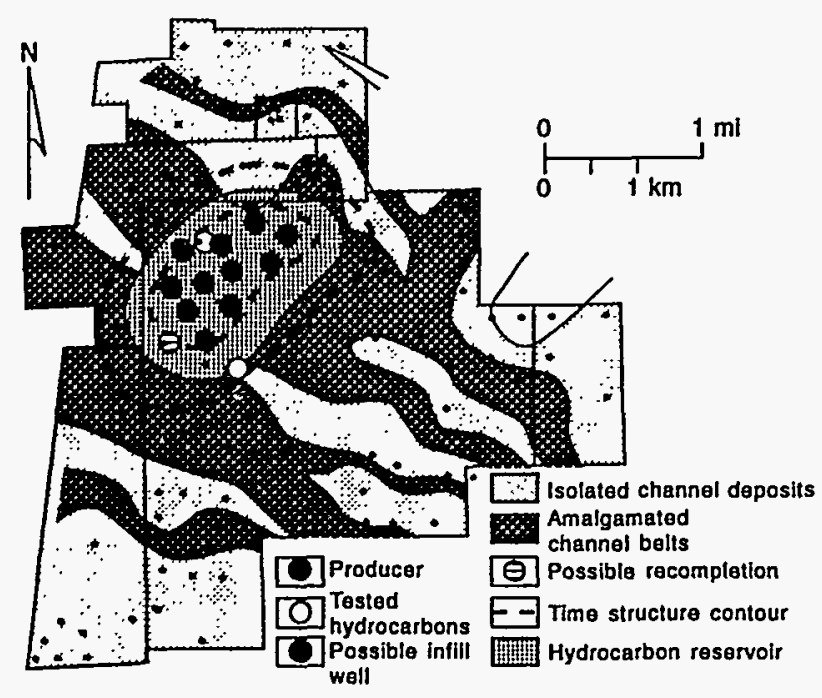

(b)

Fig. 3 Infill potential of upper Whitehill reservoir (a) and upper Scott reservoir (b).

In comparison, the Fall River formation is composed of shallow-marine facies tracts locally incised by valley-fill deposits. Detailed work in two canyons with good exposures of the Fall River has characterized the facies, permeability structure, and architecture of valley-fill sandstone successions. Preservation of depositional elements is low in this setting, and unconformities control permeability distribution. Pronounced lateral changes in permeability occur where valley fills of different character are juxtaposed. The interpretations of the Fall River that were developed by studying the formation in outcrop are being used to guide flow modeling of Buck Draw field, which produces oil from the Fall River formation in the nearby Powder River Basin.

\section{Technology Transfer}

In addition to specific project tasks, a Bureau of Economic Geology Report of Investigations on playwide resource assessment and identification of remaining oil potential in the Frio fluvial-deltaic sandstone play ${ }^{1}$ was completed and published. Results highlighting project studies on playwide reservoir assessment ${ }^{2}$ and results from initial reservoir characterization studies in each field area ${ }^{3,4}$ were presented at the 1995 American Association of Petroleum Geologists (AAPG) annual meeting. In addition, two papers discussing aspects of the Rincon ${ }^{5}$ and T-C-B ${ }^{6}$ field studies were accepted for presentation at the 1995 Gulf Coast Association of Geological Societies Meeting.

A vital part of the technology transfer activity is face-toface meetings whenever feasible with the geologic staff of operators to impart the techniques of detailed reservoir characterization. Meetings with operator representatives from both T-C-B and Rincon fields were held during this project quarter. Additionally, several requests for meetings with additional interested parties were received during the AAPG meeting in March.

\section{References}

1. M.H.Holtzand L. E.McRae, Identification and Assessment of Remaining Oil Resources in the Frio Fluvial-Deltaic Sandstone Play, South Texas, The University of Texas at Austin, Bureau of Economic Geology Report of Investigations No. 227, 1995.

2. M. H. Holtz and L. E. McRae, Modeling Reservoir Attributes and Estimating Additional Hydrocarbon Potential for Redevelopment in Fluvial-Deltaic Reservoirs: An Example from the Frio Fluvial-Deltaic Sandstone Play in South Texas (abstract) in Petroleum Technology of the World, official program for the 1995 annual convention of the American Association of Petroleum Geologists, Houston, Tex.,March5-8, 1995,pp.4243A.

3. L. E. McRae and M. H. Holtz, Reservoir Architecture and Permeability Characteristics of Fluvial-Deltaic Sandstone Reservoirs in the Frio Formation, Rincon Field, South Texas (abstract), in Petroleum Technology of the World, official program for the 1995 annual convention of the American Association of Petroleum Geologists, Houston, Tex., March 58, 1995, p. 64A.

4. P.R. Knox and L.E.McRae,High-Resolution Sequence Stratigraphy:The Key to Identifying CompartmentStyles in Frio Formation Fluvial-Deltaic Reservoirs, T-C-B Field, South Texas (abstract), in Petroleum Technology of the World, official program for the 1995 annual convention of the American Association of Petroleum Geologists, Houston, Tex., March 58, 1995, p. 51A.

5. L. E. McRae and M. H. Holtz, Strategies for Optimizing Incremental Recovery from Mature Reservoirs in Oligocene Frio Fluvial-Deltaic Sandstones, Rincon Field, South Texas, Transactions, Gulf Coast Association of Geological Societies, Vol. 45, in press.

6. P. R. Knox and L. E. McRae, Application of Sequence Stratigraphy for Prioritizing Mature Reservoirs for Incremental Growth Opportunities: An Examplefrom Frio Fluvial-DeltaicReservoirs, T-C-B Field, South Texas, Transactions, GulfCoastAssociation of Geological Socieities, Vol.45, in press. 


\section{INTEGRATED APPROACH TOWARD THE APPLICATION OF HORIZONTAL WELLS TO IMPROVE WATERFLOODING PERFORMANCE}

\section{Contract No. DE-FC22-93BC14951}

\author{
University of Tulsa \\ Tulsa, Okla.
}

Contract Date: Jan. 1, 1993

Anticipated Completion: Dec. 31, 1996

Government Award: \$250, 973

Principal Investigator:

Balmohan G. Kelkar

Project Manager:

Rhonda Lindsey

Bartlesville Project Office

Reporting Period: Jan. 1-Mar. 31, 1995

\section{Objective}

The overall objective of the project is to improve secondary recovery performance of a marginal oil field through the use of a horizontal injection well. The location and direction of the well will be selected on the basis of the detailed reservoir description with the use of an integrated approach. With the use of this method, a recovery of 2 to $5 \%$ of original oil in place (OOIP) is expected. This should extend the life of the reservoir by at least $10 \mathrm{yr}$.

The project is divided into two stages in order to accomplish its goals. In Stage I part of the Glenn Pool field (William B. Self Unit) will be selected, and additional reservoir data will be collected by conducting cross-borehole tomography surveys and formation microscanner logs through the newly drilled well. The state-of-the-art data combined with conventional core and log data will be used to develop a detailed reservoir description based on an integrated approach. After extensive reservoir simulation studies are conducted, alternate reservoir management strategies will be evaluated to improve the reservoir performance, including drilling of a horizontal injection well. The management plant will be implemented and performance will be monitored. If the performance is encouraging, the second budget period of the project will begin.

Stage II, the second budget period of the project, will involve the selection of part of the same reservoir (Berryhill Unit, tract7), development of the reservoir description with the use of only conventional data, simulation of flow performance with the use of a developed reservoir description, selection of an appropriate reservoir management plan, and implementation of the plan followed by monitoring of reservoir performance.
A comparison of the results of the two budget periods will allow evaluation of the usefulness of collecting additional data with state-of-the-art technology. In addition, the application of an optimum reservoir management plan in improving secondary recovery performance of marginal oil fields can also be evaluated. Successful completion of this project will provide new means of extending the life of marginal oil fields with readily available technology. A methodology to integrate various qualities and quantities of measured data to develop a detailed reservoir description will also be presented.

\section{Summary of Technical Progress}

\section{Implementation of Reservoir Management Plan}

A detailed evaluation of various alternatives for improving the performance of the Self Unit was presented previously. On the basis of the economic evaluation of various alternatives, the best alternative was observed to be recompletion of several wells followed by an increase in the injection rate in all the injection wells.

The reservoir management plan will be implemented in three phases. In the first phase, 7 wells will be perforated and stimulated. After the performance of these wells is monitored for a few weeks, another 10 wells will be perforated and stimulated. If excess water production is not evident, a new water injection pump will be installed to increase the water injection rate. In the last phase, the remaining wells (about 10) will be perforated and stimulated. All recompletion work is expected to be finished by mid- 1995 .

\section{Technology Transfer}

Geological work completed in this quarter was focused on the transfer of technology for efforts completed on the Self Unit. Approximately 45 slides and 20 poster figures were prepared, and two abstracts were accepted for presentation of papers at the 1995 American Association of Petroleum Geologists Annual Meeting. The poster presentation entitled "Interdisciplinary Analysis of Fluvial Dominated Deltaic Reservoirs: Glenn Pool Field, Creek County, Oklahoma,"l was presented at the student sessions (awarded second-best student paper). The oral presentation, "Characterization of Fluvial-Dominated Deltaic Reservoirs in a Mature Oil Field: Glenn Pool Field, Northeastern Oklahoma,"2 was given in the Field Compartmentalization Technical Session as of the same meeting. The results were of apparent interest to independent operators and other researchers as judged by discussions that followed the presentation.

\section{References}

1. Interdisciplinary Analysis of Fluvial Dominated Deltaic Reservoirs: Glenn Pool Field, Creek County, Oklahoma, paper presented at the American Association of Petroleum Geologists Annual Meeting, Houston, Tex., March 5-8, 1995. 
2. Characterization of Fluvial-Dominated Deltaic Reservoirs in a Mature Oil Field: Glenn Pool Field, Northeastern Oklahoma, paper presented at the American Association of Petroleum Geologists Annual Meeting, Houston, Tex., March 5-8, 1995.

\section{INCREASED OIL PRODUCTION \\ AND RESERVES FROM IMPROVED COMPLETION TECHNIQUES IN THE BLUEBELL FIELD, UINTA BASIN, UTAH}

\section{Contract No. DE-FC22-92BC14953}

\section{Utah Geological Survey \\ Salt Lake City, Utah}

Contract Date: Sept. 30, 1993

Anticipated Completion: Sept. 29, 1998

Government Award: $\$ 412,890$

\author{
Principal Investigator: \\ M. Lee Allison \\ Project Manager: \\ Edith Allison \\ Bartlesville Project Office
}

Reporting Period: Jan. 1-Mar. 3i, 1995

\section{Objective}

The objective of this project is to increase the oil production and reserves in the Uinta Basin by demonstration of improved completion techniques. Low productivity is attributed to gross production intervals of several thousand feet that contain perforated thief zones, water-bearing zones, and unperforated oil-bearing intervals. Geologic and engineering characterization and computer simulation of the Green River and Wasatch formations in the Bluebell Field will determine reservoir heterogeneities related to fractures and depositional trends. This will be followed by drilling and recompletion of several wells to demonstrate improved completion techniques based on the reservoir characterization. Technology transfer of the project results will be an ongoing component of the project.

\section{Summary of Technical Progress}

\section{Subsurface Studies}

Clay analysis with the use of X-ray diffraction (XRD) is complete on 33 outcrop (Table 1) and 35 well-core (Table 2) samples from the Green River and Wasatch formations. Preliminary analysis of clay types indicates illite, chlorite, and kaolinite in both the clastic (predominantly sandstone) and carbonate rocks. Also, minor amounts of potentially swelling mixed-layer clays (illite-smectite and chlorite-smectite) are present. Examination of core shows that, in general, the carbonate rocks have randomly orientated, interconnected fractures, whereas in the sandstones fractures are more vertical and isolated. The sandstones, however, have the best storage capacity because of greater matrix porosity.

\section{Engineering Studies}

With the use of the well records at the Utah Division of Oil, Gas and Mining, a database of completion and recompletion treatments of wells in the Bluebell Field was developed. From this database, 94 wells, a total of 150 to 250 completion and recompletion treatments, were selected for further study.

Additional details about the treatments were requested from the well operators. All the operators responded positively, and the additional treatment information is being entered into the database. When data entry is complete, it will be sent to Halliburton's Technical Team in Denver, Colo., who will evaluate each of the treatments and resulting production responses to determine what has been the most effective treatment (technique, fluids, and additives).

\section{Technology Transfer}

A paper entitled Reservoir Characterization Through $\mathrm{Fa}$ cies Analysis of the Lower Green River Formation for Hydrocarbon Production Enhancement in the Altamont-Bluebell Field, Uinta Basin, Utah was presented at the American Association of Petroleum Geologists (AAPG) 1995 Annual Meeting. ${ }^{1}$ This paper was also presented at the Ninth Annual Spring Research Conference sponsored by Brigham Young University, Provo, Utah. A paper entitled Facies Analysis of Well Cores from the Lower Green River Formation, Bluebell Field, Uinta Basin, Utah: Implications for Identifying Highly Productive Zones was also presented at the Ninth Annual Spring Research Conference sponsored by Brigham Young University, Provo, Utah. ${ }^{2}$

Project materials were displayed at the Utah Geological Survey booth during the 1995 Annual Meeting of the AAPG and at the 1995 Regional Meeting of the Society of Petroleum Engineers, in Denver, Colo. 
TABLE 1

Porosity, Permeability, and Clay and Authigenic Mineral Analysis of Samples

Collected from the Lower Green River and Upper Wasatch Transition

Outcrop in Willow Creek Canyon, Duchesne County, Utah*

\begin{tabular}{|c|c|c|c|c|c|c|c|}
\hline $\begin{array}{l}\text { Sample } \\
\text { name }\end{array}$ & $\begin{array}{c}\text { Meters } \\
\text { above } \\
\text { base }\end{array}$ & $\begin{array}{c}\text { Horizontal } \\
\text { permeability, } \\
\text { mD }\end{array}$ & $\begin{array}{c}\text { Vertical } \\
\text { permeability, } \\
\text { mD }\end{array}$ & $\begin{array}{c}\text { Porosity, } \\
\%\end{array}$ & $\begin{array}{c}\text { Clay } \\
\text { content }\end{array}$ & Comments & Lithology \\
\hline 5-DN5 & 6.3 & 0.07 & 0.05 & 10.90 & Cs, Is, K, z & Mostly K & Feldspathic wacke \\
\hline 7-DN7 & 7.8 & 0.66 & 0.02 & 2.70 & & & Fossilferous packstone \\
\hline 21-DN21 & 21.3 & & & & Cs, Is, $\mathbf{K}$. & Moderate/equal & Fossilferous wackstone \\
\hline 36-DN36 & 34.5 & & . & & $\mathrm{cS}, \mathrm{Is}, \mathrm{K}, \mathrm{z}$ & Moderate/equal & Wackstone \\
\hline 37-DN37 & 35.7 & 4.40 & 0.53 & 27.20 & $\mathrm{CS}, \mathrm{Is}, \mathrm{Ks}$ & Very little of any & Ostracodal packstone \\
\hline 43 & 48.2 & $<0.01$ & $<0.01$ & 7.70 & $\mathrm{Cs}, \mathbf{I S}, \mathbf{K}$ & Very.little of any & Mudstone \\
\hline 47-DN47 & 59.6 & $<0.01$ & 0.01 & 3.80 & $\mathrm{Cs}, 1$ & Very little of any & Mudstone \\
\hline 102-EH47 & 103.9 & 93+ & $<0.01$ & 4.70 & CS, Is & Very little of any & Mudstone \\
\hline 113-EH58 (BAG) & 129.2 & 0.01 & 0.01 & 3.10 & .cS, Is, Ks? & Very little of any & Mudstone - \\
\hline 113-EH58 (BLOCK) & 129.2 & 0.01 & 0.01 & 5.80 & $\mathrm{cS}, \mathrm{Is}, \mathrm{Ks}$ & Very little of any & Mudstone \\
\hline 140-EH85 & 149.9 & 285.00 & 208.00 & 23.70 & $\mathrm{Cs}, \mathrm{I}, \mathrm{K} / \mathrm{C}_{3}, \mathrm{Z}$ & More illite & Feldspathic arenite \\
\hline 140-EH85A & 149.9 & 46.00 & 19.00 & 23.00 & Cs, Is, Ks, z & More illite & Feldspathic arenite \\
\hline 265-RP18 & 379.8 & 0.20 & $<0.01$ & 6.60 & Cs, Is, K/Cs, Z Z & Moderate/equal & Feldspathic wacke \\
\hline 282-RP35 & 394.3 & 0.13 & 0.05 & 14.50 & Cs, Is, 2 & Moderate/equal & Feldspathic arenite \\
\hline 424-AA25 & 558.5 & 18.00 & 4.40 & $21: 90$ & $\mathrm{cS}, \mathrm{Is}, \mathrm{K} / \mathrm{C}$ & Mostly cS & Feldspathic arenite \\
\hline 438-AA39 & 571.9 & & & & cS, 15 & Mostly cS & Mudstone \\
\hline 451-AAS2 & 584.1 & 0.01 & $<0.01$ & 8.30 & $\therefore \mathrm{cS}, \mathrm{Is}, \mathrm{Ks}$ & Very little of any & Peloidal quartz mudstone \\
\hline 479-CC4 & 614.75 & $<0.01$ & $<0.01$ & 12.80 & $\mathrm{cS}, \mathrm{Is}, \mathrm{z}$ & Very little of any & Peloidal mudstone \\
\hline 608-RC2 & 752.4 & 0.69 & 0.02 & 7.70 & Is & Also.brushite & Feldspathic arenite \\
\hline 623-RC17 & 762.6 & 0.01 & $<0.01$ & 0.20 & cS & May some $i$ & Mudstone \\
\hline 638-RC32A & 776.3 & .0 .09 & 0.01 & 12.70 & cS, Is & Mostly cS & Mudstone \\
\hline 638-RC32 B & 776.3 & 0.01 & $<0.01$ & 14.10 & $\mathrm{cS}, \mathrm{Is}$ & Mostly cS & Mudstone \\
\hline GB2 & 740.2 & 0.03 & 0.02 & 14.20 & Cs, Is, $\mathbf{K}, \mathbf{Z}$ & Mostly Cs \& K & Quartz wacke w/clay clasts \\
\hline HuO & 693 & 0.63 & 0.88 & 17.20 & $\mathrm{cS}, 1 \mathrm{~s}$ & Very little of any & Fossilferous packsione \\
\hline J3. & 650.7 & 0.04 & 0.03 & 13.20 & Cs, Is, Ks, Z & Mostly Cs \& K & Feldspathic wacke \\
\hline 2nd J7 & 653.7 & 1241.00 & 1342.00 & 25.80 & $\mathrm{cS}, \mathbf{1 s}, \mathrm{K}, \mathbf{z}$ & Mostly eS \& Is & Feldspathic arenite \\
\hline 4th 57 & 654.2 & $3.4+$ & 0.01 & 4.00 & $\mathrm{CS}, \mathbf{1}, \mathrm{K} / \mathrm{Cs}, \mathrm{z}$ & Mostly cS \& is & Feldspathic arenite \\
\hline $11-10-12-1 A$ & 654.2 & 0.03 & 0.02 & 5.50 & $\mathrm{CS}, 3 \mathrm{~s}, \mathrm{z}$ & Mostly es & Feldspathic arenite \\
\hline $11-10-12-2$ & 653.7 & 0.02 & 0.02 & $3.40=$ & cS, Is, K/C, Z & Mostly cS \& Is & Feldspathic arenite \\
\hline $11-10-12-13 a A$ & 653.7 & $\mathbf{0 . 0 3}$ & 0.01 & 3.30 & is & Also brushite & Feldspathic arenite \\
\hline $11-10-12-13$ a B & 653.7 & 0.05 & NA. & 3.90 & Is & Also brushite & Feldspathic arenite \\
\hline $11-10-13-b$ & 534 & .6 .50 & 2.00 & 24.00 & Cs, Is, K, z & Moderate/equal & Feldspathic arenite \\
\hline $11-10-13-1 c$ & 528 & 2.20 & 0.53 & 23.90 & Cs, Is, K, Z & Scanty/equal & Subfeldspathic arenite \\
\hline $11-10-13-1 f$ & 535.6 & 15.00 & 1.30 & 25.10 & $\mathrm{CS}, \mathbf{I s}, \mathrm{K} / \mathrm{Cs}, \mathrm{z}$ & Mostly cS, \& Is & Feldspathic arenite \\
\hline
\end{tabular}

${ }^{*} \mathrm{C}$, chlorite; $\mathrm{I}$, illite; $\mathrm{K}$, kaolin group; S, smectite; and Z, zeolites. Multiple letters are mixed layer combinations, and the letter size is proportional to the relative abundance. Comments refer to the peak intensity on the X-ray-diffraction (XRD) plots. 
TABLE 2

Porosity, Permeability, and Clay and Authigenic Mineral Analysis of Samples

Collected from Drill Core of the Lower Green River and Wasatch Formations, Bluebell Field, Duchesne and Uintah Counties, Utah*

\begin{tabular}{|c|c|c|c|c|c|c|}
\hline Core & $\begin{array}{l}\text { Depth, } \\
\text { ft }\end{array}$ & Lithology & Clay & $\begin{array}{c}\text { Porosity, } \\
\%\end{array}$ & $\begin{array}{c}\text { Permeability, } \\
\text { mD }\end{array}$ & $\begin{array}{c}\text { Depth } \\
\text { P\&P, } \\
\text { ft }\end{array}$ \\
\hline BVP22 & 12,289 & ss & $\mathrm{K}, \mathrm{Z}$ & $2.17(\mathrm{~h})$ & $0.026(h)$ & 12,290 \\
\hline BVP22 & 12,299 & Shale & $\mathrm{K}, \mathrm{i}, \mathbf{Z}$ & 4.25 & $0.001(\mathrm{~h})$ & 12,299 \\
\hline BVP22 & 12,307 & Silty Is & $\mathrm{Z}, \mathrm{s}$ & $3.2(\mathrm{~h})$ & $\mathbf{0}(\mathrm{h})$ & 12,308 \\
\hline BVP22 & 12,365 & ss & I, Ch, k & $1.67(h)$ & $0.001(h)$ & 12,365 \\
\hline CCHAS & 10,632 & Ost. packstone & sI & $0.15(\mathrm{~h})$ & $0.001(\mathrm{~h})$ & 10,632 \\
\hline CCHAS & 10,795 & ss w/ siltstone & sI, $\mathrm{Ch}$ & $3.95(\mathrm{~h})$ & $0.001(v) ; 0.002(h)$ & 10,795 \\
\hline CCHAS & $11,010.5$ & ss & sI, sCh & $5.04(\mathrm{~h})$ & $0.2(h)$ & 11,010 \\
\hline CCHAS & 11,203 & ss & sI & $4.8(h) ; 5.08(h)$ & $0.021(\mathrm{~h})$ & 11,209 \\
\hline BVP19 & 9177 & shale & sI & $2.53(\mathrm{~h})$ & $0.034(\mathrm{~h})$ & 9191 \\
\hline BVP19 & 9638 & Ost. Is mudstone & $s I, k, c h$ & $0.27(h) 0.73(v)$ & $0.004(\mathrm{~h}) ; 0.002(\mathrm{v})$ & 9632 \\
\hline BVP19 & 9648 & ss & sI. $k$ & $3.06(h) ; 2.04(v)$ & $0.002(h) ; 0.001(v)$ & 9652 \\
\hline P17 & 13,587 & Finely crys. Is & sI, $\mathrm{Ch}$ & NA & NA & NA \\
\hline P17 & 13,590 & Wackestone & sI, $\mathrm{Ch}$ & 2.82 & 0.461 & 13,590 \\
\hline $\mathrm{P} 17$ & 13,603 & Mudstone & $s I, k$ & 0.29 & 0.001 & 13,603 \\
\hline P17 & 13,609 & Is mudstone & $\mathrm{I},(\mathrm{k})$ & 0.62 & 0.007 & 13,615 \\
\hline P17 & 13,656 & ss & sI, Ch, $\mathrm{k}$ & 1.27 & 0.024 & 13,660 \\
\hline CHIKO & 10,482 & Mudstone & $I$ & $0.27(h) ; 0.3(v)$ & $0.002(h) ; 0.004(v)$ & 10,481 \\
\hline CHIKO & 10,596 & Silty Is/dolo. & $1(k, c h, z)$ & $0.27(\mathrm{~h})$ & $0.002(\mathrm{~h})$ & 10,588 \\
\hline CHIKO & $10,629.5$ & Silty dolomite & I & NA & NA & NA \\
\hline C94B I & $11,023.5$ & Silty Mudstone & sI, Ch, $\mathrm{k}$ & 0.88 & 0.001 & 11,030 \\
\hline C94B1 & 11,094 & Is mudstone & $\mathrm{sI}, \mathrm{Ch}, \mathrm{k}$ & 1.86 & 0.113 & 11,086 \\
\hline C94BI & $11,110.5$ & ss & $\mathrm{I}, \mathrm{ch}, \mathrm{k}$ & 1.57 & 0.005 & 11,111 \\
\hline C94BI & 11,141 & Silty mudstone & sI, Ch, k & 0.49 & 0.001 & 11,143 \\
\hline C94BI & 12,671 & Mudstone & sI, Ch & NA & NA & NA \\
\hline CBOR & 12,159 & Silty Is mudstone & sI, ch & 4.24 (h) & $0.004(\mathrm{~h})$ & 12,142 \\
\hline CBOR & $12,168.5$ & ss & $\mathrm{sI}, \mathrm{Ch}, \mathrm{k}$ & $0.68(h)$ & $0.002(\mathrm{~h})$ & 12,173 \\
\hline CSM & $11,121.5$ & Siltstone & sI, sch & NA & NA & NA \\
\hline CSM & 11,128 & Wackestone & sI, ch & NA & NA & NA \\
\hline CSM & $11,146.5$ & ss (marl?) & sI, ch & NA & NA & $\mathrm{NA}$ \\
\hline CSM & $11,157.5$ & ss & sl, ch, (k) & NA & NA & NA \\
\hline Cl7Al & 12,252 & ss & sl, $\mathrm{Ch}, \mathrm{k}$ & NA & NA & NA \\
\hline CI7AI & 12,264 & ss & $\mathrm{sI}, \mathrm{Ch}$ & NA & NA & NA \\
\hline Cl7AI & 12,303 & ss & sI, sCh, z? & NA & NA & NA \\
\hline Cl7Al & 14,372 & ss & sI, $\mathrm{K}$ & NA & NA & NA \\
\hline Cl7Al & 14,384 & ss & sI, K, ch & NA & NA & NA \\
\hline
\end{tabular}

${ }^{*} \mathrm{C}$, chlorite; $\mathrm{I}$, illite; $\mathrm{K}$, kaolin group; $\mathrm{S}$, smectite; $\mathrm{Z}$, zeolites. Multiple letters are mixed layer ccombinations. Lowercase letters indicate trace amounts. NA, not available; $h$, horizontal; $v$, vertical.

\section{References}

1. A. Gamer, Reservoir Characterization Through Facies Analysis of the Lower Green River Formation for Hydrocarbon Production Enhancement in the Altamont-Bluebell Field, Uinta Basin, Utah, paper presented at the American Association of Petroleum Geologists Annual Meeting, Houston, Tex., March 5-8, 1995.
2. M. Wegner, Facies Analysis of Well Cores from the Lower Green River Formation, Bluebell Field, Uinta Basin, Utah: Implications for Identifying Highly Productive Zones, paper presented at the Ninth Annual Spring Research Conference, Provo, Utah. 


\section{AN INTEGRATED STUDY OF THE GRAYBURG/SAN ANDRES RESERVOIR, FOSTER AND SOUTH COWDEN FIELDS, ECTOR COUNTY, TEXAS}

Contract No. DE-FC22-94BC14982

\author{
Laguna Petroleum Corporation \\ Midland, Tex.
}

Contract Date: Aug. 2, 1994

Anticipated Completion: Jan. 1, 1998

Government Award: \$71,200

(Current year)

Principal Investigators:

James J. Reeves

David A. Rowland

Robert C. Trentham

\section{Project Manager: \\ Chandra Nautiyal \\ Bartlesville Project Office}

Reporting Period: Jan.-Mar. 30, 1995

\section{Objectives}

The principal objective of this study is to demonstrate a methodology for reservoir characterization of shallow-shelf carbonate reservoirs that is feasible for the independent operator. Furthermore, this study will provide one of the first public demonstrations of the enhancement of reservoir characterization with the use of high-resolution three-dimensional (3-D) seismic data. This project will evaluate the Grayburg and San Andres reservoirs in the Foster and South Cowden fields of Ector County, Tex. A multidisciplinary approach to waterflood design and implementation, along with the addition of reserves by selective infill drilling, will be applied. This approach in reservoir development is believed to be applicable to a wide range of shallow-shelf carbonate reservoirs throughout the United States. Technology transfer will occur through all phases of the project.

\section{Summary of Technical Progress}

\section{Geological Progress}

Offset wells were reviewed. Old scout tickets were reviewed for cable tool information on gas caps, oil/water contacts, and porosity increases. A secondary gas cap appears to be developed in the section to the west (sec. 35) and the SWI 4 of sec. 36. Samples for Brock No. 10 were reviewed. The core is lost, but core chips were retained. Unfortunately the chips were not labeled as to depth and therefore are unusable. Core for Sun No. 6 Witcher was reviewed. Core is available from the Queen ( 3850 to $3860 \mathrm{ft}$ ), Grayburg ( 3860 to $4025 \mathrm{ft}$ ), and San Andres ( 4260 to $4315 \mathrm{ft}$ ). A detailed core description was completed, and 31 thin-section blanks were taken. Thin sections are being made.

Information from the core is being evaluated and integrated. Subareal exposure surfaces along with a series of shallowing upward sequences and environment of deposition were identified. The best reservoir quality facies are in shallow subtidal grainstones and packstones with good interparticle porosity. This information will be integrated into the log evaluation.

\section{Reservoir Engineering}

The work performed this quarter was directed toward obtaining annual production histories for each well in the study area. This was a formidable task inasmuch as operators' records for early years were sparse and in some cases nonexistent. However, production reported to the Texas Railroad Commission (TRC) for each of the five leases (Witcher, Brock, Foster, Foster-Pegues, and Maurice) was available from Petroleum Information beginning with the year 1970. These data were made available on computer printouts. Pre1970 lease production values, also compiled by the TRC, are maintained by the Midland Public Library. For these early production data, manual retrieval was necessary.

Allocation of lease production to individual wells leading to the lease battery was performed by incorporating well test results and well status history gleaned from the well files. Considerable effort was directed toward obtaining these data; the services of a competent technician were used. The allocation process for estimating individual well production for the entire 54-yr history period was time consuming. The average daily production rate for each well was determined as required as input data by the reservoir simulator (WorkBench). The annual production by lease is calculated, which conforms with published data. Table 1 contains a summary of the total recovery by lease.

\section{TABLE 1}

Summary of Total Recovery Lease

\begin{tabular}{lcc}
\hline \multicolumn{1}{c}{ Lease } & $\begin{array}{c}\text { Number } \\
\text { of producers }\end{array}$ & $\begin{array}{c}\text { Cumulative } \\
\text { production, } \\
\text { stock tank barrels }\end{array}$ \\
\hline Witcher & 10 & $1,909,420$ \\
Brock & 10 & $1,809,399$ \\
Foster & 10 & $.651,373$ \\
Foster-Pegues & 8 & $1,447,360$ \\
Maurice & 7 & $1,358,765$ \\
Combined & 45 & $7,176,317$ \\
\hline
\end{tabular}

Plots of the production data are given in Figs. 1 to 5 for the same five leases, respectively. These graphs include annual production and cumulative production. Figure 6 represents the study area total of both annual and cumulative production. 


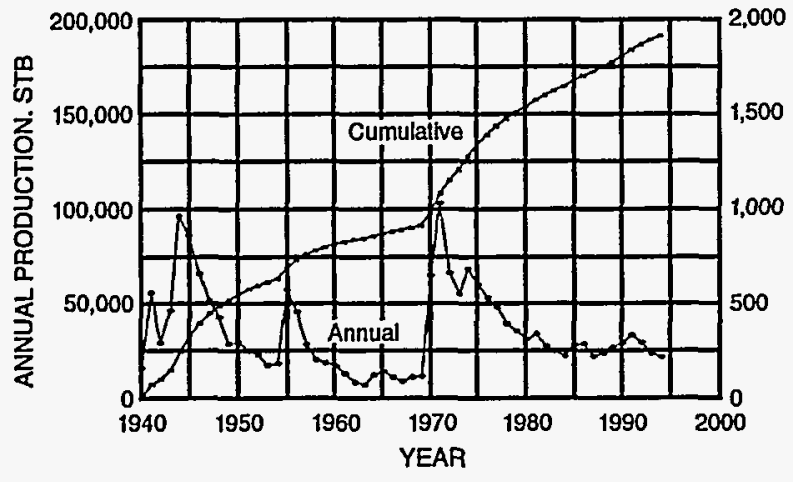

Fig. I Production history for Witcher lease-Foster field study. STB, stock tank barrels. MTSB, thousand stock tank barrels.

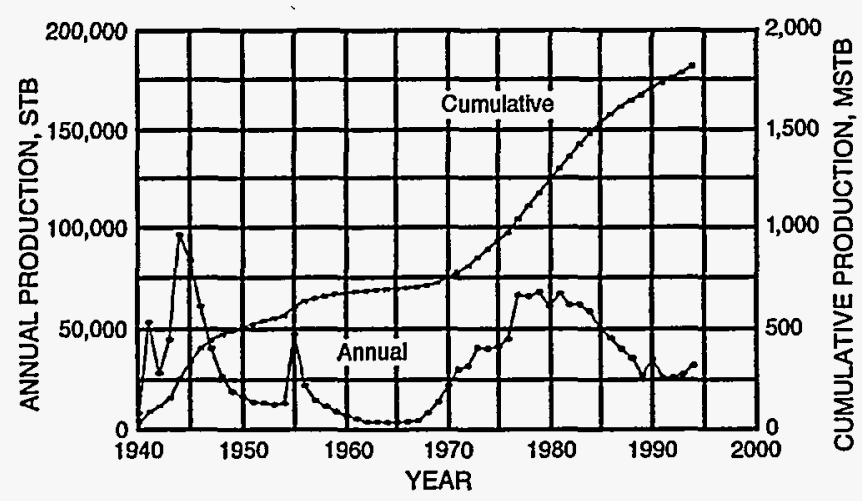

Fig. 2 Production history for Brock lease-Foster field study. STB, stock tank barrels. MSTB, thousand stock tank barrels.

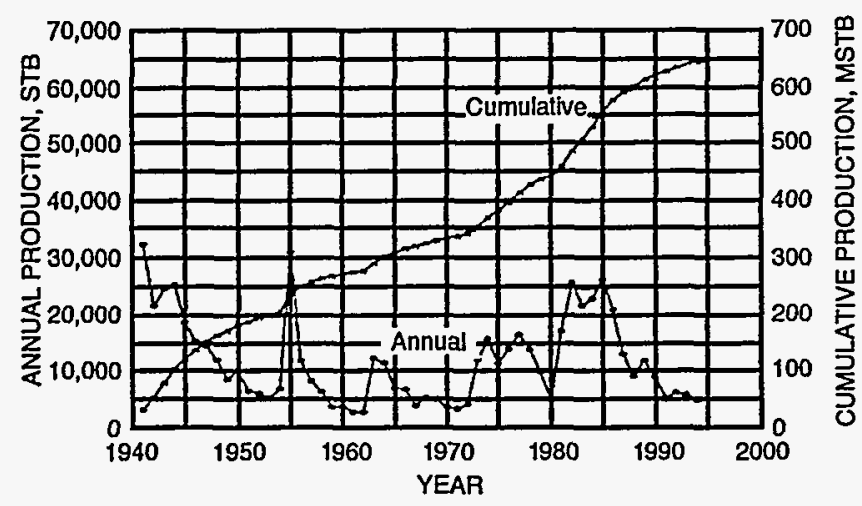

Fig. 3 Production history for Foster lease-Foster field study. STB, stock tank barrels. MSTB, thousand stock tank barrels.

Three peaks in annual production are reflected in the 55-yr history of this unit's production (see, for example, the Witcher and Foster leases). These peaks reflect distinct changes in operations identified as follows: the mid-1940s, when proration was relaxed in order to supply more oil required for World War II (then in progress); the mid-1950s, when an extensive fraction program on wells was undertaken throughout the study area; and the early 1970s, when infill drilling was initiated as well as responses to staggered waterflood efforts.

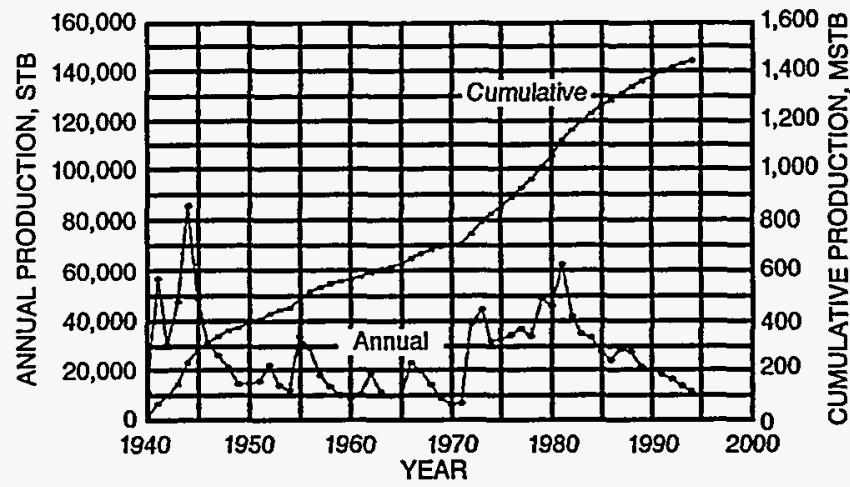

Fig. 4 Production history for Foster-Pegues lease-Foster field study. STB, stock tank barrels. MSTB, thousand stock tank barrels.

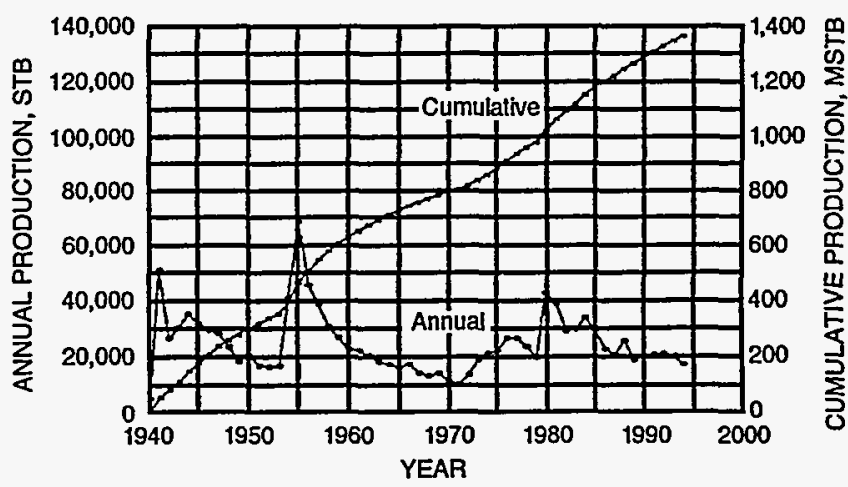

Fig. 5 Production history for Maurice lease-Foster field study. STB, stock tank barrels. MSTB, thousand stock tank barrels.

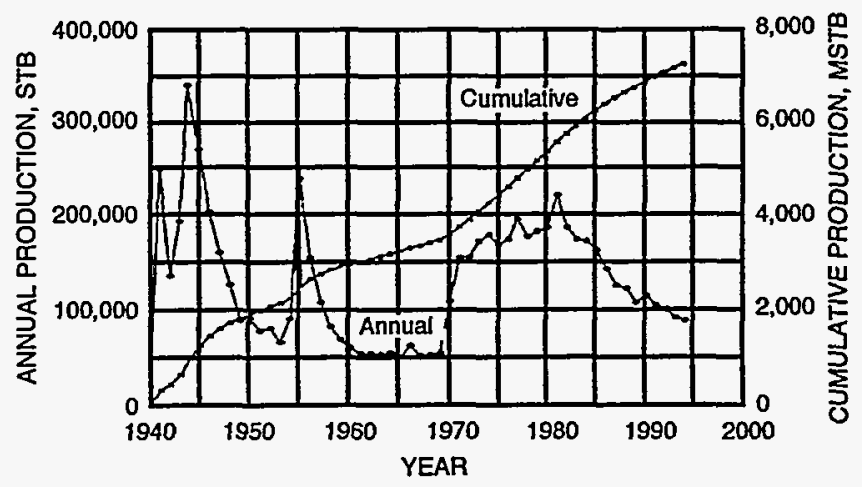

Fig. 6 Production history for combined leases-Foster field study.STB, stock tank barrels; MSTB, thousand stock tank barrels.

Finally, a three-layer simulation model was constructed with the use of the U.S. Department of Energy (DOE) program called BOAST. Values for net pay, porosity, and water saturation used in this simulation were the same as those published by Sun Oil over 10 yr ago. One significant result revealed in this early simulation effort was that insufficient oil was present to allow the simulation to run the entire 54-yr life of the project. It was obvious that, in order to produce the 1.9-million barrels recorded history, the initial 
volume of original oil in place (OOIP) had to be increased substantially.

\section{Geophysics: Systems Administration}

In February 1995, after the completion of training courses on Scientific Software Intercomp WorkBench and Schlumberger GeoQuest IESX, the software packages WorkBench, GX Technology GXII, and 3-D AIMS, and the upgrade for IESX 8.25 to 9.0 A were installed. A script was designed in UNIX to backup on $8 \mathrm{~mm}$ magnetic tape both hard disks (total of approximately $3 \mathrm{~GB}$ ) for the computer workstation. Each consultant on the technical team is responsible for purchasing $8 \mathrm{~mm}$ magnetic tapes and backing up his/her work on the workstation. An electrical surge protector and a standalone, battery-driven power supply were purchased to further protect the computer system. These devices protect the system from possible spurious voltages from the local power company and power outages. Other devices recently configured to the workstation include a Summagraphics digitizer for digitizing logs and a Digital VT420 computer terminal for system administrative tasks.

\section{Reservoir Description}

A preliminary analysis of the seismic phase of the wavelet in the 3-D seismic volume is complete. The velocity survey in the Blair and French-El Paso Production Co. No. 1 Moss Well was tied into the seismic data at the Yates, Grayburg, and San Andres intervals. Synthetic seismograms computed from sonic logs in the John L. Cox No. 1 William Moss, Atlantic Foster No. 3-X, and Atlantic Brock No. 5 wells were character-tied to $0,90,180$, and $270^{\circ}$ phased-rotated seismic sections. The best tie was obtained with the $90^{\circ}$ phase-rotated section. A more careful phase analysis is planned with the IESX tools on the computer workstation.

The following data were loaded in the computer workstation: both 3-D seismic volumes [final migrations/with and without dip moveout (DMO)]; digital base maps containing block and section lines, streams, and roads; well locations; and digital well logs. Structural time maps and seismic amplitude maps were made on the near top of Yates, Grayburg, Lower Grayburg, and San Andres.

The next step to be completed for the reservoir characterization with the use of the 3-D seismic data is the detailed integration of all digital well log data to the 3-D seismic volume.

In the ideal case, all sonic logs found in the 3-D seismic volume should be digitized. Approximately 26 wells in the 3 D seismic volume have sonic logs, of which about 11 have been partially digitized. A recommendation was made that all wells that penetrate the Grayburg/San Andres reservoir in the 3-D seismic volume should be digitized between the top of Yates and Glorieta. Several days were spent reviewing the Synthetics and Synview application modules in IESX, which will be used to tie sonic and pseudo-sonic logs to the 3-D seismic volume.
In accordance with the multidisciplinary approach in this project, the project engineer is developing a generic reservoir simulation model in the WorkBench software. The core descriptions provided by the project geologist from the Sun Witcher No. 6 well were reviewed, and interesting features in the 3-D seismic volume were noted. The project manager assisted in the development of a two-dimensional (2-D) seismic model through the study area to investigate the effects of reservoir properties on seismic attributes.

\section{Technology Transfer}

This quarter presentations and progress reports were coauthored to be presented to the following technical and scientific organization: Southwest Petroleum Short Course and GX Technology L. P. User's Conference.

Field trips were taken to visit outcrops that are similar to the Grayburg/San Andres reservoir in the Guadalupe Mountains of Texas and New Mexico, including SEPM McKitrick Canyon Field Trip and WTGS Field Trip/Guadalupe Mountains.

Agreements with Hampson and Russell in Calgary, Alberta, Canada, are in place to use their seismic inversion and geostatistics software to determine interpolation functions to evaluate reservoir properties between wells with the use of seismic attributes.

Providence Technology has recommended this project to the Gas Research Institute as one of three possible sites for funding for cross-well seismic research.

\section{IMPROVED OIL RECOVERY IN FLUVIAL- DOMINATED DELTAIC RESERVOIRS OF KANSAS-NEAR TERM}

\section{Contract No. DE-FC22-93BC14957}

\author{
University of Kansas \\ Lawrence, Kans.
}

Contract Date: June 18, 1993

Anticipated Completion: Dec. 31, 1998

Government Award: \$2,007,446

Principal Investigators:

Don W. Green

G. Paul Willhite

Project Mảnager:

Rhonda Lindsey

Bartlesville Project Office

Reporting Period: Jan. 1-Mar. 31, 1995 


\section{Objective}

The objective of this project is to address waterflood problems of the type found in Cherokee Group reservoirs in southeastern Kansas and in Morrow sandstone reservoirs in southwestern Kansas. Two demonstration sites operated by different independent oil operators are involved in the project. The Nelson Lease (an existing waterflood), located in Allen County, Kans., in the northeastern Savonburg field, is operated by James E. Russell Petroleum, Inc. The Stewart field (on latter stage of primary production), located in Finney Co., Kans., is operated by Sharon Resources, Inc.

General topics to be addressed will be reservoir management and performance evaluation, waterflood optimization, and the demonstration of recovery processes involving offthe-shelf technologies that can be used to enhance waterflood recovery, increase reserves, and reduce the abandonment rate of these reservoir types.

The reservoir management portion of the project will involve performance evaluation and will include such work as reservoir characterization and the development of a reservoir database, identification of operational problems, identification of near-wellbore problems, identification of unrecovered mobile oil and estimation of recovery factors, and identification of the most efficient and economical recovery process. The waterflood optimization portion of the project involves only the Nelson Lease. Optimization will be based on the performance evaluation and will involve design and implementation of a water cleanup system for the waterflood; application of well remedial work, such as polymer gel treatments to improve vertical sweep efficiency; and changes in waterflood patterns to increase sweep efficiency. Finally, it is planned to implement an improved recovery process, possibly polymer-augmented waterflooding on both field demonstration sites.

\section{Summary of Technical Progress}

\section{Savonburg Field Project}

\section{Engineering and Geological Analysis}

Colored cross sections were continually revised in Stratamodel throughout the field. In some instances, perforations have been added. Information for the continuation application for the Steward field project was prepared and submitted to request funding to continue the Stewart field project in Budget Period 2. On the basis of a favorable evaluation of the continuation application, the project is authorized to proceed into Budget Period 2 (covering period from 04/01/95 to 12/31/98).

\section{Water Plant Development}

The air flotation unit is working successfully. The removal of suspended oil and solids has been successful; however, the dissolved barium has caused a problem by the formation of a barium sulfate scale. The resulting scale is more difficult to remove because of the absence of oil and other solids, which in the past made the scale soft and removable. Progress is being made to reduce the barium content of the produced water before it is combined with makeup water. Cleanup of injection wells has indicated no appreciable deposits in the injection wellbores from the injected brine.

\section{Pattern Changes and Wellbore Cleanup}

The 1-in. tubing and packer were pulled and replaced on Well No. KW-51. A larger pumping unit was installed on Well No. $\mathrm{H}-13$ after pulling and servicing. Well No. H-20 was pulled, the pump rebuilt, and the 1-in. pump string replaced. The pump was then set $50 \mathrm{ft}$ deeper. Well No. H-30 was also pulled and repaired. Well No. RW-7 was placed back on injection after a pressure fall-off test and delta-temperature survey were conducted and the offset producing wells tested. Well No. K-39 was shut down as uneconomic.

\section{Field Operations}

Normal field operations have included monitoring wells on a daily basis; repairing water plant, piping, and wells as required; collecting daily rate and pressure data; and solving any other daily field operational problem that might occur. Production statistics are summarized in Table 1.

TABLE 1

Savonburg Field Oil Production

\begin{tabular}{lc}
\hline \multicolumn{1}{c}{ Month } & Oil production, BOPD \\
\hline October 1993 & 26.4 \\
November 1993 & 30.7 \\
December 1993 & 32.0 \\
January 1994 & 30.8 \\
February 1994 & 30.9 \\
March 1994 & 30.3 \\
April 1994 & 29.1 \\
May 1994 & 28.5 \\
June 1994 & 30.3 \\
July 1994 & 28.9 \\
August 1994 & 24.6 \\
October 1994 & 23.0 \\
November 1994 & 25.7 \\
December 1994 & 27.8 \\
January 1995 & 27.0 \\
February 1995 & 25.3 \\
March 1995 & 22.4 \\
April 1995 & 22.4 \\
\hline
\end{tabular}

\section{Stewart Field Project}

\section{Geological and Engineering Analysis}

Information for the continuation application for the Stewart field project was prepared and submitted to request funding to continue the Stewart field project in Budget Period 2. On the basis of a favorable evaluation of the continuation application, the project is authorized to proceed into Budget Period 2 (covering period from 04/01/95 to 12/31/98). 


\section{Laboratory Testing}

All work associated with this task has been completed.

\section{Unitization}

North American Resources Co., (NARCO) has purchased $100 \%$ of the working interest in the Stewart field from the other operators, which resolves the unitization issue. NARCO is in the process of acquiring agreements with the royalty interest owners in the field and filing for a hearing with the Kansas Corporation Commission, which will finalize unitization of the Stewart field.

\section{POST WATERFLOOD $\mathrm{CO}_{2}$ MISCIBLE FLOOD IN LIGHT OIL FLUVIAL- DOMINATED DELTAIC RESERVOIRS}

\section{Contract No. DE-FC22-93BC14960}

Texaco Exploration and Production, Inc. New Orleans, La.

Contract Date: June 1, 1993

Anticipated Completion: Dec. 31, 1997

Government Award: \$1,042,421

Principal Investigator:

Sami Bou-Mikael

Project Manager:

Chandra Nautiyal

Bartlesville Project Office

Reporting Period: Jan. 1-Mar. 31, 1995

\section{Objective}

The overall objective of this project is to integrate research on petroleum reservoir characterization and process monitoring funded by the U.S. Department of Energy (DOE). Specific objectives this quarter include

- Monitor and optimize reservoir production.

- Evaluate performing a huff 'n' puff cycle on well Polk B No. 5 .

- Evaluate the need to drill Well PolkB No. 39 in Project Area 2.

- Work on the reservoir compositional model.

\section{Summary of Technical Progress}

Production from the Marg Area 1 at Port Neches is averaging $392 \mathrm{bbl}$ of oil per day (BOPD), as shown in Fig. 1 . The production drop is caused by fluctuation in both gas/oil ratio (GOR) and basic sediment and water (BS\&W) on various producing wells coupled with low water injectivity in the reservoir. It has not been possible to inject any tangible amount of water in the reservoir since late January. Both production and injection problems are currently being evaluated to improve reservoir performance. Well Kuhn No. 6 was stimulated with 120 million cubic feet (MMCF) of $\mathrm{CO}_{2}$ and was placed on production February 1, 1995. The well was shut in for an additional month after producing dry $\mathrm{CO}_{2}$ initially. The well was opened again in early April and is currently producing about 40 BOPD. $\mathrm{CO}_{2}$ injection averaged 11.3 million cubic feet per day (MMCFD), including 4100 MMCFD purchased from Cardox (Fig. 2), whereas water injection averaged $1000 \mathrm{bbl}$ of water per day with most of the injection occurring in the month of January.

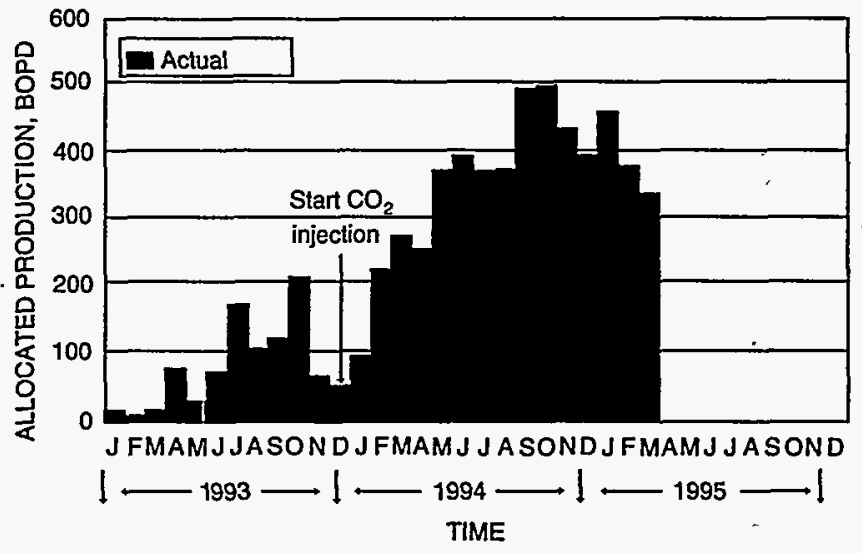

Fig. 1 Port Neches $\mathrm{CO}_{2}$ Project allocated production.

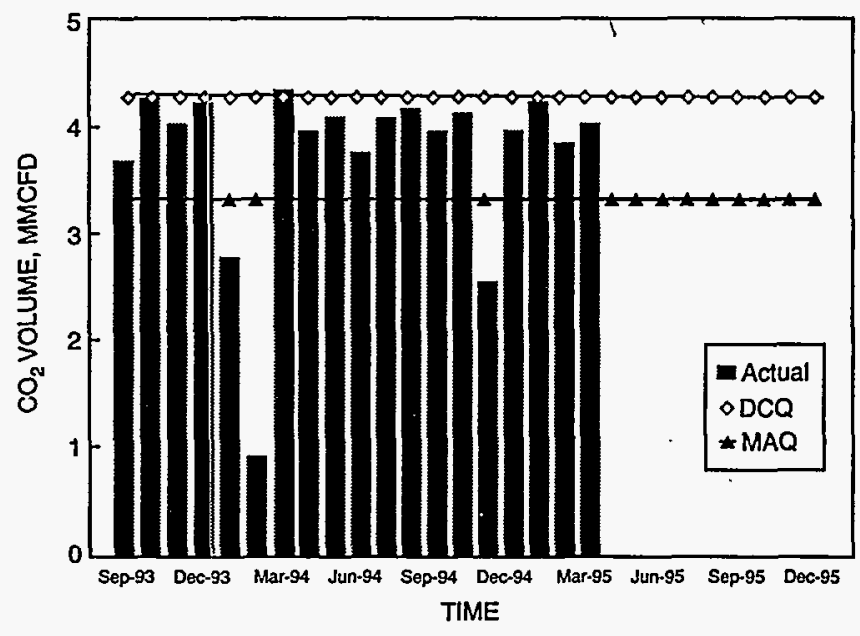

Fig. 2 Port Neches $\mathrm{CO}_{2}$ delivery (actual vs. contract). 


\section{Monitor and Optimize Reservoir Production}

Recent decline in reservoir production from 450 to 392 BOPD is attributed to fluctuation in the GOR and BS\&W of several producing wells. An evaluation is being made to determine whether the decline is caused by possible wellbore mechanical problems. A decline in the reservoir yield associated with the production drop was observed, which suggests the need to resume a second water alternating gas (WAG) cycle in order to reduce carbon dioxide $\left(\mathrm{CO}_{2}\right)$ production and increase the sweep efficiency. Plans are currently under way to improve water injectivity in the reservoir in order to maintain pressure and improve sweep efficiencies. Performance plots (production and yield vs. time) for the reservoir (Fig. 3) and individual wells are shown in Figs. 4 to 8. Most of the production decline is attributed to wells Kuhn No. 15R and Kuhn No. 38.

\section{Evaluate Performing a Huff 'n' Puff Cycle on Well Polk B No. 5}

A workover was planned on the subject well (Polk B No. 5) for the first quarter of 1995 along with the drilling of Well Polk B No. 39; however, the well workover was performed earlier on an emergency basis to install a tree and a packer because of increasing pressure in the wellbore. This work was necessary to prevent any potential oil spill in case the well started to flow.

On the basis of the well readiness and the performance of the first huff ' $n$ ' puff cycle in well Kuhn No. 6 , which is currently flowing about 35 BOPD, it is recommended that an injection line be laid to well Polk B No. 5 and that a similar volume of $\mathrm{CO}_{2}(120 \mathrm{MMCF})$ be injected. It is anticipated that this work will be performed by mid-May 1995 . Well Kuhn No. 6 performance is also indicative of a water-drive reservoir, with an initial yield of $40 \mathrm{bbl}$ of oil per million cubic feet.

\section{Evaluate the Need To Drill \\ Well Polk $B$ No. 39 in \\ Project Area 2}

Current reservoir evaluation based on recent threedimensional (3-D) interpretation and bottomhole pressure (BHP) taken in wells Kuhn No. 6 and Polk B No. 5 confirmed the suspected separation between area 1 and area 2 . Also, it confirmed that area 2 is a water-drive reservoir open to an aquifer in the south, which reduced the reservoir drainage

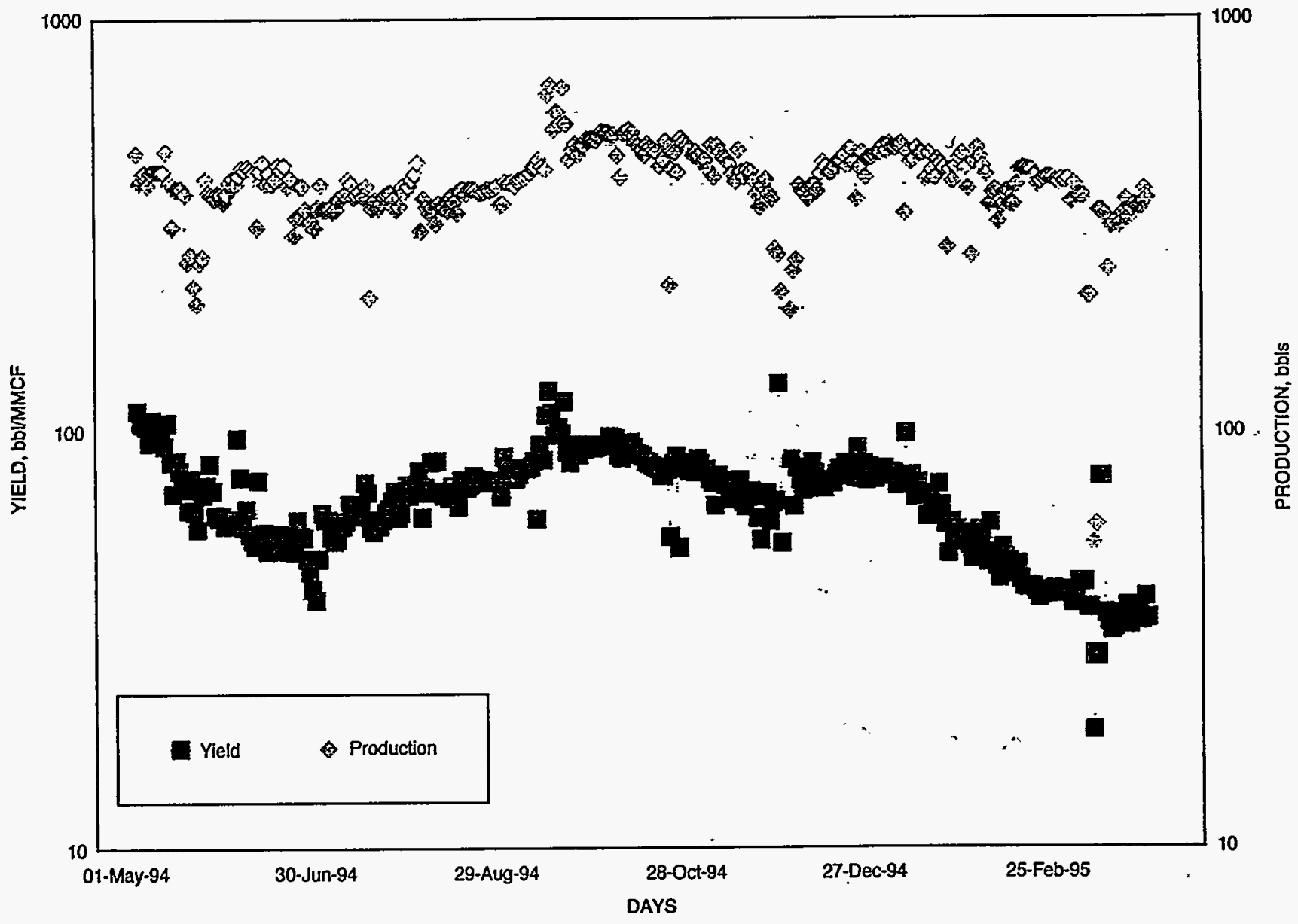

Fig. 3 Port Neches Field reservoir yield and production vs. time. 


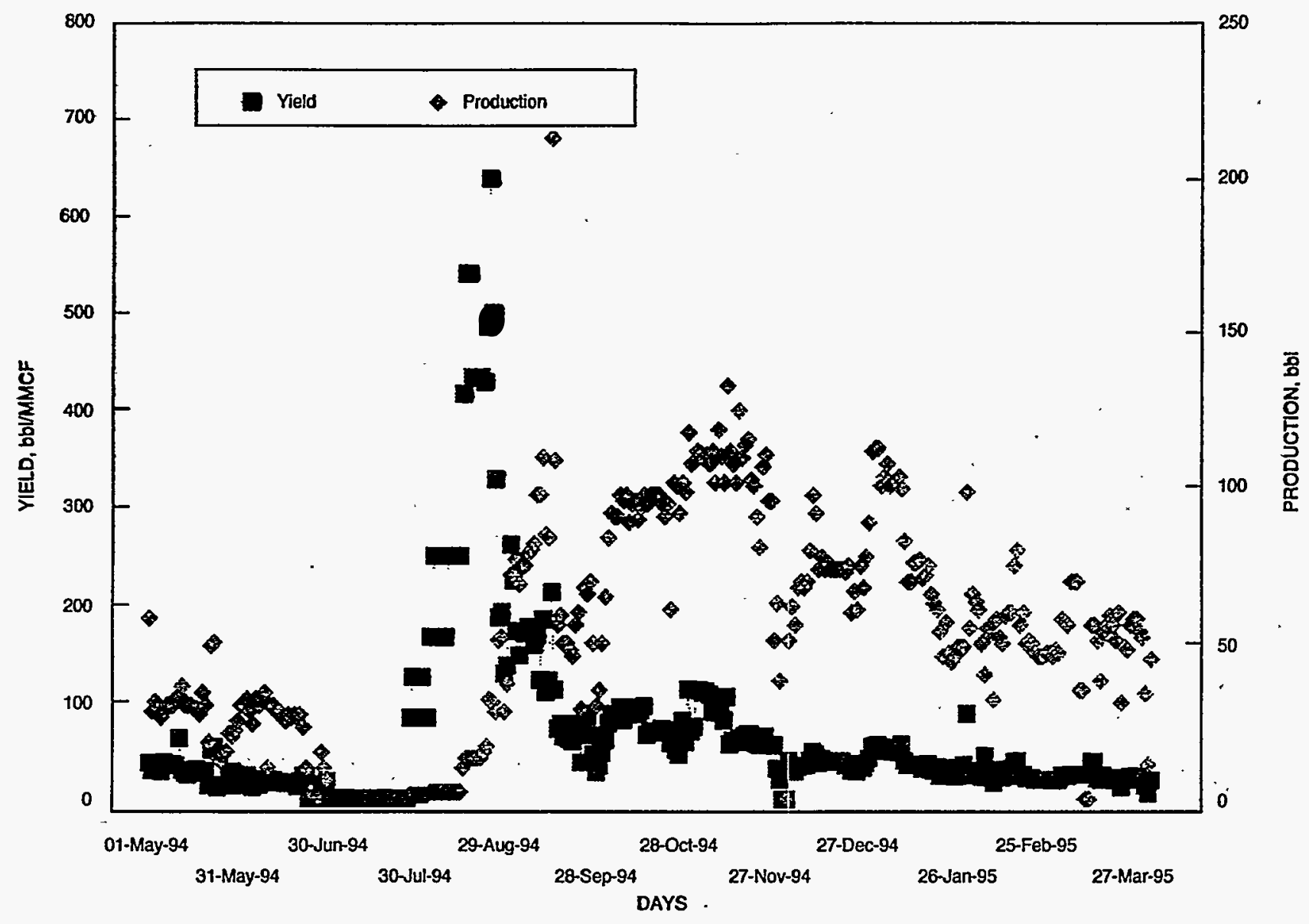

Fig. 4 . Port Neches Field well No. 8 yield and production vs. time.

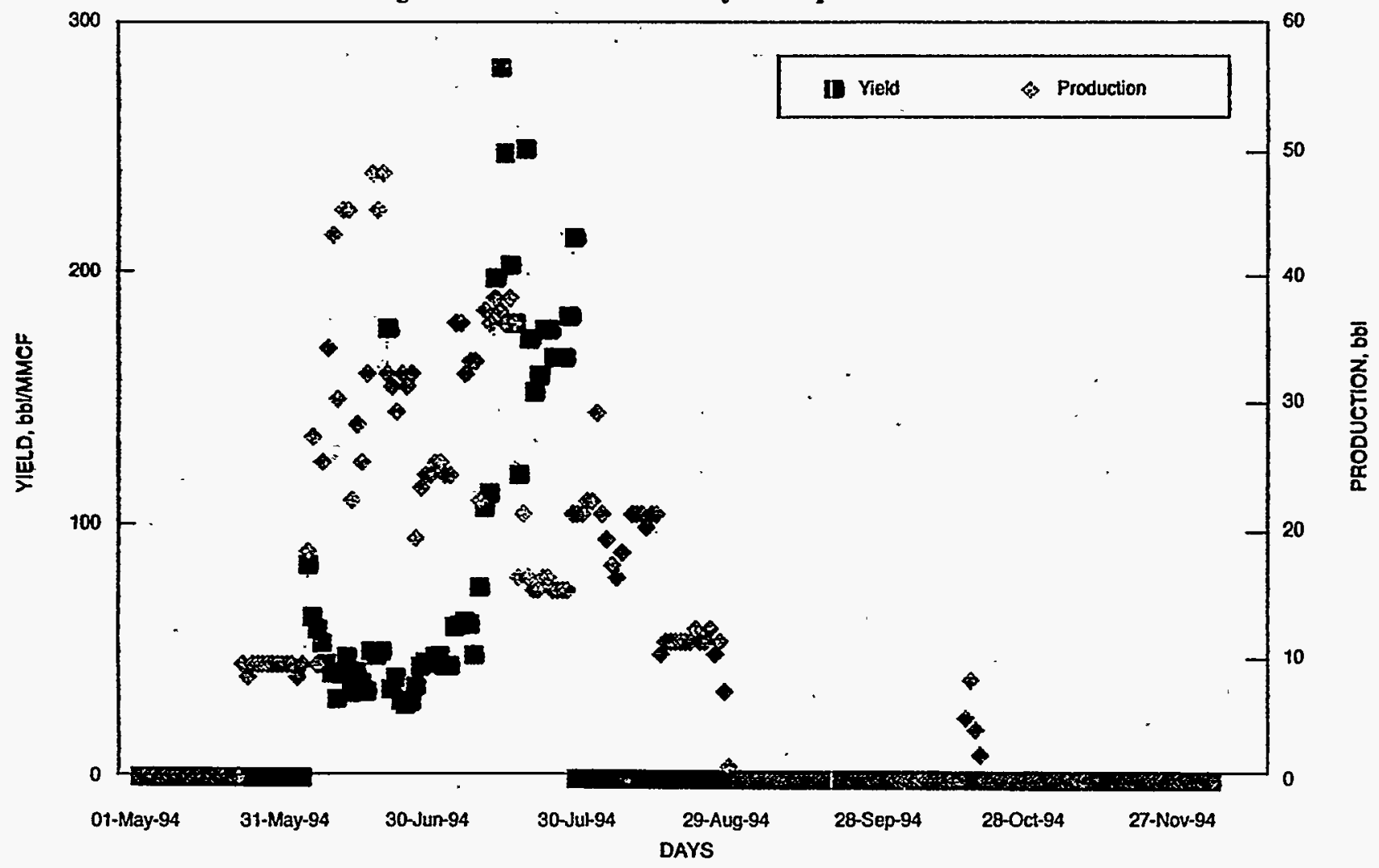

Fig. 5 Port Neches Field well No. 14 yield and production vs. time. 


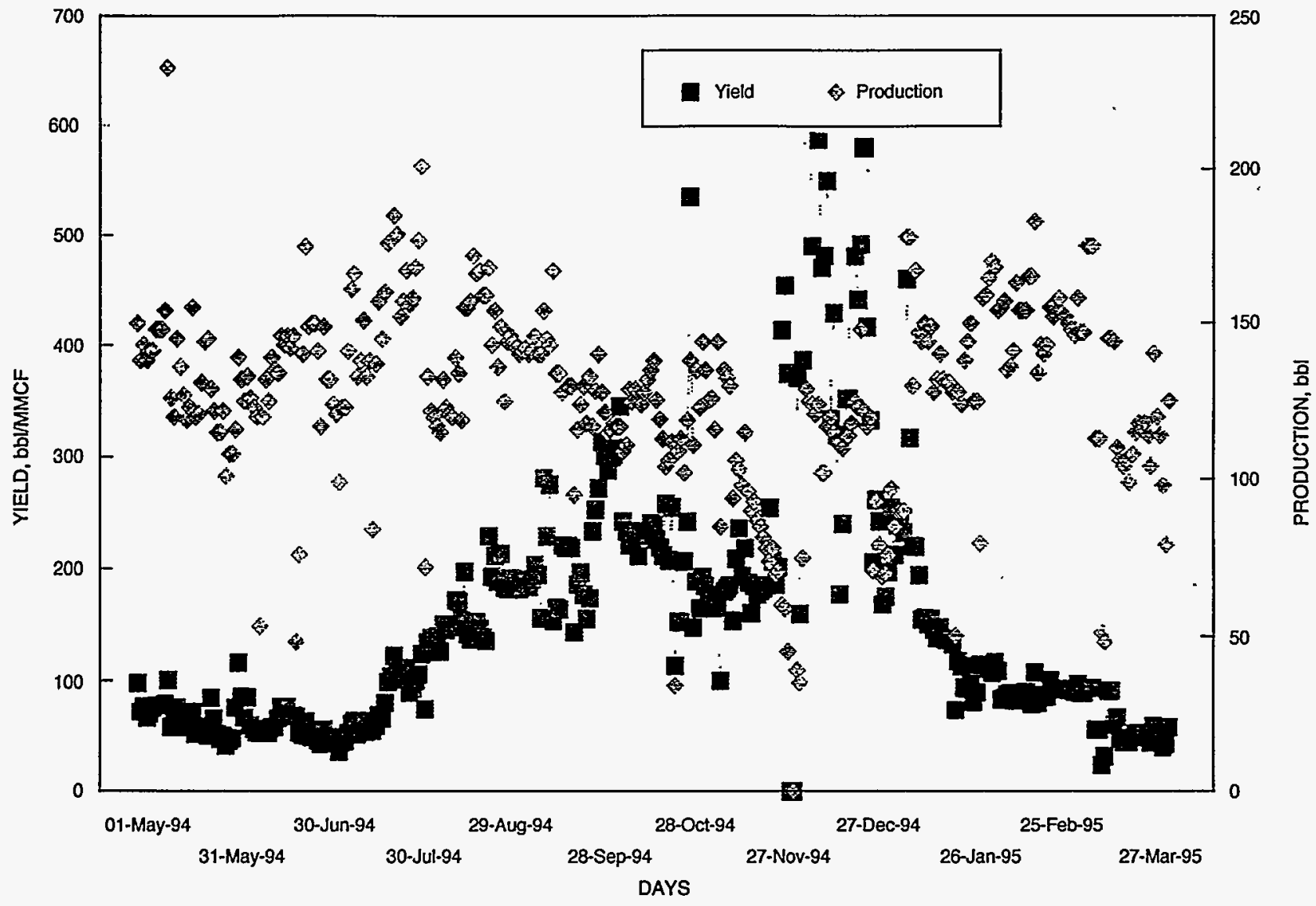

Fig. 6 Port Neches Field well No. 15R yield and production vs. time.

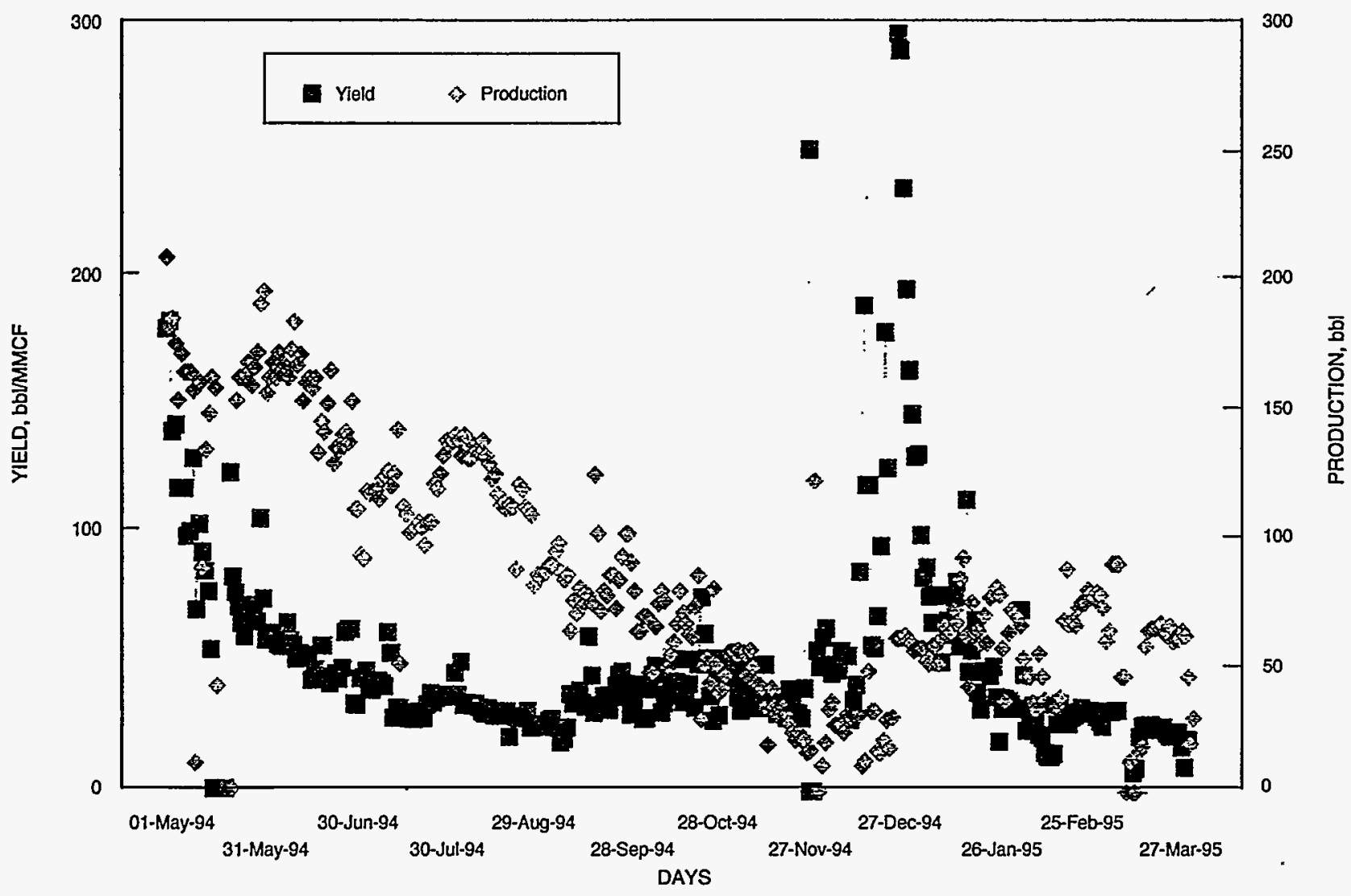

Fig. 7 Port Neches Field well No. 33 yield and production vs. time. 


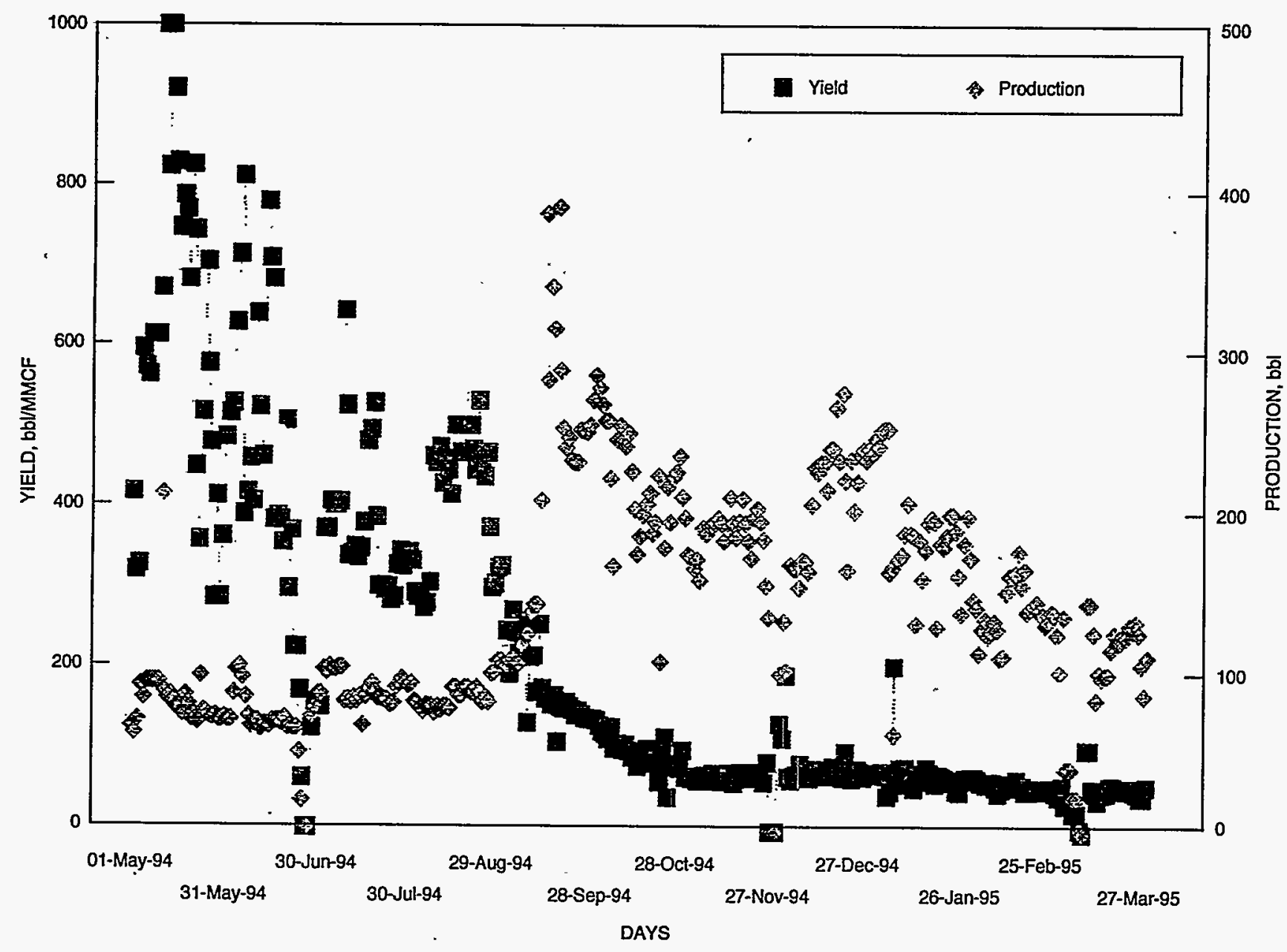

Fig. 8 Port Neches Field well No. 38 yield and production vs, time.

area, and which, in turn, reduced the remaining oil target. On the basis of the evaluation and on Texaco's prior experience of $\mathrm{CO}_{2}$ flooding strong water-drive reservoirs, the anticipated recovery from this portion of the reservoir does not justify drilling a new injection well. Therefore it is recommended to cancel the drilling of Well Polk B No. 39 in the Marg Area 2 and proceed with the huff ' $n$ ' puff of well Polk $B$ No. 5 in order to maximize recovery of hydrocarbon from this area of the reservoir.

\section{Work on the Reservoir Compositional Model}

The stratamodel was completed early this quarter, and it is available to input in the compositional model. However the compositional model of the reservoir will be delayed for.some time because of lack of personnel.

\section{Results-Field Operations}

Repeated measurement of BHP (Fig. 9) in wells Kuhn No. 6 and Polk B No. 5 confirmed the presence of a fault separating the two wells. Also, the increased BHP caused

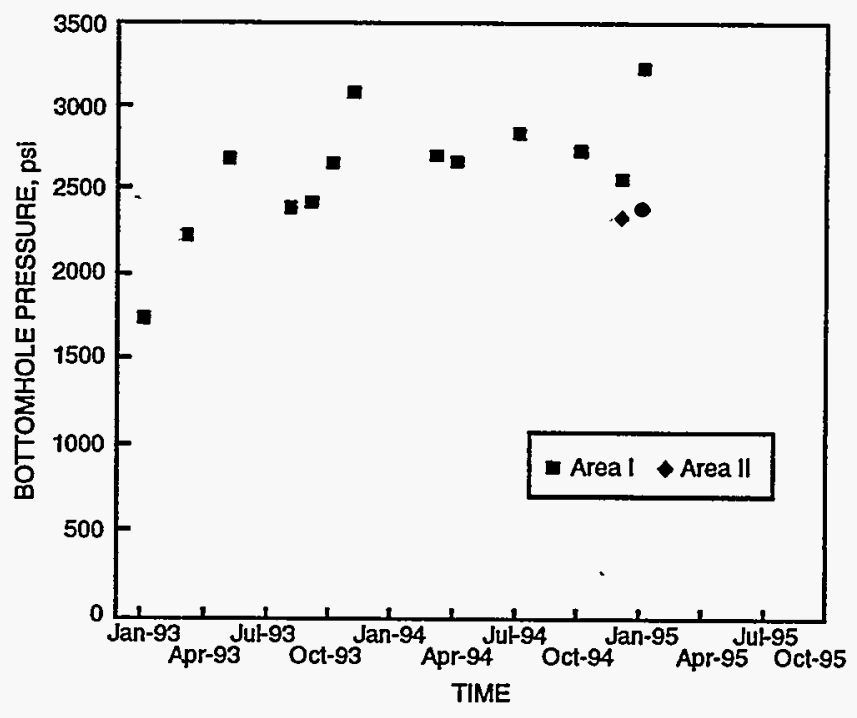

Fig. 9 Port Neches Field reservoir pressure.

by $\mathrm{CO}_{2}$ injection (Fig. 10) in well Kuhn No. 6 (3300 psi) above the normal reservoir pressure (2700 psi) suggests the 
possible presence of a permeability barrier between well Kuhn No. 6 and the main part of the reservoir. The same idea was also suggested by the stratamodel. Reservoir performance has been declining recently as the result of decreased water injectivity as well as possible mechanical problems in the producing wells (Fig. 11). Texaco is planning to check the integrity of sand control systems in the producing wells to restore higher production rates. Expense workovers may be required to change the gravel pack settings in the affected

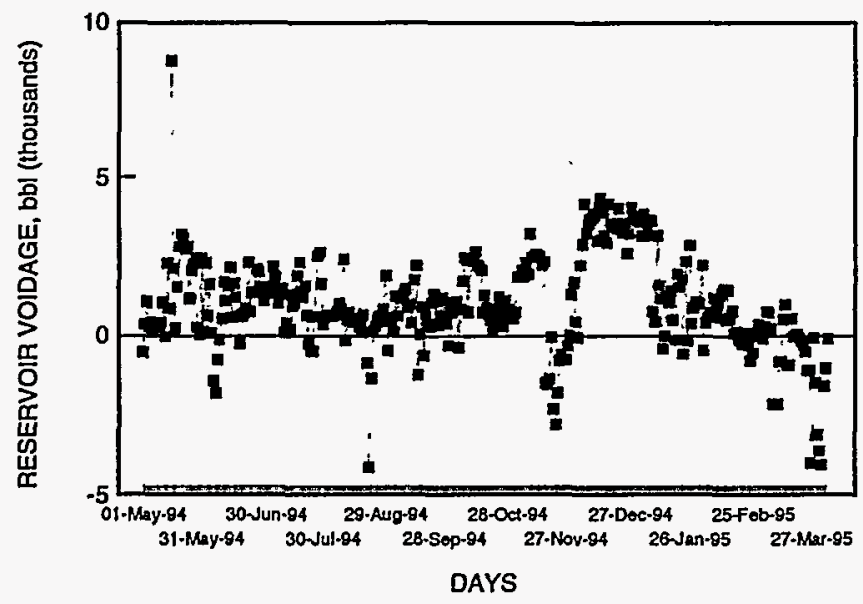

Fig. 10 Port Neches Field reservoir voidage.

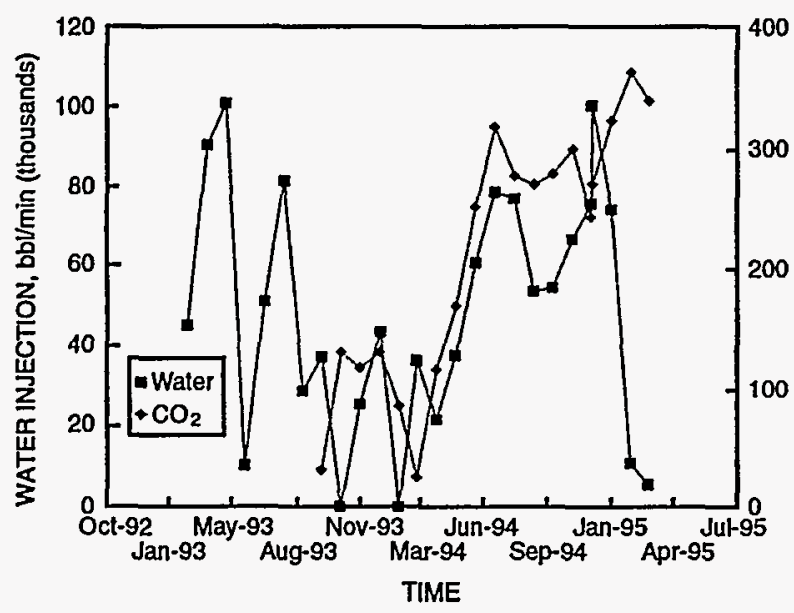

Fig. 11 Port Neches water and $\mathrm{CO}_{2}$ injection. wells. Similar evaluation will be conducted on the injection wells to restore higher production rates. Expense workovers may be required to change the gravel pack settings in the affected wells. Similar evaluation will be conducted on the injection wells to restore high water injection rates.

Table 1 lists results of the most recent well tests taken on March 31, 1995, for all the producing and injection wells.

Table 2 lists the average injection and production volumes for this quarter.

TABLE 1

Well Test Results*

\begin{tabular}{|c|c|c|c|c|c|}
\hline Well No. & BOPD & BWPD & MMCFD & Choke & Psi \\
\hline & \multicolumn{3}{|c|}{ Producing wells } & * & \\
\hline Kuhn No. 15R & 120 & 480 & 2550 & 17 & \\
\hline Kuhn No. 38 & 132 & 1335 & 2460 & 22 & \\
\hline Kuhn No. 33 & 63 & 170 & 2650 & 18 & \\
\hline Stark No. 8 & 54 & 332 & 2646 & 28 & \\
\hline Kuhn No. 6 & 0 & 0 & 0 & OL & \\
\hline Kuhn No. 14 & - & - & - & - & \\
\hline Polk No. B5 & - & - & - & - & \\
\hline \multicolumn{6}{|c|}{ Injection wells } \\
\hline $\begin{array}{l}\text { Marginulina } \\
\text { area No. 1H }\end{array}$ & & & 4312 & & 1220 \\
\hline Stark No. 7 & & & 1058 & & 1390 \\
\hline Stark No. 10 & & & 2743 & & 1400 \\
\hline Kuhn No. 17 & & & 2763 & & 1390 \\
\hline
\end{tabular}

*BOPD, barrels of oil per day; BWPD, barrels of water per day; MMCFD, million cubic feet per day; $P s i$, pounds per square inch.

TABLE 2

Average Injection and Production Volumes*

\begin{tabular}{lrl}
\hline Oil production & 392 & BOPD \\
Water production & 2208 & BWPD \\
Gas production & 7760 & MMCFD \\
Water injection & 1007 & BWPD \\
Gas injection & 11300 & MMCFD \\
Reservoir voidage & 509 & BPD \\
\hline
\end{tabular}

*BOPD, barrel of oil per day; BWPD, barrels of water perday; MMCFD, million cubic feet per day; BPD, barrels per day. 


\section{ADVANCED SECONDARY RECOVERY DEMONSTRATION FOR THE SOONER UNIT}

\author{
Contract No. DE-FC22-93BC14954 \\ Diversified Operating Corporation \\ Denver, Colo. \\ Contract Date: Oct. 21, 1992 \\ Anticipated Completion: July 31, 1994 \\ Government Award: \$788,592 \\ Principal Investigator: \\ Terry J. Cammon \\ Project Manager: \\ Edith Allison \\ Bartlesville Project Office
}

Reporting Period: Jan. 1-Mar. 31, 1995

\section{Objective}

The objective of this project is to demonstrate the cost effectiveness of geologically targeted infill drilling and improved reservoir management to increase waterflood recovery of the Cretaceous Muddy " $D$ " formation in the Denver-Julesburg Basin in northeast Colorado. The project involves multidisciplinary reservoir characterization and evaluation of process response with the use of threedimensional (3-D) seismic, reservoir simulation, and transient well tests; production tests of producing wells; and technology transfer.

\section{Summary of Technical Progress}

\section{Field Operations}

The Sooner Unit (SU) field is located about 100 miles northeast of Denver, Colo., and produces from the fluvialdeltaic Cretaceous $D$ sand formation. The Unit has been under secondary recovery operations since 1989: Both water injection and gas recycling have been used during secondary operations. Figure 1 shows the Unit area and well locations.

The following summarizes current well status:

Active production

Active water injection

Active water supply

Inactive production

Inactive water injection

Inactive water supply

Total

$\begin{array}{r}12 \\ 5 \\ 1 \\ 1 \\ 1 \\ 1 \\ \hline 21 \text { wells }\end{array}$

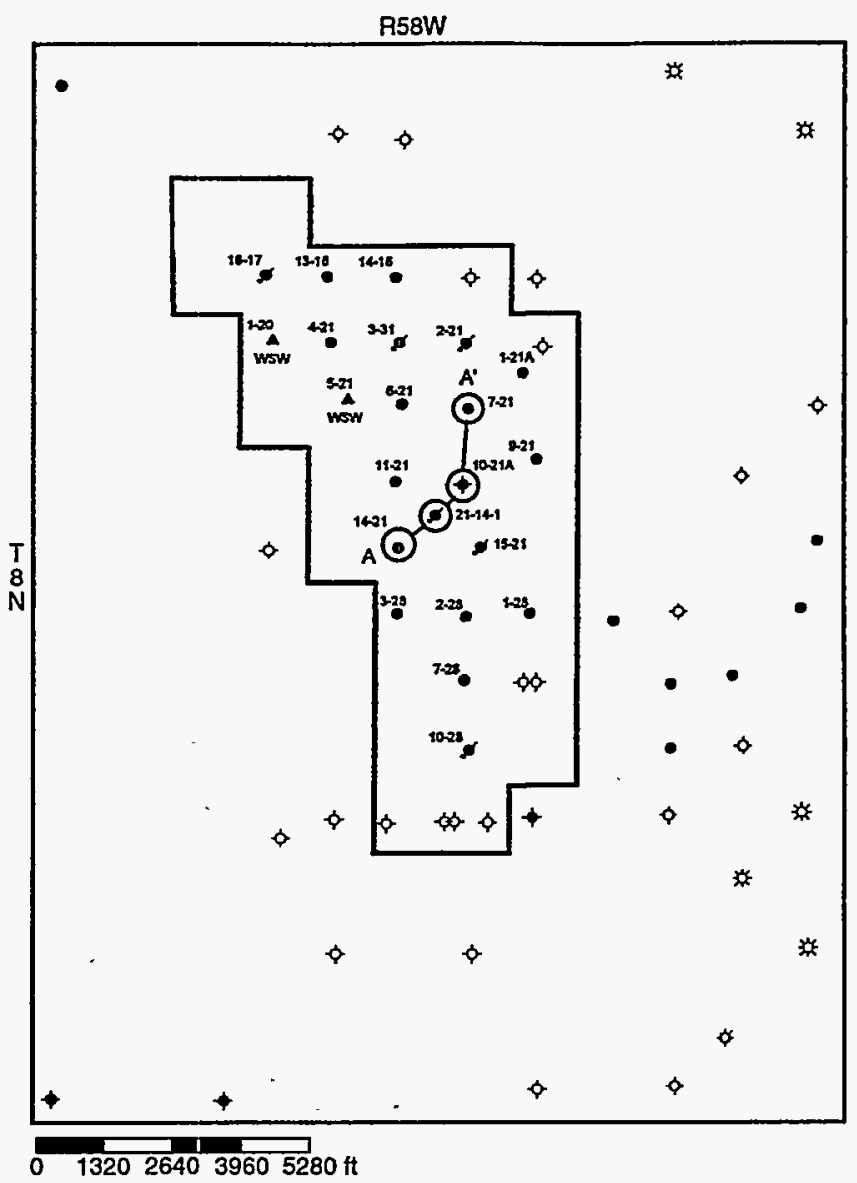

Fig. 1 Base map of the Sooner D sand unit, Weld County, Colorado, identifying well and cross-section locations.

\section{Sooner Unit No. 10-21A Well}

The SUNo. 10-21A well (NWSEsec. 21,T.8N., R.58 W.) was plugged in September 1994 after attempts to drill lateral extensions toward the southwest from the cased wellbore. Two drilling technologies were used. The first technology was ultrashort radius with articulated drill collars and turning applied through a power swivel at the surface. The second technology was short radius with a downhole mud motor and steering assembly. In both attempts the soft, overlying Graneros shale created hole problems in the curve section. The shale prevented angle building for the ultrashort radius hole and collapsed several times for the short-radius hole. An important lesson learned is that, although the heterogeneity of the reservoir rocks may seem ideal for horizontal drilling, the overlying strata play an important role in the design and success of such a completion.

\section{Sooner Unit No. 21-14-1 Well}

One objective of the reservoir management plan has been to provide water-injection support to the SU No. 14-21 and No. 11-21 wells (see Fig. 1). The horizontal attempt from the SUNo. 10-21A well was intended to meet this objective. After the failure of horizontal extensions from the SU No. 10-21A 
well, it was decided to drill a vertical well to achieve this part of the water-injection plan.

The SU No. 21-14-1 well (C-S/2 sec. 21, T. 8 N., R 58 W.) was drilled in December 1994. It is essentially a 20-acre infill between four other wells. The well encountered a thick gross D sand section $(58 \mathrm{ft})$, as was predicted from 3-D seismic and $\log$ data interpolation. There is only $6 \mathrm{ft}$ of effective sandstone in the lower transgressive facies, however. Static pressure measured with a downhole gauge was about 600 psi. This pressure was similar at the SU No. 14-21 and No. 11-21 wells, and it is concluded that the SU No. 21-14-1 should provide water-injection support for these wells.

Figure 2 shows D sand development SU No. 21-14-1 well and the stratigraphical relationship to key offset wells. The location of wells on the cross section is shown in Fig. 1. The SU No. 21-14-1 well was drilled to intersect both sandstone packages found at SU No. 10-21A and SU No. 14-21 wells. The cross section shows the poor development at the SU No. 21-14-1 well of either of these sandstone packages. The SU No. 7-21 well is also included on the cross section because there are stratigraphical and petrographical studies of core from that well. Nine sidewall cores were taken in the SU No. 21-14-1 well. These cores were described for petrographic characteristics from thin sections.

\section{Sooner Unit No. 15-21 Well}

The SU No. 15-21 well (SWSE sec. 21, T. 8 N., R. 58 W.) was converted from a shut-in oil producer to water injection. The well was last producing at a $5 \%$ oil cut when the pumping unit failed. It was converted to replace water injection from the SU No. 10-21A well.

\section{Sooner Unit No. 2-28 Well}

The SU No. 2-28 well (NWNE sec. 28 , T. 8 N., R. 58 W.) was converted from gas injection to a producing oil well. Gasrecycling operations have been suspended with the produced gas going to a sales pipeline.

\section{Sooner Unit No. 9-21 Well}

The SU No. 9-21 well (NESE sec. 21, T. 8 N., R. 58 W.) has continued a slow and steady response to water injection from the SU No. 2-21 well (NWNE sec. 21) with current production at 80 barrels of oil per day (BOPD) and 4 barrels of water per day (BWPD). The SU No. 2-21 well was converted to water injection in October 1993 when the SU No. 9-21 well was completed. The SU No. 9-21 well had an initial rate of only 10 BOPD with reservoir pressure of 535 psi. Water-injection response did not occur at the SU No. 9-21 well until February 1994 (16 months later).

\section{Inter-Well Injection Tracers}

Sodium bromide was injected into two water-injection wells to quantify reservoir anisotropy and provide data for designing gel-polymer treatments. The tracer material was injected in the SU No. 3-21 and SU No. 10-28 wells, and monitoring is in progress at offset producers. Tracer arrivals had not been detected 4 weeks after placement of the sodium bromide.

\section{Production Update}

The current production rate at the Unit averages about 252 BOPD, 1482 BWPD, and 723 MCFD. As of March 1995, $1,305,000 \mathrm{bbl}$ of cumulative oil, both primary and secondary, had been produced. This is $20 \%$ of the original oil in place (OOIP) contacted by the existing wells. The target for ultimate recovery is $34 \%$ of the OOIP, or $2,244,000 \mathrm{bbl}$. The monthly production data are shown in Fig. 3.

During this quarter production rates dipped as a result of pumping unit failure at the SU No. 7-28 well and gas compression problems. The pumping unit was replaced, and gas recycling operations were terminated. The produced gas is now being sold.

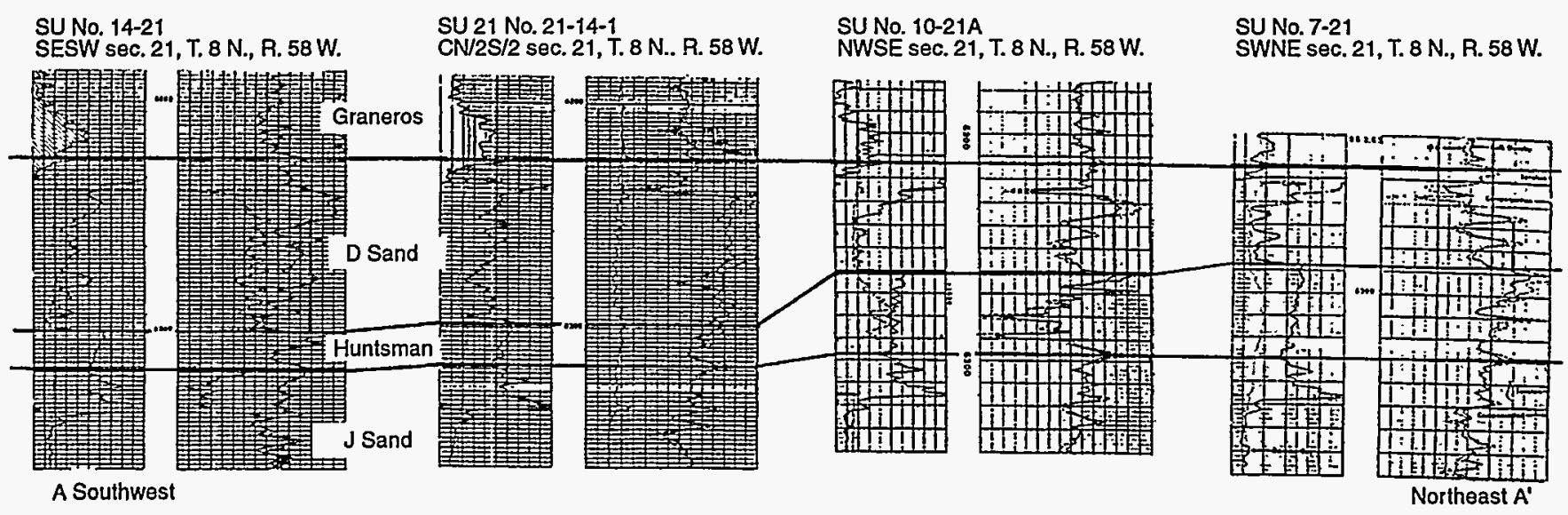

Fig. 2 D sand cross section showing depositional styles at the Sooner D sand unit. The SU No. 21-14-1 well was drilled in December 1994 and is a 20 acre infill between the SU No. 14-21 and SU No. 10-21A wells. The SU No. 14-21, 10-21A, and 7-21 wells are not in effective hydraulic communication. 


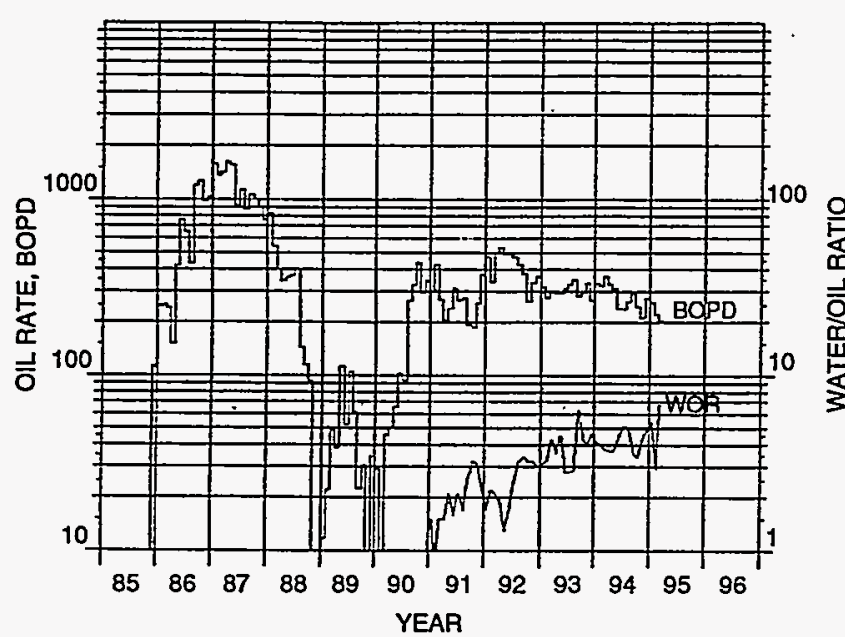

Fig. 3 Monthly production data from the Sooner Unit wells since discovery through March 1995.

\section{Petrographic Analysis SU No. 14-21-1 Well}

Nine sidewall-core samples were obtained and examined from the D sand interval in the SU No. 21-14-1 well. The samples were obtained with Schlumberger's sidewall drilling tool. A cut of each sample was impregnated with blue epoxy for the estimation of porosity, and thin sections were made. Summary results from the petrographic examination are posted on the density-neutron porosity log from the SU No. 21-14-1 well (Fig. 4). These petrographical examinations were integrated with previous petrographical work from the SU No. 7-21 core (SWNE sec. 21).

Core samples showed that the $D$ sand interval ranged from fine to very fine grained quartz arenite (to sub-arkose) sandstone, which is interbedded with calcareous, organic-rich silt and clay. The sandstone is generally well sorted with subangular to rounded grains. Mono-crystalline quartz is the dominant grain type. Other grains include feldspar (often altered to sericite), chert, calcareous siltstone clasts, and muscovite mica. Quartz overgrowths are the most volumetrically significant cement type. They were preceded only by clay-rim cement. Other cements include calcite, brown clay (pelloidal texture, possibly iron oxide stained), opal, chlorite and illite clay, and kaolinite clay with vermiculite texture.

\section{Stratigraphic Analysis}

Correlation between the SU No. 21-14-1 well (Fig. 4) and the SU No. 7-21 well (Fig. 5) indicates that the D sand is thicker and more clay rich in the SU No. 21-14-1 well. The $D$ sand is bracketed between the high gamma-ray shales in the $\mathrm{J}$ silt (below) and the Graneros shale (above), which represent periods of quiet-water deposition during maximum marine transgression. These are maximum flooding surfaces in sequence stratigraphy. Correlation from these flooding surfaces reveals that the $\mathrm{D} 3$ bench is an additional sand package in the SU No. 21-14-1 well, which includes the reservoir intervalley and the kaolin clay-rich sands (Fig. 4). This interval is bounded at the base by an erosional-sequence boundary, which was the floor of an incised valley system. It is bounded at the top by a transgressive surface and represents the lowstand systems tract in this area. The upper-sandstone package (D1 and D2 benches) is of similar thickness in the SU No. 2114-1 and 7-21 (Fig. 6) wells. These sands are characterized by calcite cements and burrowing by marine organisms (see Fig. 5). They were deposited during marine transgression into the valley system. Root structures and carbonaceous shales found in the SU No. 7-21 core suggest that these sands were deposited in an estuarine environment. They are bounded at the top eroding surface and generally fine upward. This interval is the transgressive-systems tract in sequence stratigraphy. The D1 and D2 benches are coarser grained and less clay rich in the SU No. 7-21 well than in the SU No. 21-14-1 well. They are oil reservoirs at the SU No. 7-21 well and nonproductive at the SU No. 21-14-1 well. The trend of quality sands is elongate parallel to the estuary margin. These sands were probably deposited as estuarine bar sands similar to those described for the Gironde estuary. ${ }^{1}$

\section{Reservoir Compartmentalization}

The low-stand and transgressive-systems tracts are characterized by different reservoir compartmentalization styles. Low-stand sands were deposited in fluvial point bars, which were separated by clay-rich channel fill along depositional strike (north-south to northwest-southeast). They are restricted to the deepest part of the incised valley and probably separated into reservoir pods along that trend. The most effective vertical-flow barrier is probably the kaolinitic clay pore fill between the low-stand (D3) and transgressive (D1 and D2) sandstones.

Transgressive sands were deposited in a setting with increasing accommodation space during marine transgression. Consequently they cover a wider area and are more aggradational in nature. Within the estuarine environment, elongate bar sands develop parallel to depositional strike. These bar sands form the reservoir compartments in the D1 and $\mathrm{D} 2$ benches.

\section{3-D Seismic Reservoir Characterization}

As part of the reservoir characterization at the SU, an attempt was made to use 3-D seismic attributes for predicting quantitative reservoir properties. To this end, a statistical analysis of reservoir properties and 3-D seismic attributes has been undertaken, which allows direct prediction in map view of net pay thickness and effective hydrocarbon pore volume.

These attribute maps include the following:

1. Combination amplitude (absolute difference of maximum D sand peak amplitude and Huntsman trough-amplitude).

2. D sand isochron (measured for the $D$ sand peak to the Huntsman trough).

3. D sand zero-crossing isochron (measured from the $-1+$ zero crossing above the $D$ sand peak to the $t /-$ zero crossing below the $\mathrm{D}$ sand peak). 


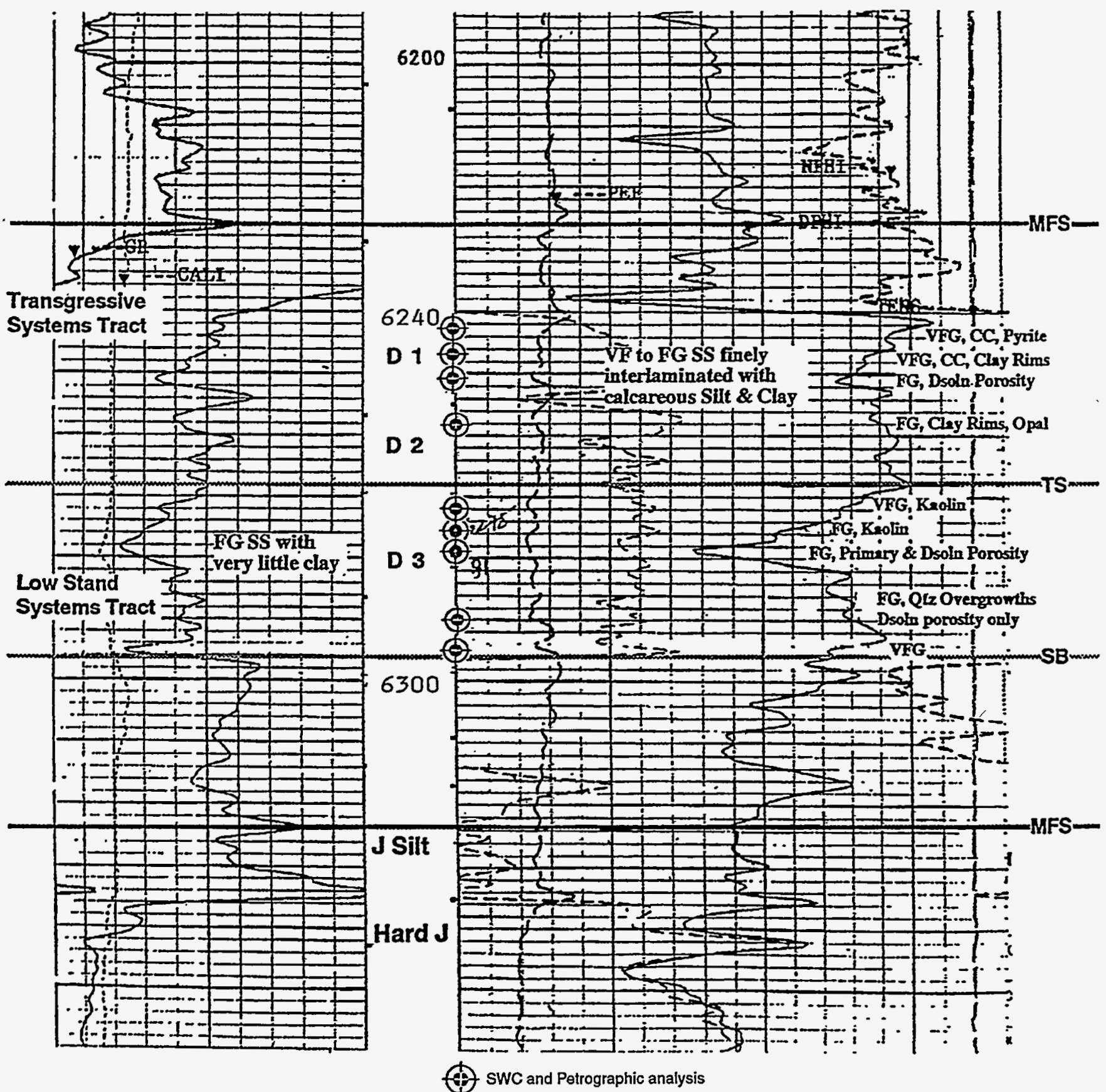

Fig. 4 Gamma-ray and density-neutron porosity log from the SU No. 21-14-1 well with sidewall-core sample points and general lithology.

4. D sand to $J$ sand isochron (measured from the $D$ sand peak to the J sand peak).

5. D sand instantaneous frequency.

6. Huntsman instantaneous frequency.

7. D sand instantaneous phase.

8. Huntsman instantaneous phase.

9. D sand Hilbert reflectivity.

10. Huntsman Hilbert reflectivity.

These 10 seismic attributes were measured at 33 well locations within the full-fold portion of the 3-D survey and compared with reservoir properties from well logs by multiple linear-regression analysis. The multiple regression analyses, which allowed the creation of correlation equations, were performed with the personal computer (PC) software program WINSTAT. Nearly equivalent correlations could probably be derived with less attributes. The elimination of poor correlation attributes for a quicker and simpler analysis is in progress.

The reservoir attributes from log data are shown in Fig. 7. The gross D sand isolith (D-ISO) is measured from the top of the $D$ sand, where the shallow resistivity is greater than $10 \Omega-\mathrm{m}$, to the erosional contact at the 


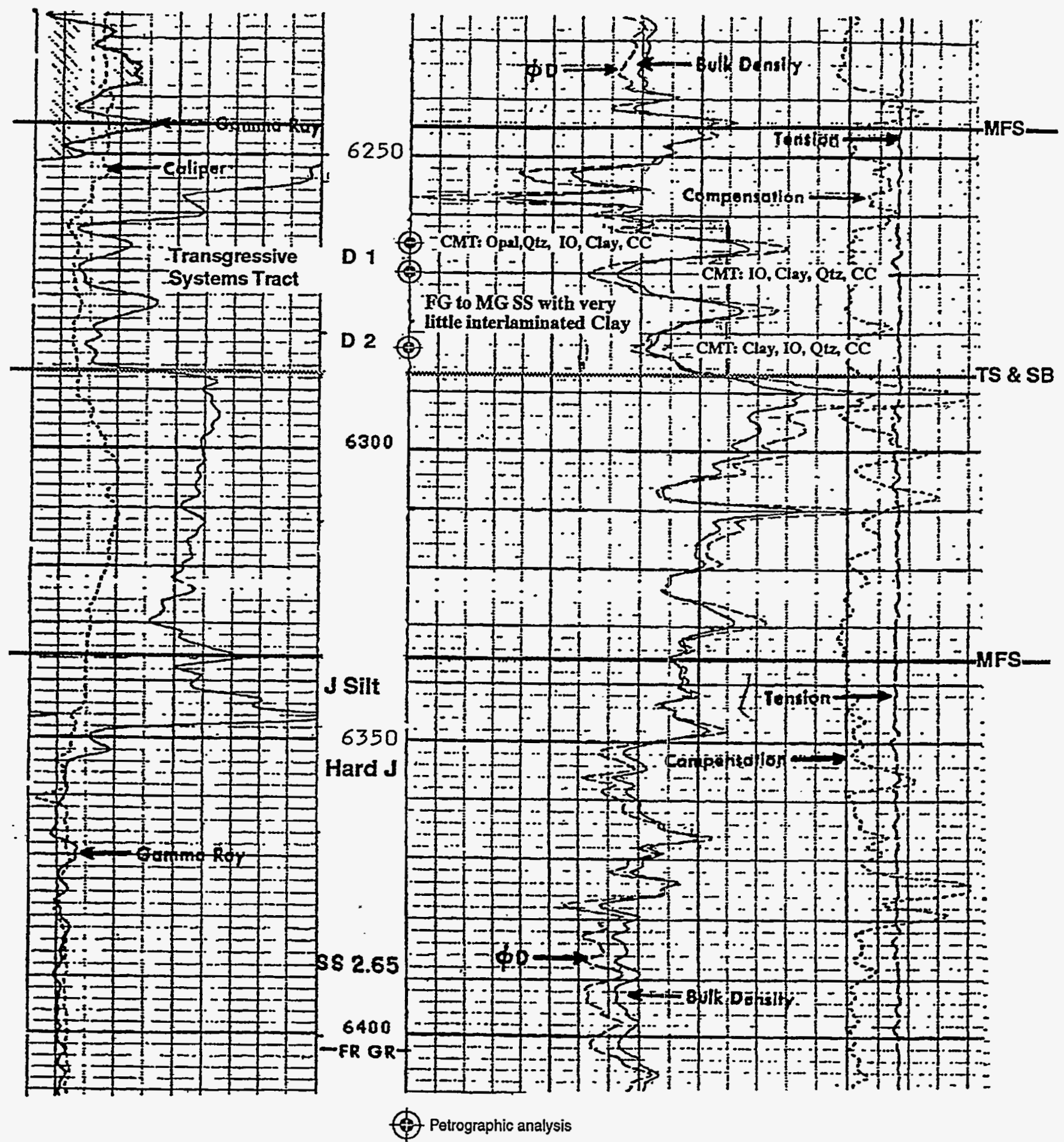

Fig. 5 Gamma-ray and density-neutron porosity log from the SU No. 7-21 well with location of thin-section samples obtained from the conventional core.

Huntsman shale, where the shallow resistivity is less than $5 \Omega-\mathrm{m}$. The net-pay thickness (D-NET) is based on density porosity greater than $6 \%$, shale volume of less than $30 \%$, and water saturation of less than $70 \%$. Effective hydrocarbon porosity (D-HCFT) is calculated with the use of the Archie method for sandstones and the previously described cutoff parameters.
The results of these correlations are shown in Table 1. Predicted reservoir properties from 3-D seismic attributes for each well location were measured (see Table 2).

\section{Conclusions}

The results of preliminary multiple-regression analysis of 3-D seismic attributes do not appear to be fully reliable; 


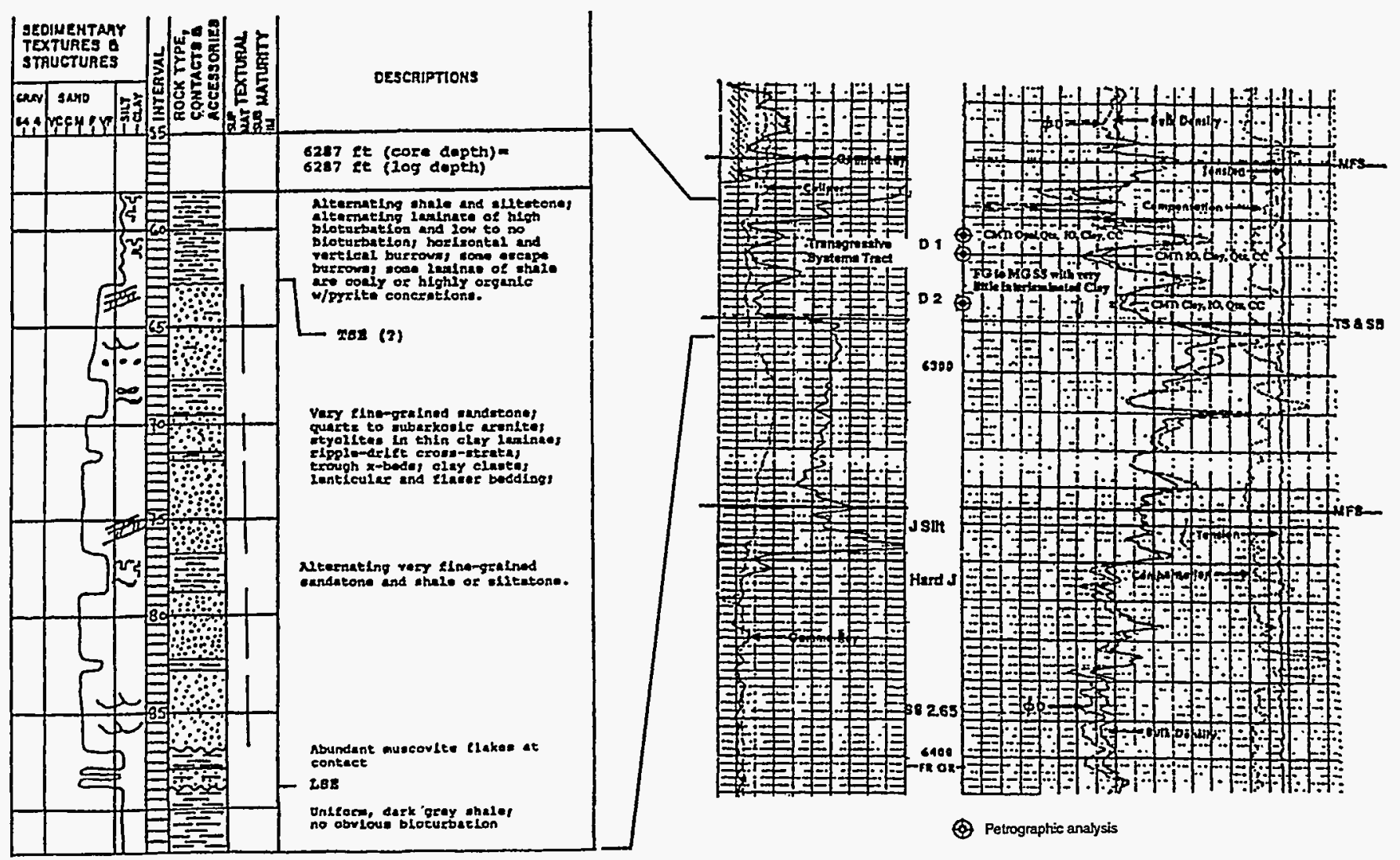

Fig. 6 Core description and porosity log from the SU No. 7-21 well.

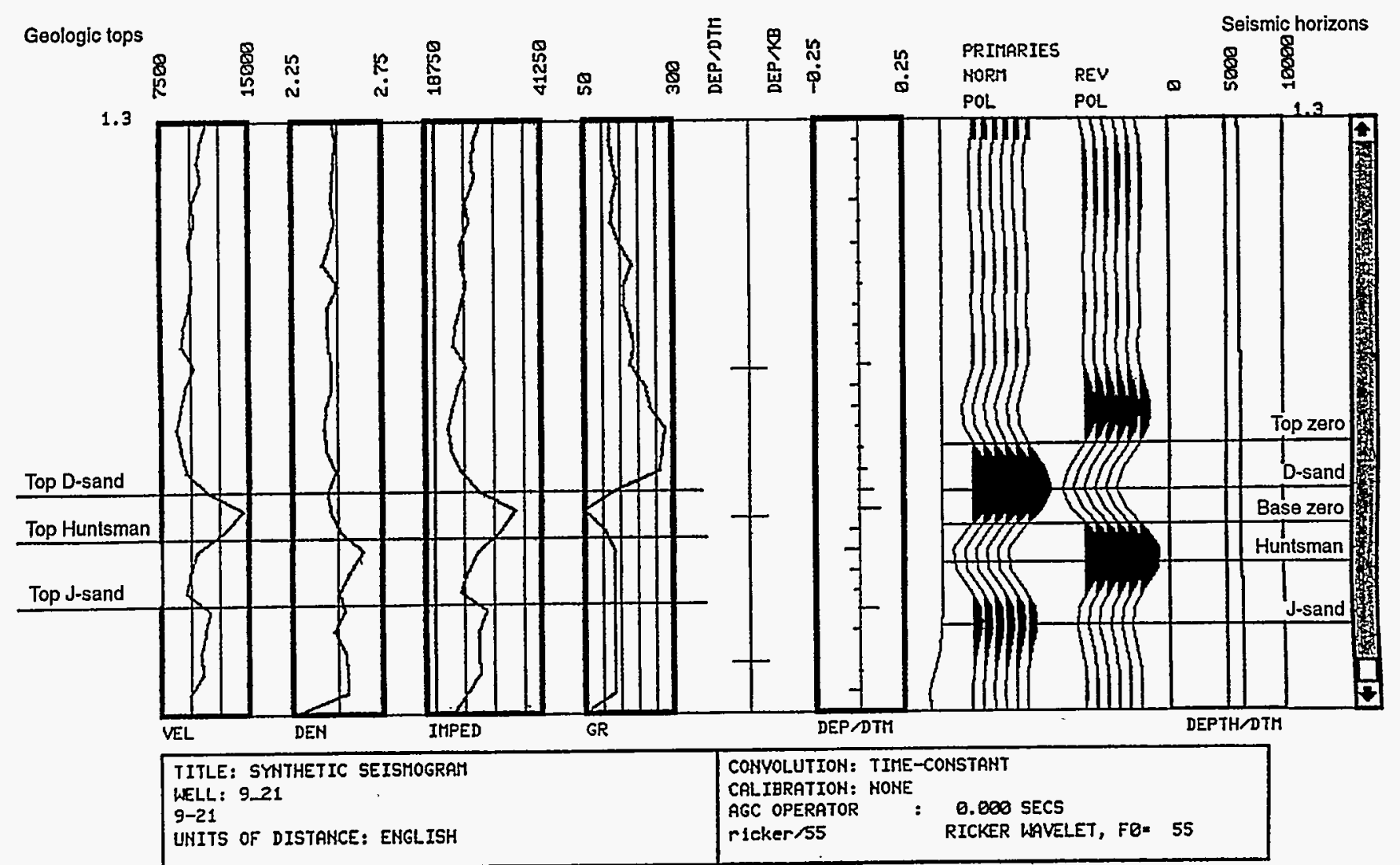

Fig. 7 Synthetic seismogram and log attributes for $D$ sand seismic attribute correlation with petrophysical properties. 
TABLE 1

Correlation Coefficients from Regression Analysis*

\begin{tabular}{cccc}
\hline Attribute & D-ISO & D-NET & D-HCFT \\
\hline 1 & $8.176 \times 10^{-4}$ & $1.018 \times 10^{-3}$ & $9.710 \times 10^{-5}$ \\
2 & $-5.411 \times 10^{0}$ & $-1.558 \times 10^{1}$ & $-1.611 \times 10^{0}$ \\
3 & $-1.316 \times 10^{1}$ & $-1.633 \times 10^{0}$ & $-8.883 \times 10^{-3}$ \\
4 & $-5.356 \times 10^{-1}$ & $3.317 \times 10^{0}$ & $3.080 \times 10^{-1}$ \\
5 & $-3.444 \times 10^{0}$ & $-2.099 \times 10^{0}$ & $1.717 \times 10^{-1}$ \\
6 & $-1.535 \times 10^{0}$ & $-6.446 \times 10^{-1}$ & $-5.333 \times 10^{-2}$ \\
7 & $5.148 \times 10^{1}$ & $1.570 \times 10^{1}$ & $5.107 \times 10^{-2}$ \\
8 & $-1.660 \times 10^{0}$ & $-1.638 \times 10^{0}$ & $-9.367 \times 10^{-3}$ \\
9 & $1.647 \times 10^{0}$ & $-1.443 \times 10^{0}$ & $-1.922 \times 10^{-1}$ \\
10 & $-2.122 \times 10^{0}$ & $6.096 \times 10^{-1}$ & $3.661 \times 10^{0}$ \\
Constant & 502.93 & 254.13 & 21.78 \\
"R," \% & 84.87 & 65.40 & 48.71 \\
Standard error, ft & 8.3 & 8.2 & 0.87 \\
\hline
\end{tabular}

*D-ISO, D-sand isolith;D-NET, net-pay thickness; and D-HCFT, hydrocarbon porosity-feet.

TABLE 2

Predicted D Sand Reservoir Properties for Infill Locations*

\begin{tabular}{cccc}
\hline Location & D-ISO, ft & D-NET, ft & D-HCFT, ft \\
\hline A & 45.3 & 20.8 & 1.73 \\
B & 65.3 & 30.2 & 2.59 \\
C & 47.8 & 19.5 & 1.69 \\
\hline
\end{tabular}

*D-ISO, D-sand isolith; D-NET, net-pay thickness; and D-HCFT, hydrocarbon porosity-feet.

however, additional work may yield breakthrough methods that can be applied to the SU. Seismic mapping of hydrocarbonporosity thickness would allow for comprehensive, volumetricreserve calculations and improved reservoir management. At the SU, seismic-attribute mapping provides a good predictive capability for mapping of gross and net sand thickness. Unfortunately, the determination of hydrocarbon pore-feet thickness from seismic data appears to be poorly constrained.

Seismic mapping of reservoir attributes from other surveys in the D sand to the south of SU shows a greater correlation of gross and net sand thickness with reservoir quality. The lack of a strong correlation between gross and net sand thickness and reservoir pay at the $\mathrm{SU}$ may indicate a more complex reservoir and depositional setting. The geological setting at $\mathrm{SU}$ is in transition from a classical incised valley to a tidally influenced marine setting, which may result in clay content playing a greater role in reservoir quality than sandstone thickness. Other 3-D seismic studies of D sand reservoirs in the D-J Basin indicate that greater D sand isolith thickness equates to more quality reservoir development. This does not appear to be the case at the SU, where gross isolith thickness correlates poorly with net pay and effective hydrocarbonporosity development.

\section{Reference}

1. G. P. Allen and H. W. Posamentier, Sequence Stratigraphy and Facies Model of an Incised Valley Fill: The Gironde Estuary, France, J. Sediment. Petrol., 63(3): 378-391 (May 1993).

\section{APPLICATION OF RESERVOIR CHARACTERIZATION AND ADVANCED TECHNOLOGY TO IMPROVE RECOVERY AND ECONOMICS IN A LOWER QUALITY SHALLOW SHELF CARBONATE RESERVOIR}

Contract No. DE-FC22-94BC14990

Oxy USA, Inc.

Midland, Tex.

Contract Date: Aug. 3, 1994

Anticipated Completion: June 14, 1996

Government Award: $\$ 1,922,000$

Principal Investigator:

Archie Taylor

Project Manager:

Chandra Nautiyal

Bartlesville Project Office

Reporting Period: Jan. 1-Mar. 31, 1995

\section{Objectives}

The main objective of the project is to demonstrate in the field how innovative technologies, such as cross-wellbore tomography, hydraulic fracture orientation detection, threedimensional (3-D) seismic methods, and cyclic carbon dioxide $\left(\mathrm{CO}_{2}\right)$ stimulation; can improve the economics of conventional $\mathrm{CO}_{2}$ flooding. Objectives to be accomplished during this quarter included complete petrophysical description on cores from observation wells, apply petrophysical data to geologic model, conduct additional laboratory analysis on cores and fluids, refine 3-D seismic interpretations, complete tomography surveys, process tomography data, establish relationship between seismic and tomography interpretations, conduct preliminary simulator runs with improved geologic model, evaluate results of cyclic $\mathrm{CO}_{2}$ stimulation treatments, and design frac treatment for linear flood fronts.

The area of greatest concern timewise is reservoir simulation. The simulator depends on the geologic model, which, in turn, depends on the petrophysical, 3-D seismic, and tomography interpretations. 


\section{Summary of Technical Progress}

\section{Reservoir Characterization}

\section{Update Existing Characterization}

The final results of the petrophysical study on cores from the two observation wells are available. The study incorporated detailed depositional environments with lateral and vertical facies distribution. Thin-section and scanning electron microscope (SEM) analyses of 84 samples, plus pore casts and pore geometry analysis of 59 samples, were used to generate synthetic capillary pressure data. These data were used to distinguish four separate rock types that should have similar production characteristics. The general characteristics of the rock types are as follows: rock type 1, large crystal size; rock type 2 , intermediate crystal size; rock type 3, finely crystalline dolostones; and rock type 4, less than $1 \mathrm{mD}$.

Capillary pressure data were used to develop a relationship among porosity, pore entry radius, and permeability. The slope of the line through these points should give the Kozeny constant with the intercept going through the origin. These data are plotted in Fig. 1. Rock types 2 and 3 appear to give straight lines through all three samples. Rock type 1 appears to have two straight lines. This suggests that type 1 rock may need to be divided into two separate rock types. Additional capillary pressure measurements are being obtained to determine if this is the situation.

Sequence stratigraphy, based on petrophysical studies, has been applied to the geological model to determine facies continuity between wells. Although sequence stratigraphy can define the pinch out of zones between wells, it does not indicate where the pinch out occurs. It is anticipated that 3-D seismic interpretations will help approximate the pinch outs, and the tomography data will further refine the interwell character of the reservoir.

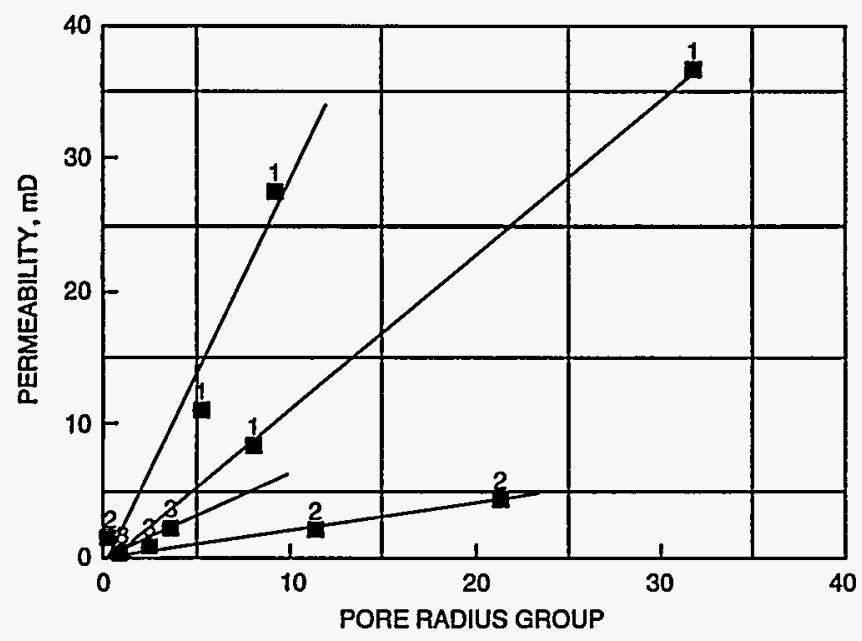

Fig. 1 DOE Project West Welch Unit.

\section{Baseline Tomography Survey}

Fifteen of the sixteen wellbore seismic-tomography surveys have been acquired (Table 1 and Fig. 2). Line 4852-4843 was deferred because well 4843 was scheduled to be treated with the cyclic $\mathrm{CO}_{2}$-injection stimulation. It is hoped that the $\mathrm{CO}_{2}$ injection into the formation will be detectable by the tomography survey. The quality of the data has been very good on the shorter tomography lines and ranges from fair to good on the longer lines, as anticipated.

Preprocessing of the tomography data is done by hand; hence it is labor-intensive. Preprocessing of the $\mathrm{P}$-wave data (compression) is well along. The setup required to preprocess the P-wave data will make the preprocessing for the shear wave and cross-well vertical sizing profiling (VSP) go much faster. A preliminary tomogram on $50-\mathrm{ft}$ spacing is complete and the results look good. All tomograms will be processed on 5 -ft spacing for additional detail.

\section{TABLE 1}

\begin{tabular}{cc}
\multicolumn{2}{c}{ Crosshole Seismic } \\
Surveys—Phase 1 \\
\hline Lines acquired & Line remaining \\
\hline $7916-3206$ & $4852-4843$ \\
$7916-4825$ & \\
$7916-3203$ & \\
$7916-4832$ & \\
$7916-7914$ & \\
$7916-4827$ & \\
$7916-4824$ & \\
$4852-4827$ & \\
$4852-4828$ & \\
$4852-4822$ & \\
$7916-7901$ & \\
$4852-4841$ \\
$4852-4809$ \\
$4852-4808$ \\
$7916-4852$ \\
\hline
\end{tabular}

\section{3-D Seismic Interpretation}

The 3-D seismic structural and stratigraphic interpretations have been refined. Five seismic horizons relevant to the main pay zone were tied to five log markers (N, M, M3, M5, and Z6) and correlated throughout the 3-D seismic volume. These time-structure horizons were each converted to depth with the use of the average velocity and gradient method. The differences between the horizons create the isopachs. Subsea structure values for the M1, M3, and M5 markers and isopach values for the M1-M5, M1-M3, and M3-M5 intervals were established at each seismic bin location. These seismic bins are spaced $110 \mathrm{ft}$ north-south and $165 \mathrm{ft}$ east-west across the U.S. Department of Energy (DOE) study area. The investigation into using seismic attributes to estimate petrophysical (log) properties revealed that there are several correlations between seismic attributes and pore volume $(\mathrm{PV})$ that might be useful. Correlations between seismic structures and PV and 


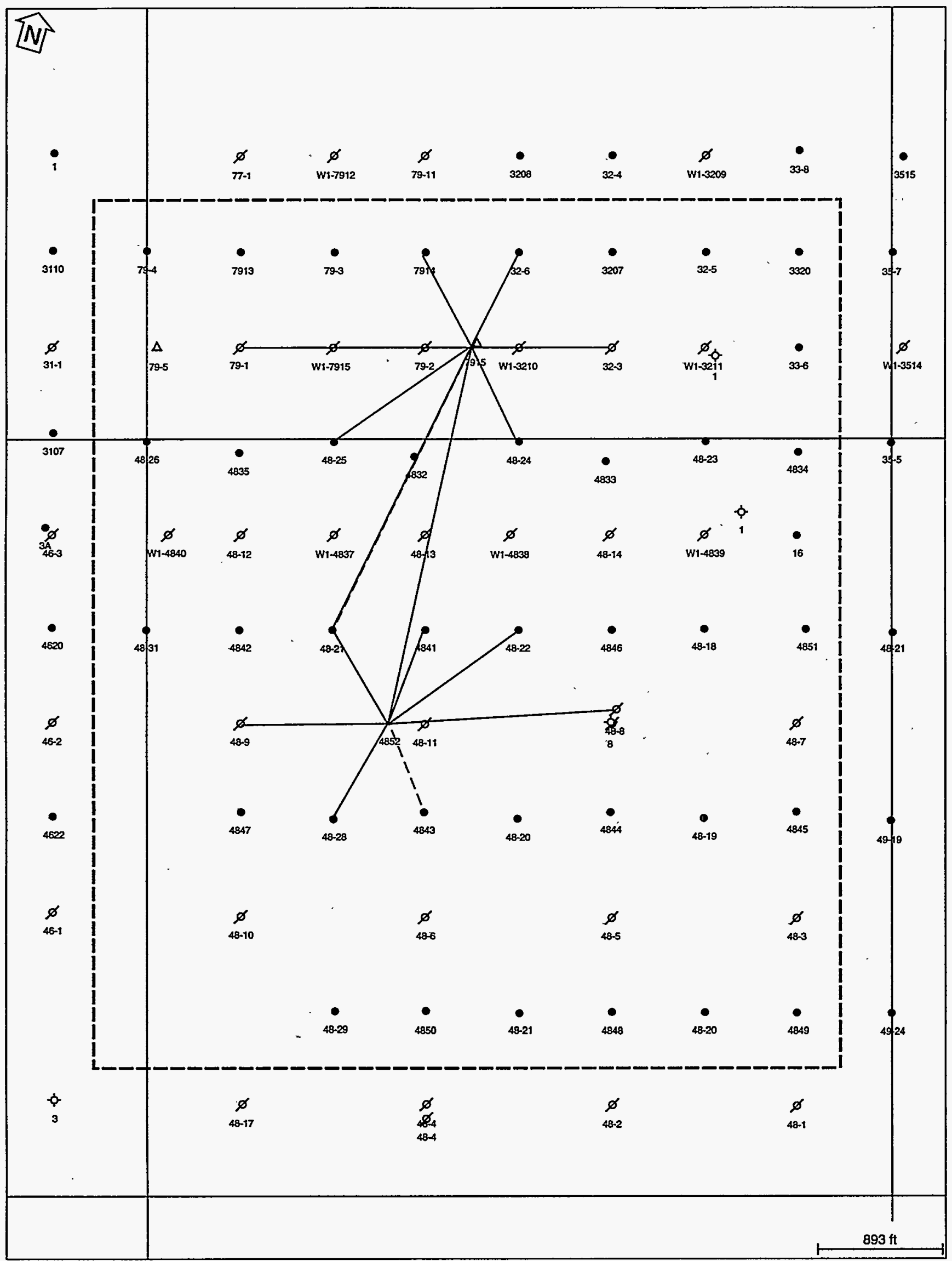

Fig. 2 Acquired tomography (solid), March 31, 1995. 
the seismic-derived isopachs and PV were excellent, as shown by the Kendall's Tau indicators (Table 2). The relative amplitude of the M3 horizon had excellent correlation with the PV across the total main pay (M1-M5) interval. The inverted seismic velocity correlation varied from fair to very good with PV. The instantaneous amplitude, instantaneous frequency, instantaneous phase did not correlate with $\mathrm{PV}$ distribution for any of the reservoir intervals.

The reservoir thickness (isopach) and the interval velocity were selected for the initial transformation to the PV values. Representative cross-plots are shown in (Figs. 3 and 4). The transformation of thickness and velocity attributes to PV was successfully applied to all three reservoir intervals (M1-M5, M1-M3, and M3-M5). The log data are being reviewed and updated, and a final seismic attribute to porosity transformation will be produced.

A detailed base map of the tomographic bin locations was developed. The process of transferring tomography data to the stacked curves (SCPC) system to integrate with well log data and 3-D seismic data has been initiated. A technique developed to tie two-dimensional (2-D) seismic line to 3-D interpretations will be used to integrate the tomography interpretations with the 3-D seismic interpretations.

\section{Saturation Distributions}

Before the start of the current DOE project, the geologic model for a 60-acre area in the West Welch Unit was upgraded to a 19-layer model with the use of sequence stratigraphy, which results in the pinch out of some layers between wells. The resulting production and injection history match was much improved over what had been obtained from the simpler geologic model. The model has been further adjusted for the results of injectivity surveys.

During the present quarter induction of a new equation of state (EOS) has given more realistic residual oil saturations. Also, additional water-oil and gas-water relative

TABLE 2

Quality Matrix: Pore Volume vs. Seismic Attributes*

\begin{tabular}{|c|c|c|c|c|c|c|c|}
\hline \multirow{2}{*}{$\begin{array}{l}\text { Reservoir } \\
\text { interval }\end{array}$} & \multirow{2}{*}{$\begin{array}{l}\text { Reservoir } \\
\text { structure }\end{array}$} & \multirow{2}{*}{$\begin{array}{l}\text { Reservoir } \\
\text { thickness }\end{array}$} & \multirow{2}{*}{$\begin{array}{l}\text { Internal } \\
\text { velocity }\end{array}$} & \multirow{2}{*}{$\begin{array}{l}\text { Relative } \\
\text { amplitude }\end{array}$} & \multicolumn{3}{|c|}{ Instantaneous } \\
\hline & & & & & Amplitude & Frequency & Phase \\
\hline Total main pay & 100.0 & 100.0 & 90.2 & 96.6 & 39.9 & 19.8 & 6.5 \\
\hline Upper main pay & 100.0 & 100.0 & 80.4 & - & 34.5 & 2.3 & 11.1 \\
\hline Lower main pay & 100.0 & 100.0 & 64.0 & - & 6.5 & 32.2 & 9.3 \\
\hline
\end{tabular}

*Kendall's Tau Indicator Calculations.

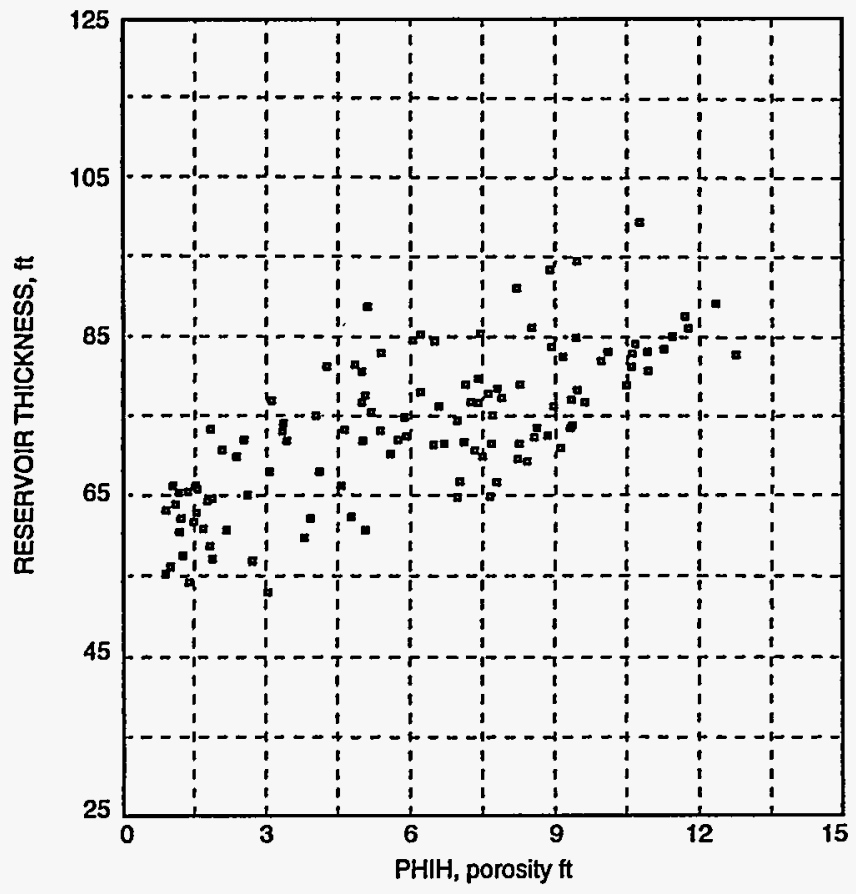

Fig. 3 Reservoir thickness (isopachs M1-M5) vs. average porosity fraction (PHIH) (M1-M5 PHIH) for 1360 wells. Number of points, 119; probability of relationship using Kendall's Tau, 100.0.

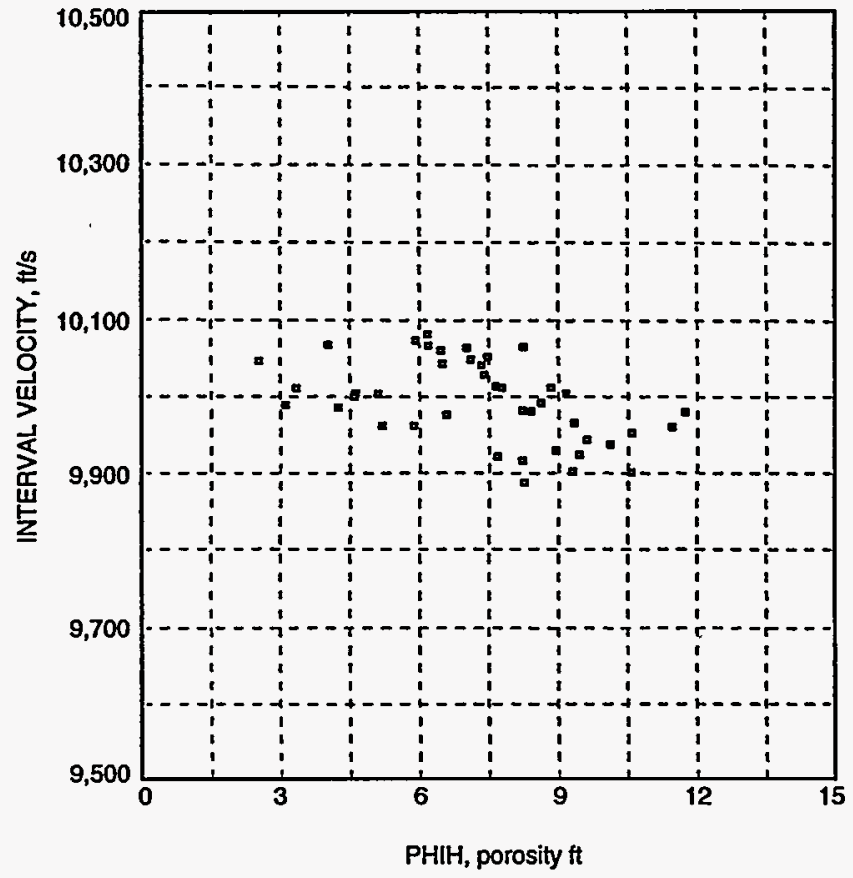

Fig. 4 Internal velocity (M1-M5) vs. average porosity fraction (PHIH) (M1-M5 PHIH) (330 wells). Number of points, 42; probability of relationship using Kendall's Tau, 90.2. 
permeability data have been obtained that will be used for simulating $\mathrm{CO}_{2}$-water alternating gas (WAG) injection. Significant advances in the simulation project, however, depend on further refinement of the geologic model. Because of the geologic model's dependency on the 3-D seismic and tomography interpretations, the simulation effort will continue to lag behind the original schedule.

\section{Fracture Geometry}

Core analysis was performed on selected samples from the No. 4852 observation well for use in the 3-D fracture simulation model. In situ stress data from full-wave sonic logs were incorporated into the model, and the initial results indicate that the fracture would grow down out of zone. However, long-term injection experience surrounding the test well (No. 4807) and a post-fracture treatment evaluation $\log$ on well No. 3811 suggest containment of the fracture within the main pay. The lower boundary zone properties are being modified in the model to limit fracture growth. Figure 5 shows a cross section of the containment zones. The orientation and extent of the actual induced fracture wing will be traced with passive seismic triangulation.

\section{Laboratory Testing Requirements}

Calculations for determining the diffusion constant from laboratory resistivity measurements are complete. The value for diffusion in a straight tube is $0.00511 \mathrm{~cm}^{2} / \mathrm{s}$. This value is found from measurements of the change in water resistivity measured as a $\mathrm{CO}_{2}$ diffused through an oil column overlying the water. Figures 6 to 8 contain the $\mathrm{CO}_{2}$ concentration and resistivity vs. time.

Additional mercury injecting capillary pressure data were obtained on 10 of the core samples from the observation wells that represented Davies's rock types 1,2 , and 3. Because rock type 1 appeared to have two separate trends, additional samples will be chosen for its capillary pressure measurements.

Seven of these ten samples were aged in crude oil and had steady-state water relative-permeability tests performed. The tests showed mixed wettability that appears to vary with pore size. Additional end-point water-gas relative-permeability data are being obtained for use with relative-permeability hysteresis curves.

Following the relative-permeability tests the core was flooded with a slim-tube-developed miscible bank. Following the flooding of the core with the slim-tube fluid, alternating cycles of water and $\mathrm{CO}_{2}$ were injected to endpoint saturations.

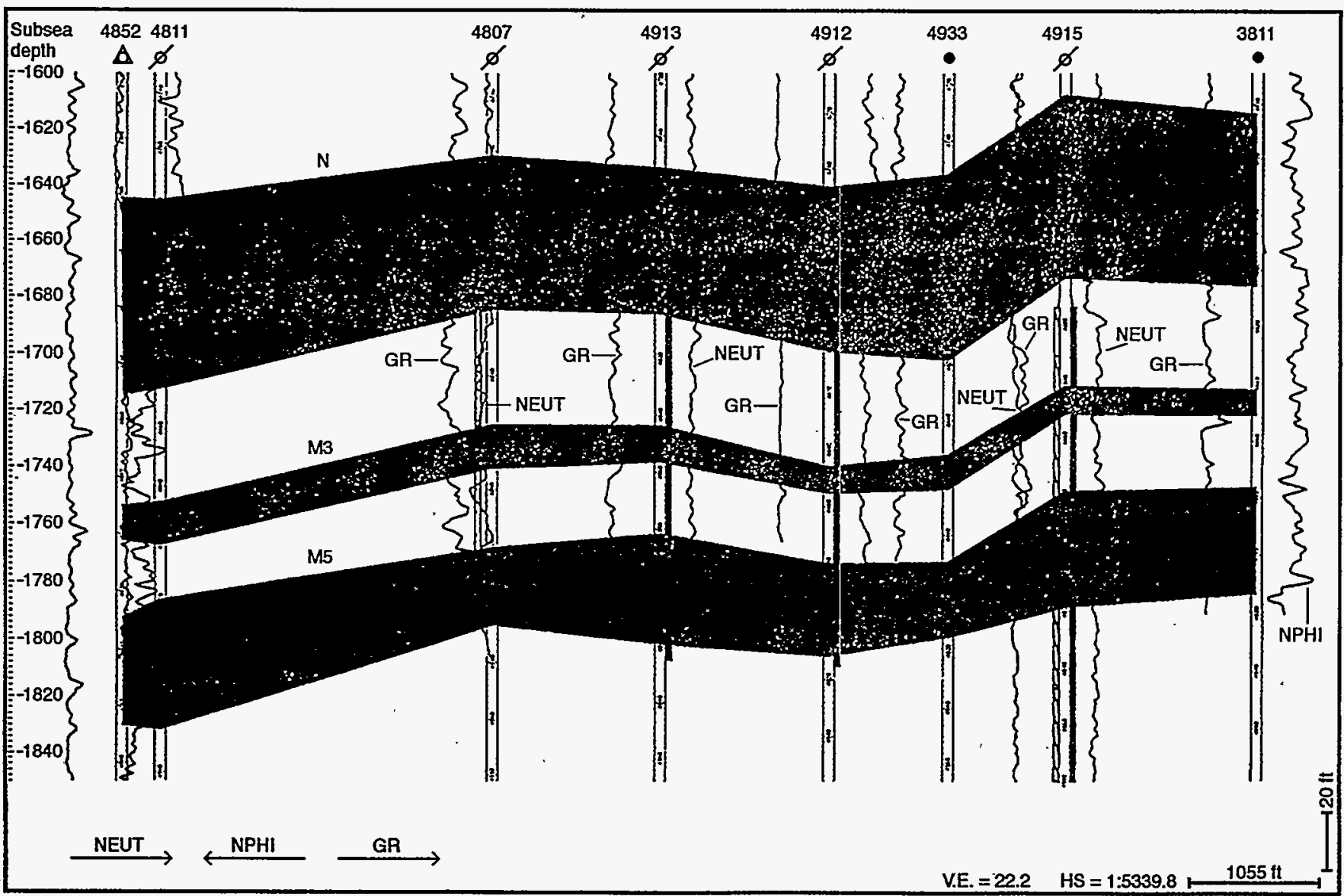

Fig. 5 West Welch area, Dawson County, Tex. 


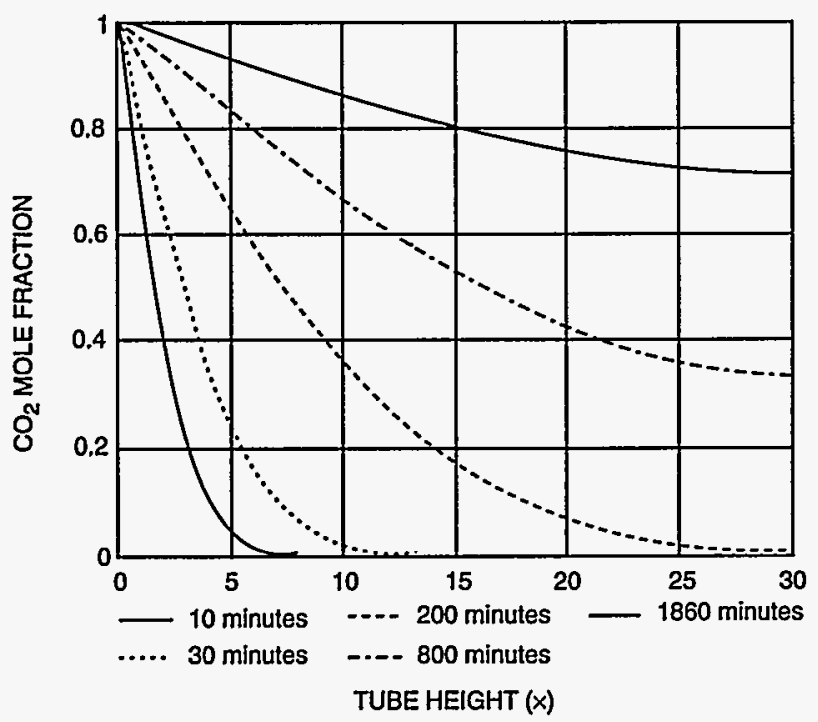

Fig. $6 \mathrm{CO}_{2}$ mole fraction vs. height at various times. $x=0 . .12 \cdot 2.54$. (Art reproduced from best available copy.)

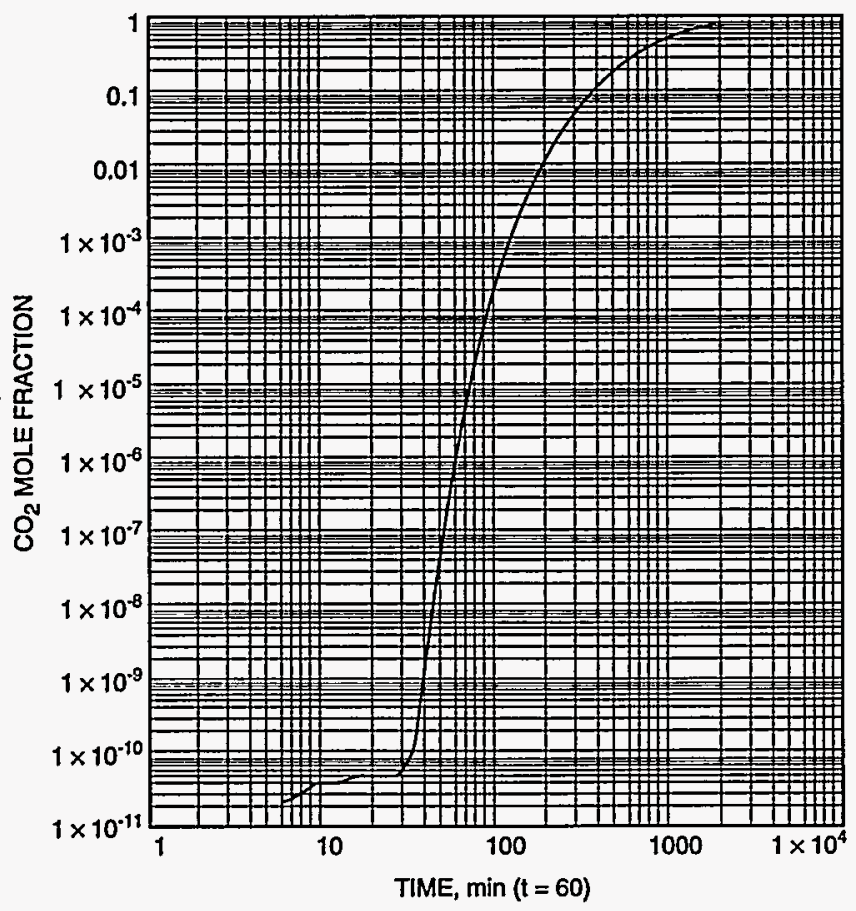

Fig. $7 \mathrm{CO}_{2}$ mole fraction vs. time at tube end. For time ranging from 5 to $1850 \mathrm{~min}$ (test times): $(t=5 \cdot 60,10 \cdot 60 \ldots 1860 \cdot 60)$.

Following the WAG cycles, the residual oil to $\mathrm{CO}_{2}$ was extracted for compositional analysis. The SCAL, Inc., results are given in Table 3. The fluid EOS has been modified to reflect the residual saturation from slim-tube experiments.

\section{Reservoir Management Plan Development}

\section{Cyclic $\mathrm{CO}_{2}$ Stimulation Evaluation}

During this quarter the fifth and final well (No. 4845) scheduled for cyclic $\mathrm{CO}_{2}$ stimulation treatment was injected

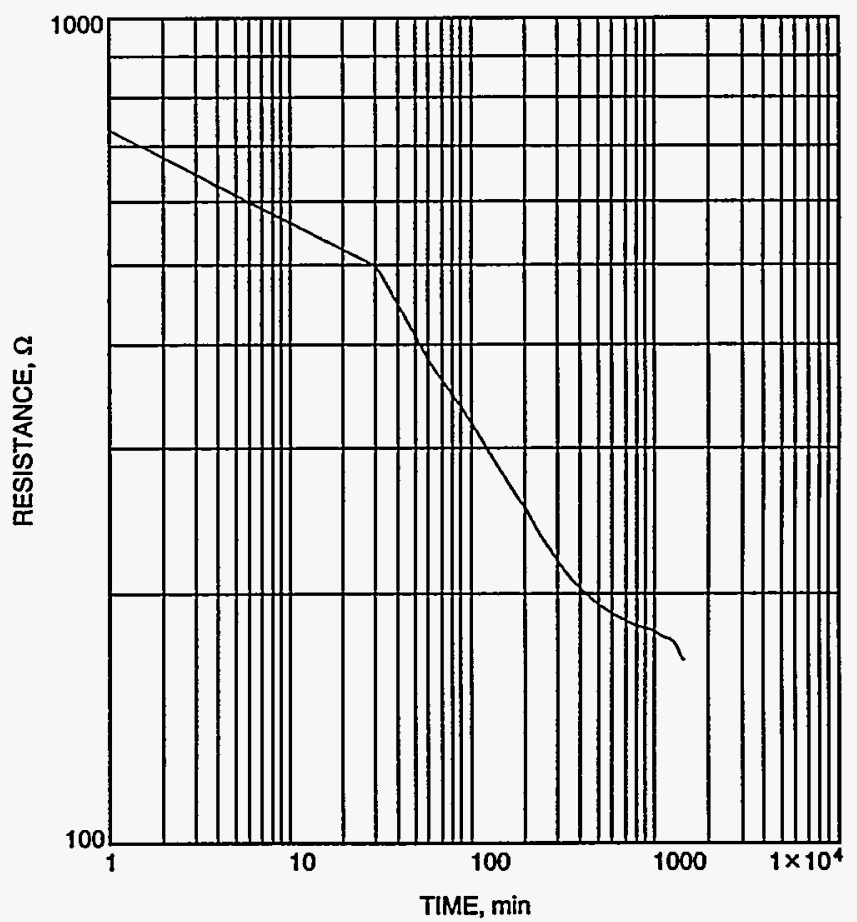

Fig. 8 Resistivity vs. time at tube end.

with 15 million cubic feet (MMCF) of $\mathrm{CO}_{2}$. After a soak period, the well was placed back on production. Oil has increased from a baseline of $12 \mathrm{bbl}$ of oil per day (BOPD) to 19 to 20 BOPD, with a significant reduction in the water cut. Recently the well productions inexplicably decreased to less than 12 BOPD. The situation is being investigated to determine if it is caused by some mechanical malfunction or actual reservoir conditions.

In summary, five wells have been treated with volumes of $\mathrm{CO}_{2}$ ranging from 5 to $15 \mathrm{MMCF}$. Only one well has experienced a significantly sustained production increase. Two wells have experienced a slight production increase. One well appears to receive no benefit from the treatment, and one well is still being evaluated. The complete evaluation of the cyclic $\mathrm{CO}_{2}$ treatments must account for the increased value of producing gas and the effect on operating cost caused by lower water production. The performance of all five wells (3205, $4835,4843,4847$, and 4851 ) will continue to be monitored.

\section{Technology Transfer}

A paper was presented at the 3-D seismic symposium sponsored by the Rocky Mountain Association of Geophysics and the Denver Geophysical Society. ${ }^{1}$ Although the actual field example discussed in the paper was not in the West Welch demonstration area, it involved the technique for using seismic-guided estimates of log properties that was developed for the West Welch DOE demonstration project. An informal presentation of some of the aspects of the West Welch demonstration project will be made to the West Texas Geophysical Society during May 1995. 
TABLE 3

Carbon Dioxide Core Flood Results*

\begin{tabular}{|c|c|c|c|c|c|c|c|c|c|c|c|c|c|c|c|c|c|}
\hline \multirow{2}{*}{$\begin{array}{l}\text { Sample } \\
\text { number }\end{array}$} & \multirow[b]{2}{*}{ Well } & \multicolumn{2}{|c|}{ Depth, } & \multirow{2}{*}{$\underset{\mathbf{m D}}{\mathbf{K}_{\text {sair }}}$} & \multirow{2}{*}{$\begin{array}{c}\text { Porosity, } \\
\%\end{array}$} & \multirow{2}{*}{$\begin{array}{l}\text { Grain } \\
\text { density, } \\
\mathrm{g}^{3} \mathrm{~cm}^{3}\end{array}$} & \multirow{2}{*}{$\underset{\%}{\text { So, }}$} & \multirow{2}{*}{$\begin{array}{c}\mathbf{K}_{\text {eo }} \\
\text { live oil, } \\
\mathbf{m D}\end{array}$} & \multirow{2}{*}{$\underset{\mathbf{m D}}{\mathbf{K}_{\mathrm{ew}}}$} & \multirow{2}{*}{$\begin{array}{c}\mathrm{KeCO}_{2} \\
\text { first, } \\
\mathbf{m D}\end{array}$} & \multirow{2}{*}{$\underset{\mathrm{mD}}{\mathrm{K}_{\mathrm{ew}}}$} & \multirow{2}{*}{$\begin{array}{c}\mathrm{KCO}_{2} \\
\text { second, } \\
\mathrm{mD}\end{array}$} & \multirow{2}{*}{$\begin{array}{l}\mathbf{K}_{\mathrm{ew}} \\
\mathbf{m D}\end{array}$} & \multirow{2}{*}{$\begin{array}{c}\mathrm{KCO}_{2} \\
\text { third, } \\
\mathrm{mD}\end{array}$} & \multirow{2}{*}{$\underset{\mathbf{m D}}{\mathbf{K}_{\mathrm{ew}}}$} & \multirow{2}{*}{$\underset{\%}{\mathbf{S}_{\mathrm{orm}}}$} & \multirow{2}{*}{$\begin{array}{c}\mathrm{Sg} \\
\text { trapped, } \\
\%\end{array}$} \\
\hline & & ft & in. & & & & & & & & & & & & & & \\
\hline 1 & 7916 & 4,812 & 8 & 1.36 & 12.47 & 2.85 & 35.10 & 0.660 & 0.184 & 0.147 & 0.675 & 0.095 & 0.650 & 0.116 & 0.675 & 6.73 & 4.46 \\
\hline 3 & 7916 & 4,822 & 3 & 2.23 & 17.70 & 2.83 & 35.90 & 0.886 & 0.130 & 0.260 & 0.681 & 0.103 & 0.686 & 0.086 & 0.729 & 8.04 & 5.02 \\
\hline 4 & 7916 & 4,826 & 2 & 4.42 & 16.13 & 2.83 & 24.40 & 2.26 & 0.530 & 0.703 & 2.30 & 0.336 & 2.28 & 0.405 & 3.46 & 7.83 & 4.79 \\
\hline 5 & 7916 & 4,856 & 8 & 0.308 & 9.49 & 2.83 & 41.20 & 0.156 & 0.051 & 0.021 & 0.058 & 0.024 & 0.056 & 0.030 & 0.057 & 13.82 & 14.5 \\
\hline 6 & 7916 & 4,859 & 3 & 8.38 & 14.30 & 2.82 & 27.70 & 3.74 & 0.976 & 0.614 & 3.59 & 0.578 & 3.65 & 0.567 & 3.41 & 7.38 & 9.09 \\
\hline \multirow[t]{2}{*}{8} & 4852 & 4,899 & 3 & 36.8 & 18.81 & 2.81 & 44.60 & 14.13 & 3.95 & 1.72 & 12.76 & 1.01 & 12.25 & 1.12 & 11.34 & 8.96 & 6.09 \\
\hline & & Average & & 8.92 & 14.82 & 2.83 & 34.82 & 3.64 & 0.970 & 0.577 & 3.34 & 0.357 & 3.26 & 0.388 & 3.28 & 8.79 & 7.33 \\
\hline
\end{tabular}

${ }^{*}$ Column $1,-; 2$, Well number; 3 , Sample depth (feet from kelly bushing); 4 , Core plug sample length (inches); 5 , air permeability; $6,-; 7,-; 8$, Residual oil saturation to waterflood; 9, Effective permeability to oil at the irreducible water saturation; 10, Effective permeability to water at the residual oil saturation; 11 , Effective permeability to $\mathrm{CO}_{2}$ during the first $\mathrm{CO}_{2}$ injection flood; 12 , Effective permeability to water after the first $\mathrm{CO}_{2}$ injection period; 13 , Effective permeability to $\mathrm{CO}_{2}$ during the second $\mathrm{CO}_{2}$ injection flood; 14 , Effective permeability to water after the second $\mathrm{CO}_{2}$ injection period; 15 , Effective permeability to $\mathrm{CO}_{2}$ during the third $\mathrm{CO}_{2}$ injection flood; 16 , Effective permeability to water after the third $\mathrm{CO}_{2}$ injection period; 17 , Residual oil saturation after WAG cycles.

A presentation concerning the tomography aspect of the project will be made to a joint SEG/AAPC/SPE meeting in San Francisco, Calif., May 3-5, 1995. ${ }^{2}$ In addition, some aspects of the demonstration project will be included in a short course entitled "Reservoir Geophysics" in Lafayette, La., April 19-20, 1995.

An informal data exchange with Texaco concerning the results of cyclic $\mathrm{CO}_{2}$ stimulation injection is in process.

\section{References}

1. G. Watts, 3-D Seismic Prediction of Reservoir Properties, West Moose Queen Field, Ector County, Texas, paper presented at the Joint SEG/ AAPC/SPE meeting in San Francisco, Calif., May 3-5, 1995.

2. J. Justice, paper prepared for presentation at the Joint SEG/AAPC/SPE meeting in San Francisco, Calif., May 3-5, 1995.

\section{DYNAMIC ENHANCED RECOVERY TECHNOLOGIES}

\section{Contract No. DE-FC22-93BC14961}

\section{Columbia University \\ New York, N.Y.}

Contract Date: July 15, 1993

Anticipated Completion: Oct. 30, 1995

Government Award: \$2,052,801

Principal Investigator:

Roger N. Anderson

Project Manager:

Edith Allison

Bartlesville Project Office

Reporting Period: Jan. 1-Mar. 31, 1995

\section{Objective}

The objective of this project is to test the concept that the growth faults in a Gulf of Mexico field are conduits through which the producing reservoirs are charged and that enhanced production can be developed by producing from the fault zone. The field demonstration will be accomplished by drilling and production testing of growth fault systems associated with the Eugene Island Block 330 (EI 330) operated by Pennzoil in federal waters off Louisiana.

\section{Summary of Technical Progress}

\section{Management Start-Up}

The purpose of this task was to equip the project with staff and resources (computer and otherwise) to accomplish the project research, to negotiate contracts to achieve task objectives, and to initiate technology transfer to industry and the public. This task was largely completed in Phase I of the project, and technology transfer has begun.

\section{Database Management}

The objectives of this task are to accumulate, archive, and disseminate geological information available within the project research area, networked database creation, generation of new seismic interpretation with high-technology software, and real-time visualization of the online database. Progress is being made in fluid-flow monitoring with the use 
of industry multiple three-dimensional (3-D) seismic data sets, geological analyses of industry 3-D seismic surveys, real-time visualization of the database, 3-D interpretation of the Shell/Exxon 3-D seismic data, and reformatting data volumes for simulation.

\section{Reservoir Characterization}

Goals of this task area are stratigraphic interpretation, salt analysis and paleogeographic reconstruction, fluid potential analysis, and amplitude mapping analysis. Core photographs, the sedimentology and petrology report, and all paper logs run on the No. A-12 well, including formation microimaging, dipmeter, and thin-bed analysis, have been received.

Stratigraphic interpretation is complete, and a report of the results has been accepted for publication.' A paper was also presented at the Global Basins Research Network (GBRN) corporate affiliates meeting, Houston, Tex., and to Conoco, Inc., Houston, Tex. ${ }^{2}$ Work is continuing on mapping other horizons in the 3-D seismic data.

The salt analysis and paleographic reconstruction task is complete.

The fluid potential analysis task is dependent on completion of the structure mapping subtask. Mapping of the GA sand is complete (Fig. 1), and the HB sand is in the process of interpretation. Mapping of the JD, KE, LF (Fig. 2), MG, $O I$, and Lentic surfaces is under way. Work during this quarter has focused on detailed interpretation of the stress field as inferred from stress measurements made in the Pathfinder well. Details of this work are reported in Hart et al. ${ }^{3}$ Pressure, temperature, and amplitude mapping are also in progress.

\section{Modeling}

The modeling task is proceeding smoothly with modification of the pre-processor, two-dimensional (2-D) modeling modification of the Akcess.Basin software, fault-plane mapping, and preparation of a 3-D model of the EI minibasin. Four publications relevant to this task are reported. ${ }^{4-7}$

\section{Geochemistry}

No systematic changes in detrital or diagenetic mineralogy have been noted with depth in the wells or in comparison between wells. Two publications relevant to this task were published. ${ }^{8,9}$

\section{Technology Transfer}

The purpose of this task is to integrate all results into one comprehensive perspective of the project's objectives and to transfer the results to industry. Once the fluid-flow model results become predictive, this information will be made part of the permanently maintained, on-line geological database, World Wide Web, which is available on Internet. Five reports relating to this task were prepared or published during the present quarter.

A petroleum resource assessment for the EI area is under way; data were acquired for the size and number of discovered hydrocarbon accumulations.

Eight additional papers or posters were presented during the quarter, ${ }^{10-17}$ and a large exhibition booth for this project was sponsored by GBRN at the 1995 Annual AAPG conference, March 5-8, 1995, in Houston, Tex.

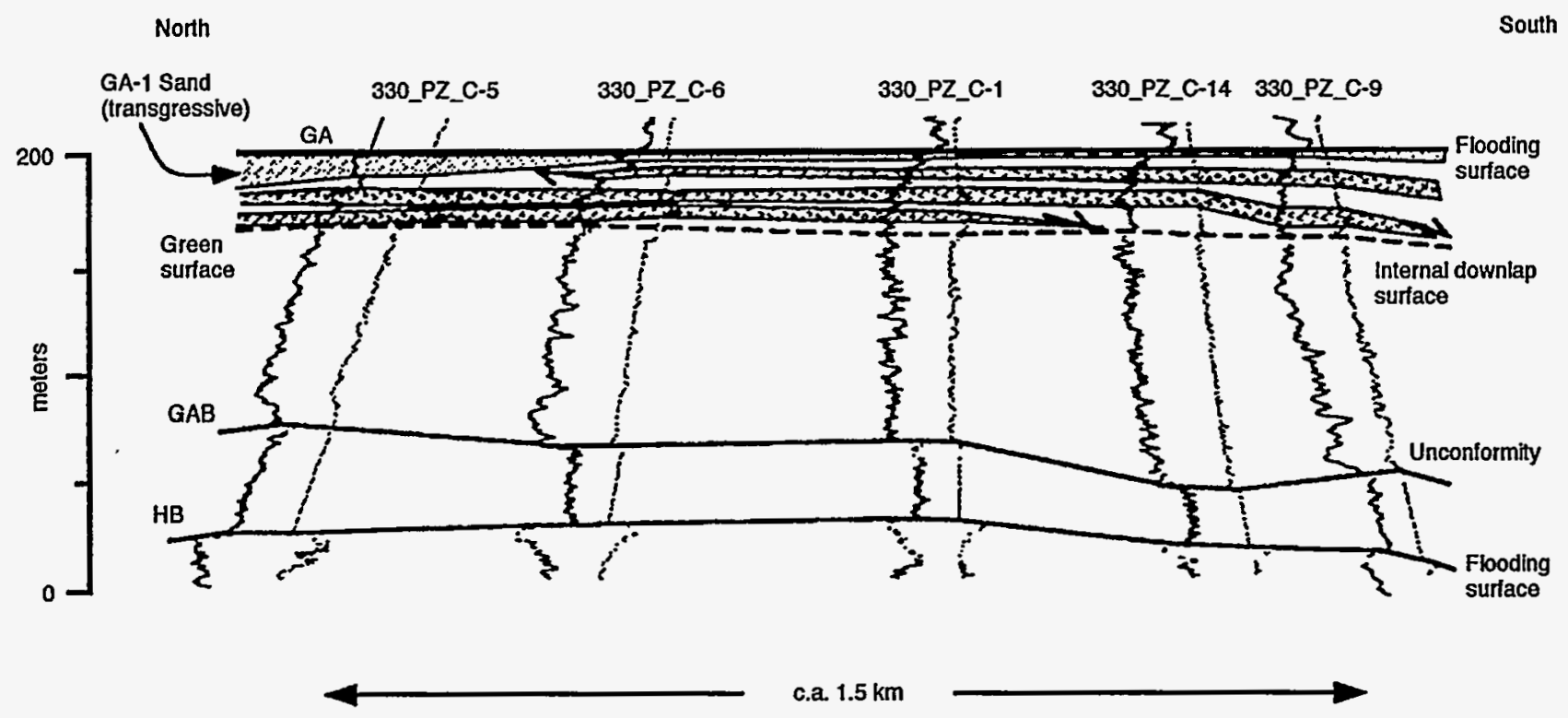

Fig. 1 Stratigraphic cross section showing detailed correlation of charged clean sands tens of feet thick of the upper portion of the GA-2 sand. The pattern shows transition from channel to deltaic clinoform deposits. Compartmentalization of the reservoir by such depositional features is visible in amplitude anomaly maps of the top of the GA as well as in production from individual wells. 


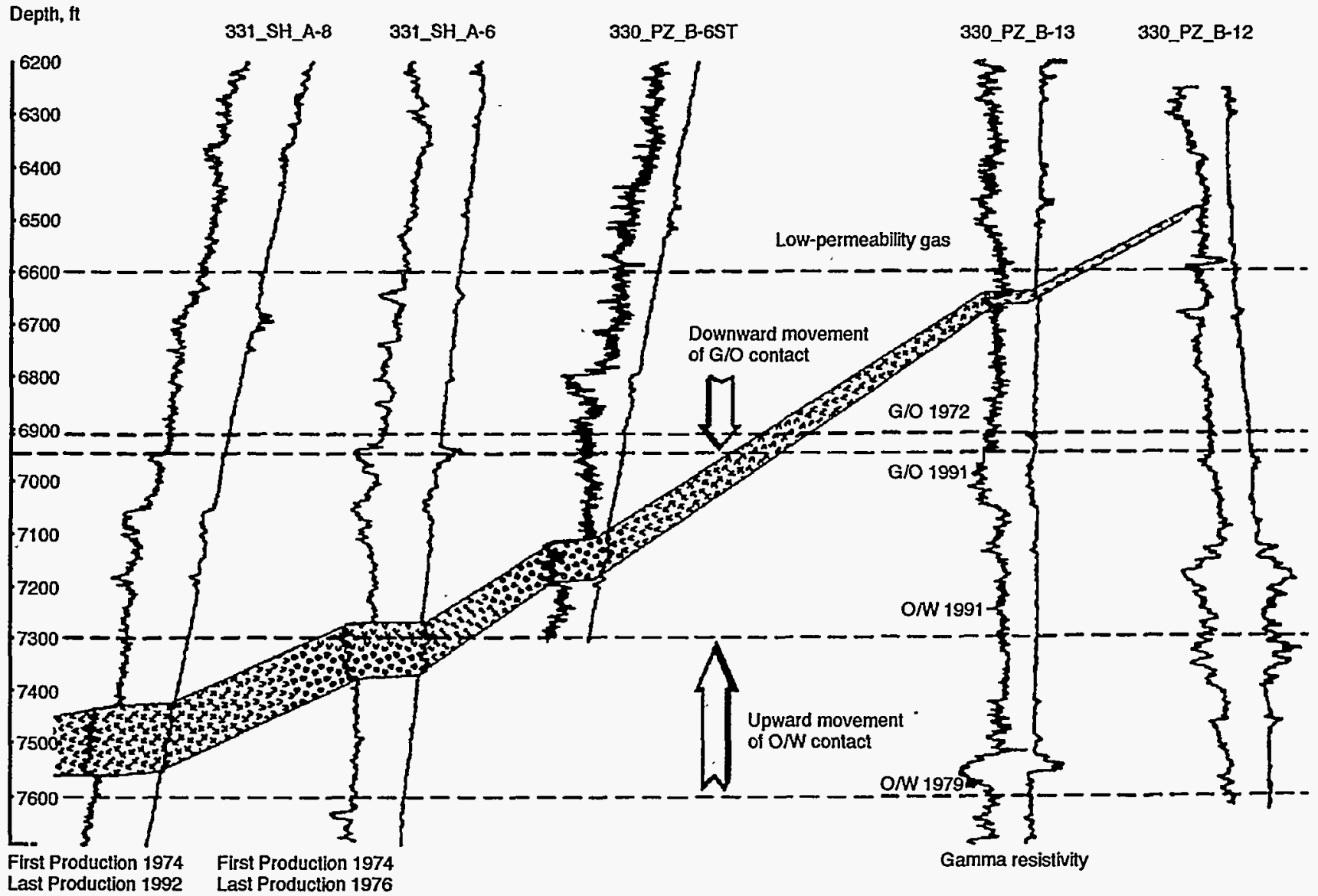

Fig. 2 Structural cross section of LF Sand in " $A$ " block showing movement of fluid contacts as inferred from production data.

\section{References}

1. L. L. Alexander and P. B. Flemings, Geologic Evolution of a PliocensePleistocene Salt-Withdrawal Mini-Basin: Eugene Island Block 330, Offshore Louisiana, Am. Assoc. Pet. Geol. (AAPG), Bull., 79: 1737-1756 (1995).

2. B. S. Hart, D. Sibley, and P. B. Flemings, paper presented at the Global Basin Research Network Meeting, Houston, Tex., March 1, 1995.

3. B.S.Hart,P.B. Flemings, and A.Deshpande, Porosity and Pressure: Role of Compaction Disequilibrium in the Development of Geopressures in a Gulf Coast Pleistocene Basin, Geology, 23(1): 45-48 (1995).

4. M. Luo, J. R. Wood, and L. M. Cathles, Using Fabric Theory to Predict Thermal Conductivity in Reservoir Rocks Based on Rock Composition, J. Appl. Phys. 32: 321-334 (1994).

5. A. Sarkar and J. Nunn, Free Haline Convection Beneath Allocthonous Salt Sheets: An Agent for Salt Tectonics and Fluid Flow in Gulf Coast Sediments, paper to be presented at the 16th Annual Gulf Coast Section Meeting of the Society of Economic Paleontologists and Mineralogists, Houston, Tex., Dec. 4, 1995.

6. J. A. Nunn, S. J. Roberts, R. N. Anderson, L. M. Cathles, and the Global Basin Research Network, Visualization Technology to Find and Develop More Oil and Gas, abstract submitted the ARCHIE Conference, The Woodlands, Tex., May 14-18, 1995.

7. L. Alexander, Geologic Evolution and Controls on Fluid Flow of the Eugene Island Block 300 Minibasin, Offshore Louisiana, GulfofMexico, Ph.D. Thesis, Cornell University, 1995.

8. S. Losh, L. Eglinton, and J. Wood, Paper on Organic Geochemistry of Pathfinder Well Oils, Part III, Chapter 1 in Results of the Pathfinder Drilling Program into a Major Growth Fault: Part of the GBRN/DOE
Dynamic Enhanced Recovery Project in Eugene Island 330 Field, Gulf of Mexico, Lamont-Doherty Earth Observatory Press, Palisades, N.Y., 1995. (CD-ROM)

9. J. J. Whelan, M. C. Kennicutt, J. M. Brooks, D. Schumacher, and L. B. Eglinton, Organic Geochemical Indicators of Dynamic Fluid Flow Processes in Petroleum Basins, Advances in Organic Geochemistry, 199, Org. Geochem., 22: 587-615 (1994).

10. R. N. Anderson, A. Boulanger, W. He, Y. F. Sun, L. Xu, D. Sibley, J. Austin, R. Woohams, R. Andre, and K. Rinehart, Method Described for Using 4D Seismic to Track Reservoir Fluid Movement, Oil Gas J., 93(14): 70-74 (April 3, 1995).

11. R. N. Anderson, W. He, Y. F. Sun, L. Xu, D. Sibley, J. Austin, R. Woodhams, R. Andre, and K. Rinehart, 4D Seismic Helps Track Drainage, Pressure Compartmentalization, Oil Gas J., 93(13): 55-58 (March 27, 1995).

12. R. N. Anderson, L. B. Billeaud, P. B. Flemings, S. Losh, J. K. Whelan, and the Global Basins Research Network, in Results of the Pathfinder Drilling Program into a Major Growth Fault: Part of the GBRN/DOE Dynamic Enhanced Recovery Project in Eugene Island 330 Field, Gulf of Mexico, Lamont-Doherty Earth Observatory Press, Palisades, N.Y., 1995. (CD-ROM)

13. S.J. Roberts and N. A. Nunn, Episodic Fluid Explusion from Geopressured Sediments, Pet. Geol., 12: 195-204 (1995).

14. A. Boulanger and W. He, The Role of Pattem Recognition and High Resolution Inversion in Basin and MiniBasin Reservoir Characterization, poster presented at the 3rd SIAM Conference on Geosciences, San Antonio, Tex., February 10, 1995

15. W. He, R. N. Anderson, X. Wang, and Y.-C. Teng, Application of the 3-D FEM Seismic Modeling Technique in Reservoir Characterization and Fluid Monitoring, paper presented at the American 
Association of Petroleum Geologists Annual Meeting, Houston, Tex., March 5-8, 1995.

16. M. G. Rowan, T. Villamil, P. Weimer, and P. B. Flemings, Composite Origin of Allochthonous Salt, Offshore Louisiana, paper presented at the American Association of Petroleum Geologists Annual Meeting, Houston, Tex., March 5-8, 1995.

17. M. G. Rowan, T. Villamil, P. Weimer, and P. B. Flemings, Paleobathymetry and Paleotopography in the Gulf of Mexico; Comparison of Resultsfrom Cross-Section Restoration and Biostratigraphic Analysis, paper presented at the American Association of Petroleum Geologists Annual Meeting, Houston, Tex., March 5-8, 1995.

\section{IDENTIFICATION AND EVALUATION \\ OF FLUVIAL-DOMINATED DELTAIC \\ (CLASS I OIL) RESERVOIRS \\ IN OKLAHOMA}

\section{Contract No. DE-FC22-93BC14956}

\section{Oklahoma Geological Survey \\ University of Oklahoma \\ Norman, Okla.}

Contract Date: Jan. 15, 1993

Anticipated Completion: Dec. 31, 1997

Government Award: \$1,390, 752

(Current year)

\section{Principal Investigators: \\ Charles J. Mankin \\ Mary K. Grasmick \\ Project Manager: \\ Rhonda Lindsey \\ Bartlesville Project Office}

Reporting Period: Jan. 1-Mar. 31, 1995

\section{Objectives}

The Oklahoma Geological Survey (OGS), the Geological Information Systems (GIS) Department, and the School of Petroleum and Geological Engineering at the University of Oklahoma are engaging in a program to identify and address Oklahoma's oil recovery opportunities in fluvial-dominated deltaic (FDD) reservoirs. This program includes the systematic and comprehensive collection and evaluation of information on all of Oklahoma's FDD reservoirs and the recovery technologies that have been (or could be) applied to those reservoirs with commercial success. This data collection and evaluation effort will be the foundation for an aggressive, multifaceted technology transfer program that is designed to support all of Oklahoma's oil industry, with particular emphasis on smaller companies and independent operators in their attempts to maximize the economic producibility of FDD reservoirs.

Specifically, this project will identify all FDD oil reservoirs in the State; group those reservoirs into plays that have similar depositional and subsequent geologic histories; collect, organize, and analyze all available data; conduct characterization and simulation studies on selected reservoirs in each play; and implement a technology transfer program targeted to the operators of FDD reservoirs to sustain the life expectancy of existing wells with the ultimate objective of increasing oil recovery.

The elements of the technology transfer program include developing and publishing play portfolios, holding workshops to release play analyses and identify opportunities in each of the plays, and establishing a computer laboratory that is available for industry users. The laboratory will contain all the play data files, as well as other oil and gas data files, together with the necessary hardware and software to analyze the information. Technical support staff will be available to assist interested operators in the evaluation of their producing properties, and professional geological and engineering outreach staff will be available to assist operators in determining appropriate recovery technologies for those properties.

\section{Summary of Technical Progress}

The execution of this project is being approached in three phases. Phase 1, Planning and Analysis, included system design, play definition, and database development activities. Phases 2 and 3 are under way. They include many ongoing activities from phase 1 but emphasize project implementation and technology transfer activities in which the collected information is organized and made available to the industry through the various methods. Activities for phases 2 and 3 have been divided into four primary tasks.

\section{Database and Applications Development}

Database, applications, and computer laboratory development efforts continued during this quarter. Computer laboratory development activities include both the acquisition of hardware and software and the development of user interfaces for the data and applications that will be available through the user lab. During this quarter the Novell Netware 3.12 system was installed. This new network will allow the management of the multiuser access and security requirements. The Oracle database management software for the NRIS databases was also installed this quarter. Work continued on the development of user interfaces to the NRIS and FDD data; several demonstrations of the well data system were conducted to get user feedback on the screen designs and menu options. 
Network-version (six concurrent users) GeoGraphix Exploration System software was received for use in the laboratory. This included the QLA 2, Jaguar, and LeaseMap modules as well as the mapping module.

User-lab activities also include the development of plans for the business management and operation of the lab facility. During this quarter additional progress was made on various issues related to the operation of the lab, including operating hours, staffing plans, training, security, and fees.

The operator database was converted to the personal computer network. This database will be used to track program participation by operators from the various plays; next quarter's mailout to Morrow oil operators will be generated from this database.

\section{Play Analyses, Publications, and Workshops}

\section{The Morrow Play}

The Morrow Play workshop has been scheduled for June 1, 1995, at the Sarkeys Energy Center at the University of Oklahoma. Preparation for this workshop was the primary focus during this quarter.

Detailed specifications were developed for the Morrow folio publication, which was designed to include a generalized introduction to FDD depositional environments, a regional overview of the Morrow FDD play, detailed information on three Morrow field studies, and the results of the Rice Northeast reservoir characterization and simulation study. The generalized introduction was developed through the efforts of all three play leaders and will be used for all the play presentations. Detailed data regarding the Rice Northeast field, a Morrow oil field in Texas Co., has been provided for the publication and workshop through the cooperation of Ensign Operating Co. This Morrow publication required significant cartographic and editorial efforts during this quarter.

Other workshop preparations include developing the workshop agenda and preparing for the workshop registration mailout. For the mailout, 604 operators have been identified as 1994 producers of Morrow oil to be targeted for this workshop. A peer review of the results of the Morrow play research is scheduled for April 1995.

\section{The Booch Play}

The Booch Play workshop has been scheduled for Aug. 31, 1995, at the Green Country Vocational-Technical School in Okmulgee, Okla. The site was selected on the basis of its proximity to many of the addresses of Booch oil operators.

This quarter's Booch play preparation included progress on the, regional Booch maps, research to select fields for moredetailed field studies, and efforts on the Greasy Creek reservoir characterization and simulation study. Updated field boundaries from the Oklahoma Nomenclature Committee (ONC) were processed for areas with high levels of unassigned Booch production in Hughes, Seminole, and Okfuskee Counties.

\section{The Layton and Osage-Layton Play}

The Layton and Osage-Layton Play workshop will be scheduled for November 1995. During this quarter the Layton and Osage-Layton efforts included progress on the regional maps and research to select a field for a reservoir characterization and simulation study.

\section{Professional Outreach}

Most of the professional outreach activities are scheduled to begin after the workshops have been initiated in June 1995. The exception to this schedule is with the reservoir characterization and simulation efforts, which require ongoing interactions with industry participants. As reported previously, these efforts continued this quarter for the Booch play in the Greasy Creek field and for the Morrow play in the Rice Northeast field.

Because the project is in its early stages of planning and analysis, no publications have resulted from the project work thus far; however, other efforts are under way to publicize the project to relevant audiences. The OGS and the GIS Department prepared an FDD display for their booth at the annual convention of the American Association of Petroleum Geologists in March 1995. Publicity about the FDD program also was provided at the Ames Structure Workshop conducted by the OGS in March 1995.

\section{Management and Reporting}

A revised milestone schedule for phases 2 and 3 was submitted to the program office. 


\section{INCREASED OIL PRODUCTION AND RESERVES UTILIZING SECONDARYI TERTIARY RECOVERY TECHNIQUES ON SMALL RESERVOIRS IN THE PARADOX BASIN, UTAH}

\section{Contract No. DE-FC22-95BC14988}

\author{
Utah Geological Survey \\ Salt Lake City, Utah
}

Contract Date: Feb. 9, 1995

Anticipated Completion: Feb. 8, 2000

Government Award: $\$ \mathbf{7 8 6 , 8 8 0}$

\section{Principal Investigator: \\ M. Lee Allison}

\section{Project Manager: \\ Rhonda Lindsey \\ Bartlesville Project Office}

Reporting Period: Jan. 1-Mar. 31, 1995

\section{Objective}

The primary objective of this project is to enhance domestic petroleum production by demonstration and technology transfer of an advanced oil-recovery technology in the Paradox Basin in southeastern Utah. If this project can demonstrate technical and economic feasibility, the technique can be applied to approximately 100 additional small fields in the Paradox Basin alone and result in increased recovery of $\mathbf{1 5 0}$ to 200 million bbl of oil. This project is designed to characterize five shallow-shelf carbonate reservoirs in the Pennsylvanian Paradox formation and to choose the best candidate for a pilot demonstration project for either a waterflood or carbon dioxide $\left(\mathrm{CO}_{2}\right)$-flood project. The field demonstration, monitoring of field performance, and associated validation activities will take place in the Paradox Basin within the Navajo Nation. The results of this project will be transferred to industry and other researchers through a petroleum extension service, creation of digital databases for distribution, technical workshops and seminars, field trips, technical presentations at national and regional professional meetings, and publication in newsletters and various technical or trade journals.

\section{Summary of Technical Progress}

During this quarter planning and initial activities for the 5-yr effort began. An amendment to the primary contract between the Utah Geological Survey (UGS) and the U.S. Department of Energy (DOE) was submitted. The subcontractor agreement between the UGS and Harken Southwest
Corp. (Harken) was submitted and modified. Most task work was delayed pending approval of the contract amendment and the subcontract. Areas of progress during the quarter included development well permitting and technology transfer.

\section{Drilling of Development Wells}

A team of geologists, reservoir engineers, and geophysicists from Harken evaluated potential development locations for the project fields. Two development wells will be drilled to increase the well density from 80 acres ( $32.3 \mathrm{ha}$ ) per well to 30 to 40 acres (12 to 16) per well. Permitting is under way for the first well, the Anasazi $6 \mathrm{H}$ No. 1 , located in the $\mathrm{SE}^{1 /} / \mathrm{NE}^{1 / 1} / 4 \mathrm{sec} .6, \mathrm{~T} .42 \mathrm{~S}$, R. 24E., Navajo Nation, San Juan Co., Utah, in the Anasazi field (Fig. 1). The proposed total depth is $5872 \mathrm{ft}(1790 \mathrm{~m})$. The principal reservoir to be evaluated, an algal mound in the Desert Creek zone of the Paradox formation, is projected to be penetrated at $5624 \mathrm{ft}(1714 \mathrm{~m})$.

The well data will enable the team to assess the frequency of reservoir compartments (reservoir heterogeneity) in a given area, the amount of communication between compartments, how a waterflood or $\mathrm{CO}_{2}$ flood will move from one compartment to another, and the areal extent of an average compartment. The following new well information will be used in the geologic and reservoir characterization:

- More accurate descriptions of the general reservoir geology and reservoir compartmentalization/ continuity.

- Pressure data in the drawn-down areas from current producers.

- Wettability and relative-permeability data from fresh cores.

- Pressure transient data to determine communication with other fields (determine communication with adjacent reservoirs previously thought separate).

- Increased data for the reservoir simulation history match to allow for better construction of models used in $\mathrm{CO}_{2}$-waterflood simulations.

\section{Technology Transfer}

The UGS, Harken, and DOE sponsored a core workshop to examine several cores from the Paradox Basin of southeastern Utah to determine oil reservoir characteristics of several types of algal mounds that comprise the five fields targeted for detailed study. The workshop was held during the 1994 American Association of Petroleum Geologists (AAPG) annual convention in Denver, Colo. Thirty-two participants attended the free workshop. This workshop was the first of several planned in the future as part of the technology transfer activities for the project.

The core workshop was a hands-on introduction to the relation between production and reservoir characteristics of algal mounds in the Paradox formation. Representative cores from five types of oil-producing algal mounds in the Paradox Basin were discussed and examined. Planned activities for this 


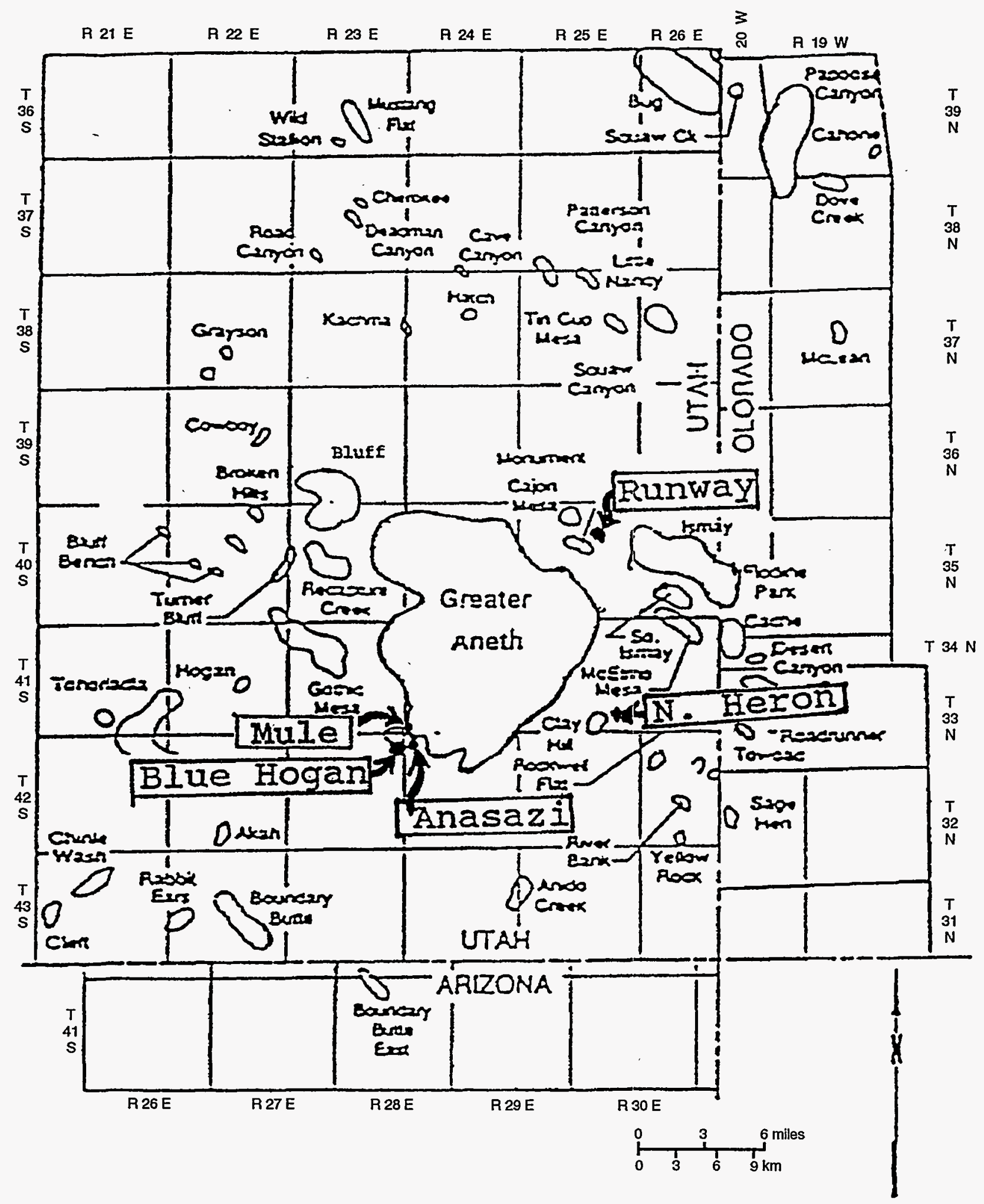

Fig. 1 Location of the five Harken fields targeted for geological and reservoir characterization. The first project development well, the Anasazi $6 \mathrm{H}$ No. 1, will be drilled in the Anasazi field, Navajo Nation, San Juan County, Utah. 
DOE project were described during the workshop. Participants were encouraged to ask questions and discuss all aspects of the project and make suggestions or recommendations concerning the project. The UGS plans to publish the workshop course notes.
Project materials were displayed at the UGS booth during the 1994 and 1995 AAPG annual conventions and at a 1995 regional convention of the Society of Petroleum Engineers. 


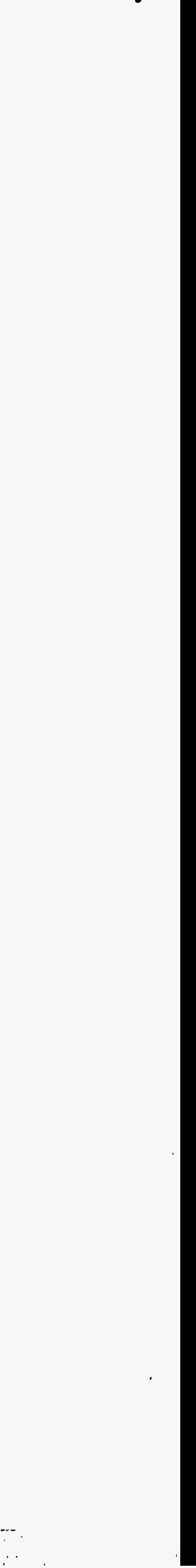

